UNIVERSIDAD DE SALAMANCA

FACULTAD DE FILOLOGÍA

DEPARTAMENTO DE LA LENGUA ESPAÑOLA

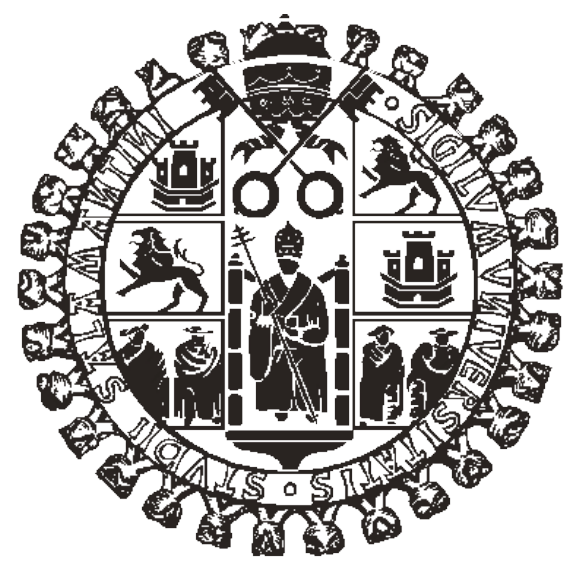

\title{
LA FLUIDEZ DISCURSIVA ORAL \\ UNA PROPUESTA DE EVALUACIÓN INTEGRAL DE LA ORALIDAD
}

TESIS DOCTORAL

MARTHA PATRICIA MENJURA TORRES 
UNIVERSIDAD DE SALAMANCA

FACULTAD DE FILOLOGÍA

DEPARTAMENTO DE LA LENGUA ESPAÑOLA

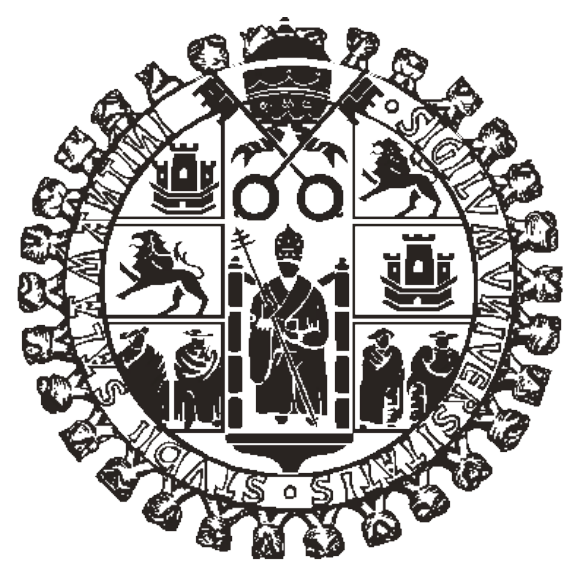

LA FLUIDEZ DISCURSIVA ORAL

UNA PROPUESTA DE EVALUACIÓN INTEGRAL DE LA ORALIDAD

TESIS DOCTORAL

MARTHA PATRICIA MENJURA TORRES

$V^{\circ} B^{\circ}$ DEL DIRECTOR:

Dr. JULIO BORREGO NIETO

SALAMANCA, 2018 


\section{TABLA DE CONTENIDO}

$\begin{array}{ll}\text { ÍNDICE DE GRÁFICOS } & 6\end{array}$

$\begin{array}{lr}\text { ÍNDICE DE TABLAS } & 8\end{array}$

$\begin{array}{lr}\text { AGRADECIMIENTOS } & 10\end{array}$

$\begin{array}{lr}\text { INTRODUCCIÓN } & 13\end{array}$

1. OBJETIVOS Y METODOLOGÍA 21

1.1. Presentación del problema 22

1.2. Objetivo General 23

$\begin{array}{ll}\text { 1.3. Objetivos específicos } & 23\end{array}$

$\begin{array}{ll}\text { 1.4. Justificación } & 24\end{array}$

1.5. Tipo de investigación 25

1.5.1. Consideraciones acerca del aspecto cualitativo de la investigación $\quad 25$

1.5.2. Consideraciones acerca del aspecto cuantitativo de la investigación 28

1.6. Problemas inherentes a este tipo de trabajo 28

1.7. Constitución de un corpus de trabajo 29

1.7.1. Elección de informantes 31

1.7.2. Grabación de narraciones $\quad 34$

$\begin{array}{ll}\text { 1.7.3. Transcripción de narraciones grabadas } & 37\end{array}$

1.7.4. Convenciones de la transcripción $\quad 38$ 
3.1. Proceso de producción de la oralidad 136

3.1.1. Perspectiva anatómico-fisiológica 136

$\begin{array}{ll}\text { 3.1.2 Perspectiva cognitiva } & 139\end{array}$

3.1.3. Proceso de producción oracional 142

3.1.4. Perspectiva psicolingüística $\quad 145$

3.1.5. Perspectiva discursiva 151

3.2. El discurso 156

3.3. El discurso narrativo 163

$\begin{array}{ll}\text { 3.3.1. Superestructura } & 163\end{array}$

3.3.1.1. Caracterización de los textos del corpus 164

3.3.1.2. La narración 167

3.3.2. Macroestructura temática 172

$\begin{array}{ll}\text { 3.3.2.1. Tema } & 172\end{array}$

$\begin{array}{ll}\text { 3.3.2.2. Coherencia discursiva } & 173\end{array}$

$\begin{array}{ll}\text { 3.3.2.3. Cohesión discursiva } & 179\end{array}$

4. MODELO DE EVALUACIÓN DE LA ORALIDAD 186

4.1. Elaboración de un instrumento de evaluación 187

4.1.1. Pasos para el diseño del instrumento 190

4.2. Descripción del instrumento de evaluación 191

4.3. Instrumento para la evaluación integral del discurso 193 
4.3.1.1. Habilidad para la superestructura narrativa

4.3.1.1.1. Caracterización de personajes

4.3.1.1.2. Desarrollo de las acciones

4.3.1.1.3. Presencia de estructura narrativa discursiva

\section{APLICACIÓN DEL MODELO DE EVALUACIÓN DE LA ORALIDAD 239}

5.1. Evaluación integral del discurso del informante 1D 
5.1.1.1. Habilidad para la superestructura narrativa

5.1.1.2. Habilidad para la progresión temática

5.1.1.3. Habilidad para crear coherencia

5.1.1.4. Cohesión

5.1.1.5. Evaluación

5.1.1.6. Contextualización

5.1.2. Evaluación de la fluidez discursiva

5.2. Evaluación del discurso del informante 11AC

5.2.1. Evaluación del discurso narrativo

5.2.1.1. Habilidad para la superestructura narrativa

5.2.1.2. Habilidad para la progresión temática

5.2.1.3. Cohesión 253

5.2.1.4. Evaluación

5.2.1.5. Contextualización

5.2.2 Evaluación de la fluidez discursiva

5.3. Evaluación del discurso del informante 58E

5.4. Evaluación del discurso del informante 590 
6.4. Resultados generales desglosados 292

6.4.1. Resultados cuantitativos (fluidez discursiva oral: FDO) 292

6.4.2. Resultados cualitativos (capacidades narrativas) y resultados integrales 299

$\begin{array}{ll}\text { 7. PROPUESTA } & 313\end{array}$

$\begin{array}{ll}\text { 7.1. Objetivo de la prueba } & 314\end{array}$

$\begin{array}{ll}\text { 7.2. Tarea } & 315\end{array}$

7.3. ¿A quién va dirigida la prueba? 316

7.4. ¿Cómo convertir la grabación en muestra? 316

$\begin{array}{ll}\text { 7.5. Pasos para evaluar } & 317\end{array}$

$\begin{array}{ll}\text { 8. CONCLUSIONES } & 322\end{array}$

9. PERSPECTIVAS DE APLICACIÓN Y NUEVAS INVESTIGACIONES 333

9.1. Aprovechamiento del corpus 334

9.2. Aprovechamiento del instrumento de evaluación 335

10. BIBLIOGRAFÍA 336 


\section{ÍNDICE DE GRÁFICOS}

1. Fluidez discursiva oral integral $\quad 14$

2. Áreas cerebrales 138

3. Porcentaje de repeticiones según tipo 216

4. Función de la repetición 217

5. Evaluación cuantitativa grupo 1. Jóvenes de 11 a 20 años 278

6. Evaluación cuantitativa grupo 2. Adultos jóvenes de 21 a 50 años 279

7. Evaluación cuantitativa grupo 3. Adultos mayores de 51 a 74 años 280

8. Evaluación cuantitativa grupo 4. Adulto avanzado de 75 a 95 años (I)

9. Evaluación cuantitativa grupo 4. Adulto avanzado de 75 a 95 años (II)

10. Evaluación cualitativa grupo 1. Jóvenes de 11 años a 20 años 282

11. Evaluación cualitativa grupo 2. Adultos jóvenes de 21 años a 283 50 años

12. Evaluación cualitativa grupo 3. Adultos mayores de 51 años a 283 74 años

13. Evaluación cualitativa grupo 4. Adulto avanzado de 75 años a $95 \quad 284$ años (I)

14. Evaluación cualitativa grupo 4. Adulto avanzado de 75 años a $95 \quad 284$ años (II) 
15. Evaluación FDOI. Rango 1

16. Evaluación FDOI. Rango 2

17. Evaluación FDOI. Rango 3 (I) 287

18. Evaluación FDOI. Rango 3 (II) 287

19. Evaluación FDOI. Rango 4A 288

20. Evaluación FDOI. Rango 4B 288

21. Porcentaje de informantes por rango 289

22. Datos evaluación integral del discurso oral 291

23. Viñetas para evaluación del discurso 315 


\section{ÍNDICE DE TABLAS}

1. Datos generales de informantes 32

2. Clasificación de informantes por variables 34

3. Convenciones de la transcripción 39

4. Indicadores de evaluación cualitativa del discurso narrativo 200

5. Correspondencia de valores cualitativos - cuantitativos 200

6. Instrumento de evaluación de la fluidez discursiva oral 204

7. Resumen del instrumento de evaluación de la fluidez con ejemplos 231

8. Evaluación integral del discurso: informante 1D 246

9. Evaluación integral del discurso: informante 11AC 256

10. Evaluación cualitativa: informante 58E 261

11. Evaluación de la fluidez oral: informante 58E 262

12. Evaluación cualitativa: informante 590

13. Evaluación de la fluidez oral: informante 590

14. Evaluación cualitativa: informante 64AV 272

15. Evaluación de la fluidez oral: informante 64AV 273

16. Resultados cuantitativos FDO. Informantes 1D - 11AC 293

17. Resultados cuantitativos FDO. Informantes 12R - 22MP 294

18. Resultados cuantitativos FDO. Informantes 23 LR - 33H 295

19. Resultados cuantitativos FDO. Informantes 34M - 44C 296

20. Resultados cuantitativos FDO. Informantes 45A - 55C 297 
21. Resultados cuantitativos FDO. Informantes 56R-66P

22. Resultados evaluación integral. Informantes 1D - 6M 302

23. Resultados evaluación integral. Informantes 7W - 12R 303

24. Resultados evaluación integral. Informantes 13H - 18CR 304

25. Resultados evaluación integral. Informantes 19MR - 24VV 305

26. Resultados evaluación integral. Informantes 25AL - 30D 306

27. Resultados evaluación integral. Informantes 31J - 36C 307

28. Resultados evaluación integral. Informantes 37CM - 42R 308

29. Resultados evaluación integral. Informantes 43E - 48L 309

30. Resultados evaluación integral. Informantes 49S - 54DM 310

31. Resultados evaluación integral. Informantes 55C - 60F 311

32. Resultados evaluación integral. Informantes 61MJ - 66P 312

33. Instrumento de evaluación integral: desglose de la fluidez oral 320

34. Instrumento de evaluación integral: habilidades narrativas y 321 resultados finales 


\section{AGRADECIMIENTOS}

Culminada esta etapa, es importante mirar hacia atrás para ver el camino y reconocer el apoyo de quienes han estado en él para alentarme, apoyarme, animarme y reconfortarme en los momentos de duda, en las vacilaciones y en las pausas del trabajo.

Gratitud especial para mi director, el doctor Julio Borrego Nieto, quien asumió el reto con gusto y con fruición; quien estuvo presto a dirigir y corregir el rumbo de este trabajo y tuvo paciencia y tiempo para soportar la espera que significó un largo silencio, después del cual sus palabras de ánimo y aliento fueron decisivas.

A Francisco Q.E.P.D., para quien era un sueño ver terminado este proyecto, mi reconocimiento, también, por haber tenido la idea de comenzar las grabaciones y por la fuerza y motivación que le imprimió a productos anteriores en los cuales trabajamos hombro a hombro.

A mis hijos, Valentina del Mar, Mauricio y Nicole, que no solo me perdieron por horas interminables durante estos años, sino que al final me ayudaron y animaron y tomaron el mando doméstico mientras yo asumía el trabajo académico. 
Al ingeniero Álvaro Díaz, le debo la cooperación en el diseño del instrumento y la asesoría en la elaboración de tablas y fórmulas matemáticas, a Mario Andrés Durán y José David Piña corresponde el diseño de la aplicación informática EVA FLODIS, que permitirá en el futuro evaluar la fluidez discursiva oral integral, y a Silvia Juliana Navarro, Siju-Nara, corresponde la autoría de las viñetas del capítulo 7.

A mis profesores en Colombia y en España, por su luz teórica y sus gestos solidarios.

A mis compañeros de trabajo que me animaron y enriquecieron con sus comentarios y observaciones. Especialmente a Edga, porque con su ejemplo me mostró que es posible, y a Rafael a quien auguro muchos éxitos en su trabajo doctoral.

A mis alumnos y exalumnos porque me enseñan todos los días.

A todos mis informantes porque sin ellos no tendría un corpus de trabajo, a las instituciones que nos permitieron grabar y al Archivo de la Guerra Civil Española por permitirme escuchar y transcribir las grabaciones de algunos informantes, testigos de la dureza de la guerra.

Al Banco Santander Central Hispano y a su Director el doctor Emilio Botín Q.E.P.D, por haberme dado la oportunidad de disfrutar de un beca de doctorado durante dos años.

A la Universidad de Salamanca por haberme acogido y apoyado académica y económicamente. 
A mis compañeras y amigas fonoaudiólogas porque con ellas aprendí las perspectivas de la evaluación del lenguaje.

A Luisa, Juan Manuel, Andrea, Álvaro y Silvia por sus aportes, lecturas, observaciones y apoyo.

Al profesor Antonio Briz porque, en su curso y a través de sus obras, iluminó el camino para crear el instrumento de evaluación de la fluidez discursiva.

A mi familia por mostrar un interés genuino en la culminación de este trabajo.

A mis amigos por su insistencia y por creer en mí, y a todos aquellos que me alentaron a retomar después de un larguísimo silencio. 


\section{INTRODUCCIÓN}

La presente tesis, denominada La fluidez discursiva oral: una propuesta de evaluación integral para la oralidad, propone un instrumento para evaluar las habilidades discursivas de los hablantes de lengua española. Esta propuesta se basa principalmente en el análisis discursivo propuesto por Van Dijk en sus obras, y en la descripción de los rasgos del español conversacional coloquial propuesta por Antonio Briz y el grupo VAL.ES.CO. Se inició en 1998 con una iniciativa propuesta por Gómez Marulanda, quien planteó la recopilación de narraciones en Colombia, Costa Rica y España, con el objetivo de comparar narrativas orales. De este proyecto surge un primer corpus de 30 narraciones de adultos mayores de 70 años (10 por cada país) que constituyen una base sobre la cual se desarrolló un primer trabajo denominado Habilidades discursivas en la vejez.

La evaluación de las habilidades discursivas orales es un tema que ofrece la novedad de especificar los parámetros e indicadores con los cuales se debe considerar cada una de las habilidades para la narración y descripción de experiencias de vida.

Pretende ser un instrumento integral que tiene en cuenta aspectos discursivos como la coherencia, la cohesión, la superestructura y la progresión temática; desde otro

\footnotetext{
${ }^{1}$ Menjura, Martha. Habilidades discursivas en la vejez. Universidad de Salamanca, Salamanca, 2003. Inédito. Tesina con la cual la autora obtuvo la suficiencia investigadora.
} 
punto de vista, tiene en cuenta aspectos orales, incluido el acompañamiento entonativo, y aspectos extraverbales, como la gestualidad.

Se especifica ampliamente lo concerniente a la fluidez discursiva utilizando condiciones, contexto y ejemplos. Este instrumento es altamente sofisticado, ya que incluye todas las constantes de la oralidad que influyen en la fluidez y se piensa la fluidez como el resultado de otras habilidades discursivas.

Es pertinente indicar que no se trata aquí de evaluar la fluidez verbal, ya que esta se ha evaluado siempre con el número de palabras que un hablante es capaz de producir en un minuto con referencia a un ítem. Son palabras sueltas y desprovistas de contexto discursivo o tan siquiera oracional.

El instrumento de evaluación propuesto parte de un análisis cualitativocuantificado y un estudio cuantitativo. El producto de estos dos análisis dará como resultado el índice de fluidez discursiva oral integral. La hipótesis teórica apunta a la integralidad del concepto fluidez discursiva oral como dependiente de la totalidad de constantes, indicadores y fenómenos discursivos presentes en el corpus de cada informante. La propuesta integral está consignada en el siguiente gráfico:

Gráfico 1: Fluidez discursiva oral integral

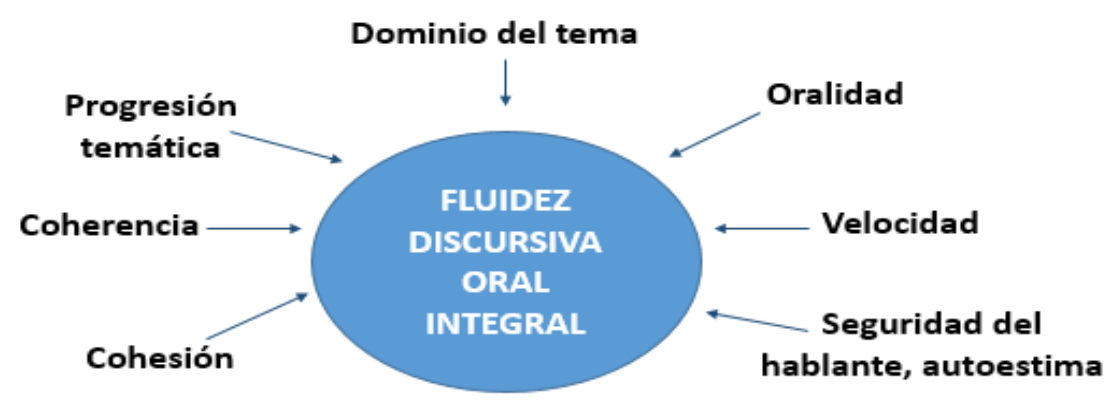


Con este gráfico se pretende mostrar que la fluidez discursiva es un producto compuesto, complejo e integral que depende de variables discursivas como el dominio que el hablante tenga del tema que está narrando, el hecho de que la narración avance e introduzca nuevos remas o nueva información, la coherencia o pertinencia de lo narrado, la cohesión entre las partes de la narración y también inter e intraenunciados.

También es importante la presencia o ausencia de fenómenos orales y su función, pertinencia o intencionalidad dentro de la producción discursiva oral. Todo esto se relaciona con la velocidad de la emisión discursiva representada en un número de palabras por minuto. No puede olvidarse el aspecto psicológico $^{2}$ de quien habla ya, que la autoestima y la seguridad se verán reflejadas en la fluidez del producto discursivo.

Esta tesis se divide en 10 capítulos. El primero explica la metodología, elección de los informantes, elaboración del corpus, grabación de las narraciones y transcripción oral de cada producción.

El segundo capítulo está formado por 66 discursos orales en versión transcrita que constituyen el corpus de trabajo al cual se aplicará el instrumento de evaluación de la oralidad. Se muestran allí los discursos con una ficha del informante en la cual se consignan datos biográficos de cada hablante grabado.

El tercer capítulo está dedicado a la fundamentación teórica del instrumento de evaluación. Están allí los autores que iluminan el análisis discursivo y de la oralidad y los

\footnotetext{
${ }^{2}$ Este aspecto lo evalúa la psicología y no hace parte del presente estudio.
} 
estudiosos que desde la psicolingüística proponen la forma en la cual se da la producción del discurso en su versión "habilidad para la producción oral".

El cuarto capítulo presenta el instrumento de evaluación. Este capítulo constituye la parte central de este trabajo y recoge la propuesta de la autora para valorar las narraciones orales de los hablantes de español. Presenta la evaluación del discurso desde el punto de vista cualitativo y la evaluación de la fluidez oral desde el punto de vista cuantitativo, aludiendo a fenómenos presentes en los registros orales y con una puntuación positiva o negativa dependiendo de la aparición del fenómeno dentro del discurso: su función, intencionalidad y pertinencia.

El quinto capítulo está dedicado a la aplicación del instrumento y a la obtención de cuadros consolidados por edades.

El sexto capítulo muestra los resultados de la evaluación y del análisis. Depende de los cuadros elaborados en el capítulo anterior y coteja los resultados de acuerdo con el resultado total de la evaluación.

El séptimo capítulo presenta una propuesta simplificada para realizar las evaluaciones en el futuro. Esta propuesta surge como resultado de la experiencia de grabación, transcripción y aplicación del instrumento y su objetivo es facilitar la aplicación de la evaluación en el mayor número de casos y grupos poblacionales posibles. Esta propuesta se inicia con la recolección del discurso, continúa con la transcripción y aplicación del instrumento y finaliza con la obtención de un resultado. 
En el capítulo 8 se presentan las conclusiones de este trabajo tanto desde el punto de vista teórico como desde el punto de vista de los resultados obtenidos.

El capítulo 9 está dedicado a las perspectivas de aplicación y nuevas investigaciones posibles como resultado del presente trabajo. Es importante señalar el alcance de esta propuesta y las modificaciones que pueden surgir para ser aplicado en diversos ámbitos.

Finalmente aparece la bibliografía que se utilizó para desarrollar este tema, tanto la referenciada como la consultada y aquella que fundamentó y alimentó la obtención de un instrumento de evaluación integral de la fluidez discursiva oral.

En el cederrón (CD) que acompaña este trabajo aparecen los cuadros, gráficos y tablas que se obtuvieron al aplicar el instrumento a los 66 discursos. Estos cuadros muestran con detalle cada evaluación tanto desde el punto de vista cualitativo, como desde el cuantitativo y finalmente señalan la forma como se obtiene un resultado integral para la producción narrativa oral de cada hablante. Se pueden observar en las tablas, las fòrmulas que dieron los resultados finales.

\section{Etapas del proceso de producción del discurso}

Contar una historia constituye una compleja tarea que involucra y pone en ejecución varios sistemas cognitivos, lingüísticos y sociales. Para que la historia llegue a 
un destinatario final (individual o colectivo) son necesarias tres etapas: producción mental, expresión verbal e interacción social.

La producción del discurso es un proceso mental de orden descendente. Se parte de una intención, se crea una idea semántica que se organiza sintáctica y fonológicamente para dar lugar a una realización concreta. El producto de ese proceso es lo que llamamos discurso.

En consecuencia, denominaré producción al proceso mental que tiene lugar en el cerebro de un hablante antes de emitir un sonido concreto. Esta fase interna del proceso es estudiada por la psicolingüística y actualmente se conocen varios modelos que muestran los pasos previos a la expresión: cómo transformar ideas en habla. (Garman, 1990).

La expresión constituye una segunda fase del proceso de producción y sucede en el momento en que se manifiesta realmente el objeto de los análisis lingüísticos y da lugar a los corpus de trabajo. "Las variables: salud, edad, desarrollo del lenguaje, conocimiento del tema y tarea, influyen en la fluidez del habla” (Menjura, 2007, p. 8).

Finalmente al hecho social mediante el cual se intercambian y comparten los productos lingüísticos se denomina interacción.

El proceso de producción de un discurso posee reglas específicas y tareas particulares que lo diferencian del proceso ascendente de la comprensión. En este sentido es preciso retomar a Kintsch y Van Dijk (1978) cuando hacen explícita la diferencia al 
afirmar: "That processes of production are not simply the reverse of processes of comprensión"33. Cuando se produce no se está desandando el camino de la comprensión.

Van Dijk y Kintsch plantean la producción del discurso mediante una serie de estrategias de tipo semántico y pragmático. Para ello establecen una distinción imprescindible entre las acciones y las intenciones y añaden que las acciones son representadas cognitivamente como intenciones, y sus objetivos, como propósitos.

A la habilidad discursiva de producir un discurso oral se la denomina fluidez discursiva oral integral (F.D.O.I.), puesto que la fluidez se toma como un producto de todas las habilidades discursivas del hablante en su expresión oral. La novedad del término está en la alternancia que surge entre la fluidez verbal, ya conocida y trabajada, y cuya evaluación se hace a través de una prueba que mide el número de palabras por minuto, que un hablante es capaz de producir; y la fluidez discursiva oral integral, que mide la fluidez en el contexto discursivo y como resultado de las constantes cualitativas y cuantitativas.

En resumen, y retomando lo dicho, esta tesis trata de una evaluación integral de la fluidez discursiva oral, teniendo en cuenta 3 aspectos fundamentales.

1. La fluidez narrativa: Entendida como la capacidad que tiene el hablante para construir una narración, atendiendo a las características y condiciones que exige la superestructura narrativa: personajes, acciones, partes, evaluación. Esta habilidad se mide a través de escalas cualitativas que son trasladadas a escalas cuantitativas con el objetivo de homogenizar los datos de todas las pruebas realizadas.

\footnotetext{
3 Pág. 261.
} 
2. La fluidez verbal: Definida como el número de palabras por minuto que un hablante es capaz de producir. En el instrumento de evaluación que se propone en esta tesis se mide el número de palabras en el contexto discursivo, no en palabras sueltas. Se cuenta el número de palabras y se divide entre el número de minutos o su fracción.

3. La fluidez oral: Corresponde al conteo de fenómenos de la oralidad tales como: repeticiones, alargamientos, pausas, bloqueos y otros que inciden positiva o negativamente en el desempeño discursivo oral del hablante. Se puntúan estos fenómenos según su aporte positivo o negativo al discurso en el cual aparecen, de acuerdo con las tablas, teorías y explicaciones propuestas que se detallarán más abajo

De la suma de los resultados para los puntos 2 y 3 se obtiene un valor (evaluación cuantitativa) que, combinada con la obtenida del punto 1 (evaluación cualitativa) da como resultado la fluidez discursiva oral integral, o evaluación definitiva para cada discurso. De todo ello se ofrecerán más pormenores en el capítulo correspondiente. 


\section{OBJETIVOS Y METODOLOGÍA}


"Lo que nue dicho a nadie se lo voa decir ahora"

Inf. 61MJ

\subsection{Presentación del problema}

Si el ser humano se comunica con discursos complejos o simples, largos o cortos, elaborados o sencillos, ¿por qué no se evalúa su producción discursiva como manifestación de sus habilidades y capacidades lingüísticas? ¿Por qué no se evalúa su producción en contextos naturales y como unidad comunicativa?

El discurso narrativo oral es de gran complejidad -“el análisis más complejo del discurso conversacional” (Briz, 2000, p. 29) -, y a esa complejidad debe atender su análisis y también su evaluación sistemática. El tejido que forma el discurso es uno en el cual todos sus elementos se relacionan, se conectan e interactúan. Y todos ellos responden a las características del hablante, son reflejo de sus habilidades comunicativas, de su capacidad cognitiva, de su competencia lingüística y también, de sus falencias en estos mismos aspectos. 


\subsection{Objetivo General}

Realizar una propuesta de análisis y evaluación de los discursos basados en la teoría psicolingüística y en la lingüística textual.

\subsection{Objetivos específicos}

- Establecer la calidad del discurso en función de la presencia de los fenómenos psicolingüísticos de la oralidad.

- Desarrollar un instrumento de tipo lingüístico para determinar la pertinencia o no pertinencia de cada uno de los fenómenos psicolingüísticos que aparecen en el corpus.

- Relacionar la co-presencia de los fenómenos en el discurso.

- Diseñar una batería de evaluación de los discursos, centrados especialmente en el estudio de las disfluencias del habla. 


\subsection{Justificación}

El estudio del discurso oral es un campo que cobra gran importancia a partir de los años $60^{4}$. Durante siglos, los estudios lingüísticos y literarios privilegiaron la palabra escrita y desconocieron la oral por considerar que la primera gozaba de incalculable valor y calidad; también por la dificultad para aprehender la oralidad y estudiarla. Hoy la historia es otra, el estudio de la lengua hablada y especialmente de la conversación, adquiere una importancia magna ya que se destaca la producción oral al considerarla como la forma natural de expresión humana.

La aparición de la investigación cualitativa es otro motor científico que impulsa la aproximación a las prácticas conversacionales en las cuales es posible encontrar historias de vida, modelos del mundo fundamentales para aprehender una cultura y para comprender los procesos individuales internos a través de los cuales el ser humano construye y transforma su propio mundo.

La investigación que se esboza en este proyecto parte precisamente de un corpus de conversaciones y narraciones; con las teorías y metodologías del análisis del discurso se aproxima a ellas para describirlas y tratar de explicar las características y las habilidades discursivas que es posible vislumbrar en estos productos.

\footnotetext{
${ }^{4}$ Se hace un esbozo en la segunda parte del libro de Teun A. Van Dijk (2003), sobre el contexto del análisis del discurso.
} 
Si tomamos la metáfora de una fábrica, tendríamos que el corpus discursivo a analizar constituye un producto, y las características de ese producto nos hablan de su productor y del tipo de procesos a través del cual se generó.

El estudio de los fenómenos psicolingüísticos en las narraciones de los ancianos constituye un tema específico cuya aproximación sistemática no ha sido desarrollada de manera ampliada y suficiente hasta el momento presente.

Su validez científica está determinada por la posibilidad que brinda de evaluar los discursos orales y cuya aplicación podría ser extensiva a todas las edades.

Particularmente sería un instrumento valioso que, junto con la evaluación de otras habilidades discursivas, permitiría evaluar objetivamente el desempeño lingüístico de las personas. Este instrumento sería muy útil en la enseñanza de segundas lenguas, psicopedagogía y en terapia del lenguaje o logopedia.

\subsection{Tipo de investigación}

\subsubsection{Consideraciones acerca del aspecto cualitativo de la investigación}

Se inscribe este trabajo dentro de la propuesta de la investigación cualitativa ya que en sí misma reúne una serie de características que hacen que adquiera este nombre: 
1. El corpus de trabajo corresponde a narraciones de hablantes reales. Se trata de una narración que corresponde a un segmento de vida y memoria del entrevistado. Es una narración de carácter biográfico que muestra una experiencia más o menos real en la vida del informante. El entrevistador construye cooperativamente la narración y le atribuye significados, se emociona y se involucra en ella. No puede mantenerse ajeno a lo que escucha. Además no debe hacerlo puesto que se trata de una interacción y el entrevistado debe sentirse escuchado y atendido y en algunos casos pide su opinión al entrevistador.

2. El observador es participante en la investigación: al menos en la primera parte, cuando se trata de hacer la aproximación preliminar a los informantes y de recoger la información, la habilidad del investigador es fundamental. En este caso se puede afirmar que el observador participa directamente en la interacción y forma parte de la escena comunicativa.

3. No es posible conocer, de antemano, los datos con los cuales se va a trabajar. No se pueden hacer hipótesis apriorísticas sino que se prefiere derivar hipótesis del corpus resultante. El observador hace preguntas para precisar algunos datos o para aclarar dudas o simplemente para mantener la conversación y no dejar que decaiga el entusiasmo del informante: función fática.

4. No es posible recuperar los datos que se hayan perdido. Si una grabación se borra, otra nueva que se haga será diferente a la primera. Las condiciones sociosituacionales habrán cambiado y las conclusiones a las cuales se llega a partir de esa grabación pueden variar con respecto a la anterior. 
5. Es pertinente delimitar el campo de observación, las grabaciones que se hagan no pueden ser ilimitadas ya que eso desbordaría las posibilidades de la investigación.

6. La muestra ha de ser suficiente y representativa. No por tratarse de una toma de muestras de carácter cualitativo se debe dejar al antojo del investigador la cantidad de muestras. Es necesario obtener un corpus suficiente para el trabajo y equilibrado en cuanto a las condiciones de los informantes. En este caso se ha tomado un número igual para cada país, se han respetado las características relativas a la edad y se ha equilibrado la muestra con relación al sexo. Es decir similar número de informantes varones que de informantes mujeres.

7. Es necesario elegir técnicas de observación adecuadas. Para cada informante se realiza un seguimiento y una "conquista". Nunca se graba a alguien sin que este lo sepa, no se graba en la primera entrevista. Se da un margen para familiarizarse con el observador, con la grabadora y con el tipo de trabajo que se hace. Se destaca el valor que la narración del informante tiene para el investigador y se le otorga la calidad de protagonista, con lo cual no se ve forzado a contar una historia, sino, antes bien, orgulloso de hacerlo, honrado por ser elegido y útil a la ciencia.

8. Contexto situacional del informante. La actitud del investigador es humilde y en ningún momento muestra relaciones de poder frente a su entrevistado. Le otorga importancia y protagonismo. Lo aborda en su contexto natural: el café, la casa, el parque, la residencia de ancianos. Un lugar donde se sienta a gusto y forme parte 
de su cotidianidad. En este caso se trata de dos encuestadores (hombre y mujer) que graban indistintamente a informantes de su mismo sexo o del sexo opuesto.

\subsubsection{Consideraciones acerca del aspecto cuantitativo de la investigación}

Una vez obtenido un texto escrito a partir de las grabaciones viene un segundo paso de naturaleza diferente a la primera. Aquí se trata de encontrar los fenómenos recurrentes en los discursos, contabilizarlos, sistematizarlos y aplicarles el tratamiento estadístico que da cuenta de la incidencia del fenómeno, de su prevalencia y de su grado de aparición.

Los datos obtenidos aquí servirán de base para elaborar la caracterización del discurso en la $3^{\mathrm{a}}$ edad. Capítulo que constituye el eje central y principal de esta investigación.

\subsection{Problemas inherentes a este tipo de trabajo}

Un trabajo de este tipo resulta enormemente escurridizo, ya que su naturaleza fronteriza lo caracteriza de este modo, y corre el riesgo de desvirtuarse y adquirir matices insospechados o escapar al control del investigador. Es preciso mantener enfocado el problema y trabajar específicamente en la resolución de las cuestiones planteadas como objetivo. 
Los informantes también plantean sus propias dificultades, ya que desaparecen temporalmente por enfermedad o cualquier otra circunstancia, o desaparecen definitivamente debido a su edad. Si se quiere constatar algún dato o hacer alguna precisión, probablemente ya no encontremos al informante.

Aparte de ello, las distancias geográficas son inconvenientes en el mismo sentido de la observación anterior. No se puede regresar fácilmente al lugar donde se hicieron las grabaciones.

El imperativo de mantener el contexto cotidiano del informante plantea dificultades para la grabación, por cuanto las condiciones técnicas de la misma son mínimas y los ruidos del entorno dificultan posteriormente la transcripción total.

Grabar las interacciones supone otro problema, en tanto que es difícil hacer acopio exhaustivo de los signos extraverbales que acompañan al discurso: gestos, ademanes y movimientos.

\subsection{Constitución de un corpus de trabajo}

El corpus de análisis en este trabajo está constituido por la grabación de 70 narraciones, y su correspondiente transcripción. De estas grabaciones fue necesario descartar algunas debido a las características teóricas de la grabación. Al final se pudieron aprovechar 66, que constituyen la base para formar el corpus discursivo. 
Se trata de analizar la producción lingüística contextualizada de un informante, con lo cual el analista toma distancia y se convierte en observador de una conducta discursiva global. Existen investigaciones en lingüística en las cuales el objeto de análisis no está desligado de la propia producción del investigador. En este trabajo el investigador forma parte de la interacción en la recopilación de las narraciones, pero al hacer el análisis toma distancia de esa producción e intenta trabajar objetivamente sobre ella.

Las muestras a analizar se toman siguiendo algunas pautas:

1. Solicitud de permiso a la residencia o a la persona elegida ${ }^{5}$, para realizar la grabación y la toma de muestras.

2. Visitas periódicas a la institución o persona para realizar un acercamiento y toma de confianza, antes de hacer las grabaciones.

3. Grabación de los discursos o entrevistas con el consentimiento del entrevistado. Se empieza una conversación normal y cotidiana, dentro de la cual se pide al informante que cuente una experiencia de su vida pasada (infancia o juventud). Si este no encuentra una anécdota o hecho para contar se le pregunta si ha estado en peligro de muerte ${ }^{6}$ o se le pregunta por su trabajo, con el fin de estimularle a que hable y narre una historia.

\footnotetext{
5 En cuanto a los informantes de las residencias geriátricas fueron los encargados de tales centros quienes determinaron la posibilidad de entrevistar o no a cada persona, de acuerdo con las condiciones de salud y disponibilidad de los ancianos, que ellos conocen de antemano.

${ }^{6}$ La idea de preguntar si ha estado en peligro de muerte fue utilizada por William Labov en sus investigaciones y con ella se pretende recuperar una situación límite del informante, ante la cual olvida que está siendo grabado y se accede de este modo más rápida y fácilmente a su registro vernacular o al registro no formal del habla.
} 
4. Elaboración de una ficha del informante en la cual se registren sus datos personales, y algunas de sus características pertinentes, como las enfermedades que puedan incidir en su discurso, así como sus aficiones y actividades, en la medida en que también puedan dar razón de la prevalencia de algunas características o la no presencia de algunos fenómenos.

5. Finalmente, se consolida el corpus al ponerlo por escrito. La labor de transcripción requiere a su vez la toma de algunas decisiones acerca de lo que se consigna o se deja de consignar. En este caso se atiende principalmente y como foco central a los elementos que se evaluarán a lo largo de la siguiente fase del trabajo, los cuales se detallarán más adelante.

\subsubsection{Elección de informantes}

Los informantes elegidos para ser grabados se ajustan a las siguientes características:

1. Edades comprendidas entre los 11 y los 93 años.

2. En uso de sus facultades mentales.

3. Con posibilidad de hablar.

4. Que aceptaron libremente ser grabados.

5. Número equilibrado entre hombres y mujeres. 
Tabla 1: Datos generales de informantes

\begin{tabular}{|c|c|c|c|}
\hline $\begin{array}{c}\text { CÓDIGO } \\
\text { INFORMANTE }\end{array}$ & $\operatorname{EDAD}^{7}$ & NACIONALIDAD ${ }^{8}$ & SEXO \\
\hline $1 \mathrm{D}$ & 14 & COLOMBIA & $M$ \\
\hline $2 \mathrm{R}$ & 18 & COLOMBIA & $M$ \\
\hline $3 \mathrm{~L}$ & 14 & COLOMBIA & $\mathrm{M}$ \\
\hline $4 \mathrm{JC}$ & 14 & COLOMBIA & M \\
\hline $5 \mathrm{G}$ & 13 & COLOMBIA & $\mathrm{F}$ \\
\hline $6 \mathrm{M}$ & 11 & COLOMBIA & $\mathrm{F}$ \\
\hline $7 \mathrm{~W}$ & 14 & COLOMBIA & M \\
\hline $8 \mathrm{D}$ & 15 & COLOMBIA & $\mathrm{M}$ \\
\hline 9DF & 20 & COLOMBIA & $\mathrm{F}$ \\
\hline $10 \mathrm{R}$ & 28 & COLOMBIA & $\mathrm{F}$ \\
\hline $11 \mathrm{AC}$ & 52 & COLOMBIA & $\mathrm{F}$ \\
\hline $12 \mathrm{R}$ & 40 & COLOMBIA & $\mathrm{M}$ \\
\hline $13 \mathrm{H}$ & 45 & COLOMBIA & $\mathrm{M}$ \\
\hline $14 \mathrm{AM}$ & 50 & ESPAÑA & M \\
\hline $15 \mathrm{MG}$ & 57 & ESPAÑA & $\mathrm{F}$ \\
\hline $16 \mathrm{MC}$ & 55 & ESPAÑA & $\mathrm{F}$ \\
\hline 17DM & 50 & ESPAÑA & $\mathrm{F}$ \\
\hline $18 \mathrm{CR}$ & 62 & ESPAÑA & $\mathrm{F}$ \\
\hline $19 \mathrm{MR}$ & 62 & ESPAÑA & $\mathrm{F}$ \\
\hline $20 \mathrm{MC}$ & 75 & ESPAÑA & $\mathrm{F}$ \\
\hline $21^{\mathrm{a}}$ & 45 & ESPAÑA & $\mathrm{M}$ \\
\hline $22 \mathrm{MP}$ & 70 & ESPAÑA & $\mathrm{F}$ \\
\hline 23LR & 50 & ESPAÑA & M \\
\hline $24 \mathrm{VV}$ & 48 & ESPAÑA & M \\
\hline $25 \mathrm{AL}$ & 63 & ESPAÑA & $\mathrm{M}$ \\
\hline 26AQ & 66 & ESPAÑA & $\mathrm{M}$ \\
\hline $27 \mathrm{MC}$ & 75 & ESPAÑA & M \\
\hline $28 \mathrm{JV}$ & 60 & ESPAÑA & $\mathrm{F}$ \\
\hline $29 \mathrm{P}$ & 50 & ESPAÑA & $\mathrm{M}$ \\
\hline $30 \mathrm{D}$ & 38 & COLOMBIA & $\mathrm{F}$ \\
\hline $31 \mathrm{~J}$ & 42 & COLOMBIA & $\mathrm{F}$ \\
\hline
\end{tabular}

\footnotetext{
${ }^{7}$ La edad de los informantes corresponde al momento en el cual se tomó la muestra o se realizó la grabación para los informantes de la guerra civil española, esta edad corresponde a las grabaciones realizadas por investigadores de la Universidad Complutense de Madrid dentro del proyecto de Fuentes Orales, y las entrevistas fueron realizadas en su mayoría en 1982 y algunas en 1983.

${ }^{8}$ Existen 3 grupos de informantes de acuerdo con su nacionalidad: Españoles, Costarricenses y Colombianos. Todos entrevistados en su país de origen.
} 


\begin{tabular}{|c|c|c|c|}
\hline 32JMC & 48 & COLOMBIA & $\mathrm{M}$ \\
\hline $33 \mathrm{H}$ & 52 & COLOMBIA & $\mathrm{F}$ \\
\hline $34 \mathrm{M}$ & 40 & COLOMBIA & $\mathrm{F}$ \\
\hline $35 \mathrm{R}$ & 85 & COLOMBIA & $\mathrm{M}$ \\
\hline $36 \mathrm{C}$ & 79 & COLOMBIA & $\mathrm{F}$ \\
\hline $37 \mathrm{CM}$ & 70 & ESPAÑA & $\mathrm{F}$ \\
\hline $38 \mathrm{M}$ & 74 & COLOMBIA & M \\
\hline $39 \mathrm{H}$ & 76 & COLOMBIA & $\mathrm{M}$ \\
\hline $40 \mathrm{~T}$ & 75 & COLOMBIA & $\mathrm{M}$ \\
\hline $41 \mathrm{~S}$ & 81 & COLOMBIA & M \\
\hline $42 \mathrm{R}$ & 80 & COLOMBIA & $\mathrm{M}$ \\
\hline $43 \mathrm{E}$ & 91 & COLOMBIA & $\mathrm{F}$ \\
\hline $44 \mathrm{C}$ & 80 & COLOMBIA & M \\
\hline $45^{\mathrm{a}}$ & 78 & COLOMBIA & $\mathrm{M}$ \\
\hline $46 \mathrm{JB}$ & 88 & COLOMBIA & $\mathrm{M}$ \\
\hline $47 \mathrm{I}$ & 76 & COLOMBIA & $\mathrm{F}$ \\
\hline $48 \mathrm{~L}$ & 80 & COLOMBIA & $\mathrm{M}$ \\
\hline $49 \mathrm{~S}$ & 75 & COLOMBIA & $\mathrm{F}$ \\
\hline $50 \mathrm{MA}$ & 88 & COSTA RICA & $\mathrm{M}$ \\
\hline $51 \mathrm{M}$ & 75 & COSTA RICA & $\mathrm{M}$ \\
\hline $52 \mathrm{TJ}$ & 76 & COSTA RICA & $\mathrm{M}$ \\
\hline $53 \mathrm{GH}$ & 80 & COSTA RICA & $\mathrm{M}$ \\
\hline $54 \mathrm{DM}$ & 75 & COSTA RICA & $\mathrm{F}$ \\
\hline $55 \mathrm{C}$ & 75 & COSTA RICA & $\mathrm{F}$ \\
\hline $56 \mathrm{R}$ & 87 & COSTA RICA & $\mathrm{M}$ \\
\hline $57^{a}$ & 88 & COSTA RICA & $\mathrm{F}$ \\
\hline $58 \mathrm{E}$ & 90 & COSTA RICA & $\bar{M}$ \\
\hline $59^{\circ}$ & 77 & COSTA RICA & $\mathrm{M}$ \\
\hline $60 \mathrm{~F}$ & 86 & ESPAÑA & $\mathrm{F}$ \\
\hline $61 \mathrm{MJ}$ & 75 & ESPAÑA & $\mathrm{F}$ \\
\hline $62 \mathrm{P}$ & 84 & ESPAÑA & $\mathrm{F}$ \\
\hline $63 \mathrm{FP}$ & 79 & ESPAÑA & $\mathrm{M}$ \\
\hline $64 \mathrm{AV}$ & 93 & ESPAÑA & $\mathrm{F}$ \\
\hline $65 \mathrm{~T}$ & 75 & ESPAÑA & $\mathrm{M}$ \\
\hline $66 \mathrm{P}$ & 75 & ESPAÑA & $\mathrm{F}$ \\
\hline
\end{tabular}


Tabla 2: Clasificación de informantes por variables

\begin{tabular}{|c|c|c|c|}
\hline \multicolumn{5}{|c|}{ NACIONALIDAD } \\
\hline Colombia & España & Costa Rica \\
\hline 32 & 24 & 10 \\
\hline \multicolumn{3}{|c|}{ EDAD } \\
\hline $\begin{array}{c}\text { Jóvenes de 11-20 } \\
\text { años }\end{array}$ & $\begin{array}{c}\text { Adultos jóvenes de } \\
21-50 \text { años }\end{array}$ & $\begin{array}{c}\text { Adultos mayores de } \\
51-74 \text { años }\end{array}$ & $\begin{array}{c}\text { Adultos avanzados } \\
75-95 \text { años }\end{array}$ \\
\hline 9 & 13 & 12 & 32 \\
\hline \multicolumn{3}{|c|}{ SEXO } \\
\hline Hombres & \multicolumn{3}{c}{ Mujeres } \\
\hline
\end{tabular}

\subsubsection{Grabación de narraciones}

La entrevista que da lugar a la obtención de las grabaciones es de tipo no estructurada-formal. En este tipo de entrevista existe un margen más o menos grande de libertad para formular las preguntas y las respuestas. No se guía por un cuestionario o modelo rígido.

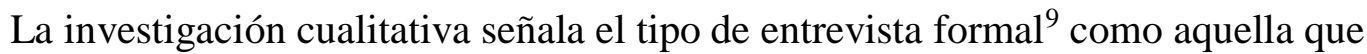
se reduce a una simple conversación sobre el tema en estudio. Lo importante no es definir los límites de lo tratado ni ceñirse a algún esquema previo, sino "hacer hablar" al entrevistado, obtener un panorama de los problemas más sobresalientes, de los mecanismos lógicos y mentales del entrevistado, y de los temas que para él resultan de

\footnotetext{
${ }^{9}$ Steinar Kvale (1996) define que el propósito de la entrevista en la investigación cualitativa es “obtener descripciones del mundo de vida del entrevistado respecto a la investigación de los significados de los fenómenos descritos".
} 
importancia. Lo más importante es dar al entrevistado la sensación clara y definida de que puede hablar libremente, alentándolo y estimulándolo para que lo haga y cuidando de no influirlo demasiado con nuestras actitudes o las palabras que decimos.

En este sentido y como se ha expresado en otros apartes de este documento, lo fundamental es plantear un estímulo al entrevistado y permitirle un desarrollo sin interferencias o con las mínimas posibles, para que dé cuenta de su vida y su relación con sus experiencias. Es una forma de dar sentido a las vivencias, sentido que está determinado por la selección de la información y por la organización de la misma, y por lo tanto, la entrevista de investigación constituye una experiencia única y enriquecedora para el entrevistado, quien a lo largo de ella puede obtener visiones nuevas acerca de su propia situación de vida.

La técnica de grabación es compatible con el tipo de entrevista, y en este sentido, se trata de grabaciones formales, aunque realizadas en un contexto habitual para el entrevistado: la cafetería, el bar, la residencia de ancianos o su domicilio familiar. Aparte de la pregunta preestablecida para animar al hablante no existe guion de grabación. Esta técnica tiene sus dificultades implícitas, ya que al no contar con condiciones especiales para la grabación se obtiene un producto que en ocasiones presenta ruidos de fondo, conversaciones simultáneas e interferencias.

Estas condiciones dificultan la trascripción de las narraciones y en ocasiones las distorsiones que impone el medio se acentúan por la inexperiencia del hablante frente a la grabadora, ya que con su cuerpo o sus manos obstaculiza la comunicación con la 
grabadora y esto hace que muchas palabras o expresiones sean imperceptibles en la trascripción.

Existen por lo menos 4 grupos de informantes de acuerdo con la forma y el lugar en el cual se tomaron las grabaciones:

1. Adultos mayores entrevistados en residencias de ancianos en Costa Rica (Residencia de mayores Francisca Valerio Badilla), Colombia (Nuestra señora del Rosario, San Francisco), y España (Los Rosales).

2. Adultos mayores entrevistados en otro lugar de permanencia habitual: cafetería, bar, parque, domicilio familiar.

3. Adolescentes grabados en el hogar de menores El Arca, en Cundinamarca, Colombia. Estos adolescentes fueron niños de la calle ${ }^{10}$ que actualmente están en proceso de acogida y reinserción ${ }^{11}$ en la sociedad, porque debido a sus circunstancias pasadas han tenido experiencias con las drogas, han sufrido abusos sexuales, han tenido embarazos y abortos, en algunos casos han cometido algún delito.

4. Adultos grabados en su lugar de trabajo, estudio o residencia familiar.

\footnotetext{
${ }^{10}$ En Colombia se les llama comúnmente gamines.

${ }^{11}$ Aunque se trata de niños de la calle que habitualmente hablan en una jerga muy característica y cerrada a su grupo, sin embargo no se ve ningún rasgo de esta jerga en las narraciones obtenidas, ya que las condiciones del hogar les prohíben utilizar su léxico, entonación y pronunciación habituales, como parte del proceso de rehabilitación. Además cada vez que llega un chico nuevo al hogar deben presentarse y contar cómo llegaron al hogar y cómo se sienten en él, con lo cual para ellos es una rutina diaria hablar de este tema y esto se nota en la fluidez, dominio y brevedad de las entrevistas realizadas.
} 
5. Grabaciones recopiladas y transcritas a partir del seminario de Fuentes Orales de la universidad Complutense de Madrid y cuyas copias magnetofónicas pertenecen al Archivo Histórico de la Guerra Civil Española que reposa en Salamanca.

En el caso de las grabaciones obtenidas en el Archivo Histórico de la Guerra Civil es necesario señalar que no fueron realizadas por la autora. Fue mediante un permiso especial que se pudo acceder a ellas y a las trascripciones hechas por los investigadores de la Universidad Complutense de Madrid. Son documentos de valor incalculable que corresponden a testimonios de personas que vivieron la guerra civil (1936-1939) y sus rigores: el miedo, el hambre, la pobreza, la muerte, la incertidumbre, la injusticia, la deportación, el exilio y el rigor de los campos de concentración. Estos testimonios hablan también de las represalias que sufrieron las víctimas del franquismo y las estrategias que utilizaron las mujeres para comunicarse con sus esposos mientras ellos permanecían en los campos de batalla, así como de los medios empleados para obtener alimentos en épocas de racionamiento de comida.

\subsubsection{Transcripción de narraciones grabadas}

Transcribir la oralidad es una dificultad que se plantea en este trabajo y ante la cual es pertinente hacer algunas precisiones.

Qué se transcribe para este trabajo:

1. El discurso como tal de los informantes, tratando en lo posible de centrarnos en el punto en el cual narran o cuentan alguna experiencia. 
2. Las informaciones contextuales y gran parte de la información gestual. Esta se pone entre paréntesis.

3. Los rasgos entonativos se marcan de acuerdo con las convenciones abajo indicadas.

4. Los énfasis, vacilaciones, alargamientos y pausas, no solo propios de la oralidad sino algunos acentuados por el enlentecimiento de habilidades propias de la edad que se estudia.

Se hace la transcripción a dos columnas. En la primera aparece la inicial del nombre del informante; en la segunda el contenido enunciado, los elementos suprasegmentales, contextuales, rasgos proxémicos y kinésicos con los cuales acompaña el informante su discurso.

\subsubsection{Convenciones de la transcripción}

A continuación se presenta la lista de convenciones utilizadas para transcribir estos discursos. Algunas de ellas son tomadas de las propuestas por los recopiladores de corpus orales y por los teóricos de la conversación ${ }^{12}$. Se han elegido no solo aquellas que responden a la caracterización de este trabajo sino también aquellas que resultasen más

12 Antonio Briz (1998), Amparo Tusón y Helena Calsamiglia (1999). Estas últimas recogen varios sistemas de convenciones en su obra. 
cómodas de insertar en el texto. ${ }^{13}$ Algunos ajustes son propios de la autora por lo cual se hacen explícitas las usadas y el fenómeno que representan.

Tabla 3: Convenciones de la transcripción

\begin{tabular}{|c|c|}
\hline CONVENCIÓN & FENÓMENO \\
\hline $\mathbf{X}$ & $\begin{array}{l}\text { Inicial del nombre del informante, del } \\
\text { entrevistador o participante. }\end{array}$ \\
\hline$(\mathbf{X X X})$ & Porción ininteligible del discurso. \\
\hline / & Pausa o corte breve en el discurso. \\
\hline // & Pausa entre 0,5 y 1 segundo. \\
\hline$/ / /$ & Pausa de entre 1 y 1,5 segundos. \\
\hline$\left(5^{\prime}\right)$ & $\begin{array}{l}\text { Las pausas de duración superior se } \\
\text { especifican entre paréntesis por ser más } \\
\text { significativas para el análisis. }\end{array}$ \\
\hline , & $\begin{array}{l}\text { Unión de dos o más palabras en una } \\
\text { misma. Fenómeno de coalescencia léxica. }\end{array}$ \\
\hline$::::$ & $\begin{array}{l}\text { Alargamiento de un sonido. El número de } \\
\text { puntos indica el mayor o menor grado de } \\
\text { alargamiento. Uno, alargamiento breve; } \\
\text { dos, tres o cuatro, alargamiento más } \\
\text { largo. }\end{array}$ \\
\hline ¿? & Pregunta o interrogación. \\
\hline$\vdots !$ & Exclamación o admiración. \\
\hline NADA & $\begin{array}{l}\text { Uso de las mayúsculas para expresar } \\
\text { énfasis o detenimiento en determinada } \\
\text { palabra o expresión. }\end{array}$ \\
\hline$[\ldots]$ & Texto que se ha dejado de transcribir. \\
\hline$\uparrow$ & Tonema ascendente. \\
\hline
\end{tabular}

${ }^{13}$ Este trabajo no da cuenta de los procesos interacciónales de la conversación; por esta razón no marca solapamientos ni toma de turnos dentro de la transcripción. 


\begin{tabular}{|c|c|}
\hline$\rightarrow$ & Tonema plano. \\
\hline$\downarrow$ & Tonema descendente. \\
\hline (EXPLICACIÓN) & $\begin{array}{c}\text { Las observaciones contextuales aparecen } \\
\text { entre paréntesis y en mayúsculas fijas. }\end{array}$ \\
\hline Sílaba & $\begin{array}{c}\text { Una sílaba subrayada marca un } \\
\text { desplazamiento acentual de su lugar de } \\
\text { origen a otro dentro de la misma palabra. }\end{array}$ \\
\hline
\end{tabular}

Aun con la comodidad que supone utilizar unas convenciones, la naturaleza oral se resiste a ser puesta por escrito, con lo cual resulta inexacto, aunque necesario, todo registro escrito de lo oral. Una muestra de lo anterior aparece en Brown y Yule (2003): "El hablante que planifica su discurso ahora, sintiéndose amenazado por el deseo de su interlocutor de iniciar su turno, se suele repetir bastante y usa la misma estructura sintáctica, las mismas piezas léxicas, echando mano de la primera palabra que le viene a la mente en vez de emprender la caza del mot juste, llenando las pausas con muletillas. El resultado global es la producción de una densidad informativa mucho menor que la que caracteriza a la lengua escrita." (p. 39)

En afirmaciones como la anterior están de acuerdo quienes se dedican a la elaboración de corpus orales, y en ese sentido es pertinente reconocer que la validez de la transcripción es relativa y que sería pertinente implementar un sistema de constitución de corpus, mucho más fiel y objetivo, como en el caso de las grabaciones en video. Sin embargo la manipulación del estudio del corpus en video resultaría mucho más incómoda para el investigador que quiere adentrarse en el posterior análisis.

El riesgo de la transcripción estriba en la incapacidad de materializar el sentido y el significado original del discurso oral, el que le fue dado por el contexto y precisado por 
la entonación y los rasgos kinésicos, los cuales se describen pero no se materializan suficientemente al realizar un ejercicio de este tipo.

La segunda parte del trabajo se hace siguiendo unas pautas preestablecidas para dar uniformidad al análisis y permitir la sistematización y comparación de los resultados.

Una vez obtenidos los datos del análisis de esta parte se procede a elaborar una síntesis, en la cual se da cuenta de los fenómenos encontrados y de la regularidad y sistematicidad o asistematicidad de los mismos. En este capítulo se conjugan todos los elementos expuestos a lo largo de todo el trabajo. Es un capítulo integrador de los resultados y logros obtenidos. 
2. CORPUS 
El presente corpus recoge la versión escrita de las grabaciones obtenidas para esta tesis. Consta de 66 producciones y es antecedida por una breve descripción del informante en la cual se consigna su edad, nacionalidad y sexo.

No recoge el nombre del informante por razones de homogeneidad, ya que algunos informantes prefirieron que se omitiera su nombre por el contenido de la historia contada o por vergüenza. En este momento de la evaluación es preferible omitir este dato.

No sucede igual en la evaluación de alumnos o pacientes en cuyo caso es imprescindible tener el nombre del informante paciente o usuario a evaluar. Por lo tanto se recomienda seguir una ficha del informante o del paciente a evaluar

El corpus escrito está dividido en dos columnas. En la primera se especifica con inicial mayúscula a los participantes en la interacción, y en la segunda se coloca el texto de lo dicho acompañado de las observaciones contextuales. Es pertinente señalar en este capítulo que existe la transcripción a tres columnas, de modo que la columna tres corresponde al contexto. Este tipo de transcripción no fue preferido para este trabajo puesto que no especifica exactamente el lugar en el que ocurren o deben incluirse los datos contextuales.

Este corpus lingüístico y discursivo se ofrece como un material valioso para trabajos posteriores, tal como queda especificado en el capítulo 9, denominado "Perspectivas de aplicación y nuevas investigaciones”. 
1D

Edad: 14 años

Nacionalidad: Colombia

Sexo: Masculino

\begin{tabular}{|c|c|}
\hline Informante & Discurso \\
\hline $\mathrm{D}$ & $\begin{array}{l}\text { Yo llegué el } 23 \text { de marzo de } 2001 \uparrow \text { a mí me recibieron María y } \\
\text { Evangelina } \downarrow \text { Yo llegué al hogar El Arca por un centro de día que se } \\
\text { llama el Álamo porque estaba en la calle } \downarrow \text { Me gusta cocinar } \uparrow \text { jugar a } \\
\text { la pelota } \downarrow \text { Me hice amigo de Lucas } \uparrow \text { Roberto y Yoly } \downarrow \text { Me llevo muy } \\
\text { bien con los coordinadores Mirta y Martín } \downarrow \text { En la calle me puse a } \\
\text { trabajar de embolador estaba en Retiro } \downarrow\end{array}$ \\
\hline
\end{tabular}

2R

Edad: 18 años

Nacionalidad: Colombia

Sexo: Masculino

\begin{tabular}{|l|l|}
\hline Informante & \multicolumn{1}{c|}{ Discurso } \\
\hline $\mathrm{R}$ & $\begin{array}{l}\text { Cuando yo decidí salir de la calle tuve que tener paciencia, no sabía que } \\
\text { había que esperar un montón } \downarrow \text { Primero pasé por un lugar de tránsito } \\
\text { donde me evaluaron como era } \uparrow \text { después de tanto me derivaron al hogar }\end{array}$ \\
Fue mi primera casa en donde vivía con muchos muchachos $\uparrow$ yo no tengo \\
hermanos// y tengo una familia despelotada $\downarrow$ En el hogar aprendí otra \\
forma de vida:/// aprendí a compartir $\uparrow$ a resolver los problemas \\
hablando $\downarrow / / /$ a confiar en los adultos porque no confiaba en nadie $\downarrow / / /$ \\
estaba hecho de rencor y odio por todo el mal trato que tuve’n los tres \\
años y medio qu'estuve en la calle $\downarrow$ Los adultos me ayudaron a poder \\
abrirme y poder charlar los problemas $\uparrow / / /$ también me consiguieron a \\
alguien para que pudiera decirle mis problemas más profundos $\uparrow /$ esa \\
persona es Guillermo $\downarrow / / /$ mi psicólogo $\downarrow$ Todavía estoy’aciendo terapia \\
$\rightarrow$ /haciendo lo que me gusta que es dibujar y’estudiar $\downarrow$ Convivo con \\
muchos muchachos $\downarrow / / /$ muchos de los que me recibieron ya se fueron \\
pero el tiempo te cambia un montón $\downarrow$ Pasé de ser mediano a ser grande y \\
de ser medio irresponsable $\uparrow$ a responsable $\downarrow$ Yo no sabía lo que era el \\
hogar $\uparrow$ con el tiempo fui conociendo y adaptándome a convivir con tanta \\
gente en una casa $\downarrow$ Me gusta mucho porque somos un montón $\uparrow$ y nos \\
ayudamos en todo $\downarrow$ También hay algo muy importante $\downarrow / / / a$ veces $\uparrow$ \\
cuando no podemos decir los problemas a los coordinadores recurrimos \\
al muchacho de más confianza para poder decírselo y poder desahogarte $\downarrow$ \\
En la década que ingresé fue un poco fuerte porque yo era mediano y \\
todos los grandes ya se estaban abriendo del hogar, cada uno fue armando \\
su vida algunos individualmente y otros en una quinta d’egreso que \\
incorporó el hogar $\downarrow$ En esa quinta ya son más independientes porque \\
ellos mismos tienen que pagar todos los impuestos $\uparrow$ no está muy lejos del \\
hogar $\downarrow$ \\
Muchas veces lo sentí cuando se fue alguno de los muchachos a su casa \\
o a la calle porque vieron que podían vivir en el hogar y no lo \\
aprovecharon $\downarrow$
\end{tabular}


3L

Edad: 14 años

Nacionalidad: Colombia

Sexo: Masculino

\begin{tabular}{|c|c|}
\hline Informante & Discurso \\
\hline $\mathrm{L}$ & $\begin{array}{l}\text { Yo vine al hogar en } 1994 \uparrow / / / \text { mi hermano Walter me trajo } \downarrow / / / \text { Conocí a } \\
\text { los muchachos } \downarrow \text { a Marta } \rightarrow \text { a Bety y a Betina } \downarrow / / / \text { Estábamos las } \\
\text { muchachas y los muchachos en la casa de Cota } \downarrow \text { La mudanza fue porque } \\
\text { la casa de Cota estaba a punto de caerse y entonces las muchachas } \\
\text { pasaron a nuestra casa y nosotros compramos otra casa mas p'arriba } \downarrow \\
\text { Tengo en el hogar de varones una piscina muy grande } \uparrow \text { un parque muy } \\
\text { lindo } \downarrow \text { un quiosco } \rightarrow \text { una parrilla y árboles muy grandes } \downarrow \\
\text { Después estuvo la fiesta de la casa; vinieron los que ayudan a los } \\
\text { hogares } \uparrow \text { bailamos la murga } \rightarrow \text { después el cumpleaños de Eduardo } \downarrow \text { Le } \\
\text { festejamos el cumpleaños a Eduardo porque nos ayuda en las buenas y } \\
\text { en las malas } \downarrow \text { Nos fuimos de vacaciones a Neusa y los más chiquitos } \\
\text { cinco días } \rightarrow \text { estuvo muy lindo } \downarrow \text { Nos fuimos a Neusa } 15 \text { días } \uparrow\left(3^{\prime \prime}\right) \text { hubo } \\
\text { muchos problemas } \uparrow / / / \text { festejamos } \downarrow . .\end{array}$ \\
\hline
\end{tabular}

4JC

Edad: 14 años

Nacionalidad: Colombia

Sexo: Masculino

\begin{tabular}{|l|l|}
\hline Informante & \multicolumn{1}{c|}{ Discurso } \\
\hline JC & $\begin{array}{l}\text { Yo soy Juan Carlos y te voy a contar m'historia en el hogar El Arca } \downarrow / / / \\
\text { yo vine en } 1997 \rightarrow / \text { a mí me trajo mi hermana María que tiene 19 años y } \\
\text { soy un muchacho rebelde y no tengo mamá ni tampoco tengo papá } \\
\text { Soy un muchacho feliz y soy muy amargo y un poco aburrido y voy a la } \\
\text { escuela a } 7^{\circ} \downarrow\end{array}$ \\
\hline
\end{tabular}

$5 \mathrm{G}$

Edad: 13 años

Nacionalidad: Colombia

Sexo: Femenino

\begin{tabular}{|c|c|}
\hline Informante & Discurso \\
\hline $\mathrm{G}$ & $\begin{array}{l}\text { Bueno } \downarrow \text { hola } \rightarrow \text { me vengo a presentar } \downarrow \text { yo me llamo Gabriela González } \uparrow \\
\text { tengo } 13 \text { años y’estoy en el hogar desde mayo } \downarrow \text { Voy a la escuela } \\
\text { Manuela Beltrán } \downarrow \text { Somos diez hermanos y se llaman Federico/Yolanda/ } \\
\text { Beatriz/ Romina/ María/ Susana/ Noemí,/ Ancelmo y Jorge } \downarrow \text { Yolanda y } \\
\text { Beatriz viven en el hogar conmigo } \uparrow \text { Tengo también un sobrino que se }\end{array}$ \\
\hline
\end{tabular}


$6 \mathrm{M}$

Edad: 11 años

Nacionalidad: Colombia

Sexo: Femenino

\begin{tabular}{|l|l|}
\hline Informante & \multicolumn{1}{|c|}{ Discurso } \\
\hline M & $\begin{array}{l}\text { Me llamo María Soledad Sosa y tengo } 11 \text { años } \downarrow \text { Yo vivo en el hogar y } \\
\text { me gusta el hogar y yo tengo derecho a tener una identida } \uparrow \text { Estoy en el } \\
\text { hogar hace } 4 \text { años } \downarrow \text { Mis mejores amigas son Gaby } \uparrow \text { Ana y Lucía } \downarrow \text { Mi } \\
\text { escuela se llama escuela Los Rosales y voy a } 4^{\circ} \text { grado } \downarrow \\
\text { Las muchachas nuevas se llaman Kari y Fátima } \downarrow \text { Yo soy de San } \\
\text { Lorenzo } \downarrow \text { Yo me llevo bien con mi compañera Natalia } \uparrow \text { y con Lucas } \rightarrow / \\
\text { Belén } \rightarrow / \text { Ricardo } \rightarrow / \text { Luis } \rightarrow / \text { César } \rightarrow / \text { Cristian } \rightarrow / \text { Néstor } \rightarrow / \text { Ezequiel } \\
\text { y Javier } \downarrow\end{array}$ \\
\hline
\end{tabular}

$7 \mathrm{~W}$

Edad: 14 años

Nacionalidad: Colombia

Sexo: Masculino

\begin{tabular}{|l|l|}
\hline Informante & \multicolumn{1}{c|}{ Discurso } \\
\hline W & $\begin{array}{l}\text { Me llamo Walter } \downarrow \text { mi edad } 14 \text { años } \uparrow \text { hincha del River } \downarrow \text { Mi hobbie es } \\
\text { andar en bicicleta y jugar al fútbol } \downarrow \text { Yo ingresé al hogar por razones de } \\
\text { que no podía ir al cole y no podía tener una vida normal } \downarrow \text { Cuando llegué } \\
\text { al hogar ya sabía de qué se trataba porque antes viví en un hogar y ya } \\
\text { sabía las reglas } \downarrow \text { Hasta ahora me va bien con los muchachos y adultos y } \\
\text { ahora puedo ir al colegio y jugar } \downarrow \text { Yo en el hogar tengo muchos amigos } \\
\text { y amigas y salgo de vacaciones } \downarrow\end{array}$ \\
\hline
\end{tabular}

8D

Edad: 15 años

Nacionalidad: Colombia

Sexo: Masculino

\begin{tabular}{|l|l|}
\hline Informante & \multicolumn{1}{|c|}{ Discurso } \\
\hline $\mathrm{D}$ & $\begin{array}{l}\text { Hola yo me llamo Diego } \rightarrow \text { tengo } 15 \text { años y vivo en un hogar que se } \\
\text { llama El Arca } \downarrow \text { Yo vine en el } 2001 \uparrow \text { vine porque tenía problemas con } \\
\text { mi papá } \downarrow \text { yo de mi casa me escapé tres veces porque mi papá me } \\
\text { pegaba } \uparrow \text { me trataba mal y yo trataba de alejarme } \downarrow \text { Hasta que un día } \\
\text { decidido escapé pero para no volver porque mi papá me dijo que mi } \\
\text { mamá estaba muerta } \downarrow \text { A mí me dolió mucho y ahí fue cuando me enteré } \\
\text { que no tenía mamá } \downarrow / / / \text { Entonces decidí ir y no volver nunca más } \downarrow \text { Una } \\
\text { maestra de mi colegio me trajo a este lugar } \uparrow \text { y me dijo que este era un } \\
\text { buen lugar } \downarrow \text { A mí me regustó y me quedé y ahora estoy protegido y me } \\
\text { siento muy bien } \downarrow \text { Ah } \uparrow / / / \text { me olvidaba que mi maestra se llama Lucía } \\
\text { Rivera de Merlo } \downarrow\end{array}$ \\
\hline
\end{tabular}


9DF

Edad: 20 años

Nacionalidad: Colombia

Sexo: Femenino

\begin{tabular}{|l|l|}
\hline Informante & \multicolumn{1}{|c|}{ Discurso } \\
\hline DF & $\begin{array}{l}\text { Bueno, mi historia es: cuando decidí estudiar teatro en Bogotá } \uparrow \text { en el } \\
\text { Teatro Nacional } \uparrow \text { e: tuve una experiencia muy emocionante que fuehaber } \\
\text { actuado en una película de cine con: unos productores conocidos de } \\
\text { Bogotá / y conociendo / los actores/ y gente de televisión // me emocioné: } \\
\text { mucho /// eh todo empezó porque llegó un p una productora necesitando } \\
\text { un casting de: niñas de quince años para'hacer una fiesta: de cumpleaños } \\
\text { y me ele m'eligieron a mí y’a un'amiga nos reunimos en día // } \\
\text { eensayamos nos dijeron que llevaran ropa para: de quince años llegamos } \\
\text { a la casa de Dago García a filmar la escena de una fiesta de quinceaños y } \\
\text { e pues pues fue muy emocionante Además que llegamos desde las: tres } \\
\text { de la tarde hasta las seis de la mañana del’otro día estuvimos grabano // } \\
\text { cambiando / mil tomas en una habitación / haciendo / cambiando de luces } \\
\text { d'esquina en esquina } \uparrow \text { charlando con personas como JuanitaCosta o } \\
\text { como con Fernando // Actores de prestigio aunque: aunque lo más } \\
\text { importante y horrible fue la burla:da de todos nos los los que estábamos } \\
\text { haciendo casting /// y: bueno no sé fue muy agradable // No puedo decir } \\
\text { más y chao gracias } \downarrow\end{array}$ \\
\hline
\end{tabular}

10R

Edad: 28 años

Nacionalidad: Colombia

Sexo: Femenino

\begin{tabular}{|c|c|}
\hline Informante & Discurso \\
\hline $\mathrm{R}$ & $\begin{array}{l}\text { Eh / le voy a contar una historia de una amiga que que es el / tío de una } \\
\text { de mis: deotramiga ( } 5^{\prime} \text { ') y la historia es así: Un amigo tenía: tenía un } \\
\text { espasmo muscular eh: en la espalda } \downarrow \text { (3'’) y lo fui a visitar porque me } \\
\text { dijeron que'stabaenfermo } \downarrow \text { cuando llegué a la casa de él estaba: acostado } \\
\text { no se podía parar y tenía un: dolor muy fuerte en: en la'spalda y: casi a } \\
\text { nivel cervical yo lo vi y le pregunté que: pues que si ya había ido al } \\
\text { médico toes me dijo que sí pero que había ido era donde un médico } \\
\text { alternativo donde el doctor Payán o y que estab'haciendo acupuntura o } \\
\text { sea que él tenía un dolor tan muy muy fuerte y encima de todo se estaba } \\
\text { haciendo hacer acupuntura } \downarrow \\
\text { Eh: yo a pesar de ser amiga de él soy pues también médica general pero } \\
\text { no quise eh: intervenir como profesional sino que lo iba a visitar } \\
\text { solamente como amiga } \downarrow \text { porque tenía que respetar la decisión que él } \\
\text { había tomado de: consultar donde el doctor: donde el alternativo a: así } \\
\text { pasaron } \downarrow \text { eso fue un día sábado y yo fui a visitarlo to nuevamente el } \\
\text { martes con la esperanza de que en verdad fuera un espasmo y que ya }\end{array}$ \\
\hline
\end{tabular}




\begin{tabular}{|l|l|}
\hline estuviera mejor $\uparrow((C A R R A S P E A))$, pero ya el martes lo encontré mucho \\
ma:s más agotado / tenía fiebre y cuando le tomé:l pulso ya'staba \\
taquicárdico y estaba TAQUIPNEA y con dificultad para respirar \\
entonces loexaminé y ya me di cuenta que estaba muy ((CARRASPEA)) \\
mal eh no solamente era ya una cosa que: DEL ESPASMO PULM e \\
DEL ESPASMO MUSCULAR sino que ya pues pensé que podría tener \\
algo en el pulmón $\downarrow / / /$ porque además tenía fiebre $\downarrow$ y: pues entonces ya \\
e: mi amigo sie se sen cincuenta años y vive con la mamá que tiene tiene \\
como ochenta $\downarrow$ y ninguno de los dos eh a él trabaja $\uparrow$ pero vive \\
solamente con la mamá $\downarrow$ ((CARRASPEA)) entonces está ahí está estai \\
muy solo no tenía pues como quien lo orientara bien para que fuera a \\
donde pues debería ir consultar que’es a su ipeese // Luego lo llevé $\downarrow$ lo \\
llevé a: a la ipeese del YAN esa noche qu'el casi no se podía ni mover \\
y llegamos allá y había una compañera mía que se graduó conmigo de: \\
de la: de la niversidadd $\downarrow / / /$ y ya le tomamos todos los exámenes que \\
había que tomarle e: él se sentía pues muy muy aburrido porque primero \\
no le gustan los hospitales y segundo pues él dolor era mucho $\downarrow$ hasta \\
que ya a a los cuando ya salieron las radiografías // e: ya vi la radiografía \\
del tórax y cuando: // o sea la la médica que lo estaba viendo me dijo no \\
no tiene nada cuando yo miré bien y se veía una masa a nivel del pulmón \\
derecho $\uparrow$ en el apix y: y entonces era que él tenía una un probable abseso \\
pulmonar y cuando le tomaron ya los exámenes le salió que era diabético \\
yera una persona que tal vez llevaba mucho tiempo / enfermo y no se \\
había ao cuenta /// pero lo que más me angustia es de todo es qu'él hizo \\
como unas cinco sesiones de: acupuntura y a pesar de no haber tenido \\
mejoría seguía insistiendo: eh la familia en: y él en que en que iba seguir \\
ahí hasta que se mejorara / Pero pues gracias a Dios él ya está en manos \\
de: profesionales de la medicina y: lo que tenía era un abseso en el \\
pulmón ///
\end{tabular}

$11 \mathrm{AC}$

Edad: 52 años

Nacionalidad: Colombia

Sexo: Femenino

\begin{tabular}{|l|l|}
\hline Informante & \multicolumn{1}{|c|}{ Discurso } \\
\hline AC & $\begin{array}{l}\text { Buenos días: } \\
\text { Hoy es } 12 \text { de febrero del } 2004 \text { y deseo e: contarles una historia de mi } \\
\text { vida que para mí ha sido muy importante // La historia es la siguiente /// } \\
\text { La familia de mi esposo es una familia m numerosa e: doce hijos: todos } \\
\text { casados con: más o menos unos cincuenta nietos: eh: dentro de ese de esa } \\
\text { familia hay un hermano que se casó cuando tenía veinte y e tuvo tres } \\
\text { hijos } \downarrow \text { la primera } \uparrow \text { Zarita: el segundo } \downarrow \text { Miguel Ángel y la tercera } \\
\text { Elizabeth } \downarrow / / / \text { La mamá de estos muchachos /// fue una persona que tuvo } \\
\text { muchachos quebrantos de salud: / y desde que Zarita tenía / seis años /// } \\
\text { e: Zarita es la hija mayor / e: su madre tuvo muchos problemas y } \\
\text { posteriormente le dio un cáncer en el cerebro y: falleció hace más o } \\
\text { menos unos 14 años } \downarrow / / / \text { e: Rafael / papá de Zarita / cuñado mío / e: se } \\
\text { enamoró de su hija desde que ella era una bebé / e: en el año 87 / yo me } \\
\text { enteré por por boca de: la mamá de Zarita que Rafael estaba enamorad }\end{array}$ \\
\hline
\end{tabular}




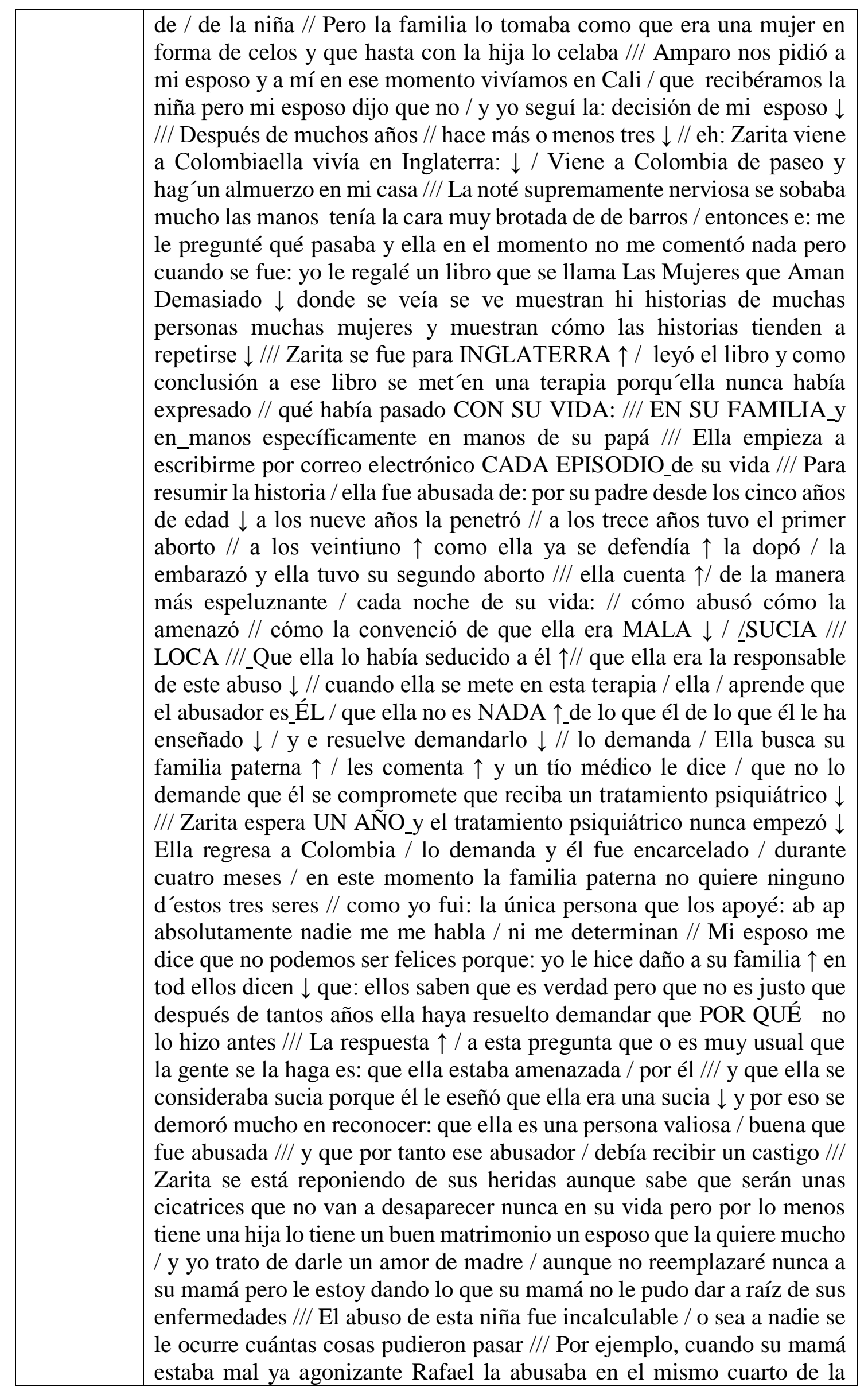




\begin{tabular}{|l|l|}
\hline $\begin{array}{l}\text { mamá /// y cuando la niña le pedía que por favor aunque fuera en un sitio } \\
\text { distinto y lloraba y le decía quélla no quería él le decía } \uparrow / \text { si no me } \\
\text { aceptas/ maltrato a tu mamá y ella por PROteger a su mamá agonizante } \\
\text { tenía que acceder } \downarrow \text { ((SE DEJA DE TRANSCRIBIR UNA PARTE)) } \\
\text { Esta es la historia } \uparrow / \text { que quería comentarles y que me parece valiosa } \\
\text { para que ante el abuso todos denunciemos y hagamos } \uparrow \text { lo que tengamos } \\
\text { que hacer para criticarlo y para castigar al responsable } \downarrow / / /\end{array}$ \\
\hline
\end{tabular}

12R

Edad: 40 años

Nacionalidad: Colombia

Sexo: Masculino

\begin{tabular}{|l|l|}
\hline Informante & \multicolumn{1}{|c|}{ Discurso } \\
\hline $\mathrm{R}$ & $\begin{array}{l}\text { Érase una vez una tortis jajajá no mentira conocí unaj'amigas en Popayán } \\
\text { cuando estaba trabajando como ingeniero // y esa historia: se fue } \\
\text { alargando alargando alargando por muchos años y volví y lajencontré } \\
\text { nuevamente reunidaj y entonces ellas se dicen tortis y me daba mucha } \\
\text { risa venía hablando con Regina y le decía tortis sí es que nos decimos } \\
\text { tortis por cariño y le digo yo o sea que por muy cariñito que sea tortis no } \\
\text { era porqueran buenas ((RISAS)) era porqu'e unas tor::tas en algo } \\
((\text { RISAS)) entonces me daba mucha risa y: le digo ya ustedes sounaj } \\
\text { profesionales son unaj mujeres grandej paque se dejen de andar tratando } \\
\text { como niñas tortis } \downarrow\end{array}$ \\
\hline
\end{tabular}

$13 \mathrm{H}$

Edad: 45 años

Nacionalidad: Colombia

Sexo: Masculino

\begin{tabular}{|l|l|}
\hline Informante & \multicolumn{1}{|c|}{ Discurso } \\
\hline $\mathrm{H}$ & $\begin{array}{l}\text { Nací el me llamo Hernán Bonilla } \\
\text { Soy una persona de Popayán a los payaneses porque se les llama patojos } \\
\text { porque hace: /// un medio siglo Un medio siglo y un poco más e: en } \\
\text { Popayán e pues había tenían muchas niguas y entonces esos animalitos } \\
\text { /// esos piojitos que se te metían en los pies /// te dejaban como como } \\
\text { caminando como Charles Chaplin // De ahí que se les haya que se ha } \\
\text { hecho una referencia imaginativa entre / lo que es un patojo //: o el Patojo } \\
\text { que ya no existe y las llamadas patojas que son también las loras } \downarrow \text { Bueno } \\
\text { la característica de los payaneses en su forma de hablar que yo no poseo } \\
\text { porque si escucha es como si hablara mejicanito o como si hablara e } \\
\text { usamos muchos diminutivos e vaa a la tiendita: vaya usté a la tiendita: / } \\
\text { y cómpres'iuna empanadita para tomar un cafecito con pancito } \downarrow / / \text { Le } \\
\text { hacemos empanadas de pipiam (5'’) es una ciudad/ tranquila } \\
\text { relativamente } \uparrow \text { que cada vez va perdiendo más su tranquilidad con esos } \\
\text { (xxx) que deterioran la calidad de vida de los nativos de aquí /// Los } \\
\text { nativos originariamente son somos pocos de ahí que se hable de la } \\
\text { colonia patoja residente en Popayán } \downarrow / / /\end{array}$ \\
\hline
\end{tabular}


14AM

Edad: 50 años

Nacionalidad: España

Sexo: Masculino

\begin{tabular}{|c|c|}
\hline Informante & Discurso \\
\hline $\mathrm{E}$ & Cómo fue tu nacimiento, dónde naciste, en la casa o en el campo? \\
\hline $\mathrm{AM}$ & $\begin{array}{l}\text { Yo lo único que sí que sí sé que u única de mis hermana } \\
\text { ((CARRASPEA)) pos mi madre esta traajando en el campo que me } \\
\text { acuerdo d'eso que venía con la panza ya con la barriga ya en la barriga / } \\
\text { trabajando / y: por y unos segundos pos no: no dio a luz en la: por la } \\
\text { escalera o en el portal donde vivíamos de alquiler y que vivíamos de } \\
\text { alquiler / y éramos po } 8 \text { hermanos uno que se murió de pequeño con } \\
\text { veintitantos meses quedamos ocho / bueno quedábamos ocho se mató } \\
\text { uno / con } 27 \text { años aquí en Madrid y quedamos pos siete / seis seis chica } \\
\text { y un varón / que soy yo } \downarrow\end{array}$ \\
\hline $\mathrm{E}$ & Todo mujeres y tus padres, tu padre, ¿tus padres qué hacían? \\
\hline $\mathrm{AM}$ & $\begin{array}{l}\text { Pos mis padres estaban trabajando en el campo cuando le salía / y eh / } \\
\text { Un día... a trabajar / las hermanas sin trabajar y nada / y no había de } \\
\text { trabajo ni para comer / para mantener a ocho hijo pos no había nada / si } \\
\text { cenabas pues no almorzabas / y si no almorzabas pues: ná; ni almorzar ni } \\
\text { cenar / ni comer al mediodía } \downarrow \text { Allí comiendo nada lo que se pillaba } \downarrow \\
\text { Íbamos a coger espárragos collejas de esas que son muy buenas / que las } \\
\text { comen también la gente rica / iba a mi madre por las casas a regalar los } \\
\text { espárragos para que le dieran un puñao de harina y un poquito de aceite } \\
\text { / pero como en aquellos tiempos/ también las criadas eran eran fastidiás } \\
\text { pues cogían los espárragos y decían "muchísimas gracias" y no le } \\
\text { decían nada a la señora pues claro pos mi madre pos se iba a otros sitio a } \\
\text { regalar otros tres o cuatro manojos de espárragos a ver si la daban una } \\
\text { poquita harina y aceite para hacer ná, un... ajo de ese que decimos en } \\
\text { Andalucía } \downarrow\end{array}$ \\
\hline $\mathrm{E}$ & Tu madre, tu madre ¿trabajaba también en el campo o no? Antonio $\downarrow$ \\
\hline $\mathrm{AM}$ & $\begin{array}{l}\text { Sí mi madre trabajaba tamibén en el campo/ y yo trabajaba con doce años } \\
\text { / doce años / pues cavando olivos y tó como los hombre, me pagaban el } \\
\text { jornal del hombre/ porque porque rendía má que los hombres ya granao, } \\
\text { que mi padres, que en paz descansen, y los demás } \downarrow \text { Y nos pagaban po } 6 \\
\text { peseta u } 8 \text { peseta a día, todo el día cavando olivo con una azada, te daban } \\
\text { una comida a mediodía que na, con eso ni comer nada para matar } \\
\text { l'hambre, pues yo no podía con la azada de tanto cava olivo, e íbamos a } \\
\text { coger aceituna mi padre, que en paz descanse, mi madre, que en paz } \\
\text { descanse, y mi hermana la mayo y yo, que éramos los que más podíamos } \\
\text { trabajar. Llevaban dos sardinas j'arengha, un cachito pan y do naranja y } \\
\text { teníamo que partir eso para los cuatro o cinco, y el que le tocaba la cabeza }\end{array}$ \\
\hline
\end{tabular}




\begin{tabular}{|c|c|}
\hline & $\begin{array}{l}\text { de arenga pues ya. Estábamos mu enfadaos porque no le tocaba nça, del } \\
\text { hambre que teníamos claro/ íbamo cogiendo aceitunas y laaceituna esa } \\
\text { que hay seca que les llamamos allí chascaros, pos ... chascaros } \downarrow \text { De esa } \\
\text { secas que son lo único que había allí, que como no había otra cosa } \downarrow \text { Po:: }\end{array}$ \\
\hline $\mathrm{E}$ & $\begin{array}{l}\text { Antonio todo esto que me estás contando, es ya después de la guerra, } \\
\text { cuando tú tenías diez o doce años, e: ¿tú recuerdas algo que te haya } \\
\text { contado tu padre, de antes de la guerra de los años de la República, si vot } \\
\text { ban, o que hacían, si eran de algún sindicato/// y qué hizo tu padre durante } \\
\text { la guerra, tú lo sabes, te acuerdas o no? }\end{array}$ \\
\hline $\mathrm{AM}$ & $\begin{array}{l}\text { Pos yo no me acuerdo d'eso/ yo lo único que sé, que nuestros padres, } \\
\text { claro/ po pos tampoco explicaban en aquellos tiempos nada a los hijos, } \\
\text { ni, lo único que sé, que mi padre se fue voluntario a la guerra y: después } \\
\text { de eso yo si m’acuerdo algo/ que venía con permiso y traía papel fuma } \\
\text { de ese dulce papé dulce, entonces nosotros como como comíamos los } \\
\text { papeles, los papeles lia los cigarrillos pos yo creo que me acuerdo } \\
\text { solamente deeso, y de cuando estaba mi padre que en paz descanse en la } \\
\text { guerra/ y entonces pos de lo que sí algo, algo, algo muy poquito, que } \\
\text { cuando tocaba la sirena l’a la que pasaban lo los aviones, pues no íbamos } \\
\text { toos todos a refugio/ y de eso me acuerdo muy poco vaya, que:: }\end{array}$ \\
\hline $\mathrm{E}$ & $\begin{array}{l}\text { ¿Y cuando acabó la guerra. Tu padre no tu no estuvo en algún campo de } \\
\text { concentración o o algo? }\end{array}$ \\
\hline $\mathrm{AM}$ & $\begin{array}{l}\text { No, mi padre ni estuvo preso, ni en el campo, ni estuvo ni estuvo preso, } \\
\text { ni en el campo/ ni estuvo ni estuvo preso después de la guerra en la casa } \\
\text { de los pueblo, ni lo molestaron para nada/ nada/ nada } \downarrow\end{array}$ \\
\hline & Porque se fue voluntario/ pero con los republicanos o con Franco? \\
\hline $\mathrm{AM}$ & $\begin{array}{l}\text { mmm D’eso ni lo sé/ ni me lo han explicado/ pero: no sé cómo decirlo/ } \\
\text { porque yo no me acuerdo de eso/ ahora sí ((CORTE EN LA } \\
\text { GRABACIÓN)) }\end{array}$ \\
\hline $\mathrm{E}$ & $\begin{array}{l}\text { Pues sigamos a Antonio, que me estabas contando lo que/ o sea cuando } \\
\text { terminó la guerra, que pasábais mucho hambre, comíais los cacarros, las } \\
\text { aceitunas secas/ bueno/ a: y sígueme contando lo que hacíais en aquellos } \\
\text { años/ y yo creo que tu madre también iba a veces al campo a coger/// y } \\
\text { que una vez las castigaron o algo así. }\end{array}$ \\
\hline $\mathrm{AM}$ & $\begin{array}{l}\text { Mi madre/ que en paz descanse/ ahora te voy a contar lo que a mi madre } \\
\text { le pasó y lo que le pasó a muchas mujeres/ cuando tenía ocho hijos/ y } \\
\text { todo e en do habitacione/ ni agua/ ni luz/ ni servicio/ teníamos que hacer } \\
\text { en un cubo luego tirarlo/ vamos que eso era u un desastre vamo y con do } \\
\text { cama solo teníamo que dormir } 10 \text { en do cama/ uno arriba/ otro por el } \\
\text { medio/ como se pillaba/ ni sábanas/ ni mant as rotas/ pero bueno/ pero } \\
\text { aparte d'eso mi madre, que en paz descanse/ salió una noche con con } \\
\text { cuatro o cinco vecinas que todas viven/ vive una/ o viven dos toavía/ pos } \\
\text { los guardas del campo pos la cogieron cogiendo co como un talego de }\end{array}$ \\
\hline
\end{tabular}




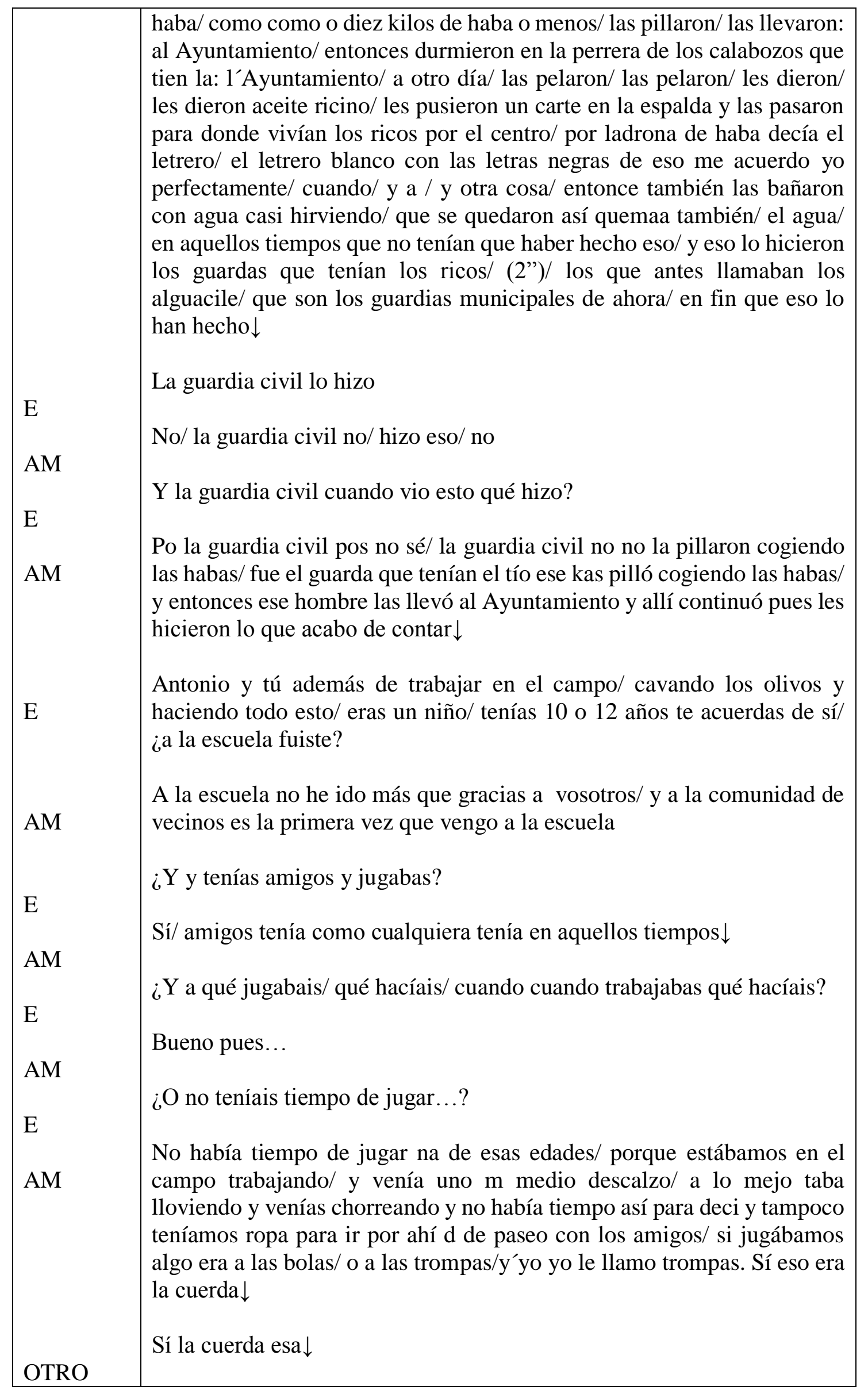




\begin{tabular}{|l|l|}
\hline AM & $\begin{array}{l}\text { Le llamo yo trompa. } \\
\text { ¿Y a las bolas y a las canicas? } \\
\text { AM }\end{array}$ \\
E las canicas y solamente eso, o sea que: \\
¿Y los domingos qué hacíais? \\
AM & $\begin{array}{l}\text { Los domingos pos esol si que/ vaya los domingos íbamos a misa/ todos } \\
\text { los domingos "fun " a misa/ y como portábamos mu bien/ pues la gente } \\
\text { rica tenía alrededor del altar tenía butacones mu hermoso para ellos y } \\
\text { nosotro no poníamos detrás y como nos portábamos bien había una } \\
\text { señora que a parte de eso/ pue bueno/ no se portaba mal entonces pos nos } \\
\text { daba unas perras/ los diez céntimos que había antes/ o pa mí que eran } \\
\text { diez céntimos y cuando }\end{array}$ \\
\hline
\end{tabular}

$15 \mathrm{MG}$

Edad: 57 años

Nacionalidad: España

Sexo: Femenino

\begin{tabular}{|c|c|}
\hline Informante & Discurso \\
\hline $\mathrm{MG}$ & $\begin{array}{l}\text { Nos apartamos del marxismo/ pues lo dejamos ya todo color de rosa y } \\
\text { viene la burguesía otra vez }\end{array}$ \\
\hline $\mathrm{E}$ & Sí... sí \\
\hline MG & $\begin{array}{l}\text {...no podrá... a que... a que no puede ser compatible/ digo yo que no } \\
\text { puede ser compatible// puede ser lo que sea/ a lo mejor// a lo mejor si sois } \\
\text { capaz vosotros/ vosotras/ de llevarlo así/ pero nosotros/ de la revolución } \\
\text { proletaria/ nosotros... claro dicen que si ahora... que sí se han marchado/ } \\
\text { los renovadores/ los leninistas/ no/ no/ no se han marchado los que están } \\
\text { descontentos con... con muchas cosas y se marcharán y se seguirán } \\
\text { marchando/ ahora/ hombre/ eso no quiere decir que las personas que } \\
\text { tengamos firmeza en nuestra ideología política/ pues hombre/ podamos } \\
\text { podamos seguir conviviendo dentro de una disciplina de partido y decir/ } \\
\text { pues no/ no me voy/ no me voy por ética/ porque/// porque yo a los } \\
\text { sesenta y ocho años no puedo dar la razón a todos los que yo se la he } \\
\text { estado quitando continuamente/ y hasta aquí la cosa/ hasta ahí// Pero... } \\
\text { pero que vosotros tenéis muchos más problemas que nosotros/ que los } \\
\text { vais a tener/ porque vais a luchar contra la corriente de cosas qué las } \\
\text { nuevas generaciones y la nueva sociedad no os las va a valorar o a } \\
\text { aceptar/ os va a poner muchos impedimentos/ os va a poner muchas } \\
\text { chinitas/ o yo qué sé lo que podría suceder en el futuro/ yo qué sé...lo } \\
\text { que... los que estudiáis quizás sepáis hacerlo/ pero nosotros pudimos/ no } \\
\text { pudimos o no supimos/ todas estas cosas/ no... no te voy a hablar de las } \\
\text { cosas de Pilar Primo de Rivera como cuando empezó/ porque como esas } \\
\text { cosas también las tocaréis vosotras... Pilar Primo de rivera... }\end{array}$ \\
\hline $\mathrm{E}$ & \\
\hline
\end{tabular}




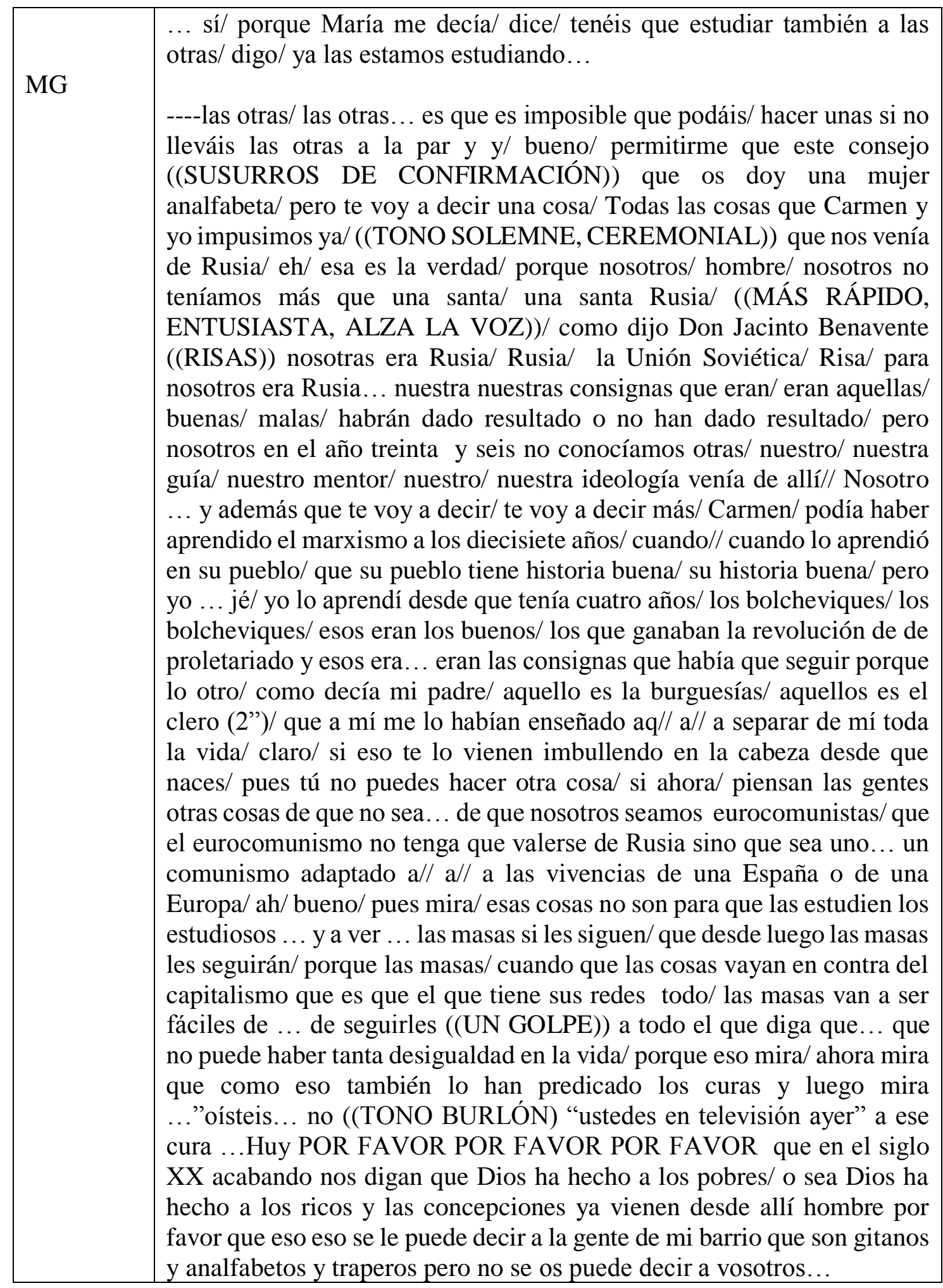

16MC

Edad: 55

Nacionalidad: España

Sexo: Femenino

\begin{tabular}{|l|l|}
\hline Informante & \multicolumn{1}{c|}{ Discurso } \\
\hline $\mathrm{E}$ & 15 años de cárcel y de guerra \\
\hline
\end{tabular}




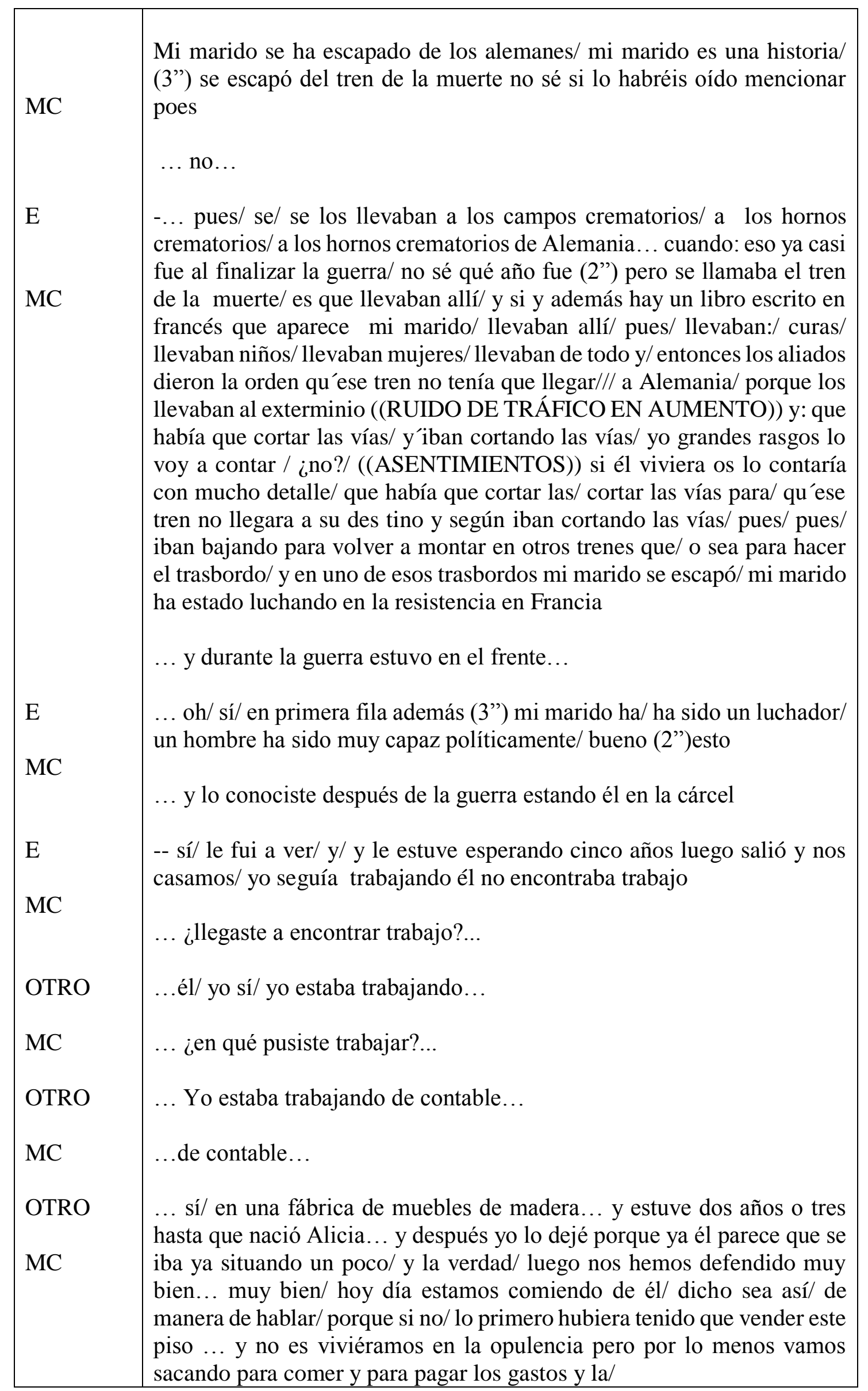




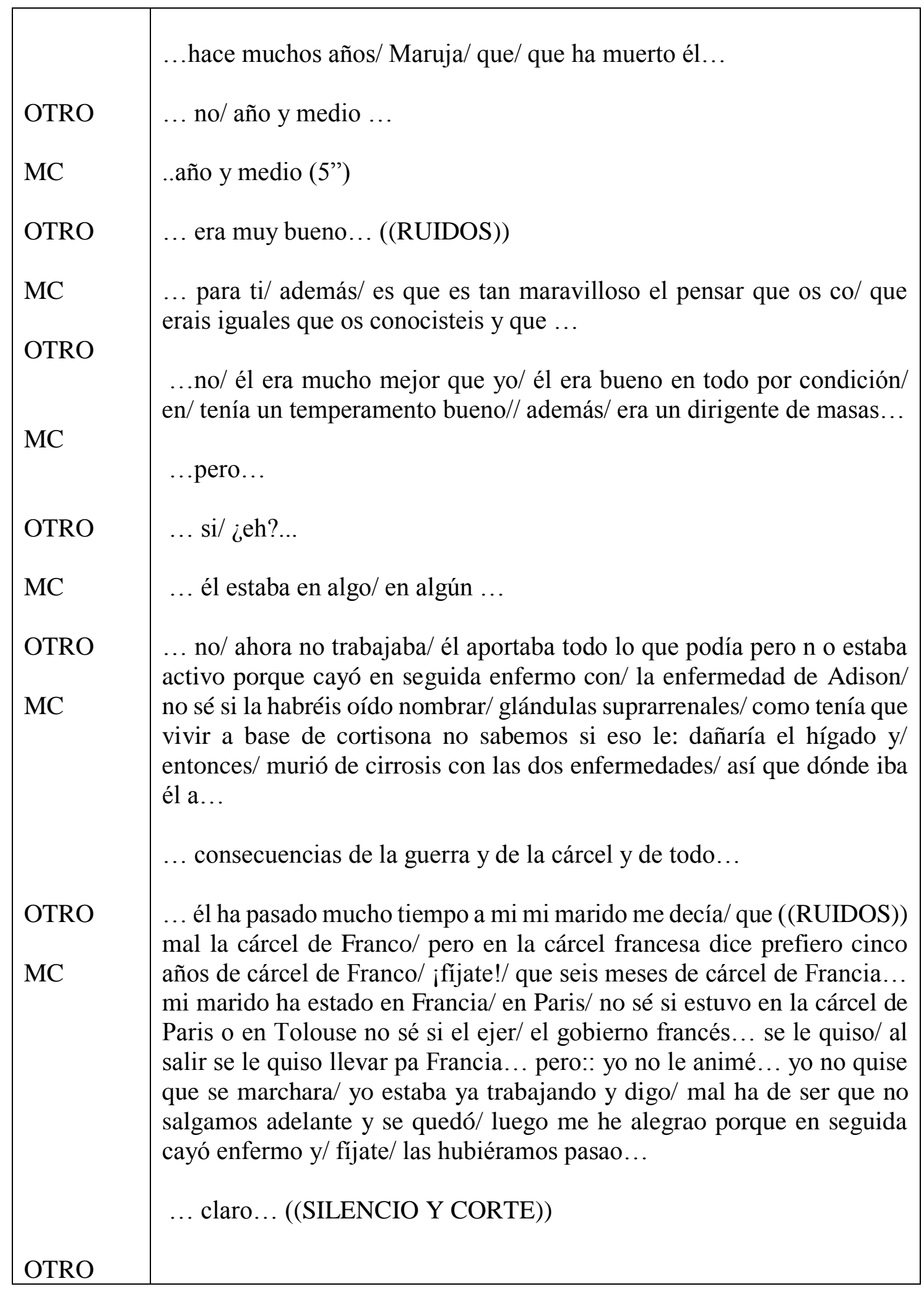

17DM

Edad: 50 años

Nacionalidad: España

Sexo: Femenino 


\begin{tabular}{|c|c|}
\hline Informante & Discurso \\
\hline DM & $\begin{array}{l}\text {.... Usted ya con él/ porque esto/ lo otro/ pues se esté usted aquí/ pero } \\
\text { nada/ en cuanto que venía a por ella se iba } \downarrow\end{array}$ \\
\hline $\mathrm{E}$ & ¿Y, tu abuela le ayudaba también en las cosas de la finca y eso? \\
\hline $\mathrm{DM}$ & $\begin{array}{l}\text { Sí/ sí/ eso como él// Eso/ trabajaban igual o no/ las hijas y la mujer pues } \\
\text { como el hombre/ eso/ trabajando al corte ((VACILANTE)) en él// No es } \\
\text { como los ganaderos/ que ya se van ellos con las cabras y eso y aunque } \\
\text { las mujeres ayudaban a lo mejor a barrer la majada o a... a ordeñar } \\
\text { también ordeñan y eso/ pero ya es distinto que el/ el campo/ el campo es } \\
\text { más duro// El campo es más duro y ahí trabajamos como una negra } \downarrow\end{array}$ \\
\hline $\mathrm{E}$ & ¿Y tus padres, Dioni? \\
\hline $\mathrm{DM}$ & $\begin{array}{l}\text { Y luego mis padres/ pues: mi padre empezó / porque tenía un caballo/ iba } \\
\text { a po leña/ iba a echarle alguna ((ININTELIGIBLE)) ... total/ eso fue al } \\
\text { principio/ antes de ... de mu recién casados tuvo que ser eso/ porqueyo } \\
\text { del caballo sí me acuerdo } \downarrow \text { Y luego ya por la guerra/// pues nada pues } \\
\text { nada/ mi padre le movilizaron/ se fue/ y nosotras nos quedamos las dos } \\
\text { pues que no teníamos na/ más que la noche ye le día// Menos mal que } \\
\text { una familia que había/ ((CORTA LA ENTREVISTA)) }\end{array}$ \\
\hline $\mathrm{E}$ & Cuando me dices las dos/ ¿quiénes sois/ tu madre y tú? \\
\hline $\mathrm{DM}$ & $\begin{array}{l}\text { Mi madre y yo/ mi madre y yo// Pues había una familia que son como/ } \\
\text { eran riquillos... }\end{array}$ \\
\hline $\mathrm{E}$ & Perdona/ Dioni/ ¿tu madre no trabajaba tampoco fuera de casa? \\
\hline $\mathrm{DM}$ & $\begin{array}{l}\text { No/ no/ trabajaba allí/ pues en el tiempo de la recolección que se iba la } \\
\text { gente a "acetonar"/ o a manillar tabaco o a acetonar los pimientos/ es } \\
\text { para asa/ hacerlo/ el pimentón/ es// Y que es una/ es como más/ de los } \\
\text { trabajos del campo lo más leve/ ¿sabes? Como lo más leve/ porque luego/ } \\
\text { pues a mullir y eso mi madre siempre ha estao delicá/ y no se ha metido } \\
\text { en } \rightarrow \text { en batalla como yo luego he estao trabajando en el campo fuerte// } \\
\text { Mi madre estaba delicada poroque le habían sacao/ yo fui la primera/ y } \\
\text { luego a los } 15 \text { meses vino un niño y se lo tuvieron que sacar con forceps } \\
\text { en aquellos tiempos en una casa/ sin clínica y si nada ... que se quedó... }\end{array}$ \\
\hline $\mathrm{E}$ & - En el mismo pueblo... \\
\hline $\mathrm{DM}$ & $\begin{array}{l}\text { Sí/ en el mismo pueblo/ se quedó destrozada y luego al año de tener ese/ } \\
\text { ese que a los } 15 \text { meses de nacer yo/ tuvo otro/ igual/ se le mataron al } \\
\text { nacer al niño } \downarrow\end{array}$ \\
\hline $\mathrm{E}$ & ¿Y el de los / y el de los 15 meses también murió? \\
\hline $\mathrm{DM}$ & $\begin{array}{l}\text { Murió también// A los dos los ... los dos al nacer tamién tamién se los } \\
\text { matar/ se/ se murieron/ porque eso se los mataron con los forceps/ y ella }\end{array}$ \\
\hline
\end{tabular}




\begin{tabular}{|c|c|}
\hline & $\begin{array}{l}\text { se quedó la v erdad es que destrozada/ porque le dolían muchísimo los } \\
\text { riñones y/ siempre ha estao muy delicá/ siempre ha estao delicá // Y ... } \\
\text { y no se ha metido ella en ... así en faena de mu/ mucho de ir a jornal así } \\
\text { a lo mejor a hacer cosas a alguna casa/ en cá mis tíos/ de esos que son } \\
\text { riquillos y que nos han tapao a nosotros mucha hambre/ eso es la verdad/ } \\
\text { porque nosotras nos quedamos las dos/ cuando mi padre se fue a la guerra } \\
\text { no nos quedamos con nada/ y/ y un plato de comida teníamos allí casi } \\
\text { siempre/ ¿sabe?// Y yo me acuerdo de cuando era pequeña de jugar allí } \\
\text { con mi primo/ que era de mi tiempo/ que era también el mayor de aquella } \\
\text { casa/ y... y que estábamos allí/ que estábamos allí/ vamos... que nos... } \\
\text { y eso... }\end{array}$ \\
\hline $\mathrm{E}$ & Dioni ¿y estos/ estos tíos tuyos qué eran/ el ... hermano de tu abuelo? \\
\hline $\mathrm{DM}$ & $\begin{array}{l}\text { Uy/ qué va/ primo hermano/ primo hermano de mi abuelo/ no/ nos toca } \\
\text { mu poco/ mu poco de familia/ lo que pasa es que como mi madre es/ mi } \\
\text { abuelo no tenía más familia/ yo no sé la familia de mi abuelo era muy } \\
\text { corta y tenía ese tío carnal/ el padre de este tío mío que ya ha muerto este } \\
\text { año/ pues tenía ese/// y él/ entonces eso eran pues que mi tío era muy } \\
\text { vividor/ era zapatero y de estos que/ que es que viven bien esos años que } \\
\text { a lo mejor arreglan a los calzaos a la gente que... que era un taller lo que } \\
\text { tenía de mu pocos oficiales/ que entonces se hacía to el calzao a mano y } \\
\ldots \text {.. y mucha/ mucha gente no los pagaba/ pero otra gente lo / los pagarían } \\
\text { doble/ porque como eran más espabilaos y había tanta gente tan } \\
\text { ignorante/ pues cuántos había que...que como tenían la costumbre de ir } \\
\text { y no pagar hasta que no lo cogían lo ... si eran ganaderos/ pues porque } \\
\text { no mataban los chivos/ si eran los del campo/ hasta que no los recogían/ } \\
\text { entonces/ entonces no pagaban// Entonces cuántos en vez de pagar } 5 \\
\text { habrán pagao 10/ pero claro/ también estaban debiendo to el año/ también } \\
\text { hay que comprender eso/ entonces él/ él hizo un capitalillo y los hijos/ } \\
\text { pues han manejao }\end{array}$ \\
\hline $\mathrm{E}$ & Y este es el os ayudó a tu madre y a ti... \\
\hline $\mathrm{DM}$ & Este no ha ayudao siempre/ a nosotras \\
\hline $\mathrm{E}$ & ¿Y tu hermana luego cuándo nació? \\
\hline $\mathrm{DM}$ & Y luego eso ya pasó/ no/ pero antes... buf. \\
\hline $\mathrm{E}$ & ¿Y tú de la guerra qué recuerdas/ Dioni? \\
\hline $\mathrm{DM}$ & $\begin{array}{l}\text { Yo de la guerra / recuerdo cuando entraron los moros/ que había un } \\
\text { camión de moros cargao/ que uno tenía un pendiente ((RISAS))/ yo me } \\
\text { acuerdo de eso porque fíjate que sería pequeña/ pero me acuerdo } \\
\text { perfectamente que en la puerta del/ del banco que se llama allí del banco } \\
\text { donde herraban/ que es en la carretera/ allí a la entrada en la parte de } \\
\text { abajo/ había un camión cargao de moros y unos tenían un pendiente } \\
\text { largo/ me acuerdo de eso ((SE RÍE)) y me acuerdo cuando entraron los: } \\
\text { moros/ ese día que entraron los moros/ pues/ ah/ corría todo el mundo pa }\end{array}$ \\
\hline
\end{tabular}




\begin{tabular}{|l|l|}
\hline & $\begin{array}{l}t \text { los laos/ porque entraron en el pueblo tirando tiros/ entraron pegando } \\
\text { tiros/ y eso entonces estaba por las derechas/ yo no sé cómo/ pero yo } \\
\text { estaba por las derechas/ no sé si eh antes o después había estado por las } \\
\text { izquierdas/ que estuvo/ pero yo no sé si eh fu antes o después }\end{array}$ \\
E & $\begin{array}{l}\text { Allí las izquierdas antes de que los moros/ claro } \\
\text { A/ antes... } \\
\text { DM }\end{array}$ \\
E & $\begin{array}{l}\text { Antes que los moros/ claro... } \\
\text { Los primeros que estuvieron alli fueron los de izquierdas }\end{array}$ \\
DM & $\begin{array}{l}\text { Si por lo visto no hicieron prácticamente nada/ nada más que mataron a } \\
\text { un cura/ lo persiguieron y le mataron porque era cuñao del Montero / y } \\
\text { el y Montero ese también le mataron// Que le llamaban el Montero } \\
\text { porque era el/ el }\end{array}$ \\
E &
\end{tabular}

18CR

Edad: 62 años

Nacionalidad: España

Sexo: Femenino

\begin{tabular}{|c|c|}
\hline Informante & Discurso \\
\hline CR & $\begin{array}{l}\text { Bueno... bueno yo recuerdo mis padres los pobres... Mi madre / pues } \\
\text { arañando todo el día... En casa no quedó nada a por cambiar / todos los } \\
\text { ovillos que tenía mi madre / eso pasó en todas las casas / Se cambia por } \\
\text { comida / bovinas / todos los hilos de mi madre que había cosido mucho } \\
\text { y todo eso // mm zapatos / los que teníamos ya que se nos habían quedao } \\
\text { un poco pequeños / mi padre los llevaba por ahí / a los pueblos / y } \\
\text { entonces pues nos traía un poco de harina o alguna cosa de esas que se } \\
\text { podían traer algo / para comer } \downarrow\end{array}$ \\
\hline $\mathrm{E}$ & ¿Ibais a las colas? \\
\hline CR & sí sí sí \\
\hline $\mathrm{E}$ & Tu madre y tú \\
\hline $\mathrm{CR}$ & $\begin{array}{l}\text { Bueno en mi casa cayó... cayó un cañonazo / un obús y tiró pues buena } \\
\text { parte de la casa } \downarrow \text { Dos pisos y quedó muy mal otro / en fin / la casa en } \\
\text { partes... y entonces de momento / estos fueron los primeros momentos } \\
\text { cuando las fuerzas de Franco se acercaron a Madrid // Y entonces pues } \\
\text { pensamos pues que francamente si estaban ahí / pues ya entrarían // } \\
\text { Tendrían que entrar pensábamos } \downarrow \text { y entonces como se había hundido } \\
\text { parte de la casa / nos fuimos pues en casa de unos amigos / de unos } \\
\text { conocidos que teníamos en La // } ~ \\
\text { Guindalera / que tenían un hotel }\end{array}$ \\
\hline
\end{tabular}




\begin{tabular}{|c|c|}
\hline & $\begin{array}{l}\text { / muy bueno // Y esa zona / era zona neutral / esa zona no se bombardeó } \\
\text { nunca // Ni en el barrio de Salamanca / ni en toda esa zona de La } \\
\text { Guindalera / nunca nunca de bombardearon los aviones / ni cayeron } \\
\text { obuses // Y entonces nos dijeron que nos fuéramos ahí y estuvimos con } \\
\text { ellos pues algo de tiempo / menos de un año // ((INTERRUMPE EL } \\
\text { ENTREVISTADOR PERO ELLA CONTINÚA)) Como la guerra no se } \\
\text { acababa / pues nos volvimos otra vez a casa // Aquello recuerdo como un } \\
\text { Edén / como un oasis // Mira / Pilar mi hermana / era un miedo que se } \\
\text { puso hasta amarilla / se puso con ictericia / la pobre / del miedo que le } \\
\text { daban los bombardeos // Pues allí vivió feliz / esos días // Allí sabíamos } \\
\text { que no bombardeaban // Mira yo es que cuando acabó la guerra ya no me } \\
\text { importaba nada de nada / yo pensar que yo me acostaba en la cama y ahí } \\
\text { no iba a sonar una sirena / y yo ir por la calle y no iba a caer un obús / un } \\
\text { cañonazo / yo ya lo demás no me importaba // Yo lo único que sabía es } \\
\text { que yo iba a poder estar / en la cama tranquila y no me iba a tener que } \\
\text { levantar a medianche para bajar al sótano // O sea / que yo era por eso / } \\
\text { cuando acabó la guerra / eso fue ya para mí... para gran parte / claro que } \\
\text { venía la paz / aunque fuera / pero venía la paz }\end{array}$ \\
\hline $\mathrm{E}$ & ¿Pasaste necesidades en la guerra? \\
\hline CR & $\begin{array}{l}\text { En la guerra en la guerra / un hambre negro // Los primeros meses bien / } \\
\text { nos íbamos defendiendo // Pero cuando ya se cercó Madrid / que era muy } \\
\text { difícil echar la comida / y además obviamente el gobierno de La } \\
\text { República no quería que ayuda y se quedó libre de todo / sin nada de } \\
\text { población civil ((SIMULTÁNEO CON LA PREGUNTA SIGUIENTE)) }\end{array}$ \\
\hline $\mathrm{E}$ & ¿Cómo fue / os vinieron a a proponer que os fuerais la familia evacuada? \\
\hline $\mathrm{CR}$ & $\begin{array}{l}\text { Bueno directamente la nuestra no / pero mandaban siempre cartas / } \\
\text { mandaban cosas / a todos / a todos // Por todos los sitios carteles // Te } \\
\text { ponían era: lo que tenemos aquí es pan para hoy y hambre para mañana } \\
\text { // Así era / porque que te repartieran un poco de aceite a la semana / un } \\
\text { poco de arroz / pues era para comer dos días y lo tenías que repartir para } \\
\text { toda la semana // Mismamente era todo lo que te daban // Querían que } \\
\text { nos fuéramos / pero claro como nosotros teníamos tan mala } \\
\text { experiencia... Luego también pasaba que muchos niños / por ejemplo / } \\
\text { ejemplo unos conocidos nuestros / de unos parientes lejanos de mis } \\
\text { padres // Y bueno no han vuelto a saber más // Del niño por lo menos no } \\
\text { han vuelto a saber más // Se lo llevaron pues a otros países // A Rusia y } \\
\text { todo eso se los llevaban / evacuados / y ya pues oye era muy duro también } \\
\text { // Sabes que te vas a Madrid y donde te mandan luego / en qué casa / } \\
\text { dónde te acoplan // Te dividen la familia / como haces // Preferíamos } \\
\text { morir en casa juntos todos y nada más // Eso es lo que pensábamos } \\
\text { nosotros / vamos y te advierto que gran parte de las personas le pasaba lo } \\
\text { mismo // Teníamos que estar por ahí rodando }\end{array}$ \\
\hline E & Muy doloroso \\
\hline CR & \\
\hline
\end{tabular}




\begin{tabular}{|l|l|}
\hline Nos quedamos en casa y aquí comeremos lo que tengamos // Pasando \\
pues necesidades // No tener nunca el hambre satisfecha // Es que eso se \\
dice... Yo por eso me acuerdo muchísimo de todos / los pobres que pasan \\
necesidades // me acuerdo mucho / mucho / mucho / mucho / es que ya \\
te digo / estar comiendo yo pensar... como he pasao hambre / además \\
años pasando
\end{tabular}

19MR

Edad: 62 años

Nacionalidad: España

Sexo: Femenino

\begin{tabular}{|c|c|}
\hline Informante & Discurso \\
\hline MR & $\begin{array}{l}\text { Al llegar las tropas ...// Bueno yo lo que oía es que nos iban a volar / que } \\
\text { nos iban a volar / o sea / que Madrid estaba minao // Y antes de: que de } \\
\text { que entraran pues íbamos a volar // Entonces claro / todo eso ahí te } \\
\text { producía un un miedo / pero vaya eso nos lo decía gente : gente que } \\
\text { parecía que tenía que saberlo / que estaba minao / no sé si si sería verdad } \\
\text { ((RISAS)) }\end{array}$ \\
\hline $\mathrm{E}$ & ((RISAS)) Que iba a estar minao \\
\hline MR & $\begin{array}{l}\text { La prueba está que luego / fíjate / como fue la cosa más sencilla de: de } \\
\text { lo que habíamos pensao / de lo que habíamos pensao / pero si eso se decía } \\
\ldots \text {. / Y yo pienso ... si es que decía / decían / que antes de rendirsen que } \\
\ldots \text { si / si / yo pienso que eso lo decían por las calles y todo } \downarrow / / \text { sí / morir } \\
\text { antes que rendirse y cosas d'esas // A lo mejor sería ... propaganda o lo } \\
\text { que fuera / pero yo pienso que sí / que se decía }\end{array}$ \\
\hline $\mathrm{E}$ & $\begin{array}{l}\text { ¿Tú nunca te largaste a ningún ningún mitin o algo sola a ver qué era o } \\
\text { por oir? }\end{array}$ \\
\hline MR & No / mitines no / mitines no // Pero por ejemplo // Manifestaciones sí \\
\hline $\mathrm{E}$ & Sí / ¿qué recuerdas? \\
\hline MR & $\begin{array}{l}\text { Yo manifestaciones manifestaciones / sí / yo es que en concreto ahora no } \\
\text { sé si fue una manifestación un poco antes de estallar la guerra } \uparrow \text { / una } \\
\text { manifestación que hubo / ENORME POR LA GRAN VİA / eh / o ya } \\
\text { después de la guerra / eh // Más bien pienso que ya esa manifestación fue } \\
\text { pues com como las vísperas de ... del } 18 \text { de julio / cuando mataron a } \\
\text { Calvo Sotelo / eh sabes / todo eso me parece / me parece que: ... }\end{array}$ \\
\hline $\mathrm{E}$ & Pero en la guerra no recuerdas \\
\hline MR & $\begin{array}{l}\text { Fíjate yo es que en la guerra no recuerdo las las manifestaciones / o sea / } \\
\text { a lo mejor ... pero a mí eso no se me no se me quedó grabao / pero yo no } \\
\text { recuerdo no recuerdo las manifestaciones / fíjate // Ahora es que en } \\
\text { realidad yo no sé si había necesidad de manifestarse porque es que como } \\
\text { era todo ... }\end{array}$ \\
\hline
\end{tabular}




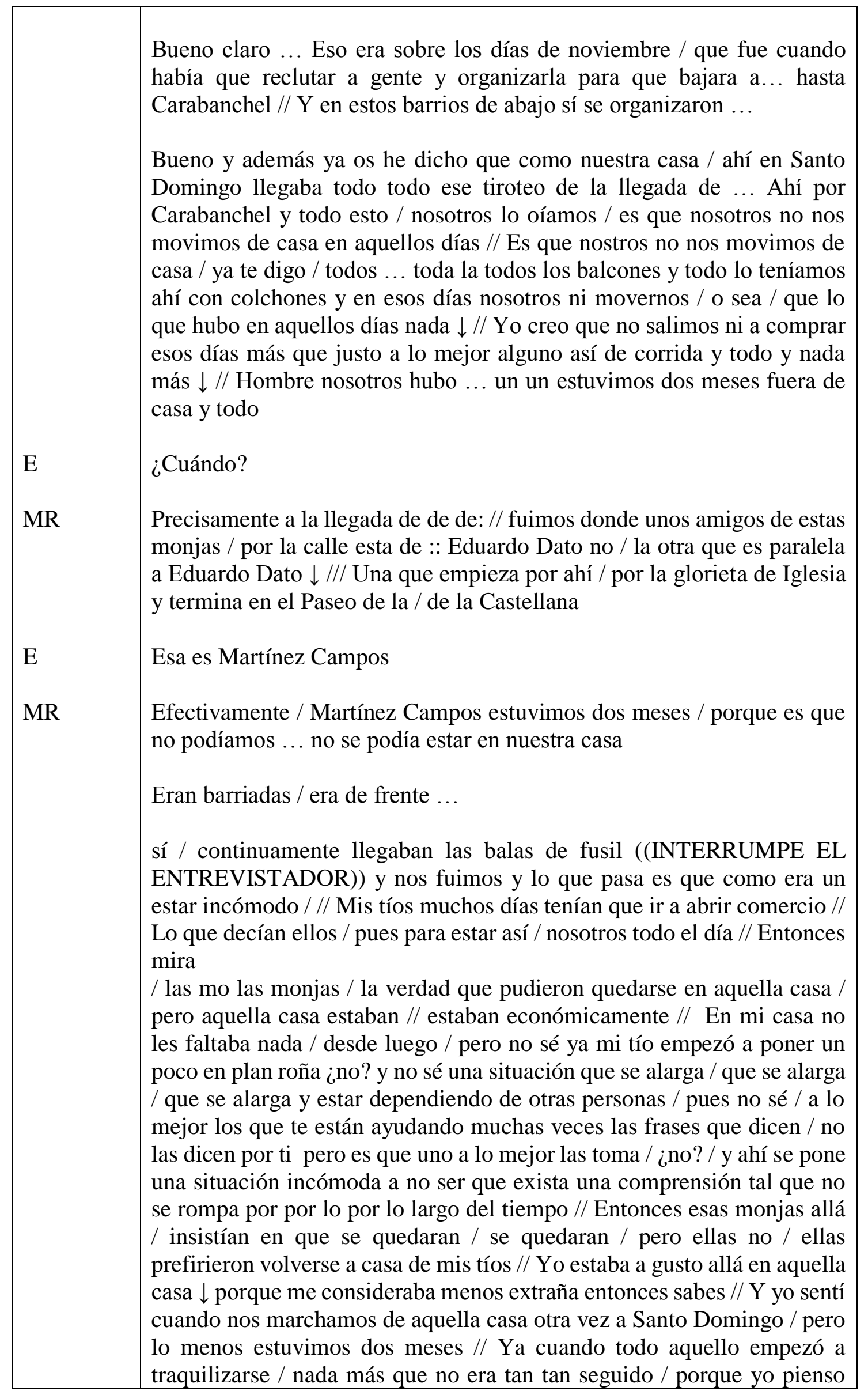




\begin{tabular}{|l|l|}
\hline que estuvimos muchos / muchos / muchos tiempos / eh / en que no se \\
pasaba una semana en que nosotros no tuviéramos que salir de la cama // \\
Y luego con frío / porque no teníamos calor // Y no teníamos comida // \\
Y no teníamos fuego / to todo aquello / bueno pues te iba minando de de \\
tal forma que que no eras tú / yo no era yo desde luego // \\
((INTERRUPCIÓN Y RISAS)) \\
Muchas / muchas noticias // Por ejemplo cuando iban a ver a las monjas \\
/ pues siempre llegaban noticias d'estas // // Que habían por ejemplo / en \\
la casa que estaban o algún conocido se se lo habían llevao // Incluso nos \\
contaban también // que de un conocido / pero esto yo siempre es a través \\
de otras personas : eh nunca ... no es tan exacto como lo de mi primo y \\
todo esto // Incluso de que había en una familia un chico / que se metió \\
como de espía / se fingió de derechas / entonces entabló $\downarrow$ se hizo novio \\
incluso de una de las una de las hijas // El ahí se metió tan a fondo / tan \\
a fondo pues que que se enteró de todo lo que había en en aquella casa // \\
Y es que acabo del tiempo pues los denunció a todos ((VOZ BAJA) // Y \\
cuando a esta a esta le hicieron juicio a esta monja a esta chica //Y yo \\
ahora no me acuerdo las frases que le decía la chica al chico / claro \\
cuando ... en el juicio ¿no? // Pero desde luego aquello debió ser aquello \\
debió de ser horrible / dice que los mataron los mataron a todos // En \\
cambio nos contaron también de otra chica que era enfermera de allí del \\
hospital de San Carlos / porque iban a ver a la ... fíjate estaba la superiora \\
/ incluso médicos / que ...// Negrín estuvo ahí / es donde estudió y las \\
conocía a ellas \\
El hijo
\end{tabular}

20MC

Edad: 75 años

Nacionalidad: España

Sexo: Femenino

\begin{tabular}{|l|l|}
\hline Informante & \multicolumn{1}{|c|}{ Discurso } \\
\hline E & $\begin{array}{l}\text { F. De la Cal que vivió durante la guerra civil en Madrid la realizan } \\
\text { Francisca Bernalte y María Escudero } \downarrow \text { Bueno pues cuéntenos un poco... } \\
\text { MC }\end{array}$ \\
$\begin{array}{l}\text { Yo me casé en el año } 1927 \downarrow \text { y la guerra empezó pues en el año } 36 \text { y claro } \\
\text { yo desde luego / vivíamos /// Hemos vivido siempre en Cuatro Caminos } \\
\text { y hemos estao muy cerca de de mis padres / pero yo he'sufrido mucho } \\
\text { porque yo era muy miedosa / sabe / y yo he sufrido mucho // Pero vamos } \\
\text { / en cuestión de eso hemos pasado bastante / porque inclusive hemos } \\
\text { tenido que ir a por leña para guisar } \uparrow / \text { hemos tenido que vender una cosa } \\
\text { para poder a:: poder coger otra ... hasta pan // Porque yo una de las veces } \\
\text { hasta una manta de mi cama tuve que llevar al pueblo de la sierra / para } \\
\text { traer patatas } \uparrow \text { y siempre saliendo pues a la aventura } \downarrow \text { ¿verdad? } \uparrow / / \text { Pero } \\
\text { vamos en cuestión ... porque yo tenía ... hemos sido cinco hermanos } \\
\text { pues han estao /// Claro el que le tocaba pues era ... pues han estao ... } \\
\text { pero gracias a Dios... un hermano sí estuvo herido / que cayó herido en }\end{array}$ \\
\hline
\end{tabular}




\begin{tabular}{|c|c|}
\hline & 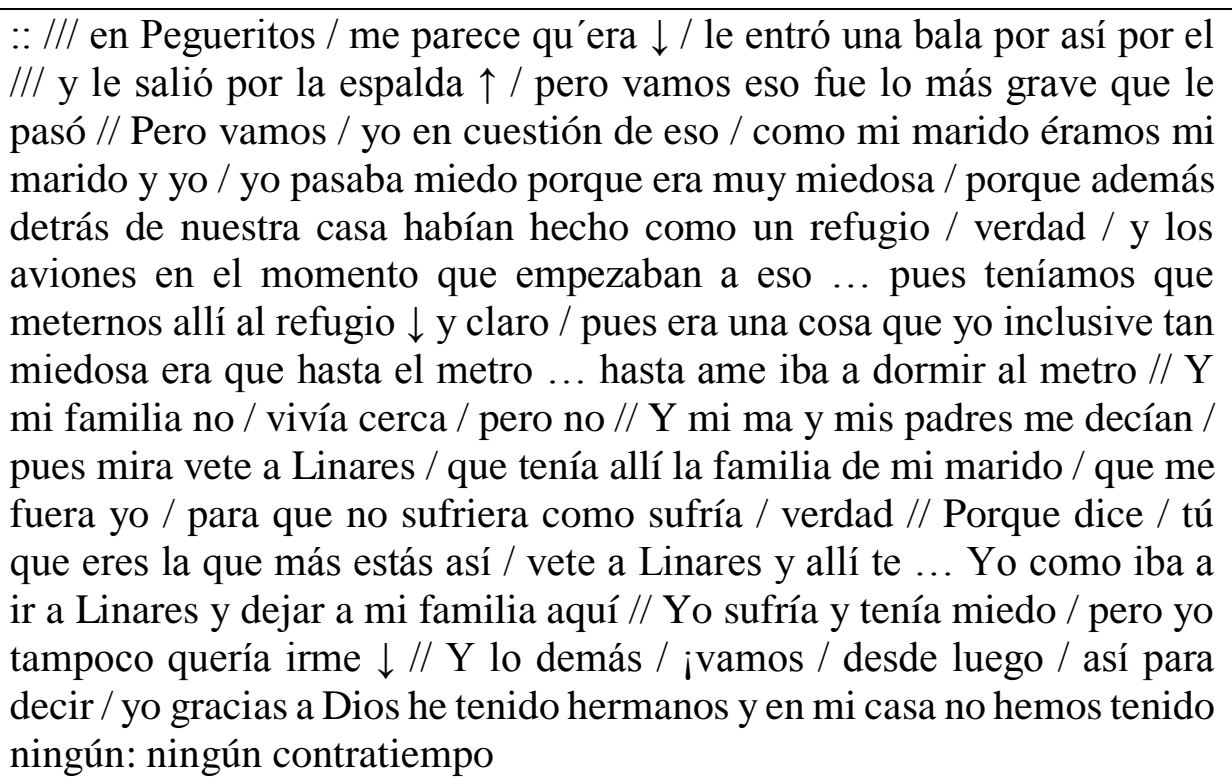 \\
\hline $\mathrm{E}$ & $\begin{array}{l}\text { Bueno pero cuéntenos / ¿usted vivía aquí / antes de casarse vivía aquí en } \\
\text { Madrid con su familia? }\end{array}$ \\
\hline $\mathrm{MC}$ & Sí / sí / sí // Yo con mi marido pero vamos cerca de mis padres $\downarrow$ \\
\hline
\end{tabular}

21A

Edad: 45 años

Nacionalidad: España

Sexo: Masculino

\begin{tabular}{|l|l|}
\hline Informante & \multicolumn{1}{c|}{ Discurso } \\
\hline E & $\begin{array}{l}\text { Vamos a hablar de otra cosa } \uparrow / \text { de las diversiones de tu juventud } \\
\text { háblame un poco de eso } \\
\text { Bueno / en eso / en eso este pueblo como era un pueblo de de veraneo / } \\
\text { pues casi te voy a decir / que casi estábamos mejor que ahora // Porque } \\
\text { entonces me acuerdo que había un cine / que había incluso los jueves un } \\
\text { cine que eran era ... las sillas eran de de los asientos eran de de bueno } \\
\text { madera // Y había cine todo en invierno había cine pues sábado y } \\
\text { domingo } \downarrow \text { había veces que había baile / venía una orquestilla por ahí / } \\
\text { de un saxofón / una trompeta y uno ahí pegando meneos // Y en el verano } \\
\text { venían los títeres / que venían circos / cosa que se ha perdido los títeres / } \\
\text { que que algunas veces salen en televisión pues había cada uno que venía } \\
\text { / que no veas // Y luego / a lo mejor / se hacía después de los títeres / se } \\
\text { hacía un poco baile / esa gente vivía pues de la rifa y de la voluntá / que } \\
\text { a la hora de dar la voluntá / la mitad de la gente se marchaba / era una } \\
\text { cosa mal hecha / pero se marchaba la mitad de la gente por no dar la } \\
\text { voluntá / entonces no había voluntá / no había nada / porque era lo que } \\
\text { había // Era vamos / que casi te puedo decir de que / concretamente / en } \\
\text { este pueblo la primer bolera que se hizo en en la provincia de Madrid fue } \\
\text { en este pueblo en Los Molinos / eso está claro / / la primera que se hizo } \\
\text { primera que se hizo fue aquí // Hubo una época / hubo unos tres o cuatro }\end{array}$ \\
\hline
\end{tabular}




\begin{tabular}{|c|c|}
\hline A & 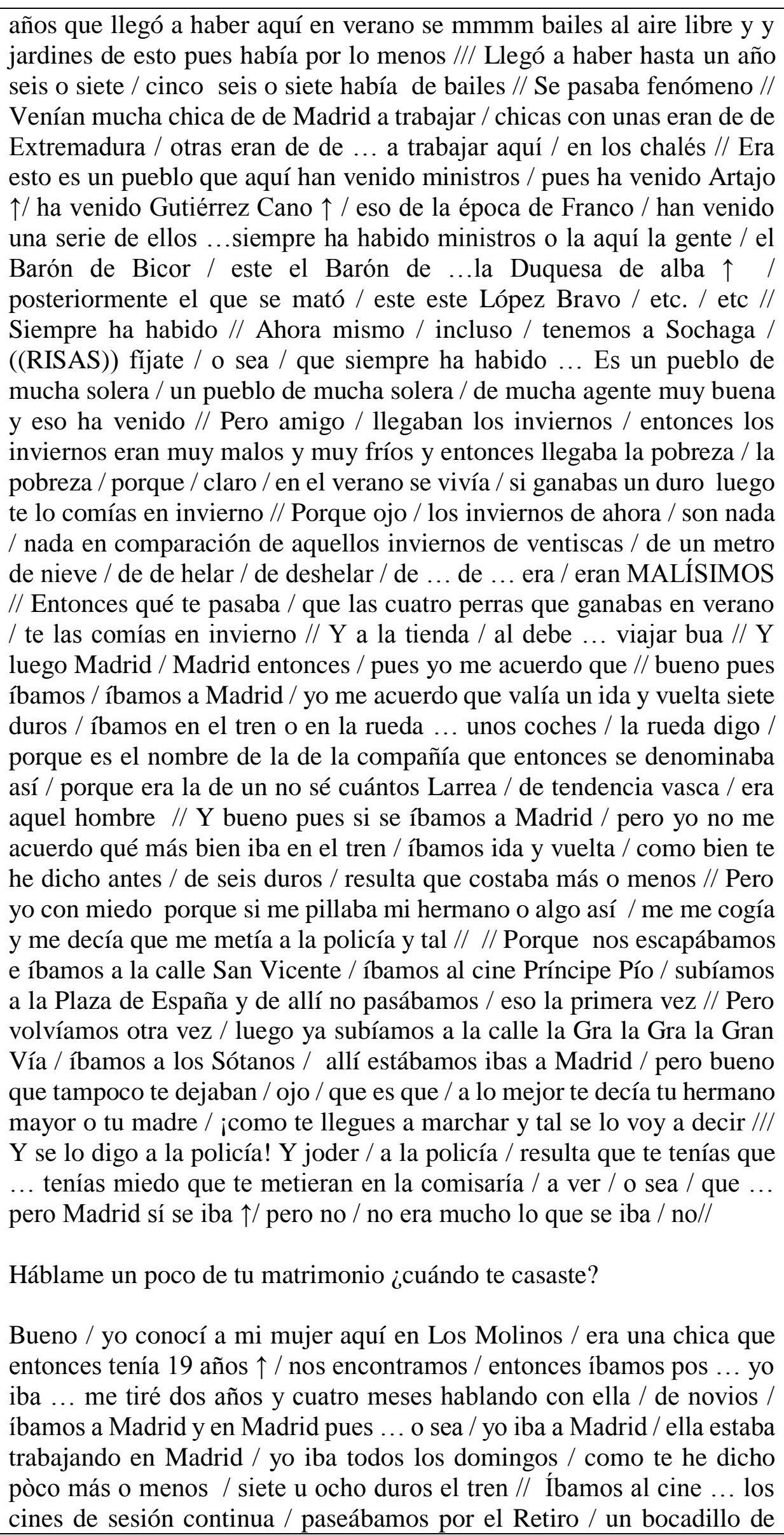 \\
\hline
\end{tabular}




\begin{tabular}{|l|l|}
\hline & $\begin{array}{l}\text { calamares / una caña de cerveza y a casa y nada más // Y ojo / que si } \\
\text { querías darla un beso / tenías que mirar / que a lo mejor veía el el guarda } \\
\text { de del Retiro / que era un un uno de allá / de la provincia de / de esto / } \\
\text { cómo se llama / asturiano y te decía que te iba a meter en el cuartel de la } \\
\text { guardia civil / porque aquello dar un beso a tu novia que no la ibas a ver } \\
\text { en ocho días / resulta que igual / a lo mejor / te metía en la comisaría o } \\
\text { algo así // Pero vamos / estuve así durante dos o tres años / hasta que me } \\
\text { casé // Me casé en el } 68 \text { y :: vamos ... } \\
\text { E }\end{array}$ \\
Aáblame un poco de tu mujer / de dónde es y ... \\
E & $\begin{array}{l}\text { Mi mujer pues es de Guadalajara / de un pueblecito de Guadalajara } \\
\text { ¿Cómo la conociste? } \\
\text { A } \\
\text { A.Se vio obligada por las circunstancias / pues a lo mejor no tan malas } \\
\text { casa di’unos señores que fueron muy buenos muy buenos muy buenos } \\
\text { tuvieron comuna hija /// Y }\end{array}$ \\
\hline
\end{tabular}

22MP

Edad: 70 años

Nacionalidad: España

Sexo: Femenino

\begin{tabular}{|c|c|}
\hline Informante & Discurso \\
\hline MP & Yo cuando empezó La República no me había casado todavía \\
\hline $\mathrm{E}$ & ¿Cuándo se casó? \\
\hline MP & $\begin{array}{l}\text {... Yo me casé el treinta y dos / el treinta y tres ... quizás el treinta y tres } \\
((\text { OTRA VOZ AL FONDO ...EL TREINTA Y SEIS ... EL TREINTA Y } \\
\text { CUATRO ... EL TREINTA Y TRES / SE CASÓ EN EL TREINTA Y } \\
\text { TRES)) ... }\end{array}$ \\
\hline $\mathrm{E}$ & ¿Y su compa? \\
\hline MP & $\begin{array}{l}\text {... el treinta y dos / el treinta y dos / que fue a última hora la víspera la } \\
\text { purísima / ((OTRA VOZ AL FONDO : EL TREINTA Y DOS }) \text { )... el } \\
\text { treinta y dos me casé }\end{array}$ \\
\hline $\mathrm{E}$ & ¿Y su marido / su marido en qué trabajaba ...? \\
\hline MP & Mi marido jornalero \\
\hline E & Jornalero \\
\hline MP & Que decimos los braceros del campo \\
\hline
\end{tabular}




\begin{tabular}{|c|c|}
\hline $\mathrm{E}$ & ¿Y usted también trabajaba en el campo? \\
\hline MP & $\begin{array}{l}\text { Yo también en el campo / que ganaba tres cincuenta y seis reales / que } \\
\text { me daban a mí un duro / teníamos que estar arrastraos / siempre tiraos en } \\
\text { el campo / claro } \downarrow \\
\text { Su marido ganaba }\end{array}$ \\
\hline MP & $\begin{array}{l}\text { Mi marido / cuando le querían / que es que no lo querían a los hombres } \\
\text { para trabajar / sabe usted / mi marido / luego / se colocó / cuando esto } \\
\text { explotó / ya de verdad y esta / estaba colocao aquí / en casa de aquí Ramos } \\
\text { de /// cómo se llamaba el padre?... Ramón / Ramón / ahí estaba de } \\
\text { capataz como decían entonces y de ahí se salió / se metió en el } \\
\text { ayuntamiento que era de los que entonces sabían mucho / sabe usted } \\
\text { ¿En los años de La República / su marido ya estaba metido en algún } \\
\text { sindicato o no? }\end{array}$ \\
\hline MP & $\begin{array}{l}\text { No cuando La República no / cuando explotó de primeras no / cuando ya } \\
\text { la guerra / como yo digo / fue cuando metieron en se el ayuntamiento } \\
\text { ¿el ayuntamiento de aquí? }\end{array}$ \\
\hline MP & $\begin{array}{l}\text { El ayuntamiento de aquí / claro / en el ayuntamiento de aquí / que } \\
\text { escogieron de los pocos que se sabía que / ((VOZ DE FONDO) / eh ... } \\
\text { la mayo / ría de hombres y mujeres analfabetas todas ... ni saben escribir } \\
\text { ¿Su marido sabía escribir? }\end{array}$ \\
\hline $\mathrm{E}$ & Muy bien / sí / la familia de mi marido es que eran los muy listos $\downarrow$ \\
\hline MP & Se había ido / tenía $\downarrow$ \\
\hline $\mathrm{E}$ & Por eso no dejaron rastro \\
\hline MP & Y us usted ¿había ido a la escuela? \\
\hline MP & $\begin{array}{l}\text { Yo fui a la escuela / pero mi madre tuvo catorce ((OTRA VOZ AL } \\
\text { FONDO / MI PADRE SE LLAMABA MANUEL GARCÍA } \\
\text { BALLESTEROS)) ... y era yo la mayor / de manera que ... pues no } \\
\text { tendría ocho años cuando ya estaba a escardar con mi padre pa ganar } \\
\text { cuatro perros que me daban y a ayudarle a mi madre a contender con los } \\
\text { chicos / de manera que ni siquiera la escuela ... si conozco algunas letras } \\
\text { es porque es porque ... nada ((OTRA VOZ AL FONDO: NI SE HA } \\
\text { PODIDO IR / NI NOSOTROS HEMOS PODIO IR...)) }\end{array}$ \\
\hline $\mathrm{E}$ & ¿Y cuántos / cuántos hijos tiene? \\
\hline MP & $\begin{array}{l}\text { Tres nada más... No me dio tiempo a más / sí estuvimos cinco años } \\
\text { casaos }\end{array}$ \\
\hline
\end{tabular}


23LR

Edad: 50 años

Nacionalidad: España

Sexo: Masculino

\begin{tabular}{|c|c|}
\hline Informante & Discurso \\
\hline & ((RUIDO DE FONDO)) \\
\hline LR & 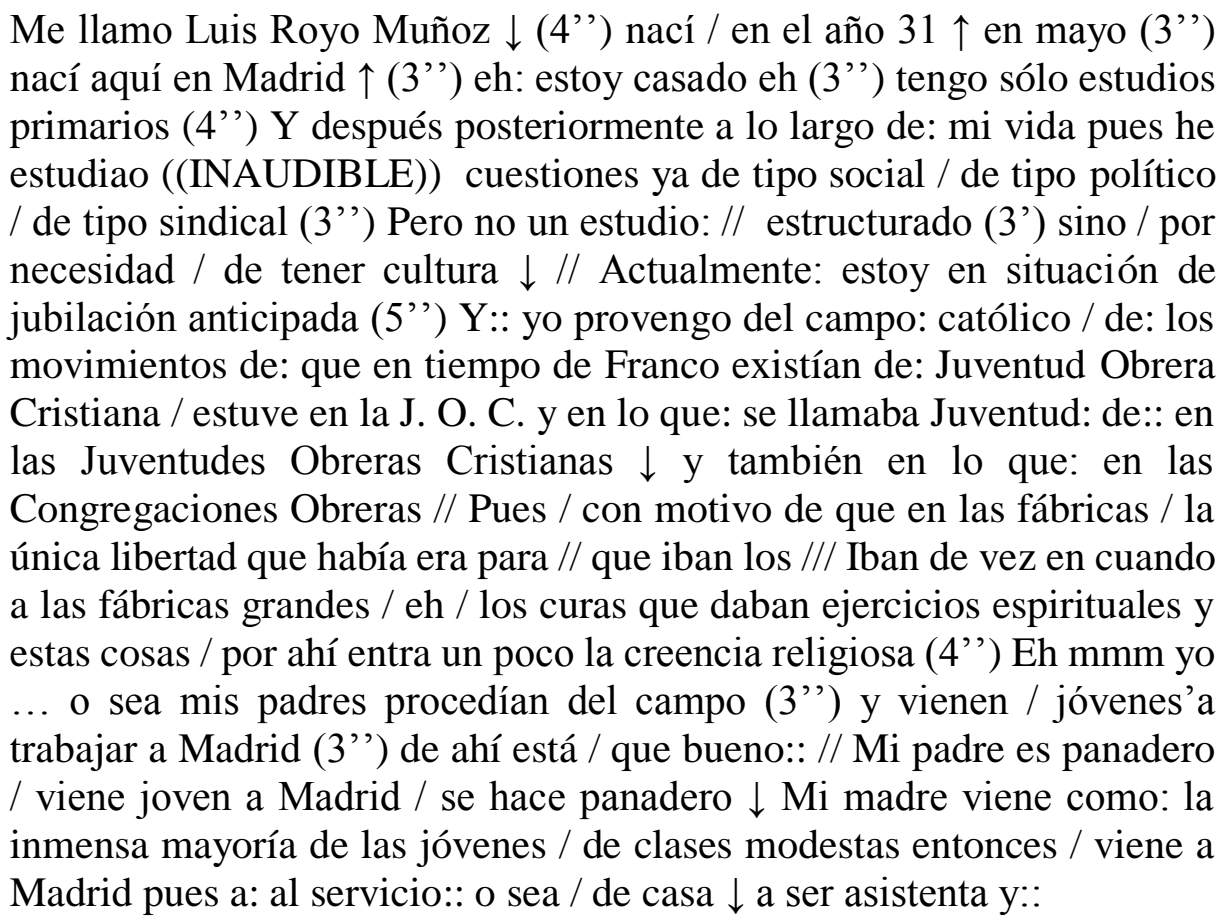 \\
\hline $\mathrm{E}$ & ¿De qué zonas procedían? \\
\hline LR & $\begin{array}{l}\text { Mi padre era de Ávila ((CARRASPEA)) / mi padre ha muerto ya / mi } \\
\text { madre vive todavía // Mi padre era de:: de un pueblo muy pequeño de } \\
\text { Ávila /// de: :: se llamaba // de Segovia / que se llamaba / se llama / } \\
\text { Madriguera / que no sé si su partido es / su cabeza de partido es Aiyón /// } \\
\text { Me parece qu'es Aiyón / de esa zona de: ahí / de Segovia // Y mi madre } \\
\text { es de Ávila / de Gredos / la parte más montañosa de Ávila // Eh: los dos } \\
\text { / nazco / eso era ... Mi padre ya entonces militaba en las: Juventudes } \\
\text { Socialistas } \downarrow / / \text { por entonces / cuando vino a Madrid / a los } 22 \text { años / } \\
\text { tengo entendido que él se afilió a las (4’’) desde las Juventudes } \\
\text { Socialistas / con la unificación pasa a la JSU } \downarrow \text { (4’') Eh: mi madre / ha } \\
\text { sido / eso que se llama apolítico / ((RISAS)) palabra que no tiene mucho } \\
\text { sentido / pero que / por definir / que no es una política concreta / Y: / } \\
\text { digamos / e:: de tipo la religión / que se les ha inculcao en los pueblos } \\
\text { una religión más bien sentimental y tal // Mi padre no: / no era creyente } \\
\text { / no era religioso / supongo que espontáneamente / en la medida que } \\
\text { como hombre puso escaparse más de: / de la influencia directa del clero } \\
\text { / de los pueblos } \downarrow \text { E::h Éramos tres hermanos } \uparrow / \text { somos todavía / pero en } \\
\text { la vida familiar tres hermanos / los tres chicos / yo era el mayor } \downarrow \text { (3") Y }\end{array}$ \\
\hline
\end{tabular}




\begin{tabular}{|c|c|}
\hline & 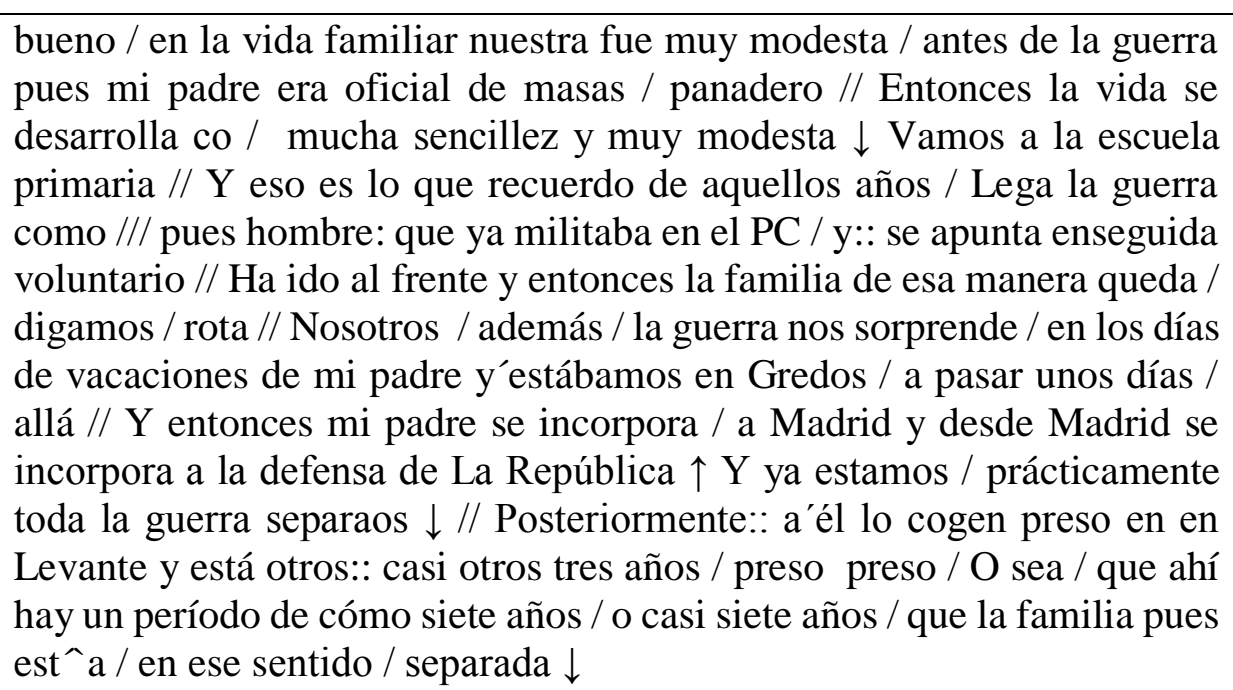 \\
\hline $\mathrm{E}$ & ¿Y de la guerra tú qué recuerdas, o sea, recuerdas algo? \\
\hline LR & $\begin{array}{l}\text { De la guerra poco porque yo entonces tenía cuando comienza la guerra / } \\
\text { teníaa cinco años recién cumplidos // Entonces sí / algunas cosas que } \\
\text { recuerdo / pues porque las han contao más posteriormente //E:h a mi } \\
\text { madre que tenía pues ((RISAS)) la desventura o ventura / según ella / de } \\
\text { ser la esposa de un comunista / cuando se enteraron / en la zona aquella } \\
\text { que se quedó // inmediatamente quedó en zona franquista / la hicieron } \\
\text { barrer las calles del pueblo / porque su marido era rojillo y eso / alguna } \\
\text { nota no que recuerdo // Porque por esa zona: no se notó la guerra / no } \\
\text { hubo una guerra directa / no hubo frente de ningún tipo / esa zona } \\
\text { inmediatamente quedó / cortada y quedó en la zona que denominaban } \\
\text { "Los Sublevaos" / o sea / Franco } \downarrow \text { Y: la guerra pues prácticamente no: } \\
\text { tuvimos noción de ella Únicamente al volver a Madrid / entonces ya sí / } \\
\text { empezaro empezamos a notar los efectos de la guerra // La represión a } \\
\text { mi padre / que queda preso: la carencia de ... mi madre tenía... }\end{array}$ \\
\hline $\mathrm{E}$ & ¿Volvéis a Madrid / una vez acabada la guerra? \\
\hline LR & 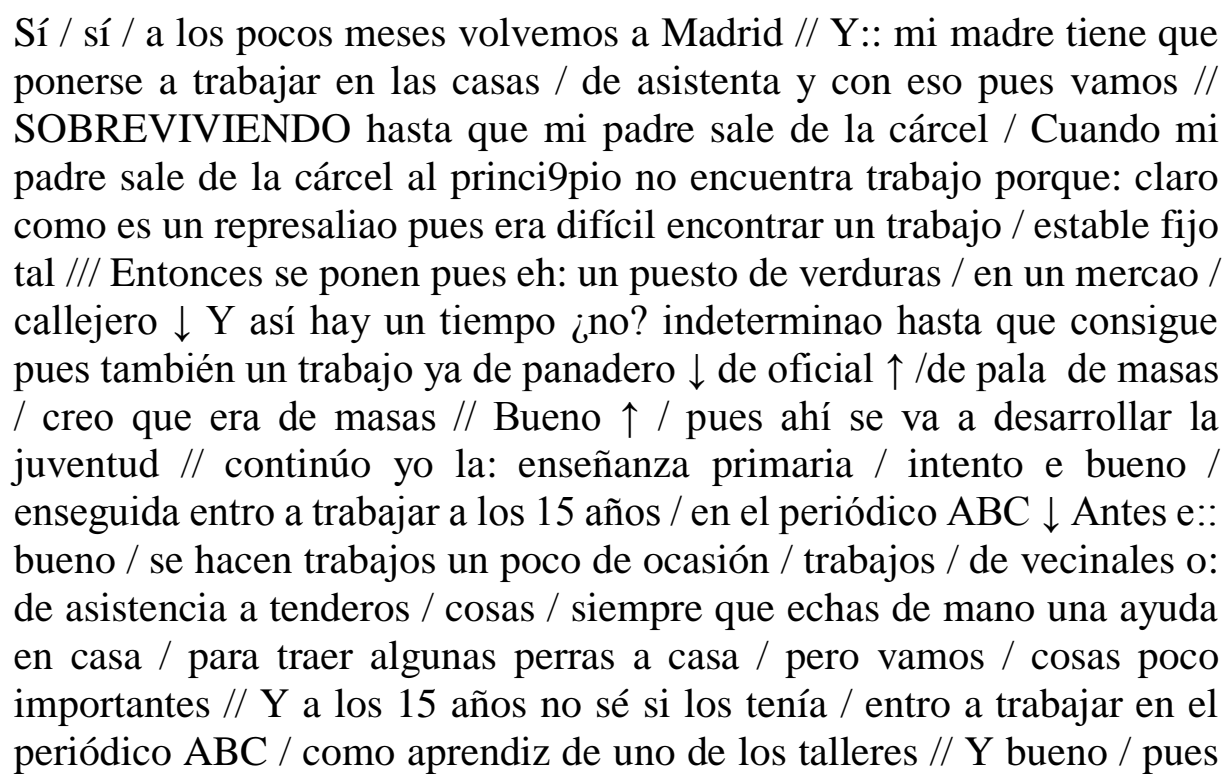 \\
\hline
\end{tabular}




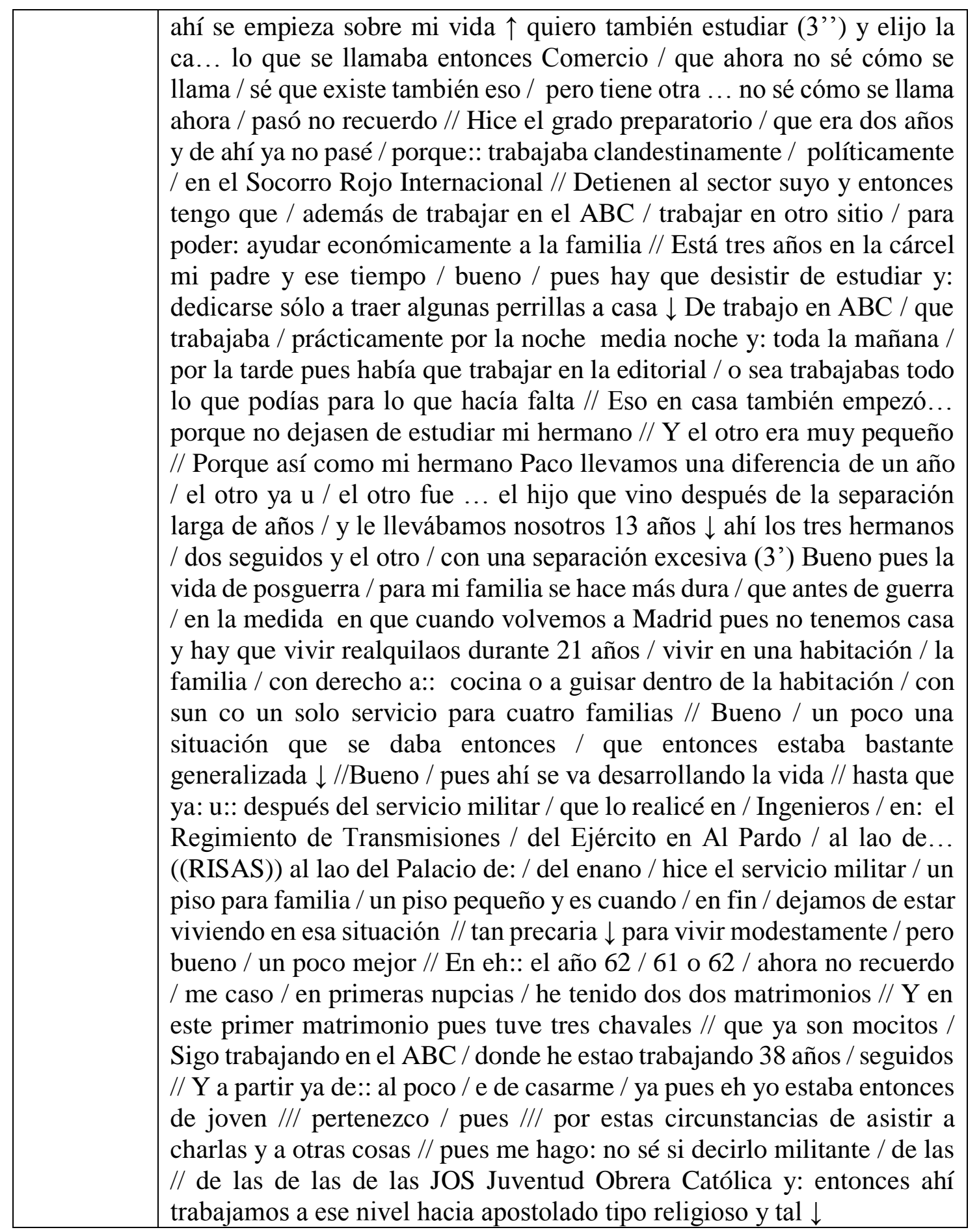

24VV

Edad: 48 años

Nacionalidad: España

Sexo: Masculino

\begin{tabular}{|l|l|}
\hline Informante & \multicolumn{1}{|c|}{ Discurso } \\
\hline E & $\begin{array}{l}\text { ¿Cuántos maestros había en su pueblo? } \\
\text { VV }\end{array}$ \\
$\begin{array}{l}\text { Pues entonces cuando Goyeneche / pues estaban tres / estaba Don Manuel } \\
\text { / estaba Don Lorenzo y estaba Don Santillana // que don Santillana y don }\end{array}$ \\
\hline
\end{tabular}




\begin{tabular}{|c|c|}
\hline & $\begin{array}{l}\text { Manuel eran hermanos y don Lorenzo } \uparrow \text { era de a era de /// tenía bastantes } \\
\text { pelas / con Doña Emilia se casó / luego al final ya se murió de viejo claro } \\
\text { // Entonce tre maestros // Yo iba a ca Don Manuel y a la más cerca de } \\
\text { casa / claro que hoy es hogar de los viejos / antes eran las escuelas nuestra } \\
\text { / es el hogar de los viejo // Y antes era depósito / se llamaba la cárcel / } \\
\text { bueno pues el depósito estaba ahí y la escuela aquí y entonce pue:: } \uparrow \text { ya } \\
\text { lo han hecho too pa los viejos / claro } \downarrow\end{array}$ \\
\hline $\mathrm{E}$ & $\begin{array}{l}\text { Cuando había un niño que se portaba mal / el maestro le castigaba ¿cómo } \\
\text { lo castigaba / qué qué pasaba? }\end{array}$ \\
\hline VV & 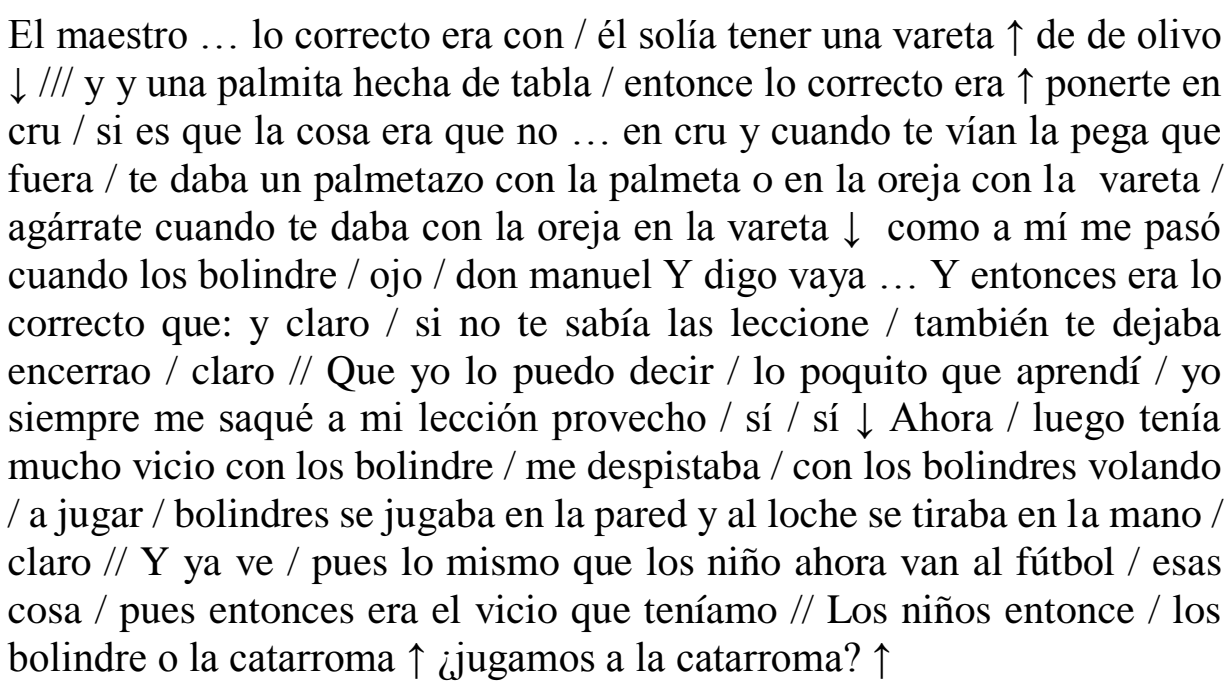 \\
\hline $\mathrm{E}$ & ¿Qué es eso? \\
\hline VV & $\begin{array}{l}\text { Eso / pues un cacho de hierro clavao en la tierra / Se ponía un poco tierra } \\
\text { / tierra / se regaba o se calaba y la pateábamo y luego a clavar la catarrosa } \\
\text { / claro / a ver quién la clavaba... }\end{array}$ \\
\hline $\mathrm{E}$ & ¿Cómo un clavo? \\
\hline VV & Como un clavo / lo mismo que un clavo / claro // Ese era el tema nuestro \\
\hline $\mathrm{E}$ & $\begin{array}{l}\text { ¿Y cuándo eran ... se sabían las lecciones y eran buenos y toas esas cosas } \\
\text { / les premiaban a ustedes? }\end{array}$ \\
\hline VV & $\begin{array}{l}\text { Bueno / nosotros de premiarnos nada / que yo sepa de premiarnos / nunca } \\
\text { // Lo único / lo único que sí / de que a lo mejor alguna tarde si tu por } \\
\text { cualquier cosa tenías que faltar o algo pues parece qúel el maestro } \\
\text { siempre te daba esa cosa / si tú habías salio bien / te decía / bueno / pues } \\
\text { no vengas esta tarde / o sea / que te daba esas felicidades }\end{array}$ \\
\hline $\mathrm{E}$ & ¿Faltaban mucho ala escuela o iban todos los días? \\
\hline VV & $\begin{array}{l}\text { Bueno / bueno / entonces se faltba más } \uparrow \text { / entoes se faltaba más } \uparrow \text { Yo los } \\
\text { tres años eso / falté muy poco lo único que sí me pasaba es que tuve hasta }\end{array}$ \\
\hline
\end{tabular}




\begin{tabular}{|c|c|}
\hline $\mathrm{E}$ & $\begin{array}{l}\text { las calenturas que no las he vuelto a tener hasta ahora / que he tenido la } \\
\text { fiebre de malta / yo no he vuelto a sentir una calentura / entonces era la } \\
\text { palúdica } \downarrow / / \text { Me daba un día fiebre y otro no / un día fiebre y otro no / un } \\
\text { día fiebre y otro día no // Así que un día a la escuela / otro día menguao / } \\
\text { así estuve tres años / así estuve // Y a la edad de diez años ya ame fui con } \\
\text { mi tío y no la he vuelto a ver la escuela / claro // } \\
\text { ¿Qué aprendió usted allí? }\end{array}$ \\
\hline VV & $\begin{array}{l}\text { Pues ya ve / aprender multiplicar / dividir y restar // Dividir ya que se te } \\
\text { ha olvidao / como te descuide // Y escribir / las letras mayúscula también } \\
\text { se te olvidan como no las uses mucho // Yo es lo que más me se olvida / } \\
\text { la letra mayúscula / más que la cuenta // Las cuenta a mí no se me han } \\
\text { olvidao mucho / pero y los problemas esos también / el echar un problema } \\
\text { ya te cuesta trabajo / te sale bien luego un problema / claro / bueno pues } \\
\text { eso / cuando estaba actuando o claro / pues te lo llevaba de calle / pero } \\
\text { luego eso ya lo dejaste / ya te fuiste al campo / ya luego no has vuelto a } \\
\text { echar u problema en tu puñetera vida y claro / / las cuentecilla a lo mejor } \\
\text { / de multiplicar no se me han olvidao / yo me sé toa la tabla / o sea / que } \\
\text { la tabla me la sé / pero lo de las letras mayúsculas y lo de los problema / } \\
\text { eso cuasi se te han ido / es así } \downarrow\end{array}$ \\
\hline $\mathrm{E}$ & $\begin{array}{l}\text { Cuan cuando cuando se fue usted de la escuela ¿se fue con pena o estaba } \\
\text { deseando...? }\end{array}$ \\
\hline VV & $\begin{array}{l}\text { Bueno yo en aquellos momentos pues estaba deseando pues irme al } \\
\text { campo } \downarrow \text { Mi tío } \uparrow / \text { porque cuantas veces me decía / muchacho aprende } \\
\text { bien a leer esoeasí y a escribir y te compro un acordeón / porque yo me } \\
\text { gustaba mucho bailar y cantar y triunfar y eso pa las fiestas eh me gustaa } \\
\text { mucho /// }\end{array}$ \\
\hline
\end{tabular}

25AL

Edad: 63 años

Nacionalidad: España

Sexo: Masculino

\begin{tabular}{|l|l|}
\hline Informante & \multicolumn{1}{|c|}{ Discurso } \\
\hline E & $\begin{array}{l}\text { Bien / de acuerdo / sí claro / estaba todo en la provincia de Toledo / pues } \\
\text { fue la ofensiva de Franco y enseguida ... Bien pasemos esta etapa así y } \\
\text { entramos ya en lo que fue tu participación en la guerra / porque al venir } \\
\text { a Madrid ... }\end{array}$ \\
AL & $\begin{array}{l}\text { Sí / yo estuve en el ejército / me enrolé ...como yo vivía en Cuatro } \\
\text { Caminos y era ... a ver / ya sabes / había amigos y eso / fuimos a } \\
\text { enrolarnos y me dijeron que a mí no me admitían porque era chico / que } \\
\text { no ... } \\
\text { Eí claro / dieciséis años }\end{array}$ \\
\hline
\end{tabular}




\begin{tabular}{|c|c|}
\hline $\mathrm{AL}$ & $\begin{array}{l}\text { Chico no sólo en edad / que era un mierda / no // Y entonces dijeron los } \\
\text { otros que venían conmigo que si no me quedaba yo / no se quedaban ellos } \\
\text { // Bueno / vale / ¡hala para adentro! // Y entonces pues me enrolé // Estuve } \\
\text { tres o cuatro meses // Y a los tres o cuatro meses / como mi hermano } \\
\text { estaban en tanques / porque ellos habían hecho un curso / estando } \\
\text { también en la sierra / estaban también en infantería / pues yo también ... } \\
\text { pues me metí / o sea / hice la instancia / la solicitud de tanques // Y } \\
\text { entonces pues me mandaron llamar / a los o dos tres meses y me fui a } \\
\text { tanques // Y estuve en tanques de guerra }\end{array}$ \\
\hline $\mathrm{E}$ & ¿Siempre como soldado o...? \\
\hline $\mathrm{AL}$ & $\begin{array}{l}\text { Bueno sí / yo era ajefe de carro / pero era ... estuve como soldao // Era } \\
\text { un soldao / como que en el carro iban tres / el conductor /Y el tirador y } \\
\text { jefe de carro / no / era lo único / pero vamos era un soldado }\end{array}$ \\
\hline $\mathrm{E}$ & $\begin{array}{l}\text { Y que... en fin / por abreviar un poco / algunas ... vamos a ver / cosas } \\
\text { que pasaron en la guerra / que pudieron influir después en tu ... en tu... }\end{array}$ \\
\hline $\mathrm{AL}$ & Bueno / en la guerra... \\
\hline $\mathrm{E}$ & $\begin{array}{l}\text { Estaba pensando / yo no dejo de pensar / en las huelgas / en el cambio de } \\
\text { régimen y tal ¿cómo viste la guerra para luego después influir en...? }\end{array}$ \\
\hline AL & $\begin{array}{l}\text { Pues yo la guerra / yo la guerra / pues tengo ((INAUDIBLE)) además con } \\
\text { fe / sabes // Y y conmigo... }\end{array}$ \\
\hline $\mathrm{E}$ & $\begin{array}{l}\text { Como todos / digamos / como todos / en el bando republicano / bueno } \\
\text { como todos... }\end{array}$ \\
\hline AL & No / todos no eran iguales \\
\hline $\mathrm{E}$ & No / pero quiero decirte que no es ... que no eran obligados \\
\hline $\mathrm{AL}$ & $\begin{array}{l}\text { Sin pertenecer a ningún político / sabes / allí en tanques imperabas los } \\
\text { comunistas // Y estaban diciéndome que por qué no me hacía del Partido } \\
\text { Comunista y tal // Y yo nunca... yo nunca dije que no // Eso sí / conmigo } \\
\text { tenían confianza / yo sabía todo lo que les pasaba / porque me lo contaban } \\
\text { // Y cuando había que hacer cualquier cosa lo hacía / pero yo de } \\
\text { pertenecer a ningún partido dije que no / que nunca } \\
\text { ¿Por qué? }\end{array}$ \\
\hline AL & $\begin{array}{l}\text { Pues por la sencilla razón / porque habían muchos por ahí mucho por ahí } \\
\text { que hablaban mucho / que eran comunistas / por ejemplo un tirador que } \\
\text { tenía yo en el carro y cuando llegaba por ahí / no veas / alardeaba de tal } \\
\text { // Pero luego llegaban / cuando llegaban al frente y te metía } \\
\text { ((INAUDIBLE)) y así era ... así que yo no / yo / eso sí cuando había que } \\
\text { dar el morro / lo dábamos los primeros / pero no / no quería pertenecer a } \\
\text { ningún partido político }\end{array}$ \\
\hline
\end{tabular}




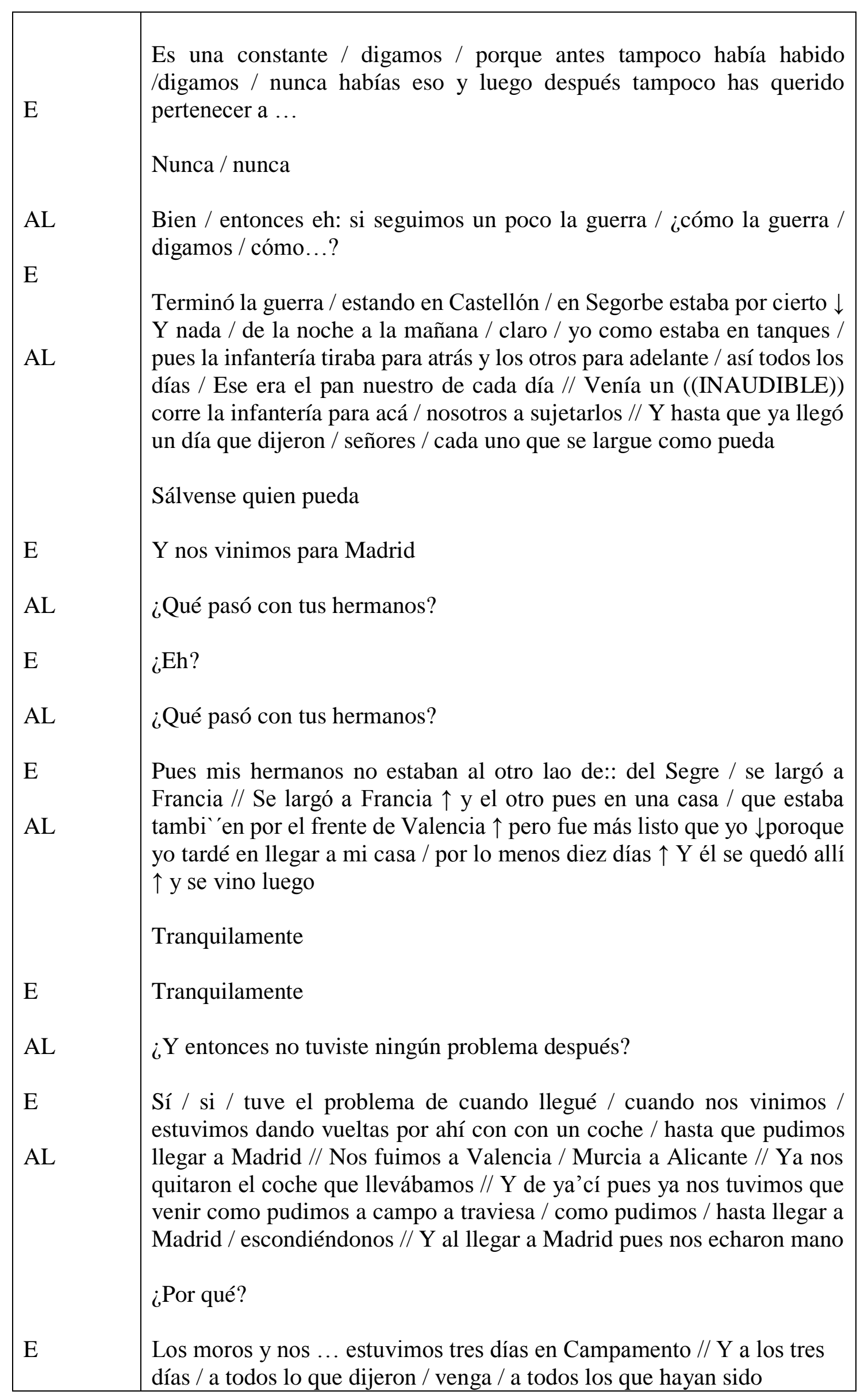




\begin{tabular}{|l|l|}
\hline AL & $\begin{array}{l}\text { oficiales y comisarios / que salgan // Salieron cuatro incautos y a los } \\
\text { demás nos dijeron / venga / hala a la calle // Y salieron diciendo Franco } \\
\text { / pues... al llegar a mi casa nada } \\
\text { No pasó nada / pero claro luego tuviste que hacer la mili / no }\end{array}$ \\
$\mathrm{E}$ & $\begin{array}{l}\text { Sí / luego después / luego después hice la mili / en un batallón de } \\
\text { trabajadores / porque había que presentar un aval / para: el que iba al } \\
\text { ejército / como yo no presenté el aval /// más bien porque me dio la gana } \\
\text { presentarlo / porque no me dio la gana de presentarlo / porque lo podía } \\
\text { haber presentao pues me consideraron desafecto al régimen y me } \\
\text { mandaron a un campo de concentración } \uparrow \text { y estuve un año } \downarrow\end{array}$ \\
\hline
\end{tabular}

26AQ

Edad: 66 años

Nacionalidad: España

Sexo: Masculino

\begin{tabular}{|c|c|}
\hline Informante & Discurso \\
\hline AQ & ...en el año 36 / en el año 36 / a partir del 36 para acá ... \\
\hline $\mathrm{E}$ & ¿Usted cuándo nació?^ \\
\hline AQ & Yo nací en el año $1926 \downarrow$ \\
\hline $\mathrm{E}$ & En el $26 \uparrow /$ en fin / yo pensaba que era más joven $\downarrow$ \\
\hline AQ & $\begin{array}{l}\text { Éramos ocho hermanos y mi padre era funcionario del Ayuntamiento y } \\
\text { de Acción Católica } \downarrow \text { ((INAUDIBLE)) ¿Está grabando no?^ ((SE OYE } \\
\text { LA INTERVENCIÓN DE OTRA PERSONA)) }\end{array}$ \\
\hline $\mathrm{E}$ & Sí / sí / estoy grabando \\
\hline AQ & $\begin{array}{l}\text { Entonces simplemente por eso / en el año } 36 \text { detuvieron a mi padre y lo } \\
\text { mataron y nos dejaron a ocho hermanos en la calle / sin nada de nada y } \\
\text { no tuvimos ... Además no pudimos asistir a clase durante los años de } \\
\text { guerra / por ser hijos de fascista }\end{array}$ \\
\hline $\mathrm{E}$ & ¿Qué estuvo en la zona de Madrid? \\
\hline AQ & $\begin{array}{l}\text { Yo estuve en Valdepeñas } \downarrow \text { / provincia de Ciudad Real } \downarrow / / \text { Y entonces } \\
\text { éramos hijos de fascista y éramos también perseguidos // Tuvimos que } \\
\text { empezar a trabajar / claro y a coger comida como fuese por ahí / porque } \\
\text { la vida fue durísima con nosotros } \downarrow \text { / Y al terminar la guerra / empezamos } \\
\text { a ir al colegio / los más pequeños de mi casa // Yo / por ejemplo } \downarrow \text { / con } \\
\text { nueve años dejé de trabajar } \uparrow y \text { ya tuve que ir a trabajar } \downarrow\end{array}$ \\
\hline $\mathrm{E}$ & No / dejaste de ir al colegio \\
\hline
\end{tabular}




\begin{tabular}{|c|c|}
\hline AQ & Dejé de ir al colegio y ponerme a trabajar \\
\hline $\mathrm{E}$ & A los nueve años \\
\hline AQ & $\begin{array}{l}\text { A los nueve años para empezar a ayudar // Y entonces iba por las tardes } \\
\text { / después del trabajo / iba al colegio // En el colegio / pues era duro / en } \\
\text { el aspecto de que había mucha rigidez en el profesorado y existía el } \\
\text { castigo corporal con la regla en la mano / o darte en el culo o darte una } \\
\text { bofetada / eh } \uparrow \text { y que no se quejaran / La enseñanza entonces era / pues } \\
\text { muy primitiva / porque simplemente tenías / a lo mejor / un libro que se } \\
\text { llama La Enciclopedia / en el cual ... }\end{array}$ \\
\hline $\mathrm{E}$ & La Enciclopedia / ahí se daba todo \\
\hline AQ & $\begin{array}{l}\text { Ahí eran todas las asignaturas // y tenía una cantidad de letras / sin figuras } \\
\text { / sin ejemplos / como ahora / los libros tan bonitos que tienen los niños / } \\
\text { son libros más explicativos que se ven ... lo otro todo era imaginación / } \\
\text { eran letras / letras / letras / letras }\end{array}$ \\
\hline $\mathrm{E}$ & Lo mismo te hablaba de una cosa que te hablaba de otra \\
\hline AQ & $\begin{array}{l}\text { No existía claro / no existía el bolígrafo / entonces teníamos que escribir } \\
\text { / escribir con el lapicero y los ejercicios tenía que hacerlos con tinta / } \\
\text { con pluma / que era ... te manchabas / se abrían las plumas / se rompían } \\
\text { y te castigaban porque la escritura... }\end{array}$ \\
\hline $\mathrm{E}$ & Hacía muchos borrones \\
\hline AQ & $\begin{array}{l}\text { Un niño pequeño ... la pluma es que entonces / no era una pluma buena } \\
\text { / se abría la pluma entonces los pupitres y eso // Y el sistema era / pues } \\
\text { muy rudimentario / Luego fue evolucionando / pero yo por desgracia / } \\
\text { pues no / conseguía ... porque entonces empecé a ir a la escuela nocturna } \\
\text { / por la noche }\end{array}$ \\
\hline $\mathrm{E}$ & ¿Y qué era / colegio nacional? \\
\hline AQ & $\begin{array}{l}\text { Era colegio nacional / sí / el único en mi casa / delos ocho hermanos / } \\
\text { que consiguió ir al Instituto / fue el pequeño Gregorio/ que empezó a ir } \\
\text { al Insituto / terminó el bachillerato y terminó haciendo la carrera de } \\
\text { derecho / el pequeño // Los demás / pues como te he dicho antes / } \\
\text { empezamos a trabajar a los nueve años y si quisimos aprender algo / } \\
\text { teníamos que ir por la noche a la escuela municipal que había / reida por } \\
\text { el Frente de juventudes / íbamos a una escuela donde te enseñaban ya } \\
\text { pues las cuatro reglas / matemáticas / la gramática y todo esto te } \\
\text { enseñaban unas nociones por si... }\end{array}$ \\
\hline $\mathrm{E}$ & Aprendizaje... \\
\hline AQ & Aprendizaje de lectura... \\
\hline
\end{tabular}




\begin{tabular}{|l|l|}
\hline E & $\begin{array}{l}\text { Las cosas más elementales } \\
\text { Lo más elemental / era la escuela que se hacía por la noche / después de } \\
\text { trabajar } \\
\text { E }\end{array}$ \\
AQ & $\begin{array}{l}\text { ¿Y eran maestros? } \\
\text { Sí / eran maestros / pero la mayoria eran voluntarios afectos al régimen } \\
\text { Que hacíamos ya los campamentos y te enseñaban también }\end{array}$ \\
E & $\begin{array}{l}\text { Ah / pero ya metidos en el Frente de Juventudes } \\
\text { Metidos en el Frente de Juventudes / fue los que nos ayudaron a aprender } \\
\text { eso }\end{array}$ \\
AQ & $\begin{array}{l}\text { Pues entonces no era propiamente una escuela / era... } \\
\text { No era escuela / no era escuela / luego sí }\end{array}$ \\
E &
\end{tabular}

27MC

Edad: 75 años

Nacionalidad: España

Sexo: Masculino

\begin{tabular}{|l|l|}
\hline Informante & \multicolumn{1}{|c|}{ Discurso } \\
\hline E & $\begin{array}{l}\text { Bien / pues estamos con Don Marcelino Camacho en su despacho y lo } \\
\text { primero que debo preguntarle es si usted está dispuesto a que la entrevista } \\
\text { que le vamos a hacer sea utilizada en una investigación histórica que está } \\
\text { haciendo el Departamento de contemporáneo de la Facultad de Historia }\end{array}$ \\
& $\begin{array}{l}\text { Por supuesto que:: para mí: / indudablemente // es un honor y un placer } \\
\text { el saber que mi vida / que yo creo que es mmm / normal // todo el mundo } \\
\text { a veces cuando me preguntan cómo soy / les digo / pues mira como me } \\
\text { ves / como soy físicamente ni alto ni bajo / ni gordo ni flaco // Yo creo } \\
\text { que soy normal / en ese aspecto y trato de serlo en general // No creo que } \\
\text { haya que tener tampoco un doble lenguaje / aparte de que los hechos son } \\
\text { los hechos / mmm y: bueno pues se pueden interpretar de diferentes } \\
\text { formas / pero indudablemente / mmm no deja de tener una base que: } \\
\text { aunque pueda confundirse y se relate de una manera u de otra / es esencial } \\
\downarrow / / \text { Así que totalmente de acuerdo y dispuesto a preguntar lo que } \\
\text { necesitéis / sin ningún tabú tampoco Yo no tengo ni doble vida / ni doble } \\
\text { imagen } \downarrow \\
\text { Bueno pues su nombre y apellidos ya los hemos dicho / de los datos } \\
\text { personales yo sólo le voy a preguntar su lugar de nacimiento y fecha / } \\
\text { que aunque lo sé / creo que puede interesar más concretamente / ya que } \\
\text { lo demás es archiconocido por todo el mundo / no es como si la entrevista } \\
\text { fuese a un personaje más desconocido // Por lo tanto nació en un } \\
\text { pueblecito de Soria / no }\end{array}$ \\
\hline
\end{tabular}




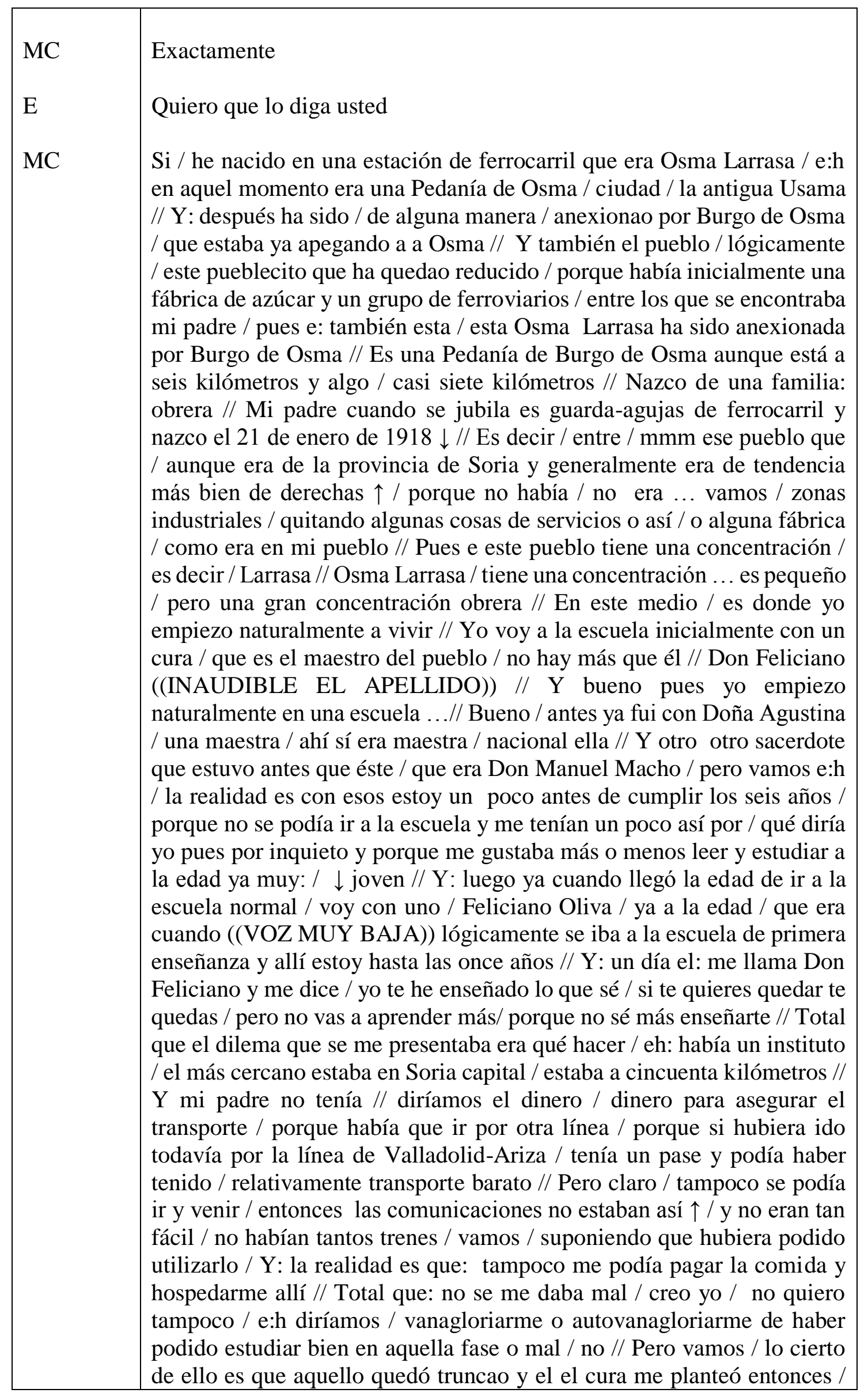




\begin{tabular}{|l|l|}
\hline & $\begin{array}{l}\text { de ir a un seminario que había en Burgo de Osma / ese pueblo que te digo } \\
\text { que es ahora al que pertenece // Y / que mi padre no era creyente / yo } \\
\text { tampoco / esa es la verdad / aunque iba a la escuela con el cura y fui } \\
\text { monaguillo mientras fui a la escuela / después ya no /Y claro / entonces } \\
\text { hace años // } \\
\text { Nunca / perdón / ¿nunca tuvo ninguna inquietud religiosa? } \\
\text { E }\end{array}$ \\
MC & No no no \\
E & No ningún tipo? \\
MC
\end{tabular}

28JV

Edad: 60 años

Nacionalidad: España

Sexo: Femenino

\begin{tabular}{|c|c|}
\hline Informante & Discurso \\
\hline JV & Bueno / yo te voy a decir / voy a retroceder un poco... \\
\hline $\mathrm{E}$ & Retrocede un poco / tu vida de niña / los estudios... \\
\hline JV & $\begin{array}{l}\text { Mi vida de niña / pues bueno / yo me eduqué en un colegio del Estado } \uparrow \\
\text { / en un colegio municipal } \uparrow \text { / en el grupo de Bailén } \uparrow \text { /que está allí en la } \\
\text { calle Bailén / que hoy es Vásquez de Mella y: después allí mismo / me: } \\
\text { en unión de otras cuatro o cinco compañeras / me parece que éramos / } \\
\text { pues / nos prepararon para el ingreso en la Normal... a los: trece años } \\
\text { bueno / a los catorce años ingresé a la Normal para hacer la carrera de: } \\
\text { magisterio } \downarrow \text { antes eh: yo / pues ya desde los siete años / se puede decir } \\
\text { desde los seis o los siete años / pertenecí a lo que entonces se denominaba } \\
\text { / hum / como es esto... espérate que ahora me acuerde / si quieres corta } \\
\ldots \text {..((CORTE)) ... buah ((RISA)) / bueno / desde / mi padre era socialista } \\
\text { / pertenecía a la Agrupación Socialista de Latina-Inclusa } \downarrow \text { y entonces } \\
\text { todas mis hermanas y yo incluida / pues / desde muy pequeñitas / ya te } \\
\text { digo / tendríamos cinco o seis años / pertenecimos al Grupo de Salud y } \\
\text { Cultura } \downarrow \text { y allí tomamos parte / pues / en todas las actividades de carácter } \\
\text { / eh / y recreativo y / en fin / que entonces tenían esta / esta Asociación } \\
\downarrow \text { y / y así / pues / estuve perteneciendo } \downarrow / \text { hasta que ingresé también en } \\
\text { / la Escuela Normal y / desde la Escuela Normal / un gru po // de jóvenes } \\
\text { / bueno / a parte de / entonces inmediatamente ingresamos a la FUE } \downarrow \text { eh } \\
\text { / la Federación Universitaria Escolar / de la que fui / representante por } \\
\text { magisterio / es decir / fui secretaria } \uparrow \text { fui secre secretaria del Grupo de } \\
\text { Magisterio ...((CORTE)) ... conozco a Julia de las Heras y conozco } \\
\text { también a / a esta otra cómo se llama / que era íntima amiga de Julia de } \\
\text { las Heras / estuvo / Julia de las Heras estaba conmigo también en la cárcel } \\
\text { ((VOZ BAJíSIMA)) / bueno / teníamos relación también antes de eso / } \\
\text { fíjate desde: Magisterio / tomé parte en to / po pa por supuesto en todas } \\
\text { las huelgas universitarias que hubo en aquellos años como preludio de la }\end{array}$ \\
\hline
\end{tabular}




\begin{tabular}{|c|c|}
\hline $\mathrm{E}$ & $\begin{array}{l}\text { proclamación de / de La República / ueno de La República en realidad ya } \\
\text { se había proclamado / pero de todos estos actos que hubo luego después } \\
\text { de huelgas etcétera / y:: yo creo que fue a los } 15 \text { años / es decir / yo ya } \\
\text { estaba en primero d magisterio } \uparrow / \text { ingresamos un grupo de ompañeras } \\
\text { en bloque en las Juventudes Socialistas / porque yo me consideraba ya / } \\
\text { ya te digo / socialista pues yo creo desde mi nacimiento ... ((RISAS)) } \\
\text { Bueno ((RISAS)) }\end{array}$ \\
\hline JV & $\begin{array}{l}\text { Si quieres que continúe ...((CORTE)) ... mi militancia política / } \\
\text { efectivamente me gustaba mucho: leer y yo leía todo lo que caía en mis } \\
\text { / mis manos / en la / leía / leí mucho en la en la biblioteca que tenían allí } \\
\text { / en la / agrupación socialista de Latín-Inclusa / influencia de / de mi } \\
\text { padre / fui con él varias veces a la Casa del Pueblo / entonces yo ya me } \\
\text { aficioné a oir a aquellos grandes maestros que había / verdad / pues Pablo } \\
\text { Iglesias / yo era muy pequeña y me acuerdo que me impresionó / } \\
\text { enormemente / oí también a Fernando d elos ríos / oía a Besteiro / luego } \\
\text { en la Normal conocí personalmente a la mujer de Basteiro / a Doña } \\
\text { dolores Cebrián / y conocí mucho porque era también / eh / afiliada a la } \\
\text { misma agrupación mía a DOLORES VERGÉ / que era secretaria de la } \\
\text { Normal y que había ido para colaborar con Doña Dolores Cebrián /// para } \\
\text { mí fueron / sobre todo Lola Vergé / pues fue como también otra maestra } \\
\text { dentro de / del socialismo / que influyó / notablemente mucho en / en mí } \\
\text { / y yo creo que / esto fue el / la motivación principal que / que me llevó } \\
\text { al socialismo / el reconocimiento / luego / por mutuo propio / por por ese } \\
\text { estudio y por esa convivencia con estos hombres / de que el socialismo } \\
\text { era la única forma / hum / yo sigo creyéndolo / que es la única forma de } \\
\text { que / de que la sociedad entre en un / en una hora / una era de } \\
\text { transformación totalmente diferente y / y feliz bajo todo punto de vista / } \\
\text { lo mismo ... }\end{array}$ \\
\hline $\mathrm{E}$ & ¡Ojalá! \\
\hline JV & Desde el punto de vista social \\
\hline $\mathrm{E}$ & ¡Ojalá! \\
\hline JV & $\begin{array}{l}\text { Política / por lo menos yo me lo creo ....((CORTE)) ... el trato era un } \\
\text { trato / hum / muy ómo te diría / muy familiar muy / muy jovial / muy } \\
\text { alegre / hacíamos muchas excursiones al campo / íbamos con / con estos } \\
\text { grupos de / de Salud y Cultura / incluso luego después / ya perteneciendo } \\
\text { a la Juventud / y con los grupos de la Juventud íbamos mucho / hum / } \\
\text { fuera / íbamos a la sierra / íbamos a otras / a otras poblaciones y } \\
\text { establecíamos contactos con los jóvenes de los pueblos de la provincia } \\
\text { principalmente / ¿verdad? / entonces allí / cuando íbamos los domingos } \\
\text { / íbamos / eh / llevábamos nuestras meriendas /// eh / que luego / } \\
\text { generalmente / comíamos al / en el campo / pues / en unión de / de los } \\
\text { chicos y chicas de / de allí / generalmente llevábamos algunas rondallas } \\
\text { que pertenecían / eran rondallas de las agrupaciones socialistas /// y / } \\
\text { entonces / pues / allí se bailaba / se cantaba / y luego había generalmente }\end{array}$ \\
\hline
\end{tabular}




\begin{tabular}{|l|l|}
\hline Siempre había una charla / iba alguna persona / ya del partido / ¿verdá? / \\
y daba alguna charla / nos interesábamos por los problemas sociales de \\
esta gente / de la forma de ida / de / sobre todo de los / de los trabajadores \\
del campo / del / convivíamos mucho / hablábamos mucho con / con la \\
gente de / de allí / las mujeres y / y las chicas de / de allí / de los distintos \\
pueblos $\uparrow$ / ya en aquella época / en cuanto / en cuanto dentro ya de la \\
FUE / nosotros / pues / creamos las universidades populares $\downarrow$ y yo \\
PARTICIPÉ también en la creación de las universidades populares $\downarrow$ y \\
dábamos clases por barriadas en / algunas veces nos servíamos de los \\
propios / de las propias casas del pueblo / otras veces pues en centros de \\
/ de carácter más o menos cultural / en escuelas que eran escuelas \\
privadas / no confesionales / o sea / escuelas que había de/compañeros \\
nuestros incluso / ¿verdad? / y allí pues se daban clases / organizamos \\
unos cursillos de arte recuerdo que eran formidables / que fueron dados \\
por Ovejero / con ese motivo / pues / programábamos visitas a museos / \\
visitas / por ejemplo / y yo recuerdo perfectamente una que / que hicimos \\
/ bueno / se hicieron varias / claro / porque íbamos por grupos / se hacían \\
grupos / y: fuimos a Toledo / Toledo / bueno / dijo Ovejero que aquello \\
era una maravilla / eh... \\
Y de ... \\
JV
\end{tabular}

29P

Edad: 50 años

Nacionalidad: España

Sexo: Masculino

\begin{tabular}{|l|c|}
\hline Informante & \multicolumn{1}{|c|}{ Discurso } \\
\hline $\mathrm{E}$ & Eso es lo que .../ eso es lo que pasaba en este sitio \\
$\mathrm{P}$ & \\
\hline
\end{tabular}




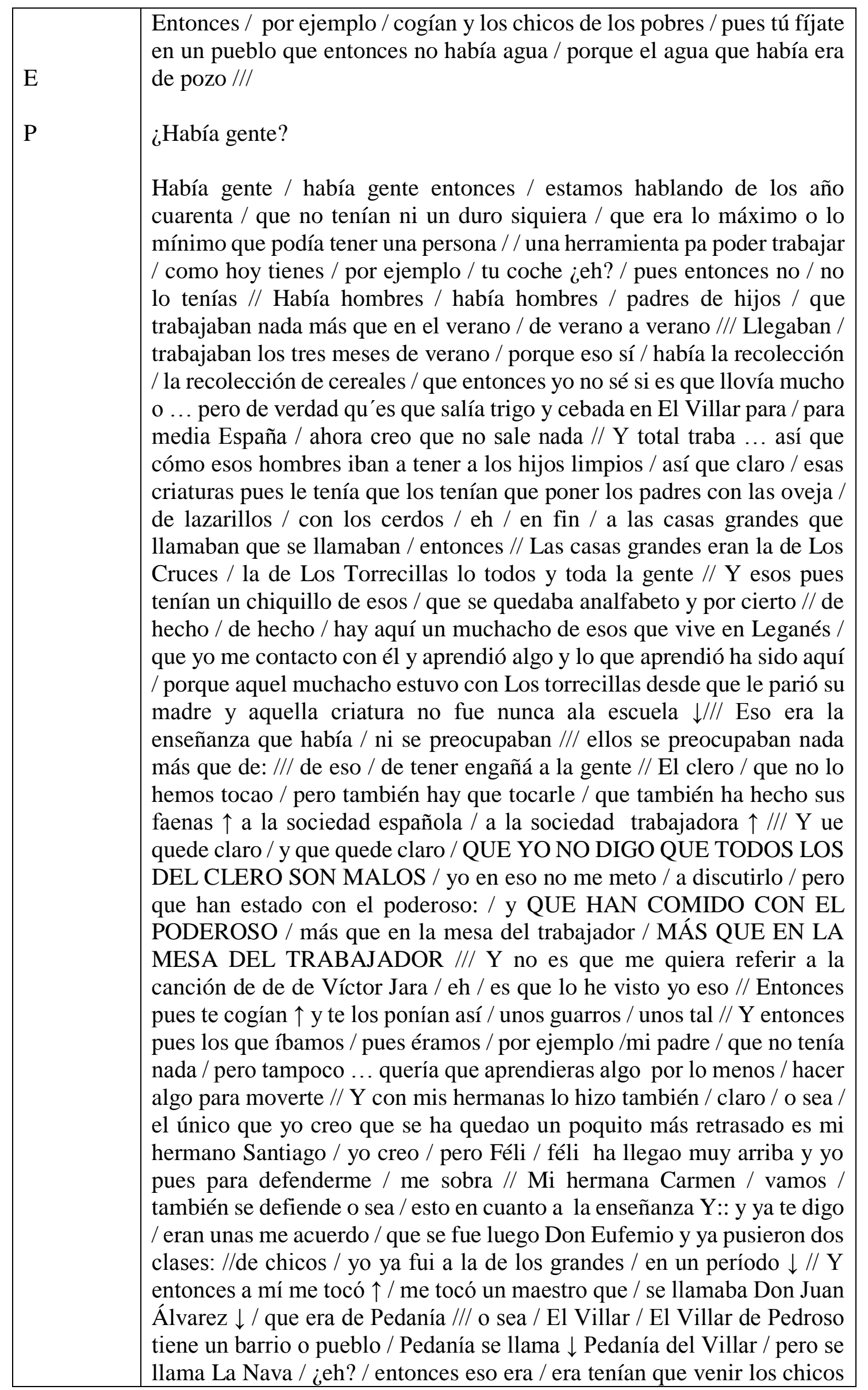


al colegio $\uparrow$ / al Villar / tenían que venir los quintos / bueno todos / todos / eso ya me parece que ahora en la democracia se ha quedao un poco mal / pero vamos / sigue siendo Pedanía / ¿eh? / porque hace poco fui yo a La Nava y como me gusta tanto leer / pues yo me voy a leer lo primero / porque yo he tenido mucho / mucho / mucho el ...Y fui y pone / Pedanía de La Nava entre sierra / Villar del Pedroso / allí está pa quien lo quiera ver en el ayuntamiento / vamos ...y hay un concejal por lo visto // Entonces este hombre era de allí / era los riquillos / yo no sé si habrá muerto // Y era un fachongo / ese todas las mañanas con su camisa / su su murgaño / eh / se ponía ahí / nos levantaba a todos / nos hacía de que levantáramos el brazo / eh / a cantar el Cara al sol y a rezar // Lo que menos se preocupaba Don Juan / era de la cultura $\downarrow$ / A él la cultura le traía y le llevaba // Como sus hijos se los podía traer a Madrid / eh / o a Cáceres o a Badajoz / ¿eh? Ellos lo que no querían es que nosotros / y de hecho así fue / o sea / porque la lucha la lucha que hubo entre La República y La Dictadura / pues no fue ni más ni que ni más ni menos que eso / que la cultu ... La República quería que La cultura avanzara y La Dictadura lo que quieren es que la cultura no avan no avance // Y tú que eres má tú qu’ eres más joven / sí / ya dijimos que nos llamábamos de tú / eh / tú que eres más joven / habrás visto / por ejemplo /// como en Chile / por ejemplo / que esa dictadura sí la has conocido / pues sí ... cuando estuvo Allende pues se abrieron colegios / las grandes a a alamedas / ¿eh? // Y cuando vino el Pinocho / pues cogió y lo recortó todo y cerró las puertas de los colegios y hala / / todo el mundo ... por el estilo aquí // Entonces ha sido / lo que ha sido ... Y a nosotros / por desgracia / por desgracia / para terminar un poco / si hay alg'otra pregunta / me la haces / eh por desgracia nos ha tocao de vivir eso $\downarrow$ claro / que no hemos tenido más // Yo me pregunto algunas veces y mucha gente me lo dice / mucha gente / yo // mucha gente me ha dicho pero bueno Jarillo / usted ha tenido estudios ( 8 ") Bueno pues (3") yo no he tenido estudios // Pero bueno / como sa como sabe usted si hablamos de Geografía / si hablamos de esto / si hablamos del otro / ¿cómo lo sabe usted?^ / Pues porque he leído mucho // Yo he estao siempre / en el caballo de batalla / siempre / en / en las asociaciones de padres de alumnos / cuando se crean la la las ... en el setenta $\uparrow$ que hasta el setenta en ningún colegio había /// Había dos colegios que las tenían solicitadas $\uparrow$ y el nuestro tres $\downarrow$ que uno era el colegio México y el colegio:: Galileo / me parece que se llama Galileo / que está ahí en la Plaza del dos de Mayo / y el nuestro / $(($ RÀPIDO $))$ el Machado $\downarrow$ que se hizo en el setenta / o sea / lo inauguramos en el setenta y rápidamente nos metimos ya con la ... Y mira que y mira que casualidad tuvimos / que no creas que no nos tocó de / de luchar ahí / en los padres de alumnos // Nos mandaron de director / ni más ni menos / al que había sido alcalde de San Ildefonso / de La Granja / hasta entonces / hasta el setenta // Le trajeron de director / de director / y él era era era alcalde // No veas qué patas / un tío nervioso / un tío ... se rodeo de de cuatro o cinco colaboradores suyos / entre ellos una chica / oyes / y a la junta de padres de alumnos nos traía ... y le le dábamos cada caña ... // Ah / y el Colegio Portugal que también está ahí en la Plaza de España / esos cuatro colegios fueron los primeros que ... las primeras y Apas que se hicieron // Pero ese ese era / ese era demente 


\begin{tabular}{|l|l|}
\hline \multirow{6}{*}{ E } & $\begin{array}{l}\text { / macho / ese Don Carlos / en cuanto nos veía se ponía malo / pegaba uno } \\
\text { portazo ... // Ya no llevaba la camisa / la llevó un día / la llevó un día / } \\
\text { te estoy hablando del setenta / la llevó un día el tío / pero en el setenta ya } \\
\text { ya se respiraba y se volaba / en fin / no podías hablar mucho / pero / pero } \\
\text { / pero / y el tío se atrevió // En cuanto nos esteramos los padres / fuimos } \\
\text { ahí y se la tuvo que quitar y no volvió /// Bueno / alguna cosilla más } \uparrow \\
\text { Yo creo que ya me has contado bastante// }\end{array}$ \\
\hline
\end{tabular}

30D

Edad: 38

Nacionalidad: Colombia

Sexo: Femenino

\begin{tabular}{|c|c|}
\hline Informante & Discurso \\
\hline $\mathrm{D}$ & $\begin{array}{l}\text { Hubieron muchas masacres } \downarrow \text { Eso lo veíamos } \uparrow \text { nosotros no lo vimos } \\
\text { porque no subíamos más arribita y que entonces no esperamos } \downarrow \text { Había } \\
\text { mucha gente que llegaban y les decían pues tienen que salir } \\
\text { inmediatamente } \uparrow \text { entonces eso nosotros no lo esperamos } \downarrow \text { nosotros } \\
\text { salimos antes que nos fueran a agredir o a matar a alguien de la familia } \downarrow / / / \\
\text { Como la familia de nosotros es poquita } \uparrow \text { entonces vivíamos todos en una } \\
\text { casita y salimos } \downarrow \text { Ajá } \uparrow \text { entonces tuvimos ese logro } \downarrow \text { Por el miedo de que } \\
(3 \text { ') }\end{array}$ \\
\hline $\mathrm{E}$ & ¿Ustedes vivían en una finca? \\
\hline $\mathrm{D}$ & $\mathrm{Si} \downarrow$ una finquita $\uparrow / / /$ pero no de nosotros $\downarrow$ \\
\hline $\mathrm{E}$ & ¿No era de ustedes? \\
\hline \multirow[t]{2}{*}{$\mathrm{D}$} & $\begin{array}{l}\text { No era de nosotros } \downarrow \text { Nosotros teníamos cinco años d'estar viviendo ahí } \downarrow \\
\text { Entonces cuando ya empezó eso a: (3'’) por ejemplo } \downarrow \text { a ponerse malo } \downarrow \text { a } \\
\text { matar la gente } \downarrow \text { muchas masacres por allá } \downarrow \text { nosotros fuimos vendiendo } \\
\text { poquito a poco los animalitos } \uparrow / / / \text { lo poquito que teníamos } \rightarrow / / / \text { gallinitas } \\
\text { y’eso } \downarrow \text { entonces } \uparrow \text { nos vamos } \downarrow\end{array}$ \\
\hline & $\begin{array}{l}\text { Nos preguntaban:: ¿ustedes se van a ir? } \uparrow \text { no } \downarrow \text { no nos vamos a ir } \downarrow \text { porque } \\
\text { no sabíamos que porque nos preguntaban } \downarrow \text { Entonces nosotros salimos } \\
\text { tranquilamente sin que (4’’) no sacamos nada porque todo lo fuimos } \\
\text { vendiendo allá } \downarrow \text { Sacamos los coroticos } \downarrow \text { tampoco era que teníamos tantas } \\
\text { cosas } \uparrow / \text { porque no teníamos muchos años de vivir por allá } \downarrow\end{array}$ \\
\hline $\mathrm{E}$ & ¿Ese Juan José, dónde es? \\
\hline $\mathrm{D}$ & $\begin{array}{l}\text { Eso es de Montelíbano p’arriba } \uparrow \text { por el río } \downarrow \text { se iba uno en "johnson" } \uparrow \\
\text { bajaba en "johnson" } \downarrow \text { ya ahora hay carretera } \rightarrow \text { ya uno se viene en carro } \downarrow \\
\text { se va en carro } \downarrow \text { Entonces así fue que nosotros no esperamos } \uparrow \text { eh } \uparrow \text { porque } \\
\text { a veces habemos muchas personas que esperamos la muert } \downarrow \text {, porque eso } \\
\text { es esperar la muerte } \downarrow \text { entonces nosotros no esperamos eso } \downarrow \text { Un:/// como }\end{array}$ \\
\hline
\end{tabular}




\begin{tabular}{|l|l|}
\hline & $\begin{array}{l}\text { le diría } \rightarrow / \text { como un trayecto como de aquí a allá a la salida de esta calle } \downarrow \\
\text { hubo una masacre grandísima } \downarrow / / / \text { hacían como tres días } \rightarrow \text { cuando } \\
\text { nosotros no venimos } \downarrow \text { y eso se veía y se veía } \downarrow / / \text { mejor dicho la gente } \rightarrow / \\
\text { entonces nosotros } \rightarrow / \text { no yo soy muy nerviosa } \downarrow / / \text { yo dije no } \\
/ / / \text { vámonos } \downarrow / / / \text { aunque sea a pedir o algo por ahí// porque la vida es } \\
\text { bonita } \uparrow / \text { así sea aguantando hambre } \downarrow(\text { RISA)) }\end{array}$ \\
Bueno $\downarrow$ llegamos aquí a Montería $\uparrow$ al principio nos fue bien porque \\
trabajábamos $\downarrow$ nos iba bien $\downarrow$ pero ya después tiempos se nos empezó a \\
poner malo $\rightarrow /$ un hermano mío me ayudaba y él me quitó esa ayuda y se \\
fue de aquí $\uparrow$ y me dejó aquí sola $\downarrow / / /$ ya quedamos nosotros $\uparrow$ luchando y \\
luchando $\rightarrow /$ hasta que llegamos al Minuto de Dios $\downarrow / /$ allá nos han dado \\
mucha ayuda $\downarrow$ Inclusive del Minuto de Dios nos pasaron a Fundecor $\uparrow$ en \\
Fundecor nos hicieron el primer préstamo $\downarrow$ y ahí empezamos a trabajar $\uparrow / /$ \\
a trabajar// hasta que llegamos aquí al quiosco $\downarrow$ Cuando me hicieron el \\
primer préstamo en Fundecor fueron cien mil pesos $\downarrow$ yo empecé a \\
trabajar aquí $\downarrow$ Yo empecé vendiendo $\downarrow$ hacía dos libritas de arroz $\uparrow / / /$ \\
compraba tres libras de hueso $\uparrow$ pero que ya hoy en día ya yo: $\rightarrow$ pues: \\
tengo una clientela y que me está yendo pues, más o menos $\downarrow$ Pagué el \\
primer préstamo $\downarrow$ ya me hicieron el segundo $\uparrow$ y voy// pues:// $\rightarrow$ quedando \\
bien $\downarrow$
\end{tabular}

31J

Edad: 42 años

Nacionalidad: Colombia

Sexo: Femenino

\begin{tabular}{|l|l|}
\hline Informante & \multicolumn{1}{|c|}{ Discurso } \\
\hline $\mathrm{J}$ & $\begin{array}{l}\text { Pasé mi niñez y adolescencia con dolores de estómago'y acomplejada } \\
\text { porque era muy flaca } \downarrow / / / \text { Mi malestar empeoró cuando estaba en el } 2^{\circ} \\
\text { mes } \rightarrow / \text { de mi primer embarazo } \downarrow \text { El médico me dijo } \downarrow / / \text { "Te'hacés una } \\
\text { transfusión de sangre o perdés a tu hijo", porque tenía una anemia MUY } \\
\text { IMPORTANTE } \downarrow \text { Ante esto decidí consultar a otro ginecólogo } \uparrow \text { el cual } \\
\text { me recetó inyecciones, } \rightarrow / \text { vitaminas’y mi estado general mejoró } \downarrow / \text { seguí } \\
\text { controlándome y pude terminar bien mi embarazo } \downarrow / / / \quad \text { A partir de ese } \\
\text { momento } \uparrow \text { los dolores de estómago } \rightarrow / \text { acidez continuaron } \downarrow / \text { me } \\
\text { realizaron una endoscopía } \rightarrow / \text { y el diagnóstico fue úlcera gastroduodenal// } \\
\text { luego del tratamiento me sentí mejor por un tiempo } \downarrow / / / \text { Cinco años } \\
\text { después } \uparrow \text { estaba embarazada de mi segunda hija } \rightarrow / \text { también con riesgo } \\
\text { de pérdida porque estaba muy anémica } \downarrow / / / \text { Luego de su nacimiento tuve } \\
\text { una diarrea que duró } 2 \text { meses aproximadamente } \downarrow / / \text { Consulté a } 3 \text { médicos } \\
\text { que me recetaban medicamentos para la diarrea sin ningún resultado } \\
\text { positivo } \downarrow(2 \text { ') } \\
\text { A esa altura yo estaba desesperada porque no sabía la causa y me sentía } \\
\text { muy débil } \downarrow / / / \text { Pasó un tiempo y la diarrea se cortó } \uparrow \text { no sé por qué } \\
\text { motivo } \downarrow \text { Hasta ese momento no me explicaba porque tenía tantos } \\
\text { problemas de salud } \downarrow / \text { a veces relacionaba esto con mi vida muy activa } \downarrow / \\
\text { trabajar } \uparrow / \text { estudiar } \uparrow / \text { cuidar'a mis hijos y tener poco tiempo para } \\
\text { alimentarme }\end{array}$
\end{tabular}




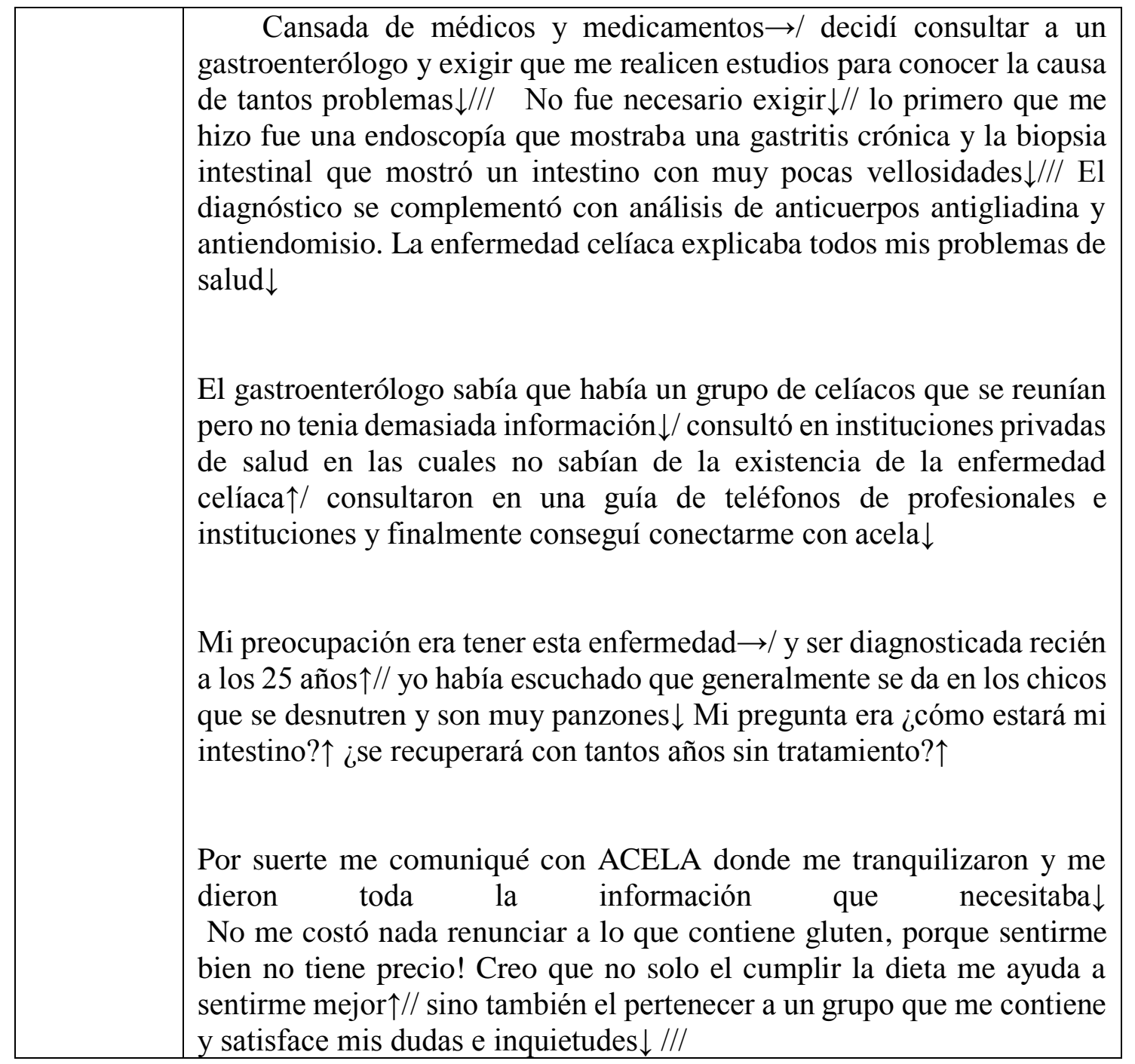

32JMC

Edad: 48 años

Nacionalidad: Colombia

Sexo: Masculino

\begin{tabular}{|l|l|}
\hline Informante & \multicolumn{1}{|c|}{ Discurso } \\
\hline $\mathrm{E}$ & $\begin{array}{l}\text { ¿De dónde se vino José María Calao? } \\
\text { Me vine de Apartadó } \rightarrow \text { Antioquia } \uparrow \text { más especialmente del barrio La } \\
\text { Chinita } \downarrow \text { Una invasión muy grande que queda al centro } \downarrow \text { al centro no } \uparrow \\
\text { pero si queda en el casco urbano de Apartadó } \uparrow\end{array}$ \\
$\mathrm{E}$ & $\begin{array}{l}\text { ¿Por qué se vino de allá José María? } \uparrow \\
\text { JMC } \\
\text { en la región entre grupos armaos al margen de la ley } \downarrow / / / \text { Obligaron al al } \\
\text { desplazamiento de uno/ porque/ imagínese } \uparrow / / \text { uno viendo sinceramente }\end{array}$ \\
\hline
\end{tabular}




\begin{tabular}{|c|c|}
\hline JMC & $\begin{array}{l}\text { mataban al uno } \uparrow / \text { que mataban al otro } \uparrow \text { llegar al término de amenazarlo a } \\
\text { uno también } \uparrow \text { pues que otra cosa tocaba si no de venirse } \downarrow \\
\text { ¿Cómo era la familia de José María allá en La Chinita? }\end{array}$ \\
\hline $\mathrm{E}$ & $\begin{array}{l}\text { Mi familia estaba compuesta por mi señora Inés María De la Rosa } \uparrow \text { mis } \\
\text { hijos } \uparrow \text { Jenny Isabel Calao De la Rosa } \uparrow \text { Jairo José Calao De la Rosa } \downarrow\end{array}$ \\
\hline JMC & ¿Qué hacían ustedes allá? \\
\hline $\mathrm{E}$ & $\begin{array}{l}\text { Nosotros allá nos dedicábamos a empacar platanitos } \uparrow \text { ¿se puede decir } \\
\text { así?// Trabajábamos ahí } \uparrow \text { pues nos iba bien gracias al Señor } \rightarrow / \text { pero así } \\
\text { es la vida } \downarrow / \text { en el momento que uno menos piensa } \uparrow \text { pues/ le toca } \\
\text { abandonarlo todo y salir } \downarrow\end{array}$ \\
\hline $\mathrm{JMC}$ & $\begin{array}{l}\text { ¿Esa es una zona muy rica } \uparrow \text { productora de banano/ plátano/ para la } \\
\text { exportación inclusive? }\end{array}$ \\
\hline $\mathrm{E}$ & $\begin{array}{l}\text { Esa es la zona considerada alma mater de Colombia en cuanto a } \\
\text { exportación de plátano y cultivo de banano y esas cosas } \downarrow / \text { Es una región } \\
\text { muy rica } \uparrow \text { muy prometedora } \downarrow\end{array}$ \\
\hline JMC & ¿Cuéntanos de eso primeros día en la llegada a Montería? \\
\hline $\mathrm{E}$ & $\begin{array}{l}\text { Los primeros días fueron muy duros } \uparrow \text { porque/ sinceramente } \rightarrow / / \text { uno no } \\
\text { sabe donde va a llegar } \downarrow \text { Uno llega y// sin ningún norte/ y a veces/ pues/ } \\
\text { uno no cuenta ni quien le tienda la mano, ni quien le diga puedes ir a tal } \\
\text { parte } \uparrow \text { o pueden ayudarte de esta manera } \uparrow / / \text { sinceramente los primeros } \\
\text { día fueron muy duros } \downarrow\end{array}$ \\
\hline JMC & $\begin{array}{l}\text { ¿Con quién hizo contactos en esos primeros días } \uparrow \text { quien le dio la primera } \\
\text { ayuda?. }\end{array}$ \\
\hline $\mathrm{E}$ & $\begin{array}{l}\text { Ayuda } \uparrow \text { pues/ digamos ino! Pero si hicimos contactos } \downarrow / / \text { llegamos al } \\
\text { hospital } \uparrow \text { ahí nos conocimos con una señora María Londoño } \rightarrow / \text { y:: } \\
\text { pues’ella nos ayudó a medio ubicarnos/ no en una casa si no más bien a } \\
\text { la intemperie } \downarrow / / \text { pero donde ahí no nos iban a molestar } \uparrow / / \text { íbamos a estar } \\
\text { ahí invadidos } \rightarrow / \text { más bien en las riberas del río Sinú } \uparrow / / \text { que cuando } \\
\text { crecía: } \uparrow \text { pues } \rightarrow / \text { y para colmo de males en ese tiempo era invierno } \downarrow \\
\text { Llovía aguaceros incesantemente y nosotros más bien al intemperie } \uparrow \\
\text { pero ahí tuvimos que acomodarnos } \downarrow\end{array}$ \\
\hline $\mathrm{JMC}$ & $\begin{array}{l}\text { ¿Y que hacía en esos primeros días para darle estudio y para darle } \\
\text { alimentación a la familia?. }\end{array}$ \\
\hline & $\begin{array}{l}\text { Para darle alimentación a la familia sencillamente } \rightarrow / / \text { pues yo } \uparrow / \text { en mi } \\
\text { condición de desplazao } \downarrow / \text { yo:::// nosotros:: pues:/ mi señora lloraba/ y } \\
\text { mis hijos estaban pequeñitos } \downarrow / / / \text { también } \rightarrow \text { pero yo le decía a ella que } \\
\text { tuviera fe } \uparrow \text { que habíamos sido desplazaos de todo lo que teníamos, de } \\
\text { todas nuestras pertenencias } \uparrow \text { pero que las ganas de salir adelante } \uparrow /\end{array}$ \\
\hline
\end{tabular}




\begin{tabular}{|l|l|}
\hline pues’esa no me la desplazaba nadie $\downarrow / /$ y que tuviera FE que íbamos a salir \\
adelante $\downarrow / /$ y yo salía a rebuscarme para el mercao $\rightarrow /$ para una parte $\rightarrow /$ \\
para la otra $\rightarrow$ / a buscar $\rightarrow /$ a veces le daban a uno plátano $\uparrow /$ y con eso/ \\
pues: plátano se comía y otro poquito se vendía $\downarrow /$ en todo caso que a mi \\
nunca se me apagó esas ganas de salir adelante $\downarrow$ porque sabía que tenía \\
una responsabilidad $\uparrow$ y que $\uparrow$ pues, $\rightarrow /$ uno adulto aguanta y si llora $\uparrow$ pues \\
sabe porque llora $\downarrow /$ pero un niño recién nacido $\uparrow /$ o un niño pequeñito $\uparrow / /$ \\
ese no sabe porque llora $\downarrow$ y uno como adulto $\uparrow /$ pues: así que le toque \\
pedir $\uparrow /$ pero uno como padre pues $\rightarrow /$ no deja que su hijo se acueste sin \\
comer $\uparrow /$ o se lleve’l día de hambre $\downarrow / / /$
\end{tabular}

$33 \mathrm{H}$

Edad: 52 años

Nacionalidad: Colombia

Sexo: Femenino

\begin{tabular}{|c|c|}
\hline Informante & Discurso \\
\hline $\mathrm{H}$ & $\begin{array}{l}\text { Mi nombre es H } \uparrow \text { tengo } 52 \text { años } \downarrow / \text { vivo en San Martín Meta desde hace } \\
\text { ocho años y hace } 6 \text { años que me descubrieron que soy celíaca } \downarrow \downarrow \text { Desde } \\
\text { muy chica } \uparrow / \text { sufría descomposturas con colitis } \uparrow / \text { a veces casi } \\
\text { crónicas } \downarrow \text { Me daban vitaminas y todo tipo de medicamentos para que } \\
\text { la comida me cayera mejor } \downarrow \text { Fue un proceso largo y que los médicos que } \\
\text { visitaba me diagnosticaban siempre una enfermedad diferente } \uparrow \text { desde } \\
\text { nervios } \rightarrow / \text { gastritis } \rightarrow / \text { lesiones cerebrales } \uparrow / / \text { por el agudo dolor de } \\
\text { cabeza } \downarrow / / \text { hasta una deformación en la carótida } \downarrow / / / \text { A principio del año } \\
94 \uparrow / / \text { empecé a tener una colitis permanente } \uparrow / / \text { bajé de peso rápidamente } \\
\text { y tenía calambres en las'extremidades } \downarrow \text { Después empezaron los ataques } \\
\text { en los que quedaba totalmente rígida y pesaba } 33 \text { kilos } \downarrow \text { En uno de los } \\
\text { ataques me internaron en el Hospital de San Martín } \downarrow / \text { allí me practicaron } \\
\text { todo tipo de estudios y se dieron cuenta que casi no tenía calcio y ningún } \\
\text { tipo de minerales en la sangre } \downarrow \text { Un médico comenzó a darme una dieta } \\
\text { celíaca, sólo por los síntomas } \uparrow \text { pero como mi’estado era crítico me } \\
\text { derivaron al } \\
\text { Allí me hicieron los estudios y me diagnosticaron la enfermedad, por } \\
\text { lo que mi vida cambió no sólo porque ya sabía lo que tenía sino que en } \\
\text { un par de meses recuperé } 10 \text { kilos y mis descomposturas d'estómago } \\
\text { desaparecieron } \downarrow \text { Ahora tengo que cuidarme de por vida, pero gracias a } \\
\text { Dios tengo una vida mejor } \downarrow\end{array}$ \\
\hline
\end{tabular}

34M

Edad: 40 años

Nacionalidad: Colombia

Sexo: Femenino

\begin{tabular}{|l|l|}
\hline Informante & \multicolumn{1}{|c|}{ Discurso } \\
\hline $\mathrm{M}$ & $\begin{array}{l}\text { Usted sabe como está eso de malo por allá } \rightarrow / \text { la guerrilla } \uparrow / \text { con el } \\
\text { ejército } \downarrow / \text { y:: no es porque nos mataran familiares ni nada } \downarrow / \text { porque a } \\
\text { nosotros } \uparrow / \text { gracias Dios no nos mataron ningún familiar } \downarrow / / / \text { pero tanta } \\
\text { violencia: } \uparrow / \text { tanta matazón } \downarrow / \text { tanta cosa } \downarrow / \text { entonces nos dio miedo y }\end{array}$ \\
\hline
\end{tabular}




\begin{tabular}{|c|c|}
\hline & $\begin{array}{l}\text { salimos } \downarrow \text { Y desde ahí } \uparrow \text { pues: luchando pa trabajá mientras su familia } \uparrow \text { por } \\
\text { aquí por allá/ porque todo eso se quedó allá } \downarrow / \text { la finca:: mi papá: mi mamá } \\
\text { fue la que se vino así/ medio logró vender una casita que tenía acá en el } \\
\text { pueblo y ahí fue que compró el lote en que ha vivido ella } \downarrow \\
\text { Y ahí } \downarrow \text { Mi papá si no ha querido venir } \rightarrow / / / \text { allá está todavía } \uparrow / / \text { ha querido } \\
\text { quedarse solo allá/ tiene una finca de más de doscientas hectáreas de } \\
\text { tierra/ ganao: todo tiene el allá } \downarrow / \text { pero gracias a Dios nunca le ha pasao } \\
\text { nada } \downarrow \text { Y aquí } \uparrow / \text { bueno } \uparrow \text { estuve trabajando trabajando/// ahora luchando } \\
\text { entre los dos } \downarrow / \text { me casé aquí } \uparrow / \text { y’entonces conseguimos el lotecito y’ahí } \\
\text { estoy viviendo } \downarrow\end{array}$ \\
\hline $\mathrm{E}$ & ¿Cuándo se vino de allá, estaba soltera? \\
\hline M & $\begin{array}{l}\text { Si yo estaba soltera } \downarrow / / / \text { yo me case fue aquí } \downarrow / / / \text { sí } \downarrow / \text { yo me casé con el } \\
\text { papá de los pelaos } \downarrow\end{array}$ \\
\hline $\mathrm{E}$ & ¿Para preguntarle si va a regresar allá? \\
\hline M & $\begin{array}{l}\text { Imagínese que ahora me dijeron que fuera en diciembre } \downarrow \text { Y de que forma } \\
\text { voy a ir yo allá, } \uparrow / \text { si el que va allá eso lo investigan también } \downarrow \text { Allá estuvo } \\
\text { una prima mía:: ahora hace como un mes// y enseguida desde que } \\
\text { llegaron } \uparrow / \text { una vez que isi quién era ella? } \uparrow \text { Y fueron/ antes que ella } \\
\text { llegara donde el tío mío } \uparrow / \text { ya habían ido donde el tío mío a ver si era } \\
\text { verdad que era sobrina de ella } \downarrow \text { Está HORRIBLE horribli'otra vez por } \\
\text { allá } \downarrow \text { Y entonces para que llego yo por allá } \downarrow / \text { Mi papá/ eso es } \\
\text { tremendísimo/ porque él dice que él mejor se muere } \uparrow / \text { pero que él para } \\
\text { acá no se viene } \downarrow Y \text { all'está } \downarrow \text { Qué podemos hacer } \downarrow\end{array}$ \\
\hline $\mathrm{E}$ & ¿Cuándo llegaron ustedes aquí, en qué año?. \\
\hline M & $\begin{array}{l}\text { Nosotros vinimos aquí en el } 96 \downarrow / \text { ya van a hacer ochu'años } \downarrow \text { Y desde ahí } \\
\text { ha sido luchando } \downarrow \text { Luchando y luchando } \downarrow / / /\end{array}$ \\
\hline
\end{tabular}

35R

Edad: 85 años

Nacionalidad: Colombia

Sexo: Masculino

\begin{tabular}{|c|c|}
\hline Informante & Discurso \\
\hline $\mathrm{E}$ & ¿Y entonces usted nos iba a contar qué?^ \\
\hline $\mathrm{R}$ & $\begin{array}{l}\text { A lo que pasó fue que... que yo quedé huérfanu a los och'uaños mmjue } \downarrow \text { ' } \\
\text { Yo no tuv'estudio } \downarrow \text { porque los po... yo tuve que salir a ganarme por ahí } \\
\text { veinte centaos qu'era lo que pagaban en ese tiempo a pa llevar cualquier } \\
\text { cosa'la casa diallá de Puerto Rico } \downarrow\end{array}$ \\
\hline $\mathrm{E}$ & Sieñor \\
\hline
\end{tabular}




\begin{tabular}{|c|c|}
\hline $\mathrm{R}$ & De Pueblo Rico \\
\hline OTRO & Eh Pueblo Rico \\
\hline $\mathrm{R}$ & $\begin{array}{l}\text { Pa llevar cualquier cos'a la casa con eso nu'era que se comprara mucho// } \\
\text { Entonces no tuv'estudio }\end{array}$ \\
\hline OTRO & NADA si= \\
\hline $\mathrm{R}$ & $\begin{array}{l}\text { Alguna vez yendo pa u pa un pa un río que llama Guadalejo qu'eso es en } \\
\text { Antioquia también cuando veníamos de allá para'cá esa es estaba la bají } \\
\text { la quebrada estaba bajita peru'esa vez esa quebrada de un momento a } \\
\text { otro aparece que crecida ay cuando veníamos diaá para'cá me dijo uno e } \\
\text { los muchachos era una muchacha y un muchacho vecinos míos vamos al } \\
\text { que se pase este río por l'agua (3") // Eso nu'era ni río era una quebrada } \\
\text { (3") y como como com'usté sabe uno es muy cañista de muchacho tons } \\
\text { me metí adelante me llevó com'una cuadra esa es'agua eh ... Y'a la } \\
\text { cuadra dijo pues lleguaquí pues vea a voltiar aquí onde onde se formó el } \\
\text { remo el ese así y'ay caí yo a la orilla jajajá // Eso le pasa a uno por qué... } \\
\text { por ser cañista }\end{array}$ \\
\hline & Jí, Por dárselas de mucho \\
\hline OTRO & Sí/ por querer tirárselas de mucho \\
\hline $\mathrm{R}$ & $\begin{array}{l}{[\ldots]} \\
\text { A ver le voa decir ((PERROS QUE LADRAN)) a otra cosa que me pasó } \\
\text { eso fue en La Esmeralda porque yo fui trabajador de La Esmeralda } \\
\text { también de la planta cierto y / entoes llegó/ estáamos trabajando con un } \\
\text { arriero que se desayunaba con alacranes ((MJM JM, RISAS SUAVES)) } \\
\text { a con un con un que manejaba una volqueta el día siempre que } \\
\text { amanecíandemoniao le dab'era le dab'era por hacernos matar a los que } \\
\text { íbamos a trabajar entoa a mí me mandó el patrón pa'u pa'un guaudal a } \\
\text { cortar guauda de todo largor pa pa sacarla a la carretera paque } \\
\text { l'echáramos en l'echáramos en en la volqueta (3'’) entonces ese día que } \\
\text { desayunó con alacranes ese ese chofer llegó y nosotros estáamos } \\
\text { asegurando el otro compañero y yo asegurando bien la guauda que no se } \\
\text { nos fuera'resbalar y nos fuera porque aquí bajaba y aquí tenía una subida } \\
\text { en esa subida podía, podía descolgar la guauda paral suelo } \downarrow \text { entonces ahí } \\
\text { mismo ahí mismo llegó y dio preste a ver presteaver quesuayque que hay } \\
\text { que amarrarlo ligero porque nos vamos nos vamos ahí siendo que a ese } \\
\text { señor no lo acosaba nadie acaso en esas volquetas acosan a uno // pues } \\
\text { nos la hizo amarrar mal amarrada y a lo que llegu'aquí que cogió la } \\
\text { empinada blum nos tirúa la carretera con guauda y todo al otro y’a mí } \\
\text { ah } \downarrow\end{array}$ \\
\hline & Eh:: \\
\hline OTRO & \\
\hline $\mathrm{R}$ & $\begin{array}{l}\text { Yo m’estaba por aquí repelaudíun brazo pero no me pasó nada pero fue } \\
\text { con el fin diacernos matar ahí, con guauday todo ah cómo le parece? } \downarrow\end{array}$ \\
\hline
\end{tabular}


36C

Edad: 79 años

Nacionalidad: Colombia

Sexo: Femenino

\begin{tabular}{|c|c|}
\hline Informante & Discurso \\
\hline $\mathrm{E}$ & ¿Y dónde vivía antes de venirse a vivir acá? \\
\hline $\mathrm{C}$ & Vi pagabarrendo en // en el barrio: /// cómo le digo // en el Parque Caldas \\
\hline $\mathrm{E}$ & Mmjm \\
\hline $\mathrm{C}$ & $\begin{array}{l}\text { Del de la esquina de La inmaculada paracá bajando a la Estreida } \\
\text { ((ESTRELLA)), una cuadra de sabe onde queda una abundancia que } \\
\text { llama El Surtidor? ahí al frente pagaba rendo yo } \downarrow\end{array}$ \\
\hline $\mathrm{E}$ & Mmjm \\
\hline $\mathrm{C}$ & $\begin{array}{l}\text { Y’allá viví como com en una casa de familia // mearrendaron una pieza } \\
\text { (4') }) \text { y: y qué más ((RUIDOS Y VOCES DE OTRAS PERSONAS)) y } \\
\text { allá en después ya vendieron la casa me tocó: conseguir por otra parte, a } \\
\text { no miento allá me viví con ellos } 47,37 \text { qué como } 7 \text { años una cosa'sí } \\
\text { entoes ya ame busqué arrendo en una casa e familia y no miarrendaron } \\
\text { seguramente me vieron muy vieja muy fea o no sé qué me vieron a mí y } \\
\text { no me quisieron arrendar la pieza / no } \downarrow \text { Cuando me mandaron a llamar } \\
\text { que volviera / que si me l'iban arrendar yo mandé decir que no/ s Sonia } \\
\text { biablao con Edelia la de: la d'estas cosas estos e:h cómo se llaman }\end{array}$ \\
\hline $\mathrm{E}$ & Centros \\
\hline $\mathrm{C}$ & Estas casas \\
\hline $\mathrm{E}$ & Estos: hogares para: \\
\hline $\mathrm{C}$ & $\begin{array}{l}\text {-Sí sí síl/ Entonces me le conté y le die ayúdame a conseguir entoes me } \\
\text { ayudó a conseguir aquí } \downarrow\end{array}$ \\
\hline $\mathrm{E}$ & Ah, ya ¿y está contenta viviendo aquí? \\
\hline $\mathrm{C}$ & Como le dijera $\uparrow$ resignada peronuhay nada más qué quehacer $\downarrow$ \\
\hline & $\begin{array}{l}\text { Yo vivo muy angustiada/ fíjese que/ figúrese que en el hogar de mis } \\
\text { padres fuimos hermanos y hermanas: y yo fui la menor: la MENOR ay } \\
\text { y me tenían AQUÍ ((SENALA LA PALMA DE LA MANO)) mis } \\
\text { hermanos mis hermanas en la palma de la mano ((IMPERCEPTIBLE)) } \\
\text { pero se fueron casando los unos y los otros ((IMPERCEPTIBLE)) } \\
\text { Ya uno viejito y yo tenía novio porque no voa decir que no muchos } \\
\text { novios yo desde los once años tenía noviecitos, me gustaba charlar y y } \\
\text { me trajeron aquí a a estudiar al queuse como es que se llama eso // Aquí }\end{array}$ \\
\hline
\end{tabular}




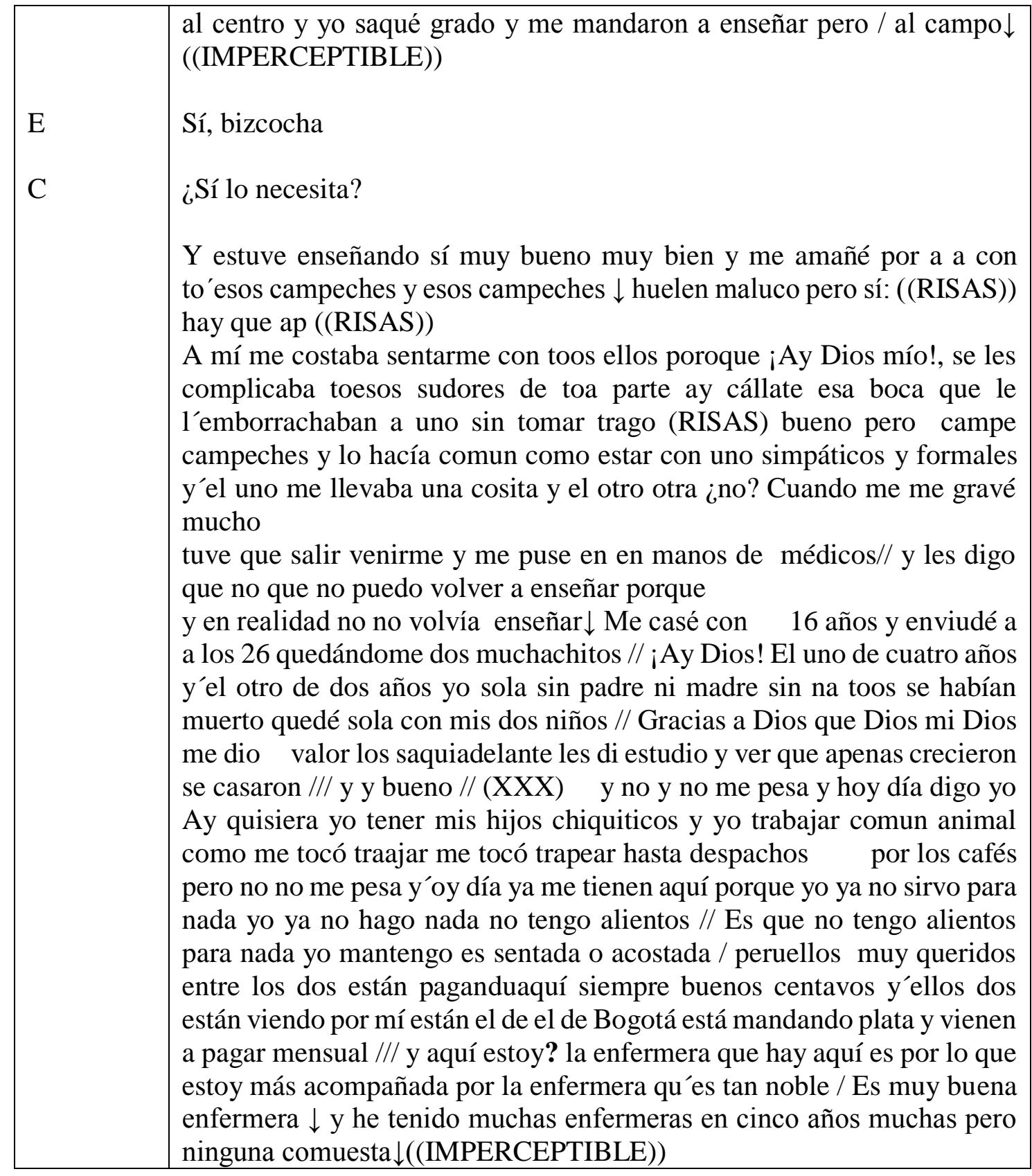

37CM

Edad: 70 años

Nacionalidad: España

Sexo: Femenino

\begin{tabular}{|c|c|}
\hline Informante & Discurso \\
\hline $\mathrm{CM}$ & A mediados de $37 \downarrow$ \\
\hline OTRO & $(($ ININTELIGIBLE) $)$ \\
\hline $\mathrm{CM}$ & Ya empezó mucho/ mucho mucho/ pero:::/// \\
\hline $\mathrm{E}$ & Cada vez más. \\
\hline
\end{tabular}




\begin{tabular}{|c|c|}
\hline $\mathrm{CM}$ & $\begin{array}{l}\text { Ya... así es que yo que estaba criando a ése/ pues } 22 \text { meses/ dándole } \\
\text { pecho/ y me dice el médico. "Como no le quites el pecho al niño/ te } \\
\text { mueres tú/ así que tú sabrás"/ ¿Y qué le voy a hacer/ qué le voy a dar?// } \\
\text { sí... estuvo } 8 \text { días sin tomar nada/ absolutamente nada/ porque no } \\
\text { quería comer.../ pero nada.../ la racioncita de pan/ se lo dejábamos pa } \\
\text { los niños/ nosotros hacíamos unas sopitas/ na más que el agua y el } \\
\text { aceite y a beber } \downarrow\end{array}$ \\
\hline $\mathrm{E}$ & Y usted durante la guerra ¿ se podía comunicar por carta con Juan?... \\
\hline $\mathrm{CM}$ & $\begin{array}{l}\text { Sí/ sí, sí/ sí/ Él / casi todos los días/ estando que no estuviera en } \\
\text { combate todos los días/ escribía } \downarrow\end{array}$ \\
\hline $\mathrm{E}$ & $\begin{array}{l}\text { Le escribía// Y ah/ bueno/ explíqueme eso que me decía que estuvo de } \\
\text { secretaria }\end{array}$ \\
\hline $\mathrm{CM}$ & $\begin{array}{l}\text { Pues es que ...Juan escribía a los maridos que estaban con él en la } \\
\text { misma brigada/ escribía a sus mujeres/ y yo escribía en nombre de las } \\
\text { mujeres a eso/ a los maridos/ así que yo me levantaba por la mañana y } \\
\text { me iba de casa en casa a ver si habían tenido carta/ y decían/ "Pues sí } \\
\text { que he tenido carta"/ mira/ en cuanto veía el sobre veí la car/ a:/// la } \\
\text { letra de Juan/ pues ya me quedaba... me la hacía leerla...No/ pero yo } \\
\text { me da lo mismo/ viendo la fecha y que veo la letra de Juan/ pues ya... } \\
\text { ya tengo noticias de él/ y él ya pues le pasaba lo mismo/ porque } \\
\text { siempre se... nos comunicábamos/ vamos/ decíamos algo de unos y } \\
\text { otros }\end{array}$ \\
\hline $\mathrm{E}$ & $\begin{array}{l}\text { Claro o sea/ que usted hacía de amanuense de las mujeres y él de/ y él } \\
\text { de los hombres...¿Y qué otras cosas recuerda/ cómo/ cómo era la } \\
\text { vida...?¿Entonces el/ el día de usted durante la guerra era muy duro? } \\
\text { ¿Qué hacía/ un día? }\end{array}$ \\
\hline $\mathrm{CM}$ & $\begin{array}{l}\text { Pues nosotros hemos hecho de todo/ Hemos guisao a los soldados/ } \\
\text { hemos/ lavao la ropa a los soldaos/ he ido a cambiar cosas.../ también } \\
\text { yo hacía el jabón/ porque había allí una fábrica de jabón también/ y de } \\
\text { la lejía que tiraban/ yo lo recogía y hacía jabón/ con el aceite/ y eh/ con } \\
\text { ese/ ese jabón lo cambiaba por tabaco/ por cien gramos de tabaco// Y } \\
\text { esos cien gramos de tabaco los llevaba a otro pueblo a } 7 \text { kilómetros } \\
\text { pero andando/ y nos daban un par de kilos de garbanzos/ un poco de } \\
\text { tocino y: así nos hemos apañao// Luego a otro pueblo pues íbamos/ nos } \\
\text { llevábamos el dinero y nos cobraban mucho ya por los huevos y por... } \\
\text { cabritos que eso... y aquí en el pecho nos lo metíamos/ porque había } \\
\text { una guardia que decían de "etapas"/ al principio del del pueblo sabían } \\
\text { ca a lo que íbamos/ porque decían: "A ver/ ¿a qué vais?// Vamos a } \\
\text { visitar a/ una conocida que tenemos aquí"// Luego cuando veníamos/ si } \\
\text { era invierno con los abrigos//"Que van muy gordas/ enseñarnos lo que } \\
\text { lleváis"/ "No llevamos nada/ no/ ¿por qué vamos a ir gordas ¿"// Nos } \\
\text { dejaban pasar/ ¿no comprende? Porque... pero así... es que una lucha } \\
\text { porque es que yo era la madre/ la madre de los 10/ de los 10/ o sea de }\end{array}$ \\
\hline
\end{tabular}




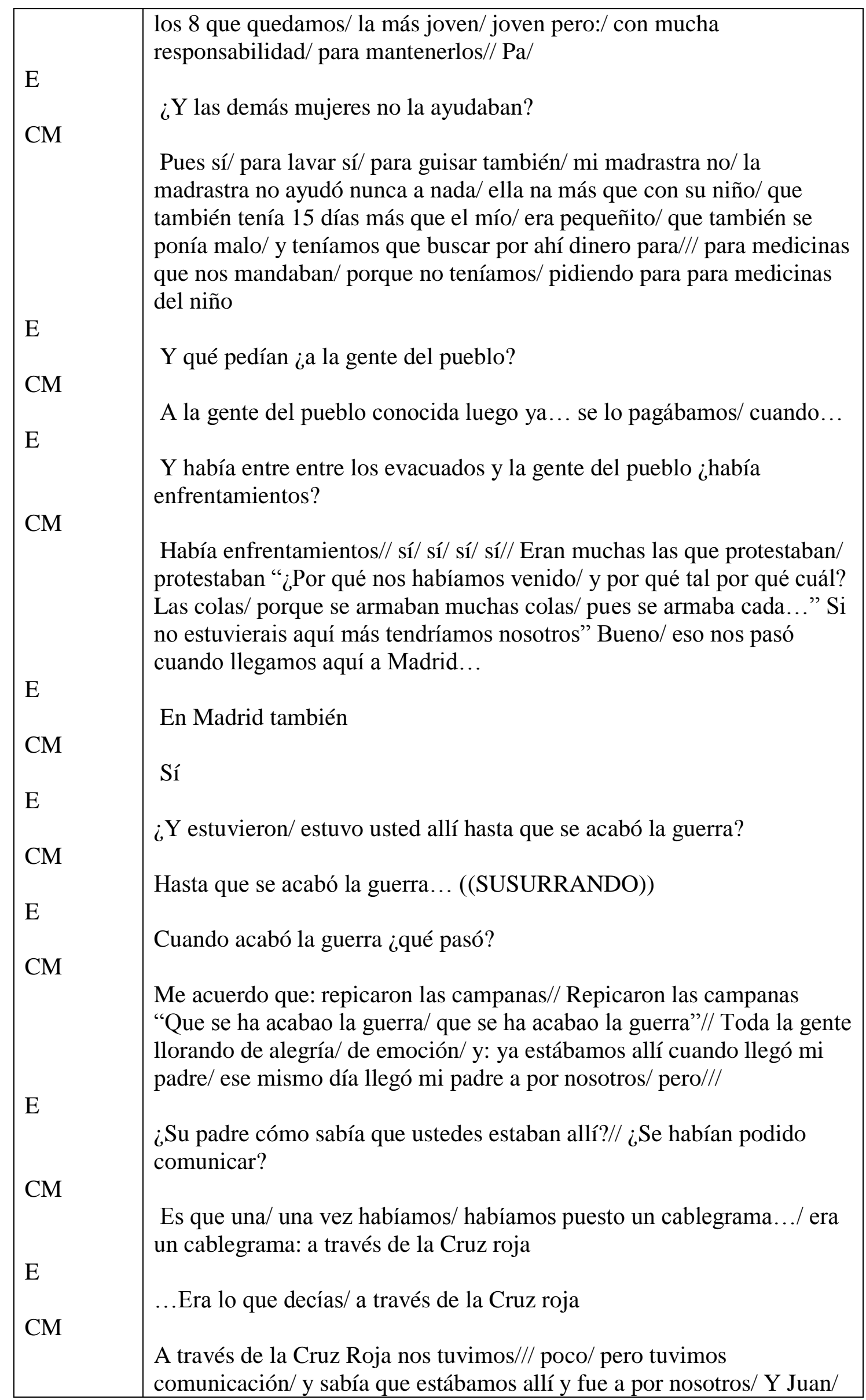




\begin{tabular}{|l|l|}
\hline $\begin{array}{l}\text { claro/ no estaba/ estaba en el frente de Extremadura/ y desde } \\
\text { Extremadura vino a aquel pueblo/ andando } \\
\text { Juan- Andando //Llegó con las/ piernas hinchadas/ los pies hinchados } \\
\text { Juan- Bueno porque tuve que ((ININTELIGIBLE)) llevaba } 300 \\
\text { pesetas/ 300/ entonces eran mucho dinero/ comprende?...// Que no } \\
\text { valían luego nada... }\end{array}$ \\
\hline
\end{tabular}

38M

Edad: 74 años

Nacionalidad: Colombia

Sexo: Masculino

\begin{tabular}{|c|c|}
\hline Informante & Discurso \\
\hline $\mathrm{E}$ & Quiubo Marco ¿está en embarazo o que’? \\
\hline M & $\begin{array}{l}\text { Hola Francisco/ qué milagro verlo/ qué más?/ sí/ de cinco meses/ ¿cierto } \\
\text { Marielita? }\end{array}$ \\
\hline $\mathrm{E}$ & Verdá, ¿qué pasó? \\
\hline M & $\begin{array}{l}\text { Me operaron del estómago y entonces se se me me: se me descolgó la } \\
\text { panza }\end{array}$ \\
\hline E & No joda \\
\hline M & $\begin{array}{l}\text { Pero aguarde me pongo la faja y verá// y monto a caballo. Vea Francisco/ } \\
\text { los médicos decían que la operación era muy peligrosa por la/ por la } \\
\text { diabetes// Entonces me tocó firmar que aceptaba todas las } \\
\text { responsabilidades/ y yo ECHE PA'LANTE/ nada de miedo/ ahí está } \\
\text { María Santísima }\end{array}$ \\
\hline $\mathrm{E}$ & Marucha \\
\hline M & $\begin{array}{l}\text { Sí/ bueno/ y me operaron y quedó la barriga brotada/ me quedó: } \\
\text { descolgada y ahí estoy pensando en que me vuelvan a operar// Los } \\
\text { médicos dicen que es muy peligroso/ que es muy riesgoso por por la } \\
\text { diabetes/ pero yo sigo haciendo papeles a ver si me resuelvo// Oiga } \\
\text { Francisco/ yo quedé:: MEDIO// ACABAO sexualmente/ no siento ni: no } \\
\text { siento nada después de la operación de la próstata// ¿a usted ya lo } \\
\text { operaron d'eso } \uparrow ?\end{array}$ \\
\hline $\mathrm{E}$ & No, yo no \\
\hline M & $\begin{array}{l}\text { Ojo con eso/ es muy jodido/ Bueno/ y: y ahí vamos/ ¿y la familia qué/ } \\
\text { ¿bien? }\end{array}$ \\
\hline $\mathrm{E}$ & $\begin{array}{l}\text { Sí, Marco, muy bien, gracias a Dios// Bueno, pues toca echar pa'delante. } \\
\text { ¿Y toma traguito/ Whisky? }\end{array}$ \\
\hline $\mathrm{M}$ & \\
\hline
\end{tabular}




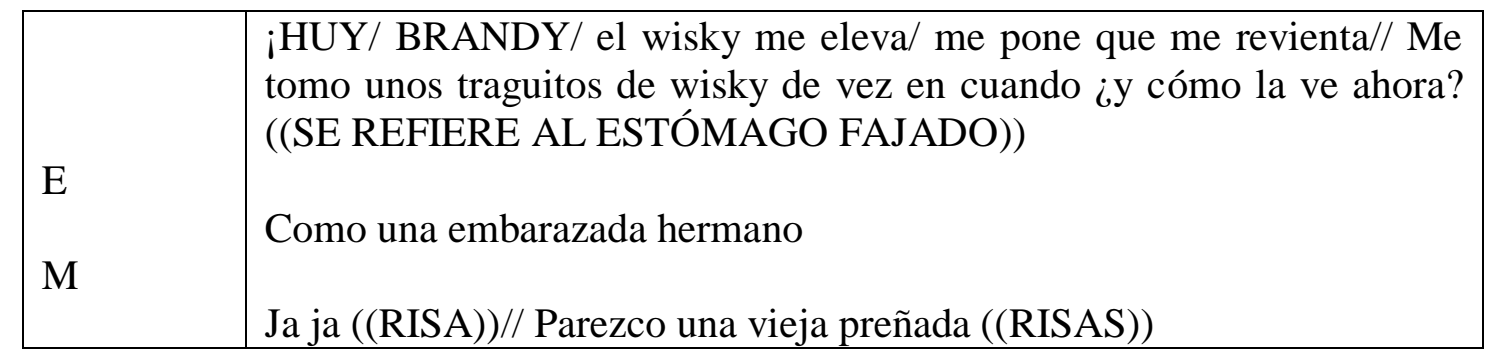

$39 \mathrm{H}$

Edad: 76 años

Nacionalidad: Colombia

Sexo: Masculino

\begin{tabular}{|c|c|}
\hline Informante & Discurso \\
\hline $\mathrm{E}$ & $\begin{array}{l}\text { Hola Nando ¿cómo fue la historia de la falta de solidaridad de la pierna } \uparrow / \\
\text { ahora/ ahora unos años que estuvo tan cojo en Pereira/ por la calle } 21 \uparrow ?\end{array}$ \\
\hline $\mathrm{H}$ & $\begin{array}{l}\text { Ah/m'hice el médico/m'hice } \downarrow / \text { hombre Hernando/ eso es un problema } \\
\text { de desgaste/ por los años// Entoes le dije/ Eso es mentira doctor/ eso es } \\
\text { mentira/ porque porque cómo le parece que esta pierna también ha } \\
\text { trabajado igual LO MISMO y no dice nada/ no se queja ni le duele nada } \downarrow \\
((\text { SE RÍE A CARCAJADAS)) }\end{array}$ \\
\hline $\mathrm{E}$ & $\begin{array}{l}\text { Venga nos sentamos allí para que me cuente una historia o un cuento/ } \\
\text { porque con este aguacero tan berraco no sale nadie de la iglesia/ un } \\
\text { cuento decente }\end{array}$ \\
\hline $\mathrm{H}$ & $\begin{array}{l}\text { Nos jodió el aguacero aquí adentro/((HACE GESTOS CON LOS OJOS } \\
\text { CERRÁNDOLOS Y ABRIÉNDOLOS)) ¿Y ahora a qué hora irá a } \\
\text { escampar? } \uparrow \text { y yo que no me puedo mojar por la artritis } \downarrow / / \text { Entró un tipo } \\
\text { a un negocio/ a una heladería/ una cosa d’esas/ tráigame un jugo bien } \\
\text { frío cualquiera/ que tengo una sed l’ahijuemadre// Se fue el muchacho } \\
\text { del negocio y le trajo un jugo/ ((PARPADEA COMO RIÉNDOSE CON } \\
\text { LOS OJOS)) como casi no había nada de qué hacer jugo/ lo completó } \\
\text { con agua y con hielo para que le quedara bien frío// El tipo se tomó: se } \\
\text { mandó: el jugo// y al ratico/ oiga señorita/ tráigame otro jugo por favor// } \\
\text { Se fue la muchacha/ le preguntó al companero de qué era el jugo y le } \\
\text { explicó que que se había miao/ orinado en el vaso porque no había nada } \\
\text { para hacer jugos/ y lo había completado con agua y con hielo para que } \\
\text { le quedara bien frío/ que él ya no tenía más ganas de orinar/ y que hiciera } \\
\text { ella lo mismo y se lo llevara// Se fue la muchacha pal: pal baño y le } \\
\text { preparó el jugo y se lo llevó al pobre pendejo// ((NUEVAMENTE SE } \\
\text { RÍE CON PICARDÍA)) el tipo se lo tomó todo// Al ratico el tipo llamó } \\
\text { otra vez al primer tipo que que había venido lo había atendido y le dijo/ } \\
\text { oiga hermano ¿esos jugos porqué sabían distinto?/ el segundo estaba más } \\
\text { bueno// A no/ respondió el mesero// es que: es que: el primero era de } \\
\text { bola- bola/ de bola-bola y el segundo de banda-banda } \downarrow \text { ((SE RÍE A } \\
\text { CARCAJADAS)) ¿Cómo le parece ah } \uparrow ?\end{array}$ \\
\hline & \\
\hline
\end{tabular}




\begin{tabular}{|c|c|}
\hline $\mathrm{H}$ & $\begin{array}{l}\text { Y eso que estamos en la iglesia// Bueno es que uno con una sed bien } \\
\text { berraca se toma lo que sea } \\
\text { Sí/ sí/ ((SE RÍE DE NUEVO A CARCAJADA))/ ¡Dos vasaos de } \\
\text { miaos!// No: hermano/ me crea tan tan pendejo// ¿Ah } \uparrow ?\end{array}$ \\
\hline
\end{tabular}

$40 \mathrm{~T}$

Edad: 75 años

Nacionalidad: Colombia

Sexo: Masculino

\begin{tabular}{|c|c|}
\hline Informante & Discurso \\
\hline $\mathrm{E}$ & $\begin{array}{l}\text { Bueno// Don Tulio/ cuéntenos una experiencia de lagancia } \downarrow \text { / } \\
\text { ((INFANCIA))E:: }\end{array}$ \\
\hline $\mathrm{T}$ & 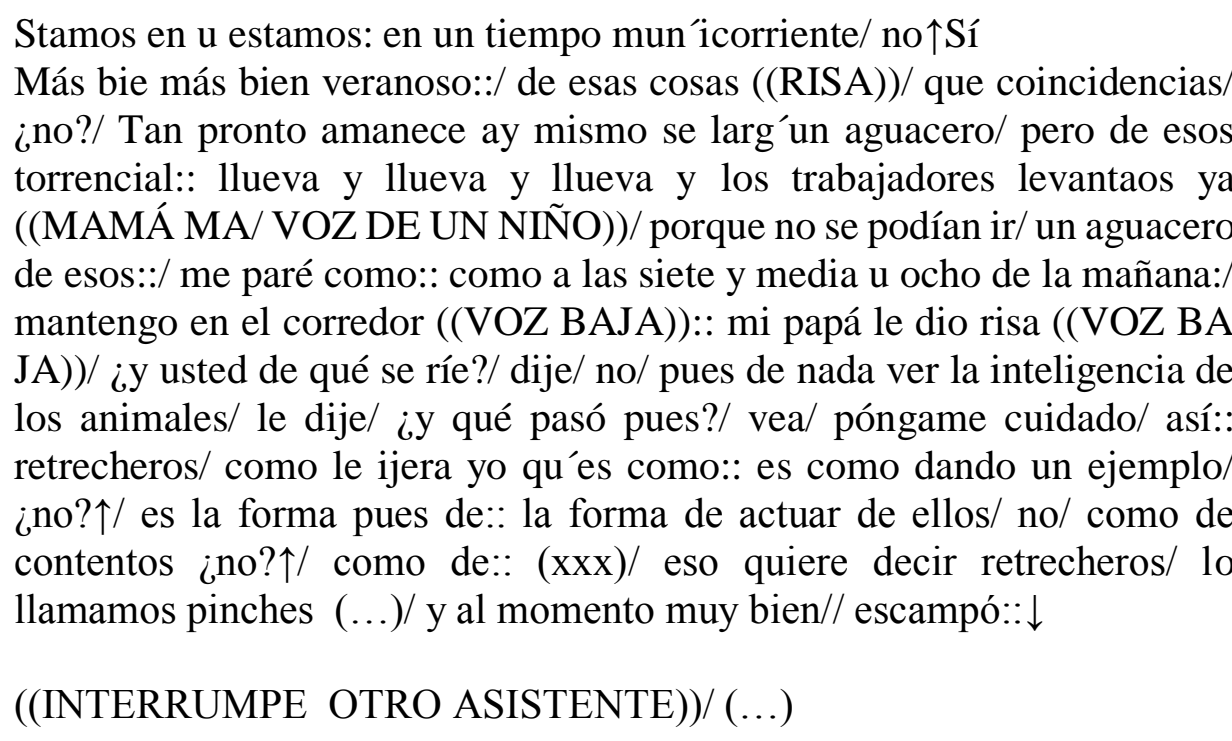 \\
\hline $\mathrm{E}$ & $\begin{array}{l}\text { ¿A Don Tulio no le tocó: la violencia o qué/ ya se acabó el cuento ese/ ya } \\
\text { se acabó?^ }\end{array}$ \\
\hline $\mathrm{T}$ & Sí/ sí/ sí/ sí/ \\
\hline $\mathrm{E}$ & $\begin{array}{l}\text { Entoes la otra ¿A Don Tulio le tocó: la violencia/ cómo vio la violencia/ } \\
\text { el problema de asesinatos y: } \rightarrow\end{array}$ \\
\hline $\mathrm{T}$ & $\mathrm{Ah} /$ eso es una cosa muy desagradable $\downarrow /$ \\
\hline $\mathrm{E}$ & ¿En qué año fue que/ $\rightarrow$ qué experiencia le tocó a usted? \\
\hline $\mathrm{T}$ & $\begin{array}{l}\text { Pues no no/ yo no/ no:: a mí no me tocó pues ver así mucha cosa/ pero sí:: } \\
\text { las escaramuzas no:: si: pero sí ub/ me di cuenta d'iun/ d'iunasesinato que } \\
\text { qu ubo cerca oye pues una cosa: real pues y muy muy desagradable de un }\end{array}$ \\
\hline
\end{tabular}




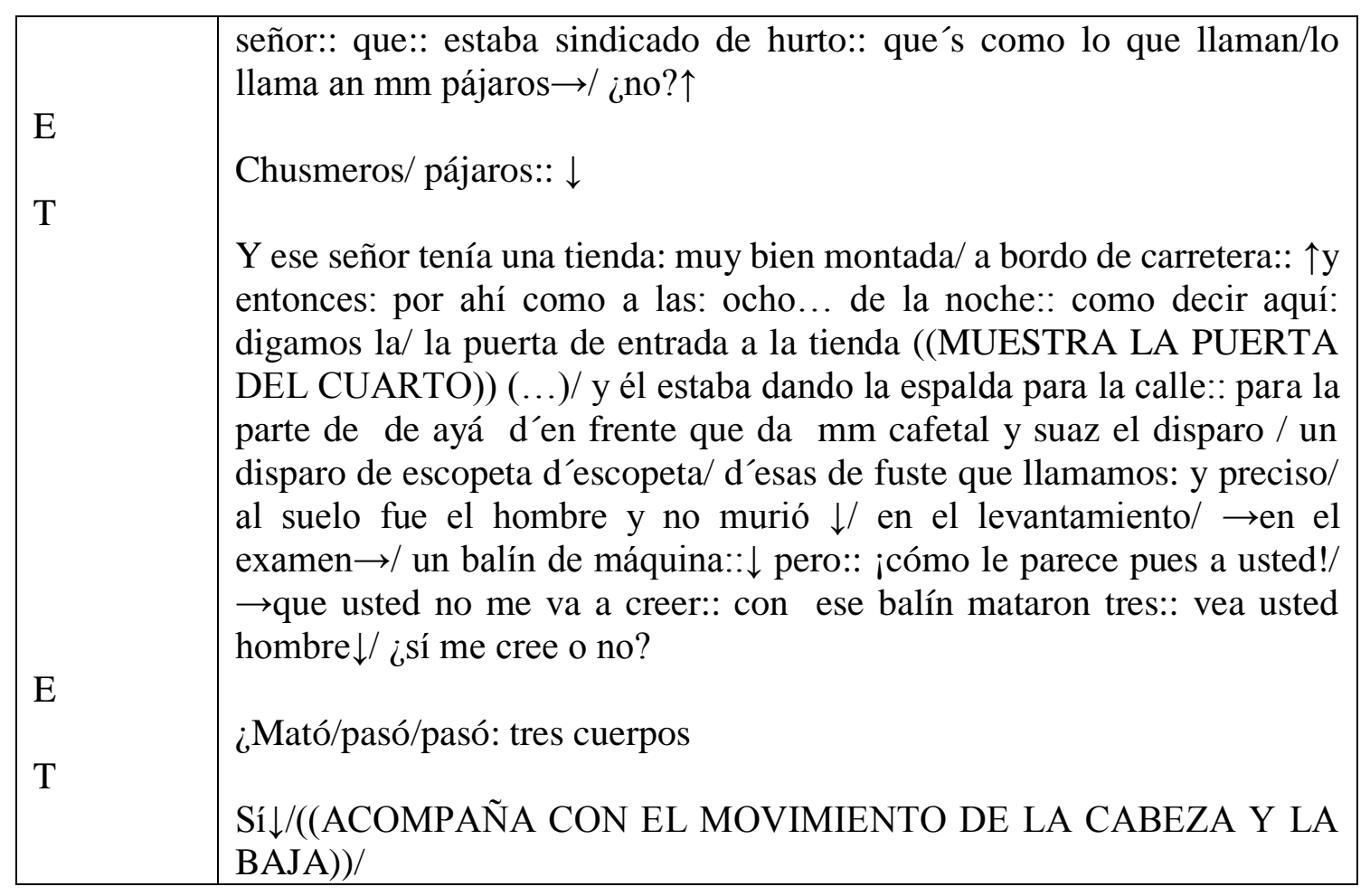

41S

Edad: 81 años

Nacionalidad: Colombia

Sexo: Masculino

\begin{tabular}{|c|c|}
\hline Informante & Discurso \\
\hline $\mathrm{E}$ & ¿Usted cuándo es que me va a prestar la ruana hombre? $\uparrow$ \\
\hline $\mathrm{S}$ & Cuando usted quiera $\uparrow /$ \\
\hline $\mathrm{E}$ & $\mathrm{He} / \mathrm{he} /$ \\
\hline $\mathrm{S}$ & $\begin{array}{l}\text { Maestro bendito/ ¡cuándo se le va a negar a usted Avemaría!/ } \uparrow \text { toda una } \\
\text { vida/ vea te tanto que el palo si lo necesita } \rightarrow /\end{array}$ \\
\hline $\mathrm{E}$ & El palo también me sirve $\downarrow /$ \\
\hline$S$ & $\mathrm{Ah} /$ pero lo malo es que de pronto le da en la nariz al perro y $\mathrm{y} \rightarrow / /$ \\
\hline $\mathrm{E}$ & 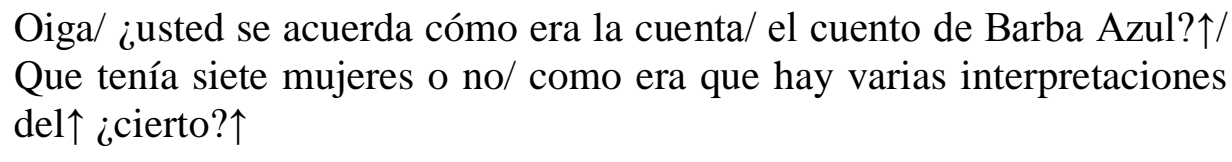 \\
\hline $\mathrm{S}$ & Ah/ sí: no me acuerdo bien d’esa historia/ $\rightarrow$ medio medio me recuerdo $\downarrow /$ \\
\hline $\mathrm{E}$ & $\begin{array}{l}\text { Écheme/ écheme pues la historia de: } \rightarrow \text { Carlo Magno } \downarrow \text { La mujer sin } \\
\text { cabeza } \downarrow /\end{array}$ \\
\hline
\end{tabular}




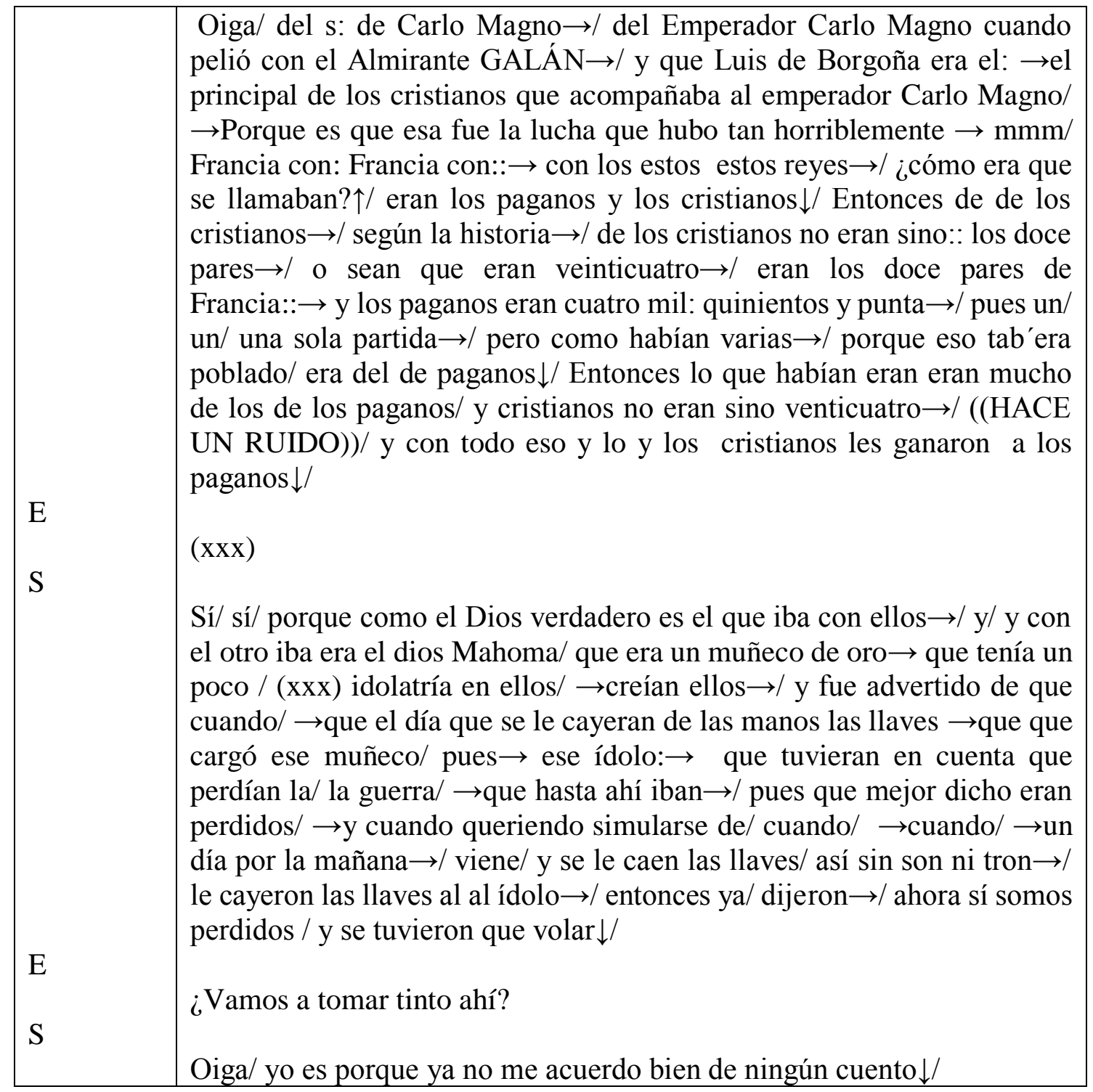

42R

Edad: 80 años

Nacionalidad: Colombia

Sexo: Masculino

\begin{tabular}{|c|c|}
\hline Informante & Discurso \\
\hline $\mathrm{E}$ & $\mathrm{Ja} / \mathrm{ja} / \mathrm{ja} /$ tomémonos un tinto/ un tinto por favor/ \\
\hline OTRO & No/ don Rafael le estaba explicando a un relacionista/ oiga $\rightarrow(x x x)$ \\
\hline $\mathrm{E}$ & Cuénteme la historia de Vargas Vila/ \\
\hline $\mathrm{R}$ & $\begin{array}{l}\text { Uno que murió allí en: } \rightarrow \text { de: } \rightarrow \text { de Gómez de } \rightarrow(\ldots) / \text { en el Parque } \\
\text { Fundadores: } \rightarrow \text { ese ese fue: el que } \rightarrow \text { el que me: propuso la renuncia/ } \\
\text { sí/no: } \rightarrow \text { yo no: } \rightarrow \text { pues sí/ si tuviera eso:: } \rightarrow(\ldots) / \text { había empleado mejor mi: } \\
\text { mi: mi:: }(\ldots) / \text { saberes que tengo: } \rightarrow \text { pero } \mathrm{mm} \text { faltó ese pie/ } \rightarrow \text { sí/ a dibujarlos/ } \\
\text { los mm los dígame }(\ldots) \rightarrow / \text { no sé cuál/ a cuál de ellos perteneció él: } \\
\text { digámole: los maristas } \rightarrow \text { /aun cuando no sean: lo tildaban de: de:: ¿cómo se }\end{array}$ \\
\hline
\end{tabular}




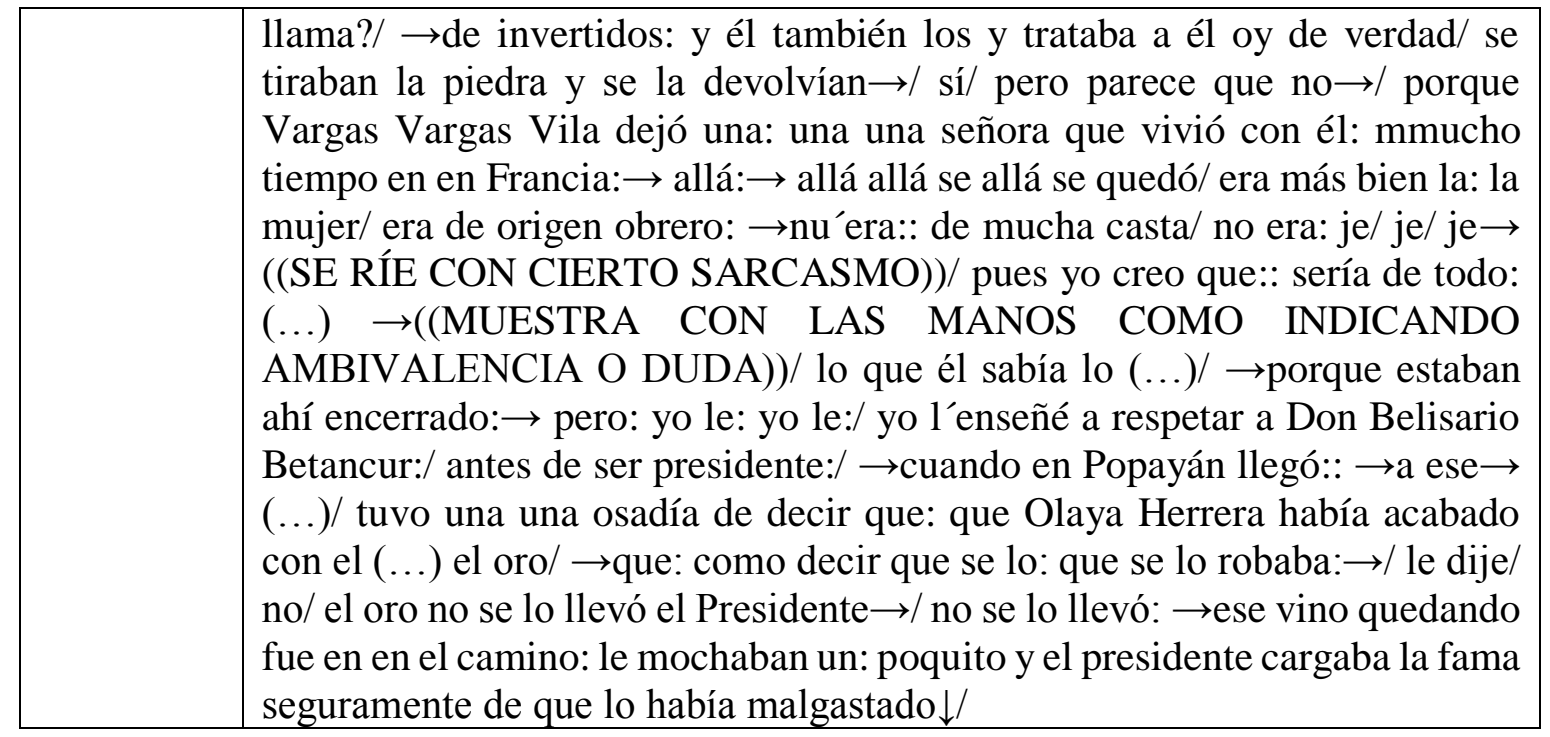

$43 \mathrm{E}$

Edad: 91 años

Nacionalidad: Colombia

Sexo: Femenino

\begin{tabular}{|c|c|}
\hline Informante & Discurso \\
\hline $\mathrm{E}$ & Muy alentada/ me ha tocao traajar mucho $\downarrow$ \\
\hline ENT & Como buen pobre/ \\
\hline $\mathrm{E}$ & $\begin{array}{l}\text { Pss/ cómo le dijera yo/ y es y es pues muy alentada y trabajo mucho } \rightarrow \text { y si } \\
\text { m'envitan pa un paseo me voy:: y así } \rightarrow \text { / yo he sido contenta pues::/ pero } \\
\text { nunca trasnocho: eso sí no puedo/ qué te dijera } \mathrm{y} \rightarrow / /\end{array}$ \\
\hline ENT & $\begin{array}{l}\text { Y ¿había historias de fantasmas y de miedo y de o no/ o de la violencia/ ¿no } \\
\text { le tocó la violencia? }\end{array}$ \\
\hline $\mathrm{E}$ & $\begin{array}{l}\text { No/ pues como yo:: he nacido aquí en Villamaría } \rightarrow \text { y no me he movido de } \\
\text { aquí:: } \rightarrow \text { no he sido pues pasiadora no/ más bien poco: ¿cierto Juancho? } \uparrow\end{array}$ \\
\hline OTRO & $((\mathrm{SU}$ HIJO $)) / ¿ \mathrm{Ah} ? \uparrow$ \\
\hline $\mathrm{E}$ & ¿Qué yo no he sido pues pasiadora?^ \\
\hline OTRO & $\mathrm{Ah} / \mathrm{no} \downarrow /$ \\
\hline ENT & $\begin{array}{l}\text { ¿Qué es lo que más le ha gustado en la vida/ además de tomar chocolatico } \\
\text { con pan? }\end{array}$ \\
\hline $\mathrm{E}$ & $\begin{array}{l}\text { Ja ja }((\text { RISA PLENA))/ } \downarrow \text { Ah/ eso sí/ sí me gusta mucho a mi: chocolate con } \\
\text { arepa/ ave/ } \uparrow \text { NO CON PAN SINO CON AREPA } \downarrow /\end{array}$ \\
\hline ENT & $\begin{array}{l}\text { ¿Y cómo son las costumbres de ahora: e cuáles son las costumbres de ahora } \\
\text { usted ha visto más distintas con respecto a las anteriores/ los novios? }\end{array}$ \\
\hline
\end{tabular}




\begin{tabular}{|c|c|}
\hline $\mathrm{E}$ & $\begin{array}{l}\text { He visto yo pues/ qué te dijera yo/ } \rightarrow \text { llos son muy confiables/ yo no por esa } \\
\text { parte de mi parte si no: } \rightarrow \text { ellos son muy confiables y y ellos se arriman se } \\
\text { besan/ y eso no me parece a mí bien/ no me parece: } \rightarrow \text { ¿usté qué dice? } \rightarrow\end{array}$ \\
\hline ENT & Esos son como otros valores/ \\
\hline $\mathrm{E}$ & ¿Son como costumbres o qué? $\uparrow$ \\
\hline ENT & ¿La situación en la vida es más es más cara ahora/ más difícil? \\
\hline $\mathrm{E}$ & Más difícil $\downarrow /$ \\
\hline ENT & Más desempleados/ \\
\hline $\mathrm{E}$ & $\begin{array}{l}\text { Y aun cuando yo pues::/ cuando me levantaron/ } \uparrow \text { levantaron/ pa decir la } \\
\text { verdad/ yo me casé inocente } \rightarrow / \text { no sabía paqué me casaba: } \rightarrow \text { mi papá nos } \\
\text { formó muy bien criaos } \rightarrow \text { no: no puedo decir más nada/d'ellos/ sino qu'ellos } \\
\text { son muy fregaos } \rightarrow \text { y nos quedó muy: muy } \rightarrow \text { y yo pa decirle la verdad/ no } \\
\text { le digo que me casé inocen:te } \downarrow /\end{array}$ \\
\hline ENT & ¿Buena cristiana/ misa diaria? \\
\hline $\mathrm{E}$ & $\begin{array}{l}\text { Diaria/ diaria/ dia: } \rightarrow \text { ahora últimamente ya me estoy yo abandonando } \\
\text { porque mm la iglesia es muy lejos } \rightarrow / \text { no me dejan salir sola: qué pesar } \downarrow /\end{array}$ \\
\hline ENT & Pero uno ora/ uno ora solo/ \\
\hline $\mathrm{E}$ & ¿Mm?个 \\
\hline ENT & Uno solo se pone a orar con Dios/ \\
\hline $\mathrm{E}$ & $\begin{array}{l}\text { Ah/ eso sí/: } \downarrow \text { yo/ yo siempre por la noche/ siempre me acuesto } \rightarrow \text { rezo un } \\
\text { ratico:: } \downarrow\end{array}$ \\
\hline ENT & Y hoy por hoy/ la satisfacción más grande es tener a sus hijos/ \\
\hline $\mathrm{E}$ & $\begin{array}{l}\text { Ah/ sí:: tener los hijos: } \rightarrow \text { porque a mí }(\ldots) \text { se se me murieron tres/ pero ya } \\
\text { u dos pequeños y y uno ya ya casado } \rightarrow \text { / iqué pesar! } \rightarrow \text { / de resto / siete:/ } \\
\text { son siete los hijos: } \downarrow /\end{array}$ \\
\hline ENT & $\begin{array}{l}\mathrm{Mmm} / \text { ¿A usted no le tocó la violencia: ni creía en fantasmas/ ni en asustos } \\
\text { ni nada? }\end{array}$ \\
\hline $\mathrm{E}$ & $\begin{array}{l}\text { No/ no/ no/ yo no me acuerdo d'eso: } \rightarrow \text { que y'ubiera visto pues/ así no: } \rightarrow \rightarrow \\
\text { porque: no yo le vo a decir cuántos años/ tengo yo } \rightarrow \text { ochen:ta y::siete } \downarrow \\
((\text { HABLA DESPACIO)):/ yo creo que no } \rightarrow / / / \text { ¿cierto que no? } \uparrow / /\end{array}$ \\
\hline ENT & La violencia fue del $40 /$ \\
\hline
\end{tabular}




\begin{tabular}{|c|c|}
\hline $\mathrm{E}$ & ¿Ah?^ \\
\hline ENT & $\begin{array}{l}\text { La violencia fue en 1940/ los liberales/ los conservadores/ de Rojas Pinilla/ } \\
\text { la guerrilla/ }\end{array}$ \\
\hline $\mathrm{E}$ & Ah/ de eso sí me acuerdo yo/ cuando hablaban tanto de Rojas Pinilla $\downarrow /$ \\
\hline ENT & ¿Y a ustedes los persiguieron/ no? \\
\hline $\mathrm{E}$ & No/ no/ a nosotros no nos persiguieron/ gracias a mm Dios $\downarrow$ / \\
\hline ENT & ¿Pero le tocó ver muchos muertos/ mucho incendio/ no? \\
\hline $\mathrm{E}$ & $\begin{array}{l}\text { No/ no/ tampoco: } \rightarrow \text { porque pa decir la verdad/ yo viví: } \rightarrow \text { yo levanté la } \\
\text { familia/ casi toda/ fue en la finca: } \rightarrow \text { ah/ casi todos en la finca: } \rightarrow \text { pero luego } \\
\text { me vine pa } 1 \text { pueblo/ } \rightarrow \text { al uni/ al único que nació en el pueblo fue éste } \rightarrow \\
((\text { SEÑALA A SU HIJO JUAN))/ de resto/ toos en la finca } \downarrow /\end{array}$ \\
\hline ENT & $\begin{array}{l}\text { Por eso es que este tonto ((SEÑALANDO AL HIJO)) es tan orgulloso/ ¿o } \\
\text { qué? }\end{array}$ \\
\hline $\mathrm{E}$ & $(($ RISA PLENA $)) /$ ¡Ay/ tan orgulloso $\uparrow /$ \\
\hline ENT & Ochenta y pico de años/ y tiene que alcanzar a los 100 años/ pa celebrarle/ \\
\hline $\mathrm{E}$ & ¡Ay!/No sea bruto/ no más/ ya he vivido mucho $\downarrow /$ \\
\hline ENT & Paqué que usted vive feliz con su familia/ usted/ \\
\hline $\mathrm{E}$ & $\begin{array}{l}\mathrm{Ah} / \mathrm{no} / \text { yo sí/ vivo contenta/ } \rightarrow \text { yo/ no/ no he sido aburrida/ uy: qué } \\
\text { horrible } \rightarrow \text { / yo he sido muy contenta/ m toda la vida/ } \rightarrow \text { ah/ y si me ponen a } \\
\text { trabajar más } \rightarrow \text { /más too me gusta } \downarrow /\end{array}$ \\
\hline ENT & ¿Toda la vida buena salud? \\
\hline $\mathrm{E}$ & Yo/ buena salud toda la santa vida $\downarrow$ / \\
\hline ENT & ¿Gripitas por ahí no más? \\
\hline $\mathrm{E}$ & ¿Qué?^ \\
\hline ENT & ¿Gripas? \\
\hline E & $\begin{array}{l}\text { Gri/ y y me da de vez en cuando: } \rightarrow \text { de vez en cuando me da:: casi no/ } \\
\text { ¿oiga? } \uparrow((\text { SUENA EL TELÉFONO))/ }\end{array}$ \\
\hline ENT & $\begin{array}{l}\text { Pues eso es una bendición de Dios/ Mi madre tiene setenta y cinco años y y } \\
\text { ha sido muy enferma/ }\end{array}$ \\
\hline
\end{tabular}




\begin{tabular}{|c|c|}
\hline $\mathrm{E}$ & ¿Sí? \\
\hline ENT & $\begin{array}{l}\text { Y yo tengo/ voy a cumplir cincuenta y cinco y nunca he tenido nada grave/ } \\
\text { pero: }\end{array}$ \\
\hline $\mathrm{E}$ & $(($ ESTORNUDA $)) / \mathrm{Ah} / \mathrm{ya} / \mathrm{y}$ vea/ yo tengo/ yo tengo $\rightarrow / /$ \\
\hline ENT & ¿Tiene nietos? \\
\hline $\mathrm{E}$ & $\begin{array}{l}\text { ¡Ja!/ bisnietos } / \rightarrow \text { cuarenta y cinco son los nietos y bisnietos } / \rightarrow \text { ah/ yo no sé/ } \\
\text { cuarenta y cinco nietos } \downarrow /\end{array}$ \\
\hline ENT & Cuarenta y cinco/ eso es mucha gente/ \\
\hline $\mathrm{E}$ & Mucha gente: es que así no más $\rightarrow / /$ \\
\hline ENT & ¿Y bisnietos cuántos? \\
\hline $\mathrm{E}$ & Ay/ yo no sé/ son bastantes $\downarrow /$ \\
\hline ENT & ¿Se le perdió la cuenta? \\
\hline $\mathrm{E}$ & $(\mathrm{xxx})$ Preguntémosle a esta niña/ $\rightarrow$ ¿sabe qué fue lo que se me perdió a mí? $\uparrow$ \\
\hline ENT & No/ pero de dónde/ por Dios/ \\
\hline $\mathrm{E}$ & $(($ RISA)) y yo ya estaba viuda $\downarrow /$ \\
\hline ENT & ¿Sí? \\
\hline $\mathrm{E}$ & A:: ver/ no no/ estaba chiquitico $\rightarrow / / /$ \\
\hline ENT & ¿Entonces cuánto tiempo/ cuántos años lleva usted de viuda? \\
\hline $\mathrm{E}$ & $\begin{array}{l}\text { Como más de cincuenta } \rightarrow / \text { sí/ hace muchos años/ muy joven/ pues quedé de } \\
\text { treinta y cinco años } \downarrow /\end{array}$ \\
\hline ENT & $\mathrm{Ah} / \mathrm{no} / \mathrm{no} /$ en plena vida/ \\
\hline $\mathrm{E}$ & $\begin{array}{l}\text { No/ yo fui muy casera o soy muy casera/ no me gusta salir ni nada: } \rightarrow \text { que } \\
\text { me gusta mucho/ es como trabajar: } \rightarrow / / \text { no/ } \rightarrow \text { yo siempre fui: duermo bien/ } \\
\text { como bien/ ¿por qué no puedo trabajar bien? } \uparrow\end{array}$ \\
\hline
\end{tabular}

44C

Edad: 80 años

Nacionalidad: Colombia

Sexo: Masculino 


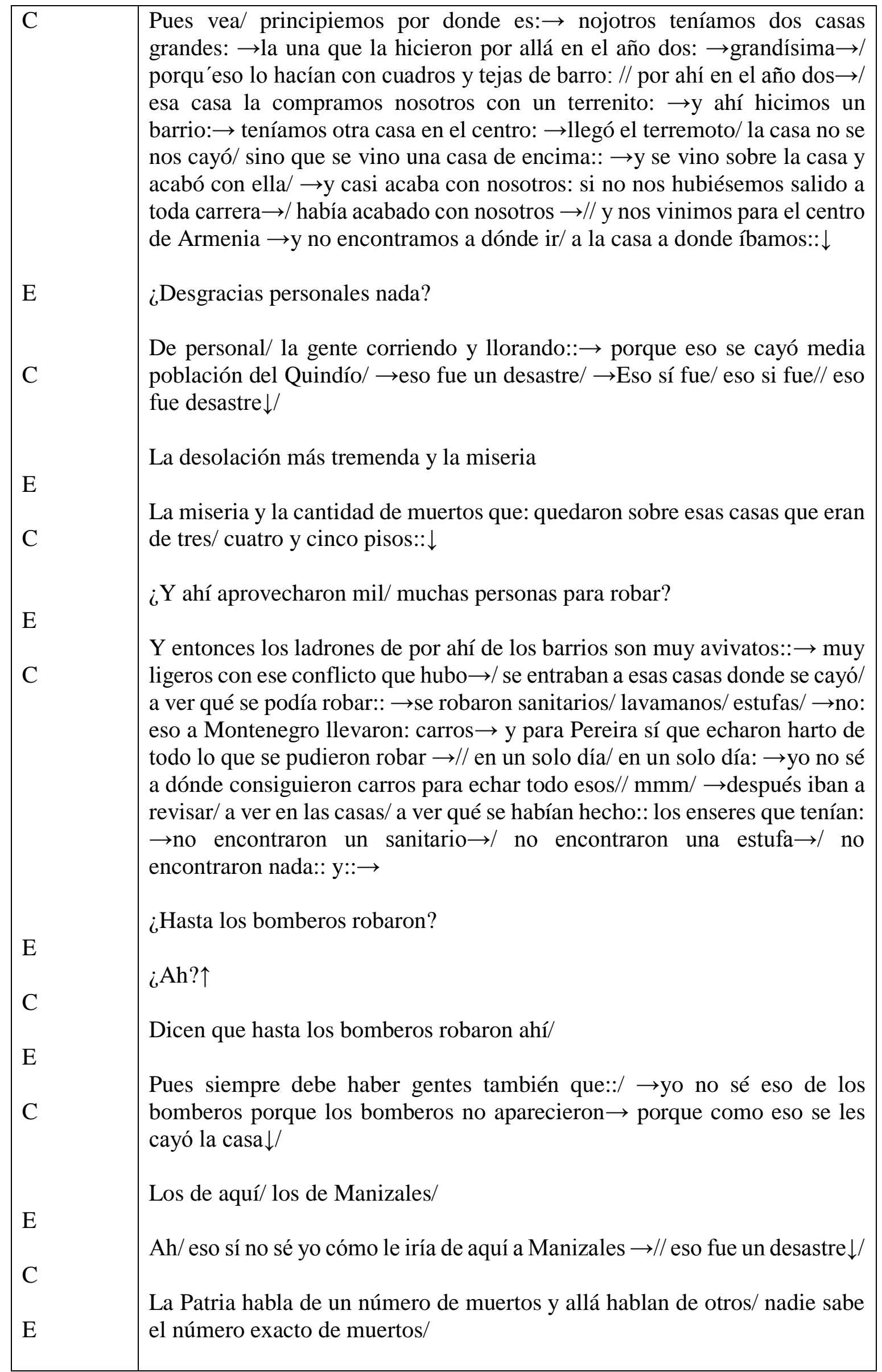




\begin{tabular}{|l|l|}
\hline $\mathrm{C}$ & $\begin{array}{l}\text { N:: porque:: en Armenia de una sola casa sacaron diecisiete muertos: } \rightarrow \text { era } \\
\text { un hotel: } \rightarrow \text { sacaron diecisiete personas a los tres días:: } \rightarrow \text { y en otra casa } \\
\text { grande fue la familia entera que:: dicen que toda se murió ahí: } \rightarrow \text { de manera } \\
\text { que allá hubo un poco de tragedias y muertos a pilas: } \rightarrow \text { eso sacaban } \rightarrow / / \\
\text { cuatro o cinco muertos } \downarrow /\end{array}$ \\
\hline
\end{tabular}

45A

Edad: 78 años

Nacionalidad: Colombia

Sexo: Masculino

\begin{tabular}{|c|c|}
\hline Informante & Discurso \\
\hline A & {$[\ldots]$ trabajadores del municipio/ $\downarrow$} \\
\hline $\mathrm{E}$ & $\begin{array}{l}\text { ¿Usted conoció/ oyó nombrar a Santiago Rengifo (xxx) que lo mataron? } \\
\uparrow\end{array}$ \\
\hline A & Sí/ no es más/ $\downarrow$ \\
\hline $\mathrm{E}$ & ¿Cuántos mataron de Pensilvania? $\uparrow$ \\
\hline A & $\begin{array}{l}\text { Pues/ e/ de Pensilvania fue un muchacho Vásquez: y de ahí de } \\
\text { Manzanares:: iba un hijo del difunto Joaquín Cardona: } \downarrow\end{array}$ \\
\hline $\mathrm{E}$ & ¿Y cuáles de los trabajadores eran? $\uparrow$ \\
\hline A & $\begin{array}{l}\text { Y Joaquín Cardona venía a ser primo de nosotros:: porque mi mamá era:: } \\
\text { Botero/ y la y la mamá de: del difunto Joaquín Cardona: llamaba } \\
\text { Ana::Cristinita me parece que llamaba: vivía ahí de / en la dentrada de } \\
\text { de Manzanares/ } \downarrow\end{array}$ \\
\hline $\mathrm{E}$ & Pero del que más mataron fue de Manzanares/ $\uparrow$ \\
\hline A & Claro:: $\downarrow$ \\
\hline $\mathrm{E}$ & $\begin{array}{l}\text { Oiga/ ¿y usted se acuerda de mi papá } / / / \uparrow \text { Usted se acuerda cómo mataron } \\
\text { los otros? } \uparrow\end{array}$ \\
\hline A & $\begin{array}{l}\text { ¿No fue a puro garrote?: } \uparrow \text { los iban sacando uno por uno de la pieza } \\
\text { donde los tenían Tirofijo encerrados } / \uparrow\end{array}$ \\
\hline $\mathrm{E}$ & Desquite/ Y el Padre Hincapié/ ¿se acuerda qué decía? $\uparrow$ \\
\hline A & $(\ldots) /$ no era más:: eso es lo único que sé yo pues: $\downarrow$ \\
\hline
\end{tabular}




\begin{tabular}{|c|c|}
\hline $\mathrm{E}$ & ¿Cuántos muertos? $\uparrow$ \\
\hline A & No tengo idea cuántos muertos fueron:: $\downarrow$ \\
\hline $\mathrm{E}$ & Las llantas de: la volqueta las machetearon/ $\downarrow$ \\
\hline A & $\begin{array}{l}\text { Sí/ demás/ así como hacen con los carros: que les meten candela:: les } \\
\text { ruchean ((ROCÍAN)) gasolina y les meten candela:: aí hacen con los } \\
\text { cristianos esos desgraciados:: } \downarrow\end{array}$ \\
\hline $\mathrm{E}$ & Caregallo/ ¿en ese entonces cuántos años tenía? $\uparrow$ \\
\hline A & ¿Quién? $\uparrow$ \\
\hline $\mathrm{E}$ & Caregallo/ de Pensilvania/ uno de los ricos de allá $(\ldots) / \downarrow$ \\
\hline A & $\begin{array}{l}\text { Yo no recuerdo (...) de los muertos que hubieron en: más debajo de } \\
\text { Marquetalia/ } \downarrow\end{array}$ \\
\hline $\mathrm{E}$ & $\begin{array}{l}\text { Y ahora dicen que hay guerrilla en Pensilvania/ ¿y usted no se acuerda } \\
\text { de Luis Alfonso/ y le dañaron la...? } \rightarrow\end{array}$ \\
\hline A & $\begin{array}{l}\text { Pero fue por adá en Pueblo Nuevo/ ahí de Guayaquil para abajo/ Pueblo } \\
\text { Nuevo que llama/ pa llegar a Nariño:: } \rightarrow\end{array}$ \\
\hline $\mathrm{E}$ & ¿Y de Pensilvania se comunica con Samaná? $\uparrow$ \\
\hline A & Claro $\downarrow$ \\
\hline $\mathrm{E}$ & Por Marulanda/ entonces es la misma guerrilla... $\rightarrow$ \\
\hline A & $\begin{array}{l}\text { Y en los campos:: no oyó decir aí de la:: cuando: cuando hirieron este } \\
\text { hijo de don del difunto Don Samuel Salazar/?^ }\end{array}$ \\
\hline $\mathrm{E}$ & ¿De Manzanares? $\uparrow$ \\
\hline A & Que lo tuvieron qu'echar para Bogotá:: $\rightarrow$ \\
\hline $\mathrm{E}$ & Pero Salazar de Manzanares $\uparrow$ \\
\hline A & De aí de Pensilvania $\downarrow$ \\
\hline $\mathrm{E}$ & Ah/ de aí de Pensilvania $\downarrow$ \\
\hline A & Eso fue ay/ ay de la Rioja para acá:: $(\ldots)$ / y ay quemaron unos carros: $\rightarrow$ \\
\hline $\mathrm{E}$ & ¿Y se iban a llevar al gobernador ahora/ ahora dos años?/ $\uparrow$ \\
\hline A & Eso si no me recuerdo/ $\downarrow$ \\
\hline
\end{tabular}


46JB

Edad: 88 años

Nacionalidad: Colombia

Sexo: Masculino

\begin{tabular}{|c|c|}
\hline Informante & Discurso \\
\hline JB & 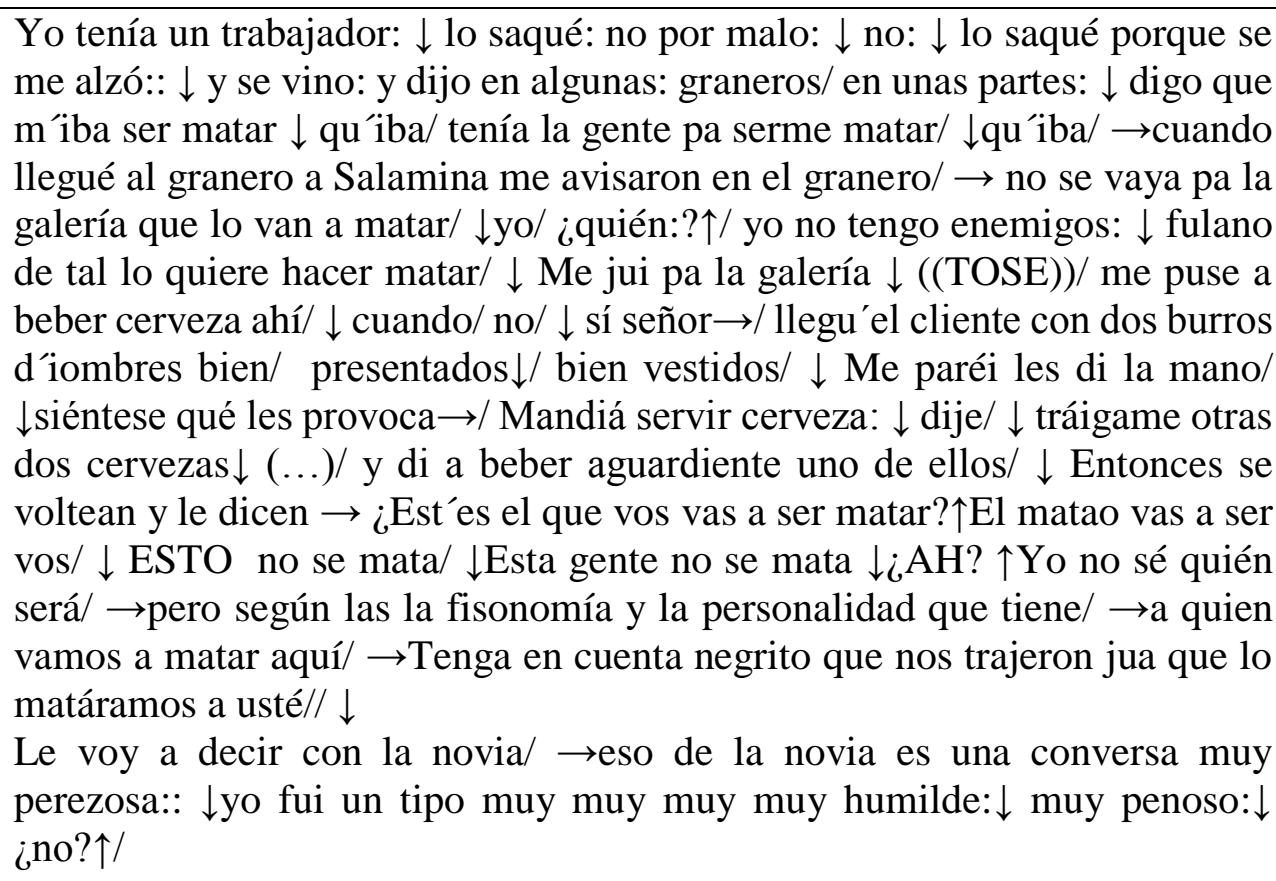 \\
\hline $\mathrm{E}$ & Muy tímido $\downarrow$ \\
\hline JB & $\begin{array}{l}\text { Ah/ harto/ muy tímido/ ah/ harto/ bueno/ sí: } \downarrow \text { pero sí/ cuando yo me fui a } \\
\text { casar } \rightarrow \text { que }(\ldots) \text { / le dije a mi papá: me voy a casar:: } \downarrow \text { que pensé casarme } \rightarrow \text { / } \\
\text { resulta que cómo le contara a usté } \rightarrow \text { m’iba a casar:: con julana: } \downarrow \text { resulta } \\
\text { que:: } \rightarrow \text { me iba a casar con julana/ } \downarrow \text { Él había arreglao un matrimonio entre } \\
\text { esa muchacha y yo: } \rightarrow \text { con el papá d'esa muchacha y el papá mío } \rightarrow \text { / habían } \\
\text { arregla: mi papá me iba }((B A J A ~ L A ~ V O Z) \text { )/ conversas d'ellos dos solos: } \downarrow \\
\text { m’iba a dar a mí el vestido/ que n'itara } \rightarrow \text { / iba a vestir la: la novia: pero }(\ldots) / \\
\rightarrow \text { Entonces eso fue... } \rightarrow \\
\text { (CONTINÚA LA GRABACIÓN) }\end{array}$ \\
\hline
\end{tabular}

47I

Edad: 76 años

Nacionalidad: Colombia

Sexo: Femenino

\begin{tabular}{|l|l|}
\hline Informante & \multicolumn{1}{|c|}{ Discurso } \\
\hline I & $\begin{array}{l}\text { Nosotros vivimos en: en un: en una parte que llaman Guamal::de de Supía } \\
\text { y me: una vereda de Guamal:: } \downarrow \text { Bajóun señor d’esos pues parranderos de } \\
\text { noche/ enamorados y too/ } \downarrow \text { Entoes subía izque a las dos de la mañana:: } \\
\\
\text { cuando él izque oía que le decían::: } \downarrow((\text { CINCO SEGUNDOS))/ Ay qué } \\
\text { sería lo que/ } \rightarrow \text { en too caso: el hombre llegó a la casa:: } \downarrow \text { izque VEA } \downarrow \\
((\text { ENFÁTICO))/ alcanzó a dentrar a a la puerta: y ahí mismo: cayó }\end{array}$ \\
\hline
\end{tabular}




\begin{tabular}{|l|l|}
\hline E & $\begin{array}{l}\text { privado: } \downarrow \text { y entiendo era que le decían/ no me acuerdo/ era que sentía } \\
\text { una persona que:: iba al lado de él/ y él fue tanto el horri/ el susto que: } \\
\text { entró a la casa: } \downarrow \text { TAN PRONTO pisó el::: umbral/ ahí mismo cayó } \\
\text { privao: } \downarrow \text { y entoes izque oían una voz que decía: } \rightarrow \text { denle agua con } \\
\text { carbón:: } \downarrow \text { que le dieran agua con carbón:: } \downarrow \text { y así el hombre izque volvió } \\
\text { a en sí: } \downarrow \text { pero casi izque lo mata ese:: } \rightarrow \text { ese espanto }(\ldots) \downarrow \\
\text { ¿Y qué qué misterio dice la gente que tiene el agua con carbón? } \\
\text { ((RISA PLENA))/ Eso sería por por asustarlo/ } \rightarrow \text { porqu'el susto fue } \\
\text { muy grande } \rightarrow \text { ýél no volvió a salir de noche/ } \downarrow \text { Sí/ hay muchos que } \\
\text { creen en las ánimas: } \downarrow \text { por ejemplo en la violencia los conservadores: } \\
\rightarrow \text { allá perseguían mucho los conservadores a los liberales: } \rightarrow \text { y en ese } \\
\text { pueblito donde yo vivo:: } \rightarrow \text { que de allá era mi esposo:/ Mm l::iban los } \\
\text { conservadores a media noche a atacarlos allá/ } \rightarrow \text { ellos son muy devotos } \\
\text { de Santana: }(\ldots) \rightarrow \text { la patrona de ese: de ese pueblito o vereda/ o co } \\
\text { corregimiento/ } \rightarrow \text { lo: y:: de decían ellos que esa era una vieja alcahuete } \\
\text { no sé qué: } \rightarrow \text { porque una vez subieron cuando vieron en el atrio que en } \\
\text { el atrio en la iglesia/ } \rightarrow \text { ¡uyss!/ } \rightarrow \text { esa señora un ejército comandao por } \\
\text { esa mujer } \downarrow / \text { Esa mujer dicen qu'era Santana por cuidar sus negritos/ le } \\
\text { tienen el el al }(x x x) / \text { le tienen mucho fervor } \rightarrow / \text { mucho fervor a Santa } \\
\text { Ana/ y allá la ve veneran y le hacen su fiesta anual/ } \downarrow\end{array}$ \\
\hline
\end{tabular}

48L

Edad: 80 años

Nacionalidad: Colombia

Sexo: Masculino

\begin{tabular}{|c|c|}
\hline Informante & Discurso \\
\hline $\mathrm{L}$ & $\begin{array}{l}\text { Estaba Toño Aristizábal vivo y lo perseguían/ y él siempre molestaban por } \\
\text { ahí mucho/ y unos que se vinieron de:: unos Velas llegaron de: por allá de } \\
\text { Santanderes sería/ ahí estuvieron: } \rightarrow \text { ¿usted no distinguió esos Velas/ Sí } \rightarrow \text { / } \\
\text { esos estuvieron ahí mucho tiempo } \rightarrow / \text { unos a: } \rightarrow \text { / estos Pavas tamién en esa } \\
\text { época vinieron e::: los Tábanos/ } \rightarrow \text { y cuáles otros eran hombre e:: no me } \\
\text { acuerdo yo/ ((RUIDO SIMULTÁNEO)) } \downarrow / \text { En esa época hubo mucha mucha } \\
\text { violencia: } \downarrow\end{array}$ \\
\hline $\mathrm{E}$ & ¿Liberales o conservadores? $\uparrow$ \\
\hline $\mathrm{L}$ & $\begin{array}{l}\text { Conservadores vinieron/ vinieron fue conservadores/ } \rightarrow \text { y unos/ unos que se } \\
\text { vinieron de de: ellos aquí no decían nada porque: no sabe uno porqué } \rightarrow \text { / } \\
\text { como:: para mí no ha sido malo nadie } \rightarrow / \text { no he tenido que: hacer con nadie/ } \\
\text { pa mí han sido buenos amigos } \rightarrow / \text { y ellos vinieron/ ahí como que les tocó } \\
\text { venirsen de por adá:: } \rightarrow \text { y después los de por aquí les tocó irsen por allá: } \rightarrow \text { lo } \\
\text { que fue: Carlos Giraldo: le tocó irse pa Victoria e:/ Don Daniel Delgado le } \\
\text { tocó irse de Marquetalia/ } \rightarrow \text { pues siempre aburrido: porque él no se metía } \\
\text { con nadie } \rightarrow \text { / pero entoces: él era muy exquisito: } \rightarrow \text { se fue a vivir a Ibagué:: } \\
\rightarrow \text { al que le:: al que le vendió a Toño López }((x x x)) \text { la esquina:: lo que llaman } \\
\text { La Cita: } \rightarrow \text { o la llamaban } \rightarrow / \text { ahora no sé cómo llamará eso:: } \downarrow \text { ((SESEO O } \\
\text { CUCHICHEO)):: y así por el estilo mucha cosa: } \rightarrow \text { mucho he he: mucha }\end{array}$ \\
\hline
\end{tabular}




\begin{tabular}{|l|l|}
\hline política/ mucha vaina/ $\downarrow$ Cuando Hincapié llegó había mucha división: $\rightarrow$ de \\
los políticos liberales y:: conservadores o laureanistas y antapistas $\rightarrow$ / y: todo \\
esu'iba repecur repercutiendo en:: en la política:: $\rightarrow$ pero a la hora de la \\
verdad: con: el al al al correr del tiempo $\rightarrow$ / la cosa fue: fue solucionándose \\
ya: $\rightarrow$ se puso vivible/ ya nn convivían eran los mismos ahí $\downarrow /$
\end{tabular}

49S

Edad: 75 años

Nacionalidad: Colombia

Sexo: Femenino

\begin{tabular}{|c|c|}
\hline Informante & Discurso \\
\hline $\mathrm{E}$ & Bueno Sonia, cuénteme pues una historia de su vida \\
\hline $\mathrm{S}$ & Pero como ¿qué historia Doña Martha? $\uparrow$ \\
\hline $\mathrm{E}$ & $\begin{array}{l}\text { Pues algo que le haya pasado hace mucho tiempo o que haya pasado en su } \\
\text { familia. }\end{array}$ \\
\hline S & $\begin{array}{l}\text { Pues a mi familia no gracias a Dios } \rightarrow \text { bueno } \rightarrow \text { sí cositas además de la } \\
\text { pobreza y que nos ha tocado trabajar mucho pa para poder vivir a mí y mis } \\
\text { hijos } \rightarrow \text { a to a todos } \downarrow \text { Pero } \rightarrow \text { sí pero sí le voy a contar lo que le pasó al } \\
\text { bobito } \downarrow\end{array}$ \\
\hline $\mathrm{E}$ & Ah, a un bobito, y de quién era el bobito, ¿de su familia? \\
\hline S & $\begin{array}{l}\text { No:: ((SE RÍE CON GRACIAS)), el bobito era de una vecina y como y } \\
\text { como le parece Doña Martha } \uparrow \text { que un día iba pasando la carretera } \rightarrow \text { ahí por } \\
\text { la Panamericana, más debajo de la casa mía } \rightarrow \text { de nosotros } \uparrow \text { cuando de } \\
\text { pronto grita el hijo mío que usted lo conoce cierto } \uparrow \text { dice } \rightarrow \text { mami/ mami/ } \\
\text { vamos a mira porque la gente está corriendo pa'bajo } \rightarrow \text { por la } \\
\text { Panamericana } \rightarrow \text { vamos a ver qué pasó } \rightarrow \text { y fuimos y } \rightarrow \text { ay Dios mío } \uparrow \text { como } \\
\text { le parece que una tartamuda había matado al bobito } \uparrow \text { y ay Dios mío } \rightarrow\end{array}$ \\
\hline $\mathrm{E}$ & ¿Quién? \\
\hline S & Una tartamula, un doble troque de 30 llantas \\
\hline $\mathrm{E}$ & Ah, una tractomula \\
\hline S & $\begin{array}{l}\text { Sí, sí eso } \rightarrow \text { y entonces la familia lloraba y todo mundo del pesar } \rightarrow \text { porque } \\
\text { al bobito lo que lo teníamos mucho pesar porque era bobito pero era muy } \\
\text { acomedido con todos } \rightarrow \text { nos ayudaba a veces a cargar las cosas del mercao } \rightarrow \\
\text { y y nos traía agua cuando la quitaba el monicipio } \rightarrow \text { y al otro día el entierro } \rightarrow \\
\text { juimos hasta el cementerio y todo } \rightarrow \text { pero no } \uparrow \text { qué pesar, jue horrible como }\end{array}$ \\
\hline
\end{tabular}




\begin{tabular}{|l|l|}
\hline quedó too estripao el cuerpo $\rightarrow$ que cuando vino cuando vinieron los la \\
policía $\rightarrow$ la radiopatrulla nos hicieron retirar y lo taparon con unas sábanas \\
y luego, luego lo recogieron no sé y bueno $\rightarrow$ ¡uy! no Dios mío $\rightarrow$ miamá \\
casi no podía ni hablar porque como son $\rightarrow$ com'uella era muy amiga de $\rightarrow$ \\
es muy amiga de la abuela del bobito $\downarrow$ iban a misa y no fue $\rightarrow$ eso fue \\
terrible y ese doble dobletroque ahí y la policía detuvo el chofer y se lo \\
llevaron pa pa yo no séonde
\end{tabular}

50MA

Edad: 88 años

Nacionalidad: Costa Rica

Sexo: Masculino

\begin{tabular}{|c|c|}
\hline Informante & Discurso \\
\hline MA & $\begin{array}{l}\text { Bueno/ le voy a contar un cuento que me pasó teniendo yo como diez } \\
\text { años: }\end{array}$ \\
\hline OTRO & $\begin{array}{l}\text { Vivíamos en una finca en Palomo de Oruz } \rightarrow \text { /yo trabajaba también allí/ } \\
\downarrow \text { El mandador me daba trabajo allí/ claro que me pagaban una cochinada/ } \\
\text { pero también era una cochinada lo que valía lo qu'iuno se comía } \rightarrow \text { / } \\
\text { Estaba: la libra de café } \rightarrow \text { / valía veinte centavos la libra de arroz/ una } \\
\text { peseta en ese tiempo/ ¿verda?^ }\end{array}$ \\
\hline $\mathrm{E}$ & ¡Mmmm! \\
\hline MA & $\begin{array}{l}\text { Entonces a mí me pagan cuarenta centavos por día y yo contento con los } \\
\text { cuarenta centavos/ cosechamos como cinco sacos de fríjoles a boca } \\
\text { abierta no eran como los sacos de ahora los sacos d'iantes } \rightarrow \text { y ya los } \\
\text { trajimos a la casa y los pusimos en la en la sala } \rightarrow \text { ahí pusimos los sacos } \\
\text { mantras mañana los echamos al sol:: } \downarrow / / \text { me acuerdo que jue domingo } \rightarrow \text { / } \\
\text { no estoy mintiendo } \rightarrow \text { eso jue lunes y'al otro día al sol los fríjoles } \\
\rightarrow \text { papa ndaba }(x x x) \rightarrow \text { al otro día como a las seis de la tarde llegó mamá } \\
\text { a comer: } \downarrow / \text { cuando oímos } \rightarrow \text { oímos com’una com’un carro cuando no } \\
\text { quiere arrancar: } \downarrow /(x x x) \text { tiene miedo? } \uparrow \text { No miedo no sia lo que sea pero } \\
\text { yo miedo no tengo peru’ay que tar prevenío (xxx) } \downarrow \text { nu'había cabao e } \\
\text { decir cuando taamos en la sala/ } \rightarrow \text { una las ventanas taban a l'altura d'esta } \\
\rightarrow \text { y por ahí se metía l'agua } \rightarrow \text { una inundación que reventó y se vino y no } \\
\text { quedó nade casa } \downarrow\end{array}$ \\
\hline $\mathrm{E}$ & AY \\
\hline MA & Ni nade sacos de fríjol $\downarrow$ nada todo lo llevó l’agua $\downarrow$ \\
\hline $\mathrm{E}$ & Ustedes estaban adentro? $\uparrow$ \\
\hline MA & $\begin{array}{l}\text { Nosotros adentro } \rightarrow \text { a mi me a mi me sacó y a pa a mamá la sacó como/ } \\
\text { papá iba guindando mamá iba guindando de papá onde lo llevaba/ }\end{array}$ \\
\hline
\end{tabular}




\begin{tabular}{|c|c|}
\hline & $\begin{array}{l}\downarrow \text { Bueno ya construimos } \rightarrow \text { A mi me sacó me llevó por una finca por la } \\
\text { misma finca } \downarrow\end{array}$ \\
\hline $\mathrm{E}$ & ¿Y cómo usted no se ahogó? $\uparrow$ \\
\hline MA & $\begin{array}{l}\text { No yu'iba l'agua apenas me dab'al pescuezo/ } \rightarrow \text { mamá no la tapó } \\
\text { tampoco/ } \rightarrow \text { Como l'iba tapar si iba guindando de la cintura e papá } \downarrow\end{array}$ \\
\hline $\mathrm{E}$ & Iba qué? $\uparrow$ \\
\hline MA & De la centura e papá iba guindando ((RISAS)) \\
\hline $\mathrm{E}$ & Agarrada pues \\
\hline MA & $\begin{array}{l}\text { Agarrada que s'íba } \rightarrow \text { que s'íba }(x x x) \rightarrow \text { y’éso oímos que traquiaba la } \\
\text { casa } \rightarrow \text { vin unpalo grandísimo y le voltió la casa y siapió todo } \rightarrow \text { mm no } \\
\text { mire } / \rightarrow \text { habían mamá tenía una criae gallinas de cien gallinas } \rightarrow \text { ella le le } \\
\text { le gustaa tener gallinas pa'tar comiendo toos los días ejem } \downarrow((\text { RISAS }))\end{array}$ \\
\hline$E$ & \\
\hline MA & $\begin{array}{l}\text { Sí y ya: cuando ya taamos nootros entre la finca } \rightarrow \text { entro }((\text { ADENTRO)) } \\
\text { llamando pidiendo auxilio } \rightarrow \text { naie nos oyó ni naie nos vio ni naie naa/ las } \\
\text { casas taan separaas como di'aquí a quella ((SEÑALA UNA CASA EN } \\
\text { FRENTE COMO A CIEN METROS)) y otras como por ahí así/ } \downarrow \text { Ahí } \\
\text { estamos toos cuando ya un señor } \rightarrow \text { quien es gritó di una istancia como } \\
\text { di'aquí }((\text { SEÑALA CON SU DEDO COMO A CINCUENTA } \\
\text { METROS)) / } \downarrow Y \text { le dijo papá } \rightarrow \text { soy yo Agustín Cortez } \rightarrow \text { que ta siendo } \\
\rightarrow \text { dijo } \rightarrow \text { que nos trajo l'aguastaquí y nos dejó sin casa } \rightarrow \text { ya voy } \rightarrow \text { ya } \\
\text { voy no se muevan di'ay y yo'stab’agarrao di'un palo/ } \downarrow Y \text { yo aquí estoy } \\
\text { baj'un palu'eguaba/ } \downarrow y \text { ya al ratico llegó. }\end{array}$ \\
\hline
\end{tabular}

$51 \mathrm{M}$

Edad: 75 años

Nacionalidad: Costa Rica

Sexo: Masculino

\begin{tabular}{|c|c|}
\hline Informante & Discurso \\
\hline $\mathrm{M}$ & $\begin{array}{l}\text { Yo pienso también decirle que uno desde que nace/ nace viejo } \downarrow / \text { porque yo } \\
\text { nací ayer/ al otro día tengo dos días de nacido/ al otro día tres } \downarrow / \text { Entonces } \\
\text { voy aumentando el tiempo } \downarrow /\end{array}$ \\
\hline $\mathrm{E}$ & Pero tienen setenta y cinco \\
\hline M & $\begin{array}{l}\text { ((RISA))/Yo'stoy padeciendo mucho/ pero los pies } \rightarrow \text { / Me sacaron un callo/ } \\
\text { y después d'eso tuve que andar una pierna enyesada/ per' un yeso } \\
\text { qu'especial al que nu'es duro/cad'ocho días/ sí } \downarrow /\end{array}$ \\
\hline $\mathrm{E}$ & Que aquí vive contento/ ¿cuánto tiempo hace? \\
\hline
\end{tabular}




\begin{tabular}{|c|c|}
\hline $\mathrm{M}$ & $\begin{array}{l}\text { Sí/ cinco años } \downarrow / \text { En la cuestión de nosotros para: estos hogares/ ya esto: } \\
\rightarrow \text { gracias a personas por ejemplo que han si han acordao de los ancianos/ } \\
\downarrow \text { el que haga uno viene aquí y'a veces hay música/ paseos y ... si tuviera que } \\
\text { volver al tiempo de joven: porque se liolvida a veces qu'está viejo/ qu'está } \\
\text { enfermo o que tiene digamos conversaciones con los compañeros } \rightarrow \text { / se ven } \\
\text { como familiar:: y me parece a mí que qu'es la mejor medicina } \downarrow / \text { ¿qué dice } \\
\text { usted? / }\end{array}$ \\
\hline $\mathrm{E}$ & $\begin{array}{l}\text { Claro/ hay países en los cuales se acuerdan de los viejos/ por ejemplo Costa } \\
\text { Rica/ en Europa/ Mi país no/ / Yo soy colombiano/ }\end{array}$ \\
\hline M & Colombiano/Colombia/ \\
\hline $\mathrm{E}$ & Allá los viejos: poco/ poco cuidan d'ellos/ \\
\hline M & Si'olvidan $\downarrow /$ \\
\hline $\mathrm{E}$ & Síl \\
\hline M & $\begin{array}{l}\text { Bueno/ y'esque:: a veces: la plata:/ la plata::/ la plata dicen que es mala/ } \\
\rightarrow \text { porque hay personas muy adineradas } \downarrow /\end{array}$ \\
\hline $\mathrm{E}$ & $\begin{array}{l}\text { Vaya par'arriba y verá/ yendo para el Monte de la Cruz / sí/ la cantidad de } \\
\text { fincas lindas qu'ihay/ }\end{array}$ \\
\hline M & $\begin{array}{l}\mathrm{Si} \text { / a veces uno dice ¡qué vaina } \rightarrow \text { / yo desiaría ira Estados Unidos } / \rightarrow \text { desiaría } \\
\text { conocer países y no conoce ni el mismo país dondi'uno nació } \downarrow /\end{array}$ \\
\hline $\mathrm{E}$ & Síl \\
\hline M & ¿Ah? \\
\hline $\mathrm{E}$ & Síl \\
\hline M & $\begin{array}{l}\text { Nosotros nos sentimos orgullosos de ver eh y el pedacito de tierra qu'hemos } \\
\text { nacido/ qu'es nuestra república } \rightarrow / \text { porque/ diamos uno nu'e/ hemos vivido } \\
\text { siempre muy en paz y tod'estas cosas/ } \rightarrow \text { pero ahorita: / lástima/ porque el } \\
\text { país si ha corrompido/ y'han venido muchos extranjeros:/ tal vez a comprar } \\
\text { fincas: } \rightarrow \text { / y talvez llaman personas buenas } \rightarrow / \text { peru'hay otros que vienen } \\
\text { huyendo/ tal vez de un de de su país por algo qu'ihan hecho:: } \rightarrow \text { vienen } \\
\text { narcotraficantes/ vienen completamente:/ a ponernos en mal a nosotros/ } \\
\rightarrow \text { y'ahora/ se dice } \rightarrow / \text { ah/ se ven } \rightarrow / \text { y todo es:tá como muy rebel/ muy } \\
\text { revuelto todo } \rightarrow / \mathrm{sh} / \text { tierras y todo eso } \rightarrow / \text { Yo no sé/ yo leo poco } \downarrow / \text { La hija } \\
\text { mía si le gusta leer: } \rightarrow \text { ice que/ yo no sé/ si eso estará en La Biblia } \rightarrow / \text { qu'el } \\
\text { mundo comenzó con guerra y terminará con guerra } \downarrow / \text { El terminar del mundo } \\
\text { es una cosa que// cuando cumplimos dos mil años } \rightarrow / \text { usté/ e: tal vez oyó } \\
\text { qu'ecía que terminaba el mundo/ qu'estuiba ser/ estuiba ser lo otro } \rightarrow \text { no:::/ } \\
\text { ya vamos con el otro año/ ¿verdad? } \rightarrow \text { / Y entonces yo pienso que tal vez el } \\
\text { mundo no se termina sino que lo que se termina es la: la: por ejemplo/ la }\end{array}$ \\
\hline
\end{tabular}




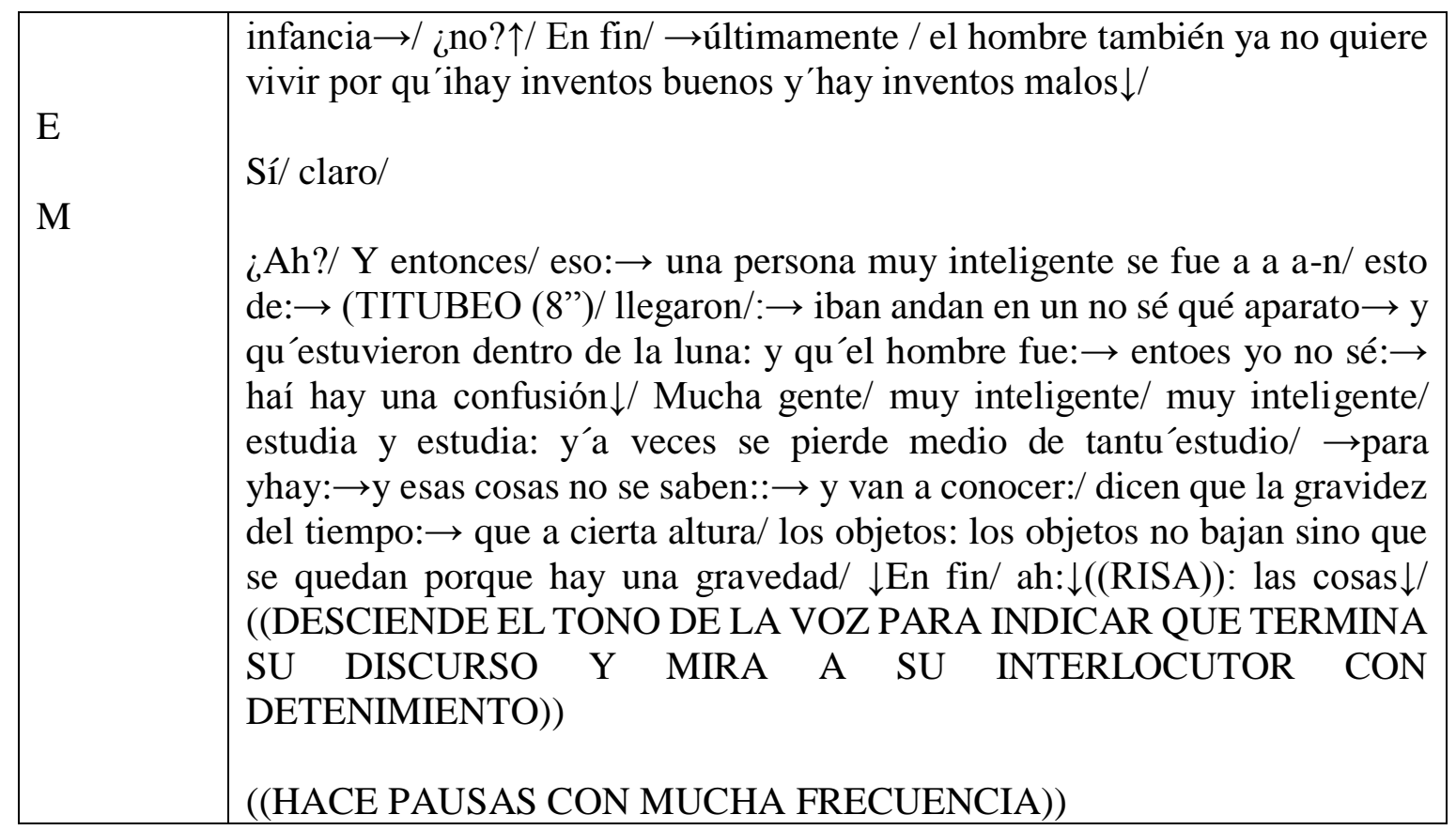

$52 \mathrm{TJ}$

Edad: 76 años

Nacionalidad: Costa Rica

Sexo: Masculino

\begin{tabular}{|c|c|}
\hline Informante & Discurso \\
\hline TJ & $\begin{array}{l}\text { y’así la gente era vana } \rightarrow \text { no tenía no }(\ldots) \rightarrow \text { ah/ y otra cosa que mire } \\
\text { antes cuando yo meecriao: } \rightarrow \text { bueno era quiabía/ era qui había mucha } \\
\text { pobreza muchacha/ } \rightarrow \text { Yo tuve una novia bizca/ }\end{array}$ \\
\hline $\mathrm{E}$ & ¡Ay/ Virgen Santísima! \\
\hline $\mathrm{TJ}$ & Eh/ llama Lala/ no se me olvida \\
\hline $\mathrm{E}$ & $\begin{array}{l}\text { ¿Sí?/ y usted sí le daba un beso a la novia bizca?/ ¿Ust’éra capaz de } \\
\text { darle un beso a la novia bizca? }\end{array}$ \\
\hline $\mathrm{TJ}$ & ¿Un beso?^ \\
\hline $\mathrm{E}$ & Ajá \\
\hline $\mathrm{TJ}$ & $\mathrm{No} / \mathrm{no} /$ nunca/ nunca $\downarrow$ \\
\hline $\mathrm{E}$ & ¿Por qué? \\
\hline $\mathrm{TJ}$ & $\begin{array}{l}\text { Porque nu'éramos novios/ así no más } \downarrow \text { Ella quería que yo míciera novio } \\
d^{\prime} \text { ella/ } \rightarrow \text { ¿Usted conoce Guapiles y Turres? } \rightarrow / \text { No conoce } \\
\text { casinada } \rightarrow((\text { DECEPCIONADO }) / ¿ \text { Turrialba? } \uparrow / \text { y el hermano se llamaba } \\
\ldots \rightarrow / \text { Y ella Lala } . . \downarrow \text { La misma hermana de Lala me dio/ } \rightarrow \text { "ve Tulio } \\
\text { acabala de educar/ } \downarrow \text { Cuando yo iba allá/ ella estaba con seis siete/ } \\
\text { ochuaños/ y yo como con DIECINUEVE y VEINTE/ } \downarrow \text { Ya yo me: entré a }\end{array}$ \\
\hline
\end{tabular}




\begin{tabular}{|c|c|}
\hline & $\begin{array}{l}\text { trabajar } \downarrow \text { Y al poco tiempo se vino ella con el hermano y con la que se }{ }^{\prime} \text { bía } \\
\text { juntao/ con el hermano d'ella (...) } \downarrow / \text { tenía un hermanito que se llamaba } \\
\text { Juan }\end{array}$ \\
\hline $\mathrm{E}$ & $\begin{array}{l}\text { Bueno/ ¿y cuál era la bizca entonces?/ Hasta ahora no me ha dicho cuál } \\
\text { era la bizca/ }\end{array}$ \\
\hline TJ & $\mathrm{LALA} \downarrow / \mathrm{LALA} \downarrow /$ \\
\hline $\mathrm{E}$ & Bueno/ ¿y entonces qué pasó con Lala? \\
\hline $\mathrm{TJ}$ & $\begin{array}{l}\text { Lala era de Germania y'ella la conocí de CATORCE años/ eh/ de } \\
\text { SIETE años } \downarrow /\end{array}$ \\
\hline $\mathrm{E}$ & ¿A usté? \\
\hline $\mathrm{TJ}$ & $\begin{array}{l}\text { Ella era tan tan tan valienta que que la otra hermana se bía casao y sólo } \\
\text { quedaba d'hermana menor } \rightarrow \text { / y entoes tenía qu'iatender a Hernán/ } \ldots \rightarrow \\
\text { a Carlo Matamoros/ Pedro Matamoros el papá/ Alfonso Matamoros/ } \\
\downarrow \text { Eran él nueve Matamoros } \rightarrow y^{\prime} \text { a la hermana y la otra hermana se'vía } \\
\text { casao qu'era mayor } \downarrow /\end{array}$ \\
\hline $\mathrm{E}$ & $\begin{array}{l}\text { ¿Y por qué tenía qu'iatender a tanta gente/ a qué se deb’esa cosa tan } \\
\text { rara? }\end{array}$ \\
\hline OTRO & ¿Todos los hermanos y’el papá? \\
\hline $\mathrm{E}$ & No/ qu'es eso/ porqué tenía qu'iatender a tanta gente? \\
\hline $\mathrm{TJ}$ & $\begin{array}{l}\text { Porque era un retiro: } \rightarrow \text { Era un retiro de la casa y p'onde s'ibair ella ? } \\
\uparrow(\ldots) / \text { ¡No/ porque ella era menor d'edad Don Víctor Hugo! } \rightarrow / \text { Nu'era/ } \\
\text { tenía apenas ¿cuántos años/ siete?/ siete años tenía } \downarrow /\end{array}$ \\
\hline OTRO & $\begin{array}{l}\text { Pero aquí en Costa Rica cuand’usté se casa/ ya si hace mayor dedá/ sí: le } \\
\text { dan hasta cédula/ }\end{array}$ \\
\hline $\mathrm{TJ}$ & Tenía un hermanito que se llamaba Juan $\downarrow /$ \\
\hline OTRO & ¿Esto en busca de un amor perdido? \\
\hline $\mathrm{TJ}$ & 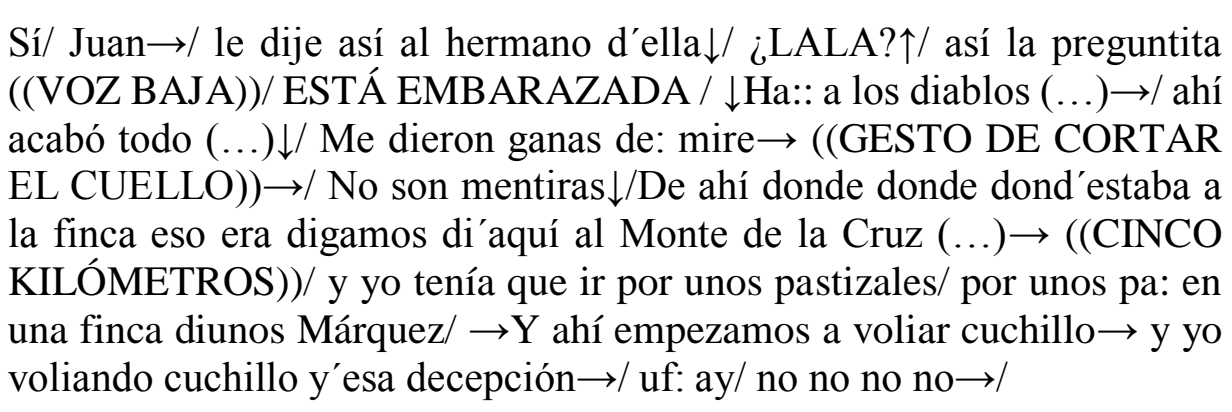 \\
\hline $\mathrm{E}$ & Voliando cuchillo y pensando en Lala/ \\
\hline
\end{tabular}




\begin{tabular}{|c|c|}
\hline $\mathrm{J}$ & No son mentiras $(\ldots) \downarrow /$ Abobao $\rightarrow$ y ya me fue pasando la la la la: \\
\hline $\mathrm{E}$ & La tusa/ \\
\hline TJ & La carajaíta/ la carajaìta $\downarrow /$ \\
\hline $\mathrm{E}$ & $\begin{array}{l}\text { ¿Cómo le dicen aquí a la tu/ a nosotros le decimos la tusa: la traga:/ la } \\
\text { la// }\end{array}$ \\
\hline TJ & Aquí se dice cavanga $\downarrow /$ \\
\hline $\mathrm{E}$ & ¿La tristeza pues por el amor? \\
\hline $\mathrm{TJ}$ & $\begin{array}{l}\text { Y ya me fue pasando/ pasando/ pasando } \downarrow / \text { Otro cimbronazo } \rightarrow \text { a los: a los } \\
\text { VEINTIÚN días/ otro cimbronazo } \rightarrow / \text { "Lo que no conviene no } \\
\text { conviene" } \downarrow /(\mathrm{xxx}) / \text { A los a los QUINCE días vamos pa'onde tenían la casa } \\
\text { propia y me dice/ } \rightarrow \text { me dice Juan/ no pensés más en LALA } \downarrow \text { ¿por qué } \\
\text { me preguntás por Lala/ es qu'ia a mí me gusta } \downarrow / \text { "No pensés más con } \\
\text { Lala } \rightarrow / \text { con Lala } \rightarrow / \text { LALA está juntá con un negro" } \downarrow / \text { BASTA YA } \\
\downarrow \text { Acabé }(\ldots) \downarrow / \text { A los QUINCE días fuimos a donde tenían a casa propia } \rightarrow \text { / } \\
\text { y voy llegando: voy viendo a Lala onde la hermana } \downarrow / \text { La vi tan rara/ tan } \\
\text { rara tan rara y pum/ } \rightarrow \text { mucha descuajada } \downarrow / \text { Se perdió todo/ y yo quedé } \\
\text { solterón } \downarrow /\end{array}$ \\
\hline $\mathrm{E}$ & ¿Y seguía bizco/ bizca? \\
\hline $\mathrm{J}$ & $\mathrm{Mjm} /$ era bizca $\downarrow /$ \\
\hline
\end{tabular}

$53 \mathrm{GH}$

Edad: 80 años

Nacionalidad: Costa Rica

Sexo: Masculino

\begin{tabular}{|c|c|}
\hline Informante & Discurso \\
\hline $\mathrm{E}$ & ¿Le tocó la guerra o no? \\
\hline $\mathrm{GH}$ & $\mathrm{Ah} / \mathrm{sí} \downarrow /$ \\
\hline $\mathrm{E}$ & ¿Cuántos años tenía cuando fue/ estaba en la guerra? \\
\hline $\mathrm{GH}$ & $\begin{array}{l}\mathrm{Ah} / \mathrm{no} / \text { ¿pa la guerra? } \rightarrow / \text { Aquí en Costa Rica/ nunca habido guerra ah } \rightarrow \text { / } \\
\text { y a ayer andiuvo u terremoto } \rightarrow / \text { fue en Salvador } \rightarrow / \text { dicen que prensó un } \\
\text { bus } /(\ldots) \rightarrow \text { iba llenitico }(\ldots) \rightarrow \text { y toos } / \text { toos se murieron } \rightarrow / \text { peru aquí } \\
\text { medio se sintió un medio remezón y deje y verá muertos por toa parte } \downarrow /\end{array}$ \\
\hline $\mathrm{E}$ & ¿Cuántos muertos? \\
\hline GH & Ah/ muchísimos/ y'estan comenzandua sacar/ $\rightarrow$ terrible en el Salvador $\downarrow /$ \\
\hline
\end{tabular}




\begin{tabular}{|c|c|}
\hline $\mathrm{E}$ & ¡Qué pesar!/ ¿no?/ ¡Qué pesar!/ usté le da miedo los terremotos/ ¿no? \\
\hline $\mathrm{GH}$ & Cuando cayó ceniza/ ¿usté si’acuerda?^ \\
\hline $\mathrm{E}$ & Claro/ sí/ $\rightarrow$ \\
\hline $\mathrm{GH}$ & $\begin{array}{l}\text { Ah/ sí/ eh// } \rightarrow \text { es que yo le comenté que pa eso fue la poda? } \rightarrow \text { / puaquí/ } \\
\text { eh: llá/ } \rightarrow \text { en aquel en: en cerro carro que se ven allá } \rightarrow((\text { MUESTRA CON } \\
\text { LA MANO))/Ahí estáamos trabajando ahí } \rightarrow \text { cuando yo ivisé las matas } \\
\text { llenas de ceniza/ } \downarrow \text { Salí/ salía uno encenizao/ vea/ qué barbaridad } \rightarrow \text { y y } \\
\text { mucha gente de Cartago también:: agarró para acá/ por ahí } \rightarrow / \text { por ahí } \\
((\text { MUESTRA LOS ALREDEDORES))/ viven otros si han muerto ya } \downarrow /\end{array}$ \\
\hline $\mathrm{E}$ & ¿Cuántos años? \\
\hline $\mathrm{GH}$ & A hace más de ¿diecisiete?/eh: $\rightarrow$ hace más de cuarentaños $\downarrow /$ \\
\hline $\mathrm{E}$ & ¡Uy! \\
\hline GH & Sí $\downarrow /$ \\
\hline $\mathrm{E}$ & ¿Y aquí cuánto tiempo tiene? \\
\hline $\mathrm{GH}$ & $\begin{array}{l}\text { De derecho ya } \rightarrow \text { / aquí estaba yo est'uera de la directora de la escuela/ } \\
\text { eh } \rightarrow / / \text { como yo no tuve ni papá/ ni mamá } \rightarrow / \text { a mí me: a mí me/ me:: me } \\
\text { pasé de primero a quinto } \rightarrow / \text { y me dijo la la directora qu'haystá } \\
\text { fotografiada qu'ella e la dueña de la/ del terreno } \rightarrow \text { me ijo/ ígale a su tía } \\
\text { que venga } \rightarrow / \text { que yo quiero conversar con ella: } \downarrow \text { Los viernes hacían } \\
\text { asamblea y ya le ie ((DIJE)) y fuimos y le io }((D I J O)) \rightarrow / \text { es que yo quiero } \\
\text { porque y'uestaba chiquillo ei saqu'el diploma en Heredia } \rightarrow \text { pa que siga } \\
\text { estudiando po qu'es muy inteligente/ } \rightarrow \text { yo yo les ayudo con la mita de too } \\
\text { el studio/ y yay... ijo ((DIJO)) la tía } \rightarrow / / \text { yay sería muy bueno porqueesque } \\
\text { nosotros no poemos } \rightarrow \text { pues entonces yo me criey me pusia traajar y y no } \\
\text { me faltó el traajo } \rightarrow / \text { sabe a cuántas prestaciones llegaré/ chres } \\
((T R E S)): \rightarrow \text { y ya'hora estoy pensionao } \downarrow /\end{array}$ \\
\hline
\end{tabular}

54DM

Edad: 80 años

Nacionalidad: Costa Rica

Sexo: Masculino

\begin{tabular}{|l|l|}
\hline Informante & \multicolumn{1}{|c|}{ Discurso } \\
\hline OTRO & Ya ve/ y le duró más que si hubiera sido casada/ \\
DM & Sí/ sí/ tuve mis cinco hijos $\downarrow$ y// $\rightarrow \mathrm{y} /$ \\
E & ¿Ah/ pero tuvo un compañero? \\
DM & \\
\hline
\end{tabular}




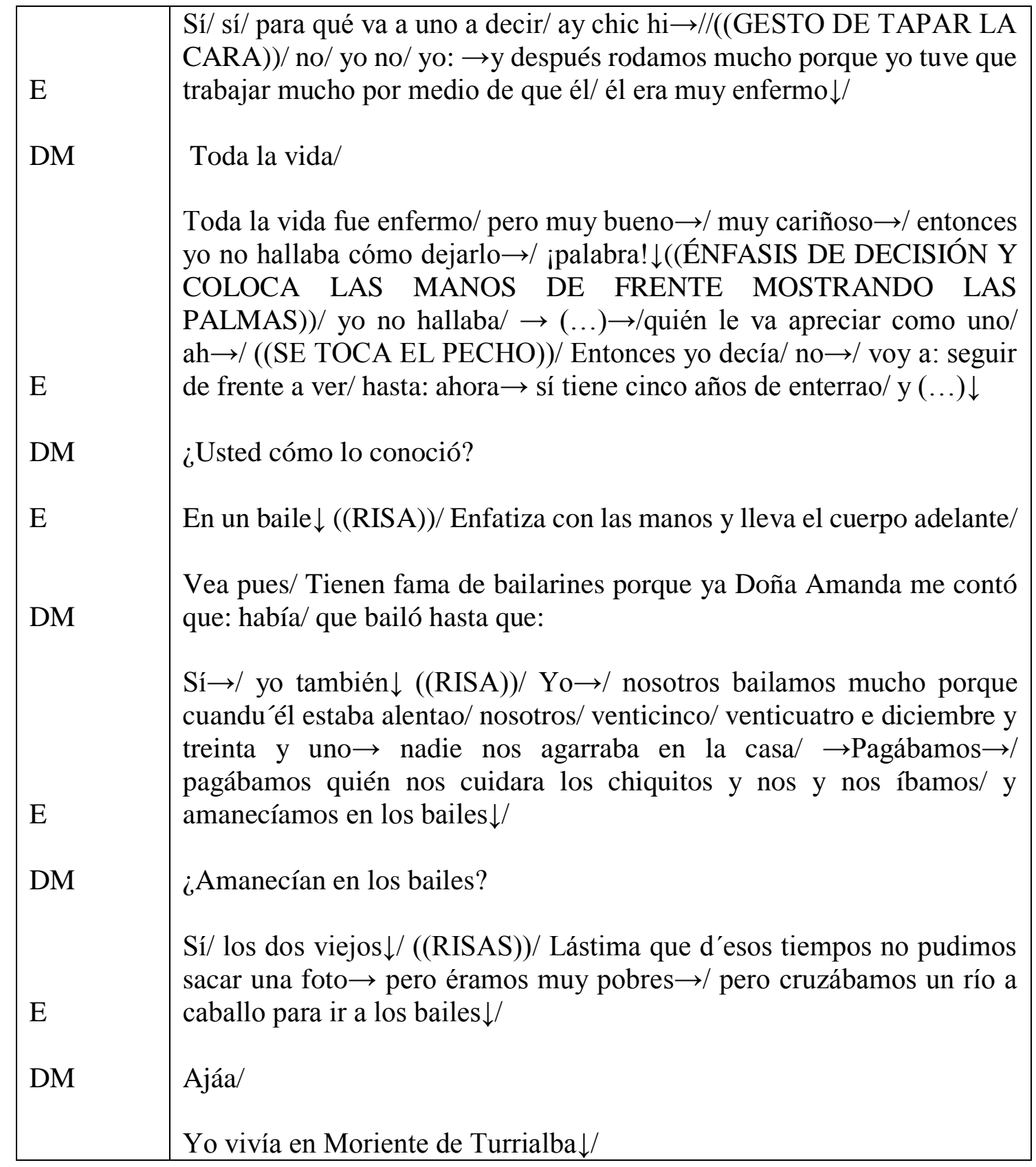

$55 \mathrm{C}$

Edad: 75 años

Nacionalidad: Costa Rica

Sexo: Femenino

\begin{tabular}{|l|l|}
\hline Informante & Discurso \\
\hline $\mathrm{C}$ & $\begin{array}{l}\text { Cuand'uno estaba pequeñillo lo quíhacía/ a uno } \rightarrow \text { lo mandaban a } \\
\text { trabajar/ a coger café } \rightarrow \text { / usté sabe lo que es coger café/ } \rightarrow \text { entonces ya uno } \\
\text { jovencillo se iba } \rightarrow \text { y ya salíamos } \rightarrow / \text { papá nos levanta a las cuatro e la } \\
\text { mañana y nos llevaba a pie } \rightarrow \text { y ya llegábamos a las: temprano al cafetal } \rightarrow \\
\\
\text { y nos volvíamos a venir a las seis de la tarde/ } \downarrow \text { Ya ya entonces } \rightarrow \text { ya casi } \\
\text { ni comía uno } \rightarrow \text { sino comía y se bañaba/ } \rightarrow \text { pues uno chiquito se } \\
\text { volvía'costar/ } \downarrow \text { Peru'era una vida muy sana muy sana } \rightarrow / \text { porque ahora } \\
\text { está esto/ ay no } \downarrow / \text { Ahora chiquito } \rightarrow / \text { acaban de matar un chiquito en }\end{array}$ \\
\hline
\end{tabular}




\begin{tabular}{|l|l|}
\hline E & $\begin{array}{l}(\ldots) \rightarrow \text { lo mataron lo por lo que se ve } \rightarrow \text { se lo llevó la una vecina al parque } \\
\text { y ice que se desapareció el chiquito } \rightarrow \text { y lu'encontraron un cafetal violao/ } \\
\text { quema'orcao } \downarrow / \text { En/ pero sí/ y'en cambio antes era todo muy sano } \rightarrow \\
\text { porque yo mi'acuerdo que mi papá nos mandaba } \rightarrow / \text { yu'era muy// } \rightarrow \text { eran } \\
\text { muchas }(\ldots) \text { que llaman } \rightarrow / \text { no al fin y al cabo nu'ay casas ni nada/ } \\
\rightarrow \text { como trillos } \downarrow /\end{array}$ \\
$\mathrm{C}$ & $\begin{array}{l}\text { ¿Cómo qué? } \\
\text { Como trillos } \rightarrow / \text { como llamaban que trillos eran cafetal a un lao cafetal al } \\
\text { otro y nada }(\mathrm{xxx}) \text { maleante } \rightarrow / \text { andaba uno con mucho/ } \rightarrow \text { muy tranquilo/ } \\
\rightarrow \text { Y ahora no/ } \rightarrow \text { ahora no puede uno salir } \downarrow /\end{array}$ \\
\hline
\end{tabular}

$56 \mathrm{R}$

Edad: 75 años

Nacionalidad: Costa Rica

Sexo: Femenino

\begin{tabular}{|c|c|}
\hline Informante & Discurso \\
\hline $\mathrm{R}$ & $\begin{array}{l}\text { Usté cone usté conoce }(\mathrm{xxx}) \text { o La Linda o Limón Chiquiri pácá donde } \\
\text { llaman el cuo }((\mathrm{CUBO})) \text { del Diablo y toueso y Pascua } \rightarrow \text { comues } \\
\text { Pascua } \rightarrow / \text { San Antonio de Pascua } \rightarrow \text { ah La florida/ } \rightarrow \text { para llegar a } \\
\text { Chiquiri } \downarrow\end{array}$ \\
\hline $\mathrm{E}$ & Peru'hace mucho tiempo qué \\
\hline $\mathrm{R}$ & $\begin{array}{l}\text { En el } 48 \text { y'estuve trabajando en La Florida desde cuarenta y seis treinta y } \\
\text { seis } \rightarrow \text { me fui de aquí para: } \downarrow\end{array}$ \\
\hline $\mathrm{E}$ & Entoes ¿usté cuántos años tiene? \\
\hline $\mathrm{R}$ & Ochenta y siete $\downarrow$ \\
\hline $\mathrm{E}$ & Eh::: pensé qui usté tenía puay sesenta y cinco años \\
\hline $\mathrm{R}$ & Quién yo ya hora en mayo cumplo ochenta y siete $\downarrow$ \\
\hline E & Y cómo vivía la gente/ como vivía la gente era más pacífica porquiahora \\
\hline $\mathrm{R}$ & $\begin{array}{l}\text { Usté ve la gente lo violenta Ahora lo matan a uno } \rightarrow \text { porque ahora } l^{\prime} \text { echan } \\
\text { el carro encima } \rightarrow \text { van en carrera pa'1lí que parecen }(\mathrm{xxx}) \rightarrow \text { con calma } \\
\text { con calma lo pasaba uno más mejor se pasa mejor ahora qui'antes } \rightarrow \mathrm{si} \rightarrow \text { / } \\
\text { porqui'antes no había mucho progreso y toos andaamos descalzos/ } \downarrow \text { Aquí } \\
\text { y'en muchas partes } \rightarrow \text { / yuestuve en La Florida } \rightarrow \text { en la finqu'e La Florida } \\
\text { qui'hace }(\mathrm{xxx}) \downarrow \text { Cuando la guerrilla } \rightarrow \text { jue cuando mataron a Nacho Cruz } \\
\text { jue }(\mathrm{xxx}) \rightarrow \text { y cuando reventaron en matina la bomba qu'el como e llama } \\
\rightarrow \text { el general el:: mestre } \rightarrow \text { e conozco toesa }((\mathrm{TODA} \text { ESA)) línea } \downarrow \text { ((SE } \\
\text { REFIERE A LA FRONTERA ENTRE COSTA RICA Y Y } \\
\text { NICARAGUA)) por allá para'llá y por acá por Guacas } \rightarrow \text { por lao e }\end{array}$ \\
\hline
\end{tabular}




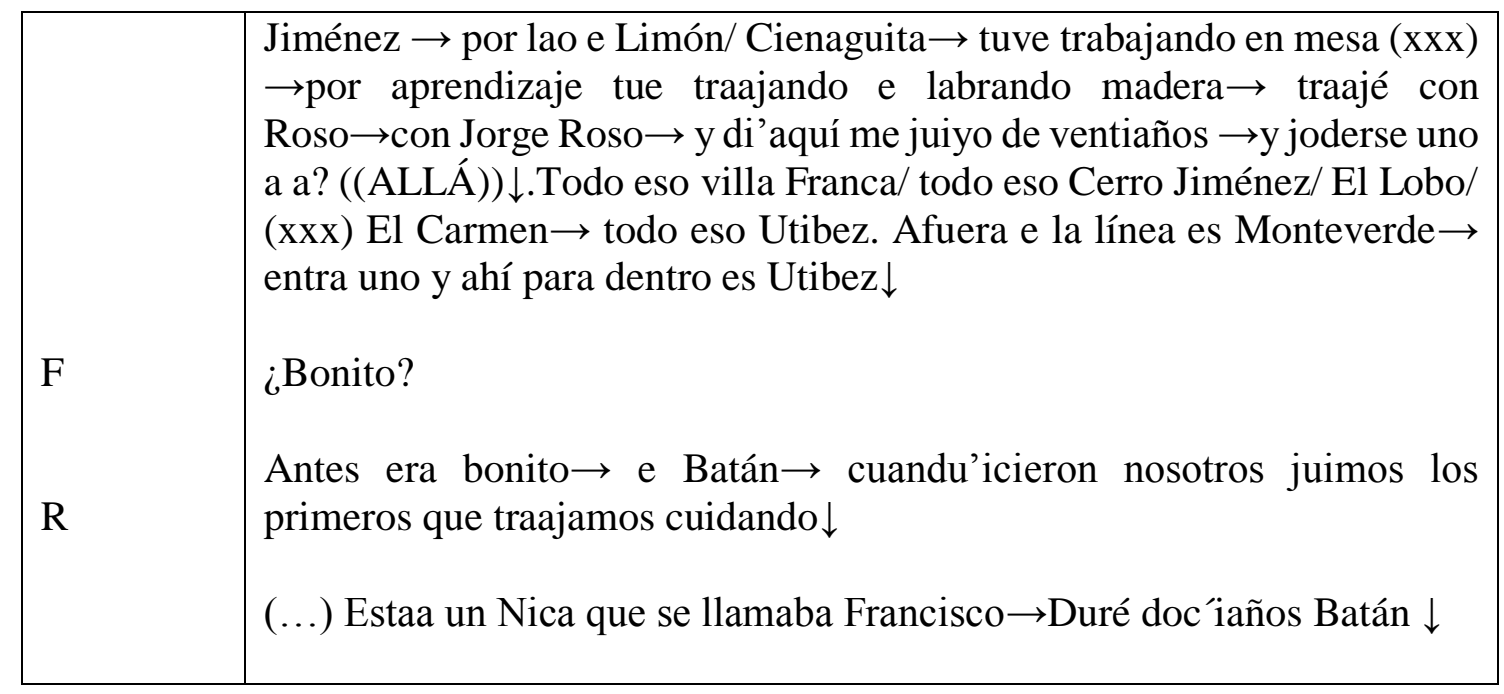

57A

Edad: 87 años

Nacionalidad: Costa Rica

Sexo: Masculino

\begin{tabular}{|c|c|}
\hline Informante & Discurso \\
\hline $\mathrm{A}$ & $\begin{array}{l}\text { Papá era un hombre acomodao }(\ldots) \rightarrow \text { un negocio como no había aquí } \\
\text { otro } \rightarrow / \text { Él tenía una finca }(\ldots) \rightarrow \text { / Fui muy derecha/ novios caso no porque } \\
\text { yo nunca fui enamorada } \rightarrow \text { porque yo me crié con hombres qu'eran mis } \\
\text { hermanos } \rightarrow \text { yo era la mayor } \rightarrow / \text { me mandaban a jugar para entretenerlos } \\
\text { ahí en la calle/ y jugaba igual como un hombre }(\ldots) / \rightarrow \text { media docena de } \\
\text { hombres } / \downarrow \text { Yo vía los hombres como }(\mathrm{xxx}) / \text { fui derecha } \downarrow /\end{array}$ \\
\hline $\mathrm{E}$ & Usté vía los hombres normalmente/ no los: \\
\hline A & $\mathrm{Ah} / \mathrm{sí} \downarrow /$ \\
\hline $\mathrm{E}$ & No los buscaba/ \\
\hline $\mathrm{A}$ & 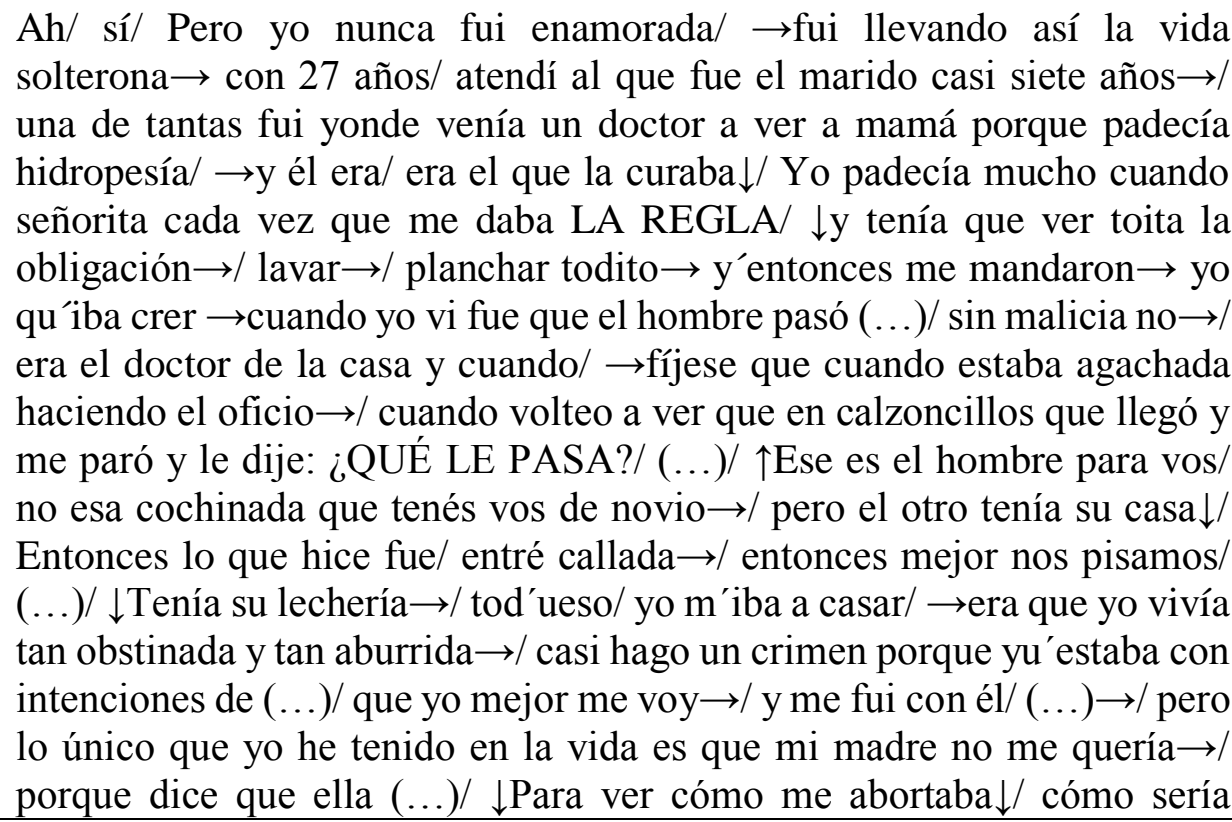 \\
\hline
\end{tabular}




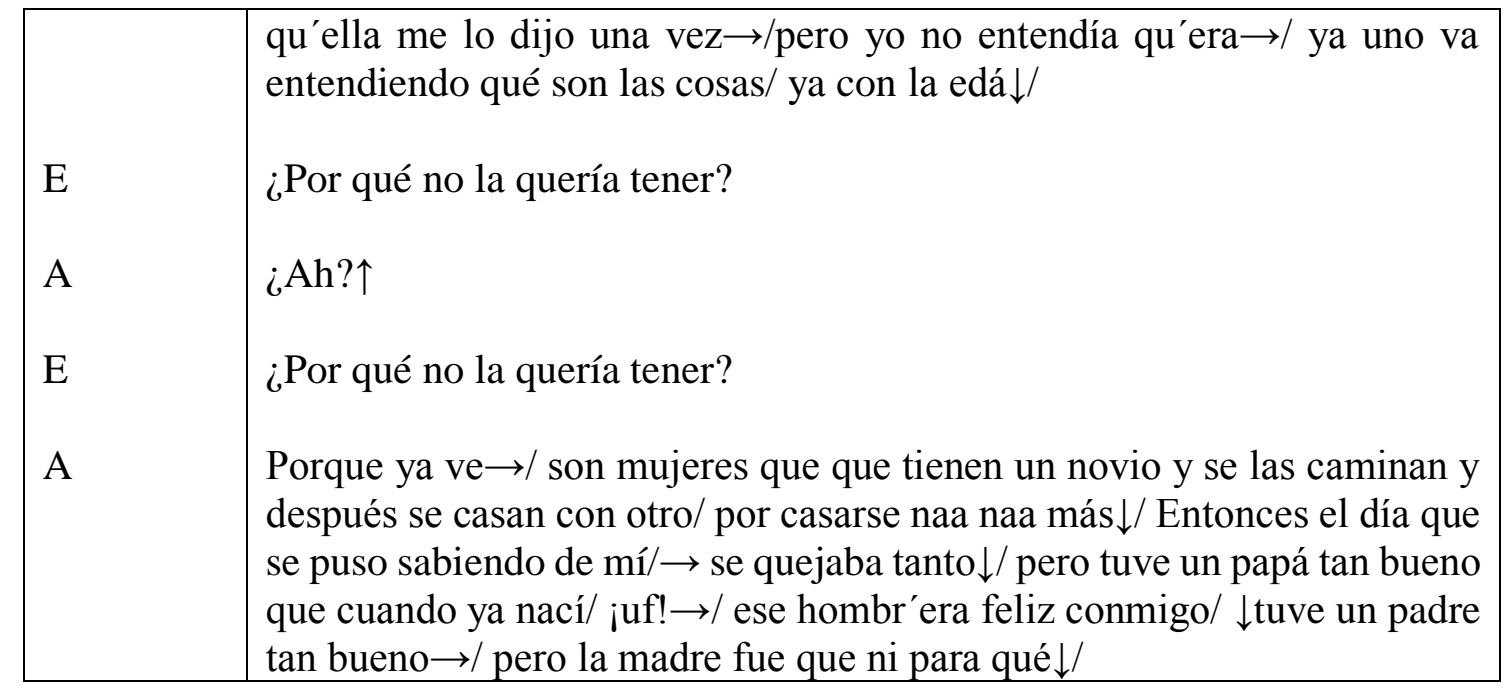

$58 \mathrm{E}$

Edad: 90 años

Nacionalidad: Costa Rica

Sexo: Masculino

\begin{tabular}{|c|c|}
\hline Informante & Discurso \\
\hline $\mathrm{E}$ & 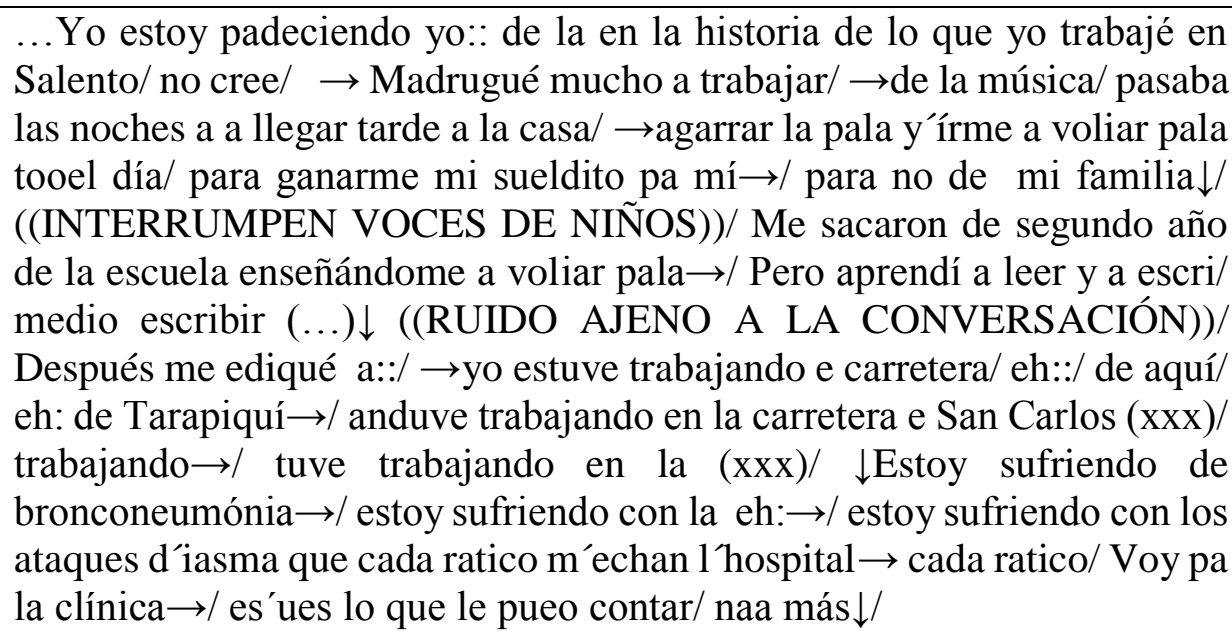 \\
\hline ENT & ¿Cuántos años tiene usté don Emilio? \\
\hline $\mathrm{E}$ & $\begin{array}{l}\text { Voy a cumplir yo d'edad/ } \rightarrow \text { yo la edad/ es que tengo noventa años y } \\
\text { medio } \downarrow /\end{array}$ \\
\hline ENT & ¡Ay/ bárbaro! \\
\hline $\mathrm{E}$ & Noventa años y medio $\downarrow$ \\
\hline ENT & ¿Tuvo hijos? \\
\hline $\mathrm{E}$ & $\begin{array}{l}\text { Hubieron trece hijos/todos críaos a base de trabajo } \rightarrow \text { / a base de jornal y } \\
\text { a la música/ que yo también me dediqué a la música } \rightarrow \text { / porque al fin de } \\
\text { cuentas/ yo/ yo/ eh/ yo toco la guitarra } \rightarrow \text { / fui un lempo de artista y trabajé } \\
\text { en muy buenas orquestas } \downarrow /\end{array}$ \\
\hline
\end{tabular}




\begin{tabular}{|c|c|}
\hline ENT & $\mathrm{Mmmj/}$ \\
\hline $\mathrm{E}$ & $\begin{array}{l}\text { (...) No conozco los vicios/ ningún vicio de nada/ no los conocí:: } \rightarrow \text { / He } \\
\text { sido muy delicado en mis cosas } \downarrow /\end{array}$ \\
\hline ENT & Muy bueno/ \\
\hline $\mathrm{E}$ & $\begin{array}{l}\text { Muy delicado }(\ldots) / \text { porque verdaderamente yo lo malo me cae mal/ } \rightarrow \text { los } \\
\text { vicios } \downarrow / \text { La juventú } \rightarrow \text { / hay juventú muy buena y hay juventú muy: muy } \\
\text { viciosa } \rightarrow \text { / Hay juventú muy buena y hay juventú muy viciosa/ } \downarrow \text { Nosotros/ } \\
\text { los viejos tenemos una historia muy grande } \rightarrow \text { / creo que podemos ser un } \\
\text { ejemplo pa la juventú } \downarrow /\end{array}$ \\
\hline ENT & ¿Usté estuvo alguna vez estuvo en peligro de muerte? \\
\hline $\mathrm{E}$ & ¿Ah?个 \\
\hline ENT & ¿Alguna vez estuvo usted en peligro de muerte? \\
\hline $\mathrm{E}$ & $\begin{array}{l}\text { SÍ/ yo agonicé } \rightarrow \text { / hace poquito agonicé con esta bronconeumonía que me } \\
\text { dio } \downarrow /\end{array}$ \\
\hline ENT & ¿Y lo revivieron/ lo reanimaron? \\
\hline $\mathrm{E}$ & ¿Ah? \\
\hline ENT & ¿Lo reanimaron/ volvió a //? \\
\hline $\mathrm{E}$ & $\begin{array}{l}\text { sí } \rightarrow / \text { yo estao en esta vida mucho tiempo malo/ pero gracias a Dios } \rightarrow \text { / } \\
\text { porquia la buena conducta }(\ldots) \rightarrow / \text { señorita paque le cuento a todo } \\
\text { gusto } \rightarrow / \text { y'hay mucha envidia en la vida } \rightarrow y^{\prime} \text { a mí m 'ian envidado mucho } \\
\text { porque sido un artista NATURALISTA } \downarrow / \text { Yo fui un guitarrista de mucha } \\
\text { fama por toa/ por toa parte } \downarrow /\end{array}$ \\
\hline
\end{tabular}

590

Edad: 77 años

Nacionalidad: Costa Rica

Sexo: Masculino

\begin{tabular}{|l|l|}
\hline Informante & Discurso \\
\hline $\mathrm{O}$ & $\begin{array}{c}\text { Yo le agarré cien hombres a José Figueres sin:: gastar un tiro } \rightarrow / \text { muy } \\
\text { fácil/ e } \rightarrow / \text { nosotros tomamos La Sierra el diez de marzo de mil } \\
\text { novecientos cuarenta y ocho a las: doce más o menos doce del día... } \rightarrow \text { y } \\
\text { al llegar: } \rightarrow \text { iba un compañero detrás de mí } \rightarrow / \text { dentramos a una casa/ } \\
\text { porque le pedimos permiso al Coronel para ispeccionar adelante } \rightarrow / \text { y nos } \\
\text { fuimos yendo y'entramos a una casa que por dentro se le había estado } \\
\text { voliando mucho plomo desde la mañana } \rightarrow \text { / pero los tiros de mortero se } \\
\text { caían a un lado y'a otro } \rightarrow \text { era muy larga la estancia y entonces no } \\
\text { llegaron } / \rightarrow \text { pero en cambio quién sabe qué tiro/ quién sabe cómo le llegó } \\
\text { el tiro de la metrallaora } / \rightarrow \text { de los revolucionarios/ los contrarios del }\end{array}$ \\
\hline
\end{tabular}




\begin{tabular}{|c|c|}
\hline$E$ & $\begin{array}{l}\text { gobierno/ tons que le había travesado la aquí } \rightarrow((\text { SEÑALA Y SE TOCA } \\
\text { LA PARTE INFERIOR POSTERIOR A LA RODILLA }) / \text { la pierna/ sí/ } \\
\rightarrow \text { entons yo llegué y le dije/ a no } \rightarrow / \text { eso no se le dé nada } \rightarrow / \text { llorando él } \\
\text { creyó que l'uíbamos a matar } \rightarrow \text { / entoes/ pero dije } \rightarrow / \text { no se le dé nada por } \\
\text { eso } \rightarrow \text { entoes ya yo había oído que: que la cosa nu'iba estar muy bien } \\
\text { porque los de Teodoro Picado lo estaba haciend'uera una traición } \rightarrow / \text { lo } \\
\text { que quería era robar y llegar a Nicaragua a decir que: que había visto: } \\
\text { obligado a salir para Nicaragua porque las fuerzas de Costa Rica no le } \\
\text { habían correspondido } \rightarrow \text { y y ¿cómo le iban a corresponder si él mismo las } \\
\text { estaba vendiendo en esa forma } \rightarrow / \text { avisándole al enemigo y dándole los } \\
\text { datos de todo? } \downarrow \text { Entoes ahí No le podían corresponder/ sí } \rightarrow / \text { más bien nos } \\
\text { fue muy bien que no nos mataron los }(\ldots) \downarrow \\
\text { Claro/ }\end{array}$ \\
\hline $\mathrm{O}$ & 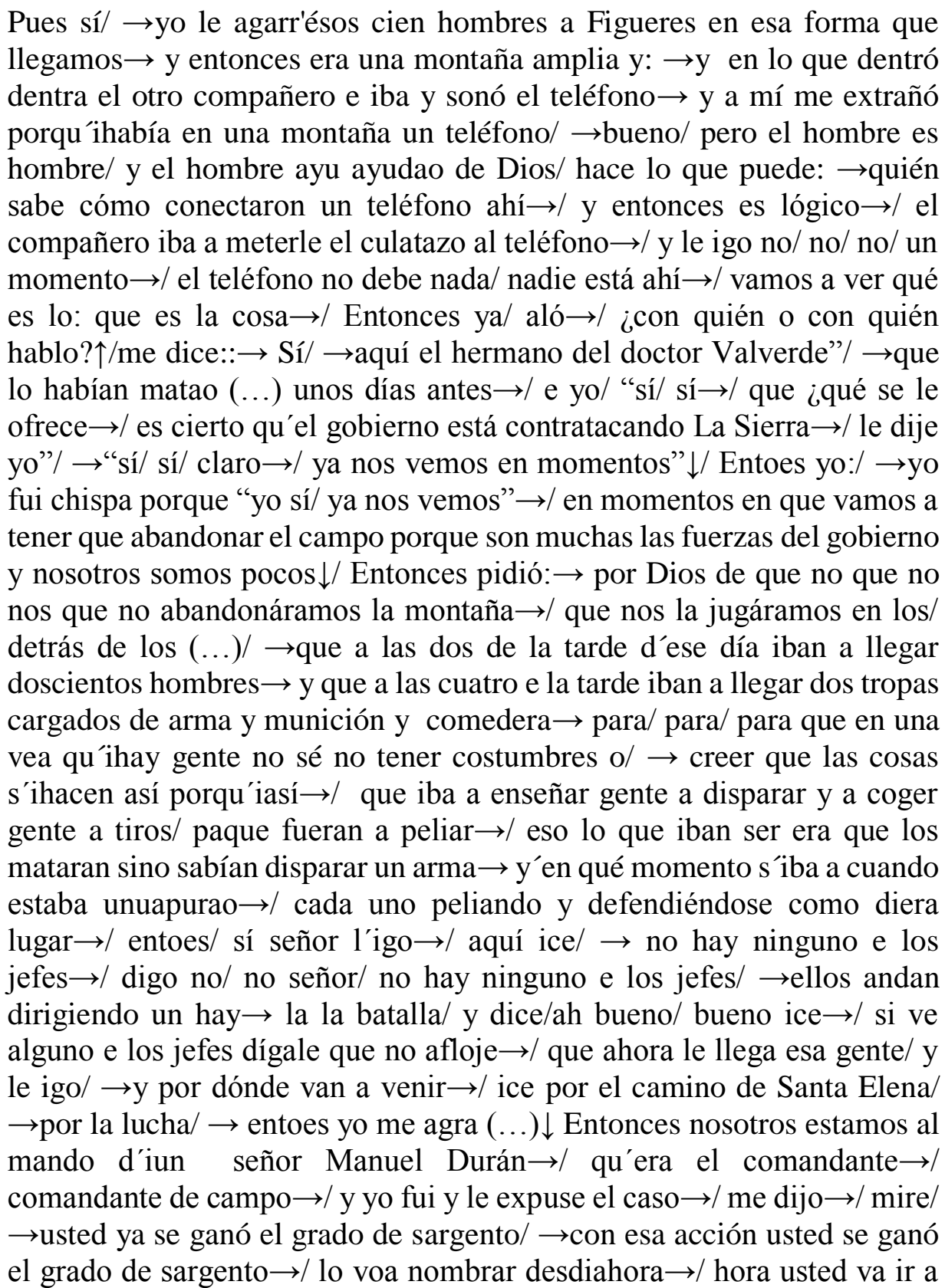 \\
\hline
\end{tabular}




\begin{tabular}{|c|c|}
\hline $\mathrm{O}$ & 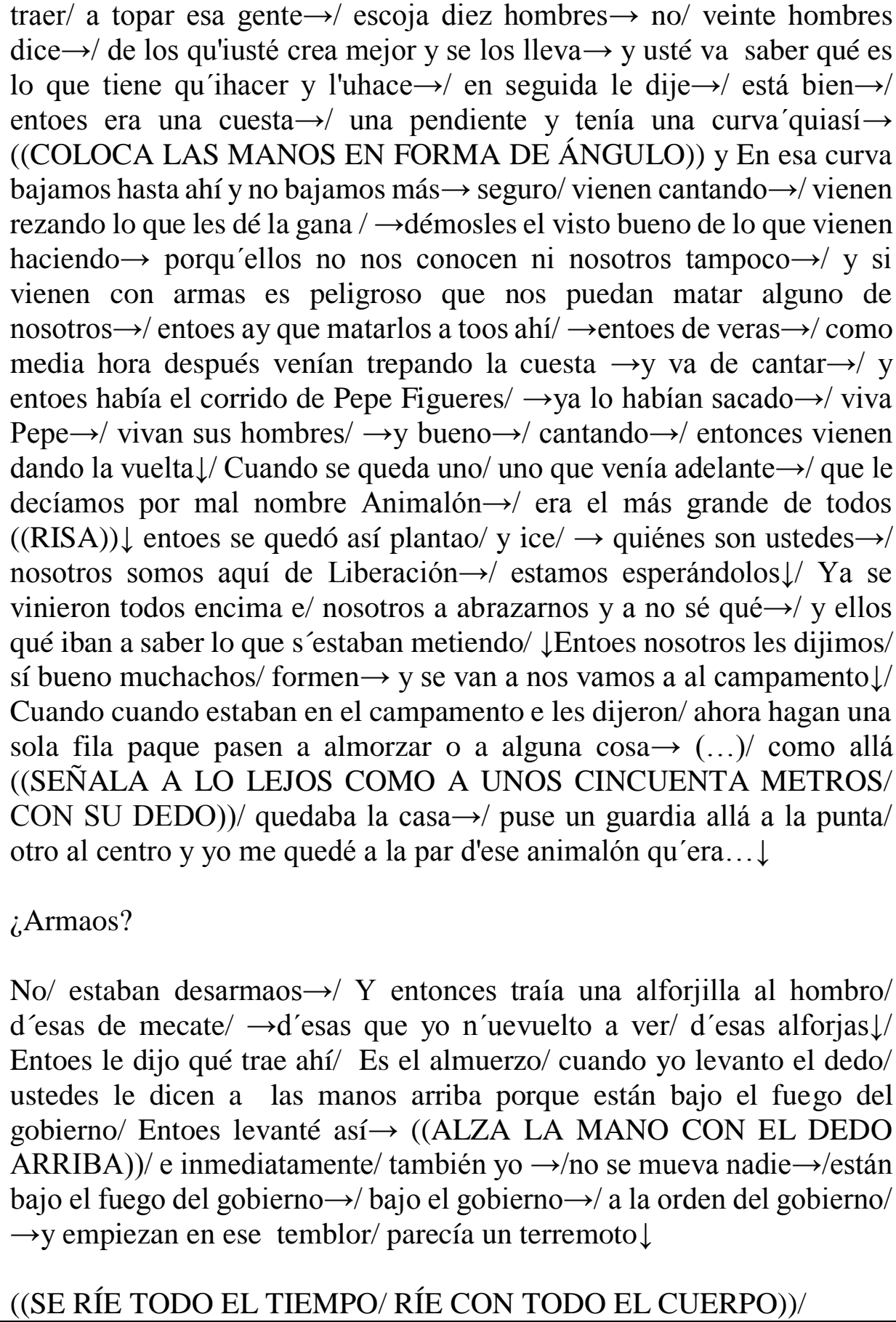 \\
\hline
\end{tabular}

60F

Edad: 86 años

Nacionalidad: España

Sexo: Femenino

\begin{tabular}{|l|l|}
\hline Informante & \multicolumn{1}{|c|}{ Discurso } \\
\hline $\mathrm{E}$ & $\begin{array}{l}\text { ¿Qué es lo que más recuerda usted con cariño de su infancia y de su } \\
\text { pueblo? }\end{array}$ \\
$\mathrm{F}$ & $\begin{array}{l}\text { Bueno/ pues mm a mm } \rightarrow /((\text { VACILACIÓN })) \text { mi casa/ } \rightarrow \text { pues bue/ me } \\
\text { tocó trabajar mucho porque pues/ esto/ como se suele decir }(\ldots) \rightarrow / \text { te }\end{array}$ \\
\hline
\end{tabular}




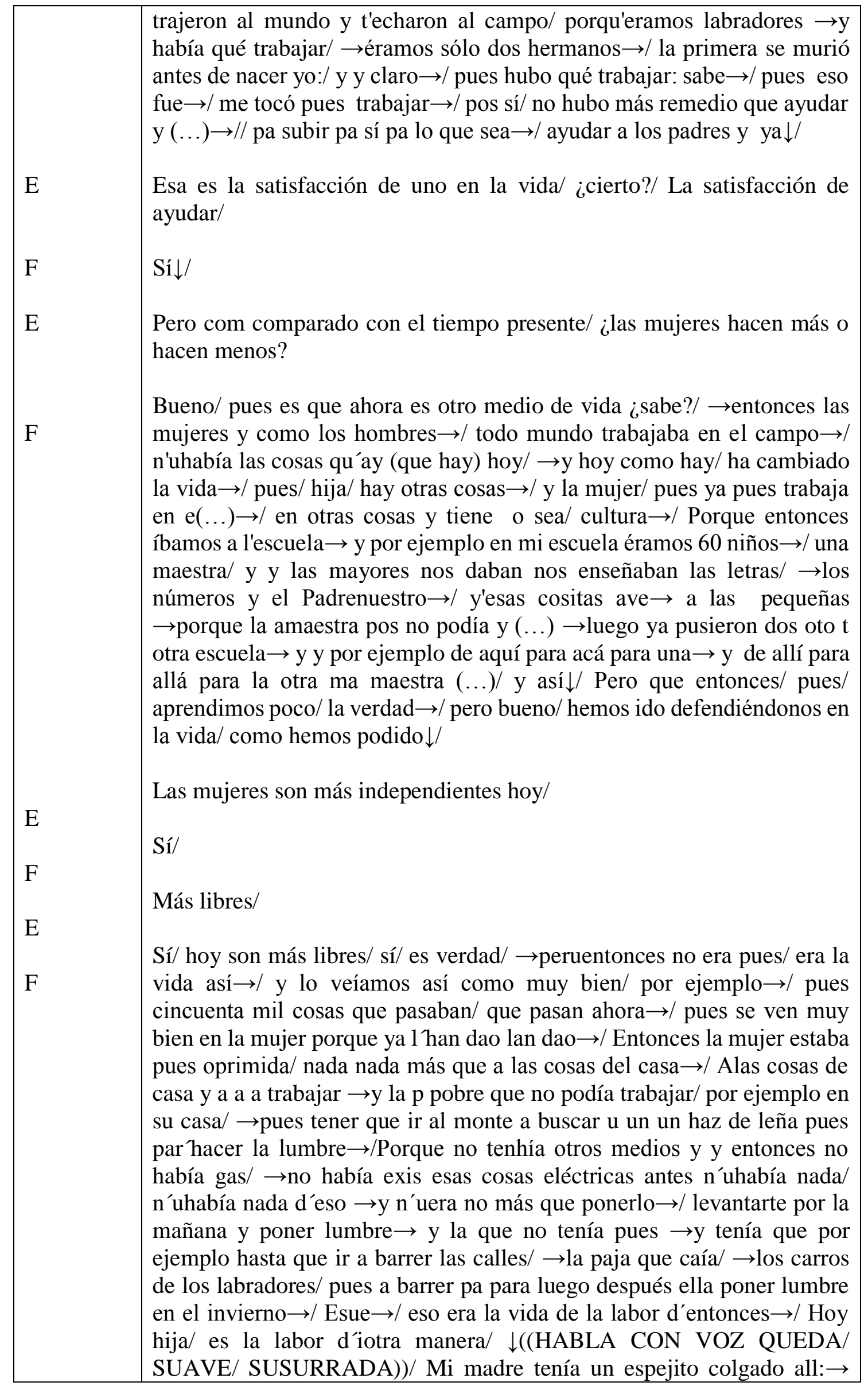




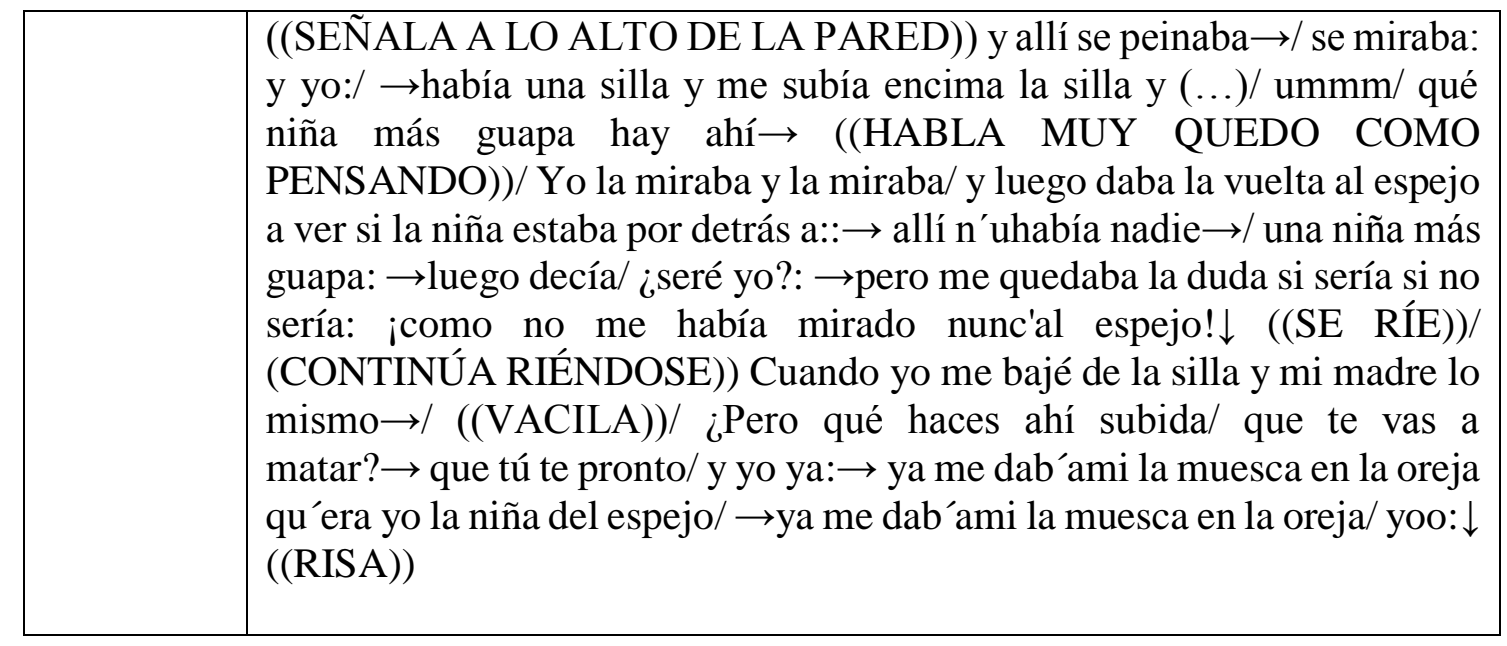

61MJ

Edad: 72 años

Nacionalidad: España

Sexo: Femenino

\begin{tabular}{|c|c|}
\hline Informante & Discurso \\
\hline MJ & $\begin{array}{l}\text { En el en el plazo de setenta y cinco años que tengo ya }(\ldots) / \rightarrow \text { pues me } \\
\text { han pasado muchas cosas/ buenas y malas } \rightarrow / \text { así que yo tuve una infancia/ } \\
\text { pues }(\ldots) / \text { no sé/ claro } \rightarrow \text { / vosotros lo conoceréis sobre todo usted } / \rightarrow \text { pues } \\
\text { cuando es }(\ldots) \text { ió la guerra d'España/ } \rightarrow \text { y tuve una infancia pues no muy } \\
(\ldots) \rightarrow / \text { entonces tenía yo seis años cuandu'estalló la guerra ¿no? } \rightarrow \text { / y casa } \\
\text { de mis padres } \rightarrow / \text { pues claro/ mi padre se quedó sin trabajo y hubo que:: } \\
\text { que trabajar/ defenderse com'uno podía } \rightarrow / \text { luo (luego) después/ cuando } \\
\text { ya fuimos mayores }(\ldots) / \text { que y'uera la mayor de } 4 \text { hermanos } \rightarrow / \text { pero } \\
\text { mech'atrabajar/ a servir/ no sé cómo lo llaman en su tierra } \rightarrow / \text { y estuve en } \\
\text { Madrid/ trabajando }(\ldots) \rightarrow / \text { estuve en Madrid trabajando/ y allí tuve un } \rightarrow \\
((\text { RISAS }) \text { )/ lo que nue dicho a nadie se lo voa decir ahora }((\mathrm{RIENDO}) \downarrow / \\
\text { Ahí tuve un novio/ tuve un novio } \downarrow / \text { Tenía yo entonces } 20 \text { años/ pues una } \\
\text { cría ¿no?/ y eso } \rightarrow / \text { Y muy bien } \rightarrow / \text { tuvimos cuatro años de relación } \rightarrow / \\
\text { relación/ no como la relación que llevan ahora/ de vivir juntos } \rightarrow / \text { relación } \\
\text { limpia/ } \rightarrow \text { Tu ya m'entiendes por onde voy yo/ ¿no? } \rightarrow \text { Porque ahora un } \\
\text { chico se junta con una chica/ y ya en seguida/ ya sihacen novios/ o sihacen } \\
\text { hablando::/ más castellanamente/ marido y mujer: } \rightarrow \text { porqu'en el } \\
\text { momento que una chica duerme ya con un hombre/ ya puede decir qu'es } \\
\text { su marido } \downarrow /\end{array}$ \\
\hline E & Claro/ \\
\hline MJ & $\begin{array}{l}\text { No/ la mía no } \rightarrow \text { / la mía entonces fue limpia/ que por cosas de esto/ de } \\
\text { que si él era más de familia más acomodada que yo/ que yo era una chica } \\
\text { de servir/ pue dejamos la relación } \downarrow / \text { Dejamos y luego después pasaron } \\
\text { untar de años y m'echéotro novio/ como es normal ¿no? } \rightarrow \text { / y fue mi } \\
\text { marido } \downarrow / P e r o \text { antes/ antes de casarnos/ pues claru'hicimos lo que no } \\
\text { debíamos:: } \rightarrow \text { y como los hombres aunquesté aquí este señor/ } \rightarrow \text { son muy } \\
\text { picarones con palabras y con cosas } \rightarrow \text { / pues t'envuelven y'amí me } \\
\text { envolvió/ y me hizo un crío ¿ve?/ dicho señor } \downarrow / \text { Cuando yo le dije } \\
\text { qu'estaba en estado desapareció del mapa/ y estuve/ claro } \rightarrow \text { / en la casa }\end{array}$ \\
\hline
\end{tabular}




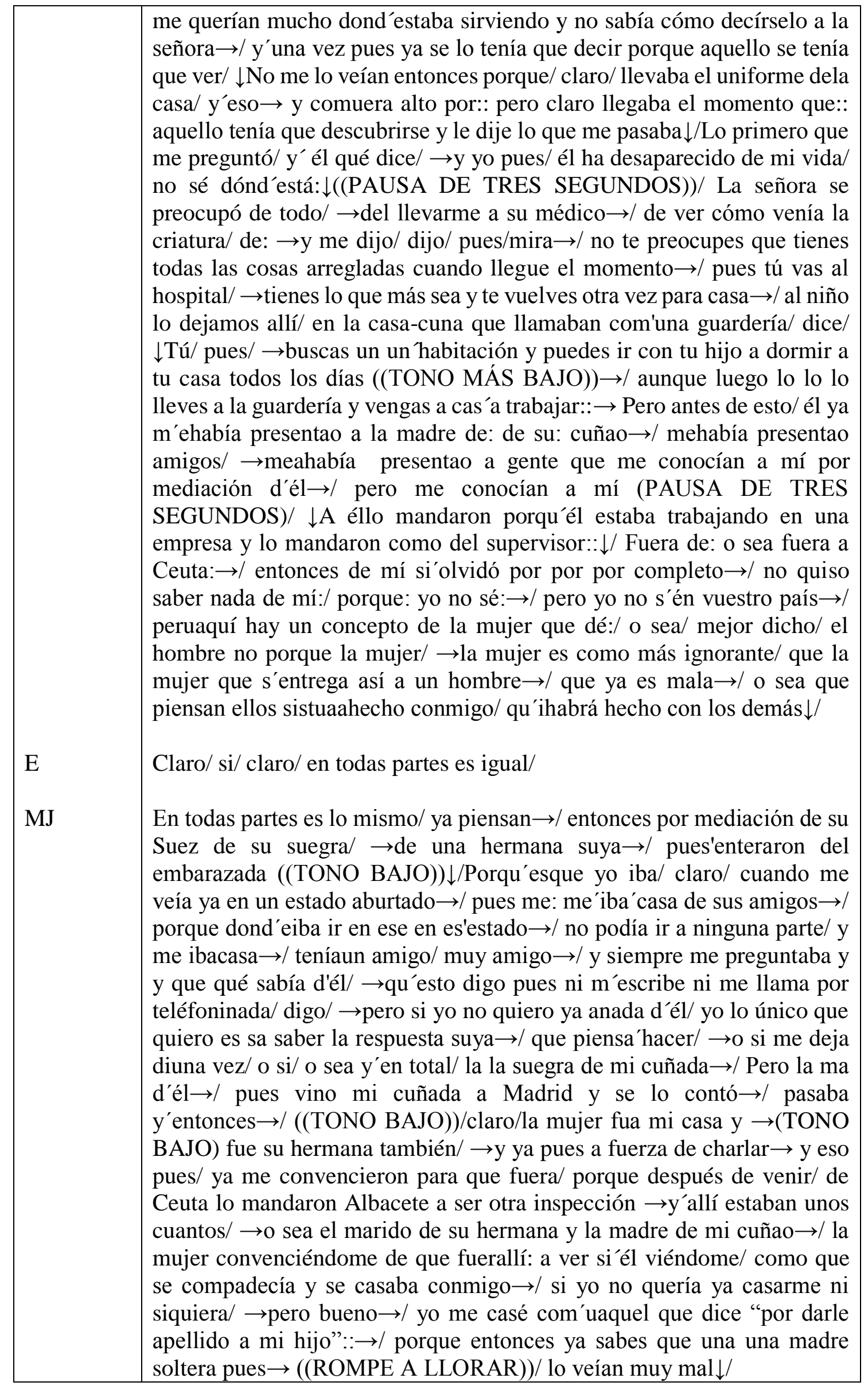




\begin{tabular}{|l|l|}
\hline E & $\begin{array}{l}\text { Claro } \downarrow / \\
\text { Y’en/ ya después } \downarrow \text { ((SOLLOZOS))/ desd'el puer momento se le vio a él } \\
\text { las intenciones/ que él no me quería:: } \downarrow \text { Sí/ él se casó conmigo por } \\
\text { lástima:: } \downarrow\end{array}$ \\
E & $\begin{array}{l}\text { Mal marido/ } \\
\text { Bueno::/ así fueron pasando los diez primeros años } \rightarrow / \text { y parece ser que } \\
\text { aunque no me quisiera/ me quería con el amor con ese que se quiere } \\
\text { cuando una persona es la primera vez } \rightarrow / \text { pues nunca antes/ } \rightarrow \text { per'uen } \\
\text { veinte años/ tengo ocho hijos que son suyos } \downarrow /\end{array}$ \\
\hline
\end{tabular}

62P

Edad: 84 años

Nacionalidad: España

Sexo: Femenino

\begin{tabular}{|c|c|}
\hline Informante & Discurso \\
\hline $\mathrm{E}$ & ¿Se acuerda de haber tenido algún peligro en su vida? \\
\hline $\mathrm{P}$ & Gracias a Dios/gracias a Dios/ peligro no he tenido nunca $\downarrow /$ \\
\hline $\mathrm{E}$ & $\mathrm{Mmm} /$ \\
\hline $\mathrm{P}$ & $\begin{array}{l}\text { Nunca } \rightarrow \text { / yo el peligro más grande qu'he tenido fue cuando me faltó mi } \\
\text { esposo } \rightarrow \text { / ese sí } \rightarrow / \text { ese sí fue } \rightarrow / \text { porque mi'e usted } \rightarrow / \text { cada vez que lo } \\
\text { miento y me lo me preguntan y todo eso/ no } \rightarrow / \text { Pero yo no no he tenido } \\
\text { ninguno gracias a Dios } \downarrow /((\text { SOLLOZOS))/ Peligros así no } \downarrow / \text { No he tenido } \downarrow \\
\text { y ya le digo } \rightarrow \text { m hepasado media vida/ más demedia vida en Madrid y } \\
\text { luego/ pos eso } \rightarrow / \text { he tenido una suerte soberbia } \downarrow /\end{array}$ \\
\hline $\mathrm{E}$ & ¡Qué bueno! \\
\hline $\mathrm{P}$ & $\begin{array}{l}\text { Soberbia con sirviendo } \rightarrow \text { desde luegu'estado sirviendo } \rightarrow / \text { pero con unos } \\
\text { señores } / \rightarrow \text { una señora com'una madre/ } \downarrow \text { Mie usted/ } \rightarrow \text { me casé } \\
\text { estand'uen su casa } \rightarrow / \text { claro } / \rightarrow \text { Ella fue la madrina qui'ay'está y el hijo de } \\
\text { los dos niños que yo cuidé en buen sentido } \rightarrow / \text { de buen sentido } \rightarrow \text { /selos } \\
\text { crié } \rightarrow / \text { pues/ es el padrino con su mamá... } \downarrow\end{array}$ \\
\hline $\mathrm{E}$ & ¡Qué bueno! \\
\hline $\mathrm{P}$ & $\begin{array}{l}\text { De mi boda/ porqu'iba ser el señor/ claro } \rightarrow / \text { y la señora } \rightarrow / \text { pero } \\
\text { empezó } \rightarrow / \text { mamá/ que quiero ser el padrino de Pepa } \rightarrow / \text { mamá/ que } \\
\text { quiero } \rightarrow \text { / y su papá dijo } \rightarrow / \text { bueno/pues eres tú } \rightarrow / \text { tú eres } / \text { y ya } \rightarrow / \text { ya le } \\
\text { digo } \rightarrow / \text { ahí los tengo } \rightarrow / \text { qu'eso fue oo }((\text { TODO }) \text { ) eso/ } \rightarrow \text { y yo pues sí } \rightarrow / \\
\text { ya le digo/ } \rightarrow \text { he tenido buena suerte sirviendo } \rightarrow / \text { que crié los niños/ he } \\
\text { ido a hoteles de veraneo con los niños yo::/ los señores } \rightarrow / \text { porqu'el señor } \\
\text { hacía edificios soberbios en Madriz } \rightarrow / \text { y tenía qu'estar allí } \rightarrow / \text { tenía } \\
\text { oficina } \rightarrow / \text { y luago iban a vernos a los niños ya mí: } \rightarrow / \text { pues en los sábados }\end{array}$ \\
\hline
\end{tabular}




\begin{tabular}{|l|l|}
\hline $\mathrm{E}$ & $\begin{array}{l}\text { y se pasaban'el domingo con nosotros } \rightarrow \text { y luego y luego se volvían a } \\
\text { Madriz y yo me quedaba con los niños } \downarrow /\end{array}$ \\
$\mathrm{P}$ & $\begin{array}{l}\text { ¿Usted era la que disfrutaba? } \\
\text { Sí/ sí } \rightarrow / \text { con ya le digo } \rightarrow / \text { los niños y y muy bien } / \mathrm{muy} \mathrm{bien} / \rightarrow \text { ya le } \\
\text { digu'he tenido suerte } \rightarrow / \text { nu'he tenido ninguna desgracia/ ya le digo } \rightarrow / \text { la } \\
\text { mejor fue:: cuando me faltó quien me faltó:: la mayor/ } \rightarrow \text { lo demás pues } \\
\text { no: un } \text { 'he teniduasí/ y eso: } \downarrow\end{array}$ \\
\hline
\end{tabular}

63FP

Edad: 79 años

Nacionalidad: España

Sexo: Masculino

\begin{tabular}{|c|c|}
\hline Informante & Discurso \\
\hline FP & $\mathrm{Mm} / \mathrm{em} / \mathrm{m} / \mathrm{m}$ Lolita $\rightarrow /$ o se $\rightarrow$ Doña Loli/ ahora/ Doña Dory/ Dory $\downarrow$ \\
\hline $\mathrm{E}$ & $\begin{array}{l}\text { En la facultad de psicología hay un libro de las experiencias/ de las/ de las } \\
\text { contada por los alumnos/ entoes me acordé de usté/ }\end{array}$ \\
\hline FP & Fíjate $\downarrow$ \\
\hline $\mathrm{E}$ & Y/ y me parece una labor bonita/ ¿y uste todavía está ahí? \\
\hline FP & Sí $\downarrow /$ \\
\hline $\mathrm{E}$ & ¿Cómo entró? \\
\hline FP & 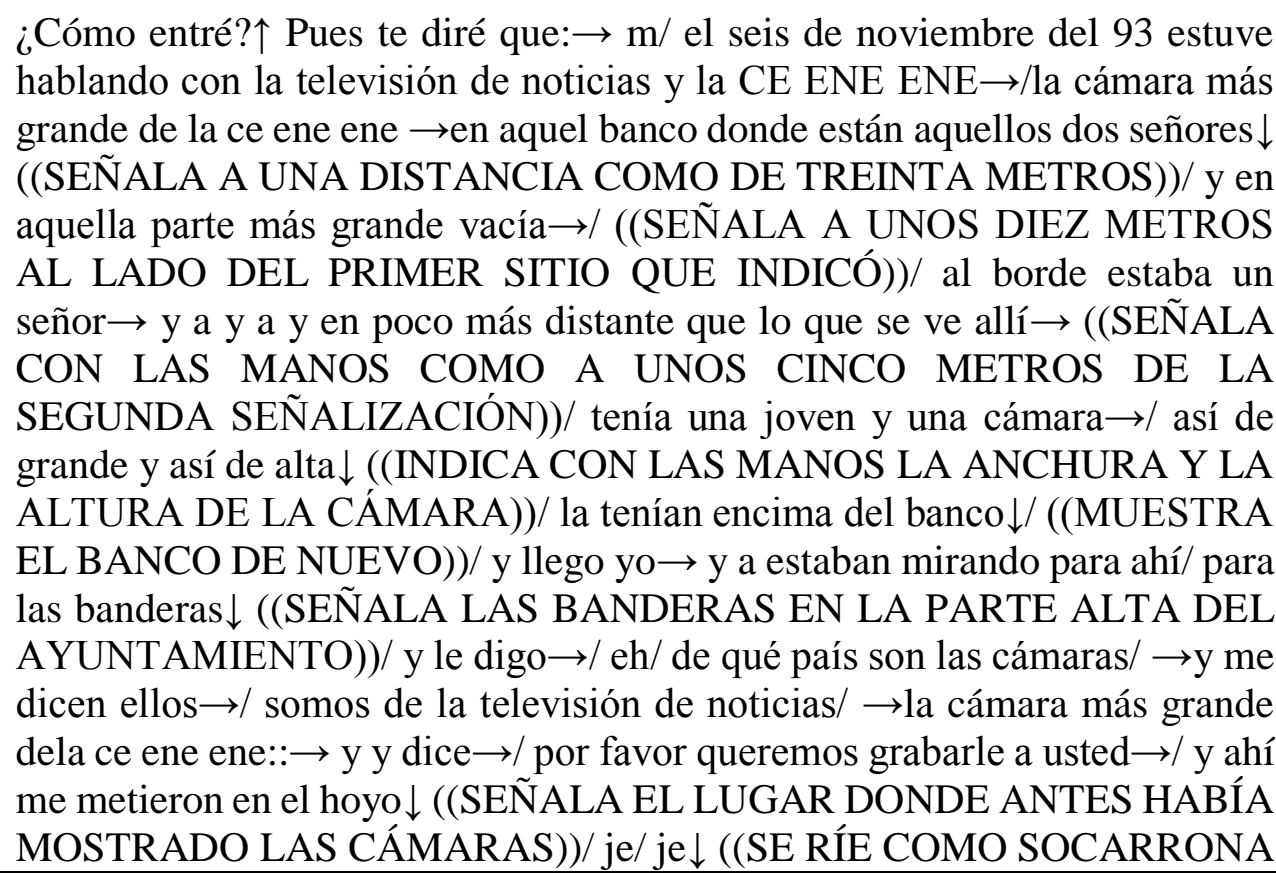 \\
\hline
\end{tabular}




\begin{tabular}{|c|c|}
\hline & $\begin{array}{l}\text { Y JACTANCIOSAMENTE AL TIEMPO QUE ME MIRA))/ ahí a grabar a } \\
\text { grabar/ } \downarrow \text { pues fue poco pero yo creo que ha dao por lo menos muchísimo } \\
\text { gusto/ eso es lo que:: } \rightarrow\end{array}$ \\
\hline $\mathrm{E}$ & $\begin{array}{l}\text { Oh/ oh/ una experiencia muy significativa/ ¿pero luego lo suyo con la poesía } \\
\text { en La Universidad? }\end{array}$ \\
\hline FP & $\begin{array}{l}\mathrm{Ah} / \text { sí/ pues sí } \rightarrow \text { / el otro día he tenido qu'echarlo a través } \rightarrow \text { / ahí en La } \\
\text { Universidad } \rightarrow \text { / en la Universidad Pontificia } \rightarrow \text { / en la aula magna } \rightarrow \text { y y había } \\
\text { que ver cómo ardían los aplausos } \rightarrow \text { había que ver cómo ardían los aplausos } \downarrow /\end{array}$ \\
\hline $\mathrm{E}$ & $\begin{array}{l}\text { ¿Y ahora en la Universidad sigue escribiendo poesía o no/ qué le gusta } \\
\text { más...? }\end{array}$ \\
\hline FP & $\begin{array}{l}\text { Todo de lo que ya puedo encontrar eh eh/ o así ideas de poder sacar } \\
\text { palabras } \rightarrow / \text { no de aquello que }(\ldots) \text { en que tenga valor/ eh: } \rightarrow \text { porque en las } \\
\text { palabras pueden ser unas y el valor puede ser otro:: } \rightarrow \text { ¿y usté de donde es/ } \\
\text { si se puede saber? } \uparrow\end{array}$ \\
\hline $\mathrm{E}$ & Colombia/ \\
\hline FP & Ah/ ah/ah/ sí $\downarrow$ \\
\hline $\mathrm{E}$ & $\begin{array}{l}\text { Estamos en la Universidad de Salamanca también/ Sí/ nosotros estamos } \\
\text { estudiando/ haciendo el doctorado por la Universidad de Salamanca/ }\end{array}$ \\
\hline FP & $\mathrm{Ah} /$ sí $\rightarrow /$ Fíjate $\downarrow /$ \\
\hline
\end{tabular}

64AV

Edad: 93 años

Nacionalidad: España

Sexo: Femenino

\begin{tabular}{|l|l|}
\hline Informante & \multicolumn{1}{|c|}{ Discurso } \\
\hline E & $\begin{array}{l}\text { ¿Y Belén? } \\
\text { Belén está en: en Calatayud me parece y Laura está en Madrid } \\
\downarrow((\text { SILENCIO })) \text { No nos traen al muchachín } \rightarrow((\text { MIRANDO LA FOTO DE } \\
\text { SU BISNIETO }) / \text { con ojos bonitos } \rightarrow \text { ¿verdad } \rightarrow \text { Tiene ojos bonitos } \downarrow\end{array}$ \\
E & $\begin{array}{l}\text { Es muy guapo TODO } \\
\text { AV }\end{array}$ \\
E & $\begin{array}{l}\text { Todo guapo } \downarrow \\
\text { AV }\end{array}$ \\
E & Alvarito tiene ojos bonitos $\rightarrow$ Alvarito $\downarrow$
\end{tabular}




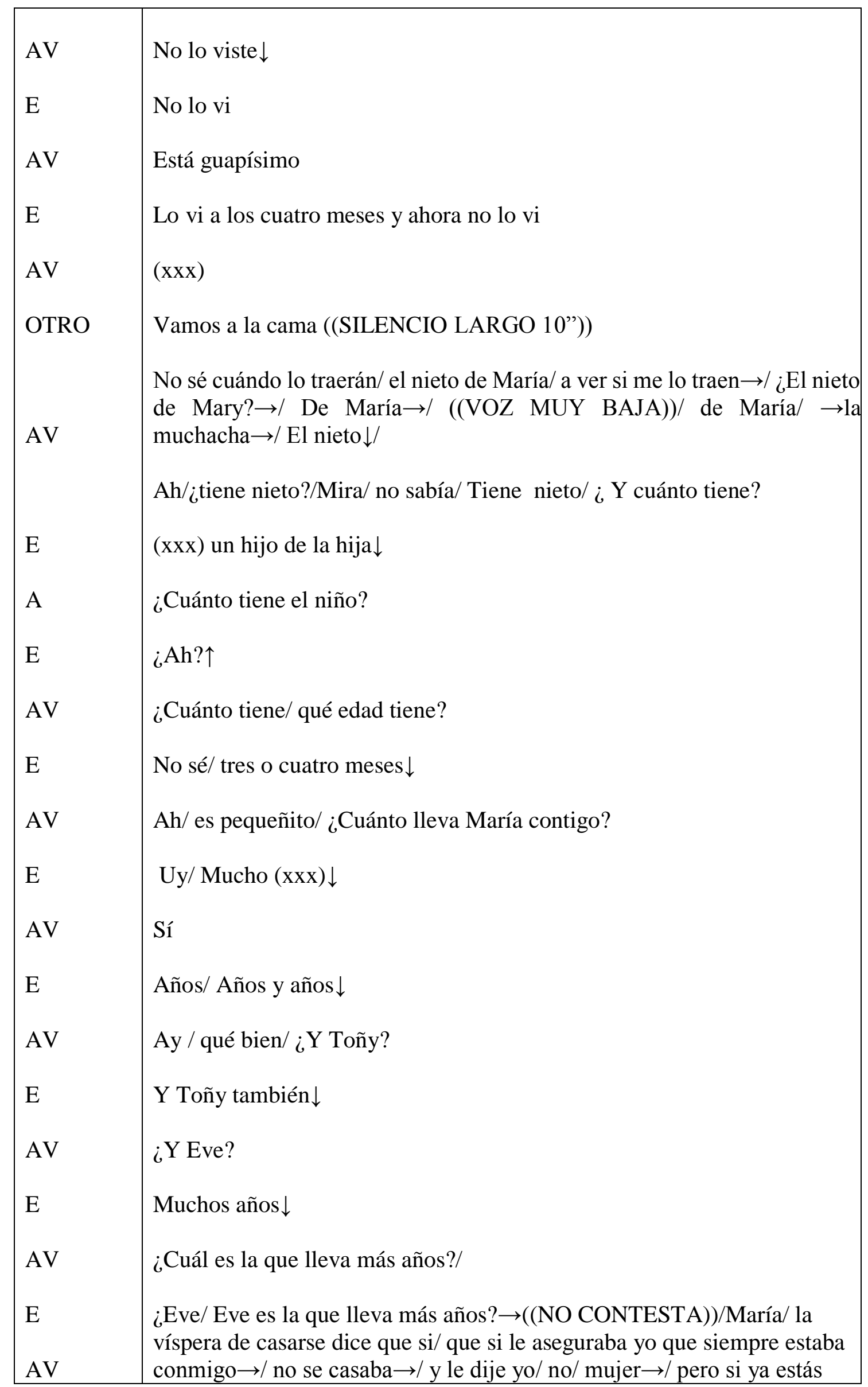




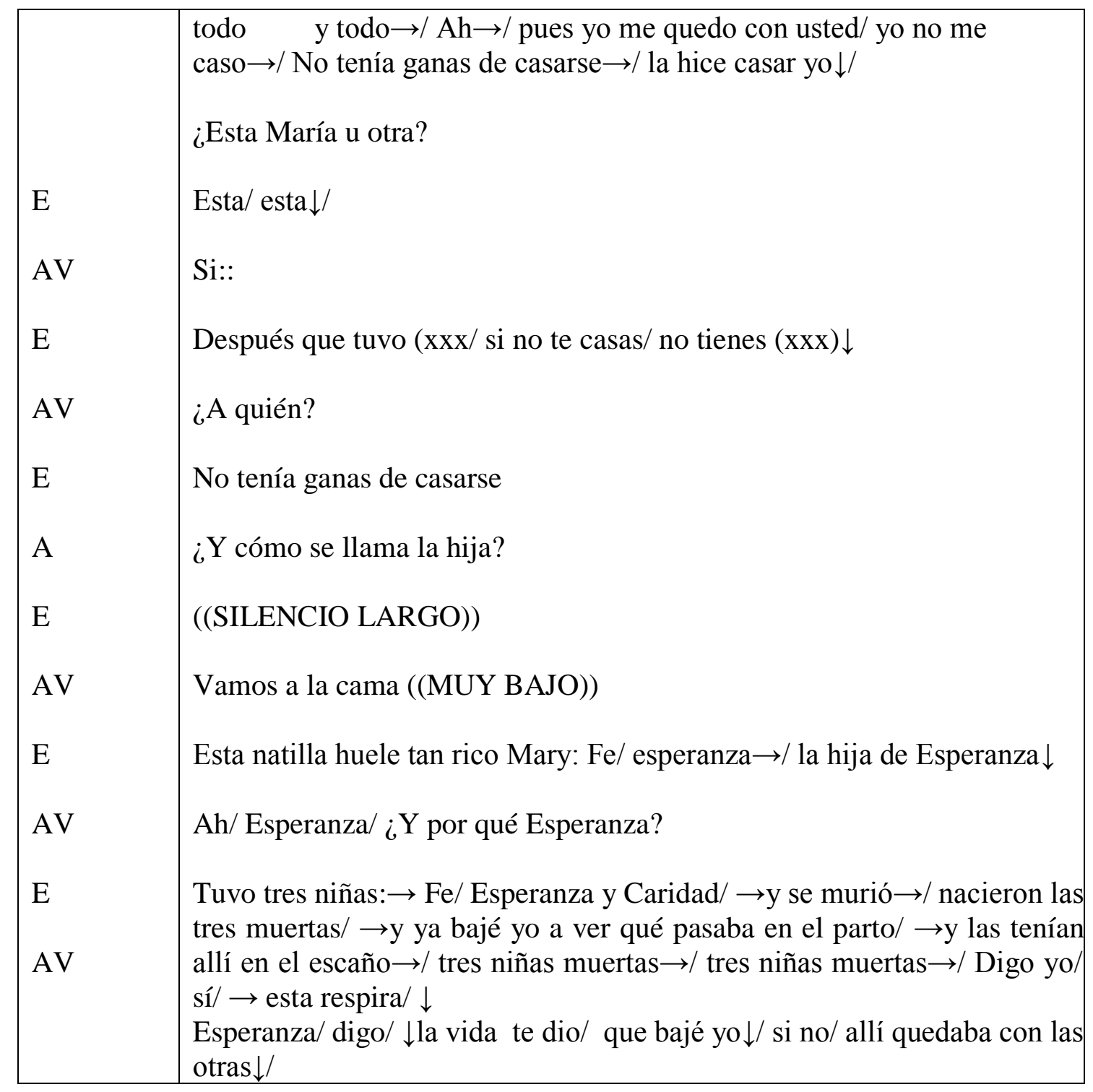

65T

Edad: 75 años

Nacionalidad: España

Sexo: Masculino

\begin{tabular}{|c|c|}
\hline Informante & Discurso \\
\hline $\mathrm{T}$ & $\begin{array}{l}{[\ldots] \text { La falange mató aquí montones de gente, } \rightarrow \text { mató gente qu'estaba }} \\
\text { en su casa, } \rightarrow \text { los sacaban, } \rightarrow \text { los llevaban a una carretera y'en una cuneta } \\
\text { y ahí quedaban, } \rightarrow \text { pero cantidad, } \rightarrow \text { aquí hay un monte que lo llaman } \\
\text { Monte e Las Varas, } \rightarrow \text { y si en ese monte escavaran/((EXCAVARAN)) } \rightarrow \\
\text { sí salen/ cadáveres a montones/ } \rightarrow \text { esto de los años treinta y seis al } \\
\text { cuarenta/ cuarenta cuarenta y cuatro } \rightarrow \text { porque fue casi peor la época de:: } \\
\text { la época de:: posterior a la guerra } \rightarrow / \text { que: incluso la guerra/ la guerra } \\
\text { fue } \rightarrow / \text { ya sabe fue fue cuando (xxx) Calderón. } \downarrow \text { Per'uesque luego } \\
\text { posteriormente los fascistas los estos (xxx) } \downarrow \text { se dedicaban ir por las } \\
\text { casas } \downarrow / \text { sacar la gente } \downarrow \text { se los llevaban y puay cuando iban quince o veinte } \\
\text { kilómetros puay le pegaban cuatro tiros y ay quedaba y eso y eso no se } \\
\text { olvida. } \downarrow \text { Yo nací en aquella época pero viví en el seno d'iunas familias }\end{array}$ \\
\hline
\end{tabular}




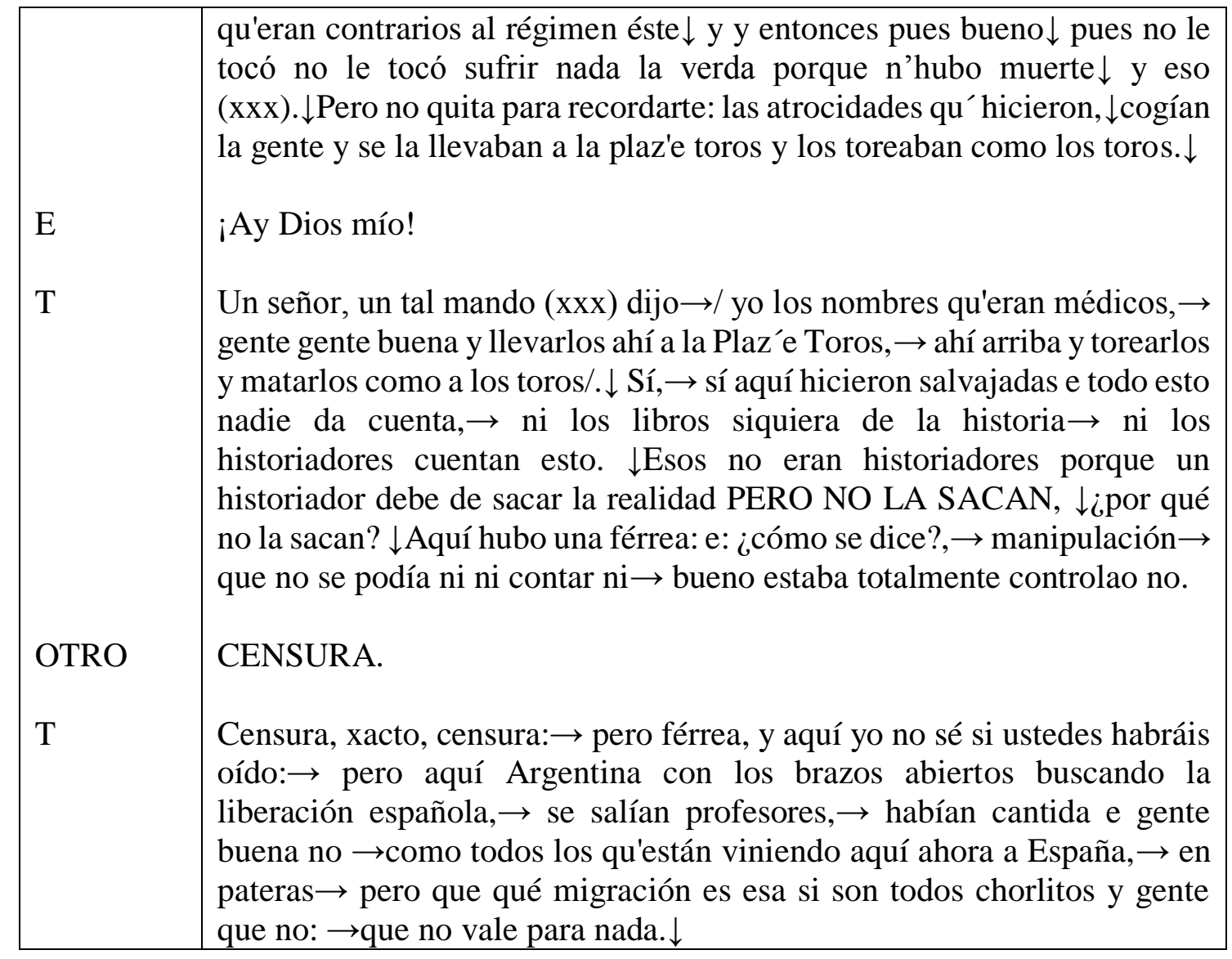

66P

Edad: 75 años

Nacionalidad: España

Sexo: Femenino

\begin{tabular}{|c|c|}
\hline Informante & Discurso \\
\hline $\mathrm{E}$ & Y dónde vive usted/ aquí en Cerk? \\
\hline $\mathrm{P}$ & $\begin{array}{l}\text { No } \rightarrow / \text { yo vivo aquí en un pueblo de a veinte kilómetros o diecisiete o } \\
\text { dieciocho kilómetros o u a cincuenta y tantos kilómetros } \rightarrow \text { me parece } \\
\text { qu'está/ un pueblo que se llama Fuentes de San Esteban } \downarrow /\end{array}$ \\
\hline $\mathrm{E}$ & ¿Debe ser muy bonito/ ¿no? \\
\hline $\mathrm{P}$ & $(\ldots) \mathrm{mmm} /$ vamos/ regularcito $\rightarrow /$ fue como pueblo: $\downarrow /$ \\
\hline $\mathrm{E}$ & ¿Y qué costumbres tienen en el pueblo/ eh? \\
\hline $\mathrm{P}$ & $\begin{array}{l}\text { Pues en el pueblo/ de pequeñitos se irá: la escuela/ } \rightarrow \text { al colegio con los } \\
\text { demás niños } \rightarrow / \text { que había una escuela graduada/ } \rightarrow \text { ir al colegio } \rightarrow \text { cuando } \\
\text { salimos de la escuela pues empezaste ya a ser mayorcita y ya ayudar a la } \\
\text { casa } \rightarrow \text { / a la familia/ en los trabajos caseros/ y y nada más/ } \downarrow \text { Trabajar/ pos } \\
\text { no trabajamos así parafuera } \rightarrow \text { / cocíamos/ hacíamos labores/ y esas } \\
\text { cositas/ }\end{array}$ \\
\hline
\end{tabular}




\begin{tabular}{|c|c|}
\hline $\mathrm{E}$ & ¿Entonces la gente trabajaba preferiblemente en el campo no? \\
\hline $\mathrm{P}$ & No yo en el campo nu'etrabajao nunca $\downarrow /$ \\
\hline $\mathrm{E}$ & La gente del pueblo/ en los pueblos hay: $\downarrow$ \\
\hline $\mathrm{P}$ & $\begin{array}{l}\text { Había fábricas de harinas y mi padre estaba d'encargao en una fábrica } \\
\text { deharinas }(\ldots) \text { / de fuentes de San Estéban } \downarrow /\end{array}$ \\
\hline $\mathrm{E}$ & ¿Grande/ pequeña? \\
\hline $\mathrm{P}$ & La fábriqu'era grande $\rightarrow$ / molía treinta vagones diarios $\downarrow /$ \\
\hline $\mathrm{E}$ & ¿Síi? \\
\hline $\mathrm{P}$ & $\begin{array}{l}\text { Sí }(\ldots) \text { / porque no paraban } \rightarrow \text { / tenían turnos y no paraban/ see }(\ldots) \rightarrow \text { / era } \\
\text { un turno y luego al terminar el turno de las ocho horas volvía otro y } \\
(\ldots) \rightarrow / \text { hasta las tres molíamos/ } \rightarrow \text { nada más paraban los días de los } \\
\text { domingos/ a las seis de la mañana o así } \rightarrow \text { / paraban y luego y’hastal } \\
\text { siguiente día } \downarrow /\end{array}$ \\
\hline $\mathrm{E}$ & ¿Entonces usted comía mucho pan? \\
\hline $\mathrm{P}$ & Bueno/ regular:: $\downarrow$ \\
\hline
\end{tabular}


3. MARCO TEÓRICO 


\subsection{Proceso de producción de la oralidad}

La producción oral ha sido trabajada a lo largo del tiempo por distintas áreas del saber: La anatomía, la fisiología, la psicología y la lingüística entre otras. La complejidad de su estudio y la heterogeneidad de su naturaleza han generado ramas interdisciplinares que modernamente intentan explicar los procesos mentales y de producción del discurso oral tales como la psicolingüística, la neurolingüística y la lingüística del texto. Estos estudios abarcan desde la producción de la palabra, y con ella los procesos fonoarticulatorios, pasando por la producción de oraciones hasta llegar a la producción de discursos y sin dejar de lado los procesos cognitivos que junto con el lenguaje permiten la producción discursiva.

Este capítulo intenta resumir las perspectivas con las cuales se ha teorizado la producción oral hasta llegar a configurar el concepto moderno de producción del discurso oral.

\subsubsection{Perspectiva anatómico-fisiológica}

A continuación se explica brevemente el punto de vista anatómico-fisiológico que permite generar una emisión de habla. 
En primer lugar es necesario acudir al ámbito-lóbulo frontal del cerebro que se encarga de administrar la conducta humana y enviar órdenes a los músculos para hacer posible ejecución de estas órdenes. La tarea ejercida por el lóbulo frontal incluye tres funciones fundamentales y previas a la emisión exterior de una respuesta: planificar, programar y controlar la conducta. Es pertinente acotar que aún no se habla aquí de conductas lingüísticas, sino en general de conductas propensas a desencadenar el movimiento.

Para precisar más en el aspecto lingüístico es necesario acudir a la región prefrontal, que se encarga de controlar la conducta verbal y activar las redes neurales destinadas a la recuperación léxica del mensaje. Cuando se produce un discurso o enunciado, en las áreas 45 y 47 el mensaje adquiere forma semántica, el área 39 se encargará de recuperar los significantes, enseguida las áreas 38, 21 y 20 se encargarán de enviar los impulsos y secuenciarlos en lexemas, a través del área de Wernicke mediante el fascículo arqueado. Estos lexemas en forma de impulsos activarán la organización sintáctica para darle forma a los enunciados. El área 47 se encargará de la programación y formulación morfosintáctica, o sea, la correspondiente a morfemas verbales y monemas gramaticales independientes.

Una vez se tiene una secuencia ordenada del enunciado se transforman los impulsos en articulemas, o esquemas motores de cada fonema, siguiendo la secuencia ordenada de los significantes de las palabras. Estos impulsos obedecen reglas espaciales y temporales en tanto deben guardar el orden de la frase y de los enunciados. 
Cuando los impulsos han adquirido el estatus de articulemas se activa el área 4 de Brodmann en donde se halla la corteza motora cuya articulación permite exteriorizar el acto comunicativo al ordenar a los pares de nervios craneales VII, IX, X, XI y XII que accionen los músculos encargados de los movimientos fonoarticulatorios.

El proceso anteriormente descrito corresponde a la explicación neurofisiológica de producción del habla. Es pertinente mencionar este proceso ya que este trabajo de tesis hablará de la habilidad de producción oral.

Más adelante se exponen otras perspectivas igualmente necesarias para entender cómo se produce el discurso en su modalidad oral.

Gráfico 2: Áreas cerebrales

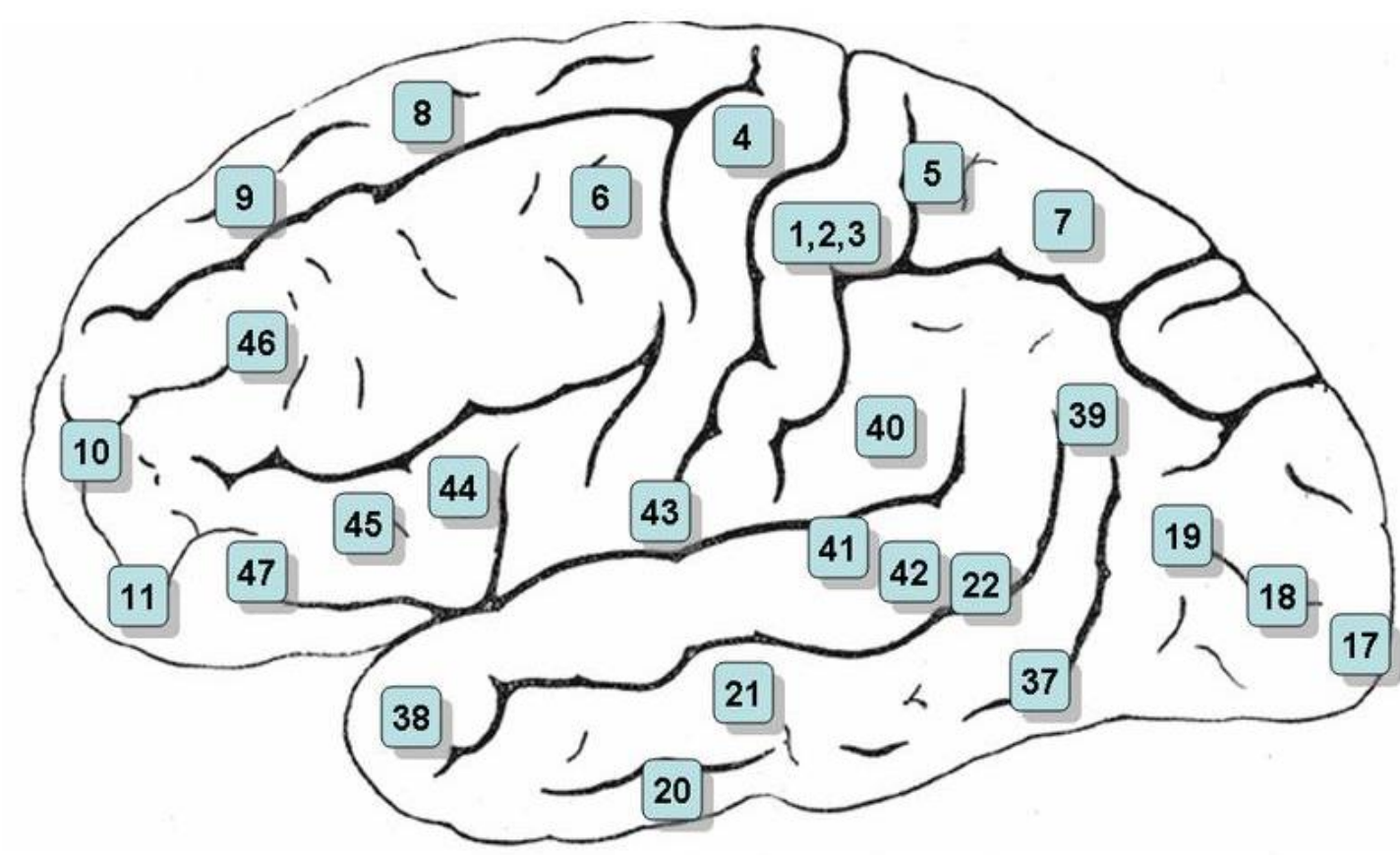




\subsubsection{Perspectiva cognitiva}

La cognición y lo cognitivo tienen diferentes sentidos y significados de acuerdo con la perspectiva desde la cual se estudien, de acuerdo con el objeto de estudio o con la visión holística de la mente humana. En este sentido se habla de cognición como conocimiento en sentido general, como estado de conocimiento activado por la mente y/o el cerebro (representación del conocimiento en estructuras cognitivas), como razonamiento, el cual incluye todas las actividades intelectuales y presta especial atención a la capacidad para resolver problemas $y$, finalmente, se refiere también a las transformaciones centrales o procesamiento de la información.

El ingreso sensorial es transformado, reducido, elaborado, almacenado, recobrado o utilizado. Es en este último sentido que interesa a este trabajo, ya que se va a tener en cuenta el proceso de decodificación y especialmente el proceso de codificación lingüística que da origen al producto hablado. También interesa a este proceso la construcción y acceso a esquemas mentales que facilitan el aprendizaje, la comprensión y la producción lingüística, el almacenamiento de información en la memoria y su posterior recuperación y procesamiento.

Se puede plantear en un sentido amplio que existen 5 grupos de procesos cognitivos, todos ellos involucrados de una u otra manera y en mayor o menor medida en la construcción o elaboración de discursos orales.

1. Aprendizaje (fortalecimiento de asociaciones). 
2. Almacenamiento en la memoria.

3. Recuperación de la información

4. Activación parcial de la memoria a corto plazo.

5. Inhibición.

El esquema genérico (género textuales) permite "producir textos (de un determinado tipo) y entender los de los demás" en virtud de las características inherentes al género o tipo (Loureda, 2003, p. 39). La idea de modelo y esquema corresponde a estructuras cognitivas que permiten, mediante una serie de acciones mínimas, características y definiciones, reconocer y etiquetar un discurso real. Podría ser equiparable a la idea de superestructura. "Los hablantes perciben los géneros como modelos, ideales intuitivos, aglutinadores, paradigmáticos, de los caracteres necesarios de todos los textos de una misma naturaleza" (Loureda, 2003, p. 37).

La competencia estratégica hace parte del aspecto cognitivo antes que del lingüístico, ya que se lleva a cabo en los procesos de evaluación, planificación y control discursivo. Según Bernárdez (1987) su papel:

Se extiende tanto a la gramática como a los aspectos sociolingüísticos, discursivos y contextuales. Según lo cual la competencia estratégica estaría relacionando lengua y cognición, o estableciendo el puente entre lo que se dice y la situación en la cual es posible, probable o adecuado decir o no decir. (p. 578)

Las reglas lingüísticas son rígidas, las estrategias son flexibles. Atienden a la situación, al contexto. Una estrategia se convierte en regla cuando ha sido probada múltiples veces y adquiere un grado importante de automatismo. 
La automatización de estrategias lingüísticas facilita enormemente el proceso comunicativo y el procesamiento lingüístico.

El concepto de estrategia ha cobrado mucho valor en el marco de la consideración del discurso y de la lengua, hasta el punto que compite en rango con la competencia lingüística y la competencia comunicativa. Hoy se habla paralelamente de competencia estratégica especialmente adscrita al aprendizaje de una segunda lengua.

Podemos imaginar el conocimiento estratégico como formado por una serie de manuales de instrucciones, que contendrían nuestra lista de estrategias, y otro manual central, que nos permitiría adaptar esas instrucciones a las situaciones cambiantes en que vivimos. (Bernárdez, 1987, p. 208)

Todo proceso se realizará de la forma que permita alcanzar el resultado final con el menor consumo de energía posible. Este hecho es posible según Bernárdez (1987, p. 207), por el conocimiento y utilización de estrategias textuales.

Sin embargo, el papel más destacado de la competencia estratégica está en la capacidad del hablante de "compensar los fallos en la comunicación debidos a limitaciones momentáneas o a una competencia insuficiente" (Canale, 1983, pp.63-81), con el objetivo de mantener una imagen discursiva del hablante.

Dicho de otro modo, el hablante utiliza la competencia estratégica para controlar su discurso, disimular o corregir sus errores, evitar equívocos y construir un discurso más 
claro, más efectivo y más adecuado. La reformulación ${ }^{14}$ constituiría una buena forma de evidenciar esta competencia; otras formas serían las pausas rellenas con muletillas o con alargamientos para evitar un silencio embarazoso, y finalmente los rodeos tanto eufemísticos como metafóricos y/o compensatorios de algún olvido léxico.

Las estrategias cognitivas son también fundamentales en este modelo, ya que son aquellas que hacen viable una macroestructura y una superestructura. Son las que dan forma a estas estructuras que no se encuentran en forma ideal en la mente del hablante: es necesario reconstruirlas y esa es la función de las estrategias.

Las estrategias y su empleo por el hablante en forma de habilidades, son funciones cognitivas fundamentales en el procesamiento discursivo, ya que como podemos observar atraviesan el discurso y relacionan lo cognitivo, lo lingüístico y lo pragmático y se ponen de manifiesto en los fenómenos discursivos que aparecen en los discursos reales y que serán evaluados dentro del rango de la fluidez oral.

\subsubsection{Proceso de producción oracional}

Los modelos más cercanos a la producción del discurso son los modelos de producción de oraciones. Estos modelos exigen un análisis pormenorizado del complejo proceso de producción; sin embargo, sabemos que el nivel discursivo va más allá del oracional en tanto que se genera en la intención del emisor, construye sentido a partir de

\footnotetext{
${ }^{14}$ Matilde Camacho Adarve (2005) dice: "la propia reformulación abarcaría al resto de los procedimientos vistos [...] refuerzo o adición argumentativa, contraargumentación, conclusión, restricción, concreción propia, enumeración, el "vestíbulo" para la compleción, rectificación y la digresión, relieve o insistencia propios, resumen, generalización, tematización o rematización y adición continuadora".
} 
la relación entre oraciones, en ocasiones estas relaciones son múltiples, en ocasiones las construcciones aisladas no representan el sentido del mensaje y este hay que buscarlo en un operador discursivo que oriente el sentido en el cual deban tomarse los enunciados constituyentes, ya que son los operadores los guías directos en la comprensión de los discursos.

Por otro lado la oración no da cuenta de las relaciones temporales o espaciales con otras oraciones, ni de otras muchas. Tampoco da cuenta de la superestructura y macroestructura del mensaje. En definitiva la oración por sí misma y, desligada del contexto, es insuficiente para explicar la producción de un hablante, sin contar con el hecho de que existen discursos cuya estructura no alcanza a coincidir con las oraciones pero que por el contexto en el cual se emiten constituyen un discurso.

Sin embargo al comenzar en la representación semántica y terminar en la expresión fonética de viva voz, la producción de oración coincide procesualmente con la producción de discurso. Cuetos Vega (1998) al hacer una aproximación cognitiva a la producción del habla lleva su teoría hasta el punto de la producción de oraciones, sin dar el salto a la producción discursiva. En adelante se expondrá esta perspectiva que deriva del sistema de procesamiento lingüístico e integra todos los niveles de lengua.

Para Cuetos Vega (1998), la producción de oraciones tiene lugar en tres estadios: el primero es el de la representación del mensaje y se corresponde con la función cognitiva de la planificación. Es un estadio de naturaleza abstracta en el cual se accede al significado que se quiere expresar. 
El segundo estadio se denomina "elaboración de las estructuras sintácticas" y es aquí donde se elige la estructura que tendrá la oración. Esta elección tiene una relación directa con la intención, ya que es esta la que va a determinar la forma de la oración. Aquí se elige el molde, estructura o modelo, tanto si es activa como si es pasiva, si es afirmativa o negativa, si es dubitativa o exhortativa, exclamativa o afirmativa. Este nivel adquiere ya un nivel de concreción que va a determinar el orden de las palabras y la ubicación de los nexos. Las funciones gramaticales son asignadas de acuerdo con la estructura.

En el tercer estadio se accede al léxico fonológico para "rellenar" la estructura sintáctica elegida. En este estadio se relaciona un significado con un significante y se coloca en el lugar asignado en el estadio anterior, este estadio corresponde con el nivel del lexema.

En los modelos de producción del habla se reconoce el acceso al léxico como un proceso fundamental, ya que este nivel se relaciona con el anterior en tanto que aporta información gramatical: nombre, verbo, adjetivo, funtor; se relaciona con el nivel semántico en tanto que en este nivel se han establecido los rasgos que lo caracterizan (Ej.: animado, carnívoro, salvaje, cuadrúpedo, etc.) y es, en el nivel léxico donde se le da un nombre concreto (tigre); y finalmente se relaciona con el nivel fonológico en la medida en que, una vez asignada una forma léxica-fonológica, es preciso activar los fonemas en los cuales debe ser estructurada la palabra. El estadio de lexicalización es un estadio central del habla y da paso a los procesos articulatorios.

El primer paso de esta tercera etapa o etapa de articulación lo constituye el retén fonológico. En el retén fonológico la forma fonológica de la palabra ya ha asignado y 
activado los fonemas que se corresponden a esa palabra y es aquí donde se retienen por un instante los fonemas que serán pronunciados antes de emitirlos con el fin de ordenar la secuencia que tendrán en la pronunciación.

Luego se activan los procesos motores que darán forma fónica a cada fonema. Los procesos motores recurren aquí al código articulatorio, o sea a los rasgos articulatorios del fonema que se deben producir. Es aquí donde se elige si el sonido es sordo o sonoro, bilabial o dental, oclusivo o fricativo, etc., y con esa información se envía la información a los músculos y órganos encargados del habla.

Este estadio se denomina "código articulatorio" y se ubica después del retén fonológico, antes de enviar los impulsos neurales a los músculos y órganos articulatorios. Una vez que se envían las órdenes a los músculos estos se mueven y finalmente aparece el producto: el habla.

\subsubsection{Perspectiva psicolingüística}

La recopilación y análisis de errores y patologías han llevado a plantear una serie de conclusiones $^{15}$ :

1. El almacenamiento de las unidades lingüísticas en el cerebro es limitado, es preciso acudir a la productividad del lenguaje.

\footnotetext{
${ }^{15}$ Según Fromkim y Bernstein 1999, p. 335-339.
} 
2. Las unidades lingüísticas son discretas y separables, aspecto que difícilmente se percibe en la cadena hablada normal, sin embargo influye en el comportamiento lingüístico.

3. Las emisiones se componen de unidades que difieren en tamaño y clase.

La primera conclusión es válida para demostrar que el cerebro no puede almacenar todos los discursos posibles ni todas las respuestas necesarias. El cerebro posee un número limitado de herramientas de tipo fonético, morfológico, sintáctico, semántico y discursivo ${ }^{16}$. Con estas, mediante los procesos de selección y combinación y con criterios de adecuación situacional, construye los enunciados y discursos necesarios. El hecho de que exista esta productividad explica que no se almacenen las unidades de orden superior.

La segunda conclusión es válida para acudir a la conciencia lingüística del hablante. Los errores son sistemáticos y clasificables porque responden a criterios lingüísticos.

Los desplazamientos y permutaciones tienen una lógica que se atiene a la discreción de la cadena hablada, esto es, que donde existe un elemento no puede existir otro. Los elementos se suceden uno a uno en cadena: si un hablante dice "sácame el pasapuntas", en lugar de "pásame el sacapuntas", notamos a simple vista que existe una construcción equivalente en los dos casos, con lo cual es claro que el hablante sabía que iba a pronunciar tres palabras, pero además existe conservación del número de sílabas,

\footnotetext{
${ }^{16}$ En lo discursivo es preciso recordar que Van Dijk propone la existencia de esquemas a los cuales acudir para comprender y producir todos y cada uno de los tipos de discurso.
} 
del lugar de los acentos y de la estructura morfologizada de cada unidad, con lo cual la única falla estuvo localizada en el orden de las sílabas.

Lo que debía ser:

$\begin{array}{llllllll}1 & 2 & 3 & 4 & 5 & 6 & 7 & 8\end{array}$

pá sa me el sa ca pun tas

Se convirtió en 5, 6, 3, 4, 1, 2, 7, 8 .

En cuanto a la tercera conclusión de arriba, reconocer la diferencia de clases y tamaños de las unidades de emisión permite explicar los pasos que debe recorrer la mente para convertir una intención en significado, un significado en forma léxica y una palabra en sílabas y sonidos. Cada uno de estos productos tiene una naturaleza lingüística diferente y se supedita a la existencia de los otros. Esta conclusión justifica que se produzcan errores entre niveles lingüísticos. Por ejemplo: una persona quiere decir síndromes o síntomas y dice realmente síndromas: el resultado es una fusión entre las dos palabras tanto en lo fonético como en lo semántico.

De otro lado, las patologías han permitido también llegar a modelos de producción lingüística. Esta construcción modélica es posible cuando los especialistas se encuentran en situaciones como las siguientes:

- Un paciente que es capaz de responder cuáles son los días de la semana pero no puede expresar lo que sucedió ayer.

- Un paciente que es capaz de cantar una canción de la infancia pero no es capaz de nombrar un objeto. 
- Un paciente que entiende lo que le hablan y es capaz de representarlo con un dibujo pero no puede repetir la palabra.

Estas situaciones y otras muchas han generado reflexiones como las siguientes:

La producción y comprensión lingüística se realiza en zonas especializadas del cerebro, con lo cual el paciente puede conservar la comprensión pero perder la capacidad de expresión y viceversa.

La producción y la comprensión lingüística no son un proceso único y uniforme, se procesa de forma diferente de acuerdo con la tarea que se va a realizar. Aunque repetir una palabra, cantar una canción conocida y relatar lo que le sucedió el día anterior, son tareas de producción, no hacen todas ellas el mismo recorrido. Sin embargo, existen diferentes recorridos para producir un enunciado, con lo cual es probable que un paciente que no puede repetir una palabra oralmente la pueda representar con gestos, la pueda dibujar, escribir o deletrear.

Lo interesante de estos casos es que cada tarea de producción lingüística posee una forma de ejecución que se considera la más rápida, económica, efectiva y eficaz. Y si no puede acceder a esa forma, su ejecución se verá afectada en algún grado. Por ejemplo, si yo le pido a alguien que repita la palabra "gato" y no puede hacerlo como forma léxica, esa persona puede recurrir a las gráficas que la integran y deletrearla o escribirla, pero ello le demandará más cantidad de tiempo y le restará eficacia en su desempeño oral. El modelo al cual se llegó a través de estas consideraciones se denomina 
SLP o sistema de procesamiento lingüístico y, se inscribe dentro de la consideración de la modularidad de la mente.

A continuación se presenta y explica este modelo en lo referente específicamente a la producción oral.

Los sistemas encargados de la producción oral son tres: el sistema semántico (conceptualización), el sistema léxico fonológico (lexicalización) y el sistema articulatorio (articulación).

El sistema semántico es el encargado de realizar la conceptualización "ya que la producción oral se inicia con la activación del concepto o de sus rasgos [...] sea cual sea la modalidad de llegada (visual, auditiva)" (García y Naranjo, 2002, p. 154).

En el sistema semántico se forman los conceptos a partir de los rasgos semánticos que son activados en ese momento.

Los conceptos son representados en forma léxica; una vez conformado, el concepto busca la forma de la palabra que le corresponde. Esta tarea corresponde a la lexicalización o recuperación de la forma verbal en el léxico fonológico. Se denomina a este módulo léxico-fonológico por oposición al léxico-ortográfico, que sería el encargado de recuperar la forma de la palabra escrita, o sea, los grafemas que deben moverse para conformarla. 
Finalmente, el sistema articulatorio se encarga de activar los programas motores que harán posible la pronunciación de cada uno de los sonidos de la palabra.

El modelo de procesamiento lingüístico está enmarcado dentro de la corriente de la neurolingüística cognitiva y esta a su vez dentro de la neuropsicología cognitiva. Se reconoce como modelo cognitivo aunque su modelo de base está fundamentado en la lingüística: se trata de un sistema de procesamiento lingüístico y por lo tanto se estudia como una teoría psicolingüística de procesamiento de la información.

Su objetivo es “descubrir la máquina cognitiva que permite comprender y expresar el lenguaje" (García y Naranjo, 2002, p. 145).

El principio que llevó a plantear este modelo obedece al hecho que: "el comportamiento del paciente lesionado permite inferir la organización del lenguaje en funcionamiento normal, porque dicho comportamiento refleja las capacidades del estado pre-mórbido". (García y Naranjo, 2002, p. 145)

El enfoque cognitivo se basa en 4 principios fundamentales que es preciso enunciar:

1. El sistema cognitivo del individuo se compone de un conjunto de módulos; cada módulo está especializado en un proceso cognitivo y por tanto realiza una tarea específica $^{17}$.

${ }^{17}$ Tareas como:

- Reconocimiento auditivo de palabras.

- Escritura al dictado de palabras.

- Repetición de palabras conocidas.

- Repetición de palabras desconocidas.

- Articulación de palabras. 
2. Cada uno de los módulos es isomorfo en su composición orgánica.

3. Cuando se presenta una lesión cerebral esta afecta a uno o varios módulos pero normalmente otros quedan en buen estado; dicho de otro modo, la funcionalidad de un módulo no se afecta porque otro esté afectado.

4. La persona afectada sigue operando lingüísticamente con los módulos que están activos. Este principio se denomina "sustractividad" (Cuetos Vega, 1998, p. 12) (García y Naranjo, 2002, p. 148).

La teoría de la modularidad del sistema lingüístico ha sufrido las críticas y objeciones normales que una teoría de tal magnitud pudiese tener, sin embargo, quienes se ocupan de objetarla lo hacen desde los presupuestos del lenguaje "normal" sin ahondar en las dificultades que supone su pérdida, y asimismo, sin ahondar en las distintas caras que poseen las afasias. Para explicar la producción discursiva, más allá de la producción oracional, tenemos el siguiente título.

\subsubsection{Perspectiva discursiva}

La perspectiva discursiva abarca los aspectos lingüísticos, cognitivos y pragmáticos de la producción de textos y discursos.

Según Van Dijk (1983) el proceso de producción textual es un proceso que precede al de comprensión y por lo tanto es imprescindible este, como proceso anterior a aquel. La comprensión fija en la memoria superestructuras y modelos de situación 
(referidos al conocimiento del mundo), a los cuales acude la mente para iniciar el proceso de elaboración de un texto.

Las intenciones se ordenan en forma de macroproposiciones. Las macroproposiciones se componen de proposiciones. Es en este nivel de las proposiciones donde tienen lugar las transformaciones que generan el discurso. Antes de producirse las transformaciones se habla de texto, plan global, superestructura y macroproposiciones. Una vez se han aplicado las reglas de transformación textual y se ha dado forma sintáctica, léxica y fonética a los materiales de la memoria, se habla de discurso.

\section{Según Van Dijk (1992):}

Mientras que en la comprensión textual había que resumir, organizar y reducir informaciones mediante macrorreglas, las reglas de la reproducción precisamente tienen que especificar, ampliar y detallar plausiblemente las informaciones existentes [...] el proceso de producción parte de esquemas, generalidades, abstracciones, superestructuras y a través de macrorreglas va construyendo estructuras y rellenando todos los espacios. (p. 217)

Utilizando la metáfora de un constructor ${ }^{18}$, se podrá decir que existe la idea de construir un edificio (discurso). Ese edificio será una iglesia (superestructura). Se necesita tener un plano de la construcción (partes) y un conocimiento de lo que es una iglesia: fieles, ceremonias y actos religiosos (modelos de situación). Luego será necesario construir una estructura esquemática (macroestructura) que posteriormente se irá rellenando con ladrillos (microestructura). Habrá que decidir qué detalles añadir (macrorregla de adición) y cuáles quitar (macrorregla de omisión), qué espacios quedarán

\footnotetext{
${ }^{18}$ Que parece ser la que utiliza Van Dijk para mostrar didácticamente el proceso.
} 
vacíos y cuáles llenos (reglas de transformación), qué materiales cambiar por otros (macrorregla de sustitución).

También es importante darle forma a las estructuras derivadas más pequeñas, como puertas o ventanas (especificación). En síntesis, producir un discurso es un proceso de rellenado, de colocación de elementos y detalles a partir de esquemas previos. Mientras que la comprensión es un proceso de omisión, de quitar los detalles, lo subsidiario, la comprensión busca la esencia, el núcleo, la idea. La construcción parte de una idea y le da forma de discurso.

Uno de los grandes aportes (y tal vez el más pertinente para este trabajo) de Van Dijk en el estudio del texto es el de establecer relaciones entre cognición y discurso y explicar, con las herramientas teóricas que poseía en la década del 70 y principios del 80 , la representación mental del texto y las estructuras discursivas. A continuación se expresan algunas de sus ideas esenciales:

$1^{\text {o }}$ "El significado global, la macroestructura tiene un papel fundamental en la planificación y ejecución del enunciado lingüístico" (Van Dijk, 1983, p. 221).

$2^{\mathrm{o}}$ "El control de la forma esquemática global, la macroestructura y, en especial la estructura y el contenido de la secuencias de oraciones, no es sólo de tipo cognitivo" (Van Dijk, 1983, p. 223). Cita que sorprende porque no sólo da prioridad a lo cognitivo en algunas tareas textuales sino que recuerda que su naturaleza es también lingüística. Con esta afirmación queda clara la posición de Van Dijk en cuanto a los procesos de 
producción discursiva, en los cuales las tareas semánticas son más próximas a lo lingüístico.

Los planes cognitivos, siguiendo esta afirmación, estarían conformados por las macroestructuras y la superestructura como elementos "imprescindibles para la estructura de las intenciones de significado y finalidad en la ejecución de tareas complejas" (Van Dijk, 1983, p. 222).

Cuando hablamos no decimos sonidos, ni fonemas, ni palabras, ni oraciones. Cuando hablamos tenemos la intención de decir algo a alguien, con un significado, y para lograrlo accedemos a instrumentos, elementos y reglas lingüísticas que ofrece el sistema.

Ese producto que resulta de tener una intención comunicativa con valor semántico y darle forma lingüística es lo que se denomina discurso. De este modo el discurso puede estar constituido por un sonido, una palabra, un enunciado o un conjunto de estos últimos, siempre y cuando albergue una intención y un contenido semántico e independiente de la extensión que pueda tener. Hablamos en discursos toda vez que estos pueden ser considerados como unidades completas y funcionales en una situación específica.

Sin embargo, de querer decir algo a decirlo hay un largo proceso que sucede en fracciones de segundo. Este proceso mental interior es lo que se denomina "proceso de producción del discurso" (Garman, 1990, p. 481).

¿Cómo se conoce actualmente el proceso mental que genera el lenguaje y que permite producir discursos? 
Una parte de la respuesta la da la psicolingüística, ciencia que a través de la recopilación, descripción y análisis de los errores lingüísticos, las difluencias y las patologías del habla y el lenguaje ha creado modelos que permiten entender aspectos puntuales del proceso como son el acceso al léxico, la especialización del cerebro, la estructuración sintáctica, los procesos mentales de planificación y monitorización que anteceden a la expresión verbal (Garman, 1990, p. 537). En términos más rudos habrá que admitir que para acceder al conocimiento del sistema lingüístico se investiga en el material de desecho, en lo descalificable y descalificado, en lo equívoco y en lo patológico.

El proceso de producción del lenguaje es complejo ya que se lleva a cabo a través de una serie de operaciones que van desde la planificación del discurso hasta su articulación. (Torras, 1997, p. 195)

Según Torras (1997) este proceso se desarrolla en tres fases: a) Planificación discursiva, que incluye la formación de una intención discursiva que recoge tanto la dimensión semántica como la pragmática. b) Codificación morfosintáctica, según la cual se transforma la intencionalidad en lenguaje material y, c) articulación motora: ejecución de las microproposiciones del nivel anterior en forma observable, o sea en el discurso propiamente dicho.

Esta tarea de producción obedece a procesos de dos tipos: automáticos y controlados. El hablante nativo adulto normal de una lengua es un sujeto que ha incorporado en su sistema, de forma automática, una gran cantidad de elementos léxicos, sintácticos, morfológicos y fonéticos que le permiten elaborar su discurso sin prestar atención a los elementos constitutivos inmediatos. No se detiene, siempre, a pensar qué 
va a decir, cómo debe pronunciar cada elemento de la cadena hablada. Gran parte las tareas del proceso son automáticas.

\subsection{El discurso}

La razón por la cual es pertinente elaborar un marco teórico acerca de la discursividad ya ha sido planteada anteriormente cuando se hacía referencia al hecho real de que los seres humanos nos comunicamos a través de discursos y no mediante palabras, sonidos, frases u oraciones. Discursos que, lógicamente, funcionan y se adecuan a las exigencias del contexto, y es este quien les imprime su sentido definitivo.

Los conceptos de discurso y texto han sido discutidos por los diversos teóricos que estudian el lenguaje, por lo tanto para llegar a formular una definición de discurso, es preciso comenzar por definir aquello que no es un discurso: una suma de oraciones, una super-oración de gran complejidad formada a su vez por otras oraciones. Lo que puede denominarse discurso es más bien un acto comunicativo, proferido en un contexto determinado, y el cual contribuye enormemente a conferir significado y sentido.

Aquí es pertinente aclarar que es mediante discursos como los seres humanos interactuamos y nos comunicamos y no con palabras o con oraciones y mucho menos con simples sonidos articulados. 
Cuando se habla de discurso es necesario también aludir a la definición de texto. Siguiendo la línea de investigación de T. A. Van Dijk ${ }^{19}$, se considera texto al plan global o estructura general que da origen al discurso. En el texto se identifican relaciones que gobernarán el discurso. En este sentido se afirma que el texto es anterior al discurso y una etapa de su planeamiento y organización.

El discurso está concebido, como toda realización de un plan textual, con una intencionalidad determinada y constituido por una secuencia de actos de habla o como mínimo un acto de habla. El discurso constituye, entonces, la parte observable de la producción del hablante, sin importar si es oral o escrita; y el texto estaría constituido por el aspecto no observable de esa producción: el plan, estructuración, y organización mental. Esta es la definición a la cual se acoge la autora de esta tesis doctoral.

Otros teóricos coinciden en afirmar que el discurso es el plan u organización y el texto la realización o manifestación real, ya sea oral o escrita de ese plan. Cualquiera que sea el concepto de discurso o de texto que trabajan los teóricos y al cual se adscriben, hay consenso en lo fundamental y una vez un autor ha decidido qué considerar texto y qué discurso, no queda lugar a las confusiones.

Los teóricos del discurso han planteado una serie de condiciones para considerar como discurso a una determinada porción de habla. La condición más importante e indispensable para la consideración de un discurso es la UNIDAD. Esta debe estar

19 Ver Van Dijk, T. A. La ciencia del texto (1989), Texto y contexto (1983) y en general en todas aquellas obras en las cuales expone sus teorías acerca del discurso. 
sustentada por la intencionalidad como principio pragmático, la coherencia como principio semántico, y la cohesión como principio sintáctico.

La coherencia ha sido definida como la característica según la cual todos los elementos, y especialmente todas y cada una de las proposiciones de un texto, son relevantes, y guardan relación unos con otros.

Según Van Dijk (1989), la coherencia se halla en el nivel macroestructural, que él mismo denomina "estructura semántica profunda", y su proyección a la superficie se realiza mediante reglas de transformación. Al poseer naturaleza semántica tenemos que considerar que en el aspecto macroestructural la coherencia está constituida por una serie de interrelaciones de tipo semántico que se establecen cada vez que se propone un tema. Estas interrelaciones se denominan "isotopías" $20 \mathrm{y}$, en conjunto, constituyen los campos semánticos en los cuales va a funcionar el discurso.

Según Lozano (1989), "la coherencia pertenece a la comprensión y a la interpretación que el lector hace del texto" (p. 27). En este sentido se estaría asignando un valor externo al discurso, y más bien de orden pragmático. Según este autor, la coherencia no es parte inherente del discurso, sino que está en la mente del receptor. Sin embargo, se puede aducir que la posibilidad para comprender e interpretar una producción depende de los elementos que esta posea y de la organización que le imprime el emisor.

\footnotetext{
${ }^{20}$ Se basa en los conceptos de repetición y redundancia, y apunta a la existencia de categorías comunes, elementos similares o compatibles entre sí.
} 
La segunda condición que impone la unidad discursiva, es la cohesión. Consiste en el proceso de ensamblaje de todos los elementos del discurso y especialmente de aquellos adyacentes. El hecho de cohesionar exige unos materiales lingüísticos específicos que cumplen esta misión: entre ellos desempeñan un papel muy relevante los denominados conectores y las conjunciones ${ }^{21}$. Aunque existen también desde el punto de vista gramatical elementos que poseen una cohesión predeterminada, como en el caso del grupo determinante + nombre, cuya presencia es siempre conjunta en el discurso.

Coherencia y cohesión son dos condiciones que se interrelacionan y se complementan mutuamente, de tal manera que no puede existir una sin la otra. Un texto no puede llamarse coherente si sus elementos constitutivos no se encuentran sólidamente relacionados. A la inversa, un texto no puede ser percibido como una serie de elementos ensamblados, si esos elementos no le aportan al significado o no tienen una relación semántica que los vincule.

Según Halliday y Hasan (1976), la definición de cohesión parte de su naturaleza semántica, al igual que la coherencia y supera el nivel superficial del discurso, ya que según ellos se trata de la relación semántica que existe entre un elemento del texto y algún otro elemento que es crucial para la interpretación de este. Este otro elemento también se encuentra en el texto. ${ }^{22}$ Es el nudo por el cual se unen estos dos elementos del texto lo que determina la cohesión.

\footnotetext{
${ }^{21}$ Las conjunciones son categorías gramaticales que se utilizan para ensamblar dos elementos dentro de la oración, mientras que los conectores son de naturaleza discursiva y se utilizan para unir dos enunciados y/o cohesionar partes del discurso.

22 Textualmente: "Cohesion is a semantic relation between an element in the text and some other element that is crucial to the interpretation of it. This other element is also to be found in the text. Pág. 8.
} 
Aparte de estas dos condiciones textuales es imprescindible considerar también la intencionalidad como elemento generador del discurso y elemento que posteriormente modaliza y condiciona la interpretación del texto. Es un elemento que dirige internamente el texto y precisa el sentido con el cual debe ser interpretado.

La intencionalidad se relaciona con las acciones, que en el campo de la filosofía del lenguaje, se estudian bajo la mirada de Searle y Austin. La intencionalidad actúa como base de la pragmática lingüística, ya que sobre este concepto se construye el concepto de acto de habla.

Un acto de habla consta de tres momentos: un momento locutivo: cuando se dice algo; un momento ilocutivo, que corresponde a la intencionalidad de quien emite el acto y un momento perlocutivo que hace referencia al efecto del acto de habla. Lo que sucede por emitir el acto.

Según Austin, gran parte de los enunciados pueden ser considerados como ilocutivos en tanto poseen una intencionalidad. Austin plantea que el acto ilocutivo representa el acto de habla por excelencia.

Etimológicamente, intención se deriva de INTUS TENERE 'tener algo dentro', y alude justamente al hecho de que la intención no siempre se manifiesta en la superficie, es mental o interna al sujeto que habla. Depende de la voluntad.

Jesús Mosterín, en el prólogo a Anscombe (1991), señala que existen dos tipos de cosas que distinguimos intuitivamente: las que hacemos y las que nos pasan: "En las cosas 
que hacemos, hay una cierta causalidad o iniciativa de parte de nosotros. En las cosas que nos pasan, nos limitamos a ser receptores de efectos que nosotros no hemos iniciado" (p.9).

Más adelante, Mosterín distingue la acción voluntaria, de la acción involuntaria: "Entre las cosas que hacemos, unas las hacemos voluntariamente, porque queremos hacerlas, mientras que otras las hacemos sin querer" (p.9).

En este trabajo interesa fundamentalmente la acción voluntaria o intencional que Mosterín en la introducción a la obra de Anscombe define claramente: "Hacemos voluntaria o intencionalmente las cosas que hacemos, queriendo hacerlas... a sabiendas y adrede, aposta. En esos casos decimos que tenemos la intención o el propósito de hacer lo que hacemos" (p.9).

Más adelante, distingue entre las acciones intencionales premeditadas y no premeditadas y pone como ejemplo una conversación: "Cuando mantengo una conversación, actúo intencionalmente, digo lo que quiero decir, pero, normalmente, no he preparado de antemano lo que voy a decir, sino que me entero de lo que voy a decir diciéndolo. A cada una de las oraciones que profiero acompaña la intención de decirla, pero esa intención no la precede, al menos no precede a la conversación misma" (p. 12).

La cita de Mosterín es afortunada, puesto que justamente de eso se trata la producción oral como se está pensando en esta tesis. Cuando participamos en una conversación, la producción discursiva es simultánea con la planificación: planificamos sobre la marcha. Según palabras de Briz "se ha de planificar sobre la marcha" (Briz, 
1996: 53) como una característica de la oralidad coloquial: "la planificación sobre la marcha del lenguaje hablado espontáneo" (Briz, 1998: 41). En este sentido se relaciona estrechamente la conversación con la ausencia de premeditación, toda vez que como dice Mosterín: "Me entero de lo que voy a decir diciéndolo". 


\subsection{El discurso narrativo}

\subsubsection{Superestructura}

“La vida no es la que uno vivió, sino la que uno recuerda y cómo la recuerda para

contarla"

\section{Gabriel García Márquez}

En cuanto a la producción narrativa de nuestros informantes ${ }^{23}$ cabe aclarar que no podemos relegar sus discursos a un sistema de producción oral neto. Conciernen a un sistema de producción oral de naturaleza narrativa y aquí surge una complicación. Al modelo de producción que se elija para explicar el proceso, es necesario agregar una gramática narrativa; siguiendo a Lotman (1970), un sistema de modalización secundaria, ya que nuestros informantes no solo hablan sino que además narran ${ }^{24}$. No solo describen una situación, sino que además organizan la información y la experiencia vivida en forma de narración.

El término superestructura aparece en Van Dijk (1983, p. 143) con la vacilación natural para ese momento histórico, en que esta denominación alternaba con la de hiperestructura. No ha cambiado, de entonces hasta hoy, el uso que en la ciencia

\footnotetext{
${ }^{23}$ En este ítem se observa la adecuación a un género propuesto por el entrevistador. Ante la solicitud: "cuénteme una experiencia de su vida", presentada por quien realiza la entrevista, únicamente queda abierta la posibilidad de responder con una narración, ya que este género discursivo es el que atiende a la premisa de contar.

24 Acerca de los aspectos cognitivos de la producción narrativa Milagros Garate (1994) elabora un cuidadoso seguimiento en español de la obra de Van Dijk (1972), en el apartado titulado: "las gramáticas del texto y de la narrativa", pp. 40-45.
} 
lingüística se asigna a este concepto y ya en ese libro se planteaba claramente que se trataba de la clasificación en la cual se podía inscribir un texto en virtud de dos elementos fundamentales: la función comunicativa y el tipo de construcción.

La definición que planteaba Van Dijk (1983): “denominaremos superestructura a las estructuras globales que caracterizan un tipo de texto" (p. 142), continua vigente y constituye un punto de partida fundamental en la caracterización y tipología de los discursos. Partir de una superestructura o una "forma de texto" es hablar de un andamiaje formal que caracterizará el desarrollo de un discurso y viceversa. Cada vez que nos enfrentamos a un discurso como producto tratamos de inscribirlo en virtud de su forma y de las relaciones que se establecen entre sus elementos, en un tipo de texto, en un género. Decimos de él que es una descripción una conferencia, un coloquio, entre otros muchos.

\subsubsection{Caracterización de los textos del corpus}

De acuerdo con la caracterización establecida por Bárbara Sanding (1972) ${ }^{25}$, resulta pertinente clasificar y tipificar los textos atendiendo a oposiciones de rasgos situacionales o comunicativos. Esta tipificación genera un haz de rasgos para las narraciones orales que componen el corpus recopilado, que vendrá a caracterizarse de la siguiente manera:

+ Hablado

- Espontáneo

+ Monológico

${ }^{25}$ Citado por Ciapuscio (1994, pp. 42-43). 
+ Contacto espacial

+ Contacto temporal

+ Contacto acústico

+ Construcción textual preestablecida

+ Tema preestablecido

+ Primera persona

+ Redundancias

+ Signos no verbales

- Participantes de la comunicación con iguales derechos

+ Formas económicas

A continuación se comenta brevemente cada uno de estos rasgos:

+ Hablado: se trata de una grabación que posteriormente se transcribe.

- Espontáneo: la situación en la cual se solicita permiso para grabar y se graba, se intenta hacer espontáneamente pero no lo es en el sentido en que no se trata de una situación real sino de una situación premeditada. Esta circunstancia trata de evitarse hablando largo rato con los entrevistados antes de comenzar la grabación para hacerlo entrar en confianza y que olviden la grabadora, sin embargo no hay un éxito total en este aspecto.

+ Monológico: ya que en lo posible se deja al informante contar su experiencia intentando no interrumpirle o hacerlo lo menos posible. La intervención del entrevistador es en la mayoría de los casos de carácter fático únicamente. 
+ Contacto espacial, temporal y acústico porque el entrevistador y entrevistado tienen contacto cara a cara, se ven y se escuchan en las mismas coordenadas espacio/temporales.

+ Construcción textual preestablecida: en este caso se pide que cuente una experiencia de su vida con lo cual la construcción textual se podría enmarcar dentro de la narración biográfica.

+ Tema preestablecido: como no se trata de un contacto habitual no se podría expresar con absoluta convicción que exista un tema para este tipo de eventos. Sin embargo, en la mente del entrevistador hay un tema preestablecido y, con las charlas anteriores a la grabación en las que se realiza una aproximación al informante, se le ha expresado el deseo de conocer experiencias de su vida.

+ Primera persona: al ser una narración autobiográfica se cuenta en primera persona en la mayoría de los casos.

+ Signos no verbales, redundancias y formas económicas (tales como interjecciones y gestos) son características de la expresión oral espontánea y coloquial, con lo cual estas características están presentes en el corpus recopilado.

- Participantes en la comunicación con iguales derechos: no se ve así porque el informante espera que se le dé la palabra y en general se somete a las normas del entrevistador.

Esta clasificación por rasgos se convierte en punto de partida para tipificar los discursos de los informantes como objeto de análisis y posterior evaluación. Así mismo 
permite visualizar con claridad qué elementos son normales y esperables en cada tipo de discurso.

\subsubsection{La narración}

Está claramente definida como un tipo de discurso. En sí misma mantiene una caracterización y una identidad muy particular. La narración relaciona una serie de acontecimientos, cuenta una experiencia propia o ajena, requiere ser contada por alguien que asume la posición de narrador y toma posición frente a lo que cuenta. Permite al narrador organizar los hechos y dotarlos de significado. Esto significa que cuanto más se narre un acontecimiento más coherente resultará la narración y más sentido tendrá para sus interlocutores.

La narración, al presentar definición, elementos, características y condiciones propias, actúa como superestructura. Labov (1972) define la narración como un "método de recopilación de la experiencia pasada a una secuencia de procesos que (se supone) ocurrieron realmente"26. Y posteriormente señala los elementos que puede presentar la narración: “resumen, orientación, complicación de la acción, evaluación, resultado o resolución y coda" 27 .

La estructura del texto narrativo la describe también Jean M. Adam (1992; 1987). Según él, esta consta de las siguientes partes:

\footnotetext{
${ }^{26}$ No necesariamente la narración debe relatar hechos pasados, puede hacerse sobre el presente o el futuro. ${ }^{27}$ citado por Silva Corvalán, (1987) pág. 207.
} 
1. Resumen o prefacio.

2. Orientación o situación inicial.

3. Complicación.

4. Acción - desarrollo de la narración.

5. Resolución.

6. Evaluación.

7. Coda.

En este sentido se piensa en un discurso narrativo completo. Nuestro trabajo partirá de esta estructuración, de modo que al evaluar las narraciones de los informantes se tendrá en cuenta si aparecen o no todas las partes propuestas por Adam. Si estas no aparecen es imprescindible que se manifiesten la orientación o situación inicial, la complicación, las acciones y la resolución.

La manera de narrar depende de varios factores:

- El primero, por supuesto, es el narrador: su estilo, su personalidad, su memoria y sus habilidades narrativas particulares.

- El segundo es la audiencia, el público o el interlocutor. A quien va dirigida la producción determina cómo se contará, la estructura, la organización, la relevancia de un elemento frente a otro, el léxico, la entonación, la pronunciación, el cuidado, el descuido y en general, una serie de características únicas. 
- El momento histórico: las palabras tabú, los hechos políticos, los miedos, los temores, la nostalgia, entre otros elementos, contribuyen a configurar la narración.

- El episodio. El hecho que se va a narrar impone sus propias características a la narración, las cuales dependen de la distancia que toma el narrador frente al acontecimiento, del impacto que el hecho genera en la memoria, la mente y los sentimientos de quien narra. Estas características se hacen notorias principalmente en el énfasis que se pone sobre determinados segmentos de la narración, del acompañamiento de gestos, mímica o entonaciones especiales, etc.

Los teóricos plantean algunas funciones importantes para las narraciones. A continuación se citan las que propone McCabe (1991) en el texto de Bernstein y Gleason $(1999)^{28}$ :

1. Hacen posible que las experiencias de las personas cobren sentido en una forma que resulte culturalmente satisfactoria.

2. Presentan al narrador bajo una determinada perspectiva (como héroe o como víctima. Se puede añadir aquí que el narrador puede ser testigo, observador u evaluador).

3. Convierten los acontecimientos del pasado en presente y transforman los conceptos abstractos en algo vivo.

\footnotetext{
28 Adaptado y resumido por la autora, del texto original que aparece en la página 315 del libro de Gleason y Bernstein (1999).
} 
4. Forjan relaciones ${ }^{29}$.

Según Bassols y Torrent (1996) los elementos comunes a toda narración “se pueden reducir a los tres siguientes: actor fijo, proceso orientado y complicado y evaluación" (p. 169).

El primer elemento “favorece la necesaria unidad de la acción” (p. 169), en el caso del presente estudio, y por tratarse de narraciones autobiográficas, sucede, generalmente que este actor fijo es el informante mismo. Él es el centro de la acción y en torno a él giran otros personajes: su familia, sus amigos, sus conocidos. Se convierte en actor protagonista de la historia y en eje de las acciones; sostiene una relación estrecha entre actor y acción por cuanto se constituye en agente o en paciente de las acciones. "Le voy a contar algo que me pasó teniendo yo como 10 años".

En algunos casos se trata de un actor testigo y en ese caso su presencia es de tipo funcional, está presente para contar, para ver lo que sucede y transmitirlo a otros.

El siguiente elemento fundamental de la narración es decisivo para este trabajo. Se trata del proceso orientado y complicado. El informante debe enlazar dos o más hechos como requisito de la narración. Según Bremond 30 “donde no hay sucesión no hay relato". Si no existen dos acciones o dos hechos conexos, no se puede hablar de complejidad del proceso, y por tanto, desaparece el elemento esencial del relato.

\footnotetext{
${ }^{29}$ Esto significa que al grado de intimidad, entre las personas, se mide, según el autor, por la cantidad y el tipo de narraciones que comparten.

${ }^{30}$ Citado por Bassols y Torrent (1997), pág 170.
} 
La moralidad: el tercer elemento planteado por Bassols y Torrent (1996) es la evaluación y que según las autoras se convierte en "motor que genera el relato" (p. 172). Las autoras plantean la evaluación en el sentido de moralidad o enseñanza para el destinatario. Cabe destacar la apreciación que aparece más adelante, con respecto a la evaluación y según la cual no es necesario "que sea explícita y a menudo sucede que la evaluación final se infiere del relato pero no se incluye en él” (p. 172). Esta afirmación es precisa para mostrar que aunque este elemento confiere sentido al relato y en ocasiones determina una finalidad, no es imperativo que se haga una valoración manifiesta. Otros autores, entre ellos Jean Michel Adam (1990) y Van Dijk (2007) destacan el valor de la evaluación ${ }^{31}$ como elemento crucial de la narración.

A propósito de la narración como superestructura, es preciso citar aquí la afirmación de Juncos (1998) al respecto: “La capacidad de construir historias, basándose en una superestructura o guion, pertenece al conocimiento del procedimiento por el cual los sujetos han aprendido que para contar algo tienen que situarlo en un escenario, desarrollarlo en el tiempo y darle un final." 32

Según Álvarez (1993), la narración debe poseer tres elementos fundamentales: la acción, los personajes y el ambiente. Con respecto a la acción afirma tajantemente: "En toda narración es fundamental que pase algo" ${ }^{33}$. Y continúa diciendo, "La acción puede estar ordenada en forma progresiva, esto es, siguiendo cronológicamente los hechos a medida que van apareciendo hasta llegar a un desenlace." 34

\footnotetext{
${ }^{31}$ Más adelante se trata la evaluación no solo como elemento global de la narración sino como habilidad discursiva y metadiscursiva.

32 Pag. 60

33 Pág. 20

34 Pág. 20
} 
También propone el tipo de narración que rompe con el orden cronológico y relata los hechos partiendo de un momento avanzado y yendo hacia atrás o hacia delante en el desarrollo de las acciones. Lo que queda claro es que fundamentalmente debe proponerse una secuencia de acciones, desarrolladas por unos personajes, en un ambiente determinado ${ }^{35}$.

\subsubsection{Macroestructura temática}

\subsubsection{Tema}

Es un elemento aglutinador en el discurso. Parte esencial de la macroestructura que permite derivar las relaciones semánticas presentes en el discurso. El tema funciona también como eje semántico del texto y por lo tanto como elemento central de la coherencia.

Para el análisis de los discursos interesa particularmente considerar el hecho de que exista un tema central que atraviese el discurso, es decir, que ese tema debe ser planteado al comienzo desarrollado a lo largo de la producción discursiva y concluido al finalizar el discurso.

Cambiar el tema, sin razón aparente, o saltar de un tema a otro demerita la unidad discursiva.

\footnotetext{
35 Esta caracterización de la superestructura narrativa da lugar a los indicadores de evaluación dentro del instrumento propuesto en el capítulo siguiente.
} 
Interesa particularmente, no solo plantear un tema como eje del esqueleto macroestructural, sino establecer una progresión temática; esto significa añadir o agregar elementos informativos nuevos que permitan un crecimiento y desarrollo discursivo. Algunos autores denominan a este juego temático información conocida, vieja o tema, en contraposición a información desconocida, nueva o rema.

En el ensamblaje discursivo es necesario mantener una información conocida y progresivamente incorporar elementos novedosos. Este juego posee dos funciones fundamentales: primero, la función de unificar el discurso y mantener un eje central común y, segundo, la función de despertar el interés del destinatario. La segunda función asegura el crecimiento de la narración y el éxito de la interacción.

El concepto de progresión temática alude a las diversas formas en que se articulan sucesivamente temas y remas en un texto.

\subsubsection{Coherencia discursiva}

La coherencia ha sido definida como la característica según la cual todos los elementos y especialmente, todas y cada una de las proposiciones de un texto, son relevantes y guardan relación unos con otros.

"Hoy en día la coherencia se considera como una propiedad global de los sistemas cognitivos" (López García, 1999, p. 350). Afirmación que ubica la coherencia en el nivel cognitivo de la producción del discurso antes que en el nivel lingüístico, con lo cual se explica la dificultad para demostrar la presencia o ausencia de coherencia en un discurso 
por métodos lingüísticos y hace obligatorio recurrir al nivel más profundo de la génesis discursiva para intentar justificar su presencia en el producto oral.

La coherencia se dirige fundamentalmente a los conceptos y su interrelación. Es una propiedad subyacente del texto, con lo cual define su carácter semántico y su carácter más próximo a lo textual como nivel generador que a lo discursivo como manifestación en una forma discursiva concreta.

Bernárdez (1987) habla de un productor y un intérprete cuando se refiere a los actores-constructores de la coherencia del texto y con ello da por hecho el papel activo de los dos participantes en el proceso de determinar la coherencia del texto.

A pesar de que desde los inicios de la teorización textual se ha hablado de los requerimientos de coherencia en los productos de los hablantes y escritores y de los mecanismos para crear coherencia o para encontrarla en un producto terminado, hoy se reconoce abiertamente, siguiendo a Van Dijk, que la coherencia no reside tanto en el texto como en la mente de los hablantes. ${ }^{36}$

Según Bernárdez (1987, p. 212 37 ) la coherencia o incoherencia de un texto es una percepción del intérprete y varía de un intérprete a otro para un mismo texto. La precisión

\footnotetext{
${ }^{36}$ Esta afirmación aparece tanto en sus obras como en varias conferencias que ha dado y de las cuales la autora ha tomado nota.

37 "La coherencia puede (y debe) verse en un continuo, desde la falta absoluta hasta su comprensión idéntica por cualesquiera hablantes intérpretes. En realidad, ambos extremos son improbables y limitados: la incoherencia total se produciría en la infructuosa tarea de interpretar un texto escrito en alguna lengua totalmente desconocida, mientras que la coherencia plena sería sólo posible, me temo, cuando intérprete y autor sean la misma persona (y aún entonces resulta improbable llegar al 100\% de coherencia). Todos los casos, entonces, se situarán sobre un continuo. De manera que un texto, un mismo texto, puede ser coherente para unos intérpretes y no para otros, a unos les puede parecer totalmente coherente y a otros solo parcialmente o nada" (p.212).
} 
que añade Bernárdez radica en considerar lo coherente como un "continuo", como un grado en la escala que va desde cero (0) o falta total de coherencia hasta $100 \%$ de coherencia (extremos ambos que él considera improbables).

Introducir la idea de grado en el concepto de coherencia es más cercana a la realidad textual y más actual en cuanto a la concepción misma de coherencia; sin embargo genera una dificultad en la evaluación del discurso, ya que introduce el fantasma de la subjetividad según el cual la percepción de la calidad de un discurso, al menos en este ítem, sería producto de la forma en la cual lo perciba el evaluador, aunque se propongan indicadores para su determinación.

El ideal de coherencia es planteado por Bernárdez, como:

El equilibrio entre la imagen mental del productor que se expresará lingüísticamente en un texto y la obtenida por el intérprete a partir de su interpretación del texto. Cuando lo que quiere decir el hablante es equivalente a lo que entiende el oyente. (2004, p. 214)

La noción de isotopía remite a lo que Adam (1990) denomina cohesión semántica. Greimas (2002, p. 142) defensor y padre de la noción de isotopía, la define como el efecto de la recurrencia de un tema. Se mantiene una redundancia de categorías que hace posible la lectura uniforme de un enunciado.

Según Van Dijk (1989), la coherencia se halla en el nivel macroestructural, que él mismo denomina estructura semántica profunda. Su proyección a la superficie se realiza mediante reglas de transformación. Al poseer naturaleza semántica tenemos que 
considerar que en el aspecto macroestructural la coherencia está constituida por una serie de interrelaciones de tipo semántico que se establecen cada vez que se propone un tema. Estas interrelaciones se denominan isotopías ${ }^{38} \mathrm{y}$, en conjunto, constituyen los campos semánticos en los cuales va a funcionar el discurso.

El concepto de isotopía es relevante para la coherencia en tanto su presencia permite la construcción de campos semánticos y con ello genera una condición de homogeneidad que es el soporte de la coherencia textual. El fundamento de la isotopía es su iteratividad ya que a través de ella se genera una red mental que construye significado y así da lugar a los campos semánticos. Según Rastier (1972 p. 82) isotopía es “toda iteración de una unidad lingüística". Para la evaluación que se propone en el capítulo siguiente se tomará la isotopía únicamente desde el punto de vista semántico, aunque algunos autores consideran isotopías en otros niveles de la lengua. Un ejemplo de redes isotópicas que configuran un campo semántico surge en el cuento Almas con olor a cebolla de Cecilia Courtoisie Nin. En este aparecen las palabras y expresiones: "algo especial en las manos", "Sus dedos gruesos hablan", "dolor atrasado", "estómago oprimido", "los huesos sufren, pero se callan", "seres que explotan de vida, de angustia". En este cuento se muestra la angustia reflejada en el cuerpo de una mujer. En su manos, sus dedos, sus huesos, su estómago.

Según Lozano et al. (1989), "la coherencia pertenece a la comprensión y a la interpretación que el lector hace del texto" (p. 27). En este sentido se estaría asignando un valor externo al discurso, y más bien de orden pragmático. Según este autor, la

\footnotetext{
${ }^{38}$ Se basa en los conceptos de repetición y redundancia, y apunta a la existencia de categorías comunes, elementos similares o compatibles entre sí.
} 
coherencia no es parte inherente del discurso, sino que está en la mente del receptor. Sin embargo, se puede aducir que la posibilidad para comprender e interpretar una producción depende de los elementos que esta posea, y de la organización que le imprime el emisor.

Según Charolles (1989) la coherencia no es solamente un principio que rige la comprensión o la interpretación del discurso, tal y como lo han expuesto los autores que intentan explicar la comprensión discursiva acudiendo al principio de coherencia discursiva, sino también un principio que regula la emisión discursiva ${ }^{39}$ y distribuye instrucciones interpretativas acordes con un razonamiento (o cálculo) que tiene en cuenta:

- Su plan (o proyecto) de comunicación al momento preciso del proceso discursoproducción.

- Su representación de las habilidades interpretativas del receptor.

El concepto de coherencia aparece en Patry y Nespoulous (1990) y también Charolles (1990), Van Dijk y Kintsh (1990) como un principio general que gobierna la interpretación de las acciones humanas. La coherencia, según estos autores, no está especialmente centrada en el lenguaje sino principalmente en el análisis de cadenas de hechos y de eventos, sin precisar el medio por el cual se expresen.

\footnotetext{
${ }^{39}$ Charolles trabaja específicamente en la producción del discurso escrito, y sobre problemas generales de producción del habla y estrategias en el planeamiento del discurso, recomienda ver Zammuner, 1981.
} 
La macro-continuidad del discurso se logra a través de la coherencia. La mayor diferencia entre cohesión y coherencia -según los autores mencionados- es que la primera tiene que ver con relaciones semánticas del nivel de la palabra, y la segunda con procesos discursivos de más alto nivel (higher-discourse processes), no siempre realizados en material lingüístico.

Schiffrin (1985, p. 21) por otra parte, no es tan exhaustiva en su consideración sobre la coherencia. (La autora) establece que a pesar de que el concepto de coherencia es central para el análisis del discurso, es notoriamente difícil de definir. Añade que aunque normalmente tenemos una intuición de por qué un fragmento discursivo es coherente o incoherente, no contamos con un sistema de principios que dé cuenta de esas intuiciones y mucho menos un sistema de predicción de cuáles secuencias de elementos serán interpretadas como coherentes. Ella propone un modelo del discurso en el cual la estructura discursiva, el significado y la acción son integradas por los hablantes y los oyentes en un esfuerzo mutuo de construcción de la coherencia.

Propone la autora que tanto los marcadores discursivos como ciertas secuencias de preguntas y respuestas para aclarar situaciones en el discurso (quests for clarification), o las enmiendas (repairs) funcionan como hitos, como señalizaciones que indican a los participantes en el acto discursivo cuáles son los caminos a seguir. De este modo, los marcadores discursivos del tipo “oh”, “ah”, “bueno”, “y”, “pero”, “o”, “pues”, “o sea”, "tú sabes”, “entonces”; las secuencias aclaratorias explícitas o implícitas del tipo “¿Qué quieres decir?” “Cómo?” "Quiero decir”, “es decir”, “o sea”; y las enmiendas iniciadas 
por el hablante o el oyente, cada uno a su manera, evalúan la contribución propia y la del interlocutor y conducen el barco del discurso al buen puerto que se llama coherencia ${ }^{40}$.

Hemos señalado anteriormente que, de manera general, se ha propuesto que la coherencia depende en alto grado de la cohesión, es decir, de las interrelaciones semánticas entre los diferentes elementos léxicos del discurso o del texto. El estudio de las perturbaciones lingüísticas en la afasia nos proporciona interesantes datos para contribuir a la discusión sobre la relación entre la coherencia y la cohesión lingüísticas.

\subsubsection{Cohesión discursiva}

Llamada también conectividad o conexión (Van Dijk 1989: 83), es una de las propiedades esenciales del texto (junto con la intencionalidad y la situacionalidad), y se refiere más directamente a su estructura interna. En este orden de ideas, en todas las lenguas existen procedimientos especiales para la constitución de textos. Estos presentan una organización que los hace inteligibles, los cohesiona y los integra.

En consecuencia, cuando observamos un texto nos damos cuenta de que algunas de las oraciones que lo integran no podrían aparecer aisladamente. Este fenómeno ha sido obviado por la gramática tradicional porque sobrepasaba los límites de la oración. Sin embargo, la moderna gramática del texto recupera su estudio.

\footnotetext{
${ }^{40} \mathrm{Si}$ bien es cierto que la coherencia de un discurso es un tanto abstracta y subyacente, no es exacto que la coherencia sea una construcción interactiva entre los participantes, ya que en ocasiones existen interlocutores no colaboradores o no se da interacción y sin embargo no puede hablarse de ausencia de coherencia.
} 
Por otro lado, la cohesión está constituida por el conjunto de todos aquellos procedimientos lingüísticos que indican relaciones entre los elementos de un texto. Esta característica proporciona trabazón entre los constituyentes del texto, pero no garantiza por sí sola la coherencia del texto.

A la cohesión de un texto contribuyen múltiples y variados procedimientos, como la recurrencia (total o parcial) de elementos o estructuras, la paráfrasis, la sustitución, así como los tiempos verbales, el aspecto, los marcadores u operadores discursivos y, en el caso de los textos orales, la entonación.

\section{Procedimientos de cohesión textual}

\section{1) La recurrencia}

La recurrencia es la repetición de un elemento del texto en el texto mismo y se considera como uno de los procedimientos fundamentales de cohesión textual. Existen distintos tipos:

- Mera reiteración léxica. Se repite un elemento léxico en su identidad material y semántica.

- Repetición léxica sinonímica. Se reitera el significado de un elemento utilizando un sinónimo léxico. Son raros los casos de sinónimos totales.

- Repetición léxica de lo designado. Se produce identidad referencial o coincidencia en la designación extralingüística (correferencia): balón, esférico, pelota, cuero... 
La recurrencia suele ir asociada a determinadas piezas lingüísticas con valor anafórico o catafórico: el artículo, los demostrativos, elementos como "tal”, "semejante", "tanto..." El artículo que posee relevancia cohesiva se fundamenta en el conocimiento general del mundo y en el hecho de compartir unos mismos presupuestos culturales: "Había un naranjo en el patio. Tenía las ramas secas".

\section{2) La sustitución}

La sustitución consiste en la reiteración de una determinada unidad del texto mediante empleo de proformas de contenido muy general, especializadas en esta función sustitutoria. Casado Velarde (1991) distingue entre proformas léxicas, pronombres y proadverbios.

Las proformas léxicas son lexemas especializados en la sustitución que pueden tener un valor nominal (palabras baúl) o un valor verbal (verbo hacer, etc.). El verbo "hacer" y otras proformas léxicas pueden emplearse también con función catafórica: ¿Qué hace? Leer". Solo sustituye a verbos que significan acción pero no a los verbos caracterizados con el significado de estado.

Los pronombres personales, en este caso solo los de tercera persona, pueden considerarse sustitutos textuales, es decir, sustitutos de elementos ya aparecidos: "Ayer llegaron Elisa y Luis. Él estaba contento, ella no". Las formas "él” y "ella" anteriores cumplen una función endofórica: remiten a unidades del texto. A veces pueden referirse 
a unidades que están fuera del texto y entonces son unidadades exofóricas, como cuando se emite "Él dice que no" mientras se señala a la persona en cuestión.

Por otra parte, los pronombres personales de primera y segunda persona se usan siempre con función exofórica, por lo que solo se consideran sustitutos textuales los de tercera persona. También poseen función sustitutiva textual los reflexivos, recíprocos, relativos, indefinidos, posesivos y demostrativos.

\section{3) Estructuras: función informativa y orden de los constituyentes}

La organización de un texto también contribuye a la cohesión. Se puede, básicamente, estructurar en torno a dos ejes: tema y rema. Se entiende por tema la información que se considera ya conocida. Rema sería la información que se presenta como nueva.

Mathesius (1928) considera que la estructuración del contenido puede seguir dos modelos: un orden objetivo (el tema antecede al rema) y uno subjetivo (el rema antecede al tema).

Existe la teoría generalizada de que todos los enunciados poseen una estructura informativa bimembre (tema y rema); sin embargo Casado Velarde (1991) señala la existencia de enunciados bimembres (los llama categóricos) y unimembres (los llama téticos). El enunciado tético establece, según el autor, un hecho de modo global y posee, por ello, estructura informativa unimembre; un enunciado categórico representa una predicación acerca de un actante y es, por ello, bimembre. 
El enunciado tético puede subdividirse en:

- Enunciado presentador de existencia. Establece la existencia de un hecho, de una cosa o de un actante: "Hay pan".

- Enunciado presentador de un suceso. Contienen actantes pero la atención no se concentra en ellos: "Llamaron por teléfono"

En español, según Casado Velarde (1991), la oposición tética a lo categórico se realiza a través del orden de los constituyentes del enunciado. La estructura tética puede tener varios actantes en función de lo que aparezca detrás del verbo.

Son frecuentes las construcciones téticas en español con actante indeterminado y verbo en tercera persona del plural: "Dijeron que..." Importantísimo aspecto en un hipotético comentario.

Uno de los fenómenos más relevantes relacionados con el orden de constituyentes es la topicalización. Consiste en la selección de un elemento como "tópico" o tema de la predicación. En español existen diferentes formas de marcar esa selección: asignando al elemento topicalizado la posición inicial, o bien -si esa posición ya le correspondeseparándolo del resto de la oración por una pausa: “Antonio, ¿cuándo vendrás?”

Existen en español algunos marcadores especializados en la función tematizadora o topicalizadora, tales como "en cuanto a", "por lo que se refiere a", etc. Ejemplo: "En cuanto a ventas, vamos bien". 
Un procedimiento tematizador frecuente en la lengua coloquial es la reduplicación léxica. El tema aparece en infinitivo y el verbo se repite luego en forma personal: "Llegar, llegaron, pero tardísimo".

Con adjetivos se puede hacer también. Este mantiene la concordancia: "Listo, es muy listo, pero vago".

Cuando el componente tematizado es una frase nominal determinada, no se admite la repetición, sino que debe aparecer un pronombre átono correferencial con la frase: "El bacalao, (sí que) lo odia".

\section{4) Los marcadores discursivos}

Son elementos lingüísticos (“o sea", "pues", "por ejemplo...”) que marcan relaciones más allá de los límites oracionales. Han recibido diversas denominaciones. Existe gran dificultad para deslindar el valor general del valor ocasional. Son piezas multifuncionales.

Presentan una gran heterogeneidad gramatical (conjunciones, locuciones, etc.) pero, al mismo tiempo, coinciden en su carácter invariable y en su casi total lexicalización. Casado Velarde (1991) engloba todas estas formas bajo la denominación general de marcadores de función transoracional.

José Portolés (1998) define los marcadores como: "Unidades lingüísticas invariables, no ejercen una función sintáctica en el marco oracional y poseen un cometido 
coincidente en el discurso: el de guiar, de acuerdo con sus distintas propiedades morfosintácticas, semánticas y pragmáticas, las inferencias que se realizan en la comunicación" (pp. 25, 26). Portolés incluye los conectores como una categoría que hace parte de los marcadores discursivos, Se hace énfasis en la categoría conector dentro de este título, ya que son las categorías directamente encargadas de mantener la cohesión.

Portolés (1998) y Portolés y Martín Zorraquino (1999) señalan 3 tipos de conectores: 1.Conectores Aditivos: "Unen a un miembro discursivo anterior otro con la misma orientación argumentativa" (Portolés 1998, p. 139). 2. Conectores consecutivos: "Presentan el miembro del discurso en el que se encuentran como una consecuencia de un miembro anterior" (p. 139). 3. Conectores contraargumentativos: "Vinculan dos miembros del discurso de tal modo que el segundo se presenta como supresor o atenuador de alguna conclusión que se pudiera obtener del primero"(p. 140). 
4. MODELO DE EVALUACIÓN DE LA

ORALIDAD 


\subsection{Elaboración de un instrumento de evaluación}

Se pretende aquí describir la manera como se llega a plantear un instrumento de evaluación del discurso narrativo oral.

En primer lugar se plantean las características del discurso oral tomando como referencia las teorías actuales del análisis del discurso, como Van Dijk, Briz, Moreno Fernández, Tusón Valls; la teoría conversacional y los temas específicos de descripción del lenguaje oral que apuntan a elaborar una gramática del mismo.

A partir de las características de la producción oral se construye una lista de indicadores que dan cuenta de la calidad de un discurso en virtud de la ocurrencia o coocurrencia de determinados fenómenos en cada producción.

Es pertinente observar que algunos hablantes presentan características patológicas del discurso; aquellas que se derivan de los cambios propios de la edad y que se conocen con el nombre de "deterioro cognitivo".

El instrumento que aquí se presenta pretende evaluar, pues, la calidad de los discursos de determinados hablantes de español. 
Un instrumento de evaluación, en este contexto, es fruto de un análisis que tiene su fundamentación teórica en el campo de la lingüística aplicada; en concreto, es sobre todo una aplicación de los conceptos y características planteadas por el análisis del discurso y la conversación. Se inscribe en el ámbito de la lingüística aplicada en el sentido en el cual no se hace ningún planteamiento teórico, no se profundiza en un campo del saber específico, sino que más bien se aplican los saberes constituidos, derivados de un área del conocimiento, el análisis del discurso, a un corpus de trabajo constituido para tal fin.

Llegar a este punto implica que hay una madurez teórica desde el punto de vista del análisis discursivo. Esto significa que el análisis del discurso ha sido probado en diferentes contextos ${ }^{41}$ y comunidades ${ }^{42}$ y ha dado resultados satisfactorios. Por atender al mayor número posible de fenómenos discursivos y por el grado de adherencia entre sus partes. Esta solidez garantiza el éxito de un proyecto de estas características.

El instrumento se basa en el planteamiento de una serie de indicadores mediante los cuales se puede medir el desempeño discursivo de un hablante. En este sentido es pertinente mencionar uno a uno el alcance de los términos que componen este epígrafe.

El término indicadores se refiere a una serie de parámetros que por su presencia, ausencia o co-presencia contribuyen a indicar el grado de calidad de un discurso.

\footnotetext{
${ }^{41}$ Cabe mencionar aquí los estudios realizados desde comienzos de la década de los 80 y en los cuales se analizaron obras literarias de todo tipo a la luz del análisis discursivo. Posteriormente se pasa al análisis de textos periodísticos y de allí a textos científicos. Pero el gran reto lo constituye el análisis de la conversación y el discurso coloquial.

42 Se ha hecho aplicaciones en comunidades educativas, alumnos de lenguas extranjeras, en niños, universitarios y grupos minoritarios etc.
} 
Cada uno de los indicadores representa un elemento constitutivo de una característica observable en el discurso. Este indicador debe ser comparado con un referente o estándar, el cual consiste en el resultado que se debe lograr y hacia el cual hay que aproximarse. En este caso, el análisis del mismo como teoría señala los lineamientos ideales que debe cumplir el discurso. En este sentido, el desempeño discursivo ideal sería aquel que cumpliese con todas las condiciones y mecanismos propuestos por la lingüística textual.

El indicador en este caso particular expresa información tanto cuantitativa como cualitativa respecto del producto generado por el hablante.

Si tenemos en cuenta las cuatro habilidades psicolingüísticas fundamentales: hablar, escuchar, leer y escribir, se ha atendido en esta investigación únicamente a la producción discursiva hablada. La decisión anterior implica que se han descartado metodológicamente las otras habilidades para atender únicamente a la producción oral. Pero aún existen más restricciones: dentro del campo de la producción oral se atiende únicamente a la producción narrativa y, dentro de ella, se trabaja solamente en el campo autobiográfico de las historias de vida. "Cuénteme una experiencia de su infancia o de su vida" era, recuérdese, el estímulo utilizado.

Es preciso señalar que este instrumento de evaluación se aplica directamente en el producto y en ningún momento en el proceso. Con lo cual se pretende hacer una mirada retrospectiva que nos señale habilidades, fortalezas o dificultades del proceso que se pueden inferir a través del análisis y características del producto. Esta afirmación se justifica por el hecho de hacer un trabajo de tipo lingüístico con apoyo de otras disciplinas. 


\subsubsection{Pasos para el diseño del instrumento}

Como se señala anteriormente, para llegar a constituir un haz de indicadores eficaces de la producción narrativa oral, fue necesario trabajar desde dos perspectivas.

1. Perspectiva teórica.

Nos señala el estado de la cuestión, los fundamentos propuestos por los autores para el análisis del discurso, como Van Dijk, Briz, entre otros; y los aportes que hacen otras ciencias como la psicología, la medicina, la gerontología, la literatura...

Aquí se recogen la caracterización de los discursos orales, los principios fundamentales de la unidad del discurso, las características de las narraciones.

Desde el punto de vista psicolingüístico, se especifica que se trata de un modelo para la producción discursiva. En este sentido se exponen los pasos de la producción desde la idea hasta la constitución del producto final.

Con estos elementos se elabora una lista de elementos que a juicio de los teóricos, están presentes en el discurso y dan cuenta del principio de unidad, de la habilidad narrativa del informante y de la fluidez con la cual se produce determinado discurso. 
2. Perspectiva práctica.

Esta perspectiva se refiere al aspecto operativo que fue necesario desarrollar para la finalización del análisis. El primer paso fue la recolección de un corpus, proceso que se explica en la metodología, junto con sus fuentes y la particularidad de las transcripciones.

Posteriormente se somete este corpus al instrumento creado para dar cuenta de la presencia y ausencia de indicadores y con ello verificar la solidez del tejido discursivo, su calidad. Características comunes a todos los discursos.

\subsection{Descripción general del instrumento de evaluación}

El instrumento consta de dos elementos fundamentales:

- El aspecto discursivo

- El aspecto oral

El aspecto discursivo se centra en indicadores que están relacionados con el logro del ideal de unidad discursiva, los cuales se apoyan en dos pilares: la coherencia y la cohesión textual (Van Dijk, 2000, p. 32). A su vez cada uno de estos pilares es evaluado a partir de los indicadores que se enumeran en el listado que se expondrá más adelante. 
Dado el objetivo del trabajo, el análisis discursivo se enfocará de modo especial en el aspecto narrativo, cotejando los indicadores que exponen y reafirman la adscripción a una superestructura textual y que se incluyen dentro de ese ítem al realizar la evaluación cualitativa.

La segunda parte del instrumento hace alusión a la fluidez verbal que posee el informante.

Esta parte difiere metodológica y formalmente de la primera, en tanto que para analizar la producción oral de un individuo se han tomado como punto de referencia los avances que, en gramática de los textos orales coloquiales y de la conversación, han realizado los investigadores del grupo VA.LES.CO. (Briz, 2000). En este sentido se toman como fenómenos normales y naturales de la comunicación oral los siguientes: repeticiones, pausas, alargamientos, silencios, circunloquios, gestos, movimientos, vacilaciones, retrazados, carraspeos y muletillas. Este componente del análisis se expone gráficamente en tres columnas.

La primera señala el fenómeno de la oralidad que se detecta, la segunda señala el contexto en el cual se presenta el fenómeno y la tercera se refiere a las condiciones en las cuales opera el fenómeno. Finalmente hay una casilla para el ejemplo ilustrativo y una más para la valoración positiva o negativa de este fenómeno. En este sentido se considera que un elemento añade valor a un discurso si es producido voluntaria e intencionalmente y si multiplica la fuerza semántica del enunciado del cual hace parte. En el caso contrario este fenómeno no solo no añade valor al discurso (no lo cualifica), sino que le resta. 
A esta circunstancia es pertinente agregar el contexto en el cual se produce el fenómeno ya que un elemento como la repetición léxica no tiene igual valor si el elemento repetido es un sustantivo o si es una conjunción. En el primer caso se hace énfasis en un elemento lleno de la lengua, mientras que una conjunción, al ser repetida, resta, en general, valor al discurso en el sentido en que no aporta semanticidad al enunciado sino que detiene la fluidez y progresión del mismo.

De esta forma se analiza el fenómeno en el contexto en el cual se encuentra, en su relación con otros fenómenos, en su valor semántico, pragmático y también ocasionalmente, si es pertinente, en su valor narrativo.

El contexto en el cual aparece el fenómeno constituye, una guía para que quien aplique el instrumento pueda determinar si es válido este fenómeno o no lo es.

\subsection{Instrumento para la evaluación integral del discurso}

\subsubsection{Evaluación del discurso narrativo}

La evaluación cualitativa en este instrumento se realiza mediante la valoración de todos y cada uno de los componentes del discurso narrativo, producto de la pregunta realizada a los informantes para obtener el corpus: “ ¿Ha estado usted en peligro de

muerte?" Ante esta pregunta surgen variadas respuestas que abarcan el desplazamiento forzado, la guerra, desastres naturales, el abuso sexual y otras circunstancias negativas 
por las cuales atraviesa el ser humano a los largo de su existencia, y que son consideradas como situaciones límite o de gran peligro o inestabilidad emocional.

Si el hablante responde en forma negativa ante la pregunta se le solicita que cuente una experiencia que haya vivido. En consecuencia, se obtiene un conjunto de narraciones que son los discursos constitutivos del corpus oral.

Una vez obtenida y transcrita la narración y recogidos determinados aspectos formales de la misma como los datos del informante, se procede a la evaluación de los aspectos siguientes:

1. Habilidad para la superestructura narrativa.

2. Habilidad para la progresión temática.

3. Habilidad para la coherencia local.

4. Habilidad para la cohesión.

5. Habilidad para la evaluación.

6. Habilidad para la contextualización.

Todos los ítems se evalúan primero de forma cualitativa y después se traslada esta valoración a números para obtener una cifra cuantificada que pueda ser computable con la fluidez del discurso, reflejada mediante índices numéricos relacionados, como se verá, con el tiempo, el número de palabras y el número de fenómenos que aparecen. 


\subsubsection{Habilidad para la superestructura narrativa}

Esta categoría se evalúa mediante 4 indicadores a través de los cuales se demuestra la habilidad discursiva que posee un hablante para narrar o relatar una historia. Estos indicadores son: la caracterización de personajes, el desarrollo de las acciones, la presencia de estructura narrativa y la creación de un ambiente o entorno.

\subsection{Caracterización de personajes}

La caracterización de personajes es un indicador del discurso narrativo y hace parte de las características y condiciones de la superestructura narrativa. El personaje o personajes, que en este caso son personas del mundo real del informante, pueden estar caracterizados por su aspecto físico, moral, emocional o por sus cualidades o defectos en el plano espiritual.

Se trata de un indicador que se deriva de la descripción pero que da realismo, verosimilitud y vivacidad a la narración. Pueden estar incluidos en este indicador aspectos relacionados con la edad, el sexo, el vestuario, la apariencia física, la voz y otros elementos intrínsecos a la descripción de personas y personajes.

La caracterización de personajes se evalúa en la escala de uno (1) a cinco (5) teniendo en cuenta lo siguiente: Uno (1) si la caracterización es pobre, insuficiente o inexistente; dos (2) si es regular, es decir que aporte pocos detalles; tres (3) si es buena; cuatro (4) si aporta muchos detalles, es prolija, es rica en adjetivación; y cinco (5) si es excelente, es decir, si es sorprendente, usa metáforas, usa comparaciones extraordinarias. 


\subsection{Desarrollo de las acciones}

No existe discurso narrativo sin el desarrollo de acciones. La acción es el fundamento de la discursividad narrativa y su presencia se hace imprescindible. Por lo tanto, se evalúa la presencia y desarrollo de las acciones en el discurso. Cualitativamente, se evalúa con un "Sí" la presencia de acciones y con un "No", la ausencia de las mismas. Estos valores se trasladan a cifras cuantitativas que corresponden a cinco (5), para la presencia de acciones en movimiento, y cero (0), para la ausencia de acciones o la ausencia de desarrollo en las mismas.

\subsection{Presencia de estructura narrativa}

Se valora cuantitativamente de cero (0) a cuatro (4), teniendo en cuenta que cero (0) es la ausencia de todas las partes que suelen atribuirse al texto narrativo: situación inicial, complicación, acción, resolución; uno (1) si aparece solamente una, dos (2) si aparecen dos, tres (3) si aparecen tres, y cuatro (4) si se dan todas las partes.

\subsection{Creación de un ambiente o entorno}

Se refiere a la ubicación físico-temporal de las acciones. Dónde, cuándo y en qué circunstancias se llevan a cabo las acciones. En términos de la estructura narrativa se denomina contextualización. Cualitativamente se evalúa este aspecto del discurso acudiendo a la escala: insuficiente, regular, bueno, muy bueno y excelente. A esta valoración se asignan posteriormente los valores cuantitativos de uno (1) a cinco (5), en donde uno (1) es insuficiente y cinco (5) es excelente. 


\subsubsection{Habilidad para la progresión temática.}

Los ítems pertinentes son los siguientes: presencia de un asunto común o un tema unitario, selección adecuada de la información, información suficiente, información excesiva, organización lógica de ideas y progresión temática acertada. Se evalúan con "Sí" o "No", dependiendo de la presencia o ausencia del fenómeno. Estos se trasladan al valor cinco (5) para "Sí”, y cero (0) para "No".

Para el indicador "información excesiva" varían los valores. Si la información es excesiva, el valor cualitativo es "Sí" que corresponde a cero (0); y si la información es justa, se evalúa con un "No" que corresponde a cinco (5). La organización lógica de las ideas se evalúa como: nunca, casi nunca, algunas veces, casi siempre y siempre; estos rangos pasan a términos numéricos en orden de cero (0) a cuatro (4), donde cero (0) corresponde a "nunca", y cuatro (4) corresponde a "siempre".

\subsubsection{Coherencia local}

Se evalúa aquí la presencia de campos semánticos, redes isotópicas, pertinencia de los enunciados y el hecho de que no se dé contradicción entre enunciados. La existencia de campos semánticos y la presencia de redes isotópicas se evalúan con "Sí” o "No", dependiendo de la presencia o ausencia de los mismos y corresponde cuantitativamente a cinco (5) (Sí) y cero (0) (No). 
Los enunciados claros y no contradictorios se evalúan con la escala: "Nunca", “casi nunca", "algunas veces", “casi siempre” y "siempre”, que corresponden a "cero (0), uno (1), dos (2), tres (3) y cuatro (4)" respectivamente.

\subsubsection{Cohesión}

Los indicadores que corresponden a la evaluación de la cohesión son: el enlace secuencial de los hechos, la presencia de conectores, enlaces anafóricos y catafóricos. Todos los ítems de esta categoría se evalúan en la escala cualitativa que va de "siempre" a "nunca" y corresponden a la escala cuantitativa de cero (0) a cuatro (4). La cohesión textual es una categoría insustituible del discurso, ya que sin esta categoría se vería desmembrado el texto.

\subsubsection{Evaluación}

La evaluación hace parte de la superestructura narrativa según la propuesta de J. M. Adam (1992; 1987). La evaluación en la propuesta de Adam se da siempre en los discursos, ya sea de manera implícita o explícita. En la narración aparece como un elemento estructural. Según Adam, el mero hecho de elegir contar algo, y la forma de contarlo, supone una evaluación: si cuento algo es porque lo considero digno de ser contado, y por lo tanto destacado o valioso.

Se puede evaluar el discurso como tal, su novedad, su creatividad, sus estrategias; o se pueden evaluar los hechos narrados. En el discurso se hacen explícitas las formas de evaluación a través de la presencia de juicios de valor, tanto del discurso como de los hechos narrados. Igual procedimiento opera sobre la entonación enfática y las expresiones 
valorativas tales como intensificadores, atenuantes, comparadores, correlativos, expresiones adjetivales y adverbiales que cumplen esta función discursiva.

Ej: "pues me han pasado muchas cosas/ buenas y malas $\rightarrow$ /" (Inf. 61MJ).

Ej: "lleguelcliente con dos burros di'hombres bien presentados, bien vestidos" (Inf. 46JB).

Ej: "Y'encambio antes era todo muy sano" (Inf $52 \mathrm{TJ})$. Compara el tiempo de antes y el de ahora ya que acaban de asesinar a un niño en Costa Rica.

\subsubsection{Contextualización}

La contextualización a la que hace referencia esta categoría se vincula con las relaciones exofóricas que establece el discurso con su contexto mediante la presencia de deícticos y referentes externos como la cita de nombres propios de lugares, personas o fechas. Los indicadores son, pues, los dos que se acaban de mencionar: uso de deícticos y presencia de referencias a lugares, personas o fechas. Se evalúan con la escala cualitativa de: "nunca", "casi nunca", "algunas veces", "casi siempre" y "siempre". En la escala cuantitativa se reflejará en evaluación numérica de cero (0) a cuatro (4).

Las categorías anteriores junto con sus ítems están representados a continuación en las siguientes tablas: 
Tabla 4: Indicadores de evaluación cualitativa del discurso narrativo

\begin{tabular}{|c|c|}
\hline $\mathbf{N}^{\mathbf{o}}$ & INDICADORES / INFORMANTE \\
\hline I & HABILIDADES SUPERESTRUCTURA NARRATIVA \\
\hline 1 & Caracterización de personajes \\
\hline 2 & Desarrollo de acciones (cambio de estado) \\
\hline 3 & $\begin{array}{l}\text { Presencia de estructura narrativa (situación inicial, complicación, acción, } \\
\text { resolución) }\end{array}$ \\
\hline 4 & Creación de un ambiente o entorno \\
\hline II & TEMÁTICA, COHERENCIA GLOBAL \\
\hline 5 & Presencia de un asunto común o tema unitario \\
\hline 6 & Selección adecuada de información ${ }^{43}$ \\
\hline 7 & Información suficiente ${ }^{44}$ \\
\hline 8 & Información excesiva \\
\hline 9 & Organización de ideas \\
\hline 10 & Progresión temática acertada \\
\hline III & COHERENCIA LOCAL \\
\hline 11 & Existencia de campos semánticos claramente definidos \\
\hline 12 & Presencia de redes isotópicas \\
\hline 13 & Enunciados claros y no contradictorios \\
\hline 14 & Enunciados pertinentes \\
\hline I & COHESIÓN \\
\hline 15 & Enlace secuencial de los hechos \\
\hline 16 & Presencia de conectores de discurso \\
\hline 17 & Presencia de enlaces anafóricos y catafóricos \\
\hline V & EVALUACIÓN \\
\hline 18 & Presencia de juicios de valor acerca de los hechos narrados \\
\hline 19 & Presencia de juicios de valor acerca del discurso \\
\hline 20 & $\begin{array}{l}\text { Presencia de expresiones valorativas: Intensificadores, Comparadores, Correlativos } \\
\text { explicativos, Atenuantes }\end{array}$ \\
\hline 21 & Entonación enfática \\
\hline VI & CONTEXTUALIZACIÓN \\
\hline 22 & Uso de deícticos gramaticales \\
\hline 23 & Referencias a lugares, personas y fechas \\
\hline
\end{tabular}

Tabla 5: Correspondencia de valores cualitativos - cuantitativos

\begin{tabular}{|c|c|c|c|c|c|c|}
\hline $\mathbf{N}^{\mathbf{o}}$ & INDICADORES & \multicolumn{5}{|c|}{$\begin{array}{l}\text { CORRESPONDENCIA DE VALORES } \\
\text { CUALITATIVOS - CUANTITATIVOS }\end{array}$} \\
\hline I & \multicolumn{6}{|c|}{ HABILIDAD PARA LA SUPERESTRUCTURA NARRATIVA } \\
\hline \multirow[t]{2}{*}{1} & $\begin{array}{l}\text { Caracterización de } \\
\text { personajes }\end{array}$ & $\begin{array}{l}\text { Insuficient } \\
\mathrm{e}\end{array}$ & Regular & Bueno & $\begin{array}{l}\text { Muy } \\
\text { bueno }\end{array}$ & Excelente \\
\hline & & 1 & 2 & 3 & 4 & 5 \\
\hline 2 & & \multicolumn{3}{|c|}{ SÍ } & \multicolumn{2}{|c|}{$\mathrm{NO}$} \\
\hline
\end{tabular}

\footnotetext{
${ }^{43}$ Alude a la calidad de la información, a su pertinencia.

${ }^{44}$ El ítem siete (7) y ocho (8) aluden a la cantidad de información. Muy poca o suficiente en siete (7) y mucha o excesiva en ocho (8).
} 


\begin{tabular}{|c|c|c|c|c|c|c|}
\hline & $\begin{array}{l}\text { Desarrollo de } \\
\text { acciones }{ }^{45} \text { (Cambio de } \\
\text { estado) }\end{array}$ & \multicolumn{3}{|c|}{5} & \multicolumn{2}{|c|}{0} \\
\hline \multirow[t]{2}{*}{3} & \multirow[t]{2}{*}{$\begin{array}{l}\text { Presencia de estructura } \\
\text { narrativa }\end{array}$} & $\begin{array}{c}\text { Insuficient } \\
\mathrm{e}\end{array}$ & Regular & Bueno & $\begin{array}{c}\text { Muy } \\
\text { bueno }\end{array}$ & Excelente \\
\hline & & 1 & 2 & 3 & 4 & 5 \\
\hline \multirow[t]{2}{*}{4} & \multirow[t]{2}{*}{$\begin{array}{l}\text { Creación de un } \\
\text { ambiente o entorno }\end{array}$} & Nunca & $\begin{array}{l}\text { Casi } \\
\text { nunca }\end{array}$ & $\begin{array}{l}\text { Algunas } \\
\text { veces }\end{array}$ & $\begin{array}{c}\text { Casi } \\
\text { siempre }\end{array}$ & Siempre \\
\hline & & 0 & 1 & 2 & 3 & 4 \\
\hline II & \multicolumn{6}{|c|}{ TEMÁTICA, COHERENCIA GLOBAL } \\
\hline \multirow[t]{2}{*}{5} & \multirow{2}{*}{$\begin{array}{l}\text { Presencia de un asunto } \\
\text { común o tema unitario }\end{array}$} & \multicolumn{3}{|c|}{\begin{tabular}{c|c} 
SÍ & \\
\end{tabular}} & \multicolumn{2}{|c|}{ NO } \\
\hline & & \multicolumn{3}{|c|}{5} & \multicolumn{2}{|c|}{0} \\
\hline \multirow[t]{2}{*}{6} & \multirow{2}{*}{$\begin{array}{l}\text { Selección adecuada de } \\
\text { información }\end{array}$} & \multicolumn{3}{|c|}{ SÍ } & \multicolumn{2}{|c|}{ NO } \\
\hline & & \multicolumn{3}{|c|}{5} & \multicolumn{2}{|c|}{0} \\
\hline \multirow[t]{2}{*}{7} & \multirow[t]{2}{*}{ Información suficiente } & \multicolumn{3}{|c|}{ SÍ } & \multicolumn{2}{|c|}{$\mathrm{NO}$} \\
\hline & & \multicolumn{3}{|c|}{5} & \multicolumn{2}{|c|}{0} \\
\hline \multirow[t]{2}{*}{8} & \multirow{2}{*}{ Información excesiva } & \multicolumn{3}{|c|}{ SÍ } & \multicolumn{2}{|c|}{ NO } \\
\hline & & & 0 & & 5 & \\
\hline 9 & $\begin{array}{l}\text { Organización lógica de } \\
\text { ideas }\end{array}$ & Nunca & $\begin{array}{c}\text { Casi } \\
\text { nunca }\end{array}$ & $\begin{array}{l}\text { Algunas } \\
\text { veces }\end{array}$ & $\begin{array}{c}\text { Casi } \\
\text { siempre }\end{array}$ & Siempre \\
\hline & & 0 & 1 & 2 & 3 & 4 \\
\hline 10 & Progresión temática & & SÍ & & $\mathrm{N}$ & \\
\hline & acertada & & 5 & & ( & \\
\hline III & & COHER & ENCIA L & CAL & & \\
\hline 11 & & & SÍ & & $\mathrm{N}$ & \\
\hline & $\begin{array}{l}\text { semánticos claramente } \\
\text { definidos }\end{array}$ & & 5 & & ( & \\
\hline 12 & Presencia de redes & & Sí & & $\mathrm{N}$ & \\
\hline & isotópicas & & 5 & & ( & \\
\hline 13 & $\begin{array}{l}\text { Enunciados claros y nos } \\
\text { contradictorios }\end{array}$ & Nunca & $\begin{array}{c}\text { Casi } \\
\text { nunca }\end{array}$ & $\begin{array}{l}\text { Algunas } \\
\text { veces }\end{array}$ & $\begin{array}{c}\text { Casi } \\
\text { siempre }\end{array}$ & Siempre \\
\hline & & 0 & 1 & 2 & 3 & 4 \\
\hline 14 & Enunciados pertinentes & Nunca & $\begin{array}{c}\text { Casi } \\
\text { nunca }\end{array}$ & $\begin{array}{l}\text { Algunas } \\
\text { veces }\end{array}$ & $\begin{array}{c}\text { Casi } \\
\text { siempre }\end{array}$ & Siempre \\
\hline & & 0 & 1 & 2 & 3 & 4 \\
\hline IV & & & )HESIÓN & & & \\
\hline 15 & $\begin{array}{l}\text { Enlace secuencial de } \\
\text { los hechos }\end{array}$ & Nunca & $\begin{array}{c}\text { Casi } \\
\text { nunca }\end{array}$ & $\begin{array}{l}\text { Algunas } \\
\text { veces }\end{array}$ & $\begin{array}{c}\text { Casi } \\
\text { siempre }\end{array}$ & Siempre \\
\hline & & 0 & 1 & 2 & 3 & 4 \\
\hline 16 & $\begin{array}{l}\text { Presencia de conectores } \\
\text { de discurso }\end{array}$ & Nunca & $\begin{array}{c}\text { Casi } \\
\text { nunca }\end{array}$ & $\begin{array}{l}\text { Algunas } \\
\text { veces }\end{array}$ & $\begin{array}{c}\text { Casi } \\
\text { siempre }\end{array}$ & Siempre \\
\hline & & 0 & 1 & 2 & 3 & 4 \\
\hline 17 & $\begin{array}{l}\text { Presencia de enlaces } \\
\text { anafóricos y catafóricos }\end{array}$ & Nunca & $\begin{array}{c}\text { Casi } \\
\text { nunca }\end{array}$ & $\begin{array}{l}\text { Algunas } \\
\text { veces }\end{array}$ & $\begin{array}{c}\text { Casi } \\
\text { siempre }\end{array}$ & Siempre \\
\hline
\end{tabular}

\footnotetext{
${ }^{45}$ Se puede utilizar un número intermedio en este ítem, de manera subjetiva, cuando la situación, lo amerite. En este caso se pondrán cifras de la siguiente manera. Cero (0) para inexistente, uno (1) para insuficiente, dos (2) para regular, tres (3) para bueno, cuatro (4) para muy bueno y cinco (5) para un excelente desarrollo de las acciones.
} 


\begin{tabular}{|c|c|c|c|c|c|c|}
\hline & & 0 & 1 & 2 & 3 & 4 \\
\hline V & \multicolumn{6}{|c|}{ EVALUACIÓN } \\
\hline \multirow[t]{2}{*}{18} & \multirow{2}{*}{$\begin{array}{l}\text { Presencia de juicios de } \\
\text { valor acerca de los } \\
\text { hechos narrados }\end{array}$} & \multicolumn{3}{|c|}{ SÍ } & \multicolumn{2}{|c|}{ NO } \\
\hline & & \multicolumn{3}{|c|}{5} & \multicolumn{2}{|c|}{0} \\
\hline \multirow[t]{2}{*}{19} & \multirow{2}{*}{$\begin{array}{l}\text { Presencia de juicios de } \\
\text { valor acerca del } \\
\text { discurso }\end{array}$} & \multicolumn{3}{|c|}{ SÍ } & \multicolumn{2}{|c|}{$\mathrm{NO}$} \\
\hline & & \multicolumn{3}{|c|}{5} & \multicolumn{2}{|c|}{0} \\
\hline \multirow[t]{2}{*}{20} & \multirow{2}{*}{$\begin{array}{l}\text { Presencia de } \\
\text { expresiones valorativas: } \\
\text { Intensificadores, } \\
\text { Comparadores, } \\
\text { Correlativos, } \\
\text { Explicativos, } \\
\text { Atenuantes }\end{array}$} & \multicolumn{3}{|c|}{ SÍ } & \multicolumn{2}{|c|}{ NO } \\
\hline & & \multicolumn{3}{|c|}{5} & \multicolumn{2}{|c|}{0} \\
\hline \multirow[t]{2}{*}{21} & \multirow[t]{2}{*}{ Entonación enfática } & \multicolumn{3}{|c|}{ SÍ } & \multicolumn{2}{|c|}{ NO } \\
\hline & & \multicolumn{3}{|c|}{5} & \multicolumn{2}{|c|}{0} \\
\hline VI & & CONTI & ГUALI & CIÓN & & \\
\hline \multirow[t]{2}{*}{22} & \multirow[t]{2}{*}{$\begin{array}{l}\text { Uso de deícticos } \\
\text { gramaticales }\end{array}$} & Nunca & $\begin{array}{c}\text { Casi } \\
\text { nunca }\end{array}$ & $\begin{array}{l}\text { Algunas } \\
\text { veces }\end{array}$ & $\begin{array}{c}\text { Casi } \\
\text { siempre }\end{array}$ & Siempre \\
\hline & & 0 & 1 & 2 & 3 & 4 \\
\hline \multirow[t]{2}{*}{23} & \multirow[t]{2}{*}{$\begin{array}{l}\text { Referencias a lugares, } \\
\text { personas y fechas }\end{array}$} & Nunca & $\begin{array}{c}\text { Casi } \\
\text { nunca }\end{array}$ & $\begin{array}{l}\text { Algunas } \\
\text { veces }\end{array}$ & $\begin{array}{c}\text { Casi } \\
\text { siempre }\end{array}$ & Siempre \\
\hline & & 0 & 1 & 2 & 3 & 4 \\
\hline
\end{tabular}

Esta tabla fue diseñada para señalar la correspondencia entre los valores cualitativos y los valores cuantitativos. La evaluación se hace teniendo en cuenta valores cualitativos que es pertinente transformar en cifras para darle homogeneidad a la prueba y convertir los valores en numéricos. La valoración cualitativa se refleja en dos (2) escalas. La primera escala va de insuficiente a excelente. Abarca: Insuficiente, regular, bueno, muy bueno y excelente. La segunda escala cubre el rango de nunca a siempre. Abarca los valores: nunca, casi nunca, algunas veces, casi siempre, siempre.

En la primera escala se asignaron los valores numéricos de uno (1) a cinco (5), así: Uno (1) insuficiente; dos (2) regular; tres (3) bueno; cuatro (4) muy bueno; y cinco (5) excelente. Esta escala se utiliza para la caracterización de personajes que hace parte de la habilidad para la superestructura narrativa. 
En la segunda escala se asignaron los valores numéricos de cero (0) a cuatro (4): Cero (0) Nunca; uno (1) casi nunca; dos (2) algunas veces; tres (3) casi siempre; y cuatro (4) siempre. Esta escala se utiliza para la coherencia global, local, cohesión y contextualización.

\subsubsection{Evaluación cuantitativa de la fluidez discursiva oral}

La fluidez discursiva oral se evalúa cuantitativamente como resultado sumatorio de dos factores: 1) La fluidez verbal, es decir, el número de palabras por minuto que emite el informante; 2) La presencia en el discurso de una serie de fenómenos orales producidos por el hablante. La fórmula quedaría este modo:

$$
\begin{aligned}
& \mathrm{V}+(\mathrm{F} \times \mathrm{m})=\text { Fluidez discursiva oral, unidades cuantitativas. } \\
& \mathrm{V}(\text { velocidad })=\text { Palabras por minuto } \\
& \mathrm{F} \times \mathrm{m}=\text { Fenómenos por minuto }
\end{aligned}
$$

Los fenómenos a los que se alude son los siguientes:

1. La repetición

2. El alargamiento

3. Las pausas

4. El enunciado truncado

5. El acompañamiento kinésico

6. Segmentos o palabras inesperadas

7. Otros fenómenos 
La siguiente es la versión esquemática del instrumento de evaluación que se aplica directamente a la transcripción del discurso del informante y en el cual se consigna el número de registros de cada fenómeno que se presentan en el corpus individual, tal como se explicará en este mismo capítulo.

Tabla 6: Instrumento de evaluación de la fluidez discursiva oral

\begin{tabular}{|c|c|c|c|c|}
\hline FENÓMENO & CONTEXTO & CONDICIONES & VALORACION & $\begin{array}{c}\text { CANTIDAD } \\
\text { DE } \\
\text { REGISTROS } \\
46\end{array}$ \\
\hline Repetición & General & Es intencional & +1 & \\
\hline Repetición & General & No es intencional & -1 & \\
\hline $\begin{array}{l}\text { Repetición } \\
\text { sonidos } \\
\text { (tartamudeos y } \\
\text { vacilaciones) }\end{array}$ & Indiferente & $\begin{array}{c}\text { No es patología del } \\
\text { hablante }\end{array}$ & -1 & \\
\hline \multirow{4}{*}{$\begin{array}{l}\text { Repetición } \\
\text { silábica }\end{array}$} & Indiferente & $\begin{array}{c}\text { Tiene valor } \\
\text { onomatopéyico o } \\
\text { descriptivo }\end{array}$ & +1 & \\
\hline & $\begin{array}{l}\text { Inicio de } \\
\text { palabra }\end{array}$ & No dialectal & -1 & \\
\hline & $\begin{array}{l}\text { Medio de } \\
\text { palabra }\end{array}$ & No dialectal & -1 & \\
\hline & $\begin{array}{l}\text { Final de } \\
\text { palabra }\end{array}$ & No dialectal & -1 & \\
\hline \multirow[b]{3}{*}{$\begin{array}{l}\text { Repetición } \\
\text { léxica }\end{array}$} & En general & No intencional & -1 & \\
\hline & $\begin{array}{l}\text { Acompañado } \\
\text { de entonación } \\
\text { enfática }\end{array}$ & $\begin{array}{c}\text { Palabra llena: } \\
\text { Nombre, verbo, } \\
\text { adverbio, adjetivo }\end{array}$ & +1 & \\
\hline & $\begin{array}{c}\text { Acompañado o } \\
\text { no de voz } \\
\text { más baja y } \\
\text { entonación } \\
\text { vacilante }\end{array}$ & $\begin{array}{l}\text { Palabra vacía } \\
\text { (determinante, } \\
\text { conjunción o } \\
\text { preposición) }\end{array}$ & -1 & \\
\hline
\end{tabular}

${ }^{46}$ Esta columna aparece en blanco para que el evaluador consigne en ella los resultados obtenidos en la evaluación del corpus. 


\begin{tabular}{|c|c|c|c|}
\hline \multirow{4}{*}{$\begin{array}{l}\text { Repetición de } \\
\text { expresiones }\end{array}$} & General & $\begin{array}{l}\text { Tiene función } \\
\text { enfática, } \\
\text { descriptiva o } \\
\text { resemantizadora }\end{array}$ & +1 \\
\hline & & $\begin{array}{l}\text { Tiene función } \\
\text { correctora } \\
\text { reformuladora }\end{array}$ & +1 \\
\hline & $\begin{array}{l}\text { Abarca todo el } \\
\text { discurso o se } \\
\text { manifiesta en } \\
\text { grandes } \\
\text { porciones del } \\
\text { mismo }\end{array}$ & $\begin{array}{l}\text { Simple repetición o } \\
\text { repetición } \\
\text { sistemática }\end{array}$ & -1 \\
\hline & & $\begin{array}{l}\text { No intencional, no } \\
\text { justificada o no } \\
\text { necesaria }\end{array}$ & -1 \\
\hline \multirow{6}{*}{ Alargamiento } & & $\begin{array}{l}\text { Es intencional, es } \\
\text { descriptivo, causa } \\
\text { un efecto }\end{array}$ & +1 \\
\hline & $\begin{array}{l}\text { En palabra } \\
\text { llena }\end{array}$ & $\begin{array}{l}\text { sobre sílaba } \\
\text { acentuada }\end{array}$ & +1 \\
\hline & $\begin{array}{l}\text { En palabra } \\
\text { llena }\end{array}$ & $\begin{array}{l}\text { sobre sílaba } \\
\text { inacentuada }\end{array}$ & -1 \\
\hline & $\begin{array}{l}\text { En palabra } \\
\text { vacía }\end{array}$ & $\begin{array}{c}\text { Sobre sílaba } \\
\text { acentuada o no }\end{array}$ & -1 \\
\hline & En general & $\begin{array}{l}\text { Antecede a una } \\
\text { palabra llena }\end{array}$ & -1 \\
\hline & General & $\begin{array}{c}\text { No intencional o no } \\
\text { necesario }\end{array}$ & -1 \\
\hline \multirow{5}{*}{ Pausa } & General & Es intencional & +1 \\
\hline & $\begin{array}{l}\text { Interenuncia- } \\
\text { dos y final }\end{array}$ & $\begin{array}{c}\text { Tiene finalidad } \\
\text { evaluativa }\end{array}$ & +1 \\
\hline & General & $\begin{array}{l}\text { Es interactiva o da } \\
\text { lugar a que el } \\
\text { interlocutor opine, } \\
\text { piense }\end{array}$ & +1 \\
\hline & $\begin{array}{c}\text { Enunciado o } \\
\text { palabra }\end{array}$ & $\begin{array}{c}\text { Rompe con el } \\
\text { sintagma o con la } \\
\text { palabra }\end{array}$ & -1 \\
\hline & General & $\begin{array}{c}\text { Hace parte de la } \\
\text { caracterización del } \\
\text { hablante }\end{array}$ & 0 \\
\hline
\end{tabular}




\begin{tabular}{|c|c|c|c|}
\hline & $\begin{array}{l}\text { Antecede a una } \\
\text { palabra llena }\end{array}$ & $\begin{array}{c}\text { Si la palabra es } \\
\text { inusual o de acceso } \\
\text { difícil }\end{array}$ & -1 \\
\hline & $\begin{array}{l}\text { Antecede a una } \\
\text { palabra llena }\end{array}$ & $\begin{array}{c}\text { Si la palabra es } \\
\text { usual }\end{array}$ & -2 \\
\hline & General & $\begin{array}{c}\text { Después de palabra } \\
\text { llena }\end{array}$ & -1 \\
\hline $\begin{array}{l}\text { Enunciado } \\
\text { truncado }\end{array}$ & General & $\begin{array}{c}\text { No continúa o } \\
\text { termina en seguida }\end{array}$ & -1 \\
\hline $\begin{array}{l}\text { Acompañamie } \\
\text { nto kinésico }\end{array}$ & General & $\begin{array}{l}\text { Intencional o } \\
\text { semántico }\end{array}$ & +1 \\
\hline Gestos & General & No intencionales & -1 \\
\hline $\begin{array}{l}\text { Palabras o } \\
\text { segmentos }\end{array}$ & $\begin{array}{c}\text { Lugares } \\
\text { inesperados }\end{array}$ & $\begin{array}{l}\text { Rompen la cadena } \\
\text { hablada }\end{array}$ & -1 \\
\hline $\begin{array}{l}\text { Carraspeos y } \\
\text { ruidos }\end{array}$ & General & No intencionales & -1 \\
\hline Otros & & No intencionales & -1 \\
\hline
\end{tabular}

La Tabla 6 recoge la síntesis del instrumento de evaluación de la fluidez oral (aspecto cuantitativo). Consta de una columna en la cual aparecen los fenómenos que se van a tener en cuenta a la hora de evaluar la fluidez. Estos fenómenos son los señalados arriba, es decir, las repeticiones, los alargamientos, las pausas, los enunciados truncados, los gestos, segmentos de habla, carraspeos, ruidos y otros. Estos fenómenos se toman como indicadores de fluidez o de ausencia de la misma.

La segunda columna se refiere al contexto y se trata de fijar el entorno en el cual se manifiesta el fenómeno, sea cual sea este fenómeno.

La tercera columna se refiere a las condiciones en las cuales puede aparecer determinado fenómeno. 
La cuarta columna específica si el fenómeno se evalúa de forma positiva o negativa.

Y la última columna, que aparece en blanco, está pensada para que el evaluador consigne el número de registros de cada fenómeno hallados en el discurso del informante.

A continuación se señalan algunos posibles entornos situacionales de los que figuran en la segunda columna (CONTEXTO):

General: Se refiere a todo entorno sin especificar una determinada ubicación. Se utiliza el contexto general en los casos en los cuales un fenómeno con una condición específica siempre tiene la misma valoración. Para el caso de la repetición se considera siempre la condición: Intencionalidad como positiva. Por esta razón siempre que aparece una repetición intencional en todo contexto (general) se considera positivo.

Indiferente: No se tiene en cuenta el contexto o este no genera variaciones en la valoración. El entorno no afecta la valoración puesto que el fenómeno en sí mismo es positivo o negativo. En el caso del bloqueo, este siempre será negativo.

Inicio, mitad o final de palabra: Generalmente se tiene en cuenta este contexto en casos en los cuales se pueden dar metaplasmos o fenómenos fonéticos similares. El metaplasmo no altera la fluidez oral aunque se considera error en la producción discursiva. Si el metaplasmo es dialectal, es decir, si hace parte de la caracterización regional del hablante, no se tiene en cuenta ni positiva ni negativamente. 
Si la repetición no es dialectal, ni intencional se considera disfluencia y afecta negativamente la calidad del discurso. Sin embargo, si va acompañado de entonación enfática es un contexto de orden suprasegmental que incide positivamente en la percepción y valoración del discurso.

Abarca todo el discurso: Si un fenómeno es repetitivo y se convierte en una constante puede tratarse de una muletilla o de un fenómeno idiolectal.

Palabra llena: Si el fenómeno se ubica en palabras con carga semántica como es el caso de verbos, sustantivos, adjetivos y adverbios.

Palabra vacía: Si el fenómeno a evaluar se ubica dentro de una palabra funcional o vacía como preposiciones, artículos y conjunciones.

En enunciados: Si el fenómeno no se ubica en la palabra sino en la frase o enunciado para romperlo o pausarlo.

El contexto se supedita a la condición ya que este se limita al lugar de incidencia del fenómeno o al lugar en el que se ubica, y solo determina parcialmente la valoración que se le da al fenómeno, mientras que las condiciones son determinantes ya que son ellas las que dan la pauta principal a la hora de evaluar. En la tercera columna (CONDICIONES) aparecen las siguientes: 
Es intencional: El hablante quiere realizar el fenómeno. Se esmera en repetir, alargar, pausar, carraspear, hacer un ruido u onomatopeya. Y esta condición resemantiza o enfatiza la palabra utilizada.

Patología: Si la persona es un paciente de terapia del lenguaje, ya sea afásico, disfásico o con tartamudez, esa condición altera totalmente la forma en que se ve un fenómeno ya que de hecho y en principio esta persona tendrá alterada la fluidez discursiva oral. Por lo tanto debe evaluarse su fluidez con patrones especiales.

Tiene valor onomatopéyico o descriptivo: Esta condición refleja habilidades dramatúrgicas del informante y una clara capacidad para ilustrar lo que se está narrando.

No dialectal: Esta condición de los fenómenos ya fue explicada en la columna del contexto y se refiere al hecho de encontrar fenómenos de tipo repetición, que en ocasiones son propias de una región o país. Es el caso de la palabra "arrascar" por "rascar" pronunciada por un español. No se puede pensar que los fenómenos dialectales inciden en la fluidez ya que estos están fuertemente arraigados en la mente y producción oral del hablante. Por lo tanto, cuando se habla de repeticiones se habla de aquellas no dialectales que revelen disfluencias o vacilaciones y de aquellas intencionales que resemanticen el discurso.

A continuación se expresa, de modo más explícito, en qué contextos y en qué condiciones un elemento se evalúa positiva o negativamente dentro del discurso del informante. 


\subsubsection{La Repetición}

Con base en las palabras de José Ángel Agudo (2000), se define como “Aparición sucesiva en el discurso de segmentos del mismo, de variable extensión y exactamente iguales en forma y función, es uno de los fenómenos cuantitativa y cualitativamente más importantes del discurso oral”.

La repetición produce la intensificación externamente, incide sobre el decir, por ejemplo para aumentar la garantía de verdad del contenido proposicional, tiene una intención comunicativa o está ahí para reforzar esa intención. ${ }^{47}$

\section{Tipos de repetición}

De acuerdo con la naturaleza de la repetición se pueden tipificar las repeticiones que aparecen en el corpus de discursos orales.

Si atendemos al contexto, la repetición se presenta en sonidos, sílabas, palabras o expresiones. En todos los casos las repeticiones cambian su tipificación si se considera la función que estas cumplen al interior del discurso o su efecto sobre el interlocutor. En este sentido, una repetición puede ser: descriptiva, enfática, resemantizadora o reformuladora. Pero si se acude a la pragmática discursiva, los elementos reiterados pueden estar presentes en el discurso por el deseo expreso de un emisor que pretende crear un efecto a través de ese fenómeno o simplemente por la velocidad con la cual se

\footnotetext{
${ }^{47}$ Más adelante se especificará en qué caso opera este sentido y en qué casos es concebido como elemento obstructor de la fluidez del hablante.
} 
emite el discurso o por el estrecho lapso entre la planeación de un discurso y su ejecución real. En ese caso se habla de fenómenos intencionales o no intencionales.

En el primer caso tenemos:

Ej: "Me daba un día fiebre y otro no/ un día fiebre y otro no/ un día fiebre y otro día no//" (Inf. 24VV)

En el segundo caso:

Ej: “y luego ya por la guerra/// pues nada pues nada /" (Inf. 17DM)

Repetición de sonidos: Constituye una característica o rasgo común que aparece en los discursos orales, normalmente ante la inmediatez con la cual el hablante ha de emitir su mensaje y el hecho de no tener todavía todos los elementos dispuestos para hacerlo. La selección léxica está en proceso o la inclusión de un elemento en la cadena hablada no ha sido determinada.

Aparecen entonces los balbuceos, tartamudeos y murmullos como en:

Ej: "llegó a haber aquí en verano se mmmm bailes al aire libre y y” (Inf. 21 A)

Ej: "m m zapatos" (Inf. 18CR)

Ej: “entre/ mmm ese pueblo" (Inf. 27MC)

Ej: "yo creo que es mmm normal” (Inf. 27MC) 
Con ellos se llena un espacio, se evita un silencio o se disimula un olvido léxico. Sobra expresar que este fenómeno normal en la producción oral deja de ser considerado como tal cuando se está ante una patología del habla, en cuyo caso se explica desde esta perspectiva y no hay lugar para separar lo normal de lo patológico.

Repetición silábica: funciona y aparece en el discurso de la misma manera que la repetición de sonidos.

Ej: "la gra la gra la gran vía” (Inf. 21A)

No todas las repeticiones silábicas tienen el mismo valor o aportan el mismo grado de calidad a un discurso.

Si la repetición tiene una función descriptiva u onomatopéyica su valor es positivo, ya que se convierte en imagen auditiva y contribuye a garantizar la comprensión del discurso, a escenificarlo y a mantener el interés del interlocutor.

Las repeticiones silábicas no solo son característica de la oralidad, sino que en ocasiones hacen parte del inventario lingüístico de algunas zonas dialectales, en cuyo caso se consideran como una característica dialectal y no como un rasgo discursivo. Toda vez que el hablante no tiene una intencionalidad al emitirlas, la naturalidad con las que produce se explica por el hecho de estar presentes en su entorno, su cultura, su cotidianidad y por ende en su sistema léxico, con lo cual caracterizan un discurso pero no son indicativos de una especial habilidad oral ni tampoco de una dificultad del hablante en su producción. 
Repetición léxica: La repetición léxica puede ser igualmente interpretada como intencional o no de acuerdo con el contexto discursivo, la entonación y el elemento reiterado. De este modo, una repetición que no cumple una función pragmática o semántica se considera no intencional toda vez que no se pueda constatar con el hablante si tuvo el deseo expreso de producirla o no.

Ej: "No he tenido ningún: ningún contratiempo.” (Inf. 20MC)

El hablante que pretende destacar un elemento, marcarlo, enfatizarlo o distinguirlo afectivamente actúa sobre la palabra llena: nombres o sustantivos, verbos, adverbios y adjetivos, toda vez que son estos elementos los encargados de portar significado y resultaría ineficaz intentar marcar semánticamente un elemento que no tiene valor semántico en su naturaleza inicial. En el siguiente ejemplo se enfatiza la acción verbal a través de la repetición del adverbio:

Ej: "Me acuerdo mucho/ mucho/ mucho/ mucho/ es que ya te digo" (Inf. 18CR).

Lo anterior no excluye la repetición intencional de algunos conectores como el "pero" y el "que", los cuales, al ser destacados, inciden sobre el elemento siguiente o marcan la intención expresa de destacar la relación entre los elementos del enunciado que estén vinculando.

Cuando un hablante no encuentra la palabra necesaria o precisa para construir un sintagma o cuando la olvida momentáneamente, la repetición se produce sobre la palabra 
anterior a la misma, la cual es normalmente una preposición, un artículo o una conjunción.

Ello da lugar a ejemplos como:

Ej: "y:: y ya te digo" (Inf 29P)

Ej: "Yo he estao siempre en el caballo de batalla/ siempre/ en/ en las asociaciones" (Inf 29P).

Estos elementos repetitivos funcionan como pausas o silencios llenos de sonido que dan tiempo al hablante para encontrar el lexema o recordarlo. En ocasiones estos elementos reiterados se producen en voz más baja o con entonación vacilante. $\mathrm{Su}$ presencia constante resulta pesada para el interlocutor y en ocasiones genera pérdida de interés en el tema tratado.

Repetición de expresiones: Al igual que en el caso anterior, puede cumplir una función al interior del discurso, la cual puede ser de tipo fático, semántico o descriptivo.

Ej: “que se alarga, que se alarga, que se alarga”. (Inf. 19MR)

También suele aparecer una expresión reiterada total o parcialmente cuando el hablante detecta una imprecisión u observa que puede mejorar la calidad del producto introduciendo un cambio de último momento. Este tipo de repetición se conoce como reformulación ${ }^{48}$, tiene una función correctora dentro del discurso y alude a la capacidad metadiscursiva del hablante, capaz de evaluar su producción y mejorarla.

\footnotetext{
${ }^{48}$ Gülich y Kotschi (1995) consideran todas las repeticiones como reformulaciones, tanto en el sentido en el cual se quiere corregir o mejorar un enunciado como en el que se quiere enfatizar. Este sentido de la palabra se deriva de la definición que hacen de reformular como formular dos veces. Sin embargo, en este
} 
Ej: "Pero nosotros pudimos/ no pudimos o no supimos/ todas esas cosas" (Inf. 15MG).

Ej: "se los llevaban a los acampos crematorios/ a los hornos crematorios/ a los hornos crematorios de Alemania/" (Inf. 16MC)

Las reformulaciones conllevan modificaciones, es decir, desplazamientos de sentido discursivo muy variados, que coincidirían con los procesos que Gülich y Kotschi (1995) denominan "procedimientos de tratamiento"; entienden estos mecanismos como un conjunto de actividades encaminadas a salvar obstáculos en la comunicación, porque es un hecho muy habitual el que el emisor considere insuficiente o inapropiado lo dicho; por consiguiente, vuelve a formularlo. Estos procesos, a su vez, pueden resultar parafrásticos respecto a la modificación del enunciado fuente, si su sentido es equivalente, o bien no parafrásticos, en el caso de que tal sentido sea nuevo, resultado que se consigue mediante disociaciones o correcciones.

No es el mismo caso de repeticiones sistemáticas a lo largo del discurso que indican vacilación, duda o nerviosismo del hablante y no aportan un valor nuevo al mensaje, sino que se limitan a repetir por repetir.

Ej: “Militante/ de las// de las de las de las JOS” (Inf. 23LR)

O de la repetición no intencional, no justificada o no necesaria como en el caso de:

trabajo se da una categoría muy especial a la reformulación para el uso de precisar, ampliar, explicar o definir tanto el sentido como el significado del enunciado, mecanismo este que se lleva a cabo tanto en forma de repetición como de paráfrasis. 
Ej: "Había hombres/ había hombres/ padres de hijos" (Inf. 29P)

El fenómeno de la repetición comparte con el alargamiento dos características. La primera, su naturaleza fónica y la segunda, su función primordial, la de actuar como resemantizador del discurso ${ }^{49}$. Las formas de la repetición en el discurso cumplen además una función semántica globalizante ya que contribuyen a la formación de campos semánticos. La repetición, aunque en esencia es fónica, no se limita a la multiplicación de un sonido, sílaba o palabra, sino que se extiende en ocasiones a la expresión. El siguiente gráfico ilustra el porcentaje de cada tipo de repetición en los discursos analizados.

Gráfico 3: Porcentaje de repeticiones según tipo

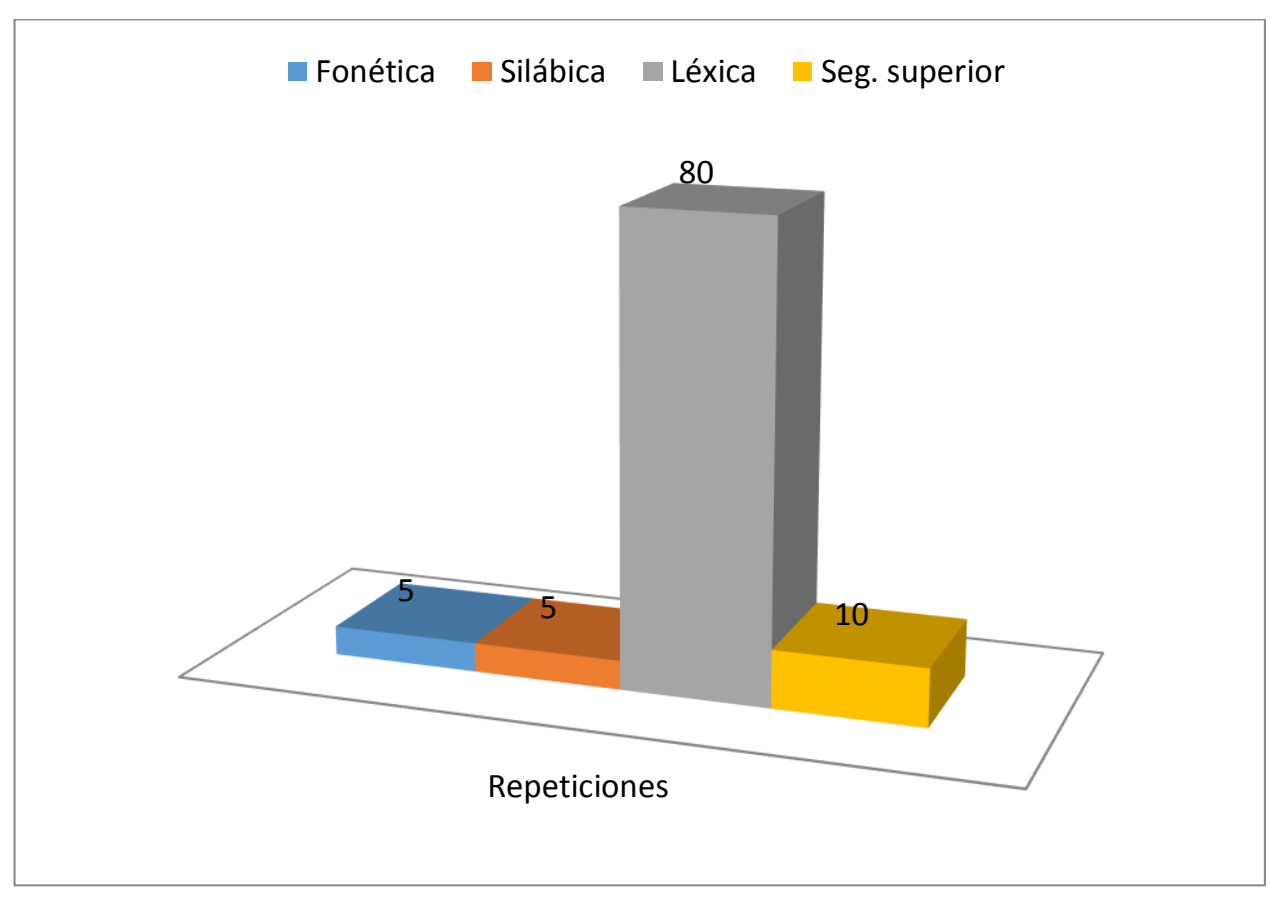

${ }^{49}$ Siempre y cuando sean intencionales. 
El 5\% corresponde a repeticiones de sonidos del tipo uu, una o de tipo $\mathrm{mm}$, el 5\% a repeticiones de sílabas: co corregimiento, el mayor porcentaje, $80 \%$, corresponde a la repetición de unidades léxicas: la la puerta, y el 10\% corresponde a la repetición de una expresión completa: a las cosas de casa, a las cosas de casa y a trabajar.

Como ya se ha señalado, las repeticiones obtenidas en el corpus cumplen funciones disímiles: en primer lugar se repite para enfatizar, ponderar y realzar un hecho o situación. En ese caso su función será la de intensificar el significado. El 22\% de las repeticiones cumplen esta función. Pero, cuando la repetición es intencionada, son posibles otras funciones, resumidas en el gráfico siguiente, donde además se indican sus porcentajes de aparición en el corpus.

Gráfico 4: Función de la repetición

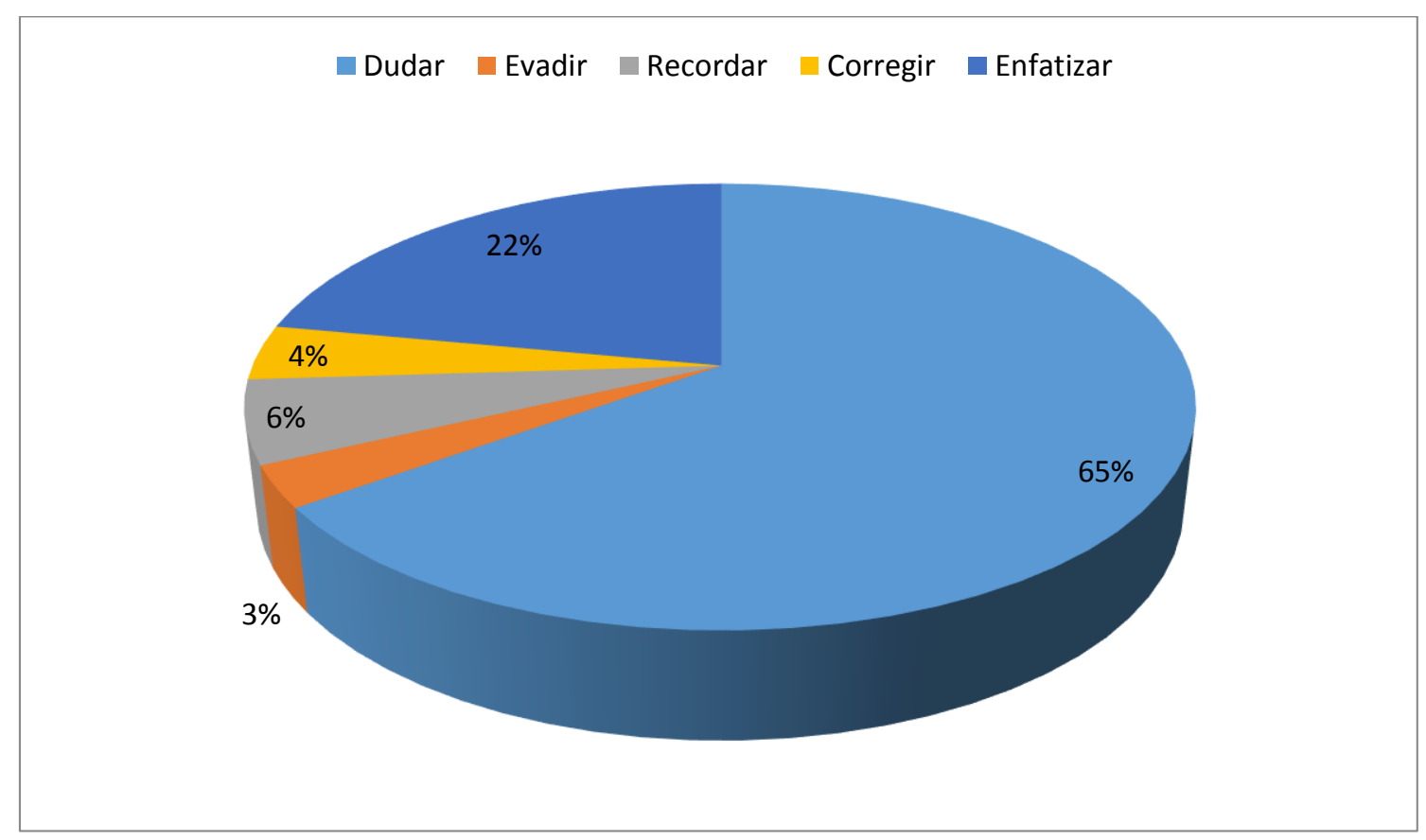

Pero, junto a las repeticiones pertinentes (cumplen una función o aluden a la intencionalidad del locutor), aparecen otras muchas no pertinentes: aquellas que permiten 
al locutor un margen de tiempo para pensar, recordar, planear o reorganizar su discurso. Según Torras (1997), las repeticiones constituyen “otra forma de obtener tiempo evitando las pausas demasiado largas" (p.198).

Una repetición en el contexto general del discurso es positiva para la calidad si es intencional, si el hablante la emite consideradamente o hace el esfuerzo para que así sea. Una repetición no intencional o no semántica interviene negativamente en la calidad del discurso, en la calidad de la producción y en ocasiones en la calidad del hablante como productor de discursos.

La repetición de sonidos toda vez que no se derive de una patología preexistente de quien habla, interviene negativamente en el hablante. La repetición silábica de inicio mitad o final de palabra constituye un error o equivocación de producción de habla. Sin embargo, si este fenómeno es dialectal no se trata de la misma manera que un error de habla sino que se considera una característica colectiva y en ese sentido está arraigada en la cultura del informante, en su cotidianidad y en su bagaje lingüístico. La forma de la palabra preexiste en la mente del hablante.

La repetición de palabras, en cambio, aporta calidad al discurso constantemente al momento en que el hablante la produzca con una intencionalidad determinada o para crear un efecto. De lo contrario se convierte en eco o ruido para la comunicación, afecta la fluidez del enunciado, da cuenta de la deficiente planificación que del discurso haga el hablante y detiene la progresión temática. 
La repetición léxica, preferiblemente acompañada de entonación enfática (subrayado oral) de palabras llenas como verbos, sustantivos, adverbios o adjetivos, actúa como refuerzo semántico y cualifica la producción.

Sin embargo, una repetición que recae sobre palabras vacías, sin intencionalidad marcada; o una repetición en tono de duda o vacilación intervienen negativamente en la calidad del discurso ya que indica errores, olvidos, cambios en la producción o anomias del elemento siguiente al repetido.

\subsubsection{Alargamiento}

Los alargamientos se definen como la prolongación de un sonido más allá del promedio de los que le anteceden y preceden, en el contexto discursivo. En este sentido se considera como fenómeno de naturaleza fonética. Sin embargo el efecto que produce el alargamiento supera lo estrictamente fonético.

El alargamiento es un fenómeno que puede ser caracterizado desde dos perspectivas funcionales:

La primera es su función enfática, que resemantiza la palabra o expresión en la cual aparece. El alargamiento contribuye a significar o hace que no quepa duda de lo expresado. Generalmente el alargamiento es de orden afectivo-valorativo y es de este modo como contribuye a configurar el significado y sentido de la expresión. Se considera como un fenómeno intensificador de significado. 
La segunda función es la de atenuar el sentido de una expresión. Las órdenes y los reclamos poseen cargas emocionales negativas que es preciso atenuar para mantener la interacción. Briz y el grupo Val.Es.Co. (2000, p. 46) reconocen las funciones intensificadoras y atenuantes del alargamiento, pero también atribuyen su presencia en el discurso a causas externas al mismo: "Y cuyo valor es el de una pausa para pensar lo que va a decir a continuación”. Y en este sentido hace parte de los fenómenos que caracterizan la carencia lingüística del hablante.

La afirmación anterior es altamente significativa ya que permite establecer dos categorías en la aparición de los alargamientos: una categoría que denominaré alargamientos pertinentes y que incluye a los intensificadores, atenuantes y descriptores y en general a todos aquellos que cumplen una función dentro del discurso o responden a la intención del hablante, y otra categoría que corresponde a los alargamientos no pertinentes o sea a aquellos que no cumplen una función al interior del discurso pero que dan tiempo al locutor para organizar su discurso o para recordar una palabra o un hecho.

Para Briz (2001, p. 94):

"Los alargamientos silábicos son un fenómeno fónico frecuente en la conversación [...] su valor es el de servir de apoyo para pensar lo que se va a decir a continuación; en otras ocasiones son alargamientos significativos que actúan como refuerzos del decir y/o de lo dicho."

A continuación se ofrecen algunos ejemplos de "alargamientos pertinentes". En ellos el alargamiento actúa como un refuerzo semántico para destacar el valor de un elemento léxico nuclear del enunciado. Obsérvese cómo en estos casos el alargamiento opera sobre la sílaba acentuada o sobre el último sonido de una palabra llena: 
Ej: “Tanta violencia:” (Inf. 34M)

Ej: “un cablegrama: a través de Cruz Roja” (Inf. 37CM)

Ej: "Ya vendieron la casa me tocó: conseguir por otra parte/" (Inf. 36C)

En otros casos, como se dijo arriba, el alargamiento de un sonido actúa como pausa vacía para dar tiempo al hablante de completar un enunciado, elaborar una respuesta o recordar un elemento sintagmático. Estos alargamientos usualmente anteceden a una palabra llena y por lo tanto están marcados sobre conjunciones, artículos, determinantes y preposiciones. Dada su caracterización y el efecto que causa su presencia en un enunciado, caben en la tipología de vacilaciones y se evalúan como estas.

Ej: "un:// como le diría / como un trayecto" (Inf. 30D)

Ej: “y:: pues ella nos ayudó” (Inf. 32JMC)

No es usual encontrar alargamientos sobre sílaba inacentuada no final, pero estos existen; además algunos de ellos por su atipicidad y efecto restan calidad a la producción y normalmente forman parte de discursos de hablantes con alguna patología del habla o disprosodia.

En términos generales, el alargamiento es positivo si cumple una función semántica o pragmática. Será negativo siempre y cuando se utilice para llenar una pausa, un silencio o constituya una vacilación del hablante. 


\subsubsection{Pausa}

La pausa constituye un elemento dentro de la cadena hablada. Su presencia es necesaria desde el punto de vista lingüístico, así como también desde el fisiológico, ya que si no existiese la pausa, el hablante no tendría el espacio para respirar y descansar.

Desde el punto de vista lingüístico la pausa es un elemento vital que tiene validez en cada uno de los niveles de la lengua: en el fonético-fonológico, en el sintáctico como marcador de límites entre sintagmas, entre enunciados, en lo semántico, en lo pragmático, en el cual tiene una función fática, interactiva. Pero también constituye en ocasiones un elemento idiolectal, lo que favorece la caracterización del hablante, o un elemento dialectal. La región a la cual pertenece un hablante determina la velocidad o lentitud con la que emite un enunciado, lo cual está relacionado en gran medida con las pausas.

Las pausas no están solas dentro de un discurso (Briz, 2001, p. 92). Normalmente van marcadas por la entonación y juntas definen el valor que se le da a un enunciado; además estas adquieren valor semántico y pragmático al interior del discurso: de acuerdo con su función, en alguno de los niveles anteriores, elevan el estatus discursivo cuando apropian del lugar que les es natural o funcional.

Sin embargo no todas las pausas de un discurso tienen o aportan valor al mismo. La presencia abundante de pausas puede generar un discurso lento y monótono o un discurso que se nota dudoso o inexacto. 
Si no existe una función o si no es una pausa intencional se puede catalogar negativamente este elemento discursivo.

En consecuencia, son pausas negativas dentro de la producción oral del hablante las pausas intra-enunciados, o intra-sintagmas o intra-léxicas que rompen unidades naturales de la lengua como en:

Ej: "La mayo/ría de hombres y mujeres analfabetas todas" (Inf. 22MP)

Ej: "Estuve trabajando 38 años/ seguidos" (Inf. 23LR)

Ej: “en: el regimiento de transmisiones/ del ejército" (Inf. 23LR)

Las pausas que anteceden a una palabra de difícil acceso o a una palabra inusual para el hablante, se califican con también como un factor negativo.

Ej: “se los llevaban/ evacuados ${ }^{50 "}$ (Inf. 37CM)

Ej: "unos conocidos que teníamos en la // Guindalera" (Inf. 18CR)

Ej: "pero no un estudio:// estructurado" (Inf. 23LR)

En el segundo ejemplo se presenta una búsqueda en el almacén léxico en la, debido a que la palabra "Guindalera" no es de uso común, por lo tanto la búsqueda puede dar lugar a una pausa hasta cierto punto justificada. A pesar de ello, se puntúa

\footnotetext{
${ }^{50}$ La palabra no hace parte del inventario de 5000 palabras más usuales de la lengua.
} 
negativamente porque causa una ruptura en la emisión oral. Cuando la palabra es usual, se califica como doblemente negativa, como en:

Ej: "yo creo que soy/ normal” (Inf. 27MC)

Ej: “que yo creo que es / mmm / normal $1^{51 / / "}$ (Inf. 27MC)

No se justifica la pausa de acceso al almacén léxico del hablante en cuyo caso se trata de una anomia o un olvido de quien produce el enunciado. Si una palabra es de alta frecuencia de uso, el acceso al léxico para encontrar su entrada es mucho más rápido y automático que si la palabra es de difícil acceso o de baja frecuencia, en cuyo caso es probable que se tenga que hacer una brevísima pausa a veces imperceptible para acceder a ella.

Según Torras (1997), la pausa o pausas “Suelen situarse antes de la emisión de un constituyente con el fin de obtener tiempo para poder llevar a cabo la codificación". (P. 197). Y en concordancia con lo expuesto en los ejemplos anteriores agrega "que la pausa puede estar presente también a menudo dentro del mismo constituyente antes de la(s) palabra(s) de contenido con el fin de obtener más tiempo en la búsqueda léxica" (p. 197).

“Las personas parecen tener hábitos más o menos idiosincrásicos en la producción de pausas" (Garman, 1990, p. 180), con lo cual se puede establecer una caracterización

\footnotetext{
${ }^{51}$ La palabra hace parte del inventario de 5000 palabras más usuales de la lengua.
} 
típica de cada individuo. Este fenómeno normal, natural e identificativo del hablante es necesario tenerlo en cuenta cuando se trata de evaluar el discurso.

\subsubsection{Enunciados truncados}

"Se considera intentos frustrados los inicios de emisiones lingüísticas que quedan abortadas antes de llegar a formular el mensaje. El intento frustrado va seguido normalmente de un largo silencio que a veces desemboca en el bloqueo" (Garman, 1990, pp. 200). Más adelante Garman añade que "a veces los intentos frustrados se dan en cadena sin que se pueda entrever la intención comunicativa, aunque se puede suponer que esta no existe...” (Garman, 1990, pp. 200-201).

La falta de recursos lingüísticos adecuados puede afectar todo el proceso de planificación influyendo en la selección o cambio de tópico, o de una manera más global llevar al abandono de la frase iniciada (intentos frustrados) e incluso al bloqueo comunicativo (propuesta de Torras). Cada caso de enunciado truncado se evalúa con punto negativo.

\subsubsection{Coalescencia léxica}

La coalescencia es un fenómeno fonético que consiste en la fusión de dos palabras sucesivas mediante la pérdida o cierre de alguna de las vocales en contacto. Popularmente se dice que se trata de dos palabras en una. Ejemplos de coalescencias tenemos: digu'he, luegu'estado, qu'echarlo, diasma, l'ospital, porquia, mi'han, nu'iba, l'ibamos, haciendu'era, agarr'esos. 
Se conoce también como fenómeno de fonética sintáctica y se debe a economía del lenguaje, velocidad en la emisión o pereza articulatoria. La coalescencia hace que se den más palabras por minuto, debido a su naturaleza económica, pero se considera negativo en tanto el hablante no pronuncia completamente ninguna de las palabras. Por esta razón suma y resta punto de manera simultánea. Se le asigna cero.

\subsubsection{La risa define el sentido del texto}

En ocasiones la risa funciona como atenuante que dota el discurso de carácter ligero y jovial. Elimina las fronteras y hace parecer cotidiano aquello que fuera demasiado serio y riguroso o filosófico y poético. Como si el hablante dijera con su risa "soy un ser humano normal, mortal y cotidiano. No toméis en serio mis palabras. No quiero parecer elevado ni pedante". Este es un ítem que se puede evaluar en la casilla de otros, ya que influye de manera significativa. Puede ser positiva o negativa ya que puede obstruir la fluidez del discurso o hacerlo más ameno y divertido.

\subsubsection{Premisas a tener en cuenta para la evaluación de la fluidez discursiva}

1. Toda repetición en cualquier contexto, siempre y cuando sea intencional o multiplique el efecto de significado, se valora positivamente.

2. Toda repetición en cualquier contexto y situación, si no es intencional o no aporta al significado o sentido del discurso se valora negativamente. 
3. Toda repetición de una sílaba, independientemente del contexto en el que aparezca, si tiene un valor descriptivo sonoro o motivado, o si es onomatopéyica se valora positivamente como cuando se cuenta algo y se utiliza la onomatopeya “zas, zas, zas" para describir un golpe.

4. Toda repetición silábica en inicio de palabra es valorada negativamente porque afecta la fluidez del discurso. Por ejemplo, "pepepero", por decir "pero". Se exceptúa de esta valoración el fenómeno fonético de prótesis, ya que este es un fenómeno dialectal o, al menos, colectivo, asentado en la mente del hablante y por lo tanto no afecta la fluidez, aunque se considere un error lingüístico. En Colombia, se suelen usar palabras como "rerrevisado", para decir que algo ha sido revisado varias veces, "rerreformulado", para mostrar varias reformas.

5. La repetición silábica en medio de palabra como "cenicecero" es valorada negativamente. Como en el caso anterior de repetición, se exceptúan las repeticiones silábicas por epéntesis, usadas por hablantes en determinadas regiones o países. Como ejemplo de sílaba repetida epentética tenemos la palabra “espipinaca" o "hipopopótamo", que se escucha en el habla popular colombiana.

6. Las repeticiones en final de palabra son valoradas negativamente y pueden ser síntoma de distemia o tartamudez. Por ejemplo: "Bogotatá". Son muy inusuales estas repeticiones pero pueden ocurrir también como fenómenos colectivos y entonces se denominan "adición por paragoge", como sucede en la palabra "murcielagogo". 
7. La repetición léxica o repetición de palabras no intencional, en todo contexto, es valorada negativamente. Genera la idea de vacilación o duda.

8. La repetición léxica acompañada de entonación enfática, expresa seguridad. Si la palabra que se repite es verbo, sustantivo, adverbio o adjetivo, consideradas todas estas como palabras llenas o palabras de contenido, se da valoración positiva. Por ejemplo: "come, come y come", “fea, fea, fea".

9. Si la palabra repetitiva es palabra vacía o palabra gramatical: preposiciones, conjunciones o determinantes, este tipo de repetición es vacilante. Su valoración es, por lo tanto, negativa. Casi siempre va acompañada de volumen de voz más bajo que el resto de la enunciación, y supone la planificación sobre la marcha o el olvido de palabra. Ejemplo: "De, de, de Asturias".

10. Toda repetición léxica con función enfática o resemantizadora es siempre positiva. Ejemplo: "Estaba solo y enfermo, solo y enfermo".

11. La repetición de expresiones con función correctora o reformuladora es positiva en tanto manifiesta la habilidad metalingüística del hablante y su posibilidad de corregirse. Ejemplo: “era oscura, era negra”. El ejemplo muestra la precisión que hace el hablante al autocorregirse.

12. La repetición de expresiones de carácter ecoico que abarca todo el discurso o grandes porciones del mismo, incide negativamente en la fluidez y en la progresión temática. Se refiere este ítem a la repetición sistemática o la repetición 
constante de enunciados, frases o expresiones. Generalmente se presenta en hablantes de edad avanzada o con patologías de habla.

13. En definitiva, toda repetición no intencional, no justificada o no necesaria que no pueda ser tipificada en los ítems anteriores, independientemente del contexto, es negativa para la fluidez discursiva.

14. Los alargamientos, como ya quedó descrito arriba, son fenómenos propios de la oralidad. Su presencia en el discurso es natural pero el abuso de los mismos causa dificultades en la fluidez verbal. El alargamiento intencional, descriptivo o que causa un efecto estilístico o semántico es siempre positivo ya que aporta calidad a la narración, le da vitalidad." refuerza el valor semántico de "lejos”; “mu:::cho", resemantiza el grado de "mucho".

15. El alargamiento en palabra llena sobre sílaba acentuada suele aparecer sin aportar vitalidad al discurso. En ocasiones como marca de vacilación. Ejemplo, en la palabra "en:::tro". No suele aparecer alargamiento en sílaba átona; si aparece será lógicamente negativo.

16. Si el alargamiento aparece en palabra vacía: determinante, preposición o conjunción, este fenómeno es siempre negativo. Ejemplo, cuando el hablante alarga la preposición "de...:” o el alargamiento de “у...:".

17. La pausa, siempre que sea intencional o estilística, es positiva. Ejemplo, “y quedó quieto///. Murió allí mismo". 
18. La pausa entre enunciados o al final de un enunciado es positiva siempre y cuando cumpla una función evaluativa. Es la pausa que hace el hablante para dar paso a una reflexión o a una crítica. Ejemplo: “cómo le parece a usted?///”. En este ejemplo el hablante interlocutor evalúa lo dicho y genera en la evaluación.

19. Si la pausa es interactiva siempre es positiva. Es la pausa que hace el locutor para generar o esperar o sugerir la respuesta de su interlocutor.

20. Pausa intra-sintagmática: Es una pausa negativa, ya que rompe con la fluidez natural del sintagma. Ejemplo, "el día 15 de (3") noviembre.

21. La pausa que hace parte de la caracterización del hablante debe evaluarse de manera individual, ya que en ocasiones afecta la fluidez, y sin embargo, a veces ofrece dinamismo, interactividad o estilo al discurso.

22. Si la pausa antecede a una palabra llena de carácter inusual o de acceso difícil en la mente del hablante, puede tratarse de una anomia o simplemente de un olvido ocasional. En todo caso, es negativa.

23. Si la pausa antecede a una palabra llena usual, este fenómeno es negativo pero debe contarse por dos (2) para diferenciarlo del fenómeno anterior.

24. La pausa después de palabra llena es también negativa y genera falta en la fluidez por ser vacilante y rupturadora de la frase o del enunciado. Si esta pausa es mayor 
a un segundo debe sumarse cada segundo como si fuese un fenómeno de disfluencia.

25. Todo enunciado truncado afecta la fluidez del discurso y se puntúa negativamente.

Tabla 7: Resumen del instrumento de evaluación de la fluidez con ejemplos

\begin{tabular}{|c|c|c|c|c|}
\hline FENÓMENO & CONTEXTO & CONDICIONES & EJEMPLO & VALORACIÓN \\
\hline $\begin{array}{l}\text { Repetición } \\
\text { (sumatoria) }\end{array}$ & General & Es intencional & & +1 \\
\hline $\begin{array}{l}\text { Repetición } \\
\text { (sumatoria) }\end{array}$ & General & No es intencional & & -1 \\
\hline $\begin{array}{l}\text { Repetición } \\
\text { sonidos } \\
\text { (tartamudeos, } \\
\text { vacilaciones) }\end{array}$ & Indiferente & $\begin{array}{c}\text { No es un } \\
\text { problema } \\
\text { patológico del } \\
\text { hablante } \\
\text { (tartamudez o } \\
\text { disfemia) }\end{array}$ & Eeeeste & -1 \\
\hline \multirow{2}{*}{$\begin{array}{c}\text { Repetición } \\
\text { silábica }\end{array}$} & Indiferente & $\begin{array}{c}\text { Tiene valor } \\
\text { onomatopéyico o } \\
\text { descriptivo }\end{array}$ & zas zas zas & +1 \\
\hline & $\begin{array}{l}\text { Inicio de } \\
\text { palabra }\end{array}$ & No dialectal & pepepero & -1 \\
\hline
\end{tabular}




\begin{tabular}{|c|c|c|c|c|}
\hline & $\begin{array}{c}\text { Medio de } \\
\text { palabra }\end{array}$ & No dialectal & cenicecero & -1 \\
\hline & $\begin{array}{l}\text { Final de } \\
\text { palabra }\end{array}$ & No dialectal & Bogotatá & -1 \\
\hline & En general & No intencional & & -1 \\
\hline & $\begin{array}{l}\text { Acompañado } \\
\text { de entonación } \\
\text { enfática }\end{array}$ & $\begin{array}{l}\text { Palabra llena: } \\
\text { Nombre, verbo, } \\
\text { adverbio, adjetivo }\end{array}$ & $\begin{array}{l}\text { Pide, pide y } \\
\text { pide } \\
\text { fea, fea, fea }\end{array}$ & +1 \\
\hline léxica & $\begin{array}{l}\text { Acompañado } \\
\text { de entonación } \\
\text { vacilante o en } \\
\text { voz más baja }\end{array}$ & $\begin{array}{l}\text { Palabra vacía: } \\
\text { determinante, } \\
\text { conjunción o } \\
\text { preposición }\end{array}$ & $\begin{array}{l}\text { de de de } \\
\text { el el el } \\
\text { y y y } \\
\text { en en en }\end{array}$ & -1 \\
\hline \multirow{3}{*}{$\begin{array}{c}\text { Repetición de } \\
\text { expresiones }\end{array}$} & General & $\begin{array}{l}\text { Tiene función } \\
\text { enfática o } \\
\text { resemantizadora }\end{array}$ & $\begin{array}{l}\text { Estaba solo } \\
\text { y enfermo; } \\
\text { solo y } \\
\text { enfermo }\end{array}$ & +1 \\
\hline & & $\begin{array}{l}\text { Tiene función } \\
\text { correctora } \\
\text { reformuladora }\end{array}$ & $\begin{array}{l}\text { Era oscura, } \\
\text { era negra }\end{array}$ & +1 \\
\hline & $\begin{array}{l}\text { Abarca todo } \\
\text { el discurso o } \\
\text { se manifiesta } \\
\text { en grandes }\end{array}$ & $\begin{array}{l}\text { Simple repetición } \\
\text { o repetición } \\
\text { sistemática }\end{array}$ & & -1 \\
\hline
\end{tabular}




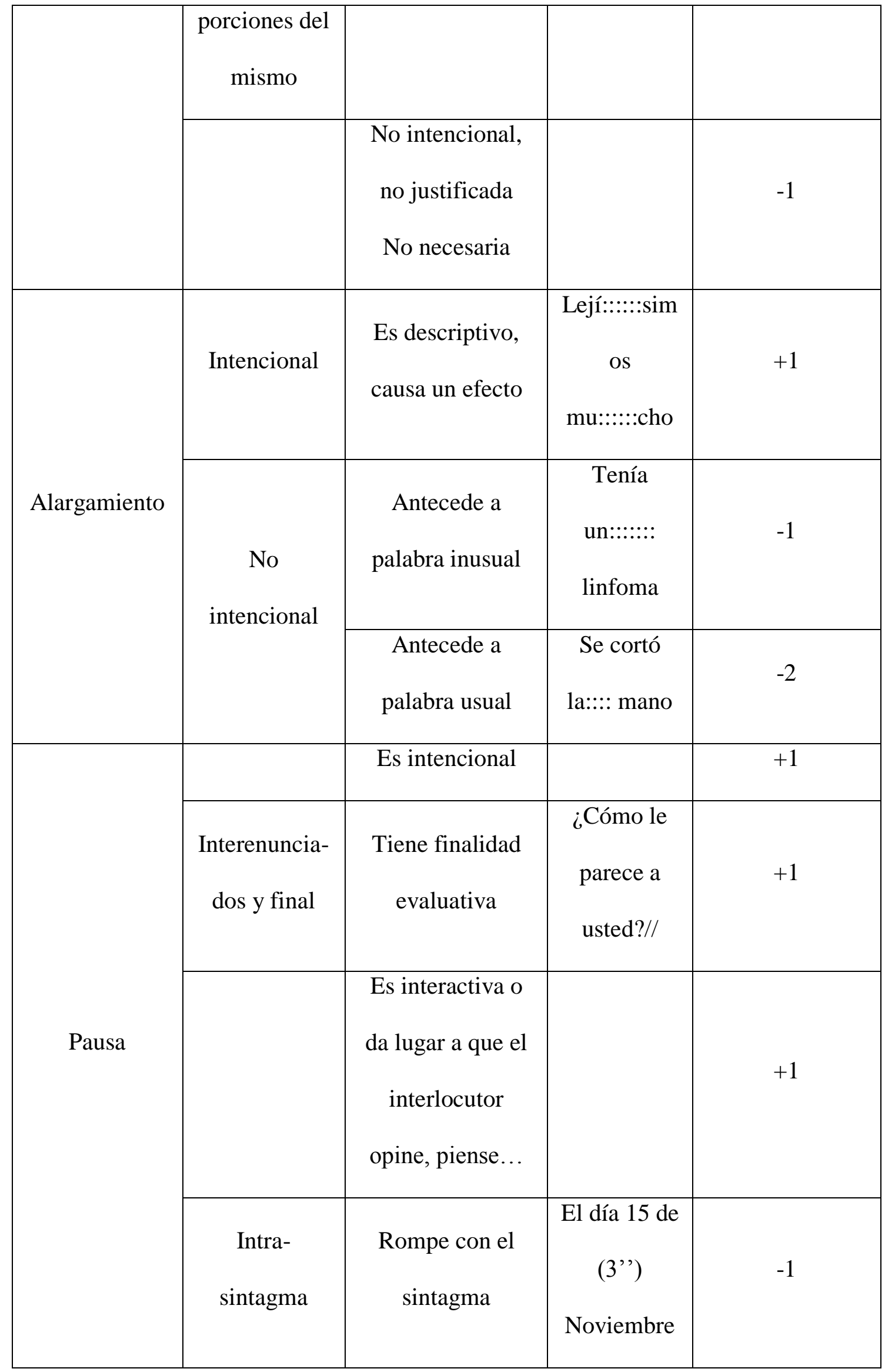




\begin{tabular}{|c|c|c|c|c|}
\hline & & $\begin{array}{l}\text { Hace parte de la } \\
\text { caracterización } \\
\text { del hablante }\end{array}$ & & $\begin{array}{c}\text { Indiferente, no } \\
\text { se valora. }\end{array}$ \\
\hline & $\begin{array}{l}\text { Antecede a } \\
\text { una palabra } \\
\text { llena }\end{array}$ & $\begin{array}{l}\text { Si la palabra es } \\
\text { inusual o de } \\
\text { acceso difícil }\end{array}$ & $\begin{array}{c}\text { Le dijeron } \\
\text { que tenían } \\
\text { que hacerle } \\
\text { una/// } \\
\text { biopsia }\end{array}$ & -1 \\
\hline & $\begin{array}{l}\text { Antecede a } \\
\text { una palabra } \\
\text { llena }\end{array}$ & Si es usual & $\begin{array}{l}\text { Lo van a } \\
\text { operar el } \\
\text { próximo/// } \\
\text { jueves }\end{array}$ & -2 \\
\hline & & $\begin{array}{l}\text { Después de } \\
\text { palabra llena }\end{array}$ & $\begin{array}{l}\text { Le fue mal } \\
\text { en el } \\
\text { examen } \\
\left(5^{\prime \prime}\right) \text { de la } \\
\text { semana } \\
\text { pasada }\end{array}$ & -1 \\
\hline & Indiferente & $\begin{array}{l}\text { No continúa o } \\
\text { termina en } \\
\text { seguida. }\end{array}$ & $\begin{array}{l}\text { Había } \\
\text { sido esa// }\end{array}$ & -1 \\
\hline $\begin{array}{c}\text { Enunciado } \\
\text { truncado }\end{array}$ & Indiferente & $\begin{array}{l}\text { Intencional } \\
\text { semántico }\end{array}$ & $\begin{array}{c}\text { (no } \\
\text { procede) }\end{array}$ & +1 \\
\hline
\end{tabular}




\begin{tabular}{|c|c|c|c|c|}
\hline \multirow{2}{*}{ Acompañamie } & \multirow{2}{*}{ Indiferente } & No concordante & (no & $-1^{52}$ \\
\cline { 3 - 5 } & & Concol discurso & procede) & +1 \\
\hline Gestos & Lugares & Rompen la & (no & \\
\hline Palabras o & inesperados & cadena hablada & procede) & $-1^{53}$ \\
segmentos & Indiferente & No intencionales & procede) & $-1^{54}$ \\
\hline Carraspeos y & & & procede) & \\
\hline ruidos & & No intencionales & & -1 \\
\hline Otros & & & & \\
\hline
\end{tabular}

\subsubsection{Integración de los dos tipos de evaluación}

Cuando se trata de evaluar la producción discursiva del hablante no puede acudirse a elementos puntuales, sino más bien a la integridad y conjunción de elementos en el discurso, a su funcionalidad y a su valor pragmático.

Un elemento es válido o no, de acuerdo con la función que cumple en el momento de la producción del enunciado, independientemente del grado de corrección o incorrección que posea.

\footnotetext{
${ }^{52}$ Siempre y cuando indique duda o vacilación del hablante.

${ }^{53}$ Siempre y cuando indique duda o vacilación del hablante.

${ }^{54}$ Siempre y cuando indique duda o vacilación del hablante.
} 
No se trata de juzgar si el discurso está elaborado correctamente, no existe una pretensión prescriptiva, sino una evaluación funcional basada en la totalidad del discurso y en la operatividad de ese discurso en la interacción comunicativa, en la situación y en el desarrollo de la intencionalidad.

También es importante tener en cuenta que los errores de habla ${ }^{55}$ son fenómenos de ocurrencia normal, regular y natural en la conversación y por si mismos no implican ni un problema ni una patología del hablante. En otras palabras, los errores del habla hacen parte de la caracterización de la oralidad y son más frecuentes cuanto más coloquial e informal sea la conversación.

La obligada planificación rápida ${ }^{56}$ de la producción oral es un fenómeno que impone una serie de características que van más allá de los errores y que en ocasiones interviene en la organización de la información, trae como consecuencia olvidos y genera situaciones atípicas en el desarrollo de la narración de los hechos. Moreno Fernández (2002) dice que "el proceso de producción del lenguaje se inicia cuando el hablante formula una intención [...] de lo que quiere decir” (p. 23).

Los fenómenos dialectales o regionales o, en general, colectivos, de tipo léxico, fonético o sintáctico hacen parte de la manera de hablar y no pueden considerarse como errores ni como marcadores de riqueza o pobreza discursiva.

\footnotetext{
55 También conocidos como spoonerismos.

${ }^{56}$ No puede hablarse de una falta de planificación en la producción oral sino de una planificación sobre la marcha u obligada planificación rápida.
} 
Una vez se ha aplicado la evaluación cualitativa al discurso narrativo, y la evaluación cuantitativa a los fenómenos orales, los datos obtenidos se incluyen en una tabla general en la cual se integran con el número total de palabras por minuto (fluidez verbal). Todos los datos deben convertirse en numéricos y generarán al incluirlos en la tabla de Excel el rango de fluidez discursiva oral integral de cada informante, tal como se aplica en el capítulo 5.

Dado que la evaluación cualitativa está comprendida en una escala de 0 a 5 , se hace necesario convertir la evaluación cuantitativa a la misma escala para poder efectuar la integración de ambas. La conversión se realizó escalando los datos mediante la siguiente fórmula en Excel:

$$
P e=\frac{P r \times 5}{I M}
$$

Donde:

- Pe: Puntaje cuantitativo escalado

- Pr: Puntaje cuantitativo real

- 5: Constante que equivale al máximo del intervalo

- IM: Ideal máximo hipotético del hablante

Se multiplica el puntaje real del hablante por 5 (máximo de la nueva escala que se obtendrá) y se divide entre el puntaje máximo que un hablante obtendría (en este caso un puntaje ideal hipotético). 
El resultado nos da un puntaje Pe que comprende un intervalo de cero (0) a cinco (5). Este nuevo valor es homogéneo con el puntaje obtenido en la evaluación de la fluidez narrativa (evaluación cualitativa) y permite promediar los dos valores.

Por último se obtiene el promedio final entre los resultados obtenidos en la evaluación cualitativa y la evaluación cuantitativa (escalada de 0 a 5). Se suma y se divide entre dos. El valor resultante es el puntaje de Fluidez Discursiva Oral Integral (F.D.O.I.) obtenido por cada hablante. 
5. APLICACIÓN DEL MODELO DE EVALUACIÓN DE LA ORALIDAD 
El modelo de evaluación de la oralidad se ha aplicado a la totalidad de las entrevistas (66) para obtener las tablas pormenorizadas. En este capítulo se hará una selección de informantes a los cuales se les aplicará el instrumento, detallando los pasos de manera explícita, y ello con dos finalidades metodológicas específicas: $1^{\text {a }}$ ) Ilustrar en la práctica la forma de aplicación en cada texto o entrevista. $2^{\text {a }}$ ) Establecer comparaciones entre cinco tipos de relatos con características distintas, tanto en lo cualitativo como en lo cuantitativo. Se eligió trabajar con los informantes: 1D, 11AC, 58E, 59O Y 64AV.

\subsection{Evaluación integral del discurso del informante 1D}

1D

Edad: 14 años

Nacionalidad: Colombia

Sexo: Masculino

\begin{tabular}{|c|c|}
\hline Informante & Discurso \\
\hline $\mathrm{D}$ & $\begin{array}{l}\text { Yo llegué el } 23 \text { de marzo de } 2001 \uparrow \text { a mí me recibieron María y } \\
\text { Evangelina } \downarrow \text { Yo llegué al hogar El Arca por un centro de día que se } \\
\text { llama el Álamo porque estaba en la calle } \downarrow \text { Me gusta cocinar } \uparrow \text { jugar a } \\
\text { la pelota } \downarrow \text { Me hice amigo de Lucas } \uparrow \text { Roberto y Yoly } \downarrow \text { Me llevo muy } \\
\text { bien con los coordinadores Mirta y Martín } \downarrow \text { En la calle me puse a } \\
\text { trabajar de embolador estaba en Retiro } \downarrow\end{array}$ \\
\hline
\end{tabular}

El informante 1D es un joven colombiano de 14 años. Fue grabado en el hogar El Arca, centro de atención para jóvenes con dependencia de las drogas. Es un informante que habla muy rápido, haciendo observación desde el punto de vista intuitivo. Su discurso se caracteriza por ser corto, descriptivo y preelaborado, ya que su intención es hacer una 
breve presentación de sí mismo ante el grupo de compañeros y terapeutas del hogar en el que se encuentra.

\subsubsection{Evaluación del discurso narrativo}

\subsubsection{Habilidad para la superestructura narrativa}

Las narraciones se caracterizan por la presencia de personajes que deben ser descritos detalladamente. Este discurso, en particular, consta de 6 cortas líneas. El protagonista se describe muy rápidamente como una persona que habitaba la calle y por dos de sus aficiones: la cocina y el juego de pelota. Por lo tanto en la caracterización de personajes se le dio un puntaje de dos (2) en la escala de uno (1) a cinco (5). No hay acciones o cambios de estado. Dicho de otro modo, no puede hablarse de una acción inicial, otra medial y otra final. Entonces este apartado se evaluó con cero (0) teniendo en cuento que 5 indica los cambios de estado y 0 indica que no se dio cambio de estado. No hubo narración.

En el ítem "presencia de estructura narrativa" se evalúa el hecho de que la narración cumpla con las partes propuestas por la superestructura textual. El corpus del informante 1D no posee todas las partes requeridas, por lo tanto se puntuó con 1 su producción, dentro de un rango de 0 a 4 puntos posibles, donde cero (0) es la ausencia de estructura narrativa, y de ahí en adelante se asigna el valor de acuerdo con las partes presentes en el discurso evaluado. 
La creación de un ambiente o entorno se refiere a las descripciones y datos contextuales que permiten ambientar el discurso y situar a los personajes que han sido mencionados en la narración. Se puntúa de 1 a 5 y en el caso de 1D se le evaluó con 1 que equivale a la referencia cualitativa.

\subsubsection{Habilidad para la progresión temática}

En este segundo ítem se evalúa la forma en la cual el tema se desarrolla y progresa hacia un fin. Aquí se tienen en cuenta 6 indicadores:

- Indicador 1: presencia de un asunto común o tema unitario; si lo hay se evalúa con 5 y, si no lo hay con cero (0). En 1D no hay un tema unitario, por lo tanto se evaluó como cero (0).

- Indicador 2: selección adecuada de la información. Sí equivale a 5 y No equivale a cero (0). Se asignó 5 a este informante.

- Indicador 3: si la información es suficiente se evalúa con 5 y si no lo es se evalúa con cero (0). Se asignó 5 a este informante.

- Indicador 4: se refiere a la cantidad de información que aporta el informante en su discurso. Este ítem se evalúa de la siguiente manera: si la información es excesiva se le asigna cero (0). La información es excesiva cuando se reitera demasiado o se detallan aspectos innecesarios. Si no es excesiva se le asigna 5. El discurso de 1D no posee información excesiva, se le asignó un valor de 5. 
- Indicador 5: organización lógica de ideas. Se evalúa con la escala de 0 a 4, según la cual la inexistencia de organización corresponde a cero (0) con el indicador cualitativo "nunca". La valoración 1 corresponde a "casi nunca", 2 corresponde a “a veces", 3 corresponde a "casi siempre" y finalmente se asigna 4, con "siempre", al hecho de tener las ideas organizadas en forma lógica.

Para el caso del informante 1D se asignó una valoración de 1 que corresponde a casi nunca. Se justifica este valor, teniendo en cuenta que el informante no asigna una escala de categorías a cada idea independiente en un mismo nivel categorial. No se da dependencia entre una idea y otra.

- Indicador 6: en la progresión temática acertada se evalúa su presencia o ausencia en el discurso. Si la hay se evalúa como cero (0). El discurso del informante 1D se evalúa con cero (0) en tanto no se conduce la idea hacia un fin específico.

\subsubsection{Habilidad para crear coherencia}

Como se explica en el marco teórico, la coherencia depende de la aplicación de reglas discursivas y de la presencia de campos semánticos claramente definidos a través de redes de isotopías. Si existe un campo semántico se puntúa con 5 y si no existe se puntúa con cero (0). De igual manera en $1 \mathrm{D}$ se puntuó cero (0) para la presencia de redes isotópicas, ya que no se puede mostrar un haz semántico que permita identificar grupos de isotopías. 
El ítem "enunciados claros y no contradictorios" se evalúa con la escala de 0 a 4 , donde cero (0) corresponde a "nunca", 1 “casi nunca", 2 "algunas veces", 3 “casi siempre" y 4 corresponde a "siempre". Este informante se puntuó con 4, ya que no hay contradicción entre sus enunciados y cada parte es muy clara. El informante dice que le gusta jugar a la pelota, que le gusta la cocina, que vivía en la calle.

En el ítem "enunciados pertinentes" la escala aplicada es la misma del ítem anterior, de 0 a 4 , y se puntuó como 4, ya que todos los enunciados son oportunos, adecuados y corresponden al discurso y tema que se menciona dentro del discurso.

\subsubsection{Cohesión}

La cohesión está evaluada atendiendo al enlace secuencial de los hechos, que se evalúa de 0 a 4. Los hechos no tienen enlaces entre sí. Más bien se trata de yuxtaposición de los mismos y por lo tanto se puntuó como cero (0). Lo mismo ocurre en la presencia de conectores de discurso cuyo indicador es puntuado en $1 \mathrm{D}$ como cero ( 0 ), ya que no se da ningún conector explícito en su discurso.

El ítem "presencia de enlaces anafóricos y catafóricos" se puntuó como 1, que corresponde a la valoración "casi nunca" en la escala de 0 a 4 , y se le da este puntaje porque el informante utiliza el pronombre como enlace anafórico que mantiene el referente (yo) y lo sustituye por los pronombres “me” y “mí'. Ejemplo: “yo llegué, a mí me recibieron, me gusta cocinar". 


\subsubsection{Evaluación}

La presencia de juicios de valor acerca de los hechos narrados se puntuó como cero (0), ya que no hace evaluación de lo contado. Este ítem se evalúa con 5 o 0 , dependiendo de la presencia o ausencia de juicios de valor respectivamente. Tampoco se evalúa el discurso como tal por lo que se puntuó como cero (0). No se dan en este discurso la presencia de intensificadores, comparadores, ni atenuantes, por lo tanto se puntuó como cero (0) este indicador.

El ítem "entonación enfática" se puntuó como cero (0), ya que no se presenta una variación considerable del tono de voz para referirse a valoraciones o evaluaciones de hechos dentro del discurso.

\subsubsection{Contextualización}

La contextualización del discurso se evalúa mediante dos indicadores: uso de deícticos gramaticales y referencias a lugares, personas y fechas. El primer indicador se evaluó como 2 en la escala de 0 a 4, que corresponde cualitativamente a la valoración “a veces" referido al uso del pronombre personal (yo, mí, me) como deíctico de persona.

El ítem "referencias a lugares, personas y fechas" se puntúa con 4, que corresponde a la valoración cualitativa "siempre", ya que se mencionan nombres de lugares: "hogar El Arca"; nombre de personas: "Mirta, Martín, Roberto, Yoly, María y Evangelina"; la fecha: "23 de enero de 2001". En este sentido se da una perfecta 
contextualización en cuanto a personas, lugares y fechas. Es un informante que especifica y detalla este aspecto de su discurso.

\subsubsection{Evaluación de la fluidez discursiva}

Este informante no presenta fenómenos ni positivos ni negativos en el momento de evaluar, por lo tanto no hay datos para cuantificar en la evaluación de la fluidez, y sería muy tedioso citar ítem por ítem este aspecto que se evaluó como cero (0) para todos los ítems, tal como se aprecia en la tabla siguiente, que se adjunta para ilustrar la evaluación del discurso y señalar cada fenómeno con su valoración. No presenta pausas, ni repeticiones, ni alargamientos positivos o negativos para la fluidez discursiva oral.

Tabla 8: Evaluación integral del discurso: informante $1 D$

\begin{tabular}{|c|c|c|c|c|c|}
\hline $\mathrm{N}^{\mathrm{o}}$ & EVALUACIÓN INTEGRAL DEL DISCURSO & $\mathrm{Dt}$ & $\mathrm{N}^{\mathrm{o}}$ & FLUIDEZ ORAL & Dt \\
\hline $\mathrm{I}$ & $\begin{array}{c}\text { HABILIDADES SUPERESTRUCTURA } \\
\text { NARRATIVA }\end{array}$ & & 1 & Rep. Int & 0 \\
\hline 1 & Caracterización de personajes & 2 & 2 & Rep. no int & 0 \\
\hline 2 & Desarrollo de acciones (cambio de estado) & 0 & 3 & Rep. son. & 0 \\
\hline 3 & Presencia de estructura narrativa & 1 & 4 & Rep. silab. desc. & 0 \\
\hline 4 & Creación de un ambiente o entorno & 1 & 5 & Rep. inic. & 0 \\
\hline II & TEMÁTICA, COHERENCIA GLOBAL & & 6 & Rep. Medio & 0 \\
\hline 5 & Presencia de un asunto común o tema unitario & 0 & 7 & Rep. Fin. & 0 \\
\hline 6 & Selección adecuada de información & 5 & 8 & Rep. lex no int. & 0 \\
\hline 7 & Información suficiente & 5 & 9 & Rep. Pal llena & 0 \\
\hline 8 & Información excesiva & 5 & 10 & Rep. Pal vacía & 0 \\
\hline 9 & Organización lógica de ideas & 1 & 11 & Rep. exp. Resem. & 0 \\
\hline 10 & Progresión temática acertada & 0 & 12 & Rep. Exp. Ref. & 0 \\
\hline III & COHERENCIA LOCAL & & 13 & Rep. Sistemática & 0 \\
\hline 11 & $\begin{array}{l}\text { Existencia de campos semánticos claramente } \\
\text { definidos }\end{array}$ & 0 & 14 & Rep. exp innec. & 0 \\
\hline 12 & Presencia de redes isotópicas & 0 & 15 & Alarg. Desc. & 0 \\
\hline 13 & Enunciados claros y no contradictorios & 4 & 16 & Alarg. Llena ac. & 0 \\
\hline 14 & Enunciados pertinentes & 4 & 17 & Alarg. Llena inac & 0 \\
\hline IV & COHESIÓN & & 18 & Alarg. Pal vacía & 0 \\
\hline
\end{tabular}




\begin{tabular}{|c|c|c|c|c|c|}
\hline 15 & Enlace secuencial de los hechos & 0 & 19 & Alarg ant. Llena & 0 \\
\hline 16 & Presencia de conectores de discurso & 0 & 20 & Alarg. Innec. & 0 \\
\hline 17 & Presencia de enlaces anafóricos y catafóricos & 1 & 21 & Pausa int. & 0 \\
\hline V & EVALUACIÓN & & 22 & Pausa fin ev. & 0 \\
\hline 18 & $\begin{array}{l}\text { Presencia de juicios de valor acerca de los } \\
\text { hechos narrados }\end{array}$ & 0 & 23 & Pausa interac & 0 \\
\hline 19 & $\begin{array}{l}\text { Presencia de juicios de valor acerca del } \\
\text { discurso }\end{array}$ & 0 & 24 & Pausa ruptura & 0 \\
\hline 20 & $\begin{array}{l}\text { Presencia de expresiones valorativas: } \\
\text { Intensificadores, Comparadores, Correlativos, } \\
\text { Explicativos, Atenuantes. }\end{array}$ & 0 & 25 & Pausa caract. $\mathrm{Hb}$ & 0 \\
\hline 21 & Entonación enfática & 0 & 26 & Pausa ante inus. & 0 \\
\hline VI & CONTEXTUALIZACIÓN & & 27 & Antec. pal llena us & 0 \\
\hline 22 & Uso de deícticos gramaticales & 2 & 28 & Desp. de llena & 0 \\
\hline \multirow[t]{2}{*}{23} & Referencias a lugares, personas o fechas & 4 & 29 & Enunciado truc. & 0 \\
\hline & RESULTADOS FINALES & & 30 & Coalesc. & 0 \\
\hline & PROMEDIO CUALITATIVO & \multicolumn{4}{|c|}{$1,52^{57}$} \\
\hline & PROMEDIO CUANTITAVO & \multicolumn{4}{|c|}{234,2} \\
\hline & PROMEDIO CUANTITATIVO DE 0 A 5 & \multicolumn{4}{|c|}{4,34} \\
\hline & PROMEDIO TOTAL & \multicolumn{4}{|c|}{2,93} \\
\hline
\end{tabular}

En la evaluación cuantitativa obtiene, pues, un puntaje de 234,2, que es el número de palabras emitidas por minuto. Con el fin de calcular valores medios con la fluidez narrativa, es decir, con el promedio cualitativo, es preciso convertir ese número en una escala de 0 a 5. Se explicarán los detalles de esta conversión en el capítulo 6. Por ahora baste con decir que el cero representaría el silencio total y el 5 una cantidad de fluidez ideal que se ha fijado en 270 palabras por minuto. En el desempeño cualitativo obtiene 1,52 y de estos dos valores se obtiene el promedio de 2,93 de acuerdo con la tabla generada en Excel. Este informante presenta buen desempeño en fluidez oral porque no presenta pausas, repeticiones, alargamientos, ni otros fenómenos que muestren disfluencias en la oralidad, pero tiene dificultades en la evaluación cualitativa en tanto su puntaje es bajo en indicadores de producción narrativa y discursiva.

\footnotetext{
${ }^{57}$ Este valor se obtuvo como resultado del promedio de los 23 ítems evaluados para la fluidez narrativa. La sumatoria da 35 que dividido entre 23 es igual a 1,52.
} 


\subsection{Evaluación del discurso del informante $11 \mathrm{AC}$}

$11 \mathrm{AC}$

Edad: 52 años

Nacionalidad: Colombia

Sexo: Femenino

\begin{tabular}{|c|c|}
\hline Informante & Discurso \\
\hline $\mathrm{AC}$ & 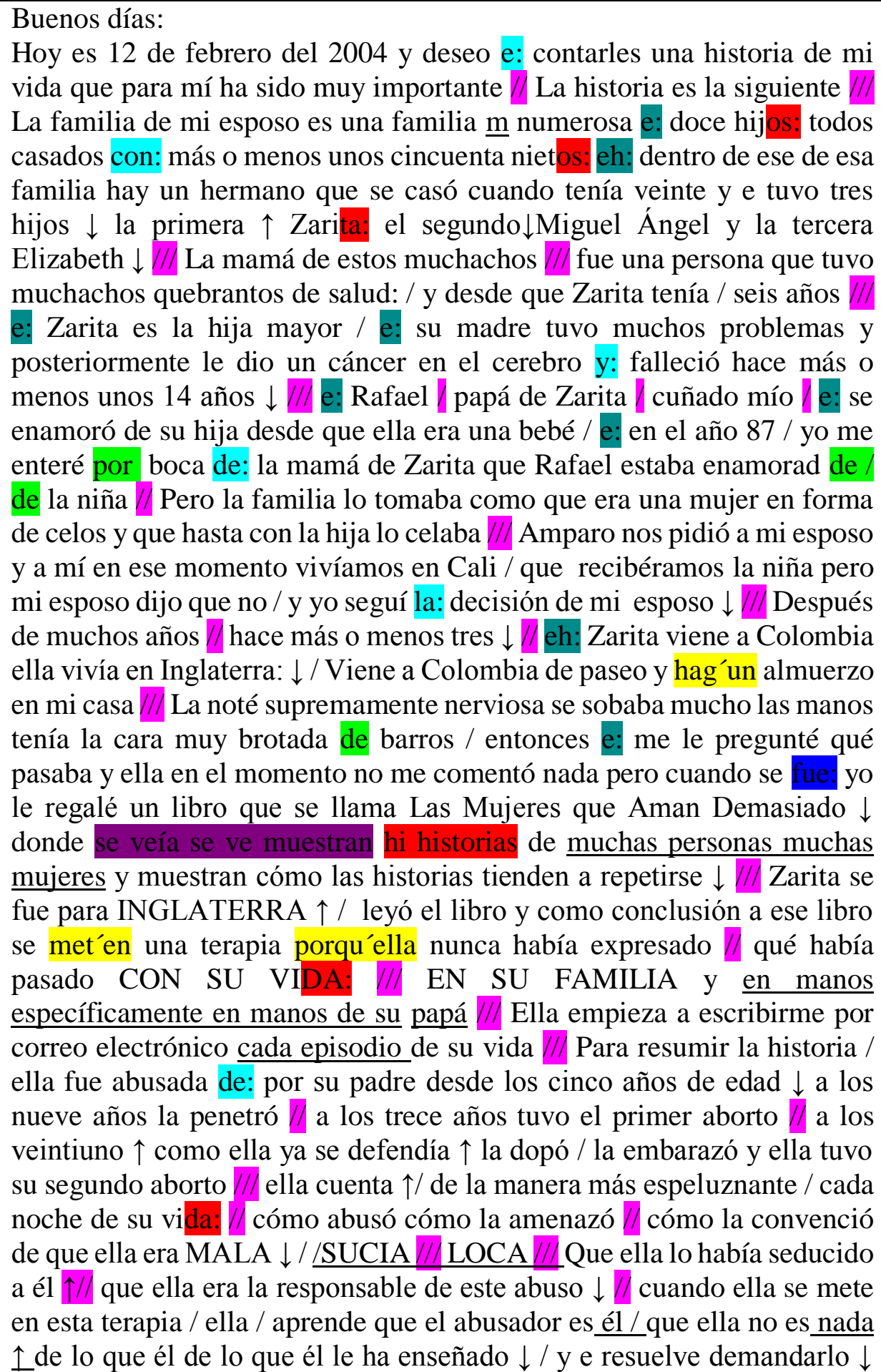 \\
\hline
\end{tabular}




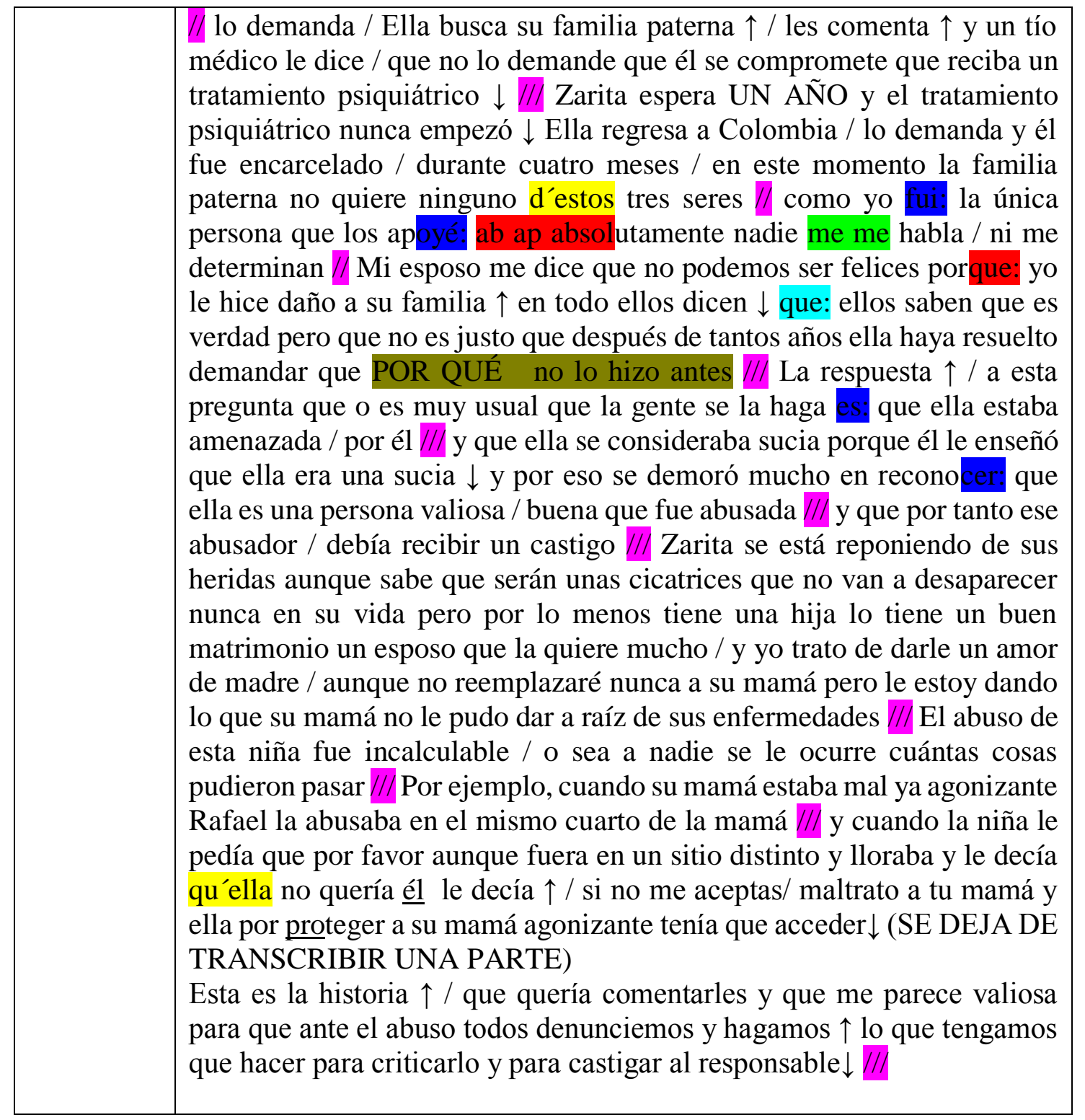

La informante $11 \mathrm{AC}$ es una mujer colombiana, profesional de 52 años. Su hablar es tranquilo, aunque se trata de un tema complicado: el abuso sexual en la familia. Su intención está claramente explícita al inicio de su intervención: denunciar el abuso sexual para que sea castigado y no quede impune. Es una denuncia que visibiliza el hecho a través del testimonio personal.

Es un discurso muy bien elaborado, que al ser evaluado con indicadores objetivos da un resultado que se ubica en un puntaje superior de los 66 informantes evaluados. 


\subsubsection{Evaluación del discurso narrativo}

\subsubsection{Habilidad para la superestructura narrativa}

En el indicador "caracterización de personajes" se le da un puntaje de 5 que corresponde a excelente, ya que muestra características tanto físicas como psicológicas de las personas descritas. Rafael es caracterizado como un hombre manipulador, chantajista, autoritario y desprovisto de valores. Zarita es la niña vulnerable, frágil, intimada: "tenía 6 años", "es la hija mayor", "la noté supremamente nerviosa", "tenía la cara muy brotada de de barros", "ella se consideraba sucia".

El desarrollo de acciones se evalúa de acuerdo con el cambio de estado de una situación inicial a una final. En 11AC se puntúa con 5 (sî) la transformación de personajes. Sobresale Zarita, quien inicia siendo una bebé y termina casada y con una familia constituida.

Hay presencia de estructura narrativa en $11 \mathrm{AC}$, ya que se dan todas las partes de la narración, situación inicial, desarrollo, nudo, desenlace y evaluación, tal como quedó planteado en el marco teórico de este trabajo. El hecho de que tenga la totalidad de las partes dentro de las condiciones de la superestructura narrativa, se puntúa como 4.

- Inicio: "buenos días, hoy es 12 de febrero", hasta: "falleció hace más o menos unos 14 años".

- Desarrollo: "Rafael, papá de Zarita", hasta tratamiento psiquiátrico. 
- Nudo: lo demanda y él fue encarcelado.

- Desenlace: tiene una hija, tiene un buen matrimonio y un esposo que la quiere mucho.

- Evaluación: "esta es una historia que quería comentarles y que me parece valiosa".

La creación de una ambiente u entorno es un indicador que se puntúa con 5, ya que se describen detalladamente tanto el entorno familiar y social, como las condiciones en que está la madre de Zarita antes de morir. Se asigna la máxima puntuación para este ítem.

\subsubsection{Habilidad para la progresión temática}

El ítem "presencia de un asunto común o tema unitario" se puntúa como 5 (sí), ya que solamente se habla en el discurso del abuso sexual proferido sobre Zarita. La “selección adecuada de la información” se puntúa como 5 (sí), teniendo como referencia el hecho de que cada dato está cuidadosamente elegido y colocado para provocar una reacción o para describir un momento dentro de lo narrado.

La “información suficiente” se puntuó como 5, ya que se considera ilustrativo lo que se dijo y no se queda corta la informante a la hora de aportar detalles acerca de los hechos narrados (abuso), acerca de las actitudes de los participantes, ni acerca de quiénes son y como son los personajes de la historia.

La “información excesiva” no se presenta, pues la información en este discurso es equilibrada en cuanto a la cantidad aportada, siendo un discurso que trata un tema 
tabuizado, no se queda corta como se expuso en el ítem anterior. Tampoco da detalles innecesarios o excesivamente repetitivos. Para este ítem se consideró, pues, que la información es justa (no excesiva) en el caso de 11AC, y se puntúa con 5.

La "organización lógica de las ideas" se puntúa en la escala de "nunca" (0) a “siempre" (4). Para el caso de 11AC se puntuó con 3 este ítem, que corresponde a "casi siempre". Se justifica por el hecho de que la informante repite una parte de la información que ya mencionó, además la reelabora. Este fenómeno se da por la espontaneidad de la grabación, y el conocido fenómeno ya explicado de la planificación sobre la marcha u obligada planificación rápida.

La "progresión temática acertada" en este discurso (11AC) tiene desde su inicio una finalidad muy bien definida: denunciar el abuso sexual infantil; en este sentido todo el discurso conduce al logro de este cometido. Por supuesto se da una progresión temática, de tal modo que se añade constantemente información nueva, hay progreso en la evolución y desarrollo temático. Se puntuó este ítem con 5, que corresponde a sí existe progresión temática acertada.

En relación con la "presencia de campos semánticos claramente definidos", se considera que en 11AC son limitados y están bien especificados. Estos son: el abuso sexual, la violencia de género, el maltrato infantil y el incesto. Todos ellos aparecen bien sustentados en isotopías. Por lo tanto este ítem se puntúa con 5.

Las redes isotópicas, consecuentemente con el indicador anterior, se presentan fuertemente establecidas. Para el abuso sexual tenemos las siguientes isotopías: "ella fue 
abusada", “a los 9 años la penetró”, “a los 21 la dopó, la embarazó y ella tuvo su segundo aborto”, “cómo abusó, cómo la amenazó”, “él le enseñó que ella era una sucia”, “el abuso de esta niña es incalculable".

Para el caso del incesto tenemos: “Rafael, papá de Zarita, cuñado mío, se enamoró de su hija desde que ella era una bebé", "me enteré por boca de la mamá de Zarita que Rafael estaba enamorado de la niña", "ella fue abusada por su padre desde los 5 años de edad", “en manos de su papá”. Por lo tanto este ítem se puntúa como 5.

El ítem "enunciados claros y no contradictorios" fue evaluado con 5, ya que todo el discurso es coherente y no se dan contradicciones entre los enunciados proferidos por 11AC. Sorprende la calidad con la cual logra describir los episodios narrados. Concretamente cito: “a los 9 años la penetró”, “a los 13 años tuvo su primer aborto”. Son enunciados que narran y describen con total claridad lo ocurrido a Zarita.

Todos los enunciados tienen una intención comunicativa y cumplen una función bien determinada. Por ejemplo cuando expresa que "tenía la cara muy brotada de barros" está describiendo a la protagonista de la historia, no solamente en su aspecto físico, sino también en la forma en que el desequilibrio emocional ha causado síntomas físicos en la niña como somatización del sufrimiento.

\subsubsection{Cohesión}

El enlace secuencial de los hechos es un indicador de evaluación que se puntuó con 3 (casi siempre) en la escala de 0 a 4 . Existe en el discurso un momento en el cual se 
adelanta la acción para luego retroceder y contar de nuevo, de otro modo, las acciones. Este discurso tiene un momento en que se adelantan las acciones, un momento en el que se describen y otro en el que se retoman. Por lo tanto se dan saltos narrativos que permiten puntuar con 3 esta producción discursiva.

La presencia de conectores en el discurso no es predominantemente explícita, más bien sucede que los hechos se enlacen mediante yuxtaposición de enunciados. Se puntúa con 2 (algunas veces) en la escala de 0 a 4 . El siguiente ejemplo justifica este puntaje: "la noté supremamente nerviosa, se sobaba mucho las manos, tenía la cara muy brotada de barros".

La presencia de enlaces anafóricos y catafóricos se puntúa con 4 que equivale a "siempre". Es constante la presencia de determinantes y pronombres con función

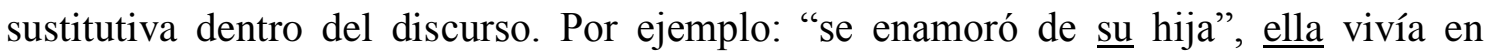
Inglaterra", "la noté" (a ella, Zarita).

\subsubsection{Evaluación}

La presencia de "juicios de valor acerca de los hechos narrados" se puntúa con 5 (sí), ya que se evalúa todo lo ocurrido con Zarita con palabras como: "incalculable”, "de la manera más espeluznante". La presencia de "juicios de valor acerca del discurso" se puntúa con 5 (sí), ya que el enunciador refiere: “esta es la historia [...] que me parece valiosa", "deseo contarles una historia de mi vida que para mí ha sido muy importante". 
La "presencia de expresiones valorativas" se puntúa con 5 y se justifica en: "MALA, SUCIA, LOCA", "supremamente nerviosa". La "entonación enfática" se da constantemente. Está señalada tipográficamente en el corpus mediante el uso de mayúsculas: “CADA EPISODIO”, “UN AÑO”, “CON SU VIDA”, “EN SU FAMILIA”.

\subsubsection{Contextualización}

El "uso de deícticos gramaticales" se refiere al uso de pronombres y determinantes con valor deíctico, ya sea por sí mismos o como sustituto de referencias a personas, lugares o fechas. Se puntuó como 4 (siempre) en la escala de 0 a 4 . 11AC hace uso amplio de deícticos gramaticales, como formas de sustituir los referentes del texto. Ejemplo: “므 celaba (a Rafael)", “ella (Zarita) vivía en Inglaterra”, "ella no me comentó nada", "la noté supremamente nerviosa", “con su vida”, entre otros.

La superestructura narrativa del discurso es de denuncia, y por esta razón es imperativo el uso de referencias a hechos y personas reales que permitan situar lo ocurrido y argumentar con elementos concretos cada hecho narrado. Este es un discurso ostensivo en este aspecto y se sustenta ya desde la introducción: "hoy es 12 de febrero de 2004". Es constante la referencia a nombres propios: Zarita, Miguel Ángel, Elizabeth, Rafael, Colombia, Cali, y a lo largo del discurso, se mantiene esta característica: Inglaterra, Colombia y la mención constante a Zarita. Por lo tanto se puntuó con 4 (siempre) el indicador de "referencias a lugares, personas o fechas". 
Tabla 9: Evaluación integral del discurso: informante 11AC

\begin{tabular}{|c|c|c|c|c|c|}
\hline $\mathrm{N}^{\mathrm{o}}$ & EVALUACIÓN INTEGRAL DEL DISCURSO & Dt & $\mathrm{N}^{\mathrm{o}}$ & FLUIDEZ ORAL & Dt \\
\hline I & HABILIDADES SUPERESTRUCTURA NARRATIVA & & 1 & Rep int & 0 \\
\hline 1 & Caracterización de personajes & 5 & 2 & Rep no int & 0 \\
\hline 2 & Desarrollo de acciones (cambio de estado) & 5 & 3 & Rep son. & 0 \\
\hline 3 & Presencia de estructura narrativa & 4 & 4 & Rep silab. desc. & 0 \\
\hline 4 & Creación de un ambiente o entorno & 5 & 5 & Rep inic. & 2 \\
\hline II & TEMÁTICA, COHERENCIA GLOBAL & & 6 & Rep medio & 0 \\
\hline 5 & Presencia de un asunto común o tema unitario & 5 & 7 & Rep. Fin. & 0 \\
\hline 6 & Selección adecuada de información & 5 & 8 & Rep lex no int. & 0 \\
\hline 7 & Información suficiente & 5 & 9 & Rep. Pal llena & 0 \\
\hline 8 & Información excesiva & 5 & 10 & Rep. Pal vacía & 5 \\
\hline 9 & Organización lógica de ideas & 3 & 11 & Rep exp. Resem. & 0 \\
\hline 10 & Progresión temática acertada & 5 & 12 & Rep. Exp. Ref. & 2 \\
\hline III & COHERENCIA LOCAL & & 13 & Rep sistemática & 0 \\
\hline 11 & $\begin{array}{l}\text { Existencia de campos semánticos claramente } \\
\text { definidos }\end{array}$ & 5 & 14 & Rep exp innec. & 2 \\
\hline 12 & Presencia de redes isotópicas & 5 & 15 & Alarg. Desc. & 0 \\
\hline 13 & Enunciados claros y no contradictorios & 3 & 16 & Alarg. Llena ac. & 3 \\
\hline 14 & Enunciados pertinentes & 4 & 17 & Alarg. Llena inac & 7 \\
\hline IV & COHESIÓN & & 18 & Alarg. Pal vacía & 7 \\
\hline 15 & Enlace secuencial de los hechos & 3 & 19 & Alarg ant. Llena & 0 \\
\hline 16 & Presencia de conectores de discurso & 2 & 20 & Alarg. Innec. & 8 \\
\hline 17 & Presencia de enlaces anafóricos y catafóricos & 4 & 21 & Pausa int. & 65 \\
\hline V & EVALUACIÓN & & 22 & Pausa fin ev. & 1 \\
\hline 18 & $\begin{array}{l}\text { Presencia de juicios de valor acerca de los } \\
\text { hechos narrados }\end{array}$ & 5 & 23 & Pausa interac & 0 \\
\hline 19 & Presencia de juicios de valor acerca del discurso & 5 & 24 & Pausa ruptura & 10 \\
\hline 20 & $\begin{array}{l}\text { Presencia de expresiones valorativas: } \\
\text { Intensificadores, Comparadores, Correlativos, } \\
\text { Explicativos, Atenuantes. }\end{array}$ & 5 & 25 & Pausa caract. $\mathrm{Hb}$ & 0 \\
\hline 21 & Entonación enfática & 5 & 26 & Pausa ante inus. & 0 \\
\hline VI & CONTEXTUALIZACIÓN & & 27 & Antec pal llena us & 1 \\
\hline 22 & Uso de deícticos gramaticales & 4 & 28 & Desp de llena & 0 \\
\hline 23 & Referencias a lugares, personas o fechas & 4 & 29 & Enunciado truc & 0 \\
\hline & RESULTADOS FINALES & & 30 & Coalesc. & 5 \\
\hline \multicolumn{3}{|c|}{ PROMEDIO CUANTITAVO } & \multicolumn{3}{|c|}{$182,7^{58}$} \\
\hline \multicolumn{3}{|c|}{ PROMEDIO CUALITATIVO } & \multicolumn{3}{|c|}{4,39} \\
\hline \multicolumn{3}{|c|}{ PROMEDIO CUANTITAVO DE 0 A 5} & \multicolumn{3}{|c|}{3,38} \\
\hline \multicolumn{3}{|c|}{ PROMEDIO TOTAL } & \multicolumn{3}{|c|}{3,89} \\
\hline
\end{tabular}

\footnotetext{
${ }^{58}$ Recuérdese que este número se obtiene calculando el número de palabras por minuto emitidas por el informante y ajustando luego esta cantidad de acuerdo con los valores positivos o negativos atribuidos a los fenómenos de fluidez oral que se describen en la columna de la derecha.
} 


\subsubsection{Evaluación de la fluidez discursiva}

Para evaluar la fluidez discursiva es necesario señalar los fenómenos orales que sirven como indicador. En la transcipción del discurso se señalaron con colores distintos de acuerdo con el tipo de fenómeno que se presenta. Las convenciones son las siguientes:

- Amarillo: coalescencia.

- Azul oscuro: alargamientos.

- Azul celeste: repeticiones reformuladores.

- Rojo: alargamientos palabra vacía.

- Verde: repetición palabra vacía.

- Verde oliva: repetición en palabra llena.

- Morado: repetición expresiones.

- Naranja: repetición de expresiones.

- Rosa: pausas.

En cuanto a las repeticiones en el discurso de $11 \mathrm{AC}$ estas son limitadas. Se describen de este modo: dos repeticiones en inicio de palabra: "hi historia", "ap absolutamente"; seis repeticiones en contexto de palabra vacía: "por por boca", "de de la niña", "de de barros", "me me habla", "de ese de esa", "muchas personas muchas". Se dan dos repeticiones de expresión tipo reformulación: “en manos específicamente en manos de su papá” y "se veía, se ve se muestra”. 
En cuanto a los alargamientos se ven cinco en palabra llena acentuada: “apoye:”, "reconocer:", "vida:" (está presente dos veces el alargamiento sobre esta palabra) y “nietos:”. Además, los alargamientos sobre palabra vacía, específicamente sobre preposiciones, artículos y conjunciones: “y”, “de”, “con”, “la”, “porque”.

Alargamientos innecesarios: suma diez, ejemplo: “eh: Zarita”, "porque:”, "la: decisión”, “se fue:”, “yo le regalé eh:”, “yo fui:”, “que los apoye:”. Se refiere a todos los alargamientos no intencionales y no semánticos que no están contemplados en ningún ítem anterior. No se dan alargamientos descriptivos, ni antes de palabra llena. Por lo tanto se coloca cero (0) en la casilla correspondiente.

Las pausas, junto con los alargamientos y las repeticiones, forman parte del conjunto de fenómenos evaluados en el instrumento. Dentro del discurso del informante $11 \mathrm{AC}$ se encuentra un uso constante de pausas intencionales, más de 33 ejemplos “con la hija lo celaba//", "después de muchos años//", "tienden a repetirse//". Estas tienen como función atenuar en un primer momento el discurso de tabú, el abuso sexual en la familia, y posteriormente, intensificar la denuncia del mismo. En general, es un informante con un discurso que se caracteriza por ser pausado, debido a que tiene como fin hacer reflexionar al interlocutor sobre el hecho narrado. Asimismo, hay presencia de pausas de ruptura, tales como "vivíamos en Cali/" y "e: Zarita es la hija mayor/".

La informante $11 \mathrm{AC}$ obtiene un promedio de 3,38 en la evaluación cuantitativa de fenómenos de fluidez. Obtiene un promedio cualitativo de 4,39 (4,4 si aproximamos a dos decimales) y es considerada como una de las informantes con un discurso de mayor calidad y con pocos fenómenos de disfluencias orales. El promedio entre lo cuantitativo: 
fluidez oral y lo cualitativo: producción discursiva, es de 3,89 con lo cual se sitúa en un rango alto de calidad de su discurso. Su promedio es el mejor de los obtenidos por los 66 informantes.

Igualmente, el informante $11 \mathrm{AC}$ posee un discurso equilibrado. En términos intuitivos se nota un discurso pausado, reposado. Esta característica se le asigna al hablante. No hay prisa en terminar y sí la necesidad de dejar clara la intención. Es un discurso que fluye tranquilamente, no deja cabos sueltos y equilibra el tema tabú con la intención de denunciar sin perder ninguno de los dos aspectos.

La evaluación del discurso y la narración arroja resultados elevados, ya que el informante posee habilidades para configurar la superestructura narrativa: el testimonio de denuncia. El informante tiene habilidad para el desarrollo temático, manifiesta esta habilidad en la presencia de un tema único, el manejo cuantitativo y cualitativo de la información es muy bueno, y la información progresa hacia un fin (progresión temática).

\subsection{Evaluación del discurso del informante $58 \mathrm{E}$}

$58 \mathrm{E}$

Edad: 90 años

Nacionalidad: Costa Rica

Sexo: Masculino

\begin{tabular}{|c|c|}
\hline Informante & Discurso \\
\hline $\mathrm{E}$ & $\begin{array}{l}\text {..Yo estoy padeciendo yo:: de la en la historia de lo que yo trabajé en } \\
\text { Salento/ no cree/ } \rightarrow \text { Madrugué mucho a trabajar/ } \rightarrow \text { de la música/ pasaba } \\
\text { las noches a a llegar tarde a la casa/ } \rightarrow \text { agarrar la pala y'írme a voliar pala } \\
\text { tooel día/ para ganarme mi sueldito pa mí } \rightarrow \text { / para no de mi familia } \downarrow / \\
((\text { INTERRUMPEN VOCES DE NINOS))/ Me sacaron de segundo año } \\
\text { de la escuela enseñándome a voliar pala } \rightarrow \text { / Pero aprendí a leer y a escri/ } \\
\text { medio escribir }(\ldots) \downarrow((\text { RUIDO AJENO A LA CONVERSACIÓN))/ } \\
\text { Después me ediqué a::/ } \rightarrow \text { yo estuve trabajando e carretera/ eh::/ de aquí/ }\end{array}$ \\
\hline
\end{tabular}




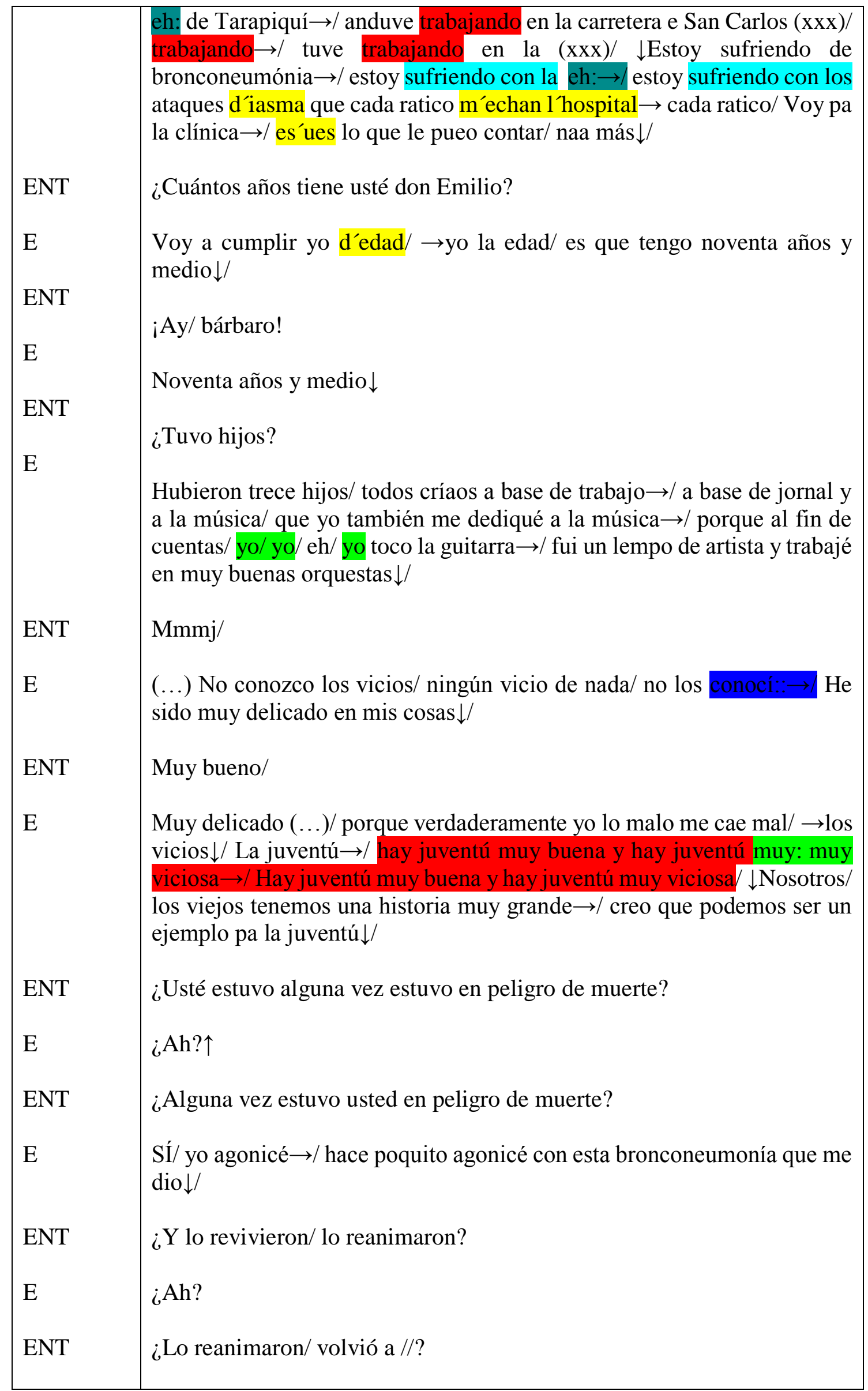




\begin{tabular}{|l|l|}
\hline E & $\begin{array}{l}\text { sí } \rightarrow / \text { yo estao en esta vida mucho tiempo malo/ pero gracias a Dios } \rightarrow / \\
\text { porquia la buena conducta }(\ldots) \rightarrow / \text { señorita paque le cuento a todo } \\
\text { gusto } \rightarrow / \text { y'hay mucha envidia en la vida } \rightarrow y^{\prime} \text { a mí m'ian envidado mucho } \\
\text { porque sido un artista NATURALISTA } \downarrow / \text { Yo fui un guitarrista de mucha } \\
\text { fama por toa/ por toa parte } \downarrow /\end{array}$ \\
\hline
\end{tabular}

El informante 58E es un hablante de Costa Rica de 90 años de edad, enfermo, en silla de ruedas y fue grabado en el Centro geriátrico Los Rosales en la localidad de San Rafael de Heredia. No posee sus dientes naturales y debido a su enfermedad presenta dificultades para mantener la fluidez discursiva. Su discurso no tiene unidad temática y exige continuamente el acompañamiento del entrevistador quien lo apoya a través de preguntas.

Tabla 10: Evaluación cualitativa: informante $58 E$

\begin{tabular}{|c|c|c|c|}
\hline $\mathrm{N}^{\mathrm{o}}$ & $\begin{array}{l}\text { EVALUACIÓN INTEGRAL DEL } \\
\text { DISCURSO }\end{array}$ & $\mathrm{Dt}$ & JUSTIFICACIÓN \\
\hline I & $\begin{array}{l}\text { HABILIDADES } \\
\text { SUPERESTRUCTURA } \\
\text { NARRATIVA }\end{array}$ & & \\
\hline 1 & Caracterización de personajes & 3 & $\begin{array}{l}\text { El informante se describe a sí } \\
\text { mismo. }\end{array}$ \\
\hline 2 & $\begin{array}{l}\text { Desarrollo de acciones (cambio de } \\
\text { estado) }\end{array}$ & 0 & $\begin{array}{l}\text { No se da cambio de situación inicial } \\
\text { a situación final. }\end{array}$ \\
\hline 3 & Presencia de estructura narrativa & 1 & $\begin{array}{l}\text { Hay alguna parte como desarrollo, } \\
\text { pero desarticulado con el resto. No } \\
\text { se verifican partes como nudo o } \\
\text { desenlace. }\end{array}$ \\
\hline 4 & Creación de un ambiente o entorno & 2 & No es muy explícito en este ítem. \\
\hline II & $\begin{array}{l}\text { TEMÁTICA, COHERENCIA } \\
\text { GLOBAL }\end{array}$ & & \\
\hline 5 & $\begin{array}{l}\text { Presencia de un asunto común o tema } \\
\text { unitario }\end{array}$ & 0 & $\begin{array}{l}\text { No se unifica la narración. Son } \\
\text { anécdotas sueltas. }\end{array}$ \\
\hline 6 & Selección adecuada de información & 0 & $\begin{array}{l}\text { Se le dio cero }(0) \text { porque no hay una } \\
\text { narración con tema único. }\end{array}$ \\
\hline 7 & Información suficiente & 5 & $\begin{array}{l}\text { Con la información aportada se } \\
\text { logra entender bien lo que narra. }\end{array}$ \\
\hline 8 & Información excesiva & 5 & No es excesiva la información. \\
\hline 9 & Organización lógica de ideas & 1 & $\begin{array}{l}\text { El informante cuenta anécdotas } \\
\text { independientes sin unidad global. }\end{array}$ \\
\hline
\end{tabular}




\begin{tabular}{|c|c|c|c|}
\hline 10 & Progresión temática acertada & 0 & $\begin{array}{l}\text { Aunque se incluyen remas como } \\
\text { información nueva, no hay un tema } \\
\text { unitario. }\end{array}$ \\
\hline III & COHERENCIA LOCAL & & \\
\hline 11 & $\begin{array}{l}\text { Existencia de campos semánticos } \\
\text { claramente definidos }\end{array}$ & 5 & $\begin{array}{l}\text { Se desarrolla el campo semántico: } \\
\text { enfermedad y trabajo. }\end{array}$ \\
\hline 12 & Presencia de redes isotópicas & 5 & $\begin{array}{l}\text { Enfermedad soporta en: "ataques } \\
\text { d'iasma" } \\
\text { "bronconeumonía" }\end{array}$ \\
\hline 13 & $\begin{array}{l}\text { Enunciados claros y no } \\
\text { contradictorios }\end{array}$ & 3 & $\begin{array}{l}\text { No se contradice. Más bien apoya } \\
\text { sus ideas. }\end{array}$ \\
\hline 14 & Enunciados pertinentes & 2 & $\begin{array}{l}\text { Algunas veces, porque al no } \\
\text { desarrollar un tema único, no se } \\
\text { puede hablar de enunciados } \\
\text { pertinentes. }\end{array}$ \\
\hline IV & COHESIÓN & & \\
\hline 15 & Enlace secuencial de los hechos & 1 & $\begin{array}{l}\text { Hechos aislados sobre un tema, se } \\
\text { puntuó con } 1 \text {, porque se cuentan } \\
\text { anécdotas independientes que } \\
\text { impiden la secuencialización } \\
\text { lógica. }\end{array}$ \\
\hline 16 & Presencia de conectores de discurso & 1 & Pocos en el corpus obtenido \\
\hline 17 & $\begin{array}{l}\text { Presencia de enlaces anafóricos y } \\
\text { catafóricos }\end{array}$ & 2 & $\begin{array}{l}\text { Pocos como en: No los conocí, para } \\
\text { referirse a los vicios. }\end{array}$ \\
\hline V & EVALUACIÓN & & \\
\hline 18 & $\begin{array}{l}\text { Presencia de juicios de valor acerca de } \\
\text { los hechos narrados }\end{array}$ & 5 & $\begin{array}{l}\text { Se da en: "los viejos tenemos una } \\
\text { historia muy grande", "creo que } \\
\text { podemos ser un ejemplo pala } \\
\text { juventú" }\end{array}$ \\
\hline 19 & $\begin{array}{l}\text { Presencia de juicios de valor acerca } \\
\text { del discurso }\end{array}$ & 0 & No hace juicios sobre el discurso. \\
\hline 20 & $\begin{array}{l}\text { Presencia de expresiones valorativas: } \\
\text { Intensificadores, Comparadores, } \\
\text { Correlativos, Explicativos, } \\
\text { Atenuantes. }\end{array}$ & 5 & $\begin{array}{l}\text { Si existe: "muy buena, juventú muy } \\
\text { muy viciosa", "hay mucha } \\
\text { envidia", "mucha fama", "muy } \\
\text { buenas orquestas" }\end{array}$ \\
\hline 21 & Entonación enfática & 5 & Se da en: "NATURALISTA" \\
\hline VI & CONTEXTUALIZACIÓN & & \\
\hline 22 & Uso de deícticos gramaticales & 3 & Se da en: "yo", "aquí" \\
\hline 23 & $\begin{array}{l}\text { Referencias a lugares, personas o } \\
\text { fechas }\end{array}$ & 1 & $\begin{array}{l}\text { Se da en: "Salentó", "Tarapiquí", } \\
\text { "hospital", "clínica", "san Carlos" }\end{array}$ \\
\hline
\end{tabular}

Tabla 11: Evaluación de la fluidez oral: informante $58 E$

\begin{tabular}{|c|c|c|c|}
\hline № & FLUIDEZ ORAL & Dt & JUSTIFICACIÓN \\
\hline 1 & Rep int & 0 & \\
\hline 2 & Rep no int & 3 & "de la en la”, “eh:// eh:/", “yo/ yo/" \\
\hline
\end{tabular}




\begin{tabular}{|c|c|c|c|}
\hline 3 & Rep son. & 0 & \\
\hline 4 & Rep silab. desc. & 0 & \\
\hline 5 & Rep inic. & 1 & "escri/ medio escribir" \\
\hline 6 & Rep medio & 0 & \\
\hline 7 & Rep. Fin. & 0 & \\
\hline 8 & Rep lex no int. & 0 & \\
\hline 9 & Rep. Pal llena & 0 & \\
\hline 10 & Rep. Pal vacía & 3 & "a a" \\
\hline 11 & Rep exp. Resem. & 0 & \\
\hline 12 & rep. Exp. Ref. & 0 & \\
\hline 13 & Rep sistemática & 0 & \\
\hline 14 & rep exp innec. & 0 & \\
\hline 15 & Alarg. Desc. & 0 & \\
\hline & Alarg. Llena ac. & 0 & \\
\hline 17 & Alarg. Llena inac & 1 & "muy:" \\
\hline 18 & Alarg. Pal vacía & 0 & \\
\hline 19 & Alarg ant. Llena & 2 & "muy:", "conocí:" \\
\hline 20 & Alarg. Innec. & 2 & "a::", "eh:" \\
\hline 21 & Pausa int. & 40 & "trabajar/", "pala/", "mal/", "ratico/" \\
\hline 22 & pausa fin ev. & 1 & "hay juventú muy: muy viciosa/" \\
\hline 23 & pausa interac & 1 & "es'ues lo que pueo contar / naa más" \\
\hline 24 & pausa ruptura & 17 & "no cree/", "yo la edad/", "a base de trabajo/" \\
\hline 25 & pausa caract. $\mathrm{Hb}$ & 0 & \\
\hline 26 & pausa ante inus. & 0 & \\
\hline 27 & Antec pal llena us & 0 & \\
\hline 28 & Desp de llena & 0 & \\
\hline 29 & Enunciado truc & 0 & \\
\hline 30 & Coalesc. & 10 & “d’iasma”, “I’hospital”, “porquia”, “m’hian” \\
\hline \multicolumn{4}{|c|}{ RESULTADOS FINALES } \\
\hline \multicolumn{2}{|c|}{ Promedio cuantitativo } & \multicolumn{2}{|r|}{$164,7^{59}$} \\
\hline \multicolumn{2}{|c|}{ Promedio cualitativo } & \multicolumn{2}{|r|}{2,39} \\
\hline \multicolumn{2}{|c|}{$\begin{array}{l}\text { Promedio cuantitativo de } \\
\qquad 0 \text { a } 5\end{array}$} & \multicolumn{2}{|r|}{3,05} \\
\hline \multicolumn{2}{|r|}{ Promedio total } & \multicolumn{2}{|r|}{2,72} \\
\hline
\end{tabular}

El informante obtiene un promedio total de 2,72 de fluidez discursiva oral integral. Este promedio se obtiene del promedio de 2,39 obtenido en la evaluación

\footnotetext{
${ }^{59}$ Como ya se ha expresado anteriormente este número se obtiene calculando el número de palabras por minuto emitidas por el informante y ajustando luego esta cantidad de acuerdo con los valores positivos o negativos atribuidos a los fenómenos de fluidez oral que se describen en la columna de la derecha.
} 
cualitativa y del promedio de 3,05 obtenido en la evaluación cuantitativa. Muestra esta evaluación las dificultades para mantener el tema y construir una narración con unidad discursiva. Es notoria en la evaluación cuantitativa la presencia de alargamientos, pausas y repeticiones no intencionales, que contribuyen a hacer un discurso vacilante y con fallas en la fluidez.

\subsection{Evaluación del discurso del informante 590}

590

Edad: 77 años

Nacionalidad: Costa Rica

Sexo: Masculino

\begin{tabular}{|c|c|}
\hline Informante & Discurso \\
\hline $\mathrm{O}$ & 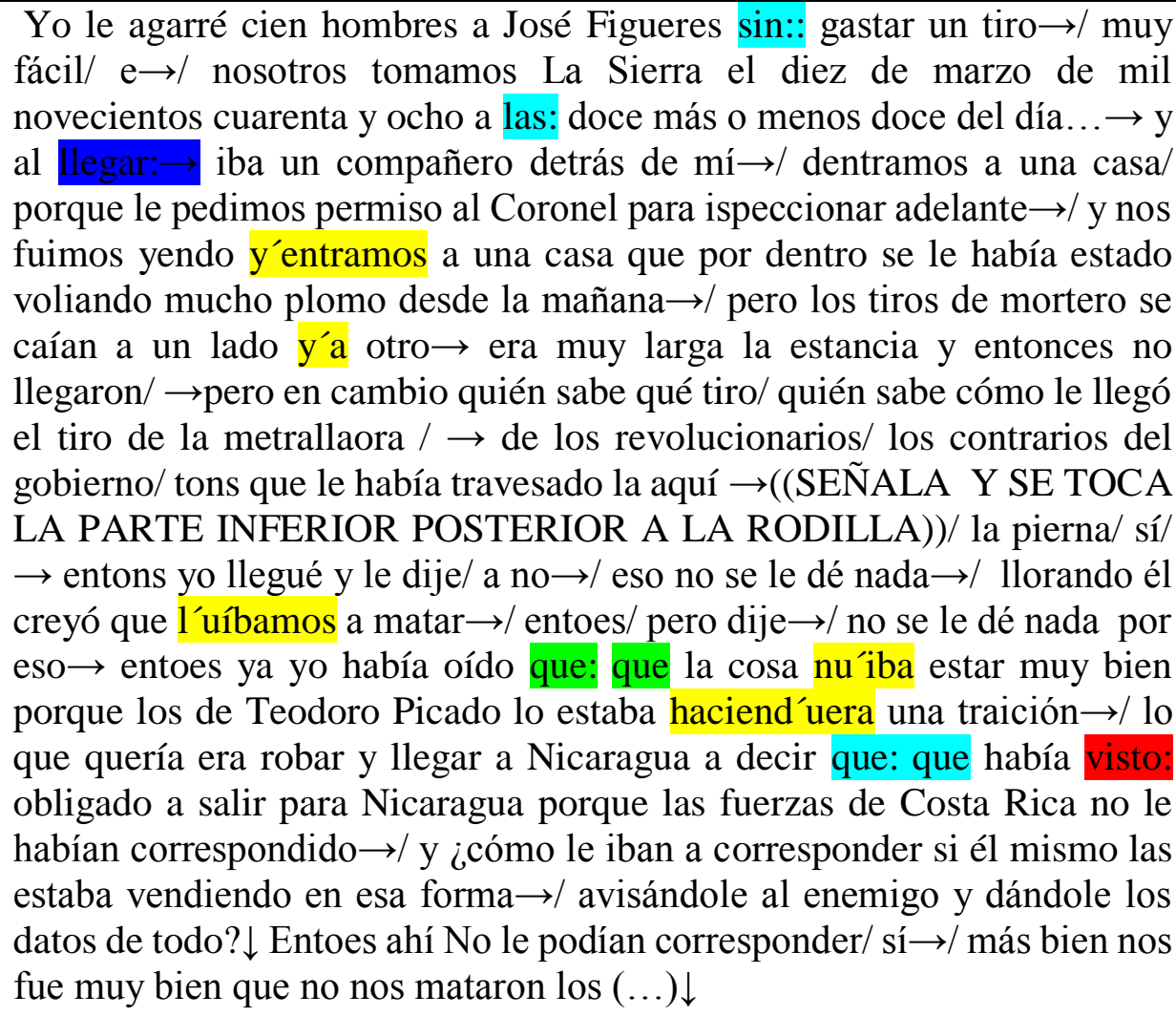 \\
\hline $\mathrm{E}$ & Claro/ \\
\hline
\end{tabular}




\begin{tabular}{|c|c|}
\hline $\mathrm{O}$ & 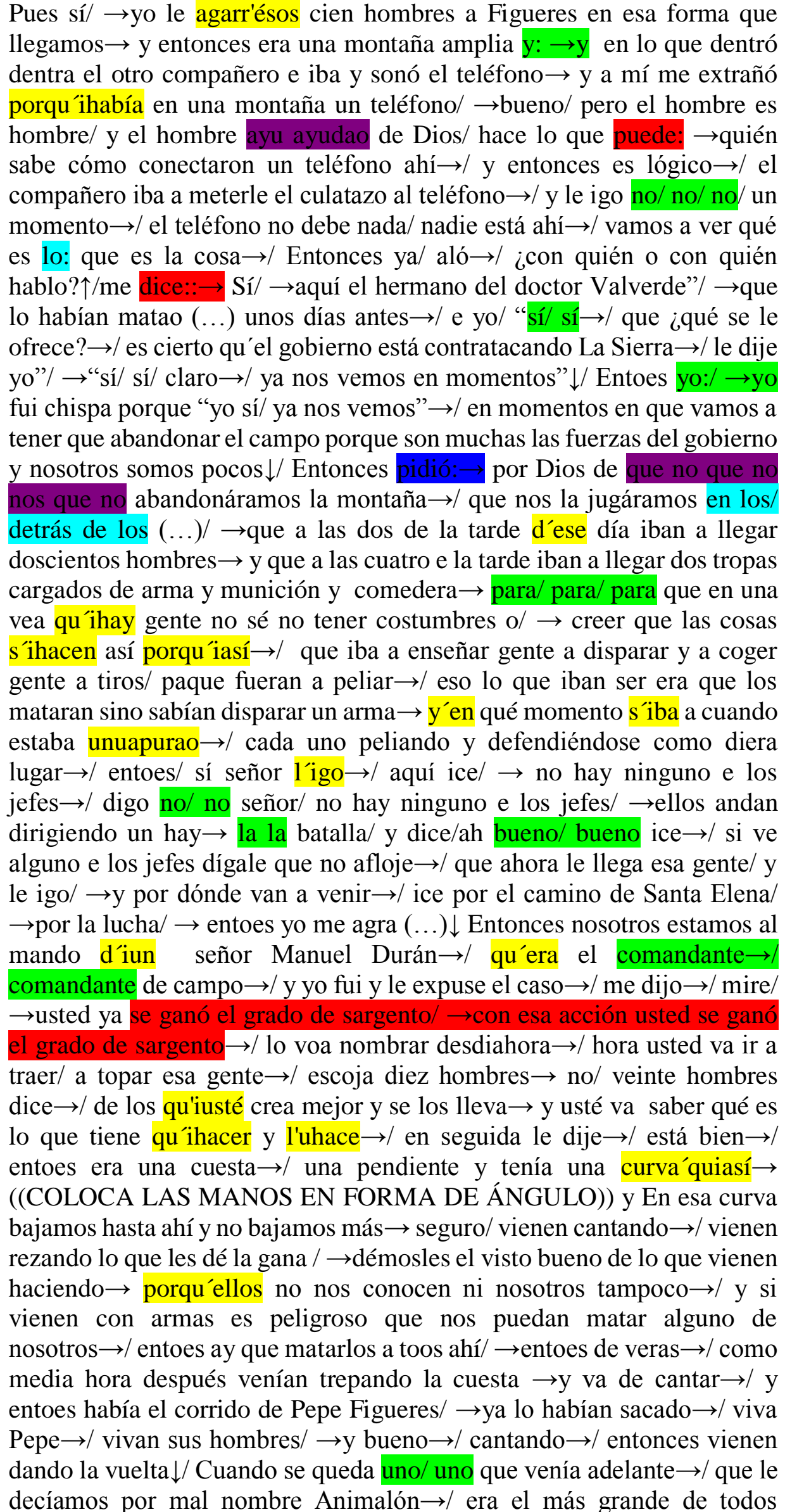 \\
\hline
\end{tabular}




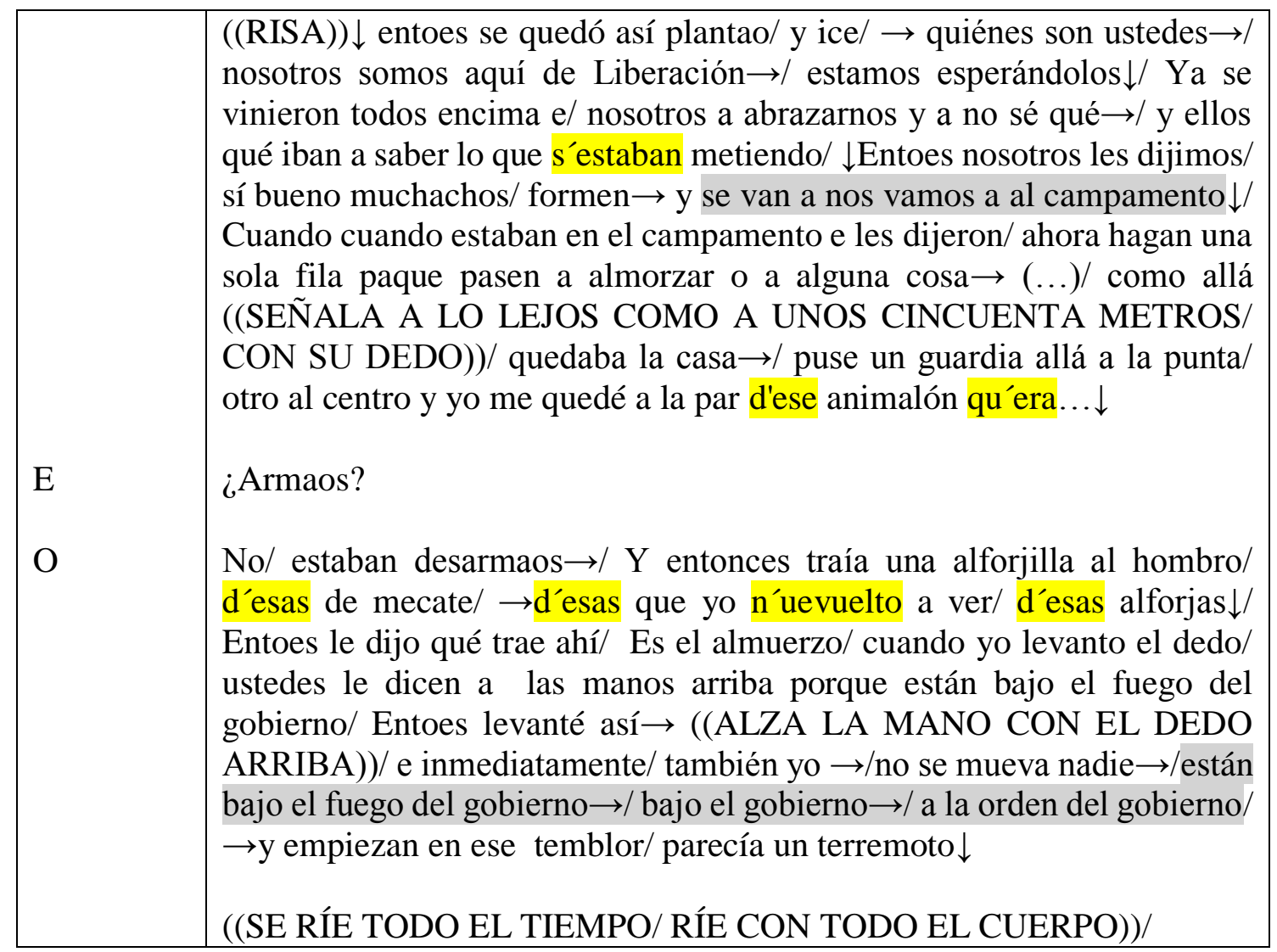

El informante 590 es un hablante de 77 años de Costa Rica. Fue grabado en el Centro geriátrico Los Rosales. Es catalogado como viejo de oro, de acuerdo con la propuesta de Juncos Rabadán. Su discurso es cualitativamente destacado ya que posee una excelente memoria que le permite ilustrar con lujo de detalles todo lo que cuenta, caracteriza los personajes y su gran capacidad descriptiva nos sitúa en la escena que está narrando. Su discurso es coherente, mantiene el tema, usa recursos contextualizadores y se apoya gestualmente para hacer más vívido su relato.

Tabla 12: Evaluación cualitativa: informante 590

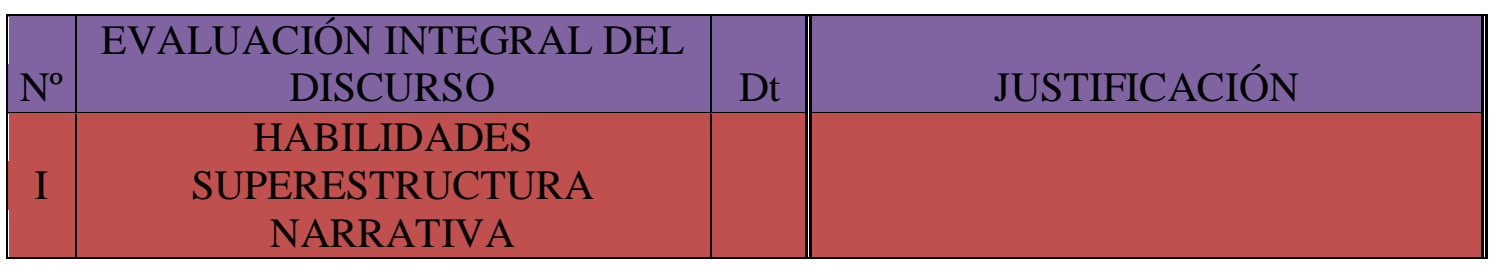




\begin{tabular}{|c|c|c|c|}
\hline 1 & Caracterización de personajes & 5 & $\begin{array}{l}\text { Detalla en la caracterización de los } \\
\text { personajes, especialmente cuando } \\
\text { describe al "animalón". }\end{array}$ \\
\hline 2 & $\begin{array}{l}\text { Desarrollo de acciones (cambio de } \\
\text { estado) }\end{array}$ & 5 & $\begin{array}{l}\text { Es evidente el cambio de estado de } \\
\text { situación inicial a situación final a } \\
\text { través de acciones. }\end{array}$ \\
\hline 3 & Presencia de estructura narrativa & 5 & Se da inicio, trama, nudo y desenlace. \\
\hline 4 & Creación de un ambiente o entorno & 5 & $\begin{array}{l}\text { Es prolijo en detalles del paisaje, } \\
\text { lugares, fechas, hora, distribución de } \\
\text { los personajes. }\end{array}$ \\
\hline II & $\begin{array}{c}\text { TEMÁTICA, COHEREN } \\
\text { GLOBAL } \\
\end{array}$ & & \\
\hline 5 & $\begin{array}{l}\text { Presencia de un asunto común o } \\
\text { tema unitario }\end{array}$ & 5 & $\begin{array}{l}\text { Desde el comienzo aclara cual es el } \\
\text { objetivo narrativo: "le cogí } 100 \\
\text { hombres a José Figueres sin gastar ni } \\
\text { un tiro", no habla de otra cosa. }\end{array}$ \\
\hline 6 & Selección adecuada de información & 5 & $\begin{array}{l}\text { Cada detalle, cada acción son descritas } \\
\text { con precisión. }\end{array}$ \\
\hline 7 & Información suficiente & 5 & $\begin{array}{l}\text { Crea imágenes a través de la } \\
\text { información que va aportando. }\end{array}$ \\
\hline 8 & Información & 5 & $\begin{array}{l}\text { La información es justa, sin detalles o } \\
\text { explicaciones redundantes. }\end{array}$ \\
\hline 9 & Organización lógica de ideas & 3 & $\begin{array}{l}\text { Hay una secuencia y un desarrollo } \\
\text { coherente. Avanza hacia el futuro. }\end{array}$ \\
\hline 10 & Progresión temát & 5 & $\begin{array}{l}\text { Agrega constantemente remas que } \\
\text { hacen progresar el tema propuesto. }\end{array}$ \\
\hline III & COHERE & & \\
\hline 11 & $\begin{array}{l}\text { Existe } \\
\text { claram }\end{array}$ & 5 & $\begin{array}{l}\text { Se ven campos semánticos como la } \\
\text { guerra, la astucia. }\end{array}$ \\
\hline 12 & Presencia de redes isotópicas & 5 & $\begin{array}{l}\text { Expresiones como: "un tiro", "100 } \\
\text { hombres", "coronel", "plomo". }\end{array}$ \\
\hline 13 & $\begin{array}{l}\text { Enuncic } \\
\text { contrad }\end{array}$ & 4 & $\begin{array}{l}\text { Siempre se dan enunciados claros en } \\
\text { este discurso. }\end{array}$ \\
\hline 14 & Enunc & 4 & $\begin{array}{l}\text { Todos los enunciados son pertinentes } \\
\text { para la construcción y comprensión del } \\
\text { discurso. }\end{array}$ \\
\hline IV & 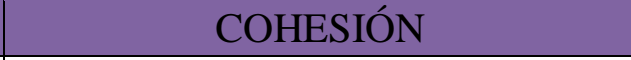 & & \\
\hline 15 & Enlace secuencial de los hechos & 4 & $\begin{array}{l}\text { Los hechos narrados están claramente } \\
\text { enlazados formando secuencias. }\end{array}$ \\
\hline 16 & Presencia de conectores de discurso & 3 & $\begin{array}{l}\text { Se le da un puntaje de } 3 \text {, porque utiliza } \\
\text { conectores, pero tiende a abusar de "y, } \\
\text { y entonces". }\end{array}$ \\
\hline 17 & $\begin{array}{l}\text { Presencia de enlaces anafóricos y } \\
\text { catafóricos }\end{array}$ & 4 & Es constante en el discurso. \\
\hline $\mathrm{V}$ & EVALUACIÓN & & \\
\hline 18 & $\begin{array}{l}\text { Presencia de juicios de valor acerca } \\
\text { de los hechos narrados }\end{array}$ & 5 & $\begin{array}{l}\text { Este informante evalúa lo que va } \\
\text { narrando: "yo fui chispa", "eso parecía }\end{array}$ \\
\hline
\end{tabular}




\begin{tabular}{|c|c|c|c|}
\hline & & & $\begin{array}{l}\text { un terremoto", la risa confirma sus } \\
\text { evaluaciones. }\end{array}$ \\
\hline 19 & $\begin{array}{l}\text { Presencia de juicios de valor acerca } \\
\text { del discurso }\end{array}$ & 0 & $\begin{array}{l}\text { No se hacen juicios al discurso como } \\
\text { tal. }\end{array}$ \\
\hline 20 & $\begin{array}{l}\text { Presencia de expresiones } \\
\text { valorativas: Intensificadores, } \\
\text { Comparadores, Correlativos, } \\
\text { Explicativos, Atenuantes. }\end{array}$ & 5 & $\begin{array}{l}\text { Es constante la presencia de } \\
\text { intensificadores y atenuantes: "muy } \\
\text { fácil", "no se le dé como tal". }\end{array}$ \\
\hline 21 & Entonación enfática & 0 & No se da. \\
\hline VI & CONTEX & & \\
\hline 22 & Uso de deícticos gramaticales & 4 & $\begin{array}{l}\text { Siempre: "a un lado y a otro nada", "un } \\
\text { teléfono ahí", "está ahí", "puse un } \\
\text { guardia allá". }\end{array}$ \\
\hline 23 & $\begin{array}{l}\text { Referencias a lugares, personas o } \\
\text { fechas }\end{array}$ & 4 & $\begin{array}{l}\text { Es constante: "José Figueres", "el } \\
\text { doctor Valverde", "10 de marzo de } \\
1948 ", \text { "a las } 12 \text { del día", "la sierra". }\end{array}$ \\
\hline
\end{tabular}

Tabla 13: Evaluación de la fluidez oral: informante 590

\begin{tabular}{|c|c|c|c|}
\hline $\mathrm{N}^{\mathrm{o}}$ & FLUIDEZ ORAL & DATOS & JUSTIFICACIÓN \\
\hline 1 & Rep int & 0 & \\
\hline 2 & Rep no int & 0 & \\
\hline 3 & Rep son. & 0 & \\
\hline 4 & Rep silab. desc. & 0 & \\
\hline 5 & Rep inic. & 1 & "a al" \\
\hline 6 & Rep medio & 0 & \\
\hline 7 & Rep. Fin. & 0 & \\
\hline 8 & Rep lex no int. & 0 & \\
\hline 9 & Rep. Pal llena & 0 & \\
\hline 10 & Rep. Pal vacía & 14 & "la la", "para/ para/ para", "que: que" \\
\hline 11 & Rep exp. Resem. & 1 & $\begin{array}{l}\text { "están bajo el fuego del gobierno/ bajo e } \\
\text { gobierno" }\end{array}$ \\
\hline 12 & rep. Exp. Ref. & 5 & $\begin{array}{l}\text { "comandante/ comandante de campo", "se van } \\
\text { a nos vamos a" }\end{array}$ \\
\hline 13 & Rep sistemática & 0 & \\
\hline 14 & rep exp innec. & 0 & \\
\hline 15 & Alarg. Desc. & 0 & \\
\hline 16 & Alarg. Llena ac. & 6 & “sin::", “las:”, “lo:", “pidió:” \\
\hline 17 & Alarg. Llena inac & 0 & \\
\hline 18 & Alarg. Pal vacía & 0 & \\
\hline 19 & Alarg ant. Llena & 0 & \\
\hline 20 & Alarg. Innec. & 0 & \\
\hline 21 & Pausa int. & 120 & "un tiro/", "casa/", "llegaron/" \\
\hline
\end{tabular}




\begin{tabular}{|c|c|c|c|c|}
\hline 22 & pausa fin ev. & 0 & & \\
\hline 23 & pausa interac & 0 & & \\
\hline 24 & pausa ruptura & 0 & & \\
\hline 25 & pausa caract. $\mathrm{Hb}$ & 0 & & \\
\hline 26 & pausa ante inus. & 0 & & \\
\hline 27 & Antec pal llena us & 0 & & \\
\hline 28 & Desp de llena & 0 & & \\
\hline 29 & Enunciado truc & 0 & & \\
\hline 30 & Coalesc. & 1 & $\begin{array}{l}\text { "I'uíbamos", "un'iba", } \\
\text { "curva'quiasi" }\end{array}$ & "unuapurao", \\
\hline \multicolumn{5}{|c|}{ RESULTADOS FINALES } \\
\hline \multicolumn{2}{|c|}{ Promedio cuantitativo } & \multicolumn{3}{|c|}{155,7} \\
\hline \multicolumn{2}{|c|}{ Promedio cualitativo } & \multicolumn{3}{|c|}{4,13} \\
\hline \multicolumn{2}{|c|}{$\begin{array}{l}\text { Promedio cuantitativo de } \\
\qquad 0 \text { a } 5\end{array}$} & \multicolumn{3}{|c|}{2,88} \\
\hline \multicolumn{2}{|r|}{ Promedio total } & \multicolumn{3}{|c|}{3,51} \\
\hline
\end{tabular}

El informante 590, cualitativamente obtuvo una puntuación de 4,13 y cuantitativamente obtuvo una puntuación de 2,88 para un promedio de 3,51 que se puede aproximar a 3,5. Este es uno de los informantes que tiene uno de los puntajes más elevados cualitativamente y que en su desempeño discursivo oral integral obtiene también un buen puntaje.

\subsection{Evaluación del discurso del informante 64AV}

64AV

Edad: 93

Nacionalidad: España

Sexo: Femenino

\begin{tabular}{|l|l|}
\hline Informante & \multicolumn{1}{|c|}{ Discurso } \\
\hline E & ¿Y Belén? \\
& $\begin{array}{l}\text { Belén está en: en Calatayud me parece y Laura está en Madrid } \\
\downarrow((\text { SILENCIO })) \text { No nos traen al muchachín } \rightarrow((\text { MIRANDO LA FOTO DE } \\
\text { SU BISNIETO }) / \text { con ojos bonitos } / \rightarrow \text { iverdad? } \rightarrow \text { Tiene ojos bonitos } \downarrow\end{array}$ \\
\hline
\end{tabular}




\begin{tabular}{|c|c|}
\hline $\mathrm{E}$ & Es muy guapo TODO \\
\hline AV & Muy guapo $\downarrow$ \\
\hline $\mathrm{E}$ & Todo todo \\
\hline AV & Alvarito tiene ojos bonitos $\rightarrow$ Alvarito $\downarrow$ \\
\hline $\mathrm{E}$ & No lo vi/ Ahora que lo trajeron la última vez no lo vi/ \\
\hline AV & No lo viste $\downarrow$ \\
\hline $\mathrm{E}$ & No lo vi \\
\hline AV & Está guapísimo \\
\hline $\mathrm{E}$ & Lo vi a los cuatro meses y ahora no lo vi \\
\hline AV & $(\mathrm{xxx})$ \\
\hline OTRO & Vamos a la cama ((SILENCIO LARGO 10”)) \\
\hline $\mathrm{AV}$ & $\begin{array}{l}\text { No sé cuándo lo traerán/ el nieto de María/ a ver si me lo traen } \rightarrow \text { ¿ ¿El nieto } \\
\text { de Mary? } \rightarrow / \text { De María } \rightarrow /((\text { VOZ MUY BAJA))/ de María/ } \rightarrow \text { la } \\
\text { muchacha } \rightarrow / \text { El nieto } \downarrow /\end{array}$ \\
\hline $\mathrm{E}$ & Ah/¿tiene nieto?/Mira/ no sabía/ Tiene nieto/ ¿ Y cuánto tiene? \\
\hline AV & (xxx) un hijo de la hija $\downarrow$ \\
\hline $\mathrm{E}$ & ¿Cuánto tiene el niño? \\
\hline AV & ¿Ah?^ \\
\hline $\mathrm{E}$ & ¿Cuánto tiene/ qué edad tiene? \\
\hline AV & No sé/ tres o cuatro meses $\downarrow$ \\
\hline $\mathrm{E}$ & Ah/ es pequeñito/ ¿Cuánto lleva María contigo? \\
\hline AV & Uy/ Mucho (xxx) $\downarrow$ \\
\hline $\mathrm{E}$ & Sí \\
\hline AV & Años/ Años y años $\downarrow$ \\
\hline $\mathrm{E}$ & Ay / qué bien/ ¿Y Toñy? \\
\hline AV & Y Toñy también $\downarrow$ \\
\hline
\end{tabular}




\begin{tabular}{|c|c|}
\hline $\mathrm{E}$ & ¿Y Eve? \\
\hline $\mathrm{AV}$ & Muchos años $\downarrow$ \\
\hline $\mathrm{E}$ & ¿Cuál es la que lleva más años?/ \\
\hline AV & $\begin{array}{l}\text { ¿Eve/ Eve es la que lleva más años? } \rightarrow((\text { NO CONTESTA })) / \text { María/ la } \\
\text { víspera de casarse dice que si/ que si le aseguraba yo que siempre estaba } \\
\text { conmigo } \rightarrow / \text { no se casaba } \rightarrow \text { / y le dije yo/ no/ mujer } \rightarrow / \text { pero si ya estás } \\
\text { todo y todo } \rightarrow / \mathrm{Ah} \rightarrow / \text { pues yo me quedo con usted/ yo no me } \\
\text { caso } \rightarrow \text { / No tenía ganas de casarse } \rightarrow / \text { la hice casar yo } \downarrow /\end{array}$ \\
\hline $\mathrm{E}$ & ¿Esta María u otra? \\
\hline AV & Esta/ esta $\downarrow /$ \\
\hline $\mathrm{E}$ & Si:: \\
\hline $\mathrm{AV}$ & Después que tuvo (xxx/ si no te casas/ no tienes ( $\mathrm{xxx}) \downarrow$ \\
\hline $\mathrm{E}$ & ¿A quién? \\
\hline $\mathrm{AV}$ & No tenía ganas de casarse \\
\hline $\mathrm{E}$ & ¿Y cómo se llama la hija? \\
\hline AV & $(($ SILENCIO LARGO)) \\
\hline $\mathrm{E}$ & Vamos a la cama ((MUY BAJO)) \\
\hline AV & Esta natilla huele tan rico Mary: Fe/ esperanza $\rightarrow$ / la hija de Esperanza $\downarrow$ \\
\hline $\mathrm{E}$ & Ah/ Esperanza/ ¿Y por qué Esperanza? \\
\hline $\mathrm{AV}$ & $\begin{array}{l}\text { Tuvo tres niñas: } \rightarrow \mathrm{Fe} / \text { Esperanza y Caridad/ } \rightarrow \text { y se murió } \rightarrow / \text { nacieron las } \\
\text { tres muertas } \rightarrow \text { y ya bajé yo a ver qué pasaba en el parto/ } \rightarrow \text { y las tenían } \\
\text { allí en el escaño } \rightarrow \text { / tres niñas muertas } \rightarrow / \text { tres niñas muertas } \rightarrow \text { / Digo yo/ } \\
\text { si/ } \rightarrow \text { esta respira/ } \downarrow \\
\text { Esperanza/ digo/ } \downarrow l \text { la vida te dio/ que bajé yo } \downarrow / \text { si no/ allí quedaba con las } \\
\text { otras } \downarrow /\end{array}$ \\
\hline
\end{tabular}

La informante 64 AV tiene 93 años, es española, fue grabada en su casa de habitación en Salamanca y su discurso posee bastantes disfluencias. Habla muy pausadamente, con dificultad. 
Tabla 14: Evaluación Cualitativa: informante 64AV

\begin{tabular}{|c|c|c|c|}
\hline $\mathrm{N}^{\mathrm{o}}$ & $\begin{array}{l}\text { EVALUACIÓN INTEGRAL } \\
\text { DEL DISCURSO }\end{array}$ & Dt. & JUSTIFICACIÓN \\
\hline $\mathrm{I}$ & $\begin{array}{c}\text { HABILIDADES } \\
\text { SUPERESTRUCTURA } \\
\text { NARRATIVA }\end{array}$ & & \\
\hline 1 & Caracterización de personajes & 1 & $\begin{array}{l}\text { El informante no explica, ni presenta } \\
\text { detalles acerca de ninguno de los } \\
\text { personajes que aparecen. }\end{array}$ \\
\hline 2 & $\begin{array}{l}\text { Desarrollo de acciones (cambio } \\
\text { de estado) }\end{array}$ & 0 & $\begin{array}{l}\text { Solamente se señala una acción, por lo } \\
\text { tanto no se puede hablar de cambio de } \\
\text { estado. }\end{array}$ \\
\hline 3 & $\begin{array}{l}\text { Presencia de estructura } \\
\text { narrativa }\end{array}$ & 1 & $\begin{array}{l}\text { No se puede hablar propiamente de una } \\
\text { narración en el corpus de esta informante. } \\
\text { No se da inicio, ni nudo, ni trama, ni } \\
\text { desenlace. }\end{array}$ \\
\hline 4 & $\begin{array}{l}\text { Creación de un ambiente o } \\
\text { entorno }\end{array}$ & 1 & $\begin{array}{l}\text { La narración no está enmarcada en un } \\
\text { ambiente, ni fechas, ni lugar, ni datos } \\
\text { contextuales. }\end{array}$ \\
\hline II & $\begin{array}{l}\text { TEMÁTICA, COHERENCIA } \\
\text { GLOBAL }\end{array}$ & & \\
\hline 5 & $\begin{array}{l}\text { Presencia de un asunto común o } \\
\text { tema unitario }\end{array}$ & 0 & $\begin{array}{l}\text { La informante divaga antes de contar la } \\
\text { única acción que hay. No desarrolla un } \\
\text { tema de principio a fin. }\end{array}$ \\
\hline 6 & $\begin{array}{l}\text { Selección adecuada de } \\
\text { información }\end{array}$ & 5 & La información es limitada. \\
\hline 7 & Información suficiente & 0 & $\begin{array}{l}\text { No se da información que contextualice } \\
\text { lo narrado. Es muy escueta la producción. }\end{array}$ \\
\hline 8 & Información excesiva & 0 & $\begin{array}{l}\text { Al contrario, es limitada, como se dijo } \\
\text { antes. }\end{array}$ \\
\hline 9 & Organización lógica de ideas & 1 & $\begin{array}{l}\text { Es un discurso deshilvanado. Se soporta } \\
\text { en las preguntas del interlocutor. }\end{array}$ \\
\hline 10 & Progresión temática acertada & 0 & $\begin{array}{l}\text { No se desarrolla un tema, no hay avance } \\
\text { puesto que no se presentan remas. Muy } \\
\text { limitado. }\end{array}$ \\
\hline III & COHERENCIA LOCAL & & \\
\hline 11 & $\begin{array}{l}\text { Existencia de campos } \\
\text { semánticos claramente } \\
\text { definidos }\end{array}$ & 0 & $\begin{array}{l}\text { Ningún campo semántico se define en la } \\
\text { producción de la informante. }\end{array}$ \\
\hline
\end{tabular}




\begin{tabular}{|c|c|c|c|}
\hline 12 & Presencia de redes isotópicas & 0 & $\begin{array}{l}\text { No se dan isotopías que permitan } \\
\text { configurar redes. La información es } \\
\text { limitada para este ítem. }\end{array}$ \\
\hline 13 & $\begin{array}{l}\text { Enunciados claros y no } \\
\text { contradictorios }\end{array}$ & 1 & $\begin{array}{l}\text { Los enunciados no se contradicen } \\
\text { específicamente. Sin embargo, las } \\
\text { vacilaciones y la ausencia de información } \\
\text { no permiten claridad en estos. }\end{array}$ \\
\hline 14 & Enunciados pertinentes & 1 & $\begin{array}{l}\text { El hecho de que no se mantenga la unidad } \\
\text { narrativa, ni temática hace que cada } \\
\text { enunciado sea desarticulado. }\end{array}$ \\
\hline IV & $\mathrm{COH}$ & & \\
\hline 15 & Enlace secuencial de los hechos & 0 & $\begin{array}{l}\text { La ausencia de hechos narrados hace que } \\
\text { este ítem sea evaluado como cero. }\end{array}$ \\
\hline 16 & $\begin{array}{l}\text { Presencia de conectores de } \\
\text { discurso }\end{array}$ & 1 & Utiliza la conjunción "y" como conector. \\
\hline 17 & $\begin{array}{l}\text { Presencia de enlaces anafóricos } \\
\text { y catafóricos }\end{array}$ & 2 & $\begin{array}{l}\text { Es escasa la presencia de anafórico o } \\
\text { catafóricos pero aparecen algunos como } \\
\text { en "las tenían", "esta respira". }\end{array}$ \\
\hline $\mathrm{V}$ & EVALUACIÓN & & \\
\hline 18 & $\begin{array}{l}\text { Presencia de juicios de valor } \\
\text { acerca de los hechos narrados }\end{array}$ & 5 & $\begin{array}{l}\text { Es escasa la presencia de juicios, sin } \\
\text { embargo: "con ojos bonitos", "mucho", } \\
\text { "años, años y años". }\end{array}$ \\
\hline 19 & $\begin{array}{l}\text { Presencia de juicios de valor } \\
\text { acerca del discurso }\end{array}$ & 0 & $\begin{array}{l}\text { No se presentan juicios acerca del } \\
\text { discurso. }\end{array}$ \\
\hline 20 & $\begin{array}{l}\text { Presencia de expresiones } \\
\text { valorativas: Intensificadores, } \\
\text { Comparadores, Correlativos, } \\
\text { Explicativos, Atenuantes. }\end{array}$ & 0 & No se dan. \\
\hline 21 & Entonación enfática & 0 & No aparece ningún elemento enfatizado. \\
\hline VI & CONTEXTUALIZACIÓN & & \\
\hline 22 & Uso de deícticos gramaticales & 1 & Son escasos los deícticos. \\
\hline 23 & $\begin{array}{l}\text { Referencias a lugares, personas } \\
\text { o fechas }\end{array}$ & 0 & $\begin{array}{l}\text { No contextualiza, es difícil seguir este } \\
\text { discurso. }\end{array}$ \\
\hline
\end{tabular}

Tabla 15: Evaluación de la fluidez oral: informante 64AV

\begin{tabular}{|c|l|c|l|}
\hline$N^{\circ}$ & FLUIDEZ ORAL & DATOS & \multicolumn{1}{c|}{ JUSTIFICACIÓN } \\
\hline 1 & Rep int & 2 & “De María/ de María”, “años/ años y años" \\
\hline 2 & Rep no int & 1 & “dice que si / que si” \\
\hline 3 & Rep son. & 0 & \\
\hline 4 & Rep silab. desc. & 0 & \\
\hline 5 & Rep inic. & 0 & \\
\hline 6 & Rep medio & 0 & \\
\hline 7 & Rep. Fin. & 0 & \\
\hline 8 & Rep. lex. no int. & 0 & \\
\hline 9 & Rep. Pal llena & 0 & \\
\hline 10 & Rep. Pal vacía & 1 & "en: en" \\
\hline
\end{tabular}




\begin{tabular}{|c|c|c|c|}
\hline 11 & Rep. exp. Resem. & 1 & "Eve/ Eve es" \\
\hline 12 & Rep. Exp. Ref. & 0 & \\
\hline 13 & Rep. sistemática & 0 & \\
\hline 14 & Rep. exp. innec. & 2 & "tres niñas muertas / tres niñas muertas" \\
\hline 15 & Alarg. Desc. & 0 & \\
\hline 16 & Alarg. Llena ac. & 0 & \\
\hline 17 & Alarg. Llena inac. & 2 & "Mary:", "niñas:" \\
\hline 18 & Alarg. Pal vacía & 1 & "en:" \\
\hline 19 & Alarg ant. Llena & 0 & \\
\hline 20 & Alarg. Innec. & 0 & \\
\hline 21 & Pausa int. & 47 & "no sé/", "lo traerán/", "la muchacha/" \\
\hline 22 & Pausa fin ev. & 0 & \\
\hline 23 & pausa interac & 1 & "no lo viste/" \\
\hline 24 & pausa ruptura & 12 & "mira/", "conmigo/", “Esperanza/", "sino/" \\
\hline 25 & Pausa caract. $\mathrm{Hb}$ & 0 & \\
\hline 26 & Pausa ante inus. & 0 & \\
\hline 27 & Antec. pal llena us & 0 & \\
\hline 28 & Desp. de llena & 0 & \\
\hline 29 & Enunciado truc. & 1 & "la vida te dio / sino" \\
\hline 30 & Coalesc. & 0 & \\
\hline \multicolumn{4}{|c|}{ RESULTADOS TOTALES } \\
\hline \multicolumn{2}{|c|}{ Promedio cuantitativo } & \multicolumn{2}{|r|}{110} \\
\hline \multicolumn{2}{|r|}{ Promedio cualitativo } & \multicolumn{2}{|r|}{0,87} \\
\hline \multicolumn{2}{|c|}{$\begin{array}{l}\text { Promedio cuantitativo de } 0 \\
\text { a } 5\end{array}$} & \multicolumn{2}{|r|}{2,04} \\
\hline \multicolumn{2}{|r|}{ Promedio total } & \multicolumn{2}{|r|}{1,45} \\
\hline
\end{tabular}

La informante 64 AV obtuvo un puntaje muy bajo en la evaluación cualitativa, con apenas 0,87 lo que indica dificultades para mantener el tema de la narración, faltas a la coherencia, información insuficiente y la necesidad constante del acompañamiento del entrevistador para lograr contar una anécdota corta.

En el aspecto cuantitativo obtuvo apenas un puntaje de 2,04 ya que hace pausas constantes y de ruptura de la estructura oracional, repite información, presenta constantes vacilaciones. El promedio total de $64 \mathrm{AV}$ es de 1,45 que la sitúa entre los promedios más bajos de todo el grupo de informantes. 
Con la descripción de estas evaluaciones se muestra la forma en que opera el instrumento con el fin de que cualquier otro investigador, o cualquier otra persona interesada en la evaluación del discurso narrativo, pueda aplicarlo en sus informantes, pacientes o usuarios. 
6. PRESENTACIÓN Y ANÁLISIS DE RESULTADOS 
Los resultados de la evaluación de los discursos de los 66 informantes aparecen en este capítulo especificados bajo 2 ítems:

1. Los resultados cuantitativos que corresponden a la evaluación de la fluidez oral.

2. Los resultados cualitativos que corresponden a la evaluación de la producción del discurso narrativo.

Y finalmente, se presenta una tabla general en la cual aparecen en orden ascendente los resultados integrales finales de la evaluación discursiva de los 66 informantes.

\subsection{Análisis de los resultados cuantitativos}

Como ya se ha señalado más arriba, la fluidez discursiva oral se evalúa cuantitativamente mediante la siguiente fórmula:

$$
\begin{gathered}
\mathrm{V}+(\mathrm{F} \times \mathrm{m})=\text { Fluidez discursiva oral, unidades cuantitativas. } \\
\mathrm{V}(\text { velocidad })=\text { Palabras por minuto } \\
\mathrm{F} \times \mathrm{m}=\text { Fenómenos por minuto }^{60}
\end{gathered}
$$

\footnotetext{
${ }^{60}$ Recuérdese que "fenómenos" se refiere a: repeticiones, alargamientos, pausas y enunciados truncados de la fluidez discursiva oral. Aquí se toma el resultado de la sumatoria entre positivos y negativos de la tabla y se suma a la velocidad.
} 
De esta fórmula se derivan los gráficos que aparecen a continuación, en que se exponen las evaluaciones cuantitativas de los informantes de nuestro corpus, diferenciados por grupos de edad: jóvenes de 11 a 20 años, adulto joven de 21 a 50 años, adulto mayor de 51 a 74 años y adulto avanzado de 75 a 95 años.

El primer grupo está conformado por 9 informantes entre 11 a 20 años. Este grupo se caracteriza por narraciones cortas y casi siempre guionísticas, en tanto son producciones que hacen usualmente los adolescentes internos en la casa de rehabilitación El Arca, especializada en el tratamiento de la dependencia de drogas. Los internos están acostumbrados a presentarse en público y decir rápidamente algunos datos personales, casi nunca narran.

El rango de velocidad en este grupo de edad es elevado y con pocos fenómenos adicionales. No hay pausas, lo cual genera un discurso rápido y nada reflexivo. El puntaje cuantitativo para la fluidez se sitúa entre 147,50 y 234,18 unidades, con un promedio de 202,03 unidades de Fluidez Discursiva Oral

Gráfico 5: Evaluación cuantitativa grupo 1. Jóvenes de 11 a 20 años

\begin{tabular}{|c|c|c|c|c|c|c|c|c|c|}
\hline 250,00 & 234,18 & \multirow{2}{*}{212,87} & \multirow[b]{2}{*}{197,16} & \multirow[b]{2}{*}{198,20} & \multirow[b]{2}{*}{183,54} & \multirow[b]{2}{*}{193,33} & 230,00 & 221,54 & \multirow{3}{*}{47,50} \\
\hline 200,00 & & & & & & & & & \\
\hline 150,00 & & & & & & & & & \\
\hline 100,00 & & & & & & & & & \\
\hline 50,00 & & & & & & & & & \\
\hline 0,00 & & & & & & & & & \\
\hline & 1D & $2 \mathrm{R}$ & \# $3 \mathrm{~L}$ & $4 \mathrm{JC}$ & - 5G & -6M & -7W & - 8D & 9DF \\
\hline
\end{tabular}


La narrativa en este grupo apenas consiste en la presentación del joven y ante la premura y el nerviosismo se quiere terminar rápido lo que se está diciendo. El discurso más corto es de 19 segundos y en términos generales los discursos se caracterizan por la ausencia de alargamientos y vacilaciones, naturales de la oralidad. Disminuyen estos fenómenos porque estamos ante un discurso cotidiano en estos jóvenes institucionalizados, quienes a diario se deben presentar ante otros jóvenes o ante los terapeutas que los atienden. Aunque se pide que cuente una experiencia, el joven no lo hace. Es ante todo un discurso ritualizado.

El segundo grupo está compuesto por 13 personas con edades entre los 21 y los 50 años. El rango de fuidez se encuentra aquí entre las 124,77 y 181,49 unidades. Este es un grupo heterogéneo ya que se compone de informantes de España y de Colombia. Los informantes colombianos no tienen un tema común y simplemente se dedican a contar una experiencia de su vida que les ha parecido digna de mencionar, ya que han estado en peligro o se han sentido de cierto modo amenazados. El grupo de informantes españoles -en este rango de edad- tuvieron que vivir la experiencia de la guerra civil y eso es lo que cuentan. Como ya se explicó antes, estas grabaciones no fueron hechas por la autora de esta tesis.

Gráfico 6: Evaluación cuantitativa grupo 2. Adultos jóvenes de 21 a 50 años

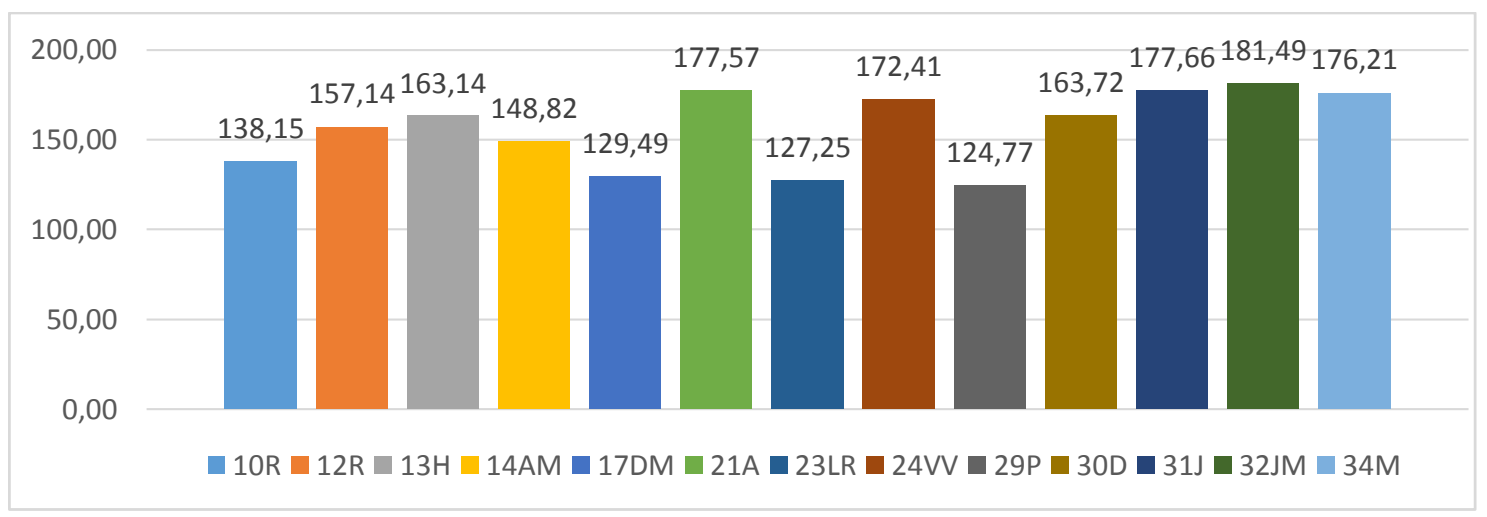


En comparación con el grupo uno se evidencia un descenso significativo del promedio de fluidez oral desde 202,3 unidades hasta las 151,75 unidades.

Gráfico 7: Evaluación cuantitativa grupo 3. Adultos mayores de 51 a 74 años

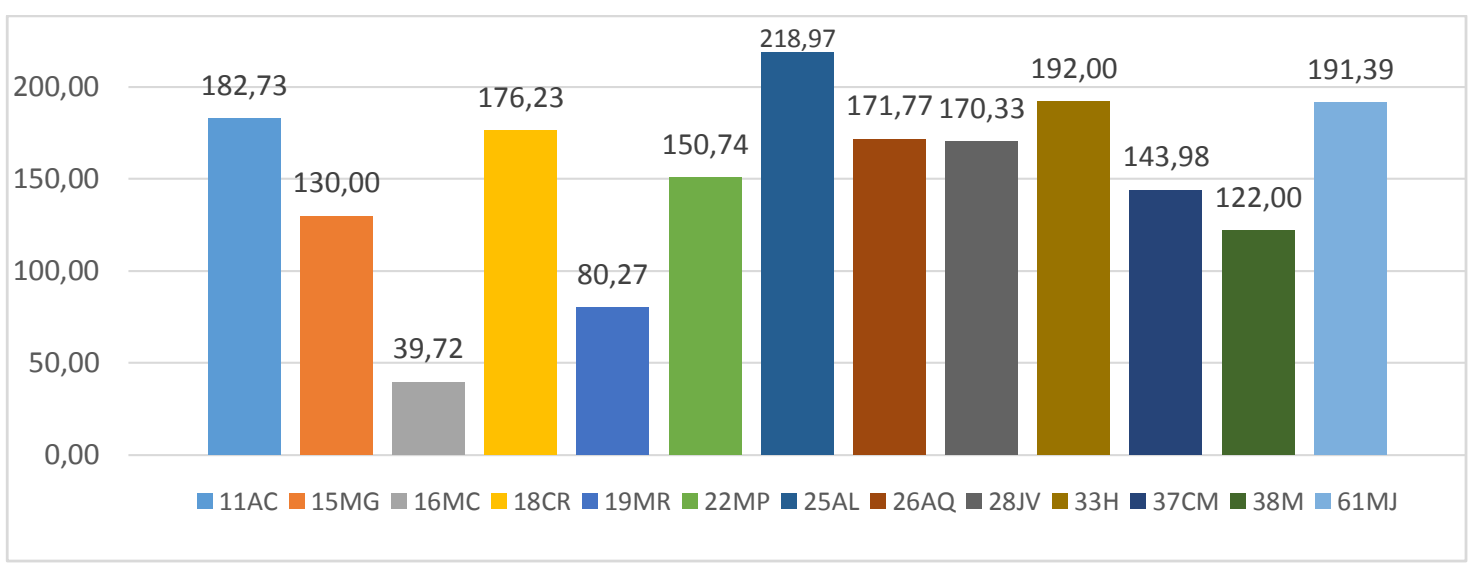

Este grupo está formado por adultos entre 51 y 74 años. El rango de fluidez va desde las 39,72 hasta las 218,97 unidades, con un promedio de 151,54 unidades. Es un grupo con resultados muy heterogéneos y se encuentra aquí uno de los resultados más bajo de todo el grupo de informantes; corresponde al informante codificado como 16MC, con 39,72 unidades de fluidez discursiva, en oposición, por ejemplo, al 25AL con un promedio mucho más elevado, superior a 200 unidades.

Gráfico 8: Evaluación cuantitativa grupo 4. Adulto avanzado de 75 a 95 años (I)

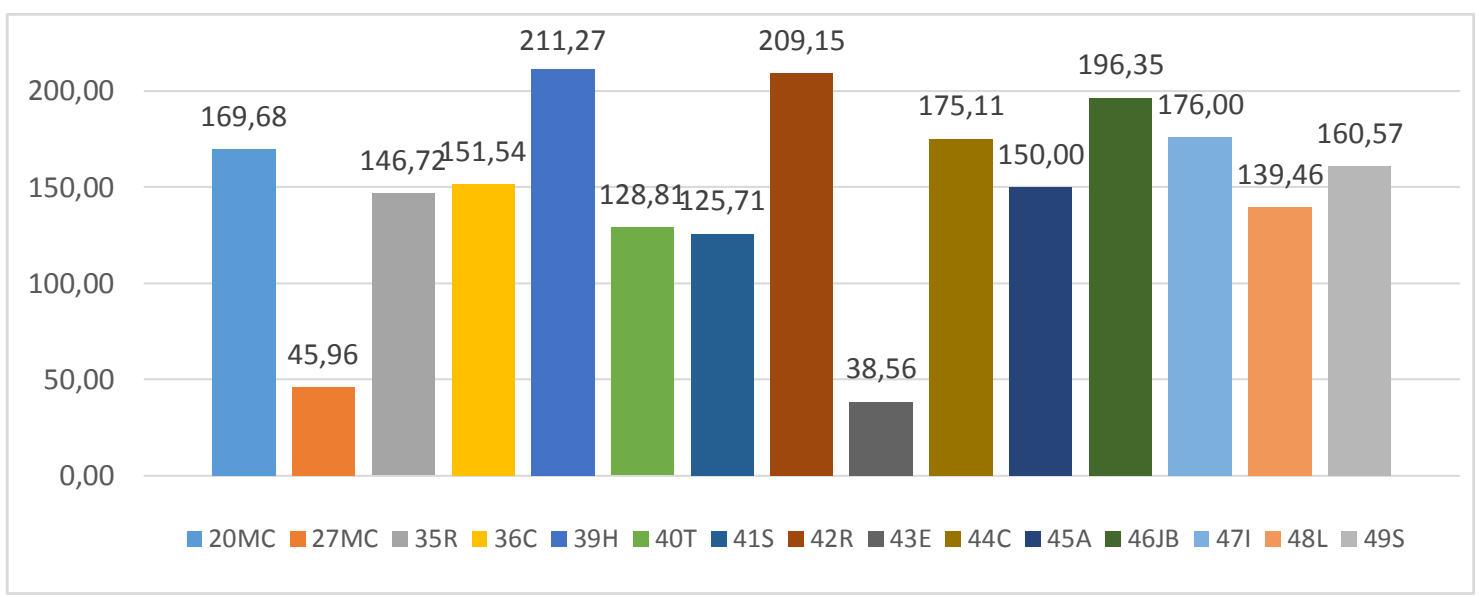


Gráfico 9: Evaluación cuantitativa grupo 4. Adulto avanzado de 75 a 95 años (II)

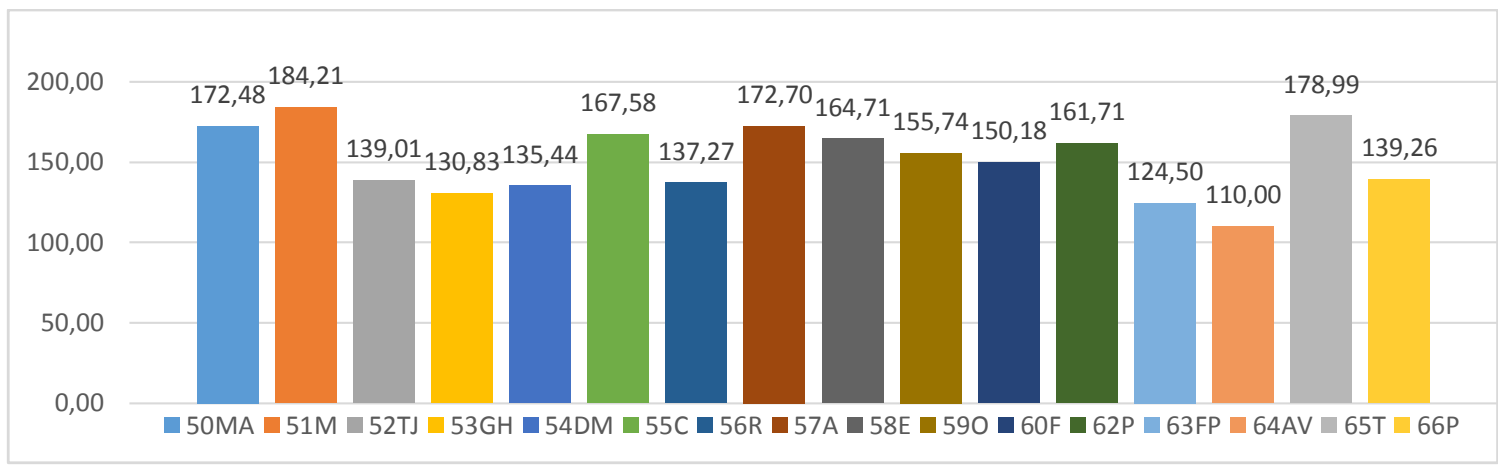

Este grupo está formado por 31 informantes mayores, cuyas edades están por encima de los 75 años y llegan hasta los 93 años. Podría pensarse en un descenso vertiginioso y notable de la fluidez en este grupo de edad, debido al deterioro cognitivo o al enlentecimiento cognitivo, pero esto solo es parcialmente cierto, ya que algunos informantes conservan la fluidez. Es un grupo de puntajes heterogéneos causado por las diferencias en habilidad oral conservadas en algunos informantes mayores y deterioradas en otros.

\subsection{Análisis de los resultados cualitativos}

En la evaluación cualitativa del discurso narrativo se utilizan, recuérdese, diferentes categorías divididas de la siguiente manera: Superestructura narrativa, coherencia global, coherencia local, cohesión, evaluación y contextualización. Los indicadores de cada categoría son clasificados con términos de "insuficiente" a "excelente", y de "nunca" a "siempre". Estas valoraciones se traducen luego a cantidades numéricas ${ }^{61}$ para poder establecer comparaciones.

\footnotetext{
${ }^{61}$ La explicación de cada valor numérico está expuesto en el modelo de evaluación de la oralidad. Capítulo 4.
} 
Una vez aplicado a los informantes el sistema descrito, estos pueden dividirse en cuatro grupos de edades, como ya se hizo con la fluidez oral: jóvenes (11 años a 20 años), adultos jóvenes (21 años a 50 años), adultos mayores (51 años a 74 años), y adultos avanzados (75 años a 95 años).

Gráfico 10: Evaluación cualitativa grupo 1. Jóvenes de 11 años a 20 años

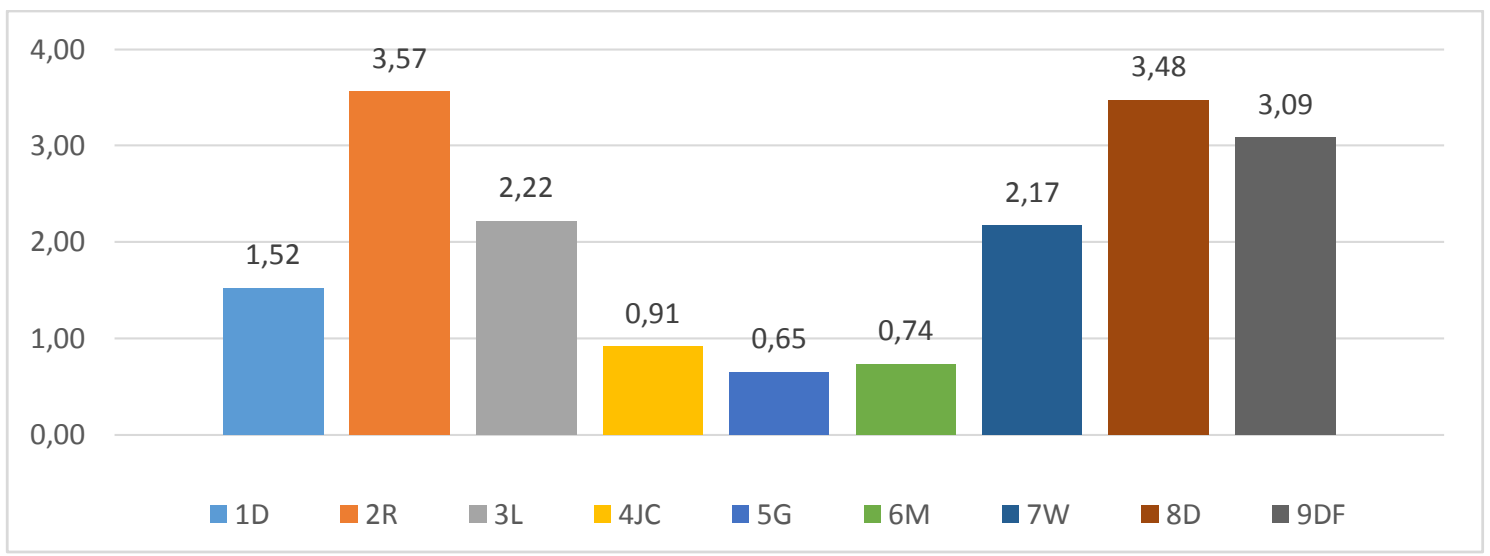

El primer grupo está conformado por 9 informantes (Gráfico 10). Entre estos el aspecto narrativo es inversamente proporcional a la fluidez oral, es decir, el descenso de la calidad del discurso es indiscutible. De todos modos, existen excepciones, puesto que hay dos informantes con valores cercanos a 3,5 puntos. La razón de estos bajos resultados es el condicionamiento de estos jóvenes a realizar una breve y rápida descripción de quiénes son y por qué están en aquel lugar. La institución les impone que constantemente se presenten y ya están acostumbrados a hacerlo. No suelen narrar. Muy pocas veces estos informantes narran un pequeño evento, algunos solo realizan una lista de datos personales, donde no se encuentran rastros de narración alguna. 
Gráfico 11: Evaluación cualitativa grupo 2. Adulto joven de 21 años a 50 años

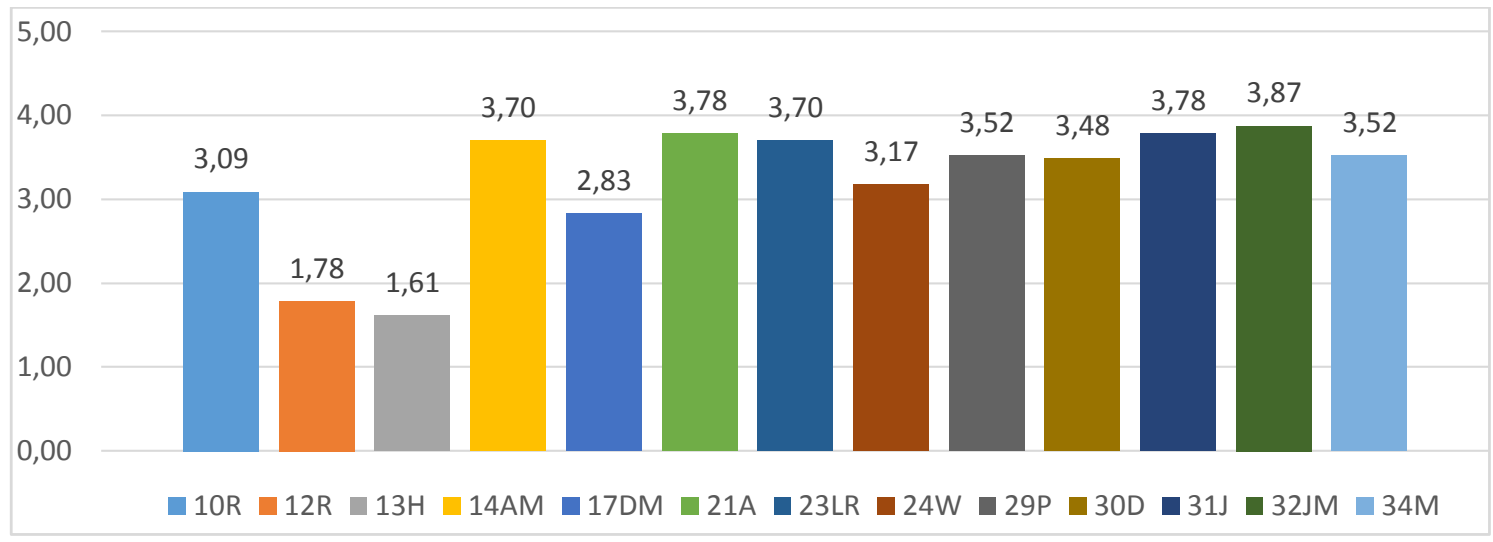

Este segundo grupo (Gráfico 11) incluye dos nacionalidades (española y colombiana) con resultados que van desde 1,61 hasta 3,87 unidades para la evaluación de la fluidez narrativa. En todo caso, predominan claramente los valores que superan los tres puntos.

En este grupo ya se observan narraciones con una estructura claramente definida, sin embargo, algunos solo tienen una introducción o la mera descripción de los lugares y personas. En algunos casos la estructuración de las oraciones impide la comprensión de los hechos narrados; como consecuencia se obtienen puntajes inferiores a 3 unidades, aunque solo en tres casos.

Gráfico 12: Evaluación cualitativa grupo 3. Adulto mayor de 51 años a 74 años

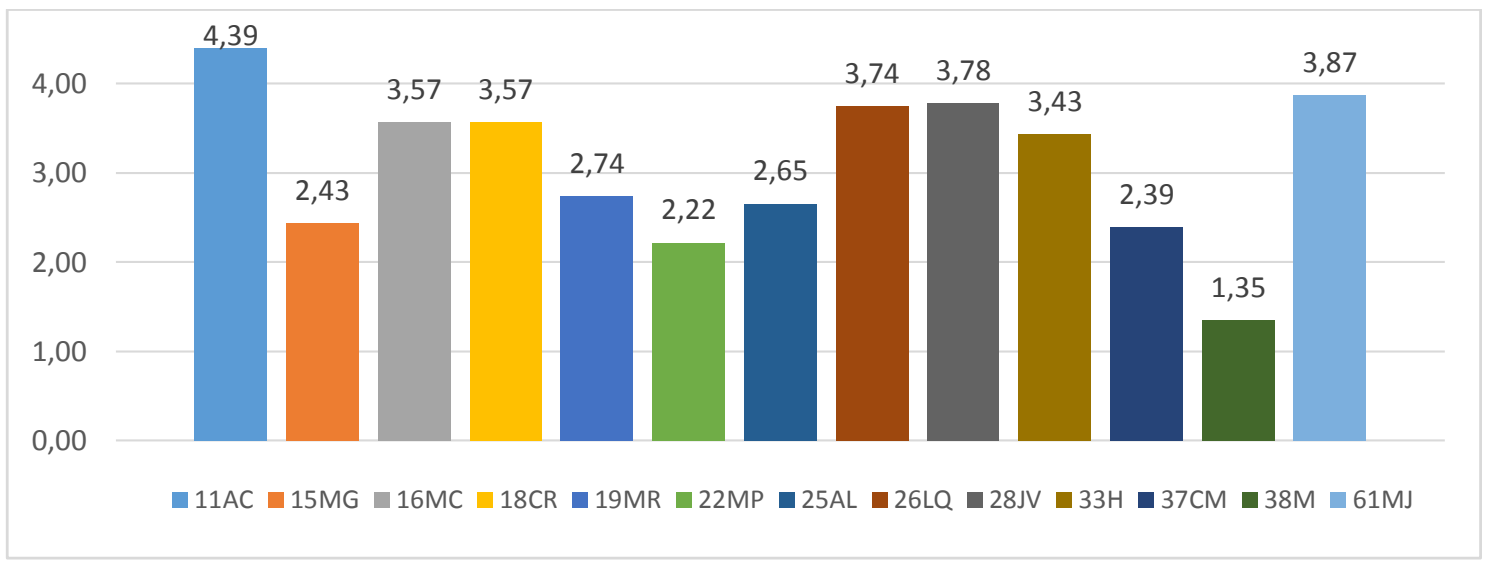


En el grupo 3 resultan valores entre 1,35 unidades y 4,39 unidades. Las edades y las nacionalidades de este grupo permiten la variedad de temas en cada narración, como el desplazamiento forzado, la guerra, el abuso sexual, entre otros. Debido a estos temas hay narraciones con características que se califican con un puntaje alto. Es el caso de 11AC, en la que durante la narración se hace una reflexión sobre los hechos narrados, propiedad muy poco común en los informantes del presente corpus.

Gráfico 13: Evaluación cualitativa grupo 4. Adulto avanzado de 75 años a 95 años (I)

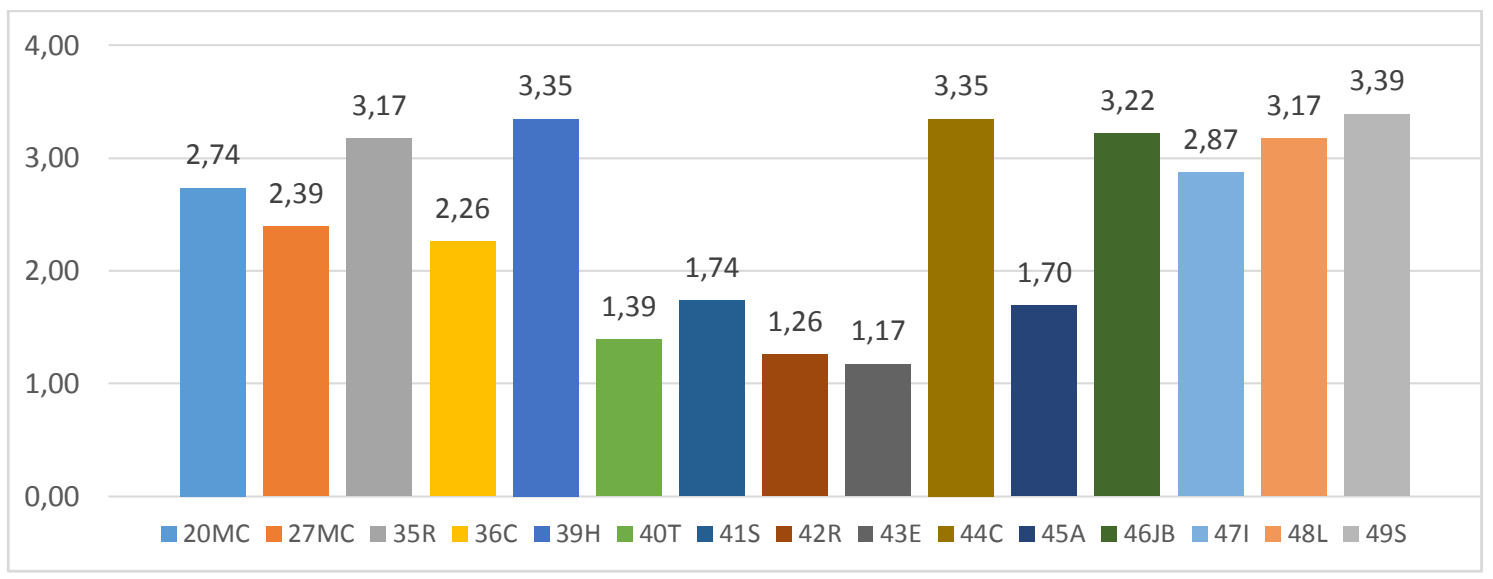

Gráfico 14: Evaluación grupo 4. Adulto avanzado de 75 años a 95 años (II)

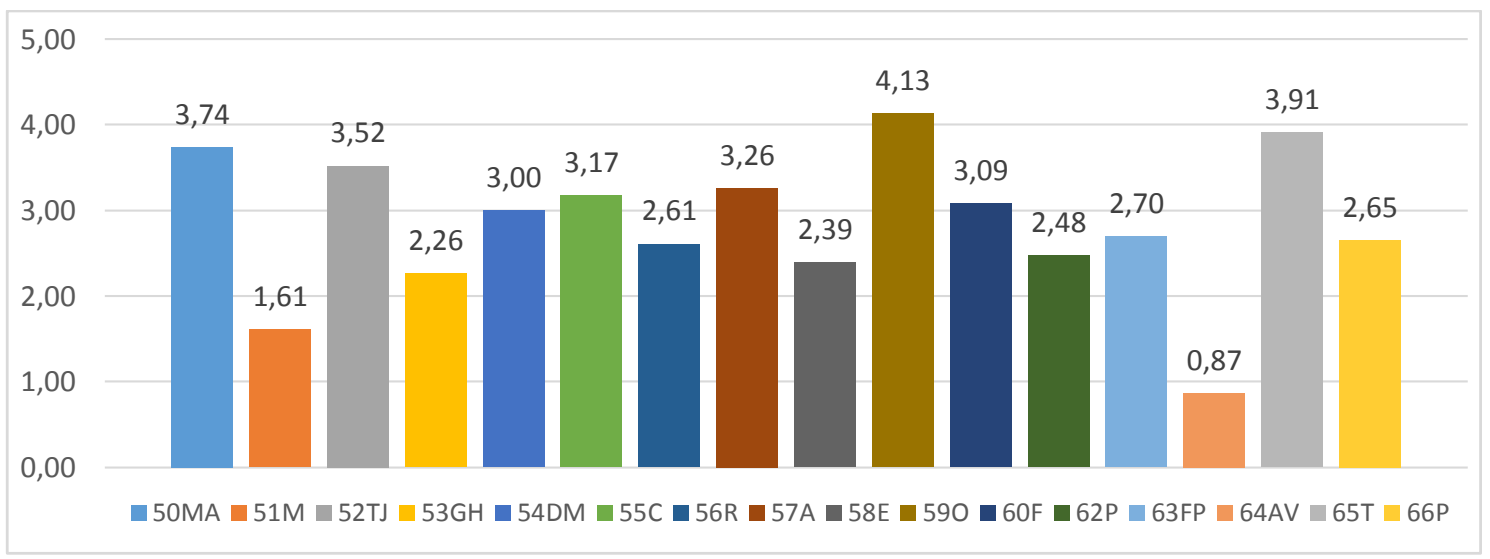

En este último grupo la edad influye en la evaluación cualitativa, ya que inciden enfermedades propias de la vejez y disminuciones de carácter físico y mental, como la 
capacidad pulmonar, cardíaca, la presión, la memoria, entre otras, las cuales dificultan la producción lingüística (Menjura, 2007, p. 8). Sin embargo, la edad no solo proporciona elementos negativos en la narración: el conocimiento de la lengua es amplio debido a la experiencia, lo que resulta en una riqueza en las descripciones. "El anciano mantiene en buenas condiciones el desempeño de su memoria operativa y, no es una característica común a todos los ancianos sino más bien privativa de aquellos denominados por los especialistas 'viejos de oro"' (Menjura, 2008. P. 22).

De acuerdo con lo anterior, en los Gráficos 13 y 14 hay valores desde 0,87 unidades hasta 4,13 unidades, una diferencia mayor que en el grupo de edad anterior. Se puede concluir que en este grupo la edad ha generado tanto deficiencias en el discurso como también habilidades excepcionales y esto se evidencia en la disparidad de resultados en la evaluación.

\subsection{Resultados generales de la evaluación integral del discurso}

\subsubsection{Jerarquización por grupos}

Los puntajes obtenidos por los informantes al aplicar el instrumento de Fluidez Discursiva Oral Integral (F.D.O.I.) se encuadraron en 5 posibles grupos:

- Rango 1: Se sitúan en este rango los informantes que obtengan un puntaje menor a uno. Entre los evaluados en este corpus se ubicó un solo informante en este rango. Aquellos informantes con deficiencias en todas las habilidades de 
producción del discurso, aparecerán en este rango. Su evaluación cualitativa sería “insuficiente" para F.D.O.I.

Gráfico 15: Evaluación FDOI. Rango 1

\begin{tabular}{|c|c|}
\hline 1,00 & 0,94 \\
\hline 0,75 & \\
\hline 0,50 & \\
\hline 0,25 & \\
\hline 0,00 & \\
\hline & $43 \mathrm{E}$ \\
\hline
\end{tabular}

- Rango 2: Los que obtuvieron puntajes de fluidez discursiva oral integral entre 1 y 1,99 y en el cual se situaron 4 informantes.

Gráfico 16: Evaluación FDOI. Rango 2

\begin{tabular}{|c|c|c|c|c|}
\hline 2,00 & & & 1,80 & 1,89 \\
\hline 1,75 & & 1,62 & & \\
\hline 1,50 & 1,45 & & & \\
\hline 1,25 & & & & \\
\hline \multirow{2}{*}{1,00} & & & & \\
\hline & - 64AV & - 27MC & - 38M & $\square$ 40T \\
\hline
\end{tabular}

- Rango 3: Los que obtuvieron puntajes de fluidez discursiva oral integral entre 2 y 2,99 en el cual se situaron la mayoría de los informantes (32). Este grupo representa al hablante promedio, con una producción narrativa aceptable y con algunos fenómenos propios de la oralidad. 
Gráfico 17: Evaluación FDOI. Rango 3 (I)

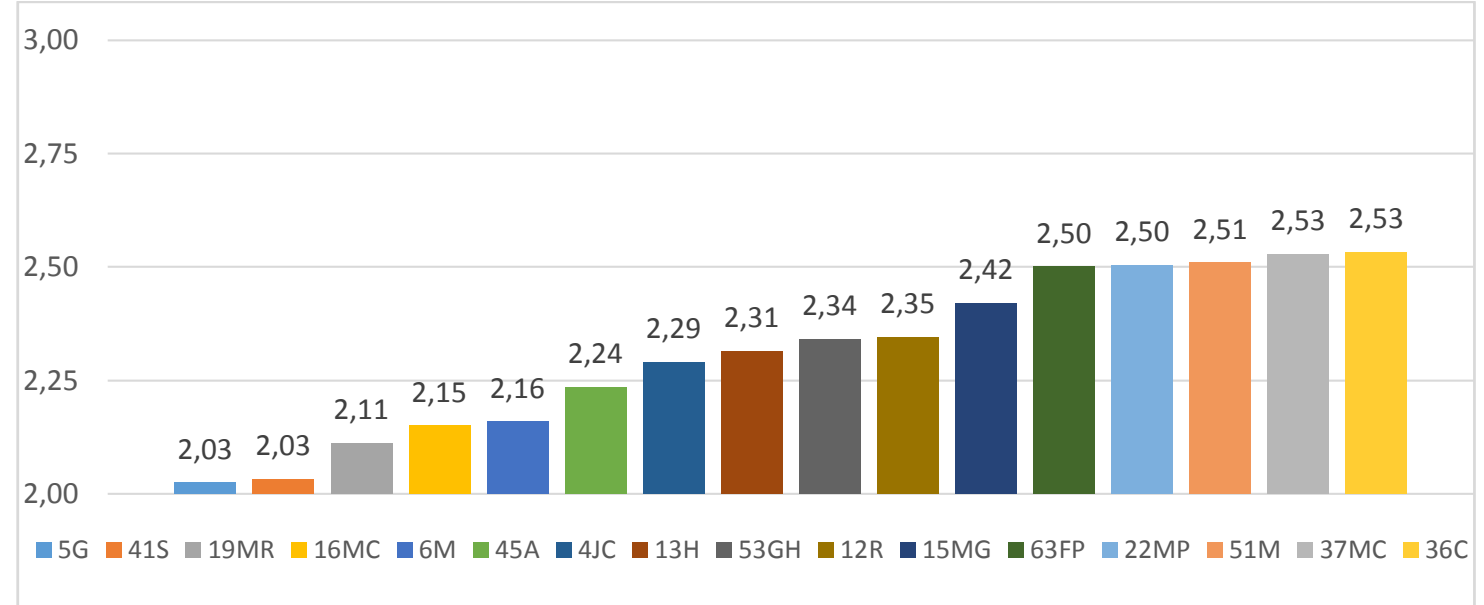

Gráfico 18: Evaluación FDOI. Rango 3 (II)

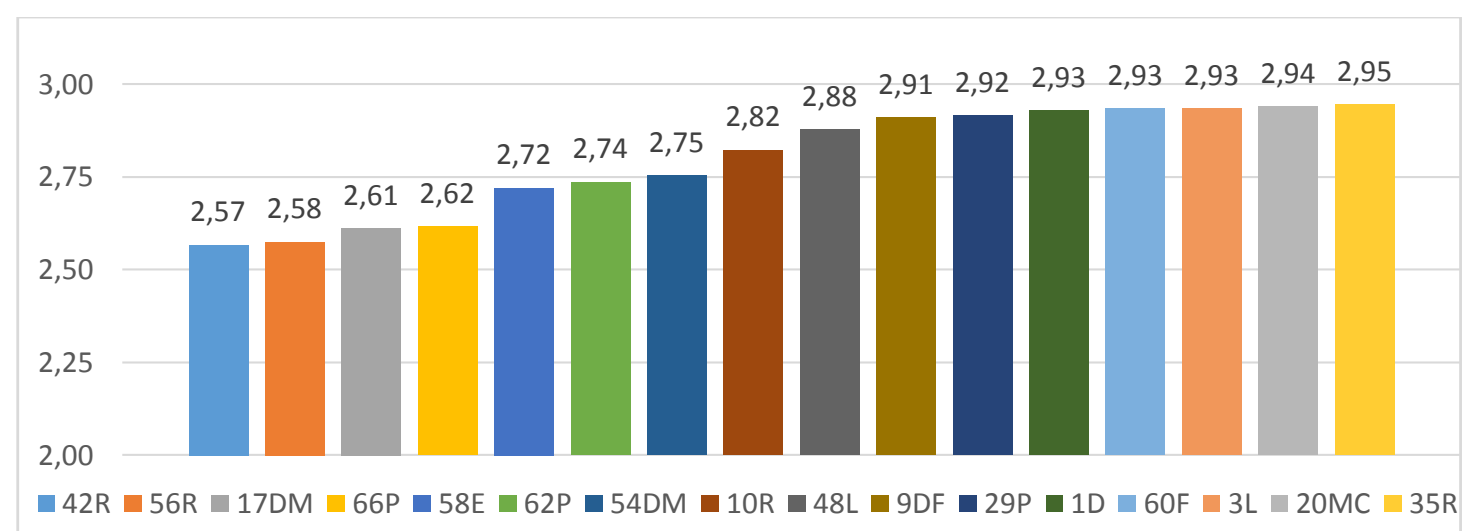

- Rango 4: Los que obtuvieron puntajes de fluidez discursiva oral integral entre 3 y 3,99 y en el cual se ubicaron 29 informantes.

Este grupo se dividió en dos subgrupos: Los que obtuvieron puntajes entre 3 y 3,49 (4A) y quienes obtuvieron puntajes desde 3,5 hasta 3,99 (4B). 
Gráfico 19: Evaluación FDOI. Rango $4 A$

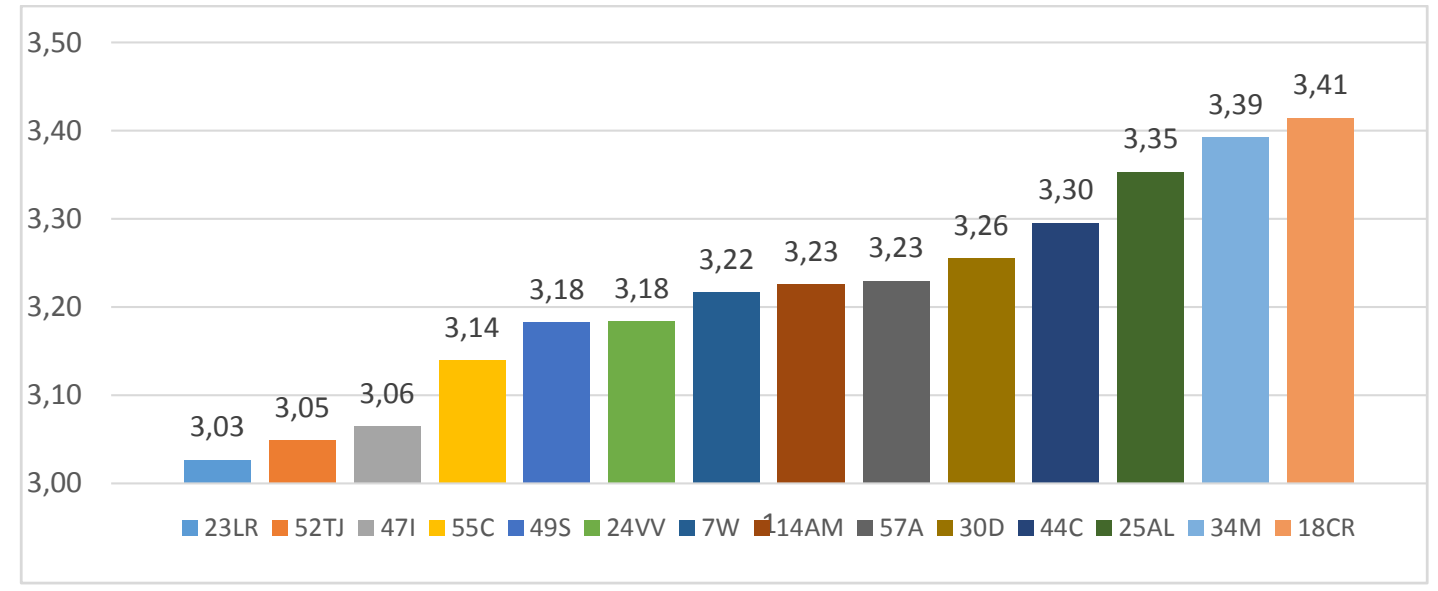

Quienes se ubican en el rango 4A se pueden catalogar como buenos narradores con algunas deficiencias; se ubicaron 14 informantes en este rango.

Gráfico 20: Evaluación FDOI. Rango 4B

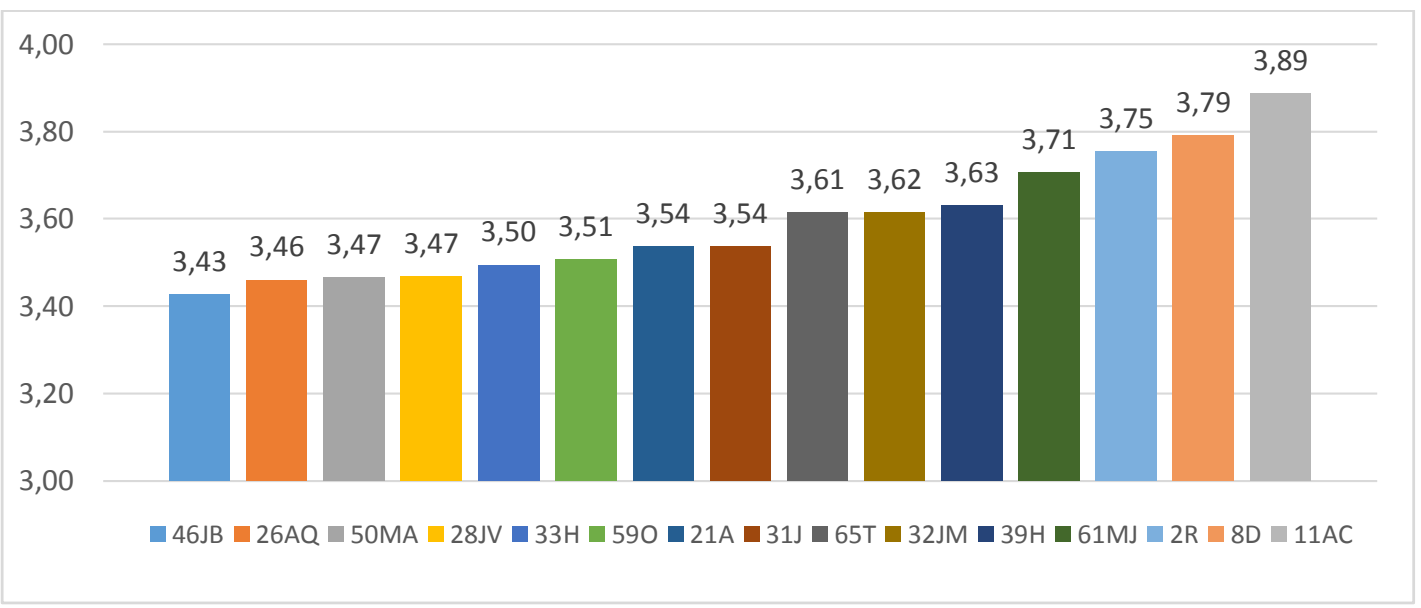

Quienes se ubican en el rango 4B demuestran habilidades superiores en todos los ítems evaluados: son fluidos, poseen pocas o ninguna disfluencia y son buenos narradores. Se ubicaron 15 informantes en este rango. 
- Rango 5: Los que obtuvieron puntajes de fluidez discursiva oral integral desde 4 en adelante. No hay informantes en el corpus de este trabajo que hayan obtenido puntajes para este rango, en cuyo caso estaríamos ante informantes de cualidades excelentes en la fluidez discursiva oral. Tal podría ser el caso de los cuenteros y otros profesionales de la narración.

Gráfico 21: Porcentaje de informantes por rango

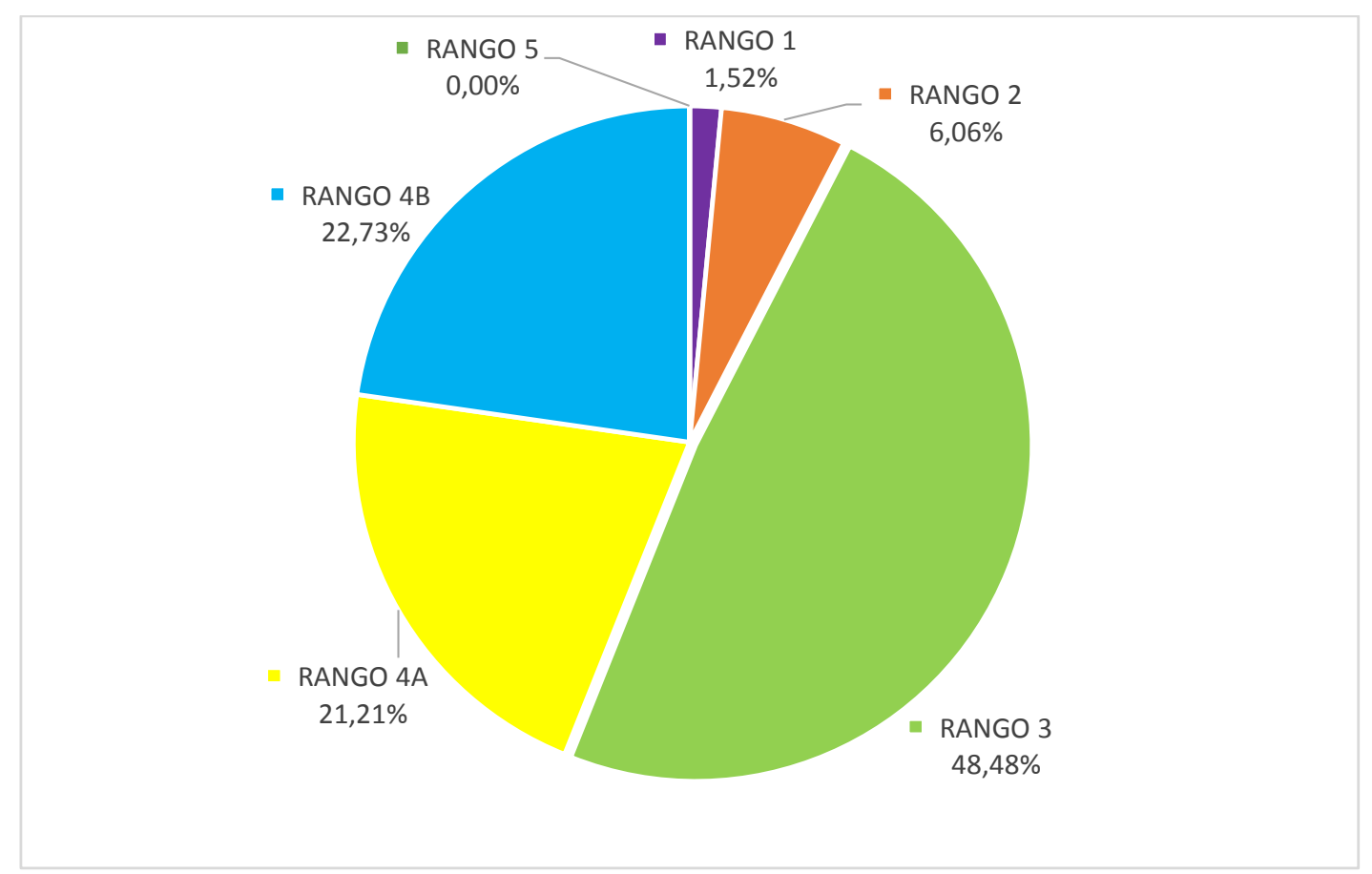

En el gráfico se puede evidenciar cómo se distribuye el porcentaje de informantes en cada categoría. Se obtuvo que la mayor parte de los evaluados se ubican en el rango 3. Como se menciona anteriormente, la mayoría de los informantes se ubican en este rango, con habilidades básicas en la narración. 


\subsubsection{Jerarquización por informantes}

El siguiente gráfico (Gráfico 22) muestra los resultados finales de fluidez discursiva oral integral de los 66 informantes evaluados. Estos se presentan en orden ascendente, desde 0,94 que obtiene el informante 43E hasta 3,89 que obtiene el informante 11AC. Entre el puntaje mínimo y el máximo se da un intervalo de 2,95 puntos y el puntaje promedio entre los 66 informantes corresponde a 2,86. 


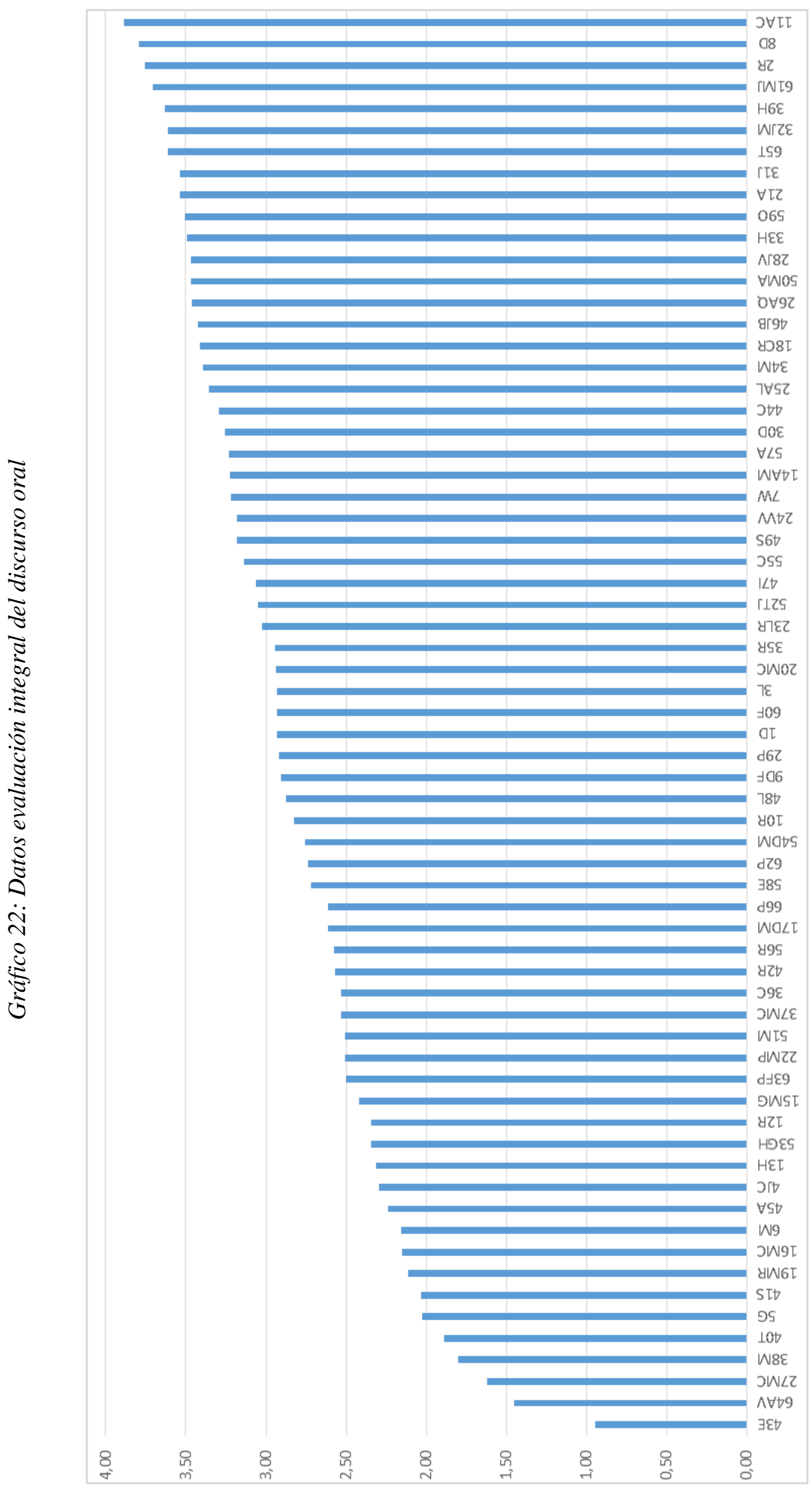




\subsection{Resultados generales desglosados}

\subsubsection{Resultados cuantitativos (fluidez discursiva oral: FDO)}

Como se ha mencionado anteriormente los resultados cuantitativos corresponden a la fluidez discursiva oral, que es el resultado de la fluidez verbal, definida como el número de palabras por minuto que un hablante produce; a la cual se suma o resta según el caso el número de fenómenos orales que posee el hablante.

A continuación se presentan las tablas dónde se evalúan los discursos de los 66 informantes. 
Tabla 16: Resultados cuantitativos FDO. Informantes $1 D-11 A C$

\begin{tabular}{|c|c|c|c|c|c|c|c|c|c|c|c|c|}
\hline \multicolumn{2}{|r|}{ Informante } & \multirow[t]{2}{*}{$1 \mathrm{D}$} & \multirow[t]{2}{*}{$2 \mathrm{R}$} & \multirow[t]{2}{*}{$3 \mathrm{~L}$} & \multirow[t]{2}{*}{$4 J C$} & \multirow[t]{2}{*}{$5 G$} & \multirow[t]{2}{*}{$6 \mathrm{M}$} & \multirow[t]{2}{*}{$7 \mathrm{~W}$} & \multirow[t]{2}{*}{$8 \mathrm{D}$} & \multirow[t]{2}{*}{ 9DF } & \multirow[t]{2}{*}{$10 \mathrm{R}$} & \multirow[t]{2}{*}{$11 \mathrm{AC}$} \\
\hline & REPETICIONES & & & & & & & & & & & \\
\hline 1 & Rep int & & & & & & & & & & & \\
\hline 2 & Rep no int & & & & & & & & & & & \\
\hline 3 & Rep son. & & & & & & & & & & & \\
\hline 4 & Rep silab. desc. & & & & & & & & & & & \\
\hline 5 & Rep inic. & & & & & & & & & & & 2 \\
\hline 6 & Rep medio & & & & & & & & & & & \\
\hline 7 & Rep. Fin. & & & & & & & & & & & \\
\hline 8 & Rep lex no int. & & & & & & & & & & & \\
\hline 9 & Rep. Pal Ilena & & & & & & & & & & 2 & \\
\hline 10 & Rep. Pal vacía & & & & & & & & & 3 & 12 & 5 \\
\hline 11 & Rep exp. Resem. & & & & & & & & & & & \\
\hline 12 & Rep. Exp. Ref. & & & & & & & & & 2 & 3 & 2 \\
\hline 13 & Rep sistemática & & & & & & & & & & & \\
\hline \multirow[t]{2}{*}{14} & Rep exp innec. & & & & & & & & & & 2 & 2 \\
\hline & ALARGAMIENTOS & & & & & & & & & & & \\
\hline 15 & Alarg. Desc. & & & & & & & & & & & \\
\hline 16 & Alarg. Llena ac. & & & & & & & & & 3 & 6 & 3 \\
\hline 17 & Alarg. Llena inac & & & & & & & & & 1 & & 7 \\
\hline 18 & Alarg. Pal vacía & & & & & & & & & 5 & 16 & 7 \\
\hline 19 & Alarg ant. Llena & & & & & & & & & & & \\
\hline \multirow[t]{2}{*}{20} & Alarg. Innec. & & & & & & & & & 1 & 6 & 8 \\
\hline & PAUSAS & & & & & & & & & & & \\
\hline 21 & Pausa int. & 1 & 5 & 3 & 1 & & & & 1 & 2 & 5 & 65 \\
\hline 22 & Pausa fin ev. & & & & & & & & & & & 1 \\
\hline 23 & Pausa interac & & & & & & & & & & 1 & \\
\hline 24 & Pausa ruptura & & & & & & & & & & & 10 \\
\hline 25 & Pausa caract. $\mathrm{Hb}$ & & & & & & & & & & & \\
\hline 26 & Pausa ante inus. & & & & & & & & & & & \\
\hline 27 & Antec pal llena us & & & & & & & & & & & 1 \\
\hline \multirow[t]{2}{*}{28} & Desp de llena & & & & & & & & & & 1 & \\
\hline & OTROS & & & & & & & & & & & \\
\hline 29 & Enunciado truc & & & & & & & & & & & \\
\hline \multirow[t]{3}{*}{30} & Coalesc. & & 5 & 1 & 1 & 1 & & & & 6 & 13 & 5 \\
\hline & Total + & 1 & 5 & 3 & 1 & 0 & 0 & 0 & 1 & 7 & 17 & 71 \\
\hline & Total - & 0 & 0 & 0 & 0 & 0 & 0 & 0 & 0 & 10 & 37 & 43 \\
\hline & úmero de palabras & 74 & 339 & 150 & 65 & 58 & 87 & 92 & 143 & 180 & 574 & 882 \\
\hline & úmero de minutos & 0.32 & 1.62 & 0.78 & 0.33 & 0.32 & 0.45 & 0.40 & 0.65 & 1.20 & 4.01 & 4.98 \\
\hline & rom. Pal. por min. & 234.2 & 209.8 & 193.3 & 195.2 & 183.5 & 193.3 & 230.0 & 220.0 & 150.0 & 143.1 & 177.1 \\
\hline & m. de neg por min. & 0.0 & 0.0 & 0.0 & 0.0 & 0.0 & 0.0 & 0.0 & 0.0 & 8.3 & 9.2 & 8.6 \\
\hline & m. de pos. por min. & 3.2 & 3.1 & 3.9 & 3.0 & 0.0 & 0.0 & 0.0 & 1.5 & 5.8 & 4.2 & 14.3 \\
\hline & TOTAL & 237.3 & 212.9 & 197.2 & 198.2 & 183.5 & 193.3 & 230.0 & 221.5 & 147.5 & 138.2 & 182.7 \\
\hline
\end{tabular}


Tabla 17: Resultados cuantitativos FDO. Informantes $12 R-22 M P$

\begin{tabular}{|c|c|c|c|c|c|c|c|c|c|c|c|c|}
\hline \multicolumn{2}{|r|}{ Informante } & \multirow[t]{2}{*}{$12 \mathrm{R}$} & \multirow[t]{2}{*}{$13 \mathrm{H}$} & \multirow[t]{2}{*}{$14 \mathrm{AM}$} & \multirow[t]{2}{*}{$15 \mathrm{MG}$} & \multirow[t]{2}{*}{$16 \mathrm{MC}$} & \multirow[t]{2}{*}{ 17DM } & \multirow[t]{2}{*}{$18 \mathrm{CR}$} & \multirow[t]{2}{*}{ 19MR } & \multirow[t]{2}{*}{$20 \mathrm{MC}$} & \multirow[t]{2}{*}{$21 \mathrm{~A}$} & \multirow[t]{2}{*}{$22 \mathrm{MP}$} \\
\hline & REPETICIONES & & & & & & & & & & & \\
\hline 1 & Rep int & & & & & & & & & & & \\
\hline 2 & Rep no int & & & & & & & & & & & \\
\hline 3 & Rep son. & & & & & & & & & & & \\
\hline 4 & Rep silab. desc. & & & 3 & & & & & & & & \\
\hline 5 & Rep inic. & & 1 & & & & 1 & & 1 & & & \\
\hline 6 & Rep medio & & & 2 & & & & & & & & \\
\hline 7 & Rep. Fin. & & & & & & & & & & & \\
\hline 8 & Rep lex no int. & & & & & & & & & & & \\
\hline 9 & Rep. Pal Ilena & 2 & & 8 & 5 & & 3 & 6 & 5 & 4 & 3 & \\
\hline 10 & Rep. Pal vacía & & & 11 & 20 & 6 & & 4 & 17 & 2 & 22 & 1 \\
\hline 11 & Rep exp. Resem. & & & 5 & 5 & 2 & 7 & 1 & 8 & & 4 & 2 \\
\hline 12 & Rep. Exp. Ref. & & 6 & 10 & 11 & 6 & 8 & 3 & 6 & 1 & 13 & 3 \\
\hline 13 & Rep sistemática & & & & & & & & & & & \\
\hline \multirow[t]{2}{*}{14} & Rep exp innec. & & 1 & 4 & 4 & & 3 & & 8 & & 2 & 1 \\
\hline & ALARGAMIENTOS & & & & & & & & & & & \\
\hline 15 & Alarg. Desc. & & & & & & & & & & & \\
\hline 16 & Alarg. Llena ac. & 1 & & 1 & 5 & 2 & 1 & 4 & 1 & 3 & & 1 \\
\hline 17 & Alarg. Llena inac & 1 & 3 & 2 & 15 & 7 & 6 & 7 & 11 & 5 & 3 & \\
\hline 18 & Alarg. Pal vacía & 1 & & 11 & & 5 & 11 & & 8 & 3 & 9 & 1 \\
\hline 19 & Alarg ant. Llena & & & & & 1 & 10 & & 1 & 2 & & \\
\hline \multirow[t]{2}{*}{20} & Alarg. Innec. & & & & 1 & & & & & & & 1 \\
\hline & PAUSAS & & & & & & & & & & & \\
\hline 21 & Pausa int. & & & & & & & 2 & 2 & 3 & 3 & 1 \\
\hline 22 & Pausa fin ev. & & & & & 1 & 1 & & & 2 & & \\
\hline 23 & Pausa interac & & & & & & & & & & 1 & \\
\hline 24 & Pausa ruptura & & & & & 5 & 1 & 1 & & & & 1 \\
\hline 25 & Pausa caract. $\mathrm{Hb}$ & & & & & & & & & & & \\
\hline \multirow[t]{2}{*}{26} & Pausa ante inus. & & 1 & & & & & & & & & \\
\hline & OTROS & & & & & & & & & & & \\
\hline 27 & Antec pal llena us & & & & & 1 & & & 2 & & & 1 \\
\hline 28 & Desp de llena & & 1 & & & & & & & 1 & 2 & \\
\hline 29 & Enunciado truc & & 1 & & & & & & & & & \\
\hline 30 & Coalesc. & 6 & 1 & 9 & & 3 & & & 2 & 1 & 1 & \\
\hline & Total + & 3 & 6 & 27 & 26 & 11 & 20 & 16 & 22 & 13 & 24 & 7 \\
\hline & Total - & 2 & 8 & 30 & 40 & 26 & 32 & 12 & 50 & 13 & 38 & 7 \\
\hline \multicolumn{2}{|c|}{ Número de palabras } & 109 & 195 & 1134 & 157 & 187 & 934 & 739 & 535 & 376 & 1035 & 314 \\
\hline \multicolumn{2}{|c|}{ Número de minutos } & 0.70 & 1.18 & 7.60 & 1.10 & 4.33 & 7.12 & 4.22 & 6.32 & 2.22 & 5.75 & 2.08 \\
\hline \multicolumn{2}{|c|}{ Prom. Pal. por min. } & 155.7 & 164.8 & 149.2 & 142.7 & 43.2 & 131.2 & 175.3 & 84.7 & 169.7 & 180.0 & 150.7 \\
\hline \multicolumn{2}{|c|}{ Prom. de neg por min. } & 2.9 & 6.8 & 3.9 & 36.4 & 6.0 & 4.5 & 2.8 & 7.9 & 5.9 & 6.6 & 3.4 \\
\hline \multicolumn{2}{|c|}{ Prom. de pos. por min. } & 4.3 & 5.1 & 3.6 & 23.6 & 2.5 & 2.8 & 3.8 & 3.5 & 5.9 & 4.2 & 3.4 \\
\hline & TOTAL & 157.1 & 163.1 & 148.8 & 130.0 & 39.7 & 129.5 & 176.2 & 80.3 & 169.7 & 177.6 & 150.7 \\
\hline
\end{tabular}


Tabla 18: Resultados cuantitativos FDO. Informantes 23 LR - 33H

\begin{tabular}{|c|c|c|c|c|c|c|c|c|c|c|c|c|}
\hline \multicolumn{2}{|r|}{ Informante } & \multirow[t]{2}{*}{$23 \mathrm{LR}$} & \multirow[t]{2}{*}{$24 \mathrm{VV}$} & \multirow[t]{2}{*}{$25 \mathrm{AL}$} & \multirow[t]{2}{*}{$26 A Q$} & \multirow[t]{2}{*}{$27 \mathrm{MC}$} & \multirow[t]{2}{*}{$28 \mathrm{JV}$} & \multirow[t]{2}{*}{$29 P$} & \multirow[t]{2}{*}{$30 D$} & \multirow[t]{2}{*}{$31 \mathrm{~J}$} & \multirow[t]{2}{*}{$32 \mathrm{JMC}$} & \multirow[t]{2}{*}{$33 \mathrm{H}$} \\
\hline & REPETICIONES & & & & & & & & & & & \\
\hline 1 & Rep int & & & & & & & & & & & \\
\hline 2 & Rep no int & & & & & & & & & & & \\
\hline 3 & Rep son. & & & & & & & & & & & \\
\hline 4 & Rep silab. desc. & & & & & & & & & & & \\
\hline 5 & Rep inic. & & & & & & 1 & 1 & & & & \\
\hline 6 & Rep medio & & & & & & & & & & & \\
\hline 7 & Rep. Fin. & & & & & & & & & & & \\
\hline 8 & Rep lex no int. & & & & & & & & & & & \\
\hline 9 & Rep. Pal Ilena & 4 & 3 & 3 & 4 & 4 & 2 & 4 & 1 & & & \\
\hline 10 & Rep. Pal vacía & 8 & 2 & 2 & & 3 & 23 & 19 & & & & \\
\hline 11 & Rep exp. Resem. & & 4 & 1 & 1 & & & 10 & 3 & & & \\
\hline 12 & Rep. Exp. Ref. & 13 & & 5 & 3 & 1 & 7 & 12 & 1 & & 3 & \\
\hline 13 & Rep sistemática & & & & & & & & & & & \\
\hline \multirow[t]{2}{*}{14} & Rep exp innec. & & 2 & 4 & 1 & & 6 & 8 & & & & \\
\hline & ALARGAMIENTOS & & & & & & & & & & & \\
\hline 15 & Alarg. Desc. & & & & & & & & & & & \\
\hline 16 & Alarg. Llena ac. & 2 & 1 & 2 & 1 & 2 & & 1 & & & & \\
\hline 17 & Alarg. Llena inac & 15 & 1 & 3 & 3 & 3 & 5 & 5 & 1 & & 1 & \\
\hline 18 & Alarg. Pal vacía & 36 & 3 & 3 & 1 & 10 & 8 & 4 & 5 & & 6 & \\
\hline 19 & Alarg ant. Llena & 2 & & & & & & & & & & \\
\hline \multirow[t]{2}{*}{20} & Alarg. Innec. & 9 & & & & 5 & 2 & & & & 1 & \\
\hline & PAUSAS & & & & & & & & & & & \\
\hline 21 & Pausa int. & 17 & 1 & 1 & & 1 & 1 & & & 6 & 2 & 2 \\
\hline 22 & Pausa fin ev. & & 1 & 1 & & & & & & & & \\
\hline 23 & Pausa interac & & & & & & & & & & 1 & \\
\hline 24 & Pausa ruptura & & & & & & & & & & & \\
\hline 25 & Pausa caract. $\mathrm{Hb}$ & & & & & & & & & & & \\
\hline \multirow[t]{2}{*}{26} & Pausa ante inus. & 1 & & & & & & & & & & \\
\hline & OTROS & & & & & & & & & & & \\
\hline 27 & Antec pal llena us & 1 & & & & & & & & & 6 & \\
\hline 28 & Desp de llena & & & & & & & 1 & & & & \\
\hline 29 & Enunciado truc & & 1 & & & & 1 & & 1 & & & \\
\hline \multirow[t]{3}{*}{30} & Coalesc. & 3 & 3 & 1 & & & & 4 & 3 & 4 & 3 & 3 \\
\hline & Total + & 36 & 10 & 13 & 9 & 8 & 10 & 27 & 5 & 6 & 6 & 2 \\
\hline & Total - & 73 & 9 & 12 & 5 & 21 & 46 & 38 & 7 & 0 & 20 & 0 \\
\hline \multicolumn{2}{|c|}{ Número de palabras } & 1441 & 749 & 904 & 568 & 157 & 1004 & 953 & 474 & 441 & 510 & 238 \\
\hline \multicolumn{2}{|c|}{ Número de minutos } & 11.03 & 4.35 & 4.13 & 3.33 & 3.13 & 5.68 & 7.55 & 2.88 & 2.52 & 2.73 & 1.25 \\
\hline \multicolumn{2}{|c|}{ Prom. Pal. por min. } & 130.6 & 172.2 & 218.7 & 170.6 & 50.1 & 176.7 & 126.2 & 164.4 & 175.3 & 186.6 & 190.4 \\
\hline \multicolumn{2}{|c|}{ Prom. de neg por min. } & 6.6 & 2.1 & 2.9 & 1.5 & 6.7 & 8.1 & 5.0 & 2.4 & 0.0 & 7.3 & 0.0 \\
\hline \multicolumn{2}{|c|}{ Prom. de pos. por min. } & 3.3 & 2.3 & 3.1 & 2.7 & 2.6 & 1.8 & 3.6 & 1.7 & 2.4 & 2.2 & 1.6 \\
\hline & TOTAL & 127.3 & 172.4 & 219.0 & 171.8 & 46.0 & 170.3 & 124.8 & 163.7 & 177.7 & 181.5 & 192.0 \\
\hline
\end{tabular}


Tabla 19: Resultados cuantitativos FDO. Informantes $34 M-44 C$

\begin{tabular}{|c|c|c|c|c|c|c|c|c|c|c|c|c|}
\hline \multicolumn{2}{|r|}{ Informante } & \multirow[t]{2}{*}{$34 \mathrm{M}$} & \multirow[t]{2}{*}{$35 R$} & \multirow[t]{2}{*}{$36 \mathrm{C}$} & \multirow[t]{2}{*}{$37 \mathrm{CM}$} & \multirow[t]{2}{*}{$38 \mathrm{M}$} & \multirow[t]{2}{*}{$39 \mathrm{H}$} & \multirow[t]{2}{*}{$40 T$} & \multirow[t]{2}{*}{$41 \mathrm{~S}$} & \multirow[t]{2}{*}{$42 R$} & \multirow[t]{2}{*}{$43 \mathrm{E}$} & \multirow[t]{2}{*}{$44 C$} \\
\hline & REPETICIONES & & & & & & & & & & & \\
\hline 1 & Rep int & & & & & & & & & & & \\
\hline 2 & Rep no int & & & & & & & & & & & \\
\hline 3 & Rep son. & & & & & & & & & & & \\
\hline 4 & Rep silab. desc. & & & & & & & & & & & \\
\hline 5 & Rep inic. & & 1 & & & & & & & & & \\
\hline 6 & Rep medio & & & & & & & & & & & \\
\hline 7 & Rep. Fin. & & & & & & & & & & & \\
\hline 8 & Rep lex no int. & & & & & & & & & & & \\
\hline 9 & Rep. Pal llena & 4 & & 4 & 13 & & & 2 & 5 & 2 & 2 & 11 \\
\hline 10 & Rep. Pal vacía & & 10 & 12 & & & & & 4 & 11 & 12 & 5 \\
\hline 11 & Rep exp. Resem. & & 2 & 2 & 4 & & & & 3 & 4 & & 3 \\
\hline 12 & Rep. Exp. Ref. & & 4 & 10 & 4 & & & & & 5 & 1 & 4 \\
\hline 13 & Rep sistemática & & & & & & & & & 2 & & \\
\hline \multirow[t]{2}{*}{14} & Rep exp innec. & 1 & 6 & 5 & & & 1 & & 2 & 2 & 1 & 2 \\
\hline & ALARGAMIENTOS & & & & & & & & & & & \\
\hline 15 & Alarg. Desc. & & & & & & & & & & & \\
\hline 16 & Alarg. Llena ac. & 6 & & 3 & & & & & 9 & 1 & 8 & 11 \\
\hline 17 & Alarg. Llena inac & 3 & & 2 & 2 & & & & 15 & & 8 & 11 \\
\hline 18 & Alarg. Pal vacía & 3 & 1 & 2 & 13 & & & 1 & 6 & 4 & 20 & 6 \\
\hline 19 & Alarg ant. Llena & & & & & & & & & & & \\
\hline \multirow[t]{2}{*}{20} & Alarg. Innec. & & 1 & & & & & & & & 2 & \\
\hline & PAUSAS & & & & & & & & & & & \\
\hline 21 & Pausa int. & & 2 & 2 & & & & 2 & & 1 & 1 & \\
\hline 22 & Pausa fin ev. & & 1 & & & 3 & & 3 & 3 & & 1 & 6 \\
\hline 23 & Pausa interac & & & & 1 & & & & & 2 & & \\
\hline 24 & Pausa ruptura & & & & & & & & & & 4 & 1 \\
\hline 25 & Pausa caract. $\mathrm{Hb}$ & & & & & & & & & & & \\
\hline \multirow[t]{2}{*}{26} & Pausa ante inus. & & & & & & & & & & & \\
\hline & OTROS & & & & & & & & & & & \\
\hline 27 & Antec pal llena us & & & & & & & & & & 3 & 2 \\
\hline 28 & Desp de llena & & & & & & & & & & 1 & \\
\hline 29 & Enunciado truc & & & 1 & & & & & & & 1 & \\
\hline \multirow[t]{3}{*}{30} & Coalesc. & 5 & 41 & 24 & & 2 & & 2 & 10 & 2 & 2 & 8 \\
\hline & Total + & 10 & 9 & 21 & 22 & 3 & 0 & 7 & 20 & 15 & 13 & 35 \\
\hline & Total - & 7 & 19 & 22 & 15 & 0 & 1 & 1 & 27 & 19 & 55 & 29 \\
\hline & úmero de palabras & 320 & 433 & 592 & 759 & 180 & 301 & 273 & 227 & 356 & 184 & 381 \\
\hline & úmero de minutos & 1.83 & 2.88 & 3.90 & 5.32 & 1.50 & 1.42 & 2.17 & 1.75 & 1.68 & 3.68 & 2.21 \\
\hline & rom. Pal. por min. & 174.6 & 150.2 & 151.8 & 142.7 & 120.0 & 212.0 & 126.0 & 129.7 & 211.5 & 50.0 & 172.4 \\
\hline & om. de neg por min. & 3.8 & 6.6 & 5.6 & 2.8 & 0.0 & 0.7 & 0.5 & 15.4 & 11.3 & 14.9 & 13.1 \\
\hline & m. de pos. por min. & 5.5 & 3.1 & 5.4 & 4.1 & 2.0 & 0.0 & 3.2 & 11.4 & 8.9 & 3.5 & 15.8 \\
\hline & TOTAL & 176.2 & 146.7 & 151.5 & 144.0 & 122.0 & 211.3 & 128.8 & 125.7 & 209.2 & 38.6 & 175.1 \\
\hline
\end{tabular}


Tabla 20: Resultados cuantitativos FDO. Informantes 45A-55C

\begin{tabular}{|c|c|c|c|c|c|c|c|c|c|c|c|c|}
\hline \multicolumn{2}{|r|}{ Informante } & \multirow[t]{2}{*}{$45 \mathrm{~A}$} & \multirow[t]{2}{*}{ 46JB } & \multirow[t]{2}{*}{471} & \multirow[t]{2}{*}{$48 \mathrm{~L}$} & \multirow[t]{2}{*}{$49 S$} & \multirow[t]{2}{*}{$50 \mathrm{MA}$} & \multirow[t]{2}{*}{$51 \mathrm{M}$} & \multirow[t]{2}{*}{$52 \mathrm{TJ}$} & \multirow[t]{2}{*}{$53 \mathrm{GH}$} & \multirow[t]{2}{*}{ 54DM } & \multirow[t]{2}{*}{$55 \mathrm{C}$} \\
\hline & REPETICIONES & & & & & & & & & & & \\
\hline 1 & Rep int & & & & & & & & & & & \\
\hline 2 & Rep no int & & & & & & & & & & & \\
\hline 3 & Rep son. & & & & & & & & & & & \\
\hline 4 & Rep silab. desc. & & & & & & & & & & & \\
\hline 5 & Rep inic. & & & & 2 & & 1 & & & & & \\
\hline 6 & Rep medio & & & & & & & & & & & \\
\hline 7 & Rep. Fin. & & & & & & & & & & & \\
\hline 8 & Rep lex no int. & & & & & & & & & & & \\
\hline 9 & Rep. Pal Ilena & & & & & 1 & 2 & & 3 & 15 & 1 & 3 \\
\hline 10 & Rep. Pal vacía & & 4 & & 5 & 6 & 3 & 2 & 1 & 6 & 5 & 2 \\
\hline 11 & Rep exp. Resem. & 5 & & & 1 & 1 & & & & & 1 & \\
\hline 12 & Rep. Exp. Ref. & & 2 & 1 & 1 & 1 & 9 & 3 & 1 & & & 1 \\
\hline 13 & Rep sistemática & & & & & & & & & & & \\
\hline \multirow[t]{2}{*}{14} & Rep exp innec. & & 1 & & 2 & 2 & 1 & 2 & 2 & 2 & 2 & 1 \\
\hline & ALARGAMIENTOS & & & & & & & & & & & \\
\hline 15 & Alarg. Desc. & & & & & & & & & & & \\
\hline 16 & Alarg. Llena ac. & 7 & 3 & 9 & 5 & & 1 & & 7 & & & \\
\hline 17 & Alarg. Llena inac & 10 & 16 & 8 & 9 & 5 & & 2 & 16 & 2 & 1 & \\
\hline 18 & Alarg. Pal vacía & 2 & 3 & 2 & 10 & 14 & & & & 5 & 4 & 3 \\
\hline 19 & Alarg ant. Llena & 3 & & & & & & & 6 & & & \\
\hline \multirow[t]{2}{*}{20} & Alarg. Innec. & & & & & 4 & & & 2 & 1 & 2 & \\
\hline & PAUSAS & & & & & & & & & & & \\
\hline 21 & Pausa int. & 2 & & 2 & & & & 3 & & 7 & 7 & 9 \\
\hline 22 & Pausa fin ev. & & & & & 1 & & 1 & 1 & & 1 & \\
\hline 23 & Pausa interac & & & & 1 & & & & & & & \\
\hline 24 & Pausa ruptura & & 1 & 2 & & & & & 1 & & & \\
\hline 25 & Pausa caract. $\mathrm{Hb}$ & & & & & & & & & & & \\
\hline \multirow[t]{2}{*}{26} & Pausa ante inus. & & & & & & & & & & & \\
\hline & OTROS & & & & & & & & & & & \\
\hline 27 & Antec pal Ilena us & 1 & & & & & & & 1 & & & \\
\hline 28 & Desp de Ilena & & 1 & & & & & & & & & 1 \\
\hline 29 & Enunciado truc & 1 & & 1 & & 1 & & & & 1 & & \\
\hline 30 & Coalesc. & & 1 & 14 & 4 & 1 & 3 & 30 & 35 & 26 & 14 & \\
\hline & Total + & 14 & 5 & 12 & 8 & 4 & 12 & 7 & 12 & 22 & 10 & 13 \\
\hline & Total - & 18 & 26 & 13 & 28 & 32 & 5 & 6 & 30 & 17 & 14 & 7 \\
\hline \multicolumn{2}{|c|}{ Número de palabras } & 217 & 322 & 309 & 278 & 309 & 473 & 524 & 472 & 298 & 171 & 209 \\
\hline \multicolumn{2}{|c|}{ Número de minutos } & 1.42 & 1.53 & 1.75 & 1.85 & 1.75 & 2.78 & 2.85 & 3.27 & 2.32 & 1.23 & 1.28 \\
\hline \multicolumn{2}{|c|}{ Prom. Pal. por min. } & 152.8 & 210.0 & 176.6 & 150.3 & 176.6 & 170.0 & 183.9 & 144.5 & 128.7 & 138.7 & 162.9 \\
\hline \multicolumn{2}{|c|}{ Prom. de neg por min. } & 12.7 & 17.0 & 7.4 & 15.1 & 18.3 & 1.8 & 2.1 & 9.2 & 7.3 & 11.4 & 5.5 \\
\hline \multicolumn{2}{|c|}{ Prom. de pos. por min. } & 9.9 & 3.3 & 6.9 & 4.3 & 2.3 & 4.3 & 2.5 & 3.7 & 9.5 & 8.1 & 10.1 \\
\hline & TOTAL & 150.0 & 196.3 & 176.0 & 139.5 & 160.6 & 172.5 & 184.2 & 139.0 & 130.8 & 135.4 & 167.6 \\
\hline
\end{tabular}


Tabla 21: Resultados cuantitativos FDO. Informantes 56R-66P

\begin{tabular}{|c|c|c|c|c|c|c|c|c|c|c|c|c|}
\hline \multicolumn{2}{|r|}{ Informante } & \multirow[t]{2}{*}{$56 \mathrm{R}$} & \multirow[t]{2}{*}{$57 \mathrm{~A}$} & \multirow[t]{2}{*}{$58 \mathrm{E}$} & \multirow[t]{2}{*}{ 59음 } & \multirow[t]{2}{*}{$60 \mathrm{~F}$} & \multirow[t]{2}{*}{$61 \mathrm{MJ}$} & \multirow[t]{2}{*}{$62 \mathrm{P}$} & \multirow[t]{2}{*}{$63 \mathrm{FP}$} & \multirow[t]{2}{*}{$64 \mathrm{AV}$} & \multirow[t]{2}{*}{$65 T$} & \multirow[t]{2}{*}{$66 \mathrm{P}$} \\
\hline & REPETICIONES & & & & & & & & & & & \\
\hline 1 & Rep int & & & & & & & & & 2 & & \\
\hline 2 & Rep no int & & & 3 & & & & & & 1 & & \\
\hline 3 & Rep son. & & & & & & & & & & & \\
\hline 4 & Rep silab. desc. & & & & & & & & & & & \\
\hline 5 & Rep inic. & & & 1 & 1 & & 3 & 1 & & & & \\
\hline 6 & Rep medio & & & & & & & & & & & \\
\hline 7 & Rep. Fin. & & & & & & & & & & & \\
\hline 8 & Rep lex no int. & & & & & & & & & & & \\
\hline 9 & Rep. Pal Ilena & & & & 0 & 7 & 1 & 2 & 3 & 1 & 4 & 3 \\
\hline 10 & Rep. Pal vacía & 1 & & 3 & 14 & 10 & 10 & 10 & 2 & 1 & 1 & 3 \\
\hline 11 & Rep exp. Resem. & 2 & 1 & & 1 & 1 & & 2 & 3 & 1 & 3 & 1 \\
\hline 12 & Rep. Exp. Ref. & 3 & 1 & & 5 & 4 & 9 & & 2 & 0 & & 3 \\
\hline 13 & Rep sistemática & & & & & & & & & 0 & & \\
\hline \multirow[t]{2}{*}{14} & Rep exp innec. & & & & & 3 & 3 & 2 & 1 & 2 & & 1 \\
\hline & ALARGAMIENTOS & & & & & & & & & & & \\
\hline 15 & Alarg. Desc. & & & & 0 & & & & & & & \\
\hline 16 & Alarg. Llena ac. & & & & 6 & 2 & 4 & 3 & 3 & 0 & 2 & \\
\hline 17 & Alarg. Llena inac & & & 1 & & 3 & 4 & 8 & & 2 & & 4 \\
\hline 18 & Alarg. Pal vacía & 1 & 2 & & 6 & 6 & 4 & 11 & 3 & 1 & & 3 \\
\hline 19 & Alarg ant. Llena & & & 2 & & & & & & & 1 & \\
\hline \multirow[t]{2}{*}{20} & Alarg. Innec. & & & 2 & & & & & & & & \\
\hline & PAUSAS & & & & & & & & & & & \\
\hline 21 & Pausa int. & 3 & 2 & 40 & 120 & & 1 & 3 & & 47 & & \\
\hline 22 & Pausa fin ev. & & & 1 & & & 1 & 3 & 1 & & & \\
\hline 23 & Pausa interac & & & 1 & & & & & & 1 & & \\
\hline 24 & Pausa ruptura & & & 17 & & & & & & 12 & & \\
\hline 25 & Pausa caract. $\mathrm{Hb}$ & & & & & & & & & & & \\
\hline \multirow[t]{2}{*}{26} & Pausa ante inus. & & & & & & & & & & & \\
\hline & OTROS & & & & & & & & & & & \\
\hline 27 & Antec pal llena us & & & & & & & & & & & \\
\hline 28 & Desp de llena & & & & & & & & & & & \\
\hline 29 & Enunciado truc & 1 & & & & 1 & & & & 1 & & \\
\hline \multirow[t]{3}{*}{30} & Coalesc. & 8 & 18 & 10 & 11 & 30 & 21 & 60 & 18 & & & 13 \\
\hline & Total + & 8 & 4 & 42 & 132 & 14 & 16 & 13 & 12 & 52 & 9 & 7 \\
\hline & Total - & 3 & 2 & 29 & 21 & 23 & 24 & 32 & 6 & 20 & 2 & 11 \\
\hline \multicolumn{2}{|c|}{ Número de palabras } & 258 & 375 & 352 & 1070 & 522 & 1035 & 302 & 272 & 232 & 356 & 192 \\
\hline \multicolumn{2}{|c|}{ Número de minutos } & 1.92 & 2.18 & 2.22 & 7.58 & 3.42 & 5.37 & 1.75 & 2.23 & 2.40 & 2.03 & 1.35 \\
\hline \multicolumn{2}{|c|}{ Prom. Pal. por min. } & 134.7 & 171.8 & 158.8 & 141.1 & 152.8 & 192.9 & 172.6 & 121.8 & 96.7 & 175.5 & 142.2 \\
\hline \multicolumn{2}{|c|}{ Prom. de neg por min. } & 1.6 & 0.9 & 13.1 & 2.8 & 6.7 & 4.5 & 18.3 & 2.7 & 8.3 & 1.0 & 8.1 \\
\hline \multicolumn{2}{|c|}{ Prom. de pos. por min. } & 4.2 & 1.8 & 19.0 & 17.4 & 4.1 & 3.0 & 7.4 & 5.4 & 21.7 & 4.4 & 5.2 \\
\hline & TOTAL & 137.3 & 172.7 & 164.7 & 155.7 & 150.2 & 191.4 & 161.7 & 124.5 & 110.0 & 179.0 & 139.3 \\
\hline
\end{tabular}




\subsubsection{Resultados cualitativos (capacidades narrativas) y resultados integrales}

Las tablas generales que vienen a continuación incorporan los resultados cualitativos que corresponden a la evaluación de la fluidez narrativa, a los que se suman los resultados de la evaluación cuantitativa. Esta se obtiene calculando la fluidez verbal, es decir, el número de palabras por minuto y ajustándola después con los fenómenos orales que cuentan de forma negativa (disfluencias) o positiva. El resultado se convierte a continuación en una escala del 0 al 5 con el fin de poder hallar la media con la evaluación de la capacidad narrativa.

En lo que sigue se dan más detalles sobre la forma de realizar todos estos cálculos, a través de las fórmulas de Excel.

La tabla general denominada "Instrumento para la evaluación integral del discurso", consta originalmente de 68 casillas verticales. Estas casillas están diseñadas para incluir los datos de cada uno de los informantes (66).

A la izquierda aparece el número de indicador, luego el aspecto evaluado; I) Superestructura narrativa, II) Coherencia global, III) Coherencia local, IV) Cohesión, V) Evaluación y VI) Contextualización. Debajo de cada aspecto aparece el indicador mediante el cual se evalúa dicho aspecto. Las 66 casillas siguientes identifican a cada uno 
de los informantes de la investigación. En estas casillas aparece el valor que corresponde a la evaluación del ítem.

En forma horizontal aparecen los datos que, para cada ítem o indicador, obtiene el informante. Aparecen en vertical 7 aspectos y 23 indicadores. Una casilla para los totales cualitativos: consta de la sumatoria y el promedio que se obtiene de dividir el resultado obtenido entre los 23 indicadores. Este procedimiento se repite con cada uno de los 66 discursos evaluados.

En la fila siguiente aparece el resultado cuantitativo que se obtuvo del conteo de fenómenos de la fluidez oral.

En la casilla inferior aparecen los resultados finales que promedian lo cualitativo y lo cuantitativo. El promedio cualitativo se toma de la casilla superior (ítem I Totales: línea 2: Promedio cualitativo) y al resultado del promedio cuantitativo (II: Resultados finales, línea 1), obtenido como arriba se indica, se le aplicó un escalado para convertirlo en un número de 0 a 5 que pudiese computarse con el resultado de la evaluación del discurso narrativo (también de 0 a 5). Para ello se utilizó la siguiente fórmula en Excel:

$$
P e=\frac{\operatorname{Pr} \times 5}{I M}
$$

Donde:

- Pe: Puntaje cuantitativo escalado

- Pr: Puntaje cuantitativo real

- 5: Constante que equivale al máximo del intervalo 
- IM: Ideal máximo hipotético del hablante

Se multiplica el puntaje real del hablante por 5 (máximo de la nueva escala que se obtendrá) y se divide entre el puntaje máximo que un hablante obtendría (en este caso un puntaje ideal hipotético).

Para el puntaje ideal hipotético se tomó el valor de 270. Este valor se propuso tomando como base el puntaje más alto obtenido en las evaluaciones de los 66 informantes $(237,3)$ y asignando un valor por encima de este, dejando un margen que permita incluir a otros hablantes que pudieran llegar a obtener puntajes superiores a los obtenidos por los informantes evaluados en esta tesis.

El resultado nos da un puntaje Pe que comprende un intervalo de cero (0) a cinco (5). Este nuevo valor es homogéneo con el puntaje cualitativo de la casilla anterior y permite computar los dos valores.

Por último se obtiene el promedio final entre los resultados obtenidos en la evaluación cualitativa y la evaluación cuantitativa (escalada de 0 a 5). Se suma y se divide entre dos. Así se obtienen los resultados de Fluidez Discursiva Oral Integral que aparecen en la fila de promedio total. 
Tabla 22: Resultados evaluación integral. Informantes $1 D-6 M$

\begin{tabular}{|c|c|c|c|c|c|c|c|}
\hline & INDICADORES / INFORMANTE & 1D & $2 \mathrm{R}$ & $3 \mathrm{~L}$ & $4 J \mathrm{C}$ & $5 G$ & $6 \mathrm{M}$ \\
\hline 1 & HABILIDADES SUPERESTRUCTURA NARRATIVA & & & & & & \\
\hline 1 & Caracterización de personajes & 2 & 3 & 2 & 2 & 1 & 2 \\
\hline 2 & Desarrollo de acciones (cambio de estado) & 0 & 5 & 0 & 0 & 0 & 0 \\
\hline 3 & Presencia de estructura narrativa & 1 & 3 & 1 & 1 & 1 & 1 \\
\hline 4 & Creación de un ambiente o entorno & 1 & 4 & 4 & 1 & 0 & 0 \\
\hline II & TEMÁTICA, COHERENCIA GLOBAL & & & & & & \\
\hline 5 & Presencia de un asunto común o tema unitario & 0 & 5 & 0 & 0 & 0 & 0 \\
\hline 6 & Selección adecuada de información & 5 & 5 & 5 & 5 & 0 & 0 \\
\hline 7 & Información suficiente & 5 & 5 & 5 & 0 & 0 & 0 \\
\hline 8 & Información excesiva & 5 & 0 & 5 & 5 & 5 & 5 \\
\hline 9 & Organización lógica de ideas & 1 & 4 & 0 & 1 & 0 & 1 \\
\hline 10 & Progresión temática acertada & 0 & 5 & 5 & 0 & 0 & 0 \\
\hline III & COHERENCIA LOCAL & & & & & & \\
\hline 11 & $\begin{array}{c}\text { Existencia de campos semánticos claramente } \\
\text { definidos }\end{array}$ & 0 & 5 & 0 & 0 & 0 & 0 \\
\hline 12 & Presencia de redes isotópicas & 0 & 5 & 0 & 0 & 0 & 0 \\
\hline 13 & Enunciados claros y no contradictorios & 4 & 4 & 3 & 0 & 4 & 1 \\
\hline 14 & Enunciados pertinentes & 4 & 4 & 4 & 0 & 1 & 1 \\
\hline IV & COHESIÓN & & & & & & \\
\hline 15 & Enlace secuencial de los hechos & 0 & 4 & 1 & 0 & 0 & 0 \\
\hline 16 & Presencia de conectores de discurso & 0 & 3 & 1 & 1 & 0 & 1 \\
\hline 17 & Presencia de enlaces anafóricos y catafóricos & 1 & 3 & 1 & 1 & 0 & 1 \\
\hline V & EVALUACIÓN & & & & & & \\
\hline 18 & $\begin{array}{l}\text { Presencia de juicios de valor acerca de los } \\
\text { hechos narrados }\end{array}$ & 0 & 5 & 5 & 0 & 0 & 0 \\
\hline 19 & $\begin{array}{l}\text { Presencia de juicios de valor acerca del } \\
\text { discurso }\end{array}$ & 0 & 0 & 0 & 0 & 0 & 0 \\
\hline 20 & $\begin{array}{c}\text { Presencia de expresiones valorativas: } \\
\text { Intensificadores, Comparadores, Correlativos, } \\
\text { Explicativos, Atenuantes. }\end{array}$ & 0 & 5 & 5 & 0 & 0 & 0 \\
\hline 21 & Entonación enfática & 0 & 0 & 0 & 0 & 0 & 0 \\
\hline $\mathrm{VI}$ & CONTEXTUALIZACIÓN & & & & & & \\
\hline 22 & Uso de deícticos gramaticales & 2 & 2 & 0 & 2 & 1 & 1 \\
\hline 23 & Referencias a lugares, personas o fechas & 4 & 3 & 4 & 2 & 2 & 3 \\
\hline 1 & TOTALES & & & & & & \\
\hline 1 & SUMATORIA & 35 & 82 & 51 & 21 & 15 & 17 \\
\hline 2 & PROMEDIO CUALITATIVO & 1,52 & 3,57 & 2,22 & 0,91 & 0,65 & 0,74 \\
\hline II & RESULTADOS FINALES & & & & & & \\
\hline \multirow[t]{2}{*}{1} & PROMEDIO CUANTITATIVO & 234.2 & 212.9 & 197.2 & 198.2 & 183.5 & 193.3 \\
\hline & PROMEDIO CUANTITATIVO DE 0 A 5 & 4.34 & 3.94 & 3.65 & 3.67 & 3.40 & 3.58 \\
\hline 2 & PROMEDIO TOTAL & 2.93 & 3.75 & 2.93 & 2.29 & 2.03 & 2.16 \\
\hline
\end{tabular}


Tabla 23: Resultados evaluación integral. Informantes $7 W-12 R$

\begin{tabular}{|c|c|c|c|c|c|c|c|}
\hline & INDICADORES / INFORMANTE & $7 W$ & $8 \mathrm{D}$ & 9DF & $10 R$ & $11 \mathrm{AC}$ & $12 \mathrm{R}$ \\
\hline 1 & HABILIDADES SUPERESTRUCTURA NARRATIVA & & & & & & \\
\hline 1 & Caracterización de personajes & 3 & 3 & 1 & 4 & 5 & 2 \\
\hline 2 & Desarrollo de acciones (cambio de estado) & 0 & 5 & 5 & 5 & 5 & 0 \\
\hline 3 & Presencia de estructura narrativa & 1 & 2 & 2 & 3 & 4 & 0 \\
\hline 4 & Creación de un ambiente o entorno & 1 & 3 & 4 & 4 & 5 & 0 \\
\hline ॥ & TEMÁTICA, COHERENCIA GLOBAL & & & & & & \\
\hline 5 & Presencia de un asunto común o tema unitario & 0 & 5 & 5 & 5 & 5 & 5 \\
\hline 6 & Selección adecuada de información & 5 & 5 & 5 & 5 & 5 & 5 \\
\hline 7 & Información suficiente & 5 & 5 & 5 & 5 & 5 & 0 \\
\hline 8 & Información excesiva & 5 & 5 & 5 & 0 & 5 & 5 \\
\hline 9 & Organización lógica de ideas & 2 & 2 & 0 & 0 & 3 & 3 \\
\hline 10 & Progresión temática acertada & 0 & 5 & 5 & 5 & 5 & 0 \\
\hline III & COHERENCIA LOCAL & & & & & & \\
\hline 11 & $\begin{array}{l}\text { Existencia de campos semánticos claramente } \\
\text { definidos }\end{array}$ & 5 & 5 & 5 & 5 & 5 & 0 \\
\hline 12 & Presencia de redes isotópicas & 5 & 5 & 5 & 5 & 5 & 0 \\
\hline 13 & Enunciados claros y no contradictorios & 4 & 3 & 0 & 0 & 3 & 0 \\
\hline 14 & Enunciados pertinentes & 4 & 4 & 4 & 1 & 4 & 0 \\
\hline IV & COHESIÓN & & & & & & \\
\hline 15 & Enlace secuencial de los hechos & 0 & 3 & 3 & 2 & 3 & 0 \\
\hline 16 & Presencia de conectores de discurso & 0 & 3 & 2 & 4 & 2 & 3 \\
\hline 17 & Presencia de enlaces anafóricos y catafóricos & 2 & 2 & 1 & 2 & 4 & 3 \\
\hline $\mathrm{V}$ & EVALUACIÓN & & & & & & \\
\hline 18 & $\begin{array}{l}\text { Presencia de juicios de valor acerca de los } \\
\text { hechos narrados }\end{array}$ & 5 & 5 & 5 & 5 & 5 & 5 \\
\hline 19 & $\begin{array}{l}\text { Presencia de juicios de valor acerca del } \\
\text { discurso }\end{array}$ & 0 & 0 & 0 & 0 & 5 & 0 \\
\hline 20 & $\begin{array}{c}\text { Presencia de expresiones valorativas: } \\
\text { Intensificadores, Comparadores, Correlativos, } \\
\text { Explicativos, Atenuantes. }\end{array}$ & 0 & 5 & 5 & 5 & 5 & 5 \\
\hline 21 & Entonación enfática & 0 & 0 & 0 & 0 & 5 & 0 \\
\hline VI & CONTEXTUALIZACIÓN & & & & & & \\
\hline 22 & Uso de deícticos gramaticales & 0 & 2 & 0 & 2 & 4 & 3 \\
\hline 23 & Referencias a lugares, personas o fechas & 3 & 3 & 4 & 4 & 4 & 2 \\
\hline 1 & TOTALES & & & & & & \\
\hline 1 & SUMATORIA & 50 & 80 & 71 & 71 & 101 & 41 \\
\hline 2 & PROMEDIO CUALITATIVO & 2.17 & 3.48 & 3.09 & 3.09 & 4.39 & 1.78 \\
\hline II & RESULTADOS FINALES & & & & & & \\
\hline \multirow[t]{2}{*}{1} & PROMEDIO CUANTITATIVO & 230.0 & 221.5 & 147.5 & 138.2 & 182.7 & 157.1 \\
\hline & PROMEDIO CUANTITATIVO DE 0 A 5 & 4.26 & 4.10 & 2.73 & 2.56 & 3.38 & 2.91 \\
\hline 2 & PROMEDIO TOTAL & 3.22 & 3.79 & 2.91 & 2.82 & 3.89 & 2.35 \\
\hline
\end{tabular}


Tabla 24: Resultados evaluación integral. Informantes $13 H-18 C R$

\begin{tabular}{|c|c|c|c|c|c|c|c|}
\hline & INDICADORES / INFORMANTE & $13 \mathrm{H}$ & 14AM & 15MG & $16 \mathrm{MC}$ & 17DM & $18 \mathrm{CR}$ \\
\hline I & HABILIDADES SUPERESTRUCTURA NARRATIVA & & & & & & \\
\hline 1 & Caracterización de personajes & 2 & 5 & 5 & 3 & 2 & 3 \\
\hline 2 & Desarrollo de acciones (cambio de estado) & 0 & 5 & 5 & 5 & 5 & 5 \\
\hline 3 & Presencia de estructura narrativa & 2 & 1 & 1 & 2 & 0 & 2 \\
\hline 4 & Creación de un ambiente o entorno & 3 & 5 & 1 & 3 & 2 & 4 \\
\hline II & TEMÁTICA, COHERENCIA GLOBAL & & & & & & \\
\hline 5 & Presencia de un asunto común o tema unitario & 5 & 5 & 0 & 5 & 0 & 5 \\
\hline 6 & Selección adecuada de información & 0 & 5 & 0 & 5 & 5 & 5 \\
\hline 7 & Información suficiente & 0 & 5 & 5 & 5 & 5 & 5 \\
\hline 8 & Información excesiva & 0 & 5 & 0 & 5 & 0 & 5 \\
\hline 9 & Organización lógica de ideas & 0 & 3 & 0 & 2 & 2 & 3 \\
\hline 10 & Progresión temática acertada & 0 & 5 & 0 & 5 & 5 & 5 \\
\hline III & COHERENCIA LOCAL & & & & & & \\
\hline 11 & $\begin{array}{c}\text { Existencia de campos semánticos claramente } \\
\text { definidos }\end{array}$ & 5 & 5 & 5 & 5 & 5 & 5 \\
\hline 12 & Presencia de redes isotópicas & 5 & 5 & 5 & 5 & 5 & 5 \\
\hline 13 & Enunciados claros y no contradictorios & 2 & 3 & 1 & 3 & 2 & 3 \\
\hline 14 & Enunciados pertinentes & 2 & 3 & 3 & 2 & 2 & 4 \\
\hline IV & COHESIÓN & & & & & & \\
\hline 15 & Enlace secuencial de los hechos & 0 & 3 & 0 & 2 & 2 & 3 \\
\hline 16 & Presencia de conectores de discurso & 2 & 3 & 3 & 3 & 2 & 2 \\
\hline 17 & Presencia de enlaces anafóricos y catafóricos & 3 & 3 & 2 & 1 & 3 & 2 \\
\hline $\mathrm{V}$ & EVALUACIÓN & & & & & & \\
\hline 18 & $\begin{array}{c}\text { Presencia de juicios de valor acerca de los } \\
\text { hechos narrados }\end{array}$ & 0 & 5 & 5 & 5 & 5 & 5 \\
\hline 19 & $\begin{array}{l}\text { Presencia de juicios de valor acerca del } \\
\text { discurso }\end{array}$ & 0 & 0 & 0 & 5 & 5 & 0 \\
\hline 20 & $\begin{array}{c}\text { Presencia de expresiones valorativas: } \\
\text { Intensificadores, Comparadores, Correlativos, } \\
\text { Explicativos, Atenuantes. }\end{array}$ & 0 & 5 & 5 & 5 & 5 & 5 \\
\hline 21 & Entonación enfática & 0 & 0 & 5 & 0 & 0 & 0 \\
\hline VI & CONTEXTUALIZACIÓN & & & & & & \\
\hline 22 & Uso de deícticos gramaticales & 2 & 2 & 1 & 2 & 2 & 2 \\
\hline 23 & Referencias a lugares, personas o fechas & 4 & 4 & 4 & 4 & 1 & 4 \\
\hline 1 & TOTALES & & & & & & \\
\hline 1 & SUMATORIA & 37 & 85 & 56 & 82 & 65 & 82 \\
\hline 2 & PROMEDIO CUALITATIVO & 1.61 & 3.70 & 2.43 & 3.57 & 2.83 & 3.57 \\
\hline II & RESULTADOS FINALES & & & & & & \\
\hline \multirow[t]{2}{*}{1} & PROMEDIO CUANTITATIVO & 163.1 & 148.8 & 130.0 & 39.7 & 129.5 & 176.2 \\
\hline & PROMEDIO CUANTITATIVO DE 0 A 5 & 3.02 & 2.76 & 2.41 & 0.74 & 2.40 & 3.26 \\
\hline 2 & PROMEDIO TOTAL & 2.31 & 3.23 & 2.42 & 2.15 & 2.61 & 3.41 \\
\hline
\end{tabular}


Tabla 25: Resultados evaluación integral. Informantes 19MR - 24VV

\begin{tabular}{|c|c|c|c|c|c|c|c|}
\hline & INDICADORES / INFORMANTE & 19MR & $20 \mathrm{MC}$ & $21 \mathrm{~A}$ & 22MP & $23 L R$ & $24 \mathrm{VV}$ \\
\hline 1 & HABILIDADES SUPERESTRUCTURA NARRATIVA & & & & & & \\
\hline 1 & Caracterización de personajes & 1 & 2 & 4 & 2 & 3 & 3 \\
\hline 2 & Desarrollo de acciones (cambio de estado) & 5 & 5 & 5 & 0 & 5 & 5 \\
\hline 3 & Presencia de estructura narrativa & 2 & 2 & 2 & 1 & 4 & 2 \\
\hline 4 & Creación de un ambiente o entorno & 3 & 3 & 5 & 2 & 4 & 3 \\
\hline II & TEMÁTICA, COHERENCIA GLOBAL & & & & & & \\
\hline 5 & Presencia de un asunto común o tema unitario & 0 & 5 & 5 & 0 & 5 & 5 \\
\hline 6 & Selección adecuada de información & 0 & 5 & 5 & 0 & 5 & 5 \\
\hline 7 & Información suficiente & 5 & 5 & 5 & 5 & 5 & 5 \\
\hline 8 & Información excesiva & 0 & 0 & 0 & 0 & 0 & 0 \\
\hline 9 & Organización lógica de ideas & 2 & 1 & 3 & 2 & 2 & 2 \\
\hline 10 & Progresión temática acertada & 0 & 2 & 5 & 5 & 5 & 5 \\
\hline III & COHERENCIA LOCAL & & & & & & \\
\hline 11 & $\begin{array}{c}\text { Existencia de campos semánticos claramente } \\
\text { definidos }\end{array}$ & 5 & 5 & 5 & 5 & 5 & 5 \\
\hline 12 & Presencia de redes isotópicas & 5 & 5 & 5 & 5 & 5 & 5 \\
\hline 13 & Enunciados claros y no contradictorios & 3 & 1 & 3 & 2 & 3 & 2 \\
\hline 14 & Enunciados pertinentes & 2 & 2 & 3 & 2 & 3 & 2 \\
\hline IV & COHESIÓN & & & & & & \\
\hline 15 & Enlace secuencial de los hechos & 0 & 1 & 3 & 1 & 3 & 2 \\
\hline 16 & Presencia de conectores de discurso & 3 & 3 & 3 & 1 & 3 & 3 \\
\hline 17 & Presencia de enlaces anafóricos y catafóricos & 4 & 1 & 3 & 2 & 2 & 2 \\
\hline $\mathrm{V}$ & EVALUACIÓN & & & & & & \\
\hline 18 & $\begin{array}{c}\text { Presencia de juicios de valor acerca de los } \\
\text { hechos narrados }\end{array}$ & 5 & 5 & 5 & 5 & 5 & 5 \\
\hline 19 & $\begin{array}{l}\text { Presencia de juicios de valor acerca del } \\
\text { discurso }\end{array}$ & 0 & 0 & 0 & 0 & 0 & 0 \\
\hline 20 & $\begin{array}{c}\text { Presencia de expresiones valorativas: } \\
\text { Intensificadores, Comparadores, Correlativos, } \\
\text { Explicativos, Atenuantes. }\end{array}$ & 5 & 5 & 5 & 5 & 5 & 5 \\
\hline 21 & Entonación enfática & 5 & 0 & 5 & 0 & 5 & 0 \\
\hline VI & CONTEXTUALIZACIÓN & & & & & & \\
\hline 22 & Uso de deícticos gramaticales & 4 & 2 & 4 & 3 & 4 & 3 \\
\hline 23 & Referencias a lugares, personas o fechas & 4 & 3 & 4 & 3 & 4 & 4 \\
\hline 1 & TOTALES & & & & & & \\
\hline 1 & SUMATORIA & 63 & 63 & 87 & 51 & 85 & 73 \\
\hline 2 & PROMEDIO CUALITATIVO & 2.74 & 2.74 & 3.78 & 2.22 & 3.70 & 3.17 \\
\hline II & RESULTADOS FINALES & & & & & & \\
\hline \multirow[t]{2}{*}{1} & PROMEDIO CUANTITATIVO & 80.3 & 169.7 & 177.6 & 150.7 & 127.3 & 172.4 \\
\hline & PROMEDIO CUANTITATIVO DE 0 A 5 & 1.49 & 3.14 & 3.29 & 2.79 & 2.36 & 3.19 \\
\hline 2 & PROMEDIO TOTAL & 2.11 & 2.94 & 3.54 & 2.50 & 3.03 & 3.18 \\
\hline
\end{tabular}


Tabla 26: Resultados evaluación integral. Informantes $25 A L-30 D$

\begin{tabular}{|c|c|c|c|c|c|c|c|}
\hline & INDICADORES / INFORMANTE & $25 A L$ & 26AQ & $27 \mathrm{MC}$ & $28 \mathrm{JV}$ & $29 P$ & $30 \mathrm{D}$ \\
\hline 1 & HABILIDADES SUPERESTRUCTURA NARRATIVA & & & & & & \\
\hline 1 & Caracterización de personajes & 3 & 3 & 2 & 4 & 5 & 3 \\
\hline 2 & Desarrollo de acciones (cambio de estado) & 5 & 5 & 5 & 5 & 5 & 5 \\
\hline 3 & Presencia de estructura narrativa & 2 & 3 & 1 & 3 & 2 & 2 \\
\hline 4 & Creación de un ambiente o entorno & 3 & 3 & 1 & 3 & 3 & 3 \\
\hline II & TEMÁTICA, COHERENCIA GLOBAL & & & & & & \\
\hline 5 & Presencia de un asunto común o tema unitario & 5 & 5 & 5 & 5 & 5 & 5 \\
\hline 6 & Selección adecuada de información & 5 & 5 & 0 & 5 & 5 & 5 \\
\hline 7 & Información suficiente & 5 & 5 & 5 & 5 & 5 & 5 \\
\hline 8 & Información excesiva & 0 & 5 & 0 & 5 & 0 & 5 \\
\hline 9 & Organización lógica de ideas & 2 & 3 & 0 & 3 & 2 & 3 \\
\hline 10 & Progresión temática acertada & 0 & 5 & 0 & 5 & 5 & 5 \\
\hline III & COHERENCIA LOCAL & & & & & & \\
\hline 11 & $\begin{array}{l}\text { Existencia de campos semánticos claramente } \\
\text { definidos }\end{array}$ & 5 & 5 & 5 & 5 & 5 & 5 \\
\hline 12 & Presencia de redes isotópicas & 5 & 5 & 5 & 5 & 5 & 5 \\
\hline 13 & Enunciados claros y no contradictorios & 2 & 3 & 2 & 3 & 2 & 3 \\
\hline 14 & Enunciados pertinentes & 1 & 3 & 2 & 3 & 2 & 3 \\
\hline IV & COHESIÓN & & & & & & \\
\hline 15 & Enlace secuencial de los hechos & 2 & 4 & 2 & 3 & 3 & 3 \\
\hline 16 & Presencia de conectores de discurso & 2 & 2 & 3 & 2 & 2 & 2 \\
\hline 17 & Presencia de enlaces anafóricos y catafóricos & 1 & 1 & 1 & 1 & 2 & 2 \\
\hline V & EVALUACIÓN & & & & & & \\
\hline 18 & $\begin{array}{l}\text { Presencia de juicios de valor acerca de los } \\
\text { hechos narrados }\end{array}$ & 5 & 5 & 5 & 5 & 5 & 5 \\
\hline 19 & $\begin{array}{c}\text { Presencia de juicios de valor acerca del } \\
\text { discurso }\end{array}$ & 0 & 5 & 0 & 0 & 0 & 0 \\
\hline 20 & $\begin{array}{c}\text { Presencia de expresiones valorativas: } \\
\text { Intensificadores, Comparadores, Correlativos, } \\
\text { Explicativos, Atenuantes. }\end{array}$ & 5 & 5 & 5 & 5 & 5 & 5 \\
\hline 21 & Entonación enfática & 0 & 0 & 0 & 5 & 5 & 0 \\
\hline $\mathrm{VI}$ & CONTEXTUALIZACIÓN & & & & & & \\
\hline 22 & Uso de deícticos gramaticales & 1 & 2 & 3 & 3 & 4 & 3 \\
\hline 23 & Referencias a lugares, personas o fechas & 2 & 4 & 3 & 4 & 4 & 3 \\
\hline 1 & TOTALES & & & & & & \\
\hline 1 & SUMATORIA & 61 & 86 & 55 & 87 & 81 & 80 \\
\hline 2 & PROMEDIO CUALITATIVO & 2.65 & 3.74 & 2.39 & 3.78 & 3.52 & 3.48 \\
\hline II & RESULTADOS FINALES & & & & & & \\
\hline \multirow[t]{2}{*}{1} & PROMEDIO CUANTITATIVO & 219.0 & 171.8 & 46.0 & 170.3 & 124.8 & 163.7 \\
\hline & PROMEDIO CUANTITATIVO DE 0 A 5 & 4.05 & 3.18 & 0.85 & 3.15 & 2.31 & 3.03 \\
\hline 2 & PROMEDIO TOTAL & 3.35 & 3.46 & 1.62 & 3.47 & 2.92 & 3.26 \\
\hline
\end{tabular}


Tabla 27: Resultados evaluación integral. Informantes $31 \mathrm{~J}-36 \mathrm{C}$

\begin{tabular}{|c|c|c|c|c|c|c|c|}
\hline & INDICADORES / INFORMANTE & $31 \mathrm{~J}$ & 32JMC & $33 \mathrm{H}$ & $34 \mathrm{M}$ & $35 \mathrm{R}$ & $36 \mathrm{C}$ \\
\hline 1 & HABILIDADES SUPERESTRUCTURA NARRATIVA & & & & & & \\
\hline 1 & Caracterización de personajes & 3 & 4 & 4 & 3 & 4 & 1 \\
\hline 2 & Desarrollo de acciones (cambio de estado) & 5 & 5 & 5 & 5 & 5 & 0 \\
\hline 3 & Presencia de estructura narrativa & 3 & 3 & 3 & 2 & 2 & 1 \\
\hline 4 & Creación de un ambiente o entorno & 4 & 4 & 2 & 3 & 3 & 1 \\
\hline II & TEMÁTICA, COHERENCIA GLOBAL & & & & & & \\
\hline 5 & Presencia de un asunto común o tema unitario & 5 & 5 & 5 & 5 & 5 & 0 \\
\hline 6 & Selección adecuada de información & 5 & 5 & 5 & 5 & 5 & 5 \\
\hline 7 & Información suficiente & 5 & 5 & 5 & 5 & 5 & 0 \\
\hline 8 & Información excesiva & 5 & 5 & 5 & 5 & 5 & 5 \\
\hline 9 & Organización lógica de ideas & 3 & 3 & 3 & 2 & 2 & 1 \\
\hline 10 & Progresión temática acertada & 5 & 5 & 5 & 5 & 5 & 5 \\
\hline III & COHERENCIA LOCAL & & & & & & \\
\hline 11 & $\begin{array}{l}\text { Existencia de campos semánticos claramente } \\
\text { definidos }\end{array}$ & 5 & 5 & 5 & 5 & 5 & 5 \\
\hline 12 & Presencia de redes isotópicas & 5 & 5 & 5 & 5 & 5 & 5 \\
\hline 13 & Enunciados claros y no contradictorios & 3 & 3 & 2 & 2 & 2 & 1 \\
\hline 14 & Enunciados pertinentes & 2 & 3 & 3 & 3 & 3 & 3 \\
\hline IV & COHESIÓN & & & & & & \\
\hline 15 & Enlace secuencial de los hechos & 3 & 3 & 3 & 2 & 2 & 0 \\
\hline 16 & Presencia de conectores de discurso & 3 & 2 & 2 & 2 & 3 & 3 \\
\hline 17 & Presencia de enlaces anafóricos y catafóricos & 1 & 2 & 0 & 2 & 3 & 3 \\
\hline $\mathrm{V}$ & EVALUACIÓN & & & & & & \\
\hline 18 & $\begin{array}{c}\text { Presencia de juicios de valor acerca de los } \\
\text { hechos narrados }\end{array}$ & 5 & 5 & 5 & 5 & 5 & 5 \\
\hline 19 & $\begin{array}{l}\text { Presencia de juicios de valor acerca del } \\
\text { discurso }\end{array}$ & 0 & 0 & 0 & 0 & 0 & 0 \\
\hline 20 & $\begin{array}{c}\text { Presencia de expresiones valorativas: } \\
\text { Intensificadores, Comparadores, Correlativos, } \\
\text { Explicativos, Atenuantes. }\end{array}$ & 5 & 5 & 5 & 5 & 0 & 5 \\
\hline 21 & Entonación enfática & 5 & 5 & 0 & 5 & 0 & 0 \\
\hline $\mathrm{VI}$ & CONTEXTUALIZACIÓN & & & & & & \\
\hline 22 & Uso de deícticos gramaticales & 3 & 4 & 4 & 4 & 2 & 3 \\
\hline 23 & Referencias a lugares, personas o fechas & 4 & 3 & 3 & 1 & 2 & 0 \\
\hline 1 & TOTALES & & & & & & \\
\hline 1 & SUMATORIA & 87 & 89 & 79 & 81 & 73 & 52 \\
\hline 2 & PROMEDIO CUALITATIVO & 3.78 & 3.87 & 3.43 & 3.52 & 3.17 & 2.26 \\
\hline II & RESULTADOS FINALES & & & & & & \\
\hline \multirow[t]{2}{*}{1} & PROMEDIO CUANTITATIVO & 219.0 & 171.8 & 46.0 & 170.3 & 124.8 & 163.7 \\
\hline & PROMEDIO CUANTITATIVO DE 0 A 5 & 4.05 & 3.18 & 0.85 & 3.15 & 2.31 & 3.03 \\
\hline 2 & PROMEDIO TOTAL & 3.35 & 3.46 & 1.62 & 3.47 & 2.92 & 3.26 \\
\hline
\end{tabular}


Tabla 28: Resultados evaluación integral. Informantes $37 C M-42 R$

\begin{tabular}{|c|c|c|c|c|c|c|c|}
\hline & INDICADORES / INFORMANTE & $37 \mathrm{CM}$ & $38 \mathrm{M}$ & $39 \mathrm{H}$ & 40T & 415 & $42 R$ \\
\hline 1 & HABILIDADES SUPERESTRUCTURA NARRATIVA & & & & & & \\
\hline 1 & Caracterización de personajes & 4 & 1 & 1 & 1 & 1 & 1 \\
\hline 2 & Desarrollo de acciones (cambio de estado) & 0 & 0 & 5 & 0 & 5 & 0 \\
\hline 3 & Presencia de estructura narrativa & 0 & 0 & 3 & 0 & 1 & 2 \\
\hline 4 & Creación de un ambiente o entorno & 3 & 1 & 3 & 1 & 1 & 1 \\
\hline II & TEMÁTICA, COHERENCIA GLOBAL & & & & & & \\
\hline 5 & Presencia de un asunto común o tema unitario & 0 & 0 & 0 & 0 & 0 & 0 \\
\hline 6 & Selección adecuada de información & 5 & 5 & 5 & 0 & 0 & 0 \\
\hline 7 & Información suficiente & 0 & 0 & 5 & 0 & 0 & 0 \\
\hline 8 & Información excesiva & 5 & 5 & 0 & 5 & 5 & 0 \\
\hline 9 & Organización lógica de ideas & 3 & 2 & 3 & 0 & 1 & 0 \\
\hline 10 & Progresión temática acertada & 0 & 0 & 5 & 0 & 0 & 0 \\
\hline III & COHERENCIA LOCAL & & & & & & \\
\hline 11 & $\begin{array}{c}\text { Existencia de campos semánticos claramente } \\
\text { definidos }\end{array}$ & 5 & 0 & 5 & 0 & 0 & 5 \\
\hline 12 & Presencia de redes isotópicas & 5 & 0 & 5 & 0 & 0 & 0 \\
\hline 13 & Enunciados claros y no contradictorios & 4 & 3 & 4 & 2 & 1 & 2 \\
\hline 14 & Enunciados pertinentes & 4 & 2 & 4 & 3 & 2 & 2 \\
\hline IV & COHESIÓN & & & & & & \\
\hline 15 & Enlace secuencial de los hechos & 1 & 0 & 3 & 1 & 1 & 3 \\
\hline 16 & Presencia de conectores de discurso & 1 & 0 & 3 & 4 & 1 & 1 \\
\hline 17 & Presencia de enlaces anafóricos y catafóricos & 2 & 1 & 4 & 3 & 3 & 1 \\
\hline V & EVALUACIÓN & & & & & & \\
\hline 18 & $\begin{array}{c}\text { Presencia de juicios de valor acerca de los } \\
\text { hechos narrados }\end{array}$ & 5 & 0 & 5 & 5 & 5 & 5 \\
\hline 19 & $\begin{array}{l}\text { Presencia de juicios de valor acerca del } \\
\text { discurso }\end{array}$ & 0 & 0 & 0 & 0 & 0 & 0 \\
\hline 20 & $\begin{array}{c}\text { Presencia de expresiones valorativas: } \\
\text { Intensificadores, Comparadores, Correlativos, } \\
\text { Explicativos, Atenuantes. }\end{array}$ & 5 & 5 & 5 & 5 & 0 & 0 \\
\hline 21 & Entonación enfática & 0 & 5 & 5 & 0 & 5 & 0 \\
\hline VI & CONTEXTUALIZACIÓN & & & & & & \\
\hline 22 & Uso de deícticos gramaticales & 3 & 1 & 4 & 2 & 4 & 2 \\
\hline 23 & Referencias a lugares, personas o fechas & 0 & 0 & 0 & 0 & 4 & 4 \\
\hline 1 & TOTALES & & & & & & \\
\hline 1 & SUMATORIA & 55 & 31 & 77 & 32 & 40 & 29 \\
\hline 2 & PROMEDIO CUALITATIVO & 2.39 & 1.35 & 3.35 & 1.39 & 1.74 & 1.26 \\
\hline ॥ & RESULTADOS FINALES & & & & & & \\
\hline \multirow[t]{2}{*}{1} & PROMEDIO CUANTITATIVO & 144.0 & 122.0 & 211.3 & 128.8 & 125.7 & 209.2 \\
\hline & PROMEDIO CUANTITATIVO DE 0 A 5 & 2.67 & 2.26 & 3.91 & 2.39 & 2.33 & 3.87 \\
\hline 2 & PROMEDIO TOTAL & 2.53 & 1.80 & 3.63 & 1.89 & 2.03 & 2.57 \\
\hline
\end{tabular}


Tabla 29: Resultados evaluación integral. Informantes $43 E-48 L$

\begin{tabular}{|c|c|c|c|c|c|c|c|}
\hline & INDICADORES / INFORMANTE & $43 \mathrm{E}$ & $44 \mathrm{C}$ & $45 \mathrm{~A}$ & $46 \mathrm{JB}$ & 471 & $48 \mathrm{~L}$ \\
\hline 1 & HABILIDADES SUPERESTRUCTURA NARRATIVA & & & & & & \\
\hline 1 & Caracterización de personajes & 1 & 1 & 1 & 5 & 1 & 3 \\
\hline 2 & Desarrollo de acciones (cambio de estado) & 0 & 5 & 0 & 5 & 5 & 5 \\
\hline 3 & Presencia de estructura narrativa & 0 & 3 & 1 & 3 & 1 & 3 \\
\hline 4 & Creación de un ambiente o entorno & 1 & 1 & 1 & 2 & 2 & 3 \\
\hline II & TEMÁTICA, COHERENCIA GLOBAL & & & & & & \\
\hline 5 & Presencia de un asunto común o tema unitario & 0 & 0 & 0 & 0 & 5 & 5 \\
\hline 6 & Selección adecuada de información & 0 & 5 & 5 & 5 & 0 & 5 \\
\hline 7 & Información suficiente & 0 & 5 & 0 & 5 & 0 & 0 \\
\hline 8 & Información excesiva & 5 & 5 & 5 & 5 & 5 & 5 \\
\hline 9 & Organización lógica de ideas & 1 & 4 & 0 & 5 & 2 & 3 \\
\hline 10 & Progresión temática acertada & 0 & 5 & 0 & 5 & 5 & 3 \\
\hline III & COHERENCIA LOCAL & & & & & & \\
\hline 11 & $\begin{array}{c}\text { Existencia de campos semánticos claramente } \\
\text { definidos }\end{array}$ & 0 & 5 & 0 & 0 & 5 & 5 \\
\hline 12 & Presencia de redes isotópicas & 0 & 5 & 0 & 0 & 5 & 5 \\
\hline 13 & Enunciados claros y no contradictorios & 3 & 3 & 4 & 3 & 2 & 2 \\
\hline 14 & Enunciados pertinentes & 4 & 2 & 3 & 4 & 2 & 2 \\
\hline IV & COHESIÓN & & & & & & \\
\hline 15 & Enlace secuencial de los hechos & 1 & 3 & 0 & 3 & 2 & 2 \\
\hline 16 & Presencia de conectores de discurso & 1 & 3 & 0 & 3 & 1 & 2 \\
\hline 17 & Presencia de enlaces anafóricos y catafóricos & 3 & 4 & 3 & 3 & 2 & 2 \\
\hline V & EVALUACIÓN & & & & & & \\
\hline 18 & $\begin{array}{c}\text { Presencia de juicios de valor acerca de los } \\
\text { hechos narrados }\end{array}$ & 5 & 5 & 5 & 5 & 5 & 5 \\
\hline 19 & $\begin{array}{l}\text { Presencia de juicios de valor acerca del } \\
\text { discurso }\end{array}$ & 0 & 0 & 0 & 0 & 0 & 0 \\
\hline 20 & $\begin{array}{c}\text { Presencia de expresiones valorativas: } \\
\text { Intensificadores, Comparadores, Correlativos, } \\
\text { Explicativos, Atenuantes. }\end{array}$ & 0 & 5 & 5 & 5 & 5 & 5 \\
\hline 21 & Entonación enfática & 0 & 5 & 0 & 5 & 5 & 0 \\
\hline VI & CONTEXTUALIZACIÓN & & & & & & \\
\hline 22 & Uso de deícticos gramaticales & 1 & 3 & 2 & 3 & 3 & 4 \\
\hline 23 & Referencias a lugares, personas o fechas & 1 & 0 & 4 & 0 & 3 & 4 \\
\hline 1 & TOTALES & & & & & & \\
\hline 1 & SUMATORIA & 27 & 77 & 39 & 74 & 66 & 73 \\
\hline 2 & PROMEDIO CUALITATIVO & 1.17 & 3.35 & 1.70 & 3.22 & 2.87 & 3.17 \\
\hline II & RESULTADOS FINALES & & & & & & \\
\hline \multirow[t]{2}{*}{1} & PROMEDIO CUANTITATIVO & 38.6 & 175.1 & 150.0 & 196.3 & 176.0 & 139.5 \\
\hline & PROMEDIO CUANTITATIVO DE 0 A 5 & 0.71 & 3.24 & 2.78 & 3.64 & 3.26 & 2.58 \\
\hline 2 & PROMEDIO TOTAL & 0.94 & 3.30 & 2.24 & 3.43 & 3.06 & 2.88 \\
\hline
\end{tabular}


Tabla 30: Resultados evaluación integral. Informantes $49 S-54 D M$

\begin{tabular}{|c|c|c|c|c|c|c|c|}
\hline & INDICADORES / INFORMANTE & 495 & 50MA & $51 \mathrm{M}$ & $52 \mathrm{TJ}$ & $53 \mathrm{GH}$ & 54DM \\
\hline 1 & HABILIDADES SUPERESTRUCTURA NARRATIVA & & & & & & \\
\hline 1 & Caracterización de personajes & 3 & 5 & 1 & 2 & 1 & 2 \\
\hline 2 & Desarrollo de acciones (cambio de estado) & 5 & 5 & 0 & 5 & 5 & 5 \\
\hline 3 & Presencia de estructura narrativa & 3 & 4 & 0 & 2 & 0 & 2 \\
\hline 4 & Creación de un ambiente o entorno & 3 & 5 & 2 & 2 & 2 & 2 \\
\hline II & TEMÁTICA, COHERENCIA GLOBAL & & & & & & \\
\hline 5 & Presencia de un asunto común o tema unitario & 5 & 5 & 0 & 5 & 0 & 5 \\
\hline 6 & Selección adecuada de información & 5 & 5 & 0 & 5 & 0 & 5 \\
\hline 7 & Información suficiente & 5 & 5 & 0 & 5 & 5 & 5 \\
\hline 8 & Información excesiva & 5 & 5 & 0 & 5 & 5 & 5 \\
\hline 9 & Organización lógica de ideas & 3 & 4 & 2 & 2 & 1 & 2 \\
\hline 10 & Progresión temática acertada & 5 & 5 & 0 & 5 & 0 & 5 \\
\hline III & COHERENCIA LOCAL & & & & & & \\
\hline 11 & $\begin{array}{c}\text { Existencia de campos semánticos claramente } \\
\text { definidos }\end{array}$ & 5 & 5 & 5 & 5 & 5 & 5 \\
\hline 12 & Presencia de redes isotópicas & 5 & 5 & 5 & 5 & 5 & 5 \\
\hline 13 & Enunciados claros y no contradictorios & 2 & 4 & 2 & 2 & 1 & 2 \\
\hline 14 & Enunciados pertinentes & 3 & 4 & 1 & 3 & 2 & 2 \\
\hline IV & COHESIÓN & & & & & & \\
\hline 15 & Enlace secuencial de los hechos & 3 & 4 & 1 & 3 & 1 & 2 \\
\hline 16 & Presencia de conectores de discurso & 1 & 2 & 2 & 1 & 1 & 1 \\
\hline 17 & Presencia de enlaces anafóricos y catafóricos & 2 & 1 & 2 & 3 & 3 & 0 \\
\hline $\mathrm{V}$ & EVALUACIÓN & & & & & & \\
\hline 18 & $\begin{array}{l}\text { Presencia de juicios de valor acerca de los } \\
\text { hechos narrados }\end{array}$ & 5 & 5 & 5 & 5 & 5 & 5 \\
\hline 19 & $\begin{array}{l}\text { Presencia de juicios de valor acerca del } \\
\text { discurso }\end{array}$ & 0 & 0 & 0 & 0 & 0 & 0 \\
\hline 20 & $\begin{array}{c}\text { Presencia de expresiones valorativas: } \\
\text { Intensificadores, Comparadores, Correlativos, } \\
\text { Explicativos, Atenuantes. }\end{array}$ & 5 & 0 & 5 & 5 & 5 & 5 \\
\hline 21 & Entonación enfática & 0 & 0 & 0 & 5 & 0 & 0 \\
\hline VI & CONTEXTUALIZACIÓN & & & & & & \\
\hline 22 & Uso de deícticos gramaticales & 3 & 4 & 2 & 3 & 3 & 2 \\
\hline 23 & Referencias a lugares, personas o fechas & 2 & 4 & 2 & 3 & 2 & 2 \\
\hline 1 & TOTALES & & & & & & \\
\hline 1 & SUMATORIA & 78 & 86 & 37 & 81 & 52 & 69 \\
\hline 2 & PROMEDIO CUALITATIVO & 3.39 & 3.74 & 1.61 & 3.52 & 2.26 & 3.00 \\
\hline II & RESULTADOS FINALES & & & & & & \\
\hline \multirow[t]{2}{*}{1} & PROMEDIO CUANTITATIVO & 160.6 & 172.5 & 184.2 & 139.0 & 130.8 & 135.4 \\
\hline & PROMEDIO CUANTITATIVO DE 0 A 5 & 2.97 & 3.19 & 3.41 & 2.57 & 2.42 & 2.51 \\
\hline 2 & PROMEDIO TOTAL & 3.18 & 3.47 & 2.51 & 3.05 & 2.34 & 2.75 \\
\hline
\end{tabular}


Tabla 31: Resultados evaluación integral. Informantes 55C-60F

\begin{tabular}{|c|c|c|c|c|c|c|c|}
\hline & INDICADORES / INFORMANTE & $55 \mathrm{C}$ & $56 \mathrm{R}$ & $57 \mathrm{~A}$ & $58 \mathrm{E}$ & 590 & $60 \mathrm{~F}$ \\
\hline 1 & HABILIDADES SUPERESTRUCTURA NARRATIVA & & & & & & \\
\hline 1 & Caracterización de personajes & 2 & 2 & 3 & 3 & 5 & 3 \\
\hline 2 & Desarrollo de acciones (cambio de estado) & 5 & 5 & 5 & 0 & 5 & 5 \\
\hline 3 & Presencia de estructura narrativa & 2 & 2 & 2 & 1 & 5 & 2 \\
\hline 4 & Creación de un ambiente o entorno & 3 & 2 & 3 & 2 & 5 & 3 \\
\hline II & TEMÁTICA, COHERENCIA GLOBAL & & & & & & \\
\hline 5 & Presencia de un asunto común o tema unitario & 5 & 5 & 5 & 0 & 5 & 5 \\
\hline 6 & Selección adecuada de información & 5 & 0 & 0 & 0 & 5 & 5 \\
\hline 7 & Información suficiente & 5 & 5 & 5 & 5 & 5 & 5 \\
\hline 8 & Información excesiva & 5 & 0 & 5 & 5 & 5 & 0 \\
\hline 9 & Organización lógica de ideas & 2 & 2 & 2 & 1 & 3 & 1 \\
\hline 10 & Progresión temática acertada & 5 & 0 & 5 & 0 & 5 & 5 \\
\hline III & COHERENCIA LOCAL & & & & & & \\
\hline 11 & $\begin{array}{c}\text { Existencia de campos semánticos claramente } \\
\text { definidos }\end{array}$ & 5 & 5 & 5 & 5 & 5 & 5 \\
\hline 12 & Presencia de redes isotópicas & 5 & 5 & 5 & 5 & 5 & 5 \\
\hline 13 & Enunciados claros y no contradictorios & 1 & 1 & 1 & 1 & 4 & 2 \\
\hline 14 & Enunciados pertinentes & 3 & 2 & 3 & 2 & 4 & 3 \\
\hline IV & COHESIÓN & & & & & & \\
\hline 15 & Enlace secuencial de los hechos & 3 & 2 & 2 & 1 & 4 & 2 \\
\hline 16 & Presencia de conectores de discurso & 3 & 1 & 2 & 3 & 3 & 2 \\
\hline 17 & Presencia de enlaces anafóricos y catafóricos & 0 & 3 & 2 & 2 & 4 & 2 \\
\hline $\mathrm{V}$ & EVALUACIÓN & & & & & & \\
\hline 18 & $\begin{array}{c}\text { Presencia de juicios de valor acerca de los } \\
\text { hechos narrados }\end{array}$ & 5 & 5 & 5 & 5 & 5 & 5 \\
\hline 19 & $\begin{array}{l}\text { Presencia de juicios de valor acerca del } \\
\text { discurso }\end{array}$ & 0 & 0 & 0 & 0 & 0 & 0 \\
\hline 20 & $\begin{array}{c}\text { Presencia de expresiones valorativas: } \\
\text { Intensificadores, Comparadores, Correlativos, } \\
\text { Explicativos, Atenuantes. }\end{array}$ & 5 & 5 & 5 & 5 & 5 & 5 \\
\hline 21 & Entonación enfática & 0 & 0 & 5 & 5 & 0 & 0 \\
\hline VI & CONTEXTUALIZACIÓN & & & & & & \\
\hline 22 & Uso de deícticos gramaticales & 3 & 4 & 3 & 3 & 4 & 4 \\
\hline 23 & Referencias a lugares, personas o fechas & 1 & 4 & 2 & 1 & 4 & 2 \\
\hline 1 & TOTALES & & & & & & \\
\hline 1 & SUMATORIA & 73 & 60 & 75 & 55 & 95 & 71 \\
\hline 2 & PROMEDIO CUALITATIVO & 3.17 & 2.61 & 3.26 & 2.39 & 4.13 & 3.09 \\
\hline II & RESULTADOS FINALES & & & & & & \\
\hline \multirow[t]{2}{*}{1} & PROMEDIO CUANTITATIVO & 167.6 & 137.3 & 172.7 & 164.7 & 155.7 & 150.2 \\
\hline & PROMEDIO CUANTITATIVO DE 0 A 5 & 3.10 & 2.54 & 3.20 & 3.05 & 2.88 & 2.78 \\
\hline 2 & PROMEDIO TOTAL & 3.14 & 2.58 & 3.23 & 2.72 & 3.51 & 2.93 \\
\hline
\end{tabular}


Tabla 32: Resultados evaluación integral. Informantes 61MJ-66P

\begin{tabular}{|c|c|c|c|c|c|c|c|}
\hline & INDICADORES / INFORMANTE & $61 \mathrm{MJ}$ & $62 \mathrm{P}$ & 63FP & 64AV & $65 T$ & $66 \mathrm{P}$ \\
\hline 1 & HABILIDADES SUPERESTRUCTURA NARRATIVA & & & & & & \\
\hline 1 & Caracterización de personajes & 4 & 2 & 2 & 1 & 3 & 2 \\
\hline 2 & Desarrollo de acciones (cambio de estado) & 5 & 5 & 0 & 0 & 5 & 5 \\
\hline 3 & Presencia de estructura narrativa & 4 & 2 & 2 & 1 & 2 & 2 \\
\hline 4 & Creación de un ambiente o entorno & 4 & 2 & 4 & 1 & 4 & 2 \\
\hline II & TEMÁTICA, COHERENCIA GLOBAL & & & & & & \\
\hline 5 & Presencia de un asunto común o tema unitario & 5 & 0 & 0 & 0 & 5 & 5 \\
\hline 6 & Selección adecuada de información & 5 & 0 & 0 & 5 & 5 & 5 \\
\hline 7 & Información suficiente & 5 & 5 & 5 & 0 & 5 & 0 \\
\hline 8 & Información excesiva & 5 & 0 & 0 & 0 & 5 & 5 \\
\hline 9 & Organización lógica de ideas & 2 & 2 & 2 & 1 & 3 & 3 \\
\hline 10 & Progresión temática acertada & 5 & 0 & 0 & 0 & 5 & 0 \\
\hline III & COHERENCIA LOCAL & & & & & & \\
\hline 11 & $\begin{array}{c}\text { Existencia de campos semánticos claramente } \\
\text { definidos }\end{array}$ & 5 & 5 & 5 & 0 & 5 & 5 \\
\hline 12 & Presencia de redes isotópicas & 5 & 5 & 5 & 0 & 5 & 5 \\
\hline 13 & Enunciados claros y no contradictorios & 3 & 3 & 3 & 1 & 4 & 3 \\
\hline 14 & Enunciados pertinentes & 3 & 3 & 3 & 1 & 2 & 3 \\
\hline IV & COHESIÓN & & & & & & \\
\hline 15 & Enlace secuencial de los hechos & 3 & 2 & 3 & 0 & 3 & 3 \\
\hline 16 & Presencia de conectores de discurso & 3 & 3 & 3 & 1 & 3 & 3 \\
\hline 17 & Presencia de enlaces anafóricos y catafóricos & 3 & 3 & 3 & 2 & 4 & 1 \\
\hline V & EVALUACIÓN & & & & & & \\
\hline 18 & $\begin{array}{c}\text { Presencia de juicios de valor acerca de los } \\
\text { hechos narrados }\end{array}$ & 5 & 5 & 5 & 5 & 5 & 5 \\
\hline 19 & $\begin{array}{l}\text { Presencia de juicios de valor acerca del } \\
\text { discurso }\end{array}$ & 0 & 0 & 0 & 0 & 0 & 0 \\
\hline 20 & $\begin{array}{c}\text { Presencia de expresiones valorativas: } \\
\text { Intensificadores, Comparadores, Correlativos, } \\
\text { Explicativos, Atenuantes. }\end{array}$ & 5 & 5 & 5 & 0 & 5 & 0 \\
\hline 21 & Entonación enfática & 5 & 0 & 5 & 0 & 5 & 0 \\
\hline VI & CONTEXTUALIZACIÓN & & & & & & \\
\hline 22 & Uso de deícticos gramaticales & 3 & 3 & 4 & 1 & 4 & 2 \\
\hline 23 & Referencias a lugares, personas o fechas & 2 & 2 & 3 & 0 & 3 & 2 \\
\hline 1 & TOTALES & & & & & & \\
\hline 1 & SUMATORIA & 89 & 57 & 62 & 20 & 90 & 61 \\
\hline 2 & PROMEDIO CUALITATIVO & 3.87 & 2.48 & 2.70 & 0.87 & 3.91 & 2.65 \\
\hline ॥ & RESULTADOS FINALES & & & & & & \\
\hline \multirow[t]{2}{*}{1} & PROMEDIO CUANTITATIVO & 191.4 & 161.7 & 124.5 & 110.0 & 179.0 & 139.3 \\
\hline & PROMEDIO CUANTITATIVO DE 0 A 5 & 3.54 & 2.99 & 2.31 & 2.04 & 3.31 & 2.58 \\
\hline 2 & PROMEDIO TOTAL & 3.71 & 2.74 & 2.50 & 1.45 & 3.61 & 2.62 \\
\hline
\end{tabular}


7. PROPUESTA 
Con el fin de dar continuidad a este trabajo de investigación, se desarrolla en el presente capítulo una propuesta de aplicación, que permita, de una forma homogénea, evaluar discursos de usuarios. La propuesta podrá ser aplicada en diversos ámbitos profesionales de acuerdo con las necesidades puntuales en cada ámbito.

La propuesta pretende unificar los productos discursivos obtenidos con el fin de poder contar con muestras homogéneas y de esta forma tener resultados más fiables a la hora de evaluar.

\subsection{Objetivo de la prueba}

El objetivo de la propuesta que se presenta en este capítulo es dotar a los profesionales de habla española de una batería actual y sofisticada basada en las teorías lingüísticas, psicolingüísticas y de la lingüística textual para la evaluación integral de la fluidez discursiva oral. Esta batería de evaluación puede ser utilizada por terapeutas del lenguaje, fonoaudiólogos, docentes, psicólogos e investigadores, y en general por todas aquellas personas interesadas en evaluar la producción discursiva oral.

De acuerdo con lo dicho a lo largo del trabajo, la fluidez discursiva oral integra: 1. la fluidez verbal, entendida como el número de palabras por minuto que un hablante es capaz de producir en un contexto discursivo narrativo; 2. la presencia o ausencia de determinados fenómenos en el discurso, tales como: alargamientos, repeticiones, pausas, 
vacilaciones, silencios y enunciados truncados; fenómenos que a veces constituyen disfluencias y a veces muestras positivas de fluidez oral; y 3 . la capacidad del hablante para producir un discurso narrativo.

\subsection{Tarea}

El informante, usuario o paciente debe crear una narración o contar una historia a partir de un grupo de 6 viñetas que se le presentan con antelación. El entrevistadorevaluador debe grabar el discurso del informante y tomar nota de los gestos, reacciones, movimientos y demás elementos que puedan ser útiles para evaluar y complementar el discurso. El informante registra sus datos en la ficha.

El entrevistador puede evaluar la pertinencia de hacer ensayo previo con otro grupo de viñetas para ilustrar al informante o usuario acerca de la tarea solicitada. En ese caso el entrevistador tendrá a la mano el grupo de viñetas que usará para poner el ejemplo a su evaluado.

\section{Gráfico 23: Viñetas para evaluación del discurso}

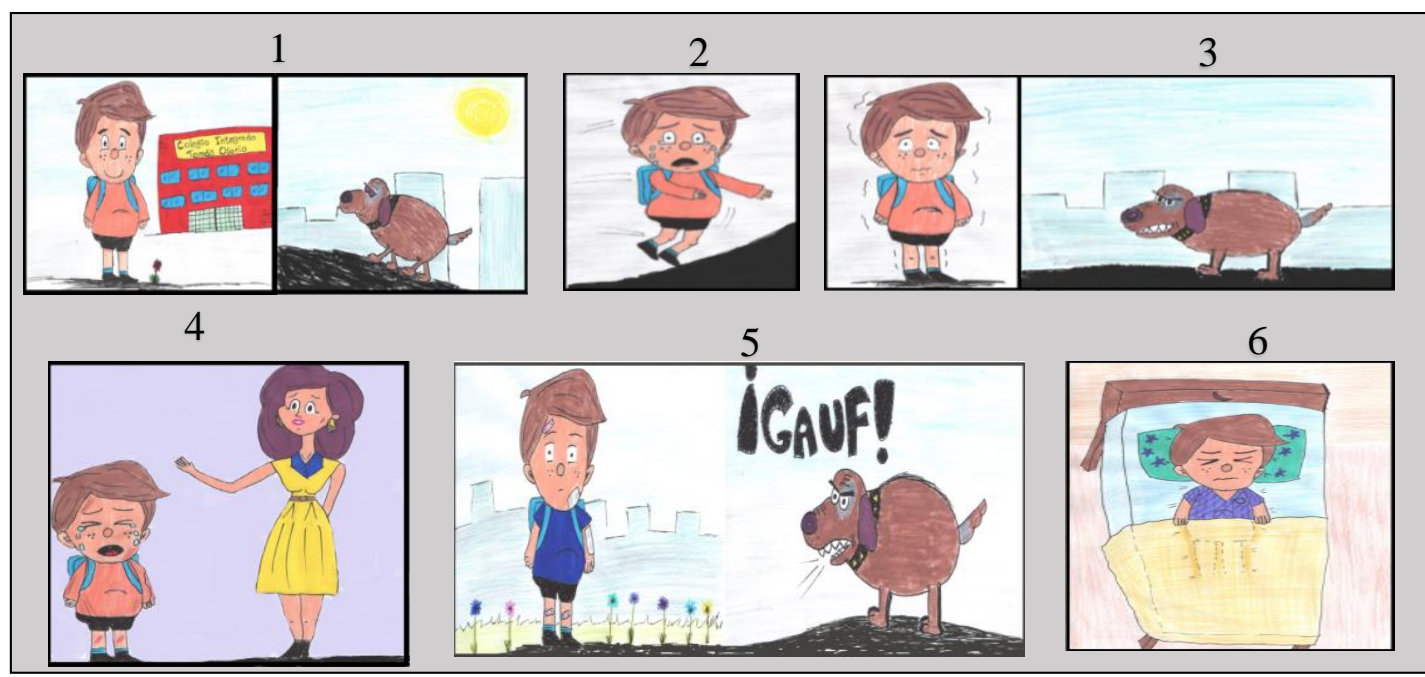




\section{3. ¿A quién va dirigida la prueba?}

A evaluadores o profesores de ELE, quienes la encontrarán útil para aplicarla a niños, adultos, ancianos que vean (videntes). Asimismo, a especialistas médicos para evaluar a pacientes de fonoaudiología, de psicología o de terapia del lenguaje. Se utiliza la palabra "informante" para sustituir "paciente", "alumno" o "usuario", dependiendo de la persona a quien se le aplique la prueba.

\section{4. ¿Cómo convertir la grabación en muestra?}

La conversión de la grabación en corpus escrito facilitará el conteo de palabras y fenómenos para ser incluidos en el cuadro general que va a generar los resultados finales de fluidez discursiva. A continuación se señalan los pasos para transformar la grabación en escrito:

1. Tome nota del tiempo empleado por el informante, o paciente, en la producción de la narración.

2. Escuche la grabación y póngala por escrito usando unas convenciones similares a las expuestas en este trabajo. Incluya en el escrito los rasgos contextuales: gestos, movimientos, etc. 


\subsection{Pasos para evaluar}

1. A través de convenciones, señale los siguientes fenómenos: alargamientos, pausas, silencios (en segundos), silabeo, murmullos, repeticiones, enunciados truncados y coalescencias. Cuente el número de fenómenos positivos y negativos y consigne esta información en la tabla Instrumento de evaluación integral: desglose de la fluidez oral, que aparece al final de este capítulo.

2. Cuente el número de palabras y anote el número de minutos y segundos que dura la emisión. Calcule el promedio de palabras por minuto, el promedio de fenómenos positivos y negativos por minuto, y la fluidez discursiva oral utilizando las siguientes fórmulas:

- $\quad$ Promedio de palabras por minuto $=\frac{\text { número de palabras }}{\text { duración de la emisión }}$

- $\quad$ Promedio de fenómenos por minuto $=\frac{\text { número de fenómenos }}{\text { duración de la emisión }}$

- $\quad$ Fluidez Discursiva Oral =

(promedio de palabras por minuto + fenómenos positivos por minuto - fenómenos negativos por minuto)

Incluya esta información en la tabla Instrumento de evaluación integral: desglose de la fluidez oral, que aparece al final de este capítulo. 
3. Evalúe cualitativamente la producción narrativa utilizando la tabla Instrumento de evaluación integral: habilidades narrativas y resultados finales, que aparece al final de este capítulo. Sume el puntaje de todos los ítems y calcule el valor de fluidez narrativa utilizando la siguiente fórmula:

$$
\text { Fluidez narrativa }=\frac{\text { Sumatoria del puntaje de todos los items }}{23}
$$

Consigne este valor en las filas SUMATORIA y PROMEDIO CUALITATIVO respectivamente de la misma tabla.

4. Incluya el resultado de "Fluidez discursiva oral" obtenido en el paso 2 en la fila PROMEDIO CUANTITATIVO de la tabla Instrumento de evaluación integral: habilidades narrativas y resultados finales, que aparece al final de este capítulo. Aplique la siguiente fórmula para obtener el valor de la fluidez discursiva oral en escala de 0 a 5 :

$$
\operatorname{Pe}=\frac{\operatorname{Pr} \times 5}{270}
$$

Consigne este valor en la fila PROMEDIO CUANTITATIVO DE 0 A 5, de la misma tabla.

5. Calcule el valor de fluidez discursiva oral integral utilizando la siguiente fórmula:

Fluidez Discursiva Oral Integral

$$
=\frac{\text { Fluidez Discursiva Oral }+ \text { Fluidez narrativa }}{2}
$$


Consigne el valor de Fluidez Discursiva Oral Integral en la fila PROMEDIO TOTAL de la tabla Instrumento de evaluación integral: habilidades narrativas y resultados finales.

Verifique el total o producto numérico en unidades de fluidez discursiva oral integral. Recuerde que los resultados están en el rango de cero (0) a cinco (5), donde cinco (5) corresponde al ideal y cero (0) corresponde al mínimo puntaje que un hablante puede obtener.

6. Una vez obtenidos los puntajes puede verificar en qué ítem tiene dificultad el hablante ya que puede tener un excelente dominio de la habilidad para narrar pero fallar en la fluidez verbal o en la presencia constante de disfluencias. El instrumento le permite verificar con precisión cual es la deficiencia o si esta es global en todas las habilidades. 


\begin{tabular}{|c|c|c|}
\hline \multicolumn{2}{|r|}{ FENÓMENOS } & \multirow[t]{2}{*}{ INFORMANTE } \\
\hline & REPETICIONES & \\
\hline 1 & Repeticiones intencionales & \\
\hline 2 & Repeticiones no intencionales & \\
\hline 3 & Repeticiones de sonidos & \\
\hline 4 & Repeticiones silábicas descriptiva & \\
\hline 5 & Repeticiones de inicio de palabra & \\
\hline 6 & Repeticiones en medio de palabra & \\
\hline 7 & Repeticiones de final de palabra & \\
\hline 8 & Repeticiones léxicas no intencionales & \\
\hline 9 & Repeticiones en palabra llena & \\
\hline 10 & Repeticiones palabra vacía & \\
\hline 11 & Repeticiones expresiones resemantizadas & \\
\hline 12 & Repeticiones expresiones reformuladoras & \\
\hline 13 & Repeticiones sistemáticas & \\
\hline \multirow[t]{2}{*}{14} & Repeticiones expresiones innecesarias & \\
\hline & ALARGAMIENTOS & \\
\hline 15 & Alargamientos descriptivos & \\
\hline 16 & Alargamientos en palabra llena sobre sílaba acentuada & \\
\hline 17 & Alargamientos en palabra llena sobre sílaba inacentuada & \\
\hline 18 & Alargamientos en palabra vacía & \\
\hline 19 & Alargamientos que anteceden a una palabra llena & \\
\hline \multirow[t]{2}{*}{20} & Alargamientos innecesarios & \\
\hline & PAUSAS & \\
\hline 21 & Pausas intencional & \\
\hline 22 & Pausas con finalidad evaluativa & \\
\hline 23 & Pausas interactivas & \\
\hline 24 & Pausas de ruptura & \\
\hline 25 & Pausas por caracterización del hablante & \\
\hline \multirow[t]{2}{*}{26} & Pausas que anteceden a una palabra llena inusual & \\
\hline & OTROS & \\
\hline 27 & Anteceden a una palabra llena usual & \\
\hline 28 & Después de palabra llena & \\
\hline 29 & Enunciados truncados & \\
\hline 30 & Coalescencia léxica & \\
\hline \multicolumn{2}{|c|}{ Total +} & \\
\hline \multicolumn{2}{|c|}{ Total - } & \\
\hline \multicolumn{2}{|c|}{ Número de palabras } & \\
\hline \multicolumn{2}{|c|}{ Número de minutos } & \\
\hline \multicolumn{2}{|r|}{ Promedio de palabras por minuto } & \\
\hline \multicolumn{2}{|r|}{ Promedio de negativos por minuto } & \\
\hline \multicolumn{2}{|r|}{ Promedio de positivos por minuto } & \\
\hline \multicolumn{2}{|c|}{ TOTAL } & \\
\hline
\end{tabular}


Tabla 34: Instrumento de evaluación integral: habilidades narrativas y resultados finales

\begin{tabular}{|c|c|c|}
\hline & INDICADORES & INFORMANTE \\
\hline 1 & HABILIDADES SUPERESTRUCTURA NARRATIVA & \\
\hline 1 & Caracterización de personajes & \\
\hline 2 & Desarrollo de acciones (cambio de estado) & \\
\hline 3 & Presencia de estructura narrativa & \\
\hline 4 & Creación de un ambiente o entorno & \\
\hline II & TEMÁTICA, COHERENCIA GLOBAL & \\
\hline 5 & Presencia de un asunto común o tema unitario & \\
\hline 6 & Selección adecuada de información & \\
\hline 7 & Información suficiente & \\
\hline 8 & Información excesiva & \\
\hline 9 & Organización lógica de ideas & \\
\hline 10 & Progresión temática acertada & \\
\hline III & COHERENCIA LOCAL & \\
\hline 11 & $\begin{array}{l}\text { Existencia de campos semánticos claramente } \\
\text { definidos }\end{array}$ & \\
\hline 12 & Presencia de redes isotópicas & \\
\hline 13 & Enunciados claros y no contradictorios & \\
\hline 14 & Enunciados pertinentes & \\
\hline IV & COHESIÓN & \\
\hline 15 & Enlace secuencial de los hechos & \\
\hline 16 & Presencia de conectores de discurso & \\
\hline 17 & Presencia de enlaces anafóricos y catafóricos & \\
\hline V & EVALUACIÓN & \\
\hline 18 & $\begin{array}{l}\text { Presencia de juicios de valor acerca de los } \\
\text { hechos narrados }\end{array}$ & \\
\hline 19 & $\begin{array}{l}\text { Presencia de juicios de valor acerca del } \\
\text { discurso }\end{array}$ & \\
\hline 20 & $\begin{array}{l}\text { Presencia de expresiones valorativas: } \\
\text { Intensificadores, Comparadores, Correlativos, } \\
\text { Explicativos, Atenuantes. }\end{array}$ & \\
\hline 21 & Entonación enfática & \\
\hline $\mathrm{VI}$ & CONTEXTUALIZACIÓN & \\
\hline 22 & Uso de deícticos gramaticales & \\
\hline 23 & Referencias a lugares, personas o fechas & \\
\hline 1 & TOTALES & \\
\hline 1 & SUMATORIA & \\
\hline 2 & PROMEDIO CUALITATIVO & \\
\hline II & RESULTADOS FINALES & \\
\hline \multirow[t]{2}{*}{1} & PROMEDIO CUANTITATIVO & \\
\hline & PROMEDIO CUANTITATIVO DE 0 A 5 & \\
\hline 2 & PROMEDIO TOTAL & \\
\hline
\end{tabular}




\section{CONCLUSIONES}


1. Las teorías acerca del discurso propuestas inicialmente por Teun A. Van Dijk, y continuadas por sus seguidores, estiman el discurso como un discurrir, como una totalidad en la que los elementos fluyen organizadamente, unos tras otros, hasta formar el entramado del texto. El discurso está determinado, en primer lugar, por la intención del hablante. Los hablantes profieren palabras para realizar acciones y esas acciones o actos de habla están claramente definidos en la intención. Hablamos para saludar, despedirnos, relatar, constatar, certificar, describir, entre otras muchas funciones.

El discurrir, que da lugar al producto discursivo, comienza en la mente del hablante. En la mente suceden los recuerdos, la planificación del mensaje, la secuencia discursiva, la atención sobre determinado referente y la adhesión al mismo. El producto discursivo externo es solamente la punta del iceberg de la actividad mental, que antecede a la producción.

2. El hablante piensa, relaciona, integra y descarta elementos antes de dar orden a los procesadores motores para que emitan las palabras que formarán el discurso. Toda la etapa de planificación antecede a la expresión oral. El producto de la actividad mental que llamamos habla o producción oral, ha sido considerada la cenicienta de los estadios del lenguaje. Durante cientos de años la clásica falacia de la superioridad de la lengua escrita como única merecedora de análisis opacó los estudios de la oralidad, y no fue sino hasta principios del siglo XX que se retomó el habla como objeto de estudio de la 
lingüística, a través de varios autores y con ellos prosperaron áreas como la dialectología, la sociolingüística, la pragmática y el estudio de la interacción y la conversación.

El paso a seguir fue el planteamiento de una gramática de la oralidad, fuertemente asentada sobre tres pilares: la gramática, la pragmática y el análisis del discurso. A esta nueva forma de abordar los estudios lingüísticos se denomina pragmagramática y entre sus objetivos más destacados está el estudio del habla coloquial en la conversación.

La pragmagramática, propuesta por Briz, afirma las bases teóricas de lo oral, distinguiendo, fervientemente, oral de interaccional, y de coloquial. No cabe duda de que sin las descripciones puntuales de estos estudios lingüísticos, no sería posible elaborar un trabajo como el actual ya que el presente trabajo se basa en las condiciones y características que deben poseer los discursos orales, la interacción y la coloquialidad. Estas características se convierten en el insumo de la propuesta que aquí se realiza.

3. La fluidez discursiva oral integral se plantea como un producto tanto de los factores cognitivos que anteceden la expresión oral, como de los elementos que aparecen en el discurso expreso, y de los cuales podemos dar cuenta a través de grabaciones en audio y video; pero también es necesario pensar en los implícitos e inferencias, en la presencia del otro como co-constructor del texto y como gestor activo de la significación.

En esta perspectiva, la fluidez discursiva oral integral se presenta como el producto de todos los elementos discursivos, tanto de los que hacen parte de la 
planificación mental como de aquellos evidentes en el discurso real: vacilaciones, muletillas, silencios, alargamientos y repeticiones.

No se puede definir la fluidez del discurso únicamente por la existencia de estos indicadores cuantitativos, sino que es pertinente realizar un análisis discursivo cualitativo que dé lugar a una evaluación integral de la fluidez. Los factores mentales como la atención y la memoria van a complementar esta visión de lo oral, ya que dan cuenta del procesamiento cognitivo que realiza el hablante.

En este orden de ideas, es preciso defender la existencia de tres estadios: la planificación discursiva, la codificación lingüística y la articulación motora. La evaluación de la oralidad dará cuenta de esos estadios, ya que se verá la primera en el fenómeno de la planificación sobre la marcha u obligada planificación rápida, la segunda en los indicadores cualitativos discursivos y la tercera en la presencia o ausencia de indicadores cuantitativos del producto discursivo (Menjura, 2008). La planificación discursiva en la oralidad es simultánea con la emisión y esto caracteriza a la oralidad con errores y disfluencias en todos los niveles de la lengua. Estos errores al aparecer en la superficie discursiva son considerados reflejos de la planificación sobre la marcha u obligada planificación rápida: pensar mientras se habla.

4. Los antecedentes de este trabajo hablan de la fluidez verbal definida como la velocidad de habla. Más exactamente como el número de palabras que un hablante es capaz de pronunciar en un minuto. La fluidez verbal es una constante que se deriva de un test realizado a pacientes de terapias del lenguaje, según el cual una persona puede recordar y articular un número determinado de nombres de objetos ante una pregunta 
puntual del tipo: "mencione nombres de frutas" o "mencione nombres de mujer que empiecen por M".

Este método es insuficiente ya que no se trabaja la palabra en el contexto discursivo y no alude a una intencionalidad discursiva específica en el ámbito comunicativo del hablante. Por otro lado, hablar de fluidez discursiva oral Integral sí supone el habla en contexto y como producto de una intención comunicativa. Esta propuesta evalúa la fluidez para narrar y lo integra con los fenómenos de la oralidad que generan disfluencias, los cuales a su vez son evaluados junto con la tradicional fluidez verbal para lograr un resultado integral. Esta es la propuesta y novedad del presente trabajo académico.

5. Esta propuesta es sofisticada en tanto especifica el contexto y las condiciones en las cuales puede aparecer determinado fenómeno y dependiendo de las intenciones, es posible puntuar el indicador para determinar la calidad del discurso. La propuesta contempla una evaluación cualitativa de la muestra o corpus, la cual es trasladada a escala cuantitativa, una evaluación puramente cuantitativa que se computa con los resultados de la anterior, y que consta de la valoración de los fenómenos discursivos propios de la oralidad y del cálculo de la velocidad de habla representada en palabras por minuto.

Se cree que no existe actualmente un instrumento de evaluación de la producción discursiva oral que incluya todos los aspectos, tanto discursivos como cognitivos y de la fluidez del hablante, con un nivel de precisión como lo propuesto en el presente trabajo. 
6. El corpus obtenido es valioso no solo para este trabajo, sino para los que se realicen en el futuro, desde distintas perspectivas como la fonoaudiología o la enseñanza del español como lengua extranjera. Pero hay otras muchas posibilidades de indagación, ya que en el corpus se recoge una gama de intenciones, como la denuncia, el testimonio, la crítica y la experiencia personal, y una gama de temas, que van desde los muy serios, como la guerra, el desplazamiento forzado, la enfermedad, la drogadicción, el matrimonio, la muerte, a otros más ligeros. No faltan tampoco las anécdotas, los chistes, las bromas. Constituye el corpus un valioso documento tanto histórico como lingüístico que se puede continuar trabajando y perfeccionando con otros afines. Las vivencias y experiencias allí narradas constituyen un verdadero tesoro, y el hecho de haber sido ya procesadas a través de la técnica de la transcripción amplía su valía para nutrir un banco de corpus orales.

7. Con el fin de ilustrar cómo se ha aplicado el instrumento de evaluación, se procedió a hacerlo de forma pormenorizada con cinco informantes. La aplicación, además de cumplir sus fines ilustrativos, puso de manifiesto las grandes distancias que se dan entre informantes. Los siguientes son las conclusiones de la aplicación y análisis individualizado:

El informante 1D es un joven colombiano de 14 años. Fue grabado en el hogar El Arca, centro de atención para jóvenes con dependencia de las drogas. Es un informante que habla muy rápido, haciendo observación desde el punto de vista intuitivo. Su discurso se caracteriza por ser corto, descriptivo y pre-elaborado, ya que su intención es hacer una breve presentación de sí mismo ante el grupo de compañeros y terapeutas del hogar en el que se encuentra. 
Obtiene un puntaje cuantitativo de 234,2, que al convertirlo en la escala de 0 a 5 resulta en 4,34. En el desempeño cualitativo obtiene 1,52 y de estos dos valores se obtiene el promedio de 2,93 de acuerdo con la tabla generada en Excel. Aparece en el rango 3 de los informantes evaluados, con muy buen desempeño en fluidez oral porque no presenta pausas, repeticiones, alargamientos, ni otros fenómenos que muestren disfluencias en la oralidad, pero con dificultades en la evaluación cualitativa en tanto su puntaje es bajo en indicadores de producción narrativa y discursiva.

La informante $11 \mathrm{AC}$ es una mujer colombiana, profesional de 52 años. Su hablar es tranquilo, aunque se trata de un tema complicado: el abuso sexual en la familia. Su intención está claramente explícita al inicio de su intervención: denunciar el abuso sexual para que sea castigado y no quede impune. Es una denuncia que visibiliza el hecho a través del testimonio personal.

Es un discurso muy bien elaborado, que al ser evaluado con indicadores objetivos da un resultado que se ubica en el rango superior de los 66 informantes evaluados.

La informante $11 \mathrm{AC}$ obtiene un promedio de 3,38 en la evaluación cuantitativa de fenómenos de fluidez. Obtiene un promedio cualitativo de 4,39 (4,4 si redondeamos en un solo decimal) y es considerada como una de las informantes con un discurso de mayor calidad y con pocos fenómenos de disfluencias orales. El promedio entre lo cuantitativo: fluidez oral y lo cualitativo: producción discursiva es de 3,89 , con lo cual se sitúa en un rango alto de calidad de su discurso. Su promedio es el más alto de los obtenidos por los 66 informantes. 
El informante 58E es un hablante de Costa Rica de 90 años de edad, enfermo, en silla de ruedas y fue grabado en el Centro geriátrico Los Rosales en la localidad de San Rafael de Heredia.

Se sitúa este informante en el rango 3 al obtener un promedio total de 2,72 de fluidez discursiva oral integral. Este promedio se obtiene del promedio de 2,39 obtenido en la evaluación cualitativa y del promedio de 3,05 obtenido en la evaluación cuantitativa.

Es notoria en la evaluación cuantitativa la presencia de alargamientos, pausas y repeticiones no intencionales, que contribuyen a hacer un discurso vacilante y con fallas en la fluidez. Muestra esta evaluación las dificultades para mantener el tema y construir una narración con unidad discursiva.

El informante 590 es un hablante de 77 años de Costa Rica. Fue grabado en el Centro geriátrico Los Rosales. Es catalogado como viejo de oro, de acuerdo con la propuesta de Juncos Rabadán (1998). Su discurso es cualitativamente destacado ya que posee una excelente memoria que le permite ilustrar con lujo de detalles todo lo que cuenta, caracteriza los personajes y su gran capacidad descriptiva nos sitúa en la escena que está narrando. Su discurso es coherente, mantiene el tema, usa recursos contextualizadores y se apoya gestualmente para hacer más vívido su relato.

Cualitativamente obtuvo una puntuación de 4,13 y cuantitativamente obtuvo una puntuación de 2,88 para un promedio de 3,51 que podemos aproximar a 3,5. Se ubica en el rango 4 como uno de los informantes que tiene uno de los puntajes más elevados 
cualitativamente, y que en su desempeño discursivo oral integral obtiene también un buen puntaje.

La informante 64AV tiene 93 años, es española, fue grabada en su casa de habitación en Salamanca y su discurso posee bastantes disfluencias. Habla muy pausadamente, con dificultad. Obtuvo un puntaje muy bajo en la evaluación cualitativa, con apenas 0,87 , lo que indica dificultades para mantener el tema de la narración, faltas a la coherencia, información insuficiente y la necesidad constante del acompañamiento del entrevistador para lograr contar una anécdota corta.

En el aspecto cuantitativo obtuvo apenas un puntaje de 2,04, ya que hace pausas constantes y de ruptura de sintagmas, repite información, presenta constantes vacilaciones. El promedio total de $64 \mathrm{AV}$ es de 1,45, que la sitúa entre los promedios más bajos de todo el grupo de informantes.

8. La evaluación de los 66 discursos orales dejó como resultado 5 grupos de informantes distribuidos así:

- Rango 1: Se sitúan en este rango los informantes que obtengan un puntaje entre cero $(0)$ y cero con noventa y nueve $(0,99)$. Entre los evaluados en este corpus se ubicó 1 informante en este rango, correspondiente al 1,5\% de la muestra. La valoración cualitativa de los discursos de este rango es: deficiente.

- Rango 2: Los que obtuvieron puntajes de fluidez discursiva oral integral entre uno (1) y uno con noventa y nueve $(1,99)$. En este rango se ubican 4 informantes, 
con un porcentaje de $6 \%$. La valoración cualitativa de los discursos de este rango es: insuficiente.

- Rango 3: Los que obtuvieron puntajes de fluidez discursiva oral integral entre dos (2) y dos con noventa y nueve $(2,99)$. En este rango se ubican 32 informantes, con un porcentaje de 48,5\%. En este rango se ubicó la mayor parte de los informantes; hablantes que no poseen habilidades excepcionales para la narración y además cometen ciertas disfluencias en su discurso. La valoración cualitativa de los discursos de este rango es: aceptable.

- Rango 4: Los que obtuvieron puntajes de fluidez discursiva oral integral tres (3) y tres con noventa y nueve $(3,99)$ y en el cual se ubicaron 29 informantes.

Este grupo se dividió en dos subgrupos: Los que obtuvieron puntajes entre tres (3) y tres con cuarenta y nueve $(3,49)$ corresponden al subgrupo $4 \mathrm{~A}$, y quienes obtuvieron puntajes entre tres con cincuenta $(3,50)$ y tres con noventa y nueve $(3,99)$ corresponden al subgrupo 4B.

En el subgrupo 4A se ubican 14 informantes, con un porcentaje de $21,21 \%$. La valoración cualitativa de los discursos de este rango es: Bueno con algunas deficiencias

En el subgrupo 4B se ubican 15 informantes, con un porcentaje de $22,72 \%$. La valoración cualitativa de los discursos de este rango es: Muy bueno: Aparecen disfluencias propias de la producción oral de un hablante normal. 
- Rango 5: Se sitúan en este rango los informantes que obtengan un puntaje entre cuatro (4) y cinco (5). Entre los evaluados en este corpus no se ubicó ninguno en este rango. El porcentaje de evaluados en este rango fue $0 \%$. La valoración cualitativa de los discursos de este rango es: excelente. Se reserva este rango para narradores excepcionales.

9. Los estándares propuestos en el Vademécum para la formación de profesores (VVAA, 2004) y los que aparecen en el Marco Europeo de Referencia para las lenguas no contextualizan este tipo de evaluación del habla espontánea, cuando se trata de evaluar a los alumnos de español como lengua extranjera, ELE.

Es necesario observar que la prueba planteada en esta tesis no contempla la corrección fonética, ni sintáctica, ni la precisión semántica, con lo cual en una propuesta de evaluación para alumnos de ELE es necesario agregar estos aspectos. 
9. PERSPECTIVAS DE APLICACIÓN Y NUEVAS

\section{INVESTIGACIONES}




\subsection{Aprovechamiento del corpus}

1. El corpus de narraciones orales puede servir para trabajar análisis crítico del discurso, teniendo en cuenta la variedad de temas que allí se tratan (Wodak).

2. Sería una buena fuente para el análisis discursivo y análisis textual (Van Dijk).

3. Es provechoso en estudios comparativos de narrativas pertenecientes a diversos países (Adam).

4. Asimismo, podría servir como fuente para llevar a cabo estudios de la cortesía verbal, con una mayor importancia en intensificadores y atenuantes (Bravo).

5. Cabe utilizarlo en estudios gramaticales de la oralidad (Briz).

6. Algunos relatos serían fuente importante para el trabajo de interacción y conversación.

7. Asimismo, para el trabajo de la "cara" y la imagen en micro-sociología.

8. En cognición y psicolingüística puede ser útil para el estudio de errores y en metacognición y habilidades metadiscursivas.

9. También en estudios culturales y sociales.

10. Igualmente en estudios de la realidad social al encontrar testimonios y denuncias de problemas puntuales de las sociedades.

11. Sirve para documentar eventos históricos.

12. Resulta aprovechable en fonoaudiología y terapia del lenguaje. 


\subsection{Aprovechamiento del instrumento de evaluación}

1. En residencias de pacientes geriátricos.

2. Para profesores de ELE a la hora de evaluar habilidad oral de habla espontánea y narración. En este ámbito sería necesario agregar la corrección fonética, la precisión semántica y la corrección sintáctica.

3. En pacientes de fonoaudiología y de terapia del lenguaje. Queda para el profesional la tarea de realizar diagnósticos basados en los resultados obtenidos, trabajo interdisciplinario.

4. Como instrumento de evaluación en el aula, en el momento de calificar la producción oral.

5. En investigación de la oralidad, de la narración, del discurso y de la fluidez.

6. En niños menores de 10 años para determinar su grado de fluidez y en niños que están empezando a crear narraciones y descripciones.

Son, pues, muchas las posibilidades que quedan abiertas para continuar este trabajo.

"Esúes lo que le pueo contar, nada más"

Emilio Arce 


\section{BIBLIOGRAFÍA}


Abarzúa, R., Caradeux, M., Jeria, P., Viano, M., Zamorano, M. (2005). Diseño y aplicación de tareas para evaluar velocidad y ritmo, como componentes de la fluidez en niños preescolares entre 4 años o mes y 5 años 11 meses de edad. Recuperado de http://repositorio.uchile.cl/tesis/uchile/2005/abarzua_r/sources/abarzua_r.pdf

Adam, J. M. (1990). Eléments de linguistique textuelle. Liège: Mardaga.

Adam, J. M. (1992). Les textes: types et prototypes. París: Nathan.

Adam, J. M. (1987). Textualité et séquentialité : l'exemple de la description. Langue française, 74, pp. 51-72.

Adam, J. M., Lorda, C. U. (1999). Lingüística de los corpus narrativos. Barcelona: Ariel, S.A.

Agudo, J. A. (2000). La repetición en el discurso oral. En J. J. de Bustos, P. Charadeau, J. L. Girón, S. Iglesias y C. López Alonso (coords.). Lengua, discurso, texto. I Simposio Internacional de Análisis del Discurso (1) (pp. 695-709). Madrid: Visor Libros.

Alcoba, S. (2000). La expresión oral. Barcelona: Ariel Practicum.

Álvarez, M. (1993). Tipos de escrito I: narración y descripción. Madrid: Arco libros.

Álvarez, M. A. (2000). Poética del habla cotidiana. Mérida: Universidad de Mérida. 
Anscombe, G. E. M. (1991). Intención. Barcelona: Paidós S. A.

Bassols, M., Torrent, A. (1996). Modelos Textuales. Teoría y práctica. Barcelona: Eumo/ Octaedro.

Beaugrande, R. A. y Dressler, W. U. (1997). Introducción a la lingüística del texto. Barcelona: Ariel.

Belinchón, M., Igoa, J.M., Rivière Gómez, A., Rivière, A. (1992). Psicología del lenguaje, investigación y teoría. Madrid: Trotta.

Bell-Berti, F., Lawrence, R. (eds.) (1995). Producing speech: contemporary issues: for Katherine Safford Harris. New York: American Institute of Physiscs.

Berkenbusch, G. (1992). « Je vous en raconte UNE »: à propos de l’histoire drole comme tache conversationnelle. En En R. Lorenzo (coord.) Actas de XIX Congreso International de Linguística et Filoloxía Románicas (3) (pp.333-350). A Coruña: Fundación «Pedro Barrié de la Maza, Conde de Fenosa».

Bernárdez, E. (comp.) (1982). Introducción a la lingüística del texto. Madrid: Editorial Espasa.

Bernárdez, E. (comp.) (1987). Lingüística del texto. Madrid: Arco libros.

Bernstein, N. y Berko J. (1999). Psicolingüística. Madrid: McGraw-Hill.

Bernstein, B. y Fromkin, V. (1999). Producción del lenguaje. En N. Bernstein y J. Berko Gleason. Psicolingüística (pp.233-287). Madrid: McGraw Hill. 
Bierbach, C. (1992). L'expression des attitudes dans la conversation. La forme du sujet. Université de Gottingen. En R. Lorenzo (coord.) Actas do XIX Congreso International de Lingüística et Filoloxía Románicas (1) (pp.101-115). A Coruña: Fundación «Pedro Barrié de la Maza, Conde de Fenosa.»

Birren, K., Schaie, W. (2001). Handbook of the psychology of aging. San Diego: Academic Press.

Bosque, I., Demonte, V. (dirs) (1999). Gramática descriptiva de la lengua española. Madrid: Espasa

Boury, I., Bonnot, J. F. (1992). Stategies sociales et operations cognitives : Quelques remarques à propos de la fonction des pauses dans un modèle d’engrammation et d'exécution du discours. En Lorenzo, R. (coord.) Actas do XIX Congreso International de Linguística et Filoloxía Románicas (3) (pp.397-403). A Coruña: Fundación «Pedro Barrié de la Maza, Conde de Fenosa.»

Bravo, D., Briz, A. (2004). Pragmática sociocultural: estudios sobre el discurso de cortesía en español. Madrid: Editorial Ariel Lingüística.

Briz, A. (coord.) (1995). La conversación coloquial. Cuadernos de filología. Anejo XVI. Valencia: Universidad de Valencia.

Briz, A. (1996). El español coloquial: situación y uso. Madrid: Arco/libros, S. L.

Briz, A. (1997). Coherencia y cohesión en la conversación coloquial. En M., Iglesias (coord.). Gramma-temas-2, VII Curso de Gramática Española (pp.9-43). León: Servicio de Publicaciones de la Universidad de León. 
Briz, A. (1998). El español coloquial en la conversación. Esbozo de pragmagramática. Barcelona: Ariel, S.A.

Briz, A. (2000). Las unidades de la conversación. En Rilce, 16 (2), 225-246.

Briz, A. (2000). El español coloquial en los textos. En J. A. Moya (coord.) Adquisición y enseñanza de la lengua española (pp.13-37). Granada: Universidad de Granada.

Briz, A. (2001). El español coloquial en la conversación. Esbozo de pragmagramática (2 ed.). Barcelona: Ariel, S.A.

Briz, A. (2004). Aportaciones del análisis del discurso oral. En VVAA. Vademécum para la formación de profesores. Enseñar español como segunda lengua (L2)/lengua extranjera (LE) (219-242). Madrid: SGEL.

Briz, A. (2004). La transcripción de la conversación. El sistema de Val.Es.Co. En R. Almela, D. A Igualada, J.M. Jiménez, A. Vera (coords.). Homenaje al profesor Estanislao Ramón Trives (1) (pp. 141-159). Murcia: Servicio de Publicaciones de la Universidad de Murcia.

Briz, A., Grupo Val.Es.Co (eds.) (2000). Cómo se comenta un texto coloquial. Barcelona: Ariel Practicum.

Brown, G., Yule, G. (1983). Teaching the spoken language. Cambrige: Cambrige University Press.

Brown, G., Yule, G. (2003). Discourse analysis. Cambrige: Cambrige University Press. 
Butman, J., Allegri, R., Harris, P., Drake, M. (2000). Fluencia verbal en español datos normativos en Argentina. En Medicina (60), 5/1. Recuperado de http://www.medicinabuenosaires.com/revistas/vol60-00/5-1/fluencia.htm

Calsamilglia, H., Tusón, A. (1999). Las cosas del decir. Barcelona: Ariel Lingüística.

Camacho, M. (2005). Las repeticiones del discurso oral como elementos delimitadores de unidades discursivas. En Espéculo: Revista de Estudios Literarios. Recuperado de http://www.ucm.es/info/especulo/numero30/disoral.html

Cantero, F., De Arriba, J. (1997). Psicolingüística del discurso. Barcelona: Octaedro.

Canale, M. (1983). De la competencia comunicativa a la pedagogía comunicativa del lenguaje. En M. Llobera (coord.) Competencia comunicativa, Documentos básicos en la enseñanza de lenguas extranjeras (pp.63-81). Madrid: Edelsa.

Carbonero, P., (1975). Funcionamiento lingüístico de los elementos de relación. Sevilla: Publicaciones de la Universidad de Sevilla.

Caron, J. (1989). Las regulaciones del discurso. Psicolingüística y pragmática del lenguaje. Madrid: Gredos.

Casado Velarde, M. (1991). Los operadores discursivos Es decir, Esto es, O sea y A saber en español actual: valores de lengua y funciones textuales. En Lingüística Española Actual (13) 1, 87-116.

Castro, M., Doorn, J., Wainchenker, R. (2002). Medición cuantitativa de la velocidad del habla. Procesamiento del lenguaje natural (28), 99-104. Recuperado de http://rua.ua.es/dspace/handle/10045/1756 
Charolles, M. (1983). Coherence as a principle in the interpretation of discourse. Text, 3 (1), 71-97.

Charolles, M. (1989). Coherence as Principle in the Regulation of Discursive Production. En: W. Haydrich, F. Neubaer, J. Petofi, E. Sozer. Connexity and Coherence (pp. 3-15). Traducción de Gabriela Folchieri. Londres: De Gruyter,

Charolles, M., Fischer, S., Jayez, J. (éds.) (1990). Le discours: représentations et interprétations. Nancy: Presses universitaires de Nancy.

Ciapuscio, G. (1994). Tipos textuales. Buenos Aires: Universidad de Buenos Aires.

Cortes, L., Bañón, A. (1997). Comentario lingüístico de textos orales. Madrid: Arco Libros.

Coulthard, M. (1992). Advanced in spoken discourse analysis. New York: Routledge.

Cuetos Vega, F. (1998). Evaluación y rehabilitación de las afasias: aproximación cognitiva. Madrid: Editorial Médica Panamericana, D. L.

Delgado, J.M., Gutiérrez, J. (eds.) (1994). Métodos y técnicas cualitativas de investigación en ciencias sociales. Madrid: Proyecto Editorial Síntesis Psicología.

Dubois, J. (1979). Diccionario de lingüística. Madrid: Alianza Editorial.

Ducrot, O., Todorov, T. (1972). Diccionario enciclopédico de las ciencias del lenguaje. Buenos Aires: Siglo Veintiuno Editores.

Escandell Vidal, V. MA. (1991). Sobre las reduplicaciones léxicas. En Lingüística española actual, 13 (1) 71-86. 
Fernández Moreno, F. (2002). Producción, expresión e interacción oral. Madrid: Arco Libros.

Fernández Solera, S. (2010). Factores sintácticos y semánticos en el procesamiento del lenguaje. Madrid: Universidad Complutense de Madrid.

Forradelas, J., Marchese, A. (1991). Diccionario de retórica, crítica y terminología literaria. Barcelona: Ariel.

Fuentes, R. C. (1999). La organización informativa del texto. Madrid: Arco Libros.

Fuentes, R.C. (1993). Conclusivos y reformulativos. En Verba, 20, 171-198.

Gallardo, B. (1998). Comentario de textos conversacionales. Madrid: Arco Libros.

Gárate, M. (1994). La comprensión de cuentos en los niños. México: Siglo Veintiuno Editores.

Garcés, M.P. (2007). La repetición: formas y funciones en el discurso oral. En Archivo de Filología Aragonesa, 56-60 (pp.437-456). Recuperado de http://ifc.dpz.es/recursos/publicaciones/26/50/ebook2589.pdf

García, A. (1988). Psicolingüística. Madrid: Síntesis.

García Hoyos, I. C., Naranjo Aristazábal, A. L. (2002). La afasia: trastornos del lenguaje oral y lecto-escrito en el adulto. Manizales: Universidad Católica de Manizales.

Garman, M. (1990). Psicolingüística. Madrid: Visor Libros.

Gili Gaya, S. (1985). Curso superior de sintaxis española. Barcelona: Bibliograf. 
Granados, M. J. (2002). Definición empírica de los factores de fluidez ideativa, originalidad y creatividad: relaciones con la personalidad. Recuperado de: http://biblioteca.ucm.es/tesis/psi/ucm-t25704.pdf

Greimas, A., Fontanille, J. (2002). Semiótica de las pasiones: de los estados de cosas a los estados de ánimo. Madrid: Siglo Veintiuno Editores.

Gülich, E. y Kotschi, T. (1995). Discourse production in oral communication. A study base on French. En Uta M., Quasthoff (ed.) Aspects of Oral Communication (pp.30-66). Berlin/New York: de Gruyter.

Halliday, M. A. K., (1990). Spoken and written language. Oxford: Oxford University Press.

Halliday, M. A. K., Hasan, R. (1991). Language. Context and text: aspects of a language in a social-semiotic perspective. Oxford: University Press.

Halliday, M. A. K., Hasan, R. (1976). Cohesion in English. London: Longman.

Hernanz, M., Brucart, J. (1987). La sintaxis. Barcelona: Crítica.

Juncos, O. (1998). Lenguaje y envejecimiento. Bases para la intervención. Barcelona: Masson.

Kerbrat-Orechioni, C. (1996). La conversation. Paris: Editions de Seuil.

Kerbrat-Orechioni, C. (1998). Les interactions verbales. Paris: Masson et Armand Colin Editeurs. 
Kock, J., Caravedo, R. (1999). Gramática Española, Enseñanza e Investigación, Apuntes Metodológicos. Salamanca: Ediciones Universidad de Salamanca.

Kristeva, J. (1974). El texto de la novela. Barcelona: Lumen.

Labos, E., Del Río, M., Zabala, K. (2009). Perfil de desempeño lingüístico en el adulto mayor. Revista Argentina de Neuropsicología (13), 1-13. Recuperado de http://www.revneuropsi.com.ar/pdf/numero13/Labosetal.pdf

Labov, W. (1972). Language in the inner city, studies in the Black English vernacular. Pennsylvania: University of Pennsylvania.

López García, A. (1999). Relaciones paratácticas e hipotácticas. En: I. Bosque / V. Demonte (dirs.) Gramática descriptiva de la lengua española, Vol. 3. 3507-3547.

Lorenzo, R. (publicador) (1992). Lingüística, Pragmática e sociolinguiística III. En Actas do XIX Congreso Internacional de Lingüística y Filología Románicas. A Coruña, Fundación "Pedro Barrié de la Masa, Conde de Fenosa".

Lotman, M. (1970). La estructura del texto. Madrid: Itsmo.

Loureda, L. (2003). Introducción a la tipología textual. Madrid: Arco Libros.

Lozano, J., Peña-Marín, C., Abril, G. (1989). Análisis del discurso. Madrid: Cátedra.

Mathesius V. (1928). On linguistic characterology, Actes du Ier Congrès International des Linguistes. pp. 56-63.

Menjura, M. (2007). La fluidez discursiva oral. Una propuesta de evaluación. En Ogigia; revista electrónica de estudios hispánicos (1), 7-16. Recuperado de http://www.ogigia.es

Menjura, M. (2008). Desempeño lingüístico en la vejez. En UIS Humanidades, 36 (2), $21-26$ 
Moreno, Fernández, F. (2002). Producción, Expresión e interacción oral. Madrid: Arco Libros.

Navarro, T. (1963). Manual de pronunciación española. Madrid: Consejo Superior de Investigaciones Científicas.

Nieto, G. J. M. (1995). Introducción al análisis del discurso hablado. Granada: Universidad de Granada.

Niño, V. M. (1998). Los procesos de la comunicación y del lenguaje (2a ed.). Bogotá: Ecoe Ediciones.

Park, D., Schwarz, N. (eds.) (2000). Cognitive aging. Philadelphia: Psychology Press.

Patry, R., Nespoulous, J. (1990). Discourse analysis in linguistics. En I. Joanette, H. Brownell (eds). Discourse ability and brain damage (pp.3-27). New York: Springer-Verlag.

Perfect, T., Maylor, E. (Eds.) (2000). Models of cognitive aging. Oxford: Oxford University Press.

Pessoa de barros, D. L. (1992). Mecanismos de correcao da fala. En R. Lorenzo (coord.) Actas do XIX Congreso Internacional de Lingüística et Filoloxía Románicas (3) (pp.275-282). A Coruña: Fundación "Pedro Barrié de la Masa, Conde de Fenosa". Picabea Torrado, I. (2008). Glosario del lenguaje. La Coruña: Netbiblio.

Pichaud, C., Thareau, I. (1996). Vivre avec des personnes âgées: à Domicile, en établissement. Lyon: Chronique Sociale, D.L.

Portolés, J. (1998). Marcadores del discurso. Barcelona: Ariel S. A.

Portolés, J., Martín Zorraquino, M. (1999). Los marcadores del discurso. En: I. Bosque / V. Demonte (dirs.) Gramática descriptiva de la lengua española, Vol. 3. 40514213. 
Rastier, F. (2005). Semántica interpretativa. Traducción de Eduardo Molina y Vedia, México: Siglo XXI.

Renkema, J. (1999). Introducción a los estudios sobre el discurso. Barcelona: Gedisa.

Ricci Bitti, P., Zani, B. (1983). La comunicación como proceso social. México: Grijalbo.

Richeit, G., Habel, C. (Eds.) (1995). Focus and coherence in discourse processing. Hamburg: Library of congress cataloguing data.

Rodríguez, F. C. (1987). Enlaces extraoracionales. Sevilla: Alfar.

Román Lapuente, I., Del Pino Sánchez, M., Rabadán Pardo, M. J. (2010). Variables de la actividad mental. En Neuropsicología (22), 1-34. Recuperado de http://ocw.um.es/cc.-sociales/neuropsicologia/material-de-clase-1/tema-4.variables-de-la-actividad-mental.pdf

Schiffrin, D. (1985 c). Conversational Coherence: The role of "well". Language, 61:640-667. Recuperado de http://www.jstor.org/stable/414389

Schiffrin, D. (1987). Discours markers. Cambrige: University Press.

Schifko, M. (1992). La coherencia de textos: un problema semántico y pragmático. En Lorenzo, R. (coord.) Actas do XIX Congreso Internacional de Lingüística et Filoloxía Románicas (3) (pp. 419-426). A Coruña: Fundación "Pedro Barrié de la Maza, conde de Fenosa".

Searle, J. R. (1983). Intentionality, an essay in the philosophy of mind. Cambrige: Cambrige University Press.

Sihvonen-hautecoeur, R. P. (1989). Particules discursives et autoreprise. En Lorenzo, R. (coord.). En Actas do XIX Congreso Internacional de Lingüística et Filoloxía Románicas (3) (pp. 435-448). A Coruña: Fundación "Pedro Barrié de la Masa, conde de Fenosa". 
Silva Corvalán, C. (1987). La narración oral española: estructura y significado. En E. Bernárdez (Ed.), Lingüística del texto (pp. 265-292). Madrid: Arco Libros.

Simone, R. (2001). Fundamentos de lingüística. Barcelona: Ariel.

Steinar, K. (1996). Interviews. An introduction to qualitative research interviewing. London: Sage.

Sridhar, S. N. (1988). Cognition and sentence production. New York: Springer-Verlag.

Stubbs, M. (1983). Análisis del discurso. Madrid: Alianza.

Stubbs, M. (1996). Text and corpus analysis. Oxford: Blackwell Publishers Ltd. U.K.

Terrádez, M. (2001). Frecuencias léxicas del español coloquial: análisis cuantitativo y cualitativo. Cuadernos de Filología. Anejo XLI. Valencia: Servicio de Publicaciones de la Universidad de Valencia.

Torras, M. R. (1997). Características de la producción oral de aprendices formales de inglés (LE) en un contexto escolar. Estudios de lingüística aplicada. En Publicaciones Universitat Jaume I, Colección Summa. Filología/8, pp. 195-204.

Tusón, A. (1997). Análisis de la conversación. Barcelona: Ariel.

Van Dijk, T. A. (1972). Some aspects of text grammars. Mouton: The Hauge.

Van Dijk, T. A. (1979). Macrostructure. Hillsdale, N. J.: Laurence Erlbaum Associates

Van Dijk, T. A. (1983). Texto y contexto. Madrid: Cátedra.

Van Dijk, T. A. (1985). Handbook of Discourse Analysis. Ed. 4 Vols. Londres: Academic Press.

Van Dijk, T. A. (1989). La ciencia del texto. Madrid: Paidós.

Van Dijk, T. A. (comp.) (2000). El discurso como estructura y proceso. Barcelona: Gedisa.

Van Dijk, T. A. (2001). Algunos principios de una teoría del contexto. Revista Latinoamericana de Estudios del Discurso, 1 (1), 69-81. 
Van Dijk, T. A. (comp.) (2002). El discurso como interacción social. Barcelona: Gedisa. Van Dijk, T. A. (2003). Ideología y discurso. Barcelona: Ariel Practicum.

Van Dijk, T. A., Kintsh, W. (1983). Strategies of Discourse comprehension. Nueva York:Academic press.

Van Dijk, T. A., Kintsh, W. (1978). Toward a model of text comprehension and production. Psychological Review, 85 (5), 363-390.

Vega, F. (1998). Evaluación y rehabilitación de las afasias. Madrid: Médica Panamericana.

Vega, J.L., Bueno, B. (1995). Desarrollo adulto y envejecimiento. Madrid: Síntesis.

Vigara Tauste, A. M. (2006). El lenguaje coloquial (humano) en Galdós. Isidora: revista de estudios galdosianos (2), 79-104.

Vigara Tauste, A. M (2002). Estudio del español coloquial: razones para el optimismo. Español actual: Revista del español vivo (77- 78), 5-26.

VVAA (2004), Vademécum para la formación de profesores. Enseñar español como segunda lengua (L2)/lengua extranjera (LE). Madrid, SGEL

Wilson R. y Keil, F. (1999). Enciclopedia de las ciencias cognitivas. Madrid: Síntesis.

Wodak R. y M. Meyer. (2003). Métodos de análisis crítico del discurso. Barcelona: Gedisa. 